\title{
Molekularanthropologische Untersuchungen zur präkolumbischen Besiedlungsgeschichte des südlichen Perus am Beispiel der Palpa-Region
}

Dissertation zur Erlangung des Doktorgrades

der Mathematisch-Naturwissenschaftlichen Fakultäten

der Georg-August-Universität zu Göttingen

vorgelegt von

Lars Fehren-Schmitz

aus Aurich

Göttingen 2008 
D7

Referent: Prof. Dr. B. Herrmann

Korreferent: Prof. Dr. K.-H. Willroth

Termin der mündlichen Prüfung: 30.04.2008 
Die Arbeit wurde angefertigt am Johann Friedrich Blumenbach Institut für Zoologie und Anthropologie, Abteilung Historische Anthropologie und Humanökologie der Georg-AugustUniversität Göttingen im Rahmen des Projektes:

„Nasca: Entwicklung und Adaptation archäometrischer Techniken zur Erforschung der Kulturgeschichte (humanökologisch-paläogenetischer Teil).“

Das Projekt wurde gefördert vom deutschen Bundesministerium für Bildung und Forschung (BMBF), Förderkennzeichen: 03HEX1VP.

Projektleitung: Prof. Dr. Bernd Herrmann und Dr. Susanne Hummel 


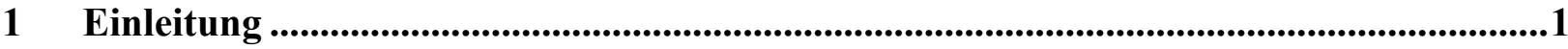

2 Grundlagen und Zugänge zur Kulturgeschichte und Genetik ...........................................4

$2.1 \quad$ Kulturwandel und Bevölkerungsmobilität ....................................................4

2.1.1 Soziologische und ökologische Erklärungsmodelle zu Kultur und Kulturwandel..4

2.1.2 Komplexe und frühstaatliche Gesellschaften ............................................... 14

2.1.3 Archäologie und Migration: Ein forschungsgeschichtlicher Überblick ................17

2.1.4 Migration und Mechanismen des Kulturwandels und ihr Nachweis in prä-

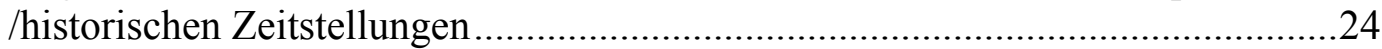

2.1.5 Zugang der Anthropologie zur Kulturentwicklung und Migration .......................35

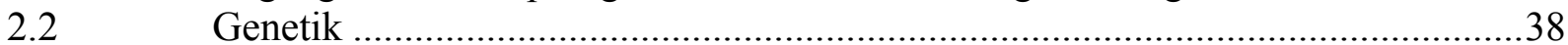

2.2.1 Molekulargenetische Grundlagen und Typisierungsmarker................................38

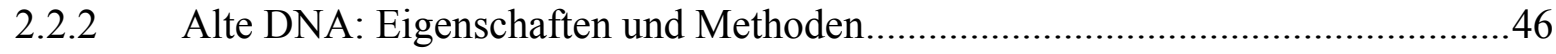

2.2.3 Haplogruppen und Bevölkerungsbewegungen ................................................51

2.3 Die Besiedlungs- und Kulturgeschichte Amerikas und des südlichen Perus ........59

2.3.1 Die initiale Besiedlung Amerikas aus molekulargenetischer und archäologischer

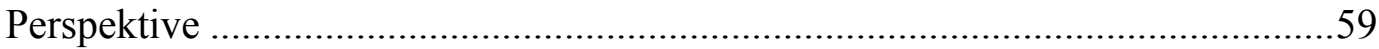

2.3.2 Besiedlung und genetische Struktur der indigenen Bevölkerung Südamerikas ....67

2.3.3 Kultur- und Umweltgeschichte der Palpa Region und des südlichen Perus .........75

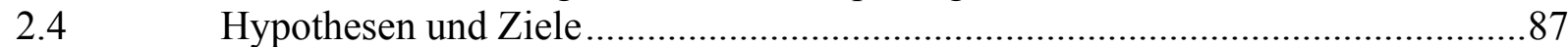

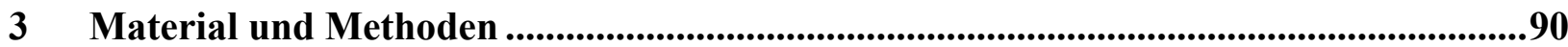

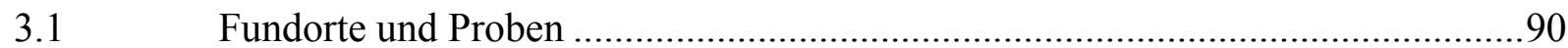

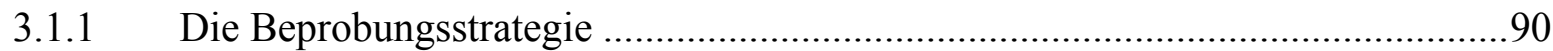

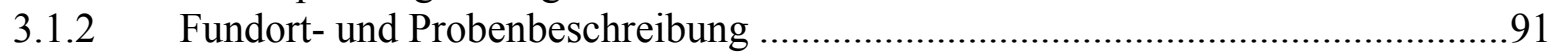

3.1.3 Die südamerikanischen Referenzpopulationen ............................................. 102

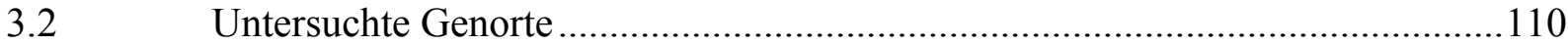

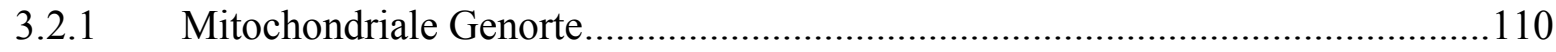

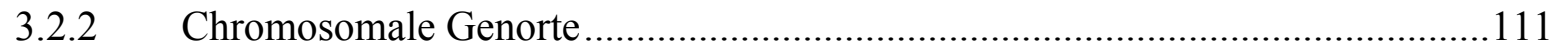

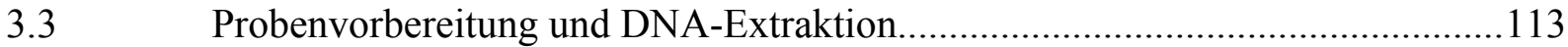

3.4 Amplifikationssysteme und Parameter für die Endpunkt PCR ..........................115

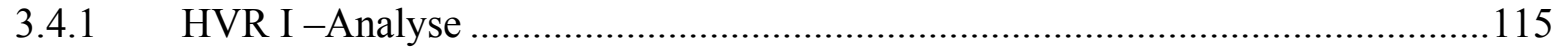

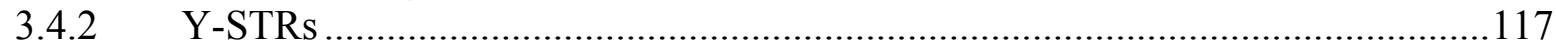

3.4.3 Autosomale STRs und Amelogenin ............................................................... 118

3.5 Amplifikation und SNP-Analysen mit der Real-Time PCR .............................119

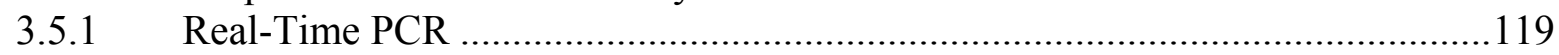

3.5.2 Genotypisierung mit Hybridisierungssonden für die qRT-PCR .........................120

3.5.3 HybProbe Assay für mitochondriale SNPs und die 9bp Deletion.......................122

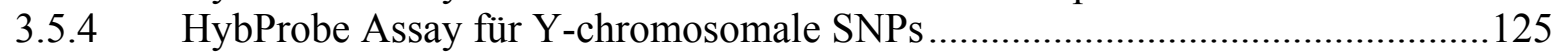

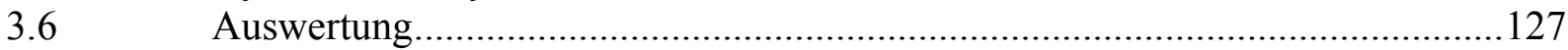

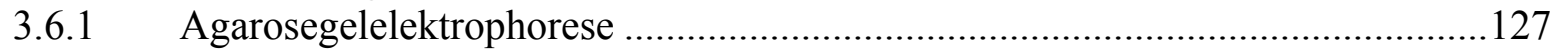

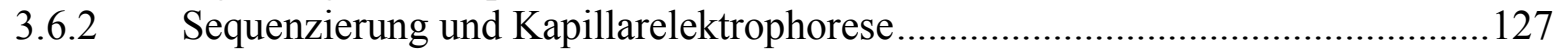

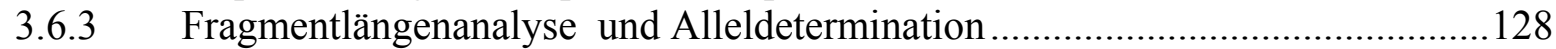

3.7 Kontaminationsprävention und Authentizitätssicherung...................................129

3.7.1 Maßnahmen zur Kontaminationsprävention .................................................. 129

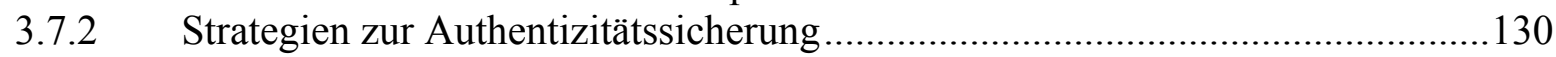

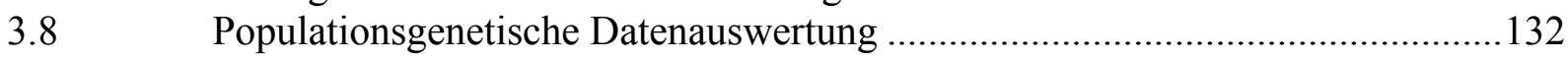

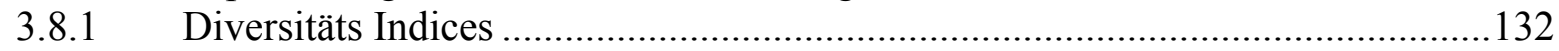

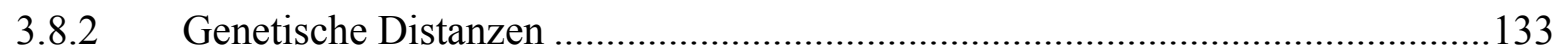

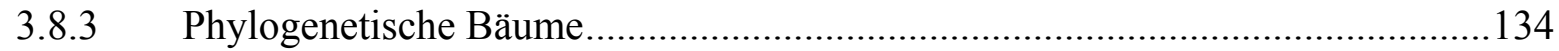

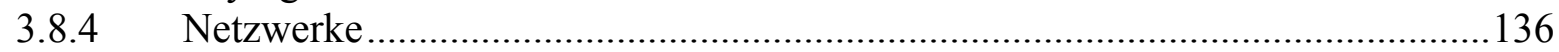

3.8.5 Tajima D-Statistik und Mismatch Distribution .................................................137

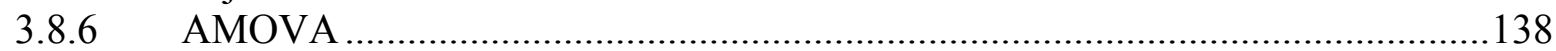


4 Ergebnisse der molekulargenetischen Untersuchungen

4.1 Proben und Erhaltung

4.2

Analyse der mitochondrialen SNPs und der 9bp-Deletion...

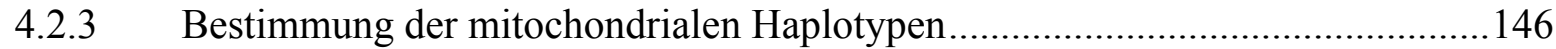

4.2.4 Bestimmung der mitochondrialen Haplogruppen.................................................151

4.3 Typisierungsergebnisse der nuklearen Marker...............................................153

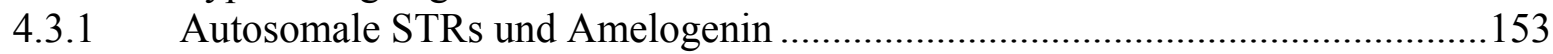

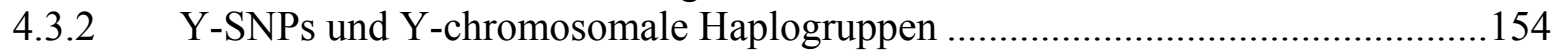

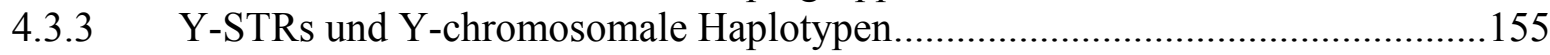

5 Auswertung der genetischen Daten für die Palpa-Region .........................................156

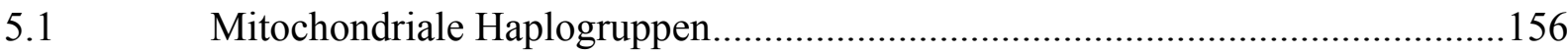

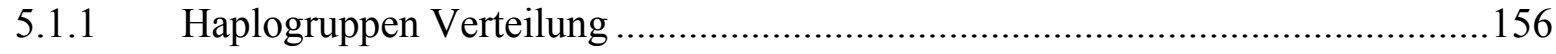

5.1.2 Genetische Diversität und Distanz ............................................................... 158

5.1.3 Zusammenfassende Auswertung der mt-Haplogruppen Daten für die Palpa-

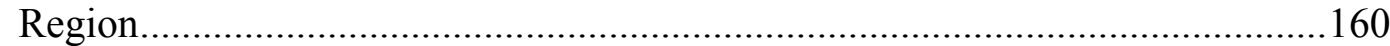

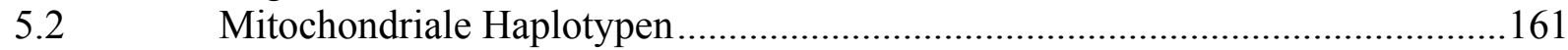

5.2.1 Räumliche und zeitliche Verteilung der Haplotypen ........................................ 161

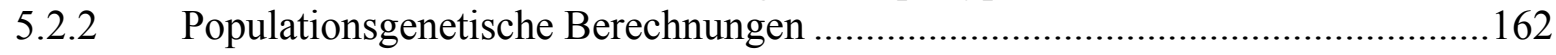

5.2.3 Zusammenfassende Auswertung der mt-Haplotypen Daten für die Palpa-Region

5.3 Zusammenführung der mitochondrialen Haplotypen- und Haplogruppendaten.167

6 Auswertung der genetischen Daten im kontinentalen Vergleich ..................................170

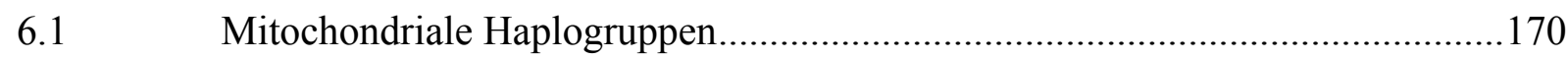

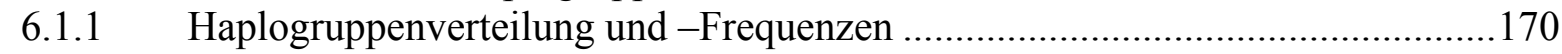

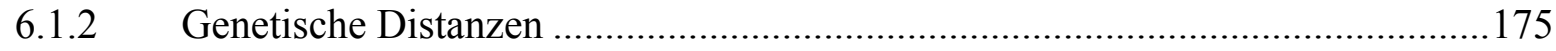

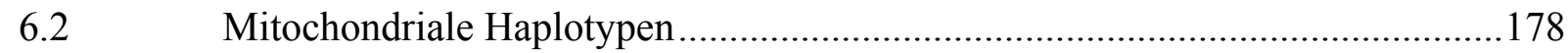

6.2.1 Intrakontinentaler Vergleich der Haplotypen aus dem Untersuchungsgebiet ......178

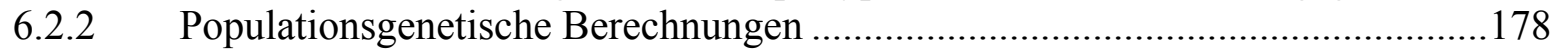

6.3 Zusammenfassende Betrachtung des kontinentalen genetischen Vergleichs.......185

7 Interpretation, Diskussion und Kontextualisierung der genetischen Daten .................187

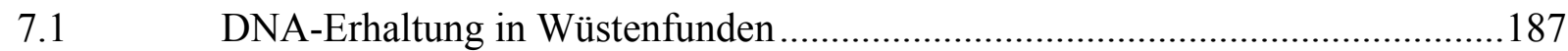

7.2 Bevölkerungs- und Kulturgeschichte der Palpa-Region und Südamerikas.........187

7.2.1 Verbreitung der Paracas-Kultur an der südperuanischen Küste..........................187

7.2.2 Die Entwicklung der Nasca-Kultur aus genetischer und archäologischer

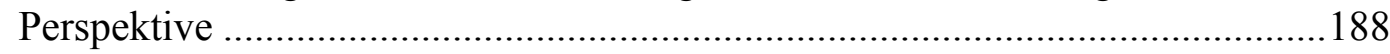

7.2.3 Der Untergang der Nasca: Invasion vs. ökologische Krise ...............................190

7.2.4 Bevölkerungswandel vom präkolumbischen zum rezenten südlichen Peru........192

7.2.5 Migration und Bevölkerungsentwicklung im westlichen Südamerika................195

7.2.6 Adaptation an das andine Hochland und genetische Selektion: Eine alternative Hypothese zum Ursprung der genetischen Bevölkerungsstruktur im südamerikanischen Hochland.

8 Zusammenfassung.

9 Literatur

10 Anhang. 


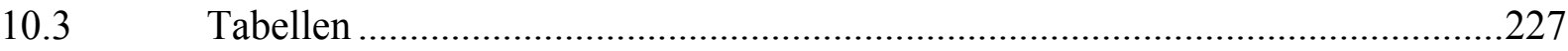

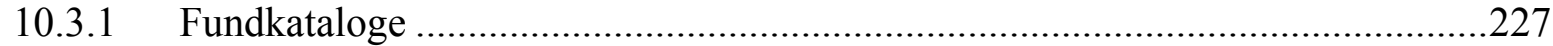

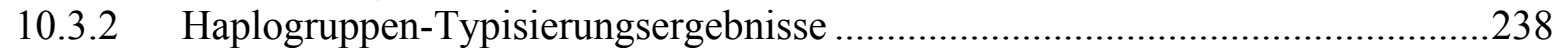

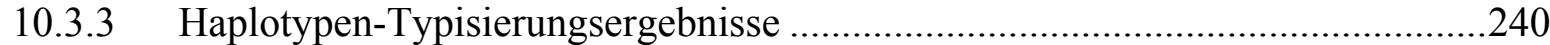

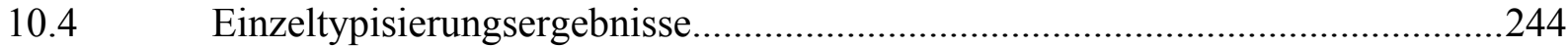

10.4.1 Einzeltypisierungsergebnisse der autosomalen STRs .....................................244

10.4.2 Einzeltypisierungsergebnisse der Y-HybProbe-Multiplex .................................245

10.4.3 Einzeltypisierungsergebnisse der HybProbe-Multiplex für die mt-Haplogruppen

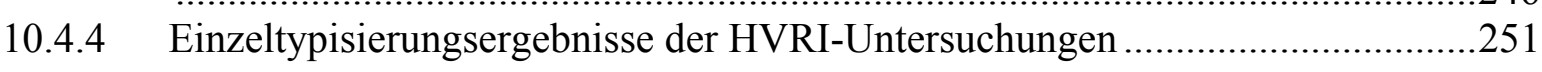

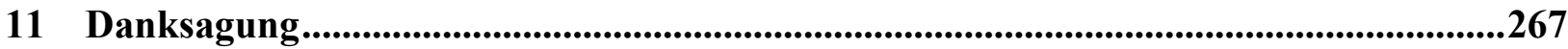




\section{$1 \quad$ Einleitung}

“Cultures don't migrate; people do" Anthony 1997

In den Kulturwissenschaften ist eine der großen Grundfragen, inwieweit kultureller Wandel in einem geographischen Raum mit bevölkerungsbiologischem Wandel verknüpft ist. Denkbar sind Entwicklungen zwischen zwei Extremen: einmal kulturelle Diffusion bei bevölkerungsbiologischer Stabilität, zum anderen bevölkerungsbiologische Verschiebung (Migration) bei kultureller Stabilität. Variationen sind durch graduelle Änderungen der Variablen in diesen beiden Grundmustern möglich. Jede kulturhistorische Entscheidung zugunsten einer Determinante innerhalb dieses Modells kann sich nur über Plausibilitätsannahmen legitimieren. Weder materielle Hinterlassenschaften archäologischer Kulturgruppen, ethnographische Analogien, noch andere extrasomatische Quellen machen diese Grundfrage grundsätzlich oder im konkreten Falle endgültig entscheidbar. Das einleitende Zitat von Anthony (1997) weist aber bereits auf das Archiv hin, das die Beantwortung dieser Frage näher bringen kann: der Mensch selbst.

Durch die Anwendung genetischer Werkzeuge wird es möglich, ein nichtbiographisches Archiv zu erschließen, das alle notwendigen Informationen über die biologische Zusammensetzung einer Bevölkerung beinhaltet. Die in den letzten Jahren entwickelten Techniken zur Untersuchung alter DNA (aDNA) aus prä/-historischen humanen Skelettkollektiven eröffnen den Zugang zu den populationsgenetischen Daten längst vergangener Kulturen. Sie ermöglichen über den synchronen überregionalen Vergleich hinaus auch eine methodische Notwendigkeit für die Untersuchung von „Wandel“: den diachronen Vergleich. Die Daten der molekularen Anthropologie können, zusammen mit den anderen archäologisch/ paläoökologisch arbeitenden Disziplinen, auf einer transdiziplinären Ebene in Kulturgeschichte übersetzt werden. Dadurch sollte es im idealen Fall auch möglich sein, die Kausalität eines beobachteten kulturellen Wandels zu klären.

Die Palpa-Region, gelegen zwischen dem westlichen Andenfuß und der nördlichen Atacama Wüste im südlichen Peru, bietet ein optimales Experimentierfeld für solche paläopopulationsgenetischen Untersuchungen. Die archäologischen Befunde belegen eine Besiedlungskontinuität bis heute, die spätestens mit der Initialzeit (ca. 1800 v. Chr.) beginnt. In diesem langen Zeitraum erlebte die Region viele mehr oder weniger dramatische kulturelle Umbrüche und das Aufkommen und Vergehen archäologischer Kulturen ${ }^{1}$, wie der Paracas- und der Nasca-Kultur, Sesshaftwerdung und das Entstehen komplexer Gesellschaftsformen. Gerade

${ }^{1}$ Der Begriff der „archäologischen Kultur“ wird im Zusammenhang dieser Arbeit nur als notwendige Klassifikationseinheit für einen räumlich und zeitlich begrenzten Ausschnitt materieller Kultur verstanden. Die durchaus kontroverse Verwendung dieses Begriffes wird in den folgenden Kapiteln thematisiert. 
die Entstehung der Nasca Kultur mit ihren weltweit bekannten ausgedehnten Bodenzeichnungen „Geoglyphen“ (UNESCO-Weltkulturerbe) werden, wenn auch nicht immer auf Basis wissenschaftlicher Grundlagen, kontrovers diskutiert. Das Untersuchungsgebiet ist also als eine kulturell-dynamische Siedlungskammer anzusehen, die die Möglichkeit des diachronen Vergleiches bietet. Im Rahmen dieser Arbeit soll durch die Nutzung molekulargenetischer Methoden versucht werden, den bevölkerungsbiologischen Anteil dieser Dynamik zu beleuchten. $\mathrm{Zu}$ klären ist, in wie weit kultureller Wandel durch Migration beeinflusst wurde oder Migrationsverhalten beeinflusst hat.

Durch die Kooperation mit den lokalen peruanischen Archäologen und denen der KAAKBonn (Kommission für Archäologie Außereuropäischer Kulturen - DAI) war der Zugriff auf eine Vielzahl von unterschiedlich datierenden Nekropolen und damit Individuen für die paläogenetischen Untersuchungen möglich. Der wissenschaftliche Rahmen, in den die hier vorliegende Arbeit eingebettet war, bot darüber hinaus die optimalen Voraussetzungen für den zuvor geforderten transdiziplinären Dialog zur Interpretation der Daten. Die hier vorgestellten Untersuchungen an humaner aDNA sind Teil des Verbundprojektes: „Nasca: Entwicklung und Adaptation archäometrischer Techniken zur Erforschung der Kulturgeschichte" des Bundesministeriums für Bildung und Forschung (BMBF). In diesem Rahmen beschäftigte sich eine Vielzahl von kultur- und naturwissenschaftlichen Disziplinen mit der Rekonstruktion der Kultur- und Umweltgeschichte der Palpa Region. Die Erkenntnisse aus den unterschiedlichen Projekten fließen mit in diese Arbeit ein.

Der bisherige Forschungsstand zur präkolumbischen Besiedlungsgeschichte Südamerikas beruht fast ausschließlich auf der Untersuchung rezenter Populationen. Damit wird allerdings nur ein moderner Ist-Zustand dargestellt, der die kulturgeschichtlichen und politischen Prozesse der ca. 10.000 Jahre seit der initialen Besiedlung Südamerikas und die damit einhergehenden möglichen bevölkerungsbiologischen Veränderungen nicht ausreichend berücksichtigt. Die vorliegende Studie ist die erste paläogenetische Arbeit zur Besiedlungsgeschichte Südamerikas, die zum einen den quantitativen Ansprüchen der Populationsgenetik genügt und zum andern auch einen diachronen Untersuchungscharakter besitzt. Durch den Vergleich des prähistorischen bevölkerungsbiologischen Ist-Zustandes, gewonnen aus den aDNA Untersuchungen, mit dem rezenten Ist-Zustand, ergibt sich die Möglichkeit die Auswirkung dieser politischen Prozesse auf die Bevölkerungszusammensetzung des südlichen Perus zu ermitteln.

Da dieser Arbeit ein kulturwissenschaftliches Interesse zu Grunde liegt, wurde eine nicht nur für Biologen verständliche Sprache gewählt. Bedingt durch dieses Grundinteresse folgt in dem ersten Abschnitt der Arbeit (Kap. 2) eine ausführliche Erläuterung der kultur- und naturwissenschaftlichen Grundlagen, die zum Verständnis der Eingangshypothesen aber auch 
der abschließenden Synthese beitragen. Die Beschäftigung mit Kulturwandel und Migration macht es notwendig, theoretische Erwägungen der Kulturanthropologie, Archäologie und Soziologie in die Analyse zu integrieren, da die populationsgenetischen Daten letztendlich nur durch die Kenntnis dieser Theorien in kulturgeschichtliche Daten transponiert werden können. Der bevölkerungsbiologische Einfluss auf die Kulturentwicklung im südlichen Peru kann nur durch die Kenntnis der Kultur- und Besiedlungsgeschichte Südamerikas erklärt werden, dementsprechend widmet sich der erste Abschnitt auch diesem Thema. Der zweite Abschnitt der Arbeit (Kap. 3 u. 4) erläutert die angewendeten molekulargenetischen Analysemethoden und deren Parameter sowie die Ergebnisse der Analysen. Im dritten Abschnitt (Kap. 5 - 7) werden die Ergebnisse populationsgenetisch ausgewertet und mit den kulturhistorischen Erkenntnissen aus Abschnitt 1 kontextualisiert. Darüber hinaus wird die Konsistenz der Ergebnisse mit den kulturtheoretischen Erwägungen überprüft. 


\section{Grundlagen und Zugänge zur Kulturgeschichte und Genetik}

\subsection{Kulturwandel und Bevölkerungsmobilität}

\subsubsection{Soziologische und ökologische Erklärungsmodelle zu Kultur und Kulturwandel}

Bevor sich die folgenden Kapitel konkret der Diskussion über den bevölkerungsbiologischen Anteil bzw. des Anteils von Migrationen am Kulturwandel in der Archäologie widmen, soll zunächst, ohne den Anspruch auf Vollständigkeit, in einem ideengeschichtlichen Überblick die Entwicklung von anthropologischen Kulturkonzepten und -theorien umrissen werden. Dabei liegt der Schwerpunkt auf humanökologischen Theorien, also solchen, die die Faktoren Mensch und Umwelt und ihre wechselseitige Beziehung zueinander in ihre Betrachtung mit einbeziehen.

Für umfassendere ideengeschichtliche Darstellungen kulturanthropologischer und kulturökologischer Theorien ist u.a. auf Bargatzky (1986), Schutkowski (1998) und Barnard (2000) zu verweisen. Dem Abschluss dieses Kapitels vorgreifend ist allerdings zu bemerken, dass am Ende weder ein einheitlicher und genereller Kulturbegriff noch ein Konsens in der Frage nach Ursachen und Mechanismen von Kulturentstehung und Wandel gefunden wird. Das kann aber auch nicht Anspruch dieser Arbeit sein.

Zwei Paradigmen dominieren im späten 19. Jahrhundert die Wahrnehmung von Kulturentstehung und Wandel in der sich zunehmend etablierenden Anthropologie / Ethnologie: Evolutionismus und Diffusionismus (Barnard 2000). Ungefähr zeitgleich mit der darwinschen Evolutionstheorie entwickelten sich Theorien der soziokulturellen Evolution. Grundlage des evolutionistischen Gedanken war, dass sich Kulturen entwickeln und im Laufe der Entwicklung an Komplexität zunehmen. Auch wenn es nahe liegend erscheint, Analogien der Kulturtheorien zu den Theorien Charles Darwins zu sehen, wohnte ihnen eher ein teleologischer, unilinearer Entwicklungsgedanke inne, dessen Wurzeln in den lamarkschen Theorien zu finden ist. Kulturen entwickeln sich von einem ,primitiven“ zu einem ,zivilisierten“ Zustand, wobei die westlichen Gesellschaften als zivilisierte angesehen werden (Harris 1968). Als herausstehende Vertreter sind Herbert Spencer, Lewis Henry Morgan oder Edward Burnett Tylor zu nennen (Barnard 2000). Der grundlegende Unterschied zu den als Reaktion auf den Evolutionismus im späten 19. Jahrhundert aufkommenden diffusionistischen Kulturtheorien ist, dass die Evolutionisten der Menschheit die grundlegende Fähigkeit zur Innovation zusprechen (Rössler 2007).

Der Diffusionismus betont die Verbreitung von Dingen und Ideen und findet seine Anwendung deshalb wohl auch hauptsächlich in der Betrachtung von materieller Kultur. In seinen extremen Ausprägungen postuliert der Diffusionismus, dass kulturelle und soziale Merkmale sich nur einmal in der Geschichte entwickeln und dann durch direkte Weitergabe oder 
Migration verbreitet werden. Die größte Popularität erreichte diese Theorie hauptsächlich in Deutschland und Österreich, aber auch die internationale Diskussion wurde von ihr beeinflusst. Als erster herausstehender Vertreter des Diffusionismus ist Friedrich Ratzel zu nennen. In seinem Werk „Völkerkunde“ (1885) vertritt er die These, dass Kultur sich hauptsächlich aus der massiven Migration und dem Sieg stärkerer Völker über schwächere entwickelt. Die von ihm definierten „Kulturkomplexe“ werden von Leo Frobenius aufgegriffen und zur Idee der „Kulturkreise“ weiterentwickelt (Ursprung der afrikanischen Kulturen, 1898). Der Kulturkreislehre liegt ein eher gemäßigter Diffusionismus zu Grunde. Es werden weltweite Parallelen in der kulturellen Entwicklung gesucht anhand derer Kulturareale definiert werden. Wandel resultiert aus der Überlagerung und Überprägung dieser Areale (Rössler 2007).

Über Ratzels Theorie findet auch die Diskussion über den ökologischen Anteil an Kultur und Kulturwandel Einzug in die Ethnologie/Anthropologie. Er betont, dass kulturelle Unterschiede aus Migration und Diffusion resultieren. Darüber hinaus ist der Mensch aber auch durch sein Habitat in der Auswahl seiner kulturellen Reaktion limitiert. Die Umwelt des Menschen determiniert also die Entwicklung kultureller Diversität (Moran 2000). Ratzel und andere Vertreter des Umweltdeterminismus gehen davon aus, dass menschliches Sozialverhalten, psychische Konstitution und auch die körperliche Erscheinung eines Menschen auf geographische und klimatische Unterschiede zurückgeführt werden können (Bargatzky 1986). Mit zunehmender Kenntnis über die subtilen Wechselwirkungen von Umwelt und Kultur durch die steigende Zahl an ethnologischen und geographischen Untersuchungen mehrten sich aber auch die Argumente gegen einen solchen Determinismus. So argumentiert z.B. Lowie in seinem Werk „Culture and Ethnology“ (1917; zit. nach Moran 2000) basierend auf seinen Beobachtungen, dass sich unter gleichen geographischen Bedingungen radikal unterschiedliche Kulturen entwickelt haben.

Als Reaktion auf die deterministischen Konzepte manifestierte sich ein ökologisches Kulturkonzept, das auch als Possibilismus oder Historischer Partikularismus bezeichnet wird (Schutkowski 1998). Der Possibilismus sieht die Natur in einer passiven Rolle. Sie bildet den Rahmen für die Möglichkeiten des Menschen zur Entwicklung von Sozialformen und Subsistenzstrategien, in dem jedoch historische und kulturelle Faktoren über die Auswahl dieser Möglichkeiten entscheiden. Unterschiede zwischen Kulturen und der Richtung kulturellen Wandels resultieren aus der jeweiligen Kulturgeschichte der Gruppen und werden nicht durch die Umwelt dieser determiniert (Moran 2000).

Einer der prominentesten Vertreter des Historischen Partikularismus und Possibilismus war Franz Boas. Neben der Ablehnung des Naturdeterminismus kontert er den evolutionistischen 
Kulturtheorien auch durch die Feststellung, dass jede Kultur relativ ist und nur aus sich selbst zu verstehen (Barnard 2000). Gleichzeitig spricht er aber auch der Menschheit die Fähigkeit zu Innovation zu, was dem Grundgedanken der diffusionistischen Theorien widerspricht.

Auch wenn Evolutionismus und Diffusionismus zwei logisch entgegengesetzte Theorien darstellen, werden sie in ihrer Verwendung doch als komplementäre Perspektiven aufgefasst. Beide verbindet der diachrone Ansatz und gerade die Darstellung der ökologischen Ansätze hat gezeigt, dass aus beiden Paradigmen Ideen übernommen wurden (Barnard 2000). Umweltdeterminismus und Possibilismus sind auch als Extreme und Generalisierungen zu verstehen, die in ihren extremen Formen nur durch wenige Akteure vertreten wurden. Sie stellen die beiden Enden eines breiten Spektrums möglicher Mensch-Habitat Interaktionen dar. Dieser Umstand war der Forschung auch am Ende des 19. und dem beginnenden 20. Jahrhundert durchaus bewusst (Moran 2000).

Die sich im frühen 20. Jahrhundert ebenfalls entwickelnden klassischen funktionalistischen Ansätze von Radcliffe-Brown und Malinowski finden hier keine größere Beachtung, da sie nicht zur Diskussion über kulturellen Wandel beitragen. Diese Ansätze berücksichtigen die synchrone Ebene und konzentrieren sich auf Aktionen unter Individuen, bzw. die Funktion von Prozessen und Strukturen innerhalb von Gesellschaften (Barnard 2000). Trotzdem haben diese Theorien einen Einfluss auf die archäologische Kulturdiskussion, der im Kapitel 2.1.3. aufgegriffen wird.

Die Kritik am klassischen sozialen Evolutionismus veranlasste die Forscher ihre Ansichten zu überdenken. Moderne Theorien und Entwicklungsmodelle versuchen, unbelegte ethnozentrische Spekulation, Vergleiche und Werturteile zu vermeiden. Leslie White greift den Evolutionismus wieder auf, weist allerdings die vorgenommene Unterteilung in ,primitive“ und „Zivilisierte“ Gesellschaften zurück. Er argumentiert jedoch, man könne die Gesellschaften nach der von ihnen genutzten Energie unterscheiden. Ein gesteigerter Nutzen und Zugang zu Energie erlaubt danach eine größere soziale Differenzierung. Die primäre Funktion der Kultur sei es, Energie nutzbar zu machen und zu kontrollieren (White 1959). Kultur ist in seinem Verständnis eine materielle und mechanische Anpassung an die Umwelt. Damit nimmt White Abstand von den naturdeterministischen Theorien, führt aber auch gleichzeitig eine neue Determinante der Kulturentwicklung ein: die Energienutzung (Schutkowski 1998). Sein neoevolutionistisches Konzept ist unilinear und liegt noch sehr nahe an den klassischen Vorstellungen von Spencer und Morgan. Durch die grundlegende Annahme, dass die Entwicklung von Kultur nur in der zunehmenden Effektivität der Nutzung natürlicher Energien begründet liegt, entsteht ein sehr eindimensionales und monokausales Bild, das Kultur auf technologische Entwicklung reduziert (Bernbeck 1997). 
Whites Überlegungen sind der Grundstein für das, was heute als ökologische Anthropologie (Ecological Anthropology) bezeichnet wird. Es werden Grundprinzipien der allgemeinen Ökologie in die Betrachtung menschlicher Gesellschaften mit einbezogen. Dadurch verlagert sich der Untersuchungsschwerpunkt weg von kulturtypischem Verhalten hin zu der physiologischen und verhaltensmäßigen Adaptation an Umweltbedingungen (Schutkowski 1998). White unterteilt Kultur in drei Subsysteme: Technologie, Soziales und Ideologie, wobei soziale Systeme durch technologische Systeme bestimmt werden (White 1959). Die Übernahme von systemtheoretischen und funktionalistischen Ansätzen in die Betrachtung von Kultur und wandel schaffen das grundlegende methodische Werkzeug, die Vorgehensweise für die Analysen der ökologischen Anthropologie. Da versucht werden soll, Adaptation als einen Prozess darzustellen und zu analysieren, wird betont eine diachrone Untersuchungspespektive gewählt. Die Untersuchung ritueller Praktiken am Beispiel der Tsembaga in Neu Guinea von Roy Rappaport (1968) kann bis heute als einflussreichste Arbeit dieser fachlichen Ausrichtung angesehen werden. Rappaport versucht in dieser Arbeit unter Anwendung ökologischer Prinzipien, die homöostatische Regulation einer Population an die gegebene Ressourcenlage aufzuzeigen (Schutkowski 1998).

Ungefähr zeitgleich zu White entwickelt Julian Steward eine andere neoevolutionistische Theorie, die allerdings im Gegensatz zu Whites Ansatz den Fortschrittsgedanken ablegt und außerdem mit den Umwelt- und Kulturdeterministischen Ansätzen bricht, in dem er die Wechselwirkung zwischen Menschen und Umwelt betont (Schutkowski 1998). Die grundlegende These seiner Arbeit ist, dass zwischen den natürlichen Umweltbedingungen, der Subsistenz und den Sozialstrukturen einer Bevölkerung kausale Verbindungen bestehen (Steward 1955). Im Vergleich zu den anderen Theorien der kulturellen Evolution nimmt er den darwinschen Gedanken der Anpassung auf. Verschiedene naturräumliche Bedingungen und Technologien führen in seinem Verständnis zu unterschiedlichen Arten der Anpassung und ein Wechsel von Ressourcen oder Technologien führt auch zum Wandel von Kultur. Kulturen ändern sich also nicht durch eine innere Logik oder zielgerichtet, sondern durch eine veränderte Beziehung zur Umgebung. Dadurch durchläuft kulturelle Entwicklung nicht etwa stets gleiche Stufen, sondern kann sehr unterschiedliche Richtungen einschlagen (Steward 1955). Entscheidende Faktoren für die Entwicklung sind Technologie und Ökonomie, aber auch das politische System, Ideologien und Religion sollten als sekundäre Faktoren berücksichtigt werden. Auf Grund dieser Annahmen wird Stewards Theorie auch als multilinearer Evolutionismus bezeichnet (Barnard 2000). Gleichzeitig ist in Stewards Theorie und seiner Wahrnehmung der Interaktion von Mensch und Umwelt auch die anthropologische Methode der 
Cultural Ecology begründet. Die Cultural Ecology versucht, Regelhaftigkeiten und Gemeinsamkeiten im menschlichen Verhalten, der Sozialstruktur und der Ideologie verschiedener Kulturen zu finden, die als Reaktion auf bestimmte Umweltsituationen entstehen (Bargatzky 1986). In Anlehnung an den klassischen Funktionalismus wird ein funktionaler Zusammenhang, nämlich die gegenseitige Beeinflussung verschiedener sozialer Institutionen in einer Gesellschaft gesehen, wodurch es möglich wird, die Auswirkung der Veränderung einer dieser Komponenten auf die Anderen innerhalb des Systems zu untersuchen. Im Gegensatz zu Malinowski oder Radcliffe-Brown wird allerdings der diachrone Vergleich betont (Barnard 2000).

Steward formuliert drei Punkte, die für die Analyse der funktionalen Zusammenhänge innerhalb einer Gesellschaft relevant sind, die er auch unter dem Begriff Kulturkern (Culture Core) zusammenfasst: Umweltbedingungen und Wirtschaftsquellen; Beschaffenheit der Kultur, Technologie und Wissen und ihre potentielle Nutzbarkeit; Sozialorganisation. Dieser Kulturkern beinhaltet also alle sozialen und ideologischen Verhaltensmuster, die in einem engen Zusammenhang zu ökonomischen Abläufen und Subsistenz gesehen werden können (Schutkowski 1998). Der Einfluss der Umwelt beschränkt sich auf den Kulturkern, die anderen Kulturelemente oder die ,totale Kultur“, die nicht nur abhängig ist von Evolution und Umwelt, sondern auch empfänglich für Diffusion, entwickelt sich in einer autonomen Kulturgeschichte (Barnard 2000). Als Grundlage für seine Untersuchungen nimmt Steward den diffusionistischen Grundgedanken der Kulturareale (s.o.) wieder auf. In diesem „culture-area-approach“ korrelieren die Areale aber zu einem Großteil mit ökologischen Zonen (Steward 1948).

Auf der Basis von Stewards und Whites ökologischen Theorien der Kulturentwicklung entsteht in den darauf folgenden Jahren eine Vielzahl anderer ökologisch-anthropologischer Theorien und Schulen mit sich weitestgehend überschneidenden Inhalten wie: Ecological Anthropology, Human Adaptability, Biocultural Anthropology, Cultural Materialism und Human Ecology. Die Inhalte gründen sich entweder auf der whiteschen Wahrnehmung von Kultur oder auf der stewartschen. Insgesamt ist in dieser Entwicklung also eher eine zunehmende Partikularisierung als ein Zuwachs an neuen Theorien zu sehen (Herrmann 2008). Fast alle haben diese die Übernahme von Prinzipien der allgemeinen Ökologie auf die Analyse von menschlicherer Kultur und Gesellschaft gemein, was im Kontrast zu den sich entwickelnden kulturrelativistischen Ansätzen boasscher Prägung steht.

In ihrem Werk „Evolution and Culture“ (1960) versuchen Marshall Sahlins und Elman Service die Ansätze von White und Steward zu vereinigen. Sie unterteilen dabei die Entwicklung von Gesellschaften in ,allgemeine“ und „spezielle“ Evolution. Die allgemeine Evolution 
bezeichnet die Tendenz kultureller und sozialer Systeme, sich bezüglich ihrer Komplexität, Organisation und Anpassung an die Umgebung zu verbessern. Da Kulturen allerdings nicht isoliert sind, kommt es zur Interaktion und Vermischung mit anderen, z.B. in Form von Diffusion technologischer Innovationen. Bedingt durch die variablen Mechanismen des kulturellen Austausches, wie den möglichen Kombinationen von Elementen, die übernommen werden, oder den unterschiedlichen Zeiträumen, in denen dies geschieht, kommt es zur unterschiedlichen Ausprägung in einzelnen Kulturen: der „speziellen Evolution“ (Sahlins u. Service, E. 1960). Kultur hat also einen adaptiven Charakter, ist aber nicht biologischen Ursprungs. Sahlin betont, dass sich das jeweilige ökonomische System einer Gesellschaft in kulturell spezifischen Weisen an bestimmte Umstände anpasst (Sahlins 1977). Er übernimmt damit also kulturalistische Grundgedanken in eine ökologische Theorie. Service entwickelt aus diesen Überlegungen ein vierstufiges Schema der sozialen Evolution von Gesellschaften, auf das im folgenden Kapitel eingegangen werden soll. Ähnliche Konzepte wurden auch von Fried (1967) und Sahlins (1968) entwickelt.

Eine weitere kulturanthropologische Theorie, die sich heute auch im Kontext der Veröffentlichungen von Jared Diamond (2000, 2005) wieder besonderer Wahrnehmung erfreut, ist Marvin Harris „Kulturmaterialismus“. Harris` Theorie führt Kultur auf ihre materiellen Voraussetzungen zurück, also auf Geographie, Klima und Umweltbedingungen. Kulturen sind demnach Systeme, die sich an gegebene Umweltbedingungen anpassen und aus der Ökologie und Geographie heraus zu erklären sind (Harris 1968). Der Kulturmaterialismus vereint Evolutionstheorie mit marxistischen Theorieansätzen. Der Theorie liegt das Prinzip des „infrastrukturellen Determinismus“ zugrunde, welcher besagt, dass die Umweltbedingungen bzw. die natürlichen Ressourcen, die ökonomischen Bedingungen und die Reproduktionsmöglichkeiten von Kultur und Gesellschaft determinieren. Harris unterscheidet drei Kulturebenen: Infrastruktur, Struktur (Kultur) und Superstruktur (Verhalten und Denken), wobei die Infrastruktur elementar für die Entwicklung und Ausprägung von Struktur und Superstruktur ist (Harris 1968). Harris versucht, sowie auch später Jared Diamond in seinem Buch „Collapse. How Societies Choose to Fail or Succeed” (Diamond 2005), den Aufstieg und Untergang von Zivilisationen auf Basis dieser Annahmen zu erklären. Die Theorie, vor allem die Feststellung, dass Kultur aus dem Anpassungsdruck an die ökologischen Rahmenbedingungen entsteht, wird auch als Gegenrichtung $\mathrm{zu}$ den Theorien des Funktionalismus und des Strukturalismus gesehen (Bernbeck 1997).

Mit dem Aufkommen von Goulds Theorie des unterbrochenen Gleichgewichts (Punktualismus) in der Evolution (Gould u. Eldredge 1977) findet die Diskussion des Verlaufs 
von Entwicklung auch Einzug in die kulturevolutionistische Theorienbildung. Es wird der graduelle Verlauf der Kulturentwicklung angezweifelt. Stattdessen wird angenommen, dass nach langen Phasen eines kulturellen Equilibriums Perioden dramatischer kultureller Diversifikation aufkommen. Die Vielzahl der entstehenden neuen soziokulturellen Systeme ist kurzlebig bzw. maladaptiv und unterliegt konkurrierenden ökonomischen Konditionen (Prentiss u. Chatter 2003). Ausgelöst werden solche Diversifikationsphasen z.B. durch Perioden extremen ökologischen Wandels, die eine Nischenneuorganisation durch Wandel in Ökonomie, Organisation und Infrastruktur einer Kulturgruppe verlangen. Solche neuen „Baupläne“ können gemäß der Theorie auch bei der Aufspaltung von menschlichen Gruppen und gefolgtem Kommunikationsabbruch entstehen, bzw. durch geographische Isolation. Dieser Prozess wird als „Kulturelle Kristallisation“ bezeichnet (Rosenberg 1994). Eine Anlehnung dieser Theorien an Harris infrastrukturellen Determinismus (s.o.) scheint offensichtlich, denn über den Erfolg solcher neuen Baupläne entscheidet allein die Kongruenz bzw. Inkongruenz zwischen Ökologie und dem Ressourcenmanagement der Gruppe. Allerdings liegt hier die Betonung auf systematisch nicht zu erfassenden historischen Zufälligkeiten und darauf, dass sich eine Vielzahl von soziokulturellen Systemen entwickelt, die keinen Anpassungserfolg haben, worin auch gleichzeitig wieder ihre Kurzlebigkeit begründet ist (Prentiss u. Chatter 2003).

Generell ist die Mehrzahl der kulturökologischen Ansätze in einem evolutionistischen Kulturbegriff verankert. Erkenntnisse der biologischen Evolutionstheorie werden immer wieder aufs Neue auf die Entwicklung von menschlicher Kultur und Gesellschaften übertragen (Durham 1976). Dabei werden kulturelle Parallelen zu biologischen Mechanismen wie Selektion, Vererbung und anderen Quellen der Variation gesucht, die das Entstehen und den Wandel von Kultur erklären (Tab. 1).

Tab. 1: Drei mögliche Parallelen der Mechanismen biologischer und kultureller Evolution. Die Gewichtung der einzelnen Faktoren unterscheidet sich von Theorie zu Theorie (nach Durham 1976).

\begin{tabular}{c|cc}
\hline & biologische & kulturelle \\
& Evolution & Evolution \\
\hline Quelle der Variation & Unterschiede zw. Individuen & Erfindung, Diffusion, Zufall \\
\hline Selektionskriterium & optimale Anpassung & Beitrag zum Überleben \\
\hline Weitergabe von Merkmalen & differentielle Reproduktion & Sozialisation, Erziehung \\
\hline
\end{tabular}

Die Anwendung von Analogien aus der Biologie auf die Kultur ist teilweise kritisch zu betrachten, da es immer wieder zu Konstruktionsfehlern durch falsche Übertragungen z.B. des 
Nischenkonzepts oder der Sukzession kommt (Bernbeck 1997). Die Versuche, das MenschUmwelt Verhalten in komplexen Modellen festzuhalten, stehen dann vor einem Problem, wenn bedingt durch die Überlieferung keine vollständigen input-output Analysen möglich sind, wie z.B. bei der Betrachtung prähistorischer Kulturen. Dieses Problem betrifft auch Ansätze, die eine emische Betrachtungsebene von Kultur fordern. Diese ist im Falle mangelnder historischer oder ethnographischer Überlieferung nicht möglich. Weitere Kritik an der ökosystemaren Betrachtung von Kultur bezieht sich auf die häufig passiv dargestellte Rolle des Menschen und die „Kalorienobsession“ mancher Ansätze (Bernbeck 1997).

Unterschiede in der Organisationsform von Gesellschaften bedeuten auch ein unterschiedliches Verhältnis in der Wahrnehmung und Wirkungsweise von Natur. Viele ökologische Konzepte eignen sich bestens für die Anwendung auf sozusagen egalitäre Gesellschaften, scheitern aber bei der Erklärung der Entstehung komplexer Gesellschaften. Vor demselben Problem stehen gleichermaßen die rein kulturalistischen Ansätze (Flannery 1972). Das eigentliche Problem ist die Polarisierung der ökologischen und der kulturalistischen Lager. Kultur als reine Adaptation zu betrachten wird genau so wenig eine Lösung bringen, wie den biologischen Einfluss, den Einfluss der Umweltgegebenheiten auf den Menschen, zu vernachlässigen. Die Opposition von Kultur und Natur an sich mag die Grundlage des Problems sein, bzw. die Tatsache, dass fast jede Theorie einem dieser scheinbaren Opponenten eine passive Rolle zuspricht. Neben dem Menschen beeinflussen naturale Faktoren, die einer Eigengesetzlichkeit folgen, die Dinge der Natur ebenso, wie sie die Dinge der Menschen beeinflussen (Herrmann 2008).

Relativ spät erhält der Verhaltensaspekt Einzug in die Konzepte soziokultureller Evolution. Tradition bzw. Kultur muss zu ihrem Fortbestand von den Trägern dieser Kultur den folgenden Generationen vermittelt bzw. vererbt werden. Die Form der Vermittlung, z.B. vertikale Vermittlung (von Eltern zu Kind) oder horizontale Vermittlung (zwischen Menschen ohne Bezug zueinander), kann einen entscheidenden Einfluss auf die Ausprägung des kulturellen Merkmals haben (Mutation / Selektion). Der behaviorale Ansatz fasst unter dem Begriff „Kultur“ all jene Verhaltensweisen einer Bevölkerung zusammen, die über Generationen durch Lernen weiter gegeben werden können (Bayer 1994). Kultureller Wandel ist damit gleichzeitig ein Verhaltenswandel, der aus Veränderungen in der Weitergabe von Verhaltensinformationen resultiert (Scott 1989). Es soll im Folgenden nicht weiter auf behaviorale, soziobiologische Theorien oder die Memetik eingegangen werden. Aber die Erkenntnis, die auch schon im ökosystemaren Ansatz enthalten ist, dass Information bzw. auch die Art des Informationsaustausches eine entscheidende Größe bei Prozessen des Kulturwandels sein kann, 
spielt gerade bei der Entscheidung über den möglichen Einfluss von Bevölkerungsmobilität auf Kultur eine große Rolle (Prentiss u. Chatter 2003).

So wie die Diskussion um den anthropogenen Einfluss auf das Klima und dessen Folgen, hat auch die Diskussion über die Folgen klimatischen Wandels auf die menschliche Kulturentwicklung in den letzten Jahren wieder an Bedeutung gewonnen. Dabei wird weniger in den Dimensionen des klassischen Naturdeterminismus (s.o.) argumentiert, sondern vielmehr unter Verwendung der stewardschen Theorien der Mensch und die Natur als „wechselwirkende Komponenten eines konkreten raumzeitlich verorteten Systems“ verstanden (Eitel u. Mächtle 2006). Die physische Umwelt stellt den Kontext, in dem soziale, kulturelle, ökonomische und technologische Innovation möglich ist, aber diese auch begrenzt. Die Theorien basieren auf den Beobachtungen, dass soziokulturell dynamische Phasen mit klimatischen Verschlechterungen, vor allem zunehmender Aridisierung, einhergehen (Brooks 2006). Globaler Temperaturrückgang und damit verbundene Aridisierung, aber auch schwächere klimatische Fluktuationen führen anscheinend vor allem in äußerst klimasensitiven Wüstenrandgebieten, wie z.B. im mittleren und nahen Osten (Issar u. Zohar 2004), Nord-China (Brooks 2006) und auch der peruanischen Küste (Eitel u. Mächtle 2006) zur Entwicklung sozialer Komplexität. Aber auch generell korrelieren klimatische Ereignisse mit kulturellen (Abb. 1). Daraus wird abgeleitet, dass klimatisch bedingte Ökosystemreaktionen, die abrupte oder massive Änderungen der Lebensbedingungen bedingen, zur Innovation und Entwicklung adaptiver Reaktionen führen.

Evolutionistischen / ökologischen Theorien kann vorgeworfen werden, dass sie adaptive Notwendigkeiten voraussetzen und individuelle Entscheidungen als Faktor vernachlässigen, aber auch Historizismus oder Kulturrelativismus setzen Notwendigkeiten voraus. Zwar wird hier die Betrachtung jeder Kultur als individuelles System gefordert und evolutionistische Gesetzmäßigkeit abgelehnt, aber diese werden dann mit Gesetzmäßigkeiten von kultureller- und gesellschaftlicher Entwicklung ersetzt (Bernbeck 1997). Neuere Forschungsansätze, wie die „Umweltgeschichte“, versuchen die Einseitigkeit der Betrachtungsebene aufzuheben, Erkenntnisse der Natur- und Kulturwissenschaft zu kontextualisieren und diese im Anschluss im transdisziplinären Dialog zu deuten (Herrmann 2008). Diese Ausrichtung steht in der Tradition der Kulturökologie und hat einen ökosystemischen Ansatz. Sie unterscheidet sich aber von anderen Ansätzen dadurch, dass sie die Auswertung der Quellen der jeweiligen fachlichen Kompetenz überlässt und erst dann auf der transdisziplinären Ebene interpretiert. Generell ist der Trend in der Forschungsentwicklung abzusehen, dass verstärkt nach der Intention menschlichen Handelns gefragt wird, z.B. die Frage nach dem Antrieb zur Manipulation der Umwelt. 


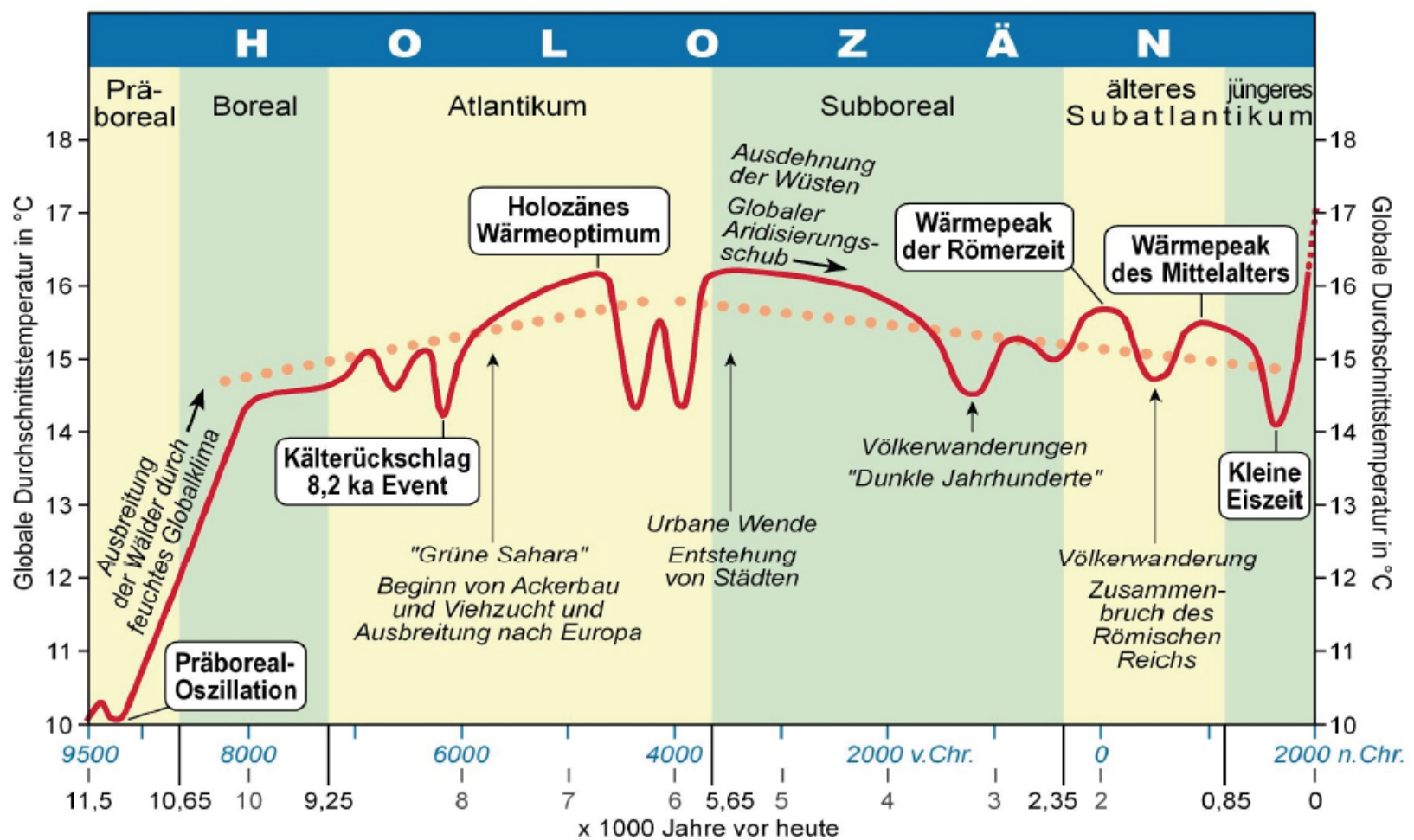

Abb. 1: Generalisierte Rekonstruktion des Temperaturverlaufs der Erdatmosphäre im Holozän. Deutlich wird, dass kurze, starke Klimaschwankungen über die gesamte Zeitspanne auftraten. Warmphasen sind dabei eher Feuchtphasen in den tropisch-subtropischen Trockengebieten, Abkühlungsphasen werden eher von Aridisierungen begleitet. Dargestellt sind einige klimatische Koinzidenzen mit kulturgeschichtlichen Umbruchsphasen in der Alten Welt (Eitel 2007)

Wie Kultur entsteht, was genau die Mechanismen kulturellen Wandels sind und welche Funktion Kultur hat, bleibt an diesem Punkt undefiniert. Es wurden verschiedene Theorien zur Bewältigung dieser Undefinierbarkeit aufgeführt. Darüber hinaus hat die ideengeschichtliche Zusammenfassung gezeigt, dass keine Einigkeit in der Bewertung der extrasomatischen Mittel zu finden ist, mit denen sich Menschen an ihre Umwelt bzw. die Ressourcenlage anpassen. Es gibt in diesem Zusammenhang keine absolute Wahrheit (frei nach K. Popper), und jegliche wissenschaftliche Erkenntnis ist geprägt durch die Ideologie des jeweiligen Wissenschaftlers. Aber gerade der zuletzt vorgestellte Ansatz verspricht durch die Einbeziehung einer Vielzahl von Quellen aber auch Interpretierender, dass man sich einer Erkenntnis relativ undogmatisch nähern kann. Da Kultur vom Menschen getragen wird und dieser sowohl ein biologisches aber auch soziales Wesen ist, sollte die Ursache für Entwicklung und Wandel von Kultur in einer Schnittmenge aus zwischenmenschlicher und Mensch-Umwelt Interaktion zu finden sein. Die Abhängigkeit von solarer Energie stellt eine definitive Grenze möglichen Wachstums einer Gesellschaft innerhalb eines Ökosystems dar. Änderungen der Bedingungen in einem Ökosystem (z.B. Klimawandel, Ressourcenverlust) können kulturelle Reaktionen zwar notwendig machen oder beeinflussen, aber nicht die Entscheidung für eine bestimmte Reaktion, bzw. die 
Entwicklung erfolgreicher Strategien erzwingen. Die große Zahl an möglichen Innovationen und adaptiven Strategien, die sich in prähistorischen aber auch rezenten Gesellschaften beobachten lassen, führt zu der zusammenfassenden Behauptung, dass Theorien zur Kulturentwicklung auf empirische Erkenntnisse zurückgreifen müssen.

\subsubsection{Komplexe und frühstaatliche Gesellschaften}

Die Pazifikküste Perus und das zentralandine Hochland sind kulturell dynamische Zonen, in denen es spätestens ab 3000 v. Chr. zur Ausbildung komplexer Gesellschaften und großer Siedlungszentren mit monumentaler Architektur wie Caral (ca. 2700 v. Chr.) bis hin zur Ausbildung frühstaatlicher Gesellschaften wie Chavín (1. Jhd. v. Chr.) bzw. den folgenden Staaten wie Tiwanaku, Moche oder Huari kam (Stanish 2001). Die Beschäftigung mit der Bevölkerungsgeschichte des südlichen Perus macht es daher notwendig, kurz die ökonomischen und ökologischen Konsequenzen dieses Aspekts des Kulturwandels anzusprechen. Als Basis der hier angestellten Überlegungen sollen Elman Services Arbeiten zur sozialen Evolution von Gesellschaften dienen. Wie bereits im Kapitel zuvor erwähnt, entwickelte Service ein vierstufiges System der Entwicklung menschlicher Gesellschaften. Die Stufen sind gleichbedeutend mit der politischen Organisationsform: Horde (Gruppe), Stamm, Häuptlingstum und Staat (Service 1962). Seine Theorien beruhen auf Analysen von Kulturen unterschiedlichster Komplexitätsgrade aus verschiedenen Zeitstellungen und Teilen der Welt. Daraus resultiert ein verallgemeinerndes Modell, das auf fast alle menschlichen Gesellschaften angewendet werden kann (Sanderson 1999). Die Charakteristika der jeweiligen Organisationsformen (nach Service) sind stichwortartig in Tabelle 2 dargestellt.

Aus der Perspektive von Sevice resultiert die Stratifizierung von frühen komplexen Gesellschaften nicht aus dem unterschiedlichen Zugang $\mathrm{zu}$ Ressourcen, sondern aus ideologischen und politischen Prozessen (Service 1962). Zugang zu und Nutzung von Energie entscheidet demnach nicht über die individuelle Stellung. Die Entwicklung von komplexen Sozialstrukturen ist damit keine notwendige Anpassung an die Umwelt.

Die wissenschaftliche Diskussion über die Gründe der Ausbildung sozialer Komplexität verläuft im Rahmen der von Determinismus und Possibilismus flankierten Ansätze und Theoriekonzepte, die in Kapitel 2.1.1. vorgestellt wurden. Sie ist durch die gleiche Dichotomie ökologischer und kulturalistischer Ideen geprägt. Etwas gesondert ist die Diskussion über die Entstehung von Staaten zu betrachten. Als grundlegende Mechanismen bzw. Determinanten werden die Anlage und Verwaltung von Bewässerungssystemen (Wittfogel 1957), Krieg 
Tab. 2: Service` Typologie der Evolution sozialer Komplexität (nach Service 1962, erweitert vom Autor). Die Tabelle zeigt die grundlegenden Charakteristika der jeweiligen sozialen Organisationsformen.

\begin{tabular}{|c|c|c|c|c|}
\hline & Gruppen & Stämme & Häuptlingstümer & Staaten \\
\hline Siedlungen & $\begin{array}{l}\text { - Mobil } \\
\text { - geringe } \\
\text { Bevölkerungs- } \\
\text { dichte }\end{array}$ & $\begin{array}{l}\text { - semipermanent } \\
\text { - autonome } \\
\text { Siedlungen }\end{array}$ & $\begin{array}{l}\text { - umfassen mehr als } \\
\text { eine Siedlung } \\
\text { - teilweise stratifiziert } \\
\text { Siedlungsstruktur }\end{array}$ & $\begin{array}{l}\text { - viele Siedlungen } \\
\text { - stark stratifizierte } \\
\text { Siedlungsstruktur }\end{array}$ \\
\hline $\begin{array}{l}\text { Subsistenz- } \\
\text { strategie }\end{array}$ & $\begin{array}{l}\text { - Jagen/Sammeln } \\
\text { - Nomadismus }\end{array}$ & $\begin{array}{l}\text { - Hortikultur } \\
\text { - Pastoralismus }\end{array}$ & - Agrikultur & $\begin{array}{l}\text { - intensive Agrikultur } \\
\text { - Handel }\end{array}$ \\
\hline Ökonomie & $\begin{array}{l}\text { - reziprok } \\
\text { (Austausch) }\end{array}$ & $\begin{array}{l}\text { - reziprok } \\
\text { - geringfügig } \\
\text { redistributiv }\end{array}$ & $\begin{array}{l}\text { - redistributiv } \\
\text { (Umverteilung) } \\
\text { - handwerkliche } \\
\text { Spezialisierungen }\end{array}$ & $\begin{array}{l}\text { - marktwirtschaftlich } \\
\text { - komplexe Arbeits- } \\
\text { Spezialisierung }\end{array}$ \\
\hline Sozialstruktur & - egalitär & $\begin{array}{l}\text { - aufkommende } \\
\text { Status- } \\
\text { Unterschiede } \\
\text { (aber nicht } \\
\text { permanent) }\end{array}$ & $\begin{array}{l}\text { - hierarchisch } \\
\text { geoordnete } \\
\text { Gesellschaft (mit } \\
\text { Variation in Größe } \\
\text { und Integration) }\end{array}$ & $\begin{array}{l}\text { - klar definierte } \\
\text { soziale Schichten } \\
\text { - stark stratifiziert }\end{array}$ \\
\hline $\begin{array}{c}\text { Politisches } \\
\text { System }\end{array}$ & $\begin{array}{l}\text { - keine } \\
\text { Zentralisierung } \\
\text { - Konsens- } \\
\text { Entscheidungen } \\
\text { - Nur informelle, } \\
\text { zeitlich befristete } \\
\text { Anführer }\end{array}$ & $\begin{array}{l}\text { - keine } \\
\text { Zentralisierung } \\
\text { - Teilzeit-Ämter } \\
\text { - Macht wird durch } \\
\text { Fähigkeiten oder } \\
\text { Wissen erlangt }\end{array}$ & $\begin{array}{l}\text { - zentralisierte } \\
\text { Regierungsgewalt } \\
\text { - Macht wird vererbt } \\
\text { oder göttlich } \\
\text { legitimiert } \\
\text { - kein formaler } \\
\text { legaler Apparat der } \\
\text { gewaltsamen } \\
\text { Repression }\end{array}$ & $\begin{array}{l}\text { - zentralisiert } \\
\text { - } \text { spezialisierte } \\
\text { politische } \\
\text { Institutionen } \\
\text { - Monopol über } \\
\text { Gewaltmittel } \\
\text { - Macht basiert auf } \\
\text { definierten Gesetzen }\end{array}$ \\
\hline
\end{tabular}

(Carniero 1970), Bevölkerungswachstum (Dumond 1972), Handel und die Symbiose verschiedener Kulturen (Feinmann 1991, zit. nach Sanderson 1999), sozioökologischer Stress oder auch multivariante Faktoren (Wright 1970, zit. nach Sanderson 1999) angegeben. Für einen umfassenden Einblick in die einzelnen Theorien sei an dieser Stelle auf Arbeiten verwiesen, die gute Kompilierungen darstellen, u.a. Flannery (1972) oder Sanderson (1999). Die Unterscheidung zwischen Häuptlingstümern und Staaten, Zivilisationen oder Hochkulturen ist an dieser Stelle zunächst nicht relevant.

Ein Charakteristikum, das mit dem Entstehen komplexer Gesellschaften einhergeht, ist die Zunahme handwerklicher oder im weiteren Verlauf auch administrativer Spezialisierungen (Tab. 2). Diese Spezialisten sind nicht, oder nur teilweise, in die Produktion von Nahrungsmitteln 
integriert, was wiederum bedeutet, dass die Nahrungsproduktion in der Gesellschaft auf die Erwirtschaftung eines Überschusses ausgerichtet sein muss. Soziale Eliten verwalten und kontrollieren die notwendigen Stoffströme und fordern ihren Anteil (Flannery 1972). Es bleibt die Frage, ob zuerst der Überschuss, z.B. durch verbesserte Produktionstechnik, da war und damit die Ausbildung von Spezialisierungen ermöglichte, oder ob Innovation und Spezialisierung den Überschuss notwendig machten. Sahlins Untersuchungen zu Jägern und Sammlern zeigt, dass Freizeit alleine nicht Innovation bedingt und auch in ,primitiven“ Agrarkulturen keine altruistische Produktionstendenz besteht, die Andere frei stellt (Sahlins 1972). Dementsprechend muss es eine Entscheidungsebene geben, die die Erwirtschaftung von Überschuss bestimmt und die Umverteilung kontrolliert. Die ökonomische Konsequenz ist also der Wandel von reziproken zu redistributiven und später marktorientierten Wirtschaftssystemen.

Der Einflussbereich einer Entscheidungsinstanz bezieht sich auf mehrere Siedlungen (vgl. Tab. 2). Es kommt zur Ausbildung von Administrativen-, Rituellen- oder einfach nur Siedlungszentren, die sich in Größe und Funktion von anderen Siedlungen unterscheiden. Diese Zentren, die unter Umständen später auch zu Städten heranwachsen, müssen von außen mit Rohstoffen und Nahrungsmitteln versorgt werden. Das bedeutet, dass eine gewisse Zahl abhängiger Siedlungen bestehen muss, um einen derart hohen Überschuss zu produzieren (Childe 2001). Auch diese Siedlungsgemeinschaften können auf die Produktion bestimmter Güter spezialisiert sein. Im Falle von Staaten oder Hochkulturen existieren stark stratifizierte, mindestens viergliedrige Siedlungsstrukturen (Hauptzentren, regionale Zentren, Dörfer und Städte, Weiler; Renfrew u. Bahn 2004). Diese Urbanisierungstendenz führt zu einem zuvor nicht gekannten Verhältnis von Produktionsflächen zu Siedlungsflächen und in Konsequenz zu dem Aufkommen einer neuen Ökosystemgattung, der Stadt. Neben Nahrungsmitteln und Rohstoffen für die Produktion von Gütern besteht auch ein erhöhter Bedarf an Baumaterial, ob nun für Profan- oder Monumentalarchitektur. Dieser kann nicht unbedingt durch das direkte Umfeld gedeckt werden (Childe 2001).

Bereits Häuptlingstümer können bis zu mehrere tausend Menschen umfassen (Flannery 1972). Die reine Zahl der Personen, die damit eine Gemeinschaft bilden, verlangt nicht nur komplexere ökonomische Strukturen, sondern darüber hinaus komplexere Informationsstrukturen und Raum. Daraus resultieren im gesamten kulturellen Einflussbereich eine Verschiebung der Interaktion von Mensch und Umwelt, aber auch die interkulturellen Verhältnisse, Stoff- und Informationsströme, von einer Individuellen- auf die Bevölkerungsebene. Wissen und Innovation verteilt sich wie auch Macht ungleich auf die Bevölkerung. Arbeitskraft kann nicht mehr in der reinen Zahl der Menschen gemessen werden, 
sondern ist abhängig von der Koordinierung und kontrollierten Verteilung der Produktionsmittel. Es besteht also, selbst vor der Ausbildung realer sozialer Stratifikation, ein komplexes Abhängigkeitsverhältnis innerhalb der Gesellschaft (vgl. auch Rosenberg 1994). Aus diesen Entwicklungen ergeben sich Veränderungen der Individual- und Bevölkerungsmobilität. Hierauf soll in Kapitel 2.1.4. eingegangen werden. Weitere Merkmale und Auswirkungen sozialer Komplexität und die Frage nach der Ausbildung staatlicher Gesellschaften werden im Rahmen der Vorstellung der peruanischen Kulturgeschichte behandelt werden. An dieser Stelle sei nur noch einmal auf Service` Typologie verwiesen (Tab. 2), die im folgenden Verlauf der Arbeit als Definitionsgrundlage dienen soll.

\subsubsection{Archäologie und Migration: Ein forschungsgeschichtlicher Überblick}

Es besteht kein Zweifel daran, dass Menschen in prähistorischer Zeit ihren Lebensraum verließen, um sich an neuen Orten niederzulassen. Wie bereits in der Einleitung erwähnt, stellt der Nachweis solcher Migrationen ${ }^{2}$ ein Problem dar, da diese in Zeiten vor der schriftlichen Dokumentation oder der staatlich gesteuerten Erfassung stattfanden. Dieser Umstand erschwert auch das Verständnis, in wie weit sie einen Einfluss auf die kulturelle Entwicklung des Ziel- und Ausgangsortes hatten. Während für die Beantwortung der Frage nach dem „ob“ mittlerweile Werkzeuge aus den Naturwissenschaften zur Verfügung stehen, auf die in folgenden Kapiteln eingegangen wird, besteht in der Archäologie immer noch ein methodisches und theoretisches Defizit hinsichtlich der Einbeziehung von Migrationen in die Begründung für Kulturwandel (Anthony 1990). Das Problem ergibt sich aus der Natur der Hauptquelle, die der Archäologie zur Verfügung stehen: materielle Hinterlassenschaften vergangener Kulturgruppen. Die daraus resultierende Frage ist, wie räumliche und zeitliche Variationen im archäologischen Fundspektrum bzw. der materiellen Kultur zu interpretieren sind (Shennan 2000). Der Wandel im theoretischen Überbau der Archäologie führte auch zu verschieden Lösungsansätzen. Deshalb soll hier ein kurzer forschungsgeschichtlicher Überblick über die Wahrnehmung des Phänomens „Migration“ in der Archäologie erfolgen.

Die Archäologie des ausgehenden 19. und beginnenden 20. Jahrhunderts war klar durch die diffusionistischen Kulturtheorien geprägt. In starker Anlehnung an Frobenius bzw. Ratzels Kulturkreislehre stand die Charakterisierung kultureller Traditionen anhand der materiellen Hinterlassenschaften sowie ihre räumliche und zeitliche Verbreitung im Zentrum des Interesses (Gramsch 2006). Die grundlegende Methode dieses, auch Kulturhistorische Schule genannten Ansatzes, war die Kartierung der Verbreitung spezifischer Artefakttypen. Anhand der sich

\footnotetext{
${ }^{2}$ Unter dem Begriff „Migration“ soll hier das gefasst werden, was in der Soziologie als „Wanderung“, also den dauerhaften Wohnortswechsel über die Gemeindegrenzen hinaus, bezeichnet wird (Knox u. Marston 2001).
} 
ergebenden Verbreitungsmuster wurden Kulturprovinzen definiert. Änderungen im Typenspektrum bildeten die Grundlage zur Einteilung von Perioden und Phasen (Shennan 2000). Diese räumlichen und zeitlichen Wesenheiten wurden nicht nur als archäologische Kulturen definiert, sondern zumeist auch mit menschlichen bzw. ethnischen Gruppen gleichgesetzt. Ein signifikanter Wandel im Typenspektrum wurde dieser Logik entsprechend mit dem Austausch der Kulturträger erklärt (Burmeister 2000). Neben dieser Form der Migration, die auch als Invasion bezeichnet werden kann, wurden Handel und soziale Kontakte als weitere Diffusionsmechanismen für materielle Kultur angenommen. Der Einfluss dieser Mechanismen auf die jeweilige Kulturentwicklung wurde allerdings als gering eingeschätzt (Shennan 2000). Dieser Ansatz ähnelte sich in Europa und Amerika. Generell galt es auf Basis induktiver Schlussfolgerungen einmalige Ereignisabfolgen zu rekonstruieren. Wie auch im Historischen Partikularismus wurde der Vergleich zwischen Kulturen als sekundär angesehen. Es stand im Vordergrund, Objektassemblagen räumlich einzugrenzen (Bernbeck 1997). Es ist allerdings zu erwähnen, dass grade in der deutschen prähistorischen Archäologie verstärkt der Einfluss von Invasionsprozessen auf den Kulturwandel betont wurde. Dieser Umstand geht wohl nicht zuletzt aus dem vorherrschenden ethnischen Paradigma der deutschen Archäologie (Gramsch 2006) hervor, welches stark von Gustav Kossinas Ausführungen seiner „Siedlungsarchäologischer Methode“ geprägt wurde:

„Scharf sich heraushebende, geschlossene archäologische Kulturprovinzen fallen unbedingt mit bestimmten Völker- und Stammesgebieten zusammen " (Kossina 1912)

Diese ethnische Ausdeutung von archäologischen Fundgruppen prägte den Kulturbegriff der deutschen Archäologie bis in die 40er Jahre des 20. Jahrhunderts und fand besonderen Anklang in der germanischen Kontinuitätstheorie des nationalsozialistischen Regimes. Es finden sich allerdings auch differenzierte Ansätze zur Erklärung von Kulturverbreitung und Kulturwandel, die nicht nur den grundlegend vulgär-sozialdarwinistischen Mechanismus der Invasion als Begründung aufführen. So findet sich in Jacob-Friesens Verbreitungslehre (1928, zit. nach Eggert 2001) der Hinweis auf die Auswirkung der „natürlichen Umwelt“ auf die Kulturentwicklung.

Unabhängig von den Entwicklungen in der deutschen Archäologie zeigt sich die Prägung durch die kulturhistorische Schule z.B. auch in den Werken von V. Gordon Childe zur Neolithisierung Europas (Childe 1925; Childe 1950). Die wertende ethnische Interpretation fand außerhalb von Deutschland kaum Gegenliebe und verlor sich auch dort spätestens ab 1945. Aber der Grundgedanke, dass Artefaktassemblagen Gesellschaften repräsentieren, die sich über Migration und Diffusion weiterentwickelten, bleibt das theoretische Erklärungsmodell der 
internationalen Archäologie bis zum Beginn der 60er Jahre des 20. Jahrhunderts (Friedlaender et al. 2002).

Einer der Hauptkritikpunkte an der kulturhistorischen Archäologie war und ist, dass nicht nach Motivation oder Kausalität der postulierten Migrationen und Invasionen gefragt wurde. Sie wurden einfach induktiv aus den Verbreitungen materieller Kultur abgeleitet. Fundverbreitungskarten wurden eins zu eins in Prozesse der Kulturentwicklung übersetzt. Die möglichen Verbreitungsmechanismen wie Migration, Handel und Diffusion wurden nicht systematisch betrachtet (Burmeister 2000). Diese inadäquate methodische und theoretische Basis der traditionellen Archäologie führte zur Ablehnung von Migration als Erklärungskonzept für Kulturwandel mit dem Aufkommen der „New Archaeology“ in der angloamerikanischen Archäologie der 1960er Jahre. In Anlehnung an Whites neoevolutionistische Theorien (s.o.) entwickelte Lewis Binford, einer der Protagonisten der New Archaeology, den prägenden Kulturbegriff für diese wissenschaftliche Strömung:

„Culture is viewed as the extrasomatic means of adaption for the human organism“ (Binford 1962)

Die Wahrnehmung von Kultur, insbesondere der materiellen Kultur, als Mittel der Adaptation an die soziale und naturale Umwelt verschiebt den Schwerpunkt der Untersuchungen von Form und Verbreitung $\mathrm{zu}$ der Funktion von Artefakten und der internen Dynamik von Kulturen (Friedlaender et al. 2002). Dieses funktionalistische Konzept stellt die Bedeutung von Migrationen zurück. Der Trend zur System Analyse verdeutlicht das Problem, dass Migrationen anhand des archäologischen Fundspektrums schwer nachzuweisen oder $\mathrm{zu}$ analysieren sind (Kuhn 1976). Die Existenz von Migrationen wird in der New Archaeology bzw. der Prozessualen Archäologie allerdings nicht generell verneint, sondern nur ein möglicher Einfluss auf die Kulturentwicklung. Kulturwandel wird in erster Linie als Adaptationsprozess gesehen und damit als autochthon. Statt zuvor postulierter Massenmigrationen steht jetzt die kulturinterne Populationsdynamik als Hauptfaktor für Wandel im Vordergrund: Bevölkerungswachstum übt Druck auf die Ressourcenlage aus, der durch technologische Innovation und Anpassung und damit einem Wandel im kulturellen Bauplan kompensiert wird (Binford u. Binford 1968; Renfrew 1973; Shennan 2000). Diese Position ist gegenläufig zu der zuvor vorherrschenden Anwendung des „neo-malthusianistischen-Axioms“ auf die demographische und kulturelle Entwicklung menschlicher Gesellschaften, wie z.B. durch Childe. Hier wurde Kulturwandel als Auslöser von Wachstum gesehen. Technologische Innovation erlaubt, über ein Limit hinaus zu wachsen und ist nicht die Konsequenz aus Wachstum, wie es in der Prozessualen Archäologie postuliert wird (Chamberlain 2006). 
Die 1960er und 70er Jahre sind geprägt durch eine Dichotomie im Bezug auf historische Migrationen. Auf der einen Seite kann man die Prozessuale Archäologie verorten, die das Interesse an Migrationen in den Hintergrund stellt und einige wenige Immobilisten, die sogar ganz und gar die Existenz solcher Prozesse verneinen (Härke 1998). Dem gegenüber steht auf der anderen Seite die Genetik, die mit fortschreitenden Möglichkeiten ein besonderes Interesse an der menschlichen Bevölkerungs- und Besiedlungsgeschichte der Erde entwickelt und sich dabei vor allem auf Massen- und Langstreckenmigrationen bezieht (Fix 1999). Auch in der Soziologie stellen die 1960er und 70er Jahre einen dynamischen Zeitabschnitt der Migrationsforschung dar. Die wissenschaftliche Untersuchung des Phänomens „Migration“ reicht hier allerdings viel weiter zurück und hat ihren Ursprung in der im ausgehenden 19. Jahrhundert von Ernest Georg Ravenstein begründeten Migrationstheorie. Ravenstein stellte auf der Basis empirischer Beobachtungen im Vereinigten Königreich seine so genannten „Wanderungsgesetze“ auf. Seine Theoreme lauten sinngemäß (zit. nach Han 2006):

1. Die Mehrzahl der Wanderungsvorgänge erfolgt über kurze Distanzen,

2. Wanderungen über größere Distanzen verlaufen häufig in Etappen (Kettenwanderung),

3. Bei Wanderungen über größere Distanzen werden große Industrie- und Hafenstädte als Zielorte bevorzugt,

4. Wanderungsströme bestehen stets aus zwei gegenläufigen Komponenten,

5. Die Landbevölkerung ist in Wanderungsströmen überrepräsentiert,

6. Frauen wandern eher über kürzere, Männer eher über längere Distanzen,

7. Die Mehrzahl der Migranten sind Alleinstehende,

8. Die Bevölkerungszunahme in Städten ist mehr durch Wanderungsgewinne, als durch natürliche Bevölkerungsbewegungen bedingt,

9. Das Wanderungsvolumen steigt synchron mit der industriellen und verkehrstechnischen Entwicklung,

10. Die meisten Wanderungsvorgänge werden durch ökonomische Anlässe ausgelöst.

Ravensteins Überlegungen aber auch vor allem Lees individualisierte „Push and Pull“ Theorie (Lee 1972), eine Weiterentwicklung der klassischen Gravitationsmodelle, wurden nur mit großer zeitlicher Verzögerung prägend für die archäologische Migrationsdiskussion. Lees Ansatz basiert vornehmlich auf der Analyse von verschiedenen, individuell relevanten Faktoren im Ausgangs- und Zielgebiet von Bevölkerungswanderungen, z.B. den demographischen, sozialen 
und ökonomischen Bedingungen, aus denen sich die Kausalität des Migrationsprozesses erklärt (Lee 1972). Das bedeutet, das im Zielgebiet eine Reihe positiver Faktoren oder Anziehungskräfte („Pull-Faktoren“) wirken und im Herkunftsgebiet mögliche negative Faktoren oder Abstoßungskräfte (,Push-Faktoren“) wirksam sind, die die Wanderungswahrscheinlichkeit erhöhen (Tab. 3).

Tab. 3: Faktoren der individuellen Migrationsmotivation nach Lee (1972). „Push“-Faktoren sind abstoßende Faktoren des Ursprungsgebietes, „Pull“-Faktoren anziehende des Zielgebietes. Die einzelnen Faktoren beziehen sich auf die Struktur moderner Gesellschaften. Die fettgedruckten Zeilen bezeichnen die Hauptmotivationsebenen.

\begin{tabular}{|c|c|}
\hline „Push“ Faktoren & „Pull“ Faktoren \\
\hline $\begin{array}{l}\text { Ökonomische Probleme } \\
\text { - Arbeitslosigkeit, kaum Einkommen } \\
\text { - niedriges Lohnniveau } \\
\text { Soziale Probleme } \\
\text { - Armut } \\
\text { - religiöse Verfolgung } \\
\text { - Unsicherheit } \\
\text { - (Rassen-)Diskriminierung } \\
\text { Ereignisse } \\
\text { - Katastrophen } \\
\text { Demographische Probleme } \\
\text { - Landknappheit } \\
\text { - Überbevölkerung } \\
\text { Politische Konflikte } \\
\text { - politische Verfolgung } \\
\text { - Gesetze } \\
\text { - Krieg } \\
\text { - Hohe Steuern } \\
\text { - Enteignung } \\
\text { • (Rassen-)Diskriminierung }\end{array}$ & $\begin{array}{l}\text { Ökonomische Vorteile } \\
\text { • Hochkonjunktur } \\
\text { - große Arbeitsnachfrage } \\
\text { - gute Verdienstmöglichkeiten } \\
\text { - informelle Sektoren } \\
\text { - gute Verkehrsanbindung } \\
\text { Soziale Vorteile } \\
\text { - Sicherheit } \\
\text { - gute Wohnmöglichkeiten } \\
\text { - Toleranz (z.B. religiöse) } \\
\text { - Bildungsmöglichkeiten } \\
\text { - entwickeltes Gesundheitssystem } \\
\text { - breit gefächertes Freizeitangebot } \\
\text { Demographische Vorzüge } \\
\text { - ausreichendes Flächenangebot } \\
\text { Politische Vorteile } \\
\text { - günstige Einwanderungsgesetze } \\
\text { - Möglichkeit illegaler Einwanderung } \\
\text { - Akzeptanz }\end{array}$ \\
\hline
\end{tabular}

Mit dem Ende der Vorherrschaft der Prozessualisten in der angloamerikanischen Archäologie in den späten 1970er und frühen 1980er Jahren wird auch der Migration wieder mehr Beachtung geschenkt und die Erkenntnisse aus Sozial- und Naturwissenschaften mit in die Theorienentwicklung einbezogen. Die Kritik der postprozessualen Archäologen bezieht sich zum einen auf den ahistorischen Funktionalismus der prozessualen Archäologie (Hodder 1982) und 
zum anderen auf das Adaptationskonzept (Eggert 2005). Erstere bezieht sich auf Binfords Forderung, die kulturinternen funktionalen Zusammenhänge von materieller Kultur zu untersuchen und nicht den diachronen interkulturellen Vergleich und die historische Entwicklung in den Vordergrund $\mathrm{zu}$ stellen (Binford u. Binford 1968). Statt gesellschaftliche Entwicklung und damit auch die materielle Kultur nur als adaptive Reaktion auf Umweltbedingungen $\mathrm{zu}$ sehen, wird jetzt gefordert, die materielle Kultur unter dem Gesichtspunkt ihrer gesellschaftlichen Bedeutung und der Motivation ihrer Herstellung und Nutzung zu betrachten (Hodder 1982). Die Archäologie steht vor dem gleichen Problem des Migrationsnachweises: der Quelle. Aber anders als in dem positivistisch materialistischen Ansatz der kulturgeschichtlichen Schule wird jetzt in Anlehnung an die soziologische Migrationsforschung (s.o.) versucht, die Motivation, also die „Push“ und „Pull“ Faktoren, der Migration $\mathrm{zu}$ ergründen und Möglichkeiten $\mathrm{zu}$ finden, diese im archäologischen Befund nachzuweisen (Anthony 1990). Dies verlangt ein stärkeres Einbeziehen der Erkenntnisse und Theorien aus den Sozialwissenschaften, der Ethnologie und anderen Humanwissenschaften und vor allem die Entwicklung eigener wissenschaftstheoretischer Konzepte bzw. eines theoretischen Überbaus.

Eine weitere Entwicklung, die aus dem stärkeren Bezug auf die Erkenntnisse der Sozialwissenschaften resultiert, ist die bewusste Herabsetzung der Bedeutung von so genannten Long-Range Migrationen (vgl. Ravensteins Theorem 1). Nachdem dieses klassische Migrationsmodell der Invasionisten und der Kulturhistorischen Archäologie sich auf eine große Bevölkerungsbewegung (Völkerwanderung) in einem mehr oder weniger scharf einzugrenzenden Zeitfenster bezog, stehen jetzt Migrationsmodelle im Vordergrund, die eher kleinräumige, aber sich zeitlich kontinuierlich fortsetzende Bevölkerungsexpansionen als den Regelfall annehmen (Friedlaender et al. 2002). Im Kontrast zur prozessualen Archäologie wird die Bedeutung autochthoner Kulturentwicklung, aber auch die aggressive Kulturüberprägung der Kulturhistorischen Schule herabgesetzt. Vielmehr werden Fremdbeeinflussung von Kulturentwicklung durch Prozesse demischer Diffusion oder Infiltration erklärt. Eines der wohl einflussreichsten Modelle war und ist das Wave of Advance Modell (Ammerman u. CavalliSforza, L. 1984). Hier wird davon ausgegangen, dass demographisches Wachstum einer Kultur zu ihrer stetigen Ausbreitung über die Perimeter des Kulturraumes führt. Die Ausbreitung von Kulturträgern in den Raum anderer führt zur kulturellen Überprägung oder Verdrängung. Dieses Modell bezieht sich vor allem auf die Ausbreitung der produzierenden Lebensweise des Neolithikums in Europa und der damit verbundenen Aufgabe aneignender Wirtschaftsweisen bzw. der Verdrängung der indigenen Jäger \& Sammler (Ammerman u. Cavalli-Sforza 1984). Als 
Argument gegen Massen- bzw. Long-Range Migrationen wird angeführt, dass kontinuierlich raumgreifende Prozesse wie die „Wave of Advance“ aus der emischen Perspektive der Archäologie betrachtet zu dem gleichen Ergebnis führen wie kurzfristige Massenbewegungen. Letztere stellen allerdings unter Berücksichtigung der Motivation hinter der Migration aber auch der Erkenntnisse der Populationsgenetik eine bessere Erklärung für die Prozesse dar (Friedlaender et al. 2002).

Erst Anfang der 1990er Jahre werden Long-Range- bzw. Massenmigrationen wieder in den Theorienkanon der Archäologie aufgenommen. Interdisziplinäre Erkenntnisse - etwa zur Besiedlungsgeschichte Australiens oder der amerikanischen Kontinente - aus Genetik, Anthropologie und Archäologie liefern die Evidenzen für solche Prozesse. Anthony (1990) beschreibt sie als separate und wichtige Phänomene der Menschheitsgeschichte. Als grundlegende Ursache sieht er Schwerpunktökonomien, die zu einer schnellen Ausbeutung bzw. Übernutzung von Ressourcen führen und damit eine starke Mobilität der Kulturgruppe verlangen. Die durch solche „Push“-Faktoren bedingten Bevölkerungsbewegungen äußern sich dann nicht in Wellen (Anthony 1990). Anthony fordert außerdem, dass Migration als ein strukturiertes menschliches Verhalten wahrgenommen werden soll. Ein Verhaltensmuster, das unter konstruktivistischer Betrachtung individueller Handlungen im historischen Kontext dadurch charakterisiert wird, das es von definierten Subgruppen einer Gesellschaft mit spezifischen Zielen ausgeführt wird. Diese gilt es zu ergründen, um zu verstehen, wie sie sich in der materiellen Kultur manifestieren können (Anthony 1990). Im Folgenden sollen ohne den Anspruch der Vollständigkeit die einflussreichsten archäologischen Migrationstheorien aufgelistet und erklärt werden:

- Invasion

- Wave of Advance

- Folk Migration
Eine aggressiv expandierende Kulturgruppe dringt in den Lebensraum einer anderen ein und verdrängt diese (vgl. Anthony 1990).

Auch „demische Diffusion“: Demographisches Wachstum führt zu einer langsamen Ausbreitung von Familiengruppen und Bildung von Nachbarsiedlungen durch die folgenden Generationen (CavalliSforza et al. 1983; Ammerman u. Cavalli-Sforza 1984).

Direktionale Bewegung einer Population von einer Siedlung oder einem Gebiet in ein neues. Bezieht sich auch auf sehr große Bevölkerungsgruppen (Mass migration) und das Zurücklegen großer Strecken (Long Range Migration) (Anthony 1990). 
- Elite Dominance

- Leapfrog Colonisation

- Frontier Mobility

- Infiltration
Einzug einer zahlenmäßigen Minderheit in ein neues Gebiet, die anschließend soziale, kulturelle und/oder sprachliche Dominanz über die indigene Bevölkerung ausübt (Renfrew 1987; Gimbutas 1994).

Zielgerichtete Kolonisierung ausgesuchter Gebiete durch kleine Gruppen. Diese Enklaven können in Arealen liegen, die von der indigenen Bevölkerung nicht genutzt werden. Von dort kann eine weitere Ausbreitung und Akkulturation von Einheimischen ausgehen (Friedlaender et al. 2002).

Durch wirtschaftliche und soziale Kontakte zwischen Bauern und Jäger-Sammlern entstehen Bindungen und Migration einzelner Personen oder kleiner Gruppen. Diese Bewegung findet in beide Richtungen statt und reflektiert die sozialen und kulturellen Hintergründe beider Gruppen (Zvelebil 1995, 1996).

Gradueller Einzug kleiner Gruppen, die sich in die bestehende Bevölkerung eingliedern und dort oft spezialisierte Aufgaben übernehmen (Neustupny 1982; Gimbutas 1994).

Die beschriebenen theoretischen Entwicklungen beziehen sich hauptsächlich auf die anglophone Archäologie. Die in Deutschland bis heute vorherrschenden Typologie- und Chronologiekonzepte, die ihren Ursprung in Montelius oder auch Kossinas Ideen haben, argumentieren auf Basis von „Einflüssen“, welche wiederum über Migration oder Diffusion verbreitet werden. Autochthone Entwicklungen spielen eine untergeordnete Rolle (Härke 1998). Diese stehen im Kontrast zur marxistisch beeinflussten Archäologie, die Kultur von der Ebene interner ökonomischer und sozialer Faktoren aus betrachtet und Kulturwandel damit als rein autochthonen Prozess versteht (Bernbeck 1997). International dominieren in den postprozessualen Strömungen der Archäologie heute hermeneutische Ansätze, die strukturelle Determinismen des Denkens ablehnen und individuelles Handeln in den Vordergrund heben (Friedlaender et al. 2002).

\subsubsection{Migration und Mechanismen des Kulturwandels und ihr Nachweis in prä- /historischen Zeitstellungen}

Nachdem sich die vorherigen Kapitel der ideengeschichtlichen Entwicklung von Theorien und Modellen des kulturellen Wandels und der Migration in prähistorischen Kulturgruppen gewidmet haben, soll jetzt auf das Phänomen der Migration an sich und die daraus resultierenden 
Folgen, sowie die Nachweisbarkeit im archäologischen Zusammenhang eingegangen werden. Das Interesse und die Erforschung von Migration reicht über verschiedene Disziplinen von den Sozialwissenschaften und der Kulturellen Anthropologie, Archäologie, Geographie und Demographie bis hin zur Biologie und der evolutionären Genetik. Daraus resultiert, dass „Migration“ kein scharf zu definierender Begriff ist, vielmehr eine Zusammenfassung verschiedenartiger Vorgänge unter dem gemeinsamen Merkmal des Ortswechsels. In der Biologie ist Migration eine der vier Kräfte der Evolution zusammen mit Mutation, natürlicher Selektion und genetischem Drift und spielt eine wichtige Rolle in der grundlegenden Theorie der Evolutions- bzw. Populationsgenetik (Wright 1931). Auch in der Ökologie ist sie ein wichtiges Thema: zum einen als Phänomen an sich und zum anderen als Variable des Verhältnisses von sozialen und genetischen Strukturen (Dingle 1996). An diese beiden Beispiele schließt sich die Demographie an, die Migration als ein dynamisches Maß der drei grundlegenden Prozesse verwendet, das neben Fertilität und Mortalität, Bevölkerungen formt und verändert (Grupe et al. 2005). Auf die Bedeutung von Migrationen in der soziologischen, ethnologischen und archäologischen Forschung wurde bereits im vorherigen Kapitel eingegangen. Es erscheint dennoch wichtig, noch einmal hervorzuheben, dass gerade in der Soziologie das Phänomen der Migration über die Dimension einer strukturellen Variabel hinaus betrachtet wird. Der Fokus liegt bei den Auswirkungen auf interkulturelle Gefüge, der Ökonomie der Ausgangs- und Zielregion, aber vor allem auch auf den individuellen Einflüssen auf den Migrierenden (vgl. Lee 1972). Um auf einer mikrostrukturellen Ebene zu verstehen, in wie weit Individual- oder Bevölkerungsmobilität die kulturelle Entwicklung prägen kann, und ob sich dies auch im archäologischem Befund niederschlägt, ist es unumgänglich, diese soziologischen aber auch bevölkerungspsychologischen Erkenntnisse mit in die Untersuchungen prähistorischen Kulturwandels aufzunehmen. Über die individuelle Ebene hinaus ist es aber gerade bei dem Phänomen der initialen Kolonisation bzw. der Erschließung neuer Räume durch eine Bevölkerung notwendig, ökologische Faktoren mit in die Untersuchungen einzubeziehen. Die Ursachen für mögliche Veränderungen im kulturellen Gefüge sind hier vor allem in der Interaktion des Menschen mit seiner neuen Umwelt zu sehen.

Die Strukturierung der verschiedenen Arten von Individual- und Bevölkerungsmobilität macht eine Typologie der Prozesse notwendig. Dabei bieten sich nicht die im vorherigen Kapitel aufgeführten archäologischen Migrationstheorien an, da sie eher einen Modellcharakter haben. Die soziologische Migrationstheorie kennt verschiedene Migrationstypologien mit deren Hilfe man den komplexen Vorgang, der im Spannungsfeld von objektiven Bedingungen und subjektiven Faktoren stattfindet, darstellen kann. Diese verschiedenen Typologien (vgl. Han 
2006) beziehen sich allerdings hauptsächlich auf die gesellschaftliche Entwicklung seit dem „demographischen Übergang“ und sind, nicht nur aufgrund der Quellenlage, nur bedingt auf prähistorische Gesellschaften anwendbar. Viele Typen wie Asylmigration, Einschleusung, Transitmigration oder Pendelmigration (Düvell 2006) sind nicht auf präkapitalistische, vornationalstaatliche Gemeinschaften ohne politische Regulierung von Bevölkerungsbewegungen übertragbar. Andererseits finden auch Typen, in leichter Abwandlung, Entsprechungen in prähistorischen Kulturgruppen, allerdings in Abhängigkeit von der sozialen und ökonomischen Komplexität (Flannery 1972). Die in diesem Zusammenhang aus soziologischer und anthropogeographischer Sicht am ehesten zu verwendende Kategorisierung von Migrationsprozessen findet sich in der Arbeit von Roger Sanjek (2003), die im weiteren Verlauf dieser Arbeit als Grundlage verwendet werden soll. Seine Typologie basiert auf dem Vergleich historischer und postmoderner Wanderungstypen und besteht aus sieben verschiedenen Prozessen:

- Expansion

- Zufluchtsuchen

- Kolonisation

\section{- Deportation}

- Handelsdiaspora
Ausbreitung einer Population über die bisherigen geographischen Grenzen hinweg in zuvor besiedelte oder unbesiedelte Gebiete unter Beibehaltung der Produktions-/Versorgungsstrategie oder Anpassung an die neu angetroffenen Bedingungen.

Migration in besiedelte oder unbesiedelte Gebiete als Fluchtbewegung z.B. aufgrund feindlicher Kolonisation des ursprünglichen Lebensraumes.

Zielgerichtete Inbesitznahme / Usurpation des Lebensraumes einer Kulturgruppe durch eine andere, bei der die Kontrollfunktion über die neue Region durch die Ursprungsregion übernommen wird. Meist mehrstufiger Prozess, bei dem in einer initialen Phase wenige Personen die Machtansprüche sichern und in folgenden Phasen erst die massenartige Besiedlung des okkupierten Gebietes beginnt.

Aus politischen oder ökonomischen Gründen erzwungene Umsiedlung von Bevölkerungsgruppen in andere Gebiete.

Auswanderung von Handelsspezialisten in die Siedlungsräume / Städte anderer Kulturgruppen zur Errichtung von Handelsnetzwerken zwischen dem Ursprungs- und dem Zielgebiet (z.B. Karawansereien), zumeist ohne vollständige kulturelle Integration. 
- Arbeitsdiaspora Zuzug in eine neue Region zur Verbesserung der individuellen oder familiären ökonomischen Situation (vgl. Arbeitsmigration weiter oben).

- Auswanderung Bewusste Aufgabe der Residenz und kulturellen Bindung zum Ursprungsgebiet, um sich an einem neuen Ort niederzulassen (unbesiedelt oder besiedelt).

Sanjeks sieben Prozesse umfassen die grundlegenden historischen Migrationsvorgänge, die für die Ausbildung der rezenten globalen Verteilung menschlicher Bevölkerungen und auch Gesellschaftsformen als verantwortlich gesehen werden können (Sanjek 2003). Zwar werden Prozesse der individuellen räumlichen Mobilität vernachlässigt, wie z.B. Heiratsmobilität, dafür lässt sich seine Typologie aber auch auf ein Phänomen anwenden, das die meisten soziologischen Migrationstypologien aufgrund der fehlenden Relevanz für moderne Gesellschaften nicht berücksichtigen: die Besiedlung bisher unbewohnter Regionen durch große Menschengruppen, die weite Distanzen zurücklegen (Fix 1999).

Um zu bewerten, in wie weit Migrationsvorgänge in prähistorischen Zeitabschnitten stattgefunden haben, und welchen Einfluss sie auf die Kultur des Ausgangs- und Zielgebietes hatten, muss also bei einem Minimum an verfügbaren Information ein Maximum an möglichen Quellen und disziplinärem Wissen herangezogen werden. Das bedeutet, dass es notwendig ist, verschiedene relevante, aber systematisch unähnliche Faktoren wie die Motivation, zurückgelegte Distanz, Menge der Migrierenden, naturräumliche Gegebenheiten, Informationsfluss, Personenkreis, Bewegungsart etc. in einen strukturellen Zusammenhang zu bringen und in kulturhistorische Informationen zu übersetzen (vgl. Anthony 1990, 1992; Burmeister 2000). Die Gewichtung der einzelnen Faktoren ist dabei an die individuelle Situation anzupassen. Abbildung 2 soll als schematische Darstellung der verschiedenen Einflussebenen dienen, auf die im Folgenden noch näher eingegangen wird. 


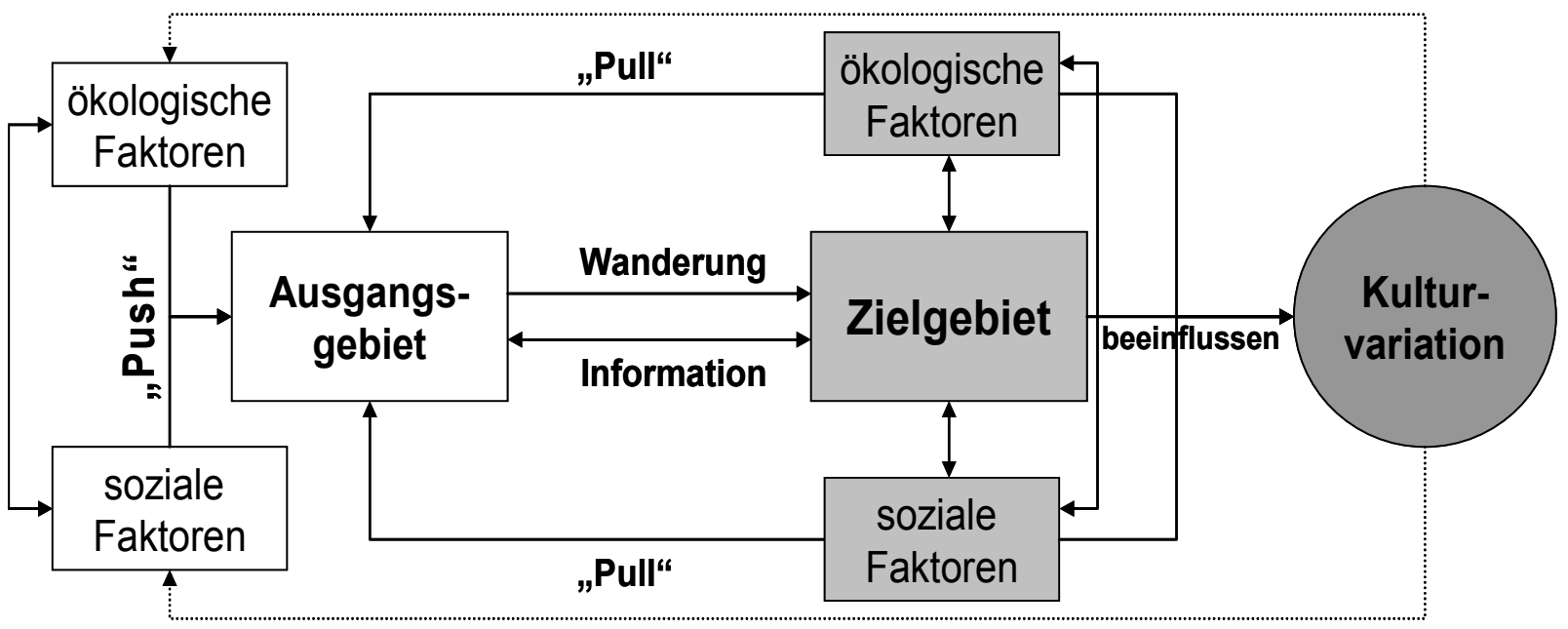

Abb. 2: Schematische Darstellung der Auswirkung von Migration auf das Entstehen kultureller Variationen im Zielgebiet unter Einbeziehung der verschiedenen, wirkenden Faktoren im Ausgangs- und Zielgebiet. Unter 'soziale Faktoren` sind auch die ökonomischen und ideologischen subsumiert.

Einer der grundlegenden Faktoren ist die Motivation (Push- und Pullfaktoren). Die verschiedenen Formen von Migration sind in einer Vielzahl von sozialen, ökonomischen und ökologischen Faktoren begründet, die im Ausgangs- und Zielgebiet der Migration wirken und sich gegenseitig beeinflussen (vgl. Abb. 2). In Tabelle 3 findet sich eine Auflistung solcher Pushund Pullfaktoren. Lees Auflistung bezieht sich im Detail auf Wirkfaktoren in modernen Gesellschaften, die sich allerdings auf einer allgemeineren Kategorisierungsebene (Tab. 4) auch direkt auf vergangene Gesellschaften anwenden lassen (Shennan 2000). Die Motivation ist zumeist die Summe der verschiedenen Push- und Pullfaktoren. So kann z.B. die Übernutzung eines Lebensraumes zu ökologischen und ökonomischen Konsequenzen wie Armut, Hunger aber auch $\mathrm{zu}$ anthropogenen Katastrophen führen. Die daraus entstehende Motivation ist die Verbesserung der Lebensumstände, die eine Migration notwendig machen. Sollten Informationen über andere Lebensräume vorliegen, die günstigere ökologische aber auch soziale Bedingungen bieten, so können diese als Push-Faktor für eine zielgerichtete Migration dienen.

Motivationen erklären nicht nur, warum Menschen migrieren, sondern beeinflussen auch, wer migriert und wie hoch die Bereitschaft ist, Informationsfluss aufrecht zu erhalten oder auch an kulturellen Traditionen festzuhalten. Je geringer der Informationsfluss zwischen Ausgangsund Zielgebiet, desto höher ist die Wahrscheinlichkeit der Veränderung kultureller Muster der Immigrierten im Zielgebiet (vgl. Abb. 2), entweder durch kulturelle Adaptation an bestehende Systeme oder durch die Ausbildung neuer Muster bei der Besiedlung neuer Nischen (Prentiss u. Chatter 2003). Im Zielgebiet wirken die sozialen Sanktionen, die den Kulturkern einer Gruppe zusammenhalten, geringer, wodurch das innovative Verhalten ansteigt (Rosenberg 1994). Die Etablierung komplexer sozialer Netzwerke durch die Migrierenden hingegen kann zur 
Beeinflussung des Ziel- und Ausgangsgebietes führen (Burmeister 2000). Der Faktor Distanz entscheidet ebenfalls über den Grad des möglichen Informationsflusses. Je größer die Distanz, über die migriert wird, ist, desto mehr Aufwand und Energie müssen investiert werden, um den Informationsfluss aufrecht $\mathrm{zu}$ erhalten. Die Bereitschaft dazu entscheidet wiederum, ob die Möglichkeit wahrgenommen wird. Information ist auch die Grundlage des Phänomens der „Kettenmigration“. Auch Massenmigrationen sind nicht unbedingt zeitlich eng zu fassende Ereignisse, sondern können langwierige, kettenreaktionsartige Prozesse sein. Der Informationsaustausch der Emigranten mit den Menschen im Ausgangsgebiet kann als „Pull“Faktor wirken, der $\mathrm{zu}$ einem stetigen Nachzug führt. Menschen, die einen permanenten Ortswechsel anstreben, tendieren dazu, vor allem Regionen mit ähnlichen sozialen Strukturen, oder zu denen einen familiäre Verbindung besteht, auszuwählen (Anthony 1997).

Etablierte Gesellschaften migrieren nicht als Ganzes, sondern eine Gruppe von Migranten repräsentiert einen mehr oder weniger klar definierten Teil einer Bevölkerung. Dieser selektive Prozess wird bedingt durch die Motivation, aber es sind auch die Konditionen zu bedenken, unter denen eine Gesellschaft es Gruppen erlaubt, sich loszulösen (Burmeister 2000). Selektive Faktoren können z.B. geschlechts-, alters- oder klassenspezifisch sein. So zeigt sich auf der Ebene der kleinräumigen individuellen Mobilität die Gruppe der 20-30 jährigen in ethnographischen und soziologischen Studien am mobilsten (Anthony 1990). Bei Massenmigrationen hingegen besteht der Hauptanteil aus sozial und ökonomisch Unterprivilegierten. Solche ökonomischen Faktoren können auch durch anthropogene- oder Naturkatastrophen, die z.B. zu Ressourcenmangel führen, ausgelöst werden. Auch wenn hier die ökologischen Faktoren Determinanten für Migration sind, kann die gleiche Bedingung trotzdem zu individuell verschiedenen Verhaltensmustern führen (Straubhaar 1993). Gesellschaften mit etablierten Mustern der Mobilität, z.B. zur Verheiratung, haben häufig eine ideologisch determinierte Matri- oder Patrilokalität, was bedeutet, dass festgelegt ist, welches Geschlecht zu einem gewissen Zeitpunkt migrieren muss. Der Wirkungsgrad von Motivationen ist also abhängig von der gesellschaftlichen Rolle des Individuums, die Mobilität fördert (Bsp.: Heiratsmobilität, Selbstbeweis) oder notwendig macht.

Die Selektivität des Ein- und Auswanderungsprozesses aber auch die Menge der Migrierenden haben Einfluss auf die Demographie von Ausgangs- und Zielgebiet, z.B. auf die Altersstruktur und Geburtenrate. Als Konsequenz daraus können wieder neue Motivationen zur Mobilität erwachsen (Burmeister 2000). Demographisches Wachstum kann auch die Expansion einer Kultur über den angestammten Raum hinweg notwendig machen. Diese Notwendigkeit an 
sich erklärt aber nicht mögliche kulturelle Variationen in den Tochtergruppen. Die Kausalität hierfür liegt in den zuvor beschriebenen Faktoren.

Auch wenn Information und Motivation als Haupteinflussebene für durch Migration beeinflusste kulturelle Variation genannt werden, ist $\mathrm{zu}$ bedenken, dass alle Entwicklungen innerhalb des Zielgebietes nur in einem gewissen ökologisch definierten Rahmens möglich sind (Steward 1955). Dieser limitierende Faktor kann durch einen verstärkten Informations- und Stoffstrom mit dem Ausgangsgebiet wenigstens zeitweise umgangen werden. Die Ressourcenabhängigkeit kann zur Entwicklung besonderer kultureller Variationen und Handlungsmuster führen, die allerdings keine neuen Kulturen hervorbringen, sondern immer Derivate der Mutterkultur bleiben. Als Beispiel sind die Pitcairn Inseln zu nennen, die im Rahmen der polynesischen Expansion um ca. 800 n. Chr. besiedelt wurden. Diese Inseln boten die notwendige Landmasse, um die wachsende Bevölkerung der weiter westlich gelegenen Inseln, wie Mangareva, aufzunehmen. Allerdings erfüllten sie nicht die ökologischen Bedingungen, um die Siedler eigenständig zu tragen. Es finden sich zwar für diese Inseln spezifische Artefakte und Siedlungsstrukturen, aber es blieb über die gesamte Zeit der Nutzung dieser Inseln eine Abhängigkeit zu Mangareva bestehen. Der Zusammenbruch der sozialen Strukturen auf dieser Insel hatte letztendlich den Zusammenbruch der Kulturen auf den Pitcairn Inseln zur Folge. Trotz eigener kultureller Variationen war es den Bewohnern, bedingt durch die naturräumliche Ausstattung dieser Inseln, nicht möglich, eine erfolgreiche ökonomische Strategie zu entwickeln, die eine selbständige Versorgung gewährleistet hätte (Diamond 2005).

Als ein Beispiel für eine Migration, bei der bewusst ein starker Informationsaustausch zum Ausgangsgebiet aufrechterhalten wird, ist die Kolonisation zu nennen. Sie unterscheidet sich von den anderen Migrationstypen dadurch, dass es zu einer bewussten kulturellen Prägung bzw. Überprägung des Zielgebietes kommt. Die Kultur des Ausgangsgebietes wird in das Zielgebiet importiert. Der Einfluss der Kultur des Zielgebietes auf die Ausbildung kultureller Variationen ist verhältnismäßig gering. Anpassung an die neue Region findet entweder nur auf der technologischen oder der ökonomischen Ebene statt (Burmeister 2000). Kolonisationsprozesse dienen häufig auch zur Ausbeutung von Ressourcen, die zur Suspendierung des Ausgangsgebietes gebraucht werden. Tabelle 4 soll die verschiedenen zuvor erläuterten Migrationstypen mit den bekannten archäologischen Modellen und den zugrunde liegenden Hauptmotivationsebenen nach Lee (vgl. Tab. 3) verbinden. 
Tab. 4: Zuordnung von Migrationsdistanz, archäologischen Modellen und Hauptmotivationsebenen (nach Lee 1972) zu den verwendeten Migrationstypologien von Sanjek (2002).

\begin{tabular}{|c|c|c|c|}
\hline $\begin{array}{l}\text { Migrationstyp } \\
\text { (nach Sanjek) }\end{array}$ & $\begin{array}{c}\text { zurückgelegte } \\
\text { Distanz }\end{array}$ & $\begin{array}{l}\text { archäologische } \\
\text { Migrationstheorie }\end{array}$ & $\begin{array}{c}\text { Haupt- } \\
\text { Motivationsebenen } \\
\text { (vgl. Tab. 3) } \\
\end{array}$ \\
\hline Expansion & klein & $\begin{array}{c}\text { Wave of Advance } \\
\text { Demic Diffusion } \\
\text { Leapfrog Colonisation } \\
\text { Individual Frontier } \\
\text { Mobility }\end{array}$ & $\begin{array}{c}\text { Demographie } \\
\text { Ökonomie }\end{array}$ \\
\hline Kolonisation & groß/klein & $\begin{array}{c}\text { Elite Dominance } \\
\text { Invasion } \\
\text { Leapfrog Colonisation }\end{array}$ & $\begin{array}{c}\text { Politik } \\
\text { Ökonomie } \\
\text { Demographie }\end{array}$ \\
\hline Auswanderung & groß & $\begin{array}{c}\text { Folk Migration } \\
\text { Infiltration }\end{array}$ & $\begin{array}{c}\text { Politik } \\
\text { Ökonomie } \\
\text { Demographie } \\
\text { Ereignisse } \\
\text { Soziales }\end{array}$ \\
\hline Deportation & groß/klein & Folk Migration & $\begin{array}{c}\text { Politik } \\
\text { Ökonomie } \\
\text { Soziales }\end{array}$ \\
\hline Zuflucht & groß/klein & $\begin{array}{c}\text { Folk Migration } \\
\text { Infiltration }\end{array}$ & $\begin{array}{c}\text { Ereignisse } \\
\text { Politik } \\
\text { Soziales }\end{array}$ \\
\hline Arbeitsmigration & groß/klein & Infiltration & $\begin{array}{c}\text { Ökonomie } \\
\text { Politik } \\
\text { Soziales }\end{array}$ \\
\hline Handelsmigration & groß/klein & Infiltration & Ökonomie \\
\hline
\end{tabular}

Migrationstypen wie auch die Einflussebene von Motivation, Informationsfluss und Selektivität sind abhängig von der sozialen Komplexität der Gesellschaften (vgl. Tab. 2). Heiratsmigration ist ein klassisches Beispiel der Archäologie für kleinräumige Bevölkerungsmobilität, die bereits in egalitären Gesellschaften auftritt (Bsp.: Tracht- und Heiratskreise in der norddeutschen Bronzezeit; Lehmkühler 1991). Arbeitsmigration hingegen, also der Zuzug in eine neue Region zur Verbesserung der individuellen oder familiären ökonomischen Situation (Sanjek 2003), findet sein prähistorisches Äquivalent erst mit dem Aufkommen von handwerklichen 
Spezialisierungen und der Abwendung von reinen Subsistenzwirtschaften in frühen komplexen Kulturen. Zentren solcher Kulturen können hier einen erhöhten Attraktionswert auf Mitglieder umliegender Kulturgruppen haben. Andererseits haben die komplexen Kulturen ein Interesse an der Einwanderung von Spezialisten und Arbeitskräften zur Produktion des notwendigen Ressourcenüberschusses. Kolonisationsprozesse sind nur möglich, wenn im Ausgangsgebiet ein komplexes System mit entsprechenden Verwaltungsorganen existiert, das zum einen den organisatorischen Aufwand koordiniert und zum anderen kann die Notwendigkeit zur Kolonisation auch erst aus einem System resultieren, in dem Machtverhältnisse klar verteilt sind und in denen ein Häuptling oder eine Regierung ein ökonomisches Interesse an der Vergrößerung von Einflusssphären entwickelt (Flannery 1972). Generell kann soziale Komplexität die Pull- Wirkung einer Region steigern (Bsp. Arbeitsmigration). Gleichzeitig können die gleichen Faktoren auch eine Push- Wirkung (staatliche Repression, Armut etc.) auf die Bevölkerung haben.

Die verschiedenen Faktoren, die notwenig sind, um Migrationen als kulturbeeinflussenden Prozess zu identifizieren, unterscheiden sich, wie bereits gezeigt wurde, nicht nur systemisch, sondern auch in ihrer Nachweisbarkeit innerhalb prähistorischer Populationen. Um die Faktoren zu untersuchen, bedarf es verschiedener fachlicher Kompetenzen. Während sich z.B. die Zahl der Migrierenden und auch der Migrationstyp in der genetischen Zusammensetzung einer Population niederschlagen können, gibt es ideologische und soziale Aspekte, die sich vor allem auf der Ebene der „Motivation“ äußern, die sich nur kulturwissenschaftlich erfassen lassen oder naturräumliche Einflüsse, die auf die Motivation einwirken, für deren Nachweis es naturwissenschaftlicher Methoden bedarf (z.B. Paläoklimatologie). Eines der grundlegenden Probleme der Archäologie ist allerdings, dass ihre Informationen zumeist nur aus dem Zielgebiet stammen. Die Tatsache, dass eine Immigration stattgefunden hat und eventuelle Rückschlüsse auf das Ursprungsgebiet dieser, lassen sich - wenn nicht der glückliche Zufall von historischen Überlieferungen besteht - nur induktiv herleiten. Reduziert auf die klassischen Quellen der Archäologie - also die materielle Kultur - bedeutet das, dass man wieder vor dem Problem der Unterscheidung von Migration, kultureller Diffusion und Handel steht (Shennan 2000). Des Weiteren verraten die Informationen aus dem Zielgebiet einer Migration zwar „,wer“ migriert, aber nicht den Grund für die Migration (Anthony 1992).

Migrationsprozesse, an denen nur wenige Personen beteiligt sind, wie z.B. die Arbeitsmigration, Handelsmigration oder auch die Heiratsmigration finden im archäologischen Befund nur durch das Einbringen kulturspezifischer Objekte der privaten Domäne Niederschlag. Ein größerer Einfluss auf die Kultur des Migrationszieles ist nicht zu erwarten, was das 
Auffinden materieller Beweise für die Immigration in Siedlungen oder Gräbern stark vom Zufall abhängig macht (Burmeister 2000). Die geringe Zahl dieser Fremdfunde lassen wieder den Schluss zu, dass sie z.B. durch Handel in das Untersuchungsgebiet gelangten. Es ist allerdings möglich, durch z.B. molekularanthropologische Methoden eine Immigration nachzuweisen oder im Zusammenhang mit dem archäologischen Befund auf die Motivation zu schließen. Ähnlich verhält es sich bei Kolonisationsprozessen wie dem Modell der „Elite Dominance“. Zwar findet bei so einem Prozess eine starke kulturelle Prägung des okkupierten Gebiets statt, die sich aber nicht unbedingt dominant in den materiellen Hinterlassenschaften äußert.

Bei Massenmigrationsprozessen wie Expansionen oder Auswanderung ist es ebenfalls schwierig, sie anhand der materiellen Kultur oder anderer archäologischer Befunde eindeutig als solche zu identifizieren oder sie gegen Typen mit wenigen Teilnehmern oder andere Diffusionsmechanismen abzugrenzen (Montgomery et al. 2005) Ein Beispiel hierfür ist die angelsächsische Kolonisation Britanniens. Der Diskussion liegen hier zwei rivalisierende Modelle zu Grunde: „Folk Migration“ (Anthony 1997; Hamerow 1997) und „Elite Dominance“ (Renfrew 1987; Arnold 1994). Das plötzliche Auflassen weiter Gebiete Dänemarks und Norddeutschlands im 5. Jhd. n. Chr. und das gleichzeitige Auftauchen kontinentaler Artefakte (Keramik, Schmuck) und Gebräuche (Bestattungssitte, Architektur, Siedeln auf leichteren Böden) in Britannien wurde als Evidenz für eine Massenmigration germanischer Bevölkerungen angesehen. Andererseits persistiert über einen langen Zeitraum auch Romano-Britische Kulturmuster, vor allem Bestattungssitte und Siedlungsweise in unmittelbarer Nähe der möglicherweise angelsächsischen Siedlungen. Dies und die Tatsache, dass es kaum klar zu definierende angelsächsische Nekropolen gibt, auf denen mehr als 50 Individuen bestattet sind (Burmeister 2000), führte zu der Annahme, dass nur eine kleine Zahl an Menschen vornehmlich mit militärischem Hintergrund migrierte, sich in der Folge als dominante Elite etablierte und es zu einer langsamen Akkulturation der indigenen Bevölkerung kam. Allerdings finden sich keine Elitegräber in Britannien, wie sie aus dem angelsächsischen Ursprungsgebiet bekannt sind (Burmeister 2000). Beide Modelle sind aufgrund der archäologischen Befunde möglich. Allerdings ist es z.B. nicht möglich, nur anhand des Vorhandenseins angelsächsischen Schmucks in einem Grab festzustellen, ob der Träger selbst wirklich angelsächsischer Herkunft war (Montgomery et al. 2005). Außerdem zeigt die Migrationstheorie, dass sich auch eine Massenmigration als zeitlich langwieriger Prozess äußern kann, in dem immer wieder Menschen in das neue Gebiet nachwandern und liefert damit eine weitere mögliche Erklärung für das angetroffene archäologische Bild (Anthony 1997). 
Bei dem Beispiel der angelsächsischen Landnahme Britanniens ist allerdings zu bemerken, dass - im Vergleich zu vielen anderen Situationen/ Regionen - die archäologischen Befunde sehr wohl ein recht genauen Einblick in die abgelaufenen Migrationsprozesse zulassen. Das gleichzeitige Auftreten (5. Jhd. n. Chr.) von archäologischem Fundgut, vor allem Fiebeln (kreuzförmige Fibeln, runde Schalenfiebeln) und Keramik (Urnen) im nordwestlichen Kontinentaleuropa und in Britannien zeigt die eindeutige Verbindung dieser Regionen auf. Gerade die Urnen sprechen für einen Technologietransfer, da sie sich aufgrund ihrer strukturellen Eigenschaften kaum für den Transport über lange Strecken eignen. Die Urnenformen, die auf den abbrechenden Friedhöfen des Elb-Weser-Dreiecks im 5. Jhd. zu finden sind, treten gleichzeitig als früheste Formen in Ost- und Südost England auf. Der archäologische Befund weist hier also darauf hin, dass Menschen mit ihren Kenntnissen der Keramikherstellung aus dem Elbe-Weser-Dreieck nach Britannien ausgewandert sind (Capelle 1990). Die synchrone Existenz der Formen in beiden Regionen weist darüber hinaus darauf hin, dass es sich nicht um eine plötzliche massenhafte Auswanderung gehandelt haben kann, sondern über einen längeren Zeitraum kleinere Gruppen von Menschen (Kettenmigration oder Elite Dominance) bereits nach Britannien übersiedelten. Dass die Traditionen der Keramik und Fibelherstellung dann auf dem Kontinent abbrechen und in Britannien weitergeführt und weiterentwickelt werden, spricht ebenfalls für eine Kontinuität in der vertikalen Vererbung. Also, das nicht nur die Produkte, sondern die Hersteller nach Britannien kamen und dort ihre Herstellungstechniken und Formen weiter entwickelten. Die Entscheidung für Migration, gegen Diffusionsmechanismen wie Handel wird auch durch einen Gesichtsurnenfund aus Wehden, Kreis Wesermünde unterstützt. In Markshall, Norfolk, findet sich ein fast identisches Urnenfragment. Die Seltenheit der Keramikform aber auch die Übereinstimmung selbst der kleinsten Details beider Gefäße kann eigentlich nur dadurch erklärt werden, dass sie vom gleichen Töpfer gefertigt wurden. Dieser ist vielleicht vom Kontinent nach England ausgewandert und hat dort seine Tätigkeit fortgesetzt (Capelle 1990).

Die aufgeführten Beispiele zeigen, dass die Validierung eines Migrationsprozesses durch die Archäologie allein nur selten möglich ist. Der reine Nachweis eines Ortswechsels durch naturwissenschaftliche Methoden ist ohne die gleichzeitige Betrachtung archäologischer/ kulturwissenschaftlicher Daten aber auch ohne erkenntnistheoretischen Nutzen. Die Wahrnehmung von Migration als einen dynamischen Prozess und nicht als Ereignis, ermöglicht, ihren Einfluss auf Kultur zu erklären (Anthony 1990) und damit letztendlich auch die Erklärung, wie sich so ein Prozess auf die materielle Kultur niederschlägt. Die Ableitung eines theoretischen Überbaus aus dieser Erkenntnis ermöglicht im Falle des Ausbleibens einer 
Bestätigung von naturwissenschaftlicher Seite immerhin die deduktive Unterscheidung von Migration zu Diffusion und Handel. Der Einfluss von Migrationen kann nur auf einer transdiziplinären Ebene verstanden werden.

\subsubsection{Zugang der Anthropologie zur Kulturentwicklung und Migration}

Die physische Anthropologie / Archäometrie kennt mehrere, mehr oder weniger Erfolg versprechende analytische Werkzeuge zur Bestimmung der regionalen Herkunft von prä/historischem Skelettmaterial und damit auch zur Validierung des Befundes der Bevölkerungsmobilität. Die klassischste Methode hierfür ist wohl die Ableitung über die Morphologie, bzw. über die morphometrischen Merkmale. Diese Methoden sind allerdings mit Vorsicht zu betrachten, da beobachtete Unterschiede bzw. Ähnlichkeiten zwischen Individuen auch durch ernährungs- oder habituationsbedingte Merkmalsausprägungen am Skelett bedingt sein können (Herrmann et al. 1990). Auch können Umweltfaktoren, Klimaadaptationen und andere äußere Einflüsse die morphologischen Merkmalsausprägungen beeinflussen, so dass es in zwei ökologisch ähnlichen Räumen zu einem ebenso ähnlichen Erscheinungsbild in Bevölkerungen kommt, ohne dass es eine evolutionäre Verbindung der beiden Variablen gibt (Perez et al. 2007a). Neu entwickelte „Landmark“ und „Semilandmark“ Analysemethoden der Craniometrie, die z.B. im Vergleich mit genetischen Populationsdaten an südamerikanischen Skelettserien entwickelt wurden, versprechen zwar eine bessere Auflösung und Differenzierung der gewonnen Daten (vgl. Pucciarelli et al. 2006; Perez et al. 2007a; Perez et al. 2007b), eine sichere geographische Zuordnung ist allerdings nur zu Großräumen möglich (Herrmann et al. 2007).

Eine etablierte und weitaus zuverlässigere Methode zum Nachweis individueller Residenzwechsel ist die Analyse stabiler Isotope schwerer Elemente wie Strontium (Sr) und Blei $(\mathrm{Pb})$ (Horn 2005). Diese Elemente werden mit der Nahrung aufgenommen und in biologischem Apatit wie im Knochen oder Zahnschmelz inkorporiert. Strontium kommt dabei eine besondere Bedeutung zu, da bei der Verstoffwechselung keine Isotopenfraktionierung stattfindet und damit die im Hartgewebe gemessenen Isotopenverhältnisse denen des jeweiligen Habitats entsprechen, welches wiederum durch das unterliegende Gestein bestimmt wird (Schutkowski 1994). Wird in einem Knochen oder Zahn aus einer Bestattung ein signifikant von dem des umgebenen Sedimentes abweichendes Isotopenverhältnis gemessen, so müssen sie einem ortsfremden Individuum zugeordnet werden. Im Knochen, der sich in einem andauernden Umbauprozess befindet, gleicht sich die Signatur an einen neuen Lebensraum an, während im Zahnschmelz nach der Anlage kein Umbau mehr stattfindet und er damit die Isotopenverhältnisse des Habitats wiedergibt, in dem die ersten Lebensjahre verbracht wurden (Grupe et al. 2005). Signifikante 
Unterschiede des Strontiumverhältnisses in Zahn und Knochen eines Individuums weisen damit auch auf einen Residenzwechsel hin. Eine umfassende Kartierung von regionalen Konzentrationen stabiler Isotope kann auch zur Herkunftsbestimmung dieser Signaturen genutzt werden und damit der Bestimmung von Orten, an denen sich ein Individuum lange aufgehalten hat oder aus denen es stammt (Rummel et al. 2007). Nachweise von Immigration und Bevölkerungsmobilität in prähistorischen Zeitstellungen anhand der Analyse von stabilen Isotopen wurden z.B. an einer Nekropole der Glockenbecherkultur in Bayern (Grupe 1997) zur angelsächsischen Kolonisation Britanniens (Montgomery et al. 2005) oder zur Bevölkerungsmobilität in der Tiwanaku-Kultur (Knudson et al. 2004) erfolgreich durchgeführt. Im Rahmen des Forschungsverbundes „Nasca: Entwicklung und Adaptation archäometrischer Techniken zur Erforschung der Kulturgeschichte“, in dem auch die hier vorliegende Arbeit beheimatet ist, wurden von der Arbeitsgruppe Peter Horn \& Stefan Hölzl der LMU München solche Untersuchungen auch für das südliche Peru vorgenommen. Dabei wurde dasselbe Skelettmaterial verwendet, welches auch den genetischen Untersuchungen zu Grunde liegt. In Hinsicht auf den Nachweis von Migrationen ist der erkenntnisbezogene Unterschied zwischen der Isotopenanalyse und der Analyse molekularer genetischer Marker an alter DNA, dass anhand der Isotopieverhältnisse die primäre Mobilität bzw. die direkte Mobilität eines Individuums nachgewiesen werden kann. Im Kontrast zu diesem biographischen Archiv ermöglicht die Untersuchung von DNA, längerfristige Auswirkungen von Bevölkerungsmobilität und Dynamik auf die genetische Zusammensetzung einer Population zu analysieren. Diese Methode, die der vorliegenden Arbeit zu Grunde liegt, wird in den folgenden Kapiteln ausgiebig behandelt.

Die ausführliche Behandlung der kultur- und migrationstheoretischen Erwägungen in dem Kapitel „Kulturwandel und Bevölkerungsmobilität““ soll die Verbindung von Kulturentwicklung zur Biologie nahe bringen. Die offensichtlichste Verbindung zwischen Kultur und Biologie ist der Kulturträger selbst: der Mensch als biologisches Wesen. Ohne Kultur alleine auf diese Funktion reduzieren $\mathrm{zu}$ wollen, ermöglicht ihre Entwicklung dem Menschen eine extrasomatische Adaptation an seine Umwelt bzw. die Erschließung neuer Nischen. Andererseits definiert die Ökologie seines Habitats den Rahmen, innerhalb dessen kulturelle Entwicklungen möglich sind. Entscheidungen des Menschen und damit auch Kultur können also durch die Biologie beeinflusst werden oder haben biologische Konsequenzen. Bevölkerungsbewegungen sind hier ein gutes Beispiel. Die Ausführungen der letzten Kapitel zeigen, dass kulturelle und ökologische Faktoren verschiedene Typen von Migration bedingen können. Die unterschiedlichen Migrationstypen haben unterschiedliche Einflüsse auf die Bevölkerungsbiologie im Ausgangs- und Zielgebiet. Zur Übersetzung der 
biologischen/genetischen Daten - die in dieser Arbeit ermittelt werden - in kulturhistorische Informationen ist es also notwendig, über ein theoretisches Grundwissen zu verfügen, das die Interaktion von Biologie und Kultur berücksichtigt. In Kapitel 2.3. soll die Verbindung von Genetik und Kulturentwicklung in Bezug auf die Besiedlungsgeschichte Amerikas verdeutlicht werden. 


\subsection{Genetik}

Die folgenden Kapitel sollen das grundlegende methodische und analytische Werkzeug dieser Arbeit vorstellen. Die Kenntnis der Inhalte ist notwendig, um das wissenschaftliche Vorgehen und auch die Aussagemöglichkeiten der Untersuchungen zu verstehen.

\subsubsection{Molekulargenetische Grundlagen und Typisierungsmarker}

Das menschliche Genom enthält alle vererbbaren Informationen, die für die Ontogenese und die Ausprägung der spezifischen Eigenschaften eines Individuums entscheidend sind. Diese Informationen liegen in jeder Zelle als Desoxyribonukleinsäure (DNA) in Basensequenzen codiert vor, die aus den vier Grundbausteinen (Basen / Nukleotide) Adenin und Guanin (Purinbasen) sowie Cytosin und Thymin (Pyrimidinbasen) gebildet werden. Das Genom eukaryonter Lebewesen wie dem Menschen gliedert sich in zwei Hauptbestandteile: Die nukleare DNA (nuclear DNA= ncDNA), die in Form von Chromosomen im Zellkern vorliegt, und die den überwiegenden Teil des Erbguts umfasst (3.10 ${ }^{9}$ Basenpaare), sowie die mitochondriale DNA (mtDNA). Dieser weitaus kleinere Teil des Genoms befindet sich nicht im Zellkern, sondern in der Matrix der Mitochondrien, den Zellorganellen, die für den Energiestoffwechsel der Zelle zuständig sind. Die mitochondriale DNA - auch als mitochondriales Genom bezeichnet - des Menschen ist ein zirkuläres, doppelsträngiges Molekül mit einer Länge von 16.569 Basenpaaren (bp) (Pakendorf u. Stoneking 2005). In jeder Zelle finden sich abhängig vom Gewebetyp bis $\mathrm{zu}$ Tausende von Mitochondrien und damit auch Kopien des mitochondrialen Genoms (Bogenhagen u. Clayton 1974). Im Gegensatz dazu liegt das chromosomale / nukleare Genom nur einmal pro Zelle vor.

Grundsätzlich kann zwischen codierender und nicht-codierender DNA unterschieden werden. Die codierende DNA umfasst die Gene, also die Abschnitte, die die Erbinformationen enthalten und die auch transkribiert werden. Dieser codierende Teil des Genoms macht nur einen Bruchteil aus. So codieren z.B. nur ca. 5\% des nuklearen Genoms, hingegen ca. 95\% des mitochondrialen Genoms, wobei das mtDNA-Molekül nur einen geringen Teil des menschlichen Genoms ausmacht (Pakendorf u. Stoneking 2005). Da Gene und damit die codierenden Abschnitte eine bestimmte Funktion erfüllen, liegt ein entsprechender Selektionsdruck auf ihnen. Daraus resultiert, dass die Möglichkeit für die Manifestationen von Mutationen, d.h. die Mutationsrate eingeschränkt ist. Codierende Sequenzen sind also meistens konservativ mit nur wenigen Ausnahmen wie z.B. Genen, die die Immunresponse regulieren und damit einem selektiven Einfluss, der aus der jeweiligen Biographie eines Individuums resultiert, unterliegen. Nichtcodierende DNA-Abschnitte unterliegen keinem Funktionsdruck, wodurch sich Mutationen 
vergleichsweise leicht manifestieren können. Aus diesem Grund sind nicht-codierende Abschnitte variabler als codierende. Als Vergleich liegt z.B. die Mutationsrate des codierenden Teiles des mitochondrialen Genoms bei 0,0017 × $10^{-6}$ Basensubstitutionen pro Genort und Jahr (Ingman et al. 2000), während die der nicht codierenden hypervariablen Regionen I und II (HVRI und HVRII) bei 0,075-0,162 $\times 10^{-6}$ liegt (Pakendorf u. Stoneking 2005). Trotz des großen codierenden Anteils übertrifft die Mutationsrate des mitochondrialen Genoms die des nuklearen um viele Größenordnungen. Die im Verlauf dieser Arbeit relevanten Mutationsereignisse sind in Tabelle 5 aufgeführt:

Tab. 5: Im Rahmen dieser Arbeit aufkommende genetische Mutationsarten.

\begin{tabular}{l|l}
\hline \multicolumn{1}{c|}{ Mutationsart } & \multicolumn{1}{c}{ Auswirkung } \\
\hline Deletionen & Verlust eines oder mehrerer Basenpaare \\
\hline Duplikationen & Verdopplung einer oder mehrerer Basen \\
\hline Insertionen & Hinzufügen einer oder mehrerer Basen \\
\hline Substitutionen & Austausch von Basen: \\
& $\begin{array}{l}\text { Transition = Austausch von Purin- zu Purinbase, bzw. } \\
\text { Pyrimidin- zu Pyrimidinbase (Bsp. C zu T) }\end{array}$ \\
& $\begin{array}{l}\text { Transversion= Austausch von Pyrimidin- zu Purinbase od. } \\
\text { umgekehrt (Bsp. C zu G) }\end{array}$ \\
\hline Mikrosatelliten Mutationen & $\begin{array}{l}\text { Einbau oder Verlust einer oder mehrerer } \\
\text { Wiederholungseinheiten }\end{array}$ \\
\hline
\end{tabular}

Die Wahrscheinlichkeit und Häufigkeit von Mutationen kann je nach Fragestellung entscheidend für die Auswahl eines genetischen Markers sein, ob nun z.B. auf dem Niveau von Individuen, Populationen oder Spezies unterschieden werden soll. So sind, sehr verallgemeinernd gesprochen, konservative Regionen für die Unterscheidung von verschiedenen Arten, schnell evolvierende Abschnitte für die Unterscheidung von Individuen geeignet. Ein weiteres entscheidendes Merkmal für die fragestellungsbezogene Auswahl von molekulargenetischen Markern ist der Vererbungsweg. Die grundlegende Unterscheidung liegt hier in diploiden Genomen, die sich zu einem Teil aus dem Genom der Mutter und zum anderen aus dem des Vaters ererben, wie z.B. Autosomen und haploiden Genomen, die nur uniparental vererbt werden, wie die mt-DNA (matrilinear) oder die Y-chromosomale DNA (patrilinear).

Im Folgenden soll nun auf die einzelnen für die Arbeit relevanten Genorte (loci) und molekulargenetischen Marker, ihre Besonderheiten und Anwendungsbeispiele eingegangen werden. Der Schwerpunkt liegt dabei auf solchen, die für die Beantwortung 
populationsgenetischer/ bevölkerungsgeschichtlicher Fragestellungen wichtig sind und welche sich aufgrund ihrer Eigenschaften auch für die Analyse an alter DNA (aDNA) eignen.

Wie bereits erwähnt, ist eine der besonderen Eigenschaften der mitochondrialen DNA, dass sie nur uniparental-maternal vererbt wird und keiner Rekombination unterliegt. Damit reflektieren Daten, die bezüglich der mtDNA gewonnen werden, über viele Generationen nahezu unveränderte Matrilinien. Variationen des Genoms resultieren alleine aus Mutationen, beeinflusst von evolutiven Kräften wie Selektion und Gendrift. Damit ist mt-DNA das Archiv der Wahl, um matrilinieare Genealogien auf Generationsebene, Populationsebene und auch phylogenetische Beziehungen zu untersuchen. Anhand von Mutationsstudien am mt-Genom konnte z.B. gezeigt werden, dass alle heute lebenden Menschen auf eine gemeinsame Vorfahrin zurückzuführen sind, die vor weniger als 200.000 Jahren in Afrika lebte (Cann et al. 1987), wodurch die „out-of-africa“ Hypothese massiv unterstützt wird. Die Untersuchung des Cytochrom-b Abschnittes (Hummel 2003) aber auch anderer konservativerer Abschnitte des Genoms (Renneberg in prep.) kann zu Zwecken der Speziesidentifikation herangezogen werden.

Die zuvor aufgeführten Eigenschaften sind in den letzten Jahren vermehrt angezweifelt worden. So gibt es immer wieder Berichte über beobachtete Heteroplasmien (Vorhandensein zweier mt-Genome), die die Frage nach der väterlichen Vererbung mitochondrialer DNA hervorbrachten (Chinnery 2006). Ein sicherer Nachweis für das Vorhandensein von väterlicher mt-DNA in einem menschlichen Individuum wurde bislang nur an einem Mann erbracht, dessen Mitochondrien der Muskelgewebszellen zu einem großen Teil das väterliche Genom aufwiesen, während im übrigen Gewebe das mütterliche Genom vorlag (Schwartz u. Vissing 2002). Es handelt sich in diesem Fall um eine pathologisch bedingte Erscheinung. Da viele andere beim Menschen beobachtete Heteroplasmien anscheinend auf Bearbeitungs- und Analysefehler zurückzuführen sind (Bandelt 2005), kann davon ausgegangen werden, dass dieses Phänomen zu vernachlässigen ist. Ähnlich verhält es sich mit der Rekombination. Es besteht die statistische Möglichkeit, dass mt-DNA rekombiniert, dieses Phänomen ist von anderen Spezies bekannt. Nachgewiesen wurde es beim Menschen aber nur in dem Fall des zuvor erwähnten Patienten (Zsurka et al. 2005). Da paternale Vererbung der mt-DNA extrem selten ist und damit in der Regel keine heteroplasmischen mitochondrialen Genome vorliegen, würde ein mögliches Rekombinationsereignis zu keiner Veränderung des Genoms führen (Pakendorf u. Stoneking 2005). Damit ist, zumindest für die Untersuchungen an humaner mt-DNA, dieses Phänomen zu vernachlässigen.

Das humane mitochondriale Genom wurde erstmals von Anderson et al. (1981) sequenziert. Diese Sequenz bzw. mittlerweile die überarbeitete Version, die revised Cambridge reference 
sequence (rCRS) (Andrews et al. 1999) dient als Grundlage für die Nomenklatur der Basenpositionen und als Bezugs-/ Referenzsequenz für den Vergleich aller im mt-Genom aufkommenden Mutationen. So bedeutet z.B. der Vermerk einer Basensubstitution/ Mutation an der Position 16223 des Genoms, das sich die entsprechende Base, die in der untersuchten Sequenz vorliegt, von der rCRS (Haplogruppe H) unterscheidet.

Mutationen bzw. Polymorphismen haploider DNA-Abschnitte wie der mt-DNA, aber auch des Y-Chromosoms, bestimmen die so genannten Haplotypen. Spezifische Kombinationen, die in vielen Individuen auftreten, eignen sich um Cluster, so genannte Haplogruppen, zu bilden. Diese Typen- und Gruppen bilden die Grundlage für eine Vielzahl von Studien zur Besiedlungsgeschichte der Welt durch den modernen Menschen und auch für kleinräumigere Bevölkerungsbewegungen und Kolonisationsprozesse (Underhill u. Kivisild 2007). Diese Untersuchungen finden zumeist auf der Basis rezenter DNA statt. Die große Zahl an Kopien des mitochondrialen Genoms, die in einer Zelle vorliegt, macht Untersuchungen an mt-DNA auch besonders interessant für die Untersuchung alter DNA (vgl. Kap. 2.2.2).

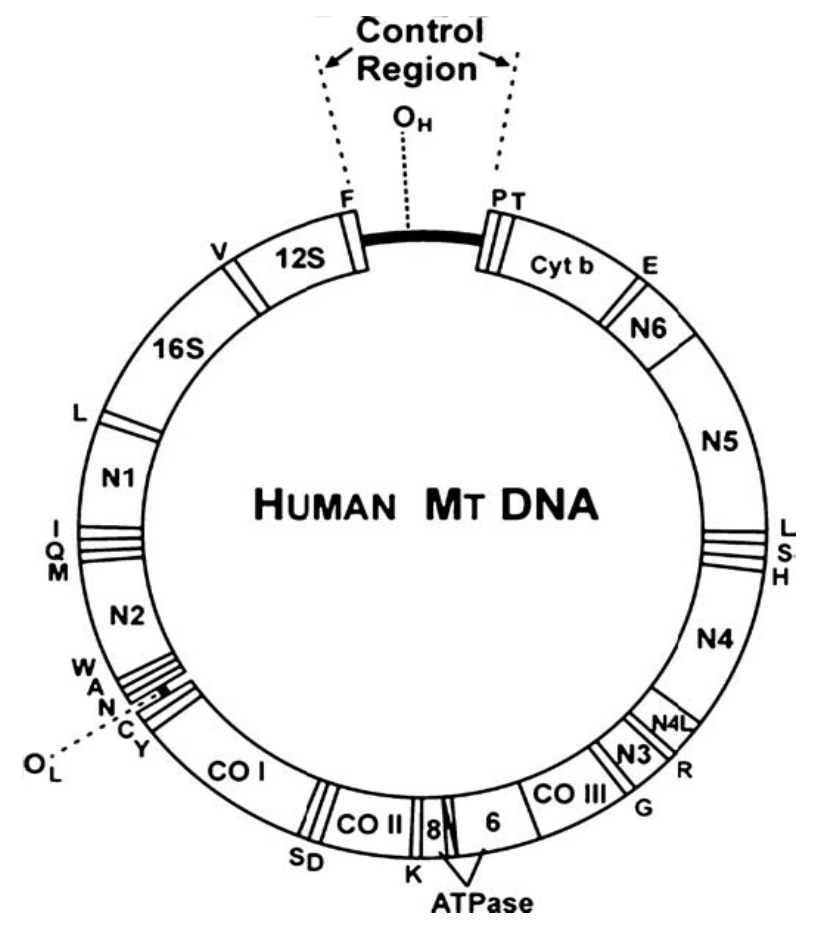

Abb. 3: Schematische Darstellung des menschlichen mitochondrialen Genoms. Beschriftungen wie N1 oder $16 \mathrm{~S}$ bezeichnen die funktionalen Regionen des Genoms. Die Kontrollregion beinhaltet die HVR I \& II (aus Pakendorf und Stoneking 2005)

Von besonderer Bedeutung für solche Untersuchungen ist der einzige, ca. 1122bp große nichtcodierende Abschnitt des mitochondrialen Genoms, die Controll Region oder auch D-Loop (displacement loop), in der sich die hypervariablen Regionen I und II (HVR I und II) befinden (Abb. 3). Die HVR I und II umfassen beide ca. 400 bp. und weisen sehr viele polymorphe 
Positionen auf. Dadurch wurden sie zu klassischen Markern der (molekularen) Populationsgenetik, sodass bereits eine Fülle von Daten zum Vergleich verfügbar ist. Die Untersuchungsmethode der Wahl ist in diesem Fall die Direktsequenzierung von Genomabschnitten, um eine Vielzahl aufeinander folgender Nukleotidpositionen gleichzeitig untersuchen zu können. Ein Großteil aller mt-DNA Arbeiten zur Bevölkerungs- und Besiedlungsgeschichte bezieht sich auf diese Regionen (vor allem auf die HVR I), wobei mittlerweile die Tendenz dazu besteht, whole-Genome Untersuchungen (also die Analyse des gesamten mt-Genoms) vorzunehmen. So wird eine bessere Auflösung der Daten erreicht (vgl. Bandelt et al. 2003; Kong et al. 2003; Macaulay et al. 2005). Ein Grund für diese Entscheidung ist der Nachweis heterogener Substitutionsraten innerhalb der Regionen. Das bedeutet, dass einige Basenpositionen häufiger und schneller evolvieren als andere (Meyer et al. 1999). Davon sind vor allem Pyrimidin-Transitionen betroffen $(\mathrm{C} \ll \mathrm{T})$. Eine Kartierung der einzelnen Nukleotidpositionen und der jeweiligen relativen Substitutionsraten findet sich in Abb. 4. Die sichere Zuordnung zu Haplogruppen kann erschwert werden, wenn die charakteristischen Polymorphismen auf wiederholt mutierenden Nukleotidpositionen (recurrent mutations), so genannten Mutational Hotspots, liegen. Einige Arbeitsgruppen bezweifelten die Existenz solcher Hotspots und führten das beobachtete Phänomen auf Rekombinationsereignisse zurück, diese Hypothesen konnten allerdings widerlegt werden (Stoneking 2000). Aufgrund der Existenz dieser hochpolymorphen Regionen in der HVR sollte die Einteilung in mitochondriale Haplogruppen ergänzend über die Untersuchung von Punktmutationen (Single Nucleotide Polymorphisms - SNPs) oder Restriktionsfragmentlängen Polymorphismen (RFLPs) in der codierenden-Region des Genoms erfolgen (Torroni et al. 2006).

SNP-Typisierungen dienen der Untersuchung einzelner variabler Positionen. SNPUntersuchungen werden z.B. dann eingesetzt, wenn nur eine einzelne Mutation zwischen verschiedenen Allelen entscheidet und eine Sequenzierung längerer Genomabschitte keinen weiteren Erkenntnisgewinn bringt. Sie können bei jeglicher Art von Polymorphismen eingesetzt werden, befinden sie sich nun auf codierenden oder nicht-codierenden Abschnitten. Einsatz finden sie z.B. bei der Untersuchung von immungenetisch assoziierten Polymorphismen (Pepperl in prep.) oder coevolutiven Merkmalen wie der Laktose-Toleranz (Swallow 2003). SNPs sind bei einer entsprechenden Auswahl der loci, wie bereits erwähnt, auch für populationsgenetische Studien geeignet. So kann über bestimmte SNPs haploider Genome, wie der mt-DNA oder des nicht rekombinierenden Teils des Y-Chromosoms, die Zuordnung zu Haplogruppen erfolgen (Underhill u. Kivisild 2007). Als Untersuchungsmethoden bieten sich in diesem Fall neben der 
HVR I

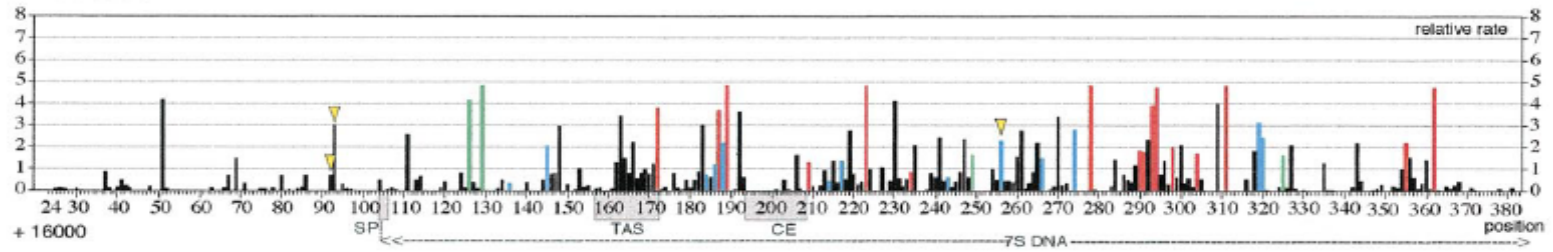

HVR II

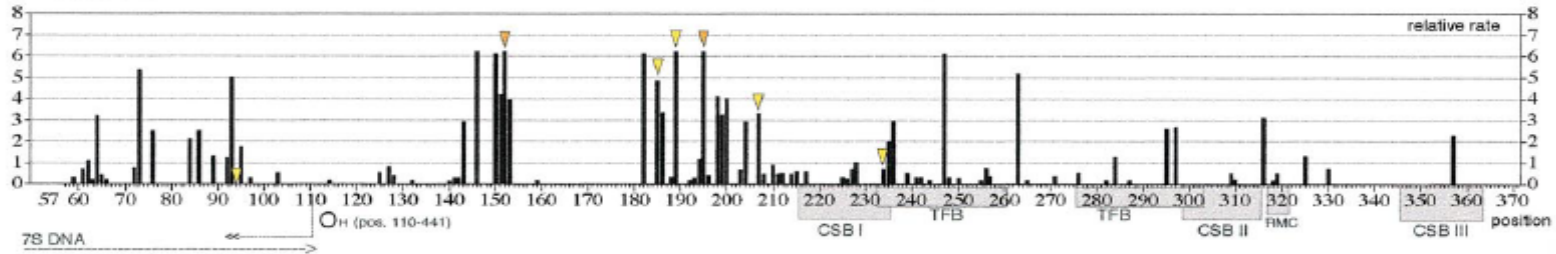

Abb. 4: Relative Substitutionsraten vs. Nukleotidpositionen in der HVR I und HVR II. Die Länge der Säulen gibt die Substitutionsraten jeder Position wieder. Die Pfeile kennzeichnen Positionen aus Verwandtschaftsanalysen, bei denen Basensubstitutionen trotz belegter maternaler Verwandtschaft nachgewiesen wurden. Die Kästen kennzeichnen Regionen mit regulierender Funktion (aus Meyer et al. 1999).

Direktsequenzierung solche an, die sich nur auf eine spezifische Nukleotidposition beziehen wie das „Minisequencing“ sowie auf molekularen Sonden basierende Methoden, die auch in Multiplex Ansätzen (mehrere Genorte werden auf einmal untersucht) durchgeführt werden können. Ein Nachteil der Methode ist, dass eine entsprechend hohe Zahl an Genorten untersucht werden muss, um aussagekräftige oder individualisierbare Daten zu bekommen.

Die Untersuchung von Restriktionslängenpolymorphismen (RFLPs) wird für die gleichen Fragestellungen angewendet. Der Unterschied liegt in der zum Nachweis verwendeten Methode. Es werden zwar auch hier einzelne polymorphe Positionen untersucht, allerdings in diesem Falle dadurch, ob ein spezifisches Enzym an der untersuchten Stelle, je nach Allel, entweder schneidet oder nicht. Anhand der Länge der verschiedenen Schnittfragmente des Produktes kann dann die an der interessanten Position realisierte Base identifiziert werden. Der Nachweis erfolgt in der Regel über hochprozentige Agarosegele oder die PAA-Gelelektrophorese. Im Rahmen dieser Arbeit wurde allerdings auf RFLP-Analysen zugunsten von SNP-Analysen über molekulare Sonden verzichtet, da so eine höhere Nachweisgenauigkeit und auch Untersuchungsgeschwindigkeit erreicht werden konnten (Fehren-Schmitz et al. 2006).

Mikrosatelliten oder auch STRs (Short-Tandem-Repeats) sind nicht-codierende Abschnitte, die eine bestimmte Abfolge weniger Basen tandemartig wiederholen. Die Wiederholungseinheiten bestehen aus zwei (Dinukleotide), drei (Trinukleotide) oder vier (Tetranukleotide) Basenpaaren, wobei erstere Möglichkeit am häufigsten auftritt und selten auch bis zu 6 Basenpaare vorkommen (Edwards et al. 1991). Allele werden über die variierende 
Anzahl an Wiederholungen bestimmt. Bedingt durch ihre Funktionsneutralität weisen STRs ein sehr hohes Maß an Heteroallelie auf, sodass sie z.B. durch die kombinierte Untersuchung weniger Systeme für die Unterscheidung auf individuellem Niveau genutzt werden können. Autosomale STRs werden kodominat vererbt und liegen somit diploid vor, ein Allel vom Vater und eines von der Mutter. Haben beide Allele die gleiche Zahl an Wiederholungseinheiten, so ist das Individuum für diesen Genort homozygot, bei zwei verschiedenen Allelen heterozygot. Zwei Merkmale sind je nach Fragestellung besonders relevant für die Auswahl eines STRs: die Häufigkeit von Allelen eines STRs in einer Population (Frequenz) und die Heterozygotenrate. Die Frequenz ist für die Unterscheidung von Populationen von besonderem Interesse. Heterozygotenraten beschreiben das Ausmaß an Variabilität eines STRs. Sie leiten sich aus der Anzahl an möglichen Allelen und ihrer Kombinationsmöglichkeiten ab. Je geringer die Variabilität von Allelen ist, desto geringer ist die Heterozygotenrate. Um auf einer individuellen Ebene zu unterscheiden, ist eine möglichst hohe Rate von Nutzen. Durch die Kombination mehrerer solcher autosomaler STR-Systeme erhöht sich die Wahrscheinlichkeit, dass die angetroffenen Allelkombinationen einzigartig sind. Man erhält einen so genannten genetischen Fingerabdruck (Butler 2005). Der Hauptanwendungsbereich liegt in der forensischen Identifikation von Personen, Tätern und Opfern. Da die längenpolymorphen Bereiche der STRs unter 400bp liegen, ist eine Anwendung auf degradierte DNA möglich. So werden autosomale STRs z.B. vom IC-MP (International Commission on Missing People) genutzt, um die aus Massengräbern geborgenen Opfer der Konflikte im ehemaligen Jugoslawien zu identifizieren (Primorac et al. 1996; Andelinovic et al. 2005). Darüber hinaus eignen sie sich auch zur Rekonstruktion kompletter Genealogien, sogar aus stark degradierter DNA (bei entsprechender Verkürzung der zu amplifizierenden Produkte). So konnten für 38 bronzezeitliche Individuen aus der Lichtensteinhöhle die verwandtschaftlichen Verhältnisse über drei Generationen nachgewiesen werden (Schilz 2006).

Eines der Hauptprobleme, das bei der Untersuchung von STRs auftreten kann, sind so genannte slippage Phänomene. Diese äußern sich durch das Stottern von Allelen, die zusätzliche Generierung von einer oder mehreren Wiederholungseinheiten. Dadurch kann es zur Fehlinterpretation von Ergebnissen kommen (Hummel 2003). Es geht in diesem Fall nicht um slippage Phänomene, die in vivo bei der Zellteilung auftreten können, sondern um Analyseartefakte, die bei der Amplifikation durch Fehler bei der Elongation der DNA-Stränge auftreten können (waving). Besonders häufig kommt es $\mathrm{zu}$ solchen Ereignissen bei Dinucleotiderepeats (Walsh et al. 1996). In Tetranucleotiderepeats sind sie weitaus seltener, weshalb diese auch für die Generierung des genetischen Fingerabdrucks genutzt werden. 
Neben den autosomalen STRs können auch gonosomale untersucht werden. Für diese Arbeit sind besonders die Y-chromosomalen STRs von Bedeutung, die wie die zuvor beschriebenen SNPs auch in dem nichtrekombinierenden Teil des Chromosoms liegen. Dieser Bereich liegt haploid vor, es gibt also nur ein Allel. Durch diese Eigenschaften eignen sich die Ychromosomalen STRs auch zur Analyse von Patrilinien über viele Generationen hinweg oder zum Vaterschaftsausschluss (bei Vater-Sohn-Vergleichen). Sie haben allerdings nicht den gleichen individualisierenden Charakter wie die autosomalen STRs, da sie ja bei allen Individuen einer Patrilinie identisch vorliegen. Die STRs bestimmen im Falle des Y-Chromosoms den YHaplotypen, die SNPs die Haplogruppe (Y-Chromosome Consortium 2002). In den letzten Jahren wurde zunehmend das Potential der Y-Haplogruppen und -typen für populationsgenetische Studien entdeckt. So konnten Muster patrilinearer Mobilität nachgewiesen werden und für die Rekonstruktion der Besiedlungsgeschichte Australiens (Hudjashov et al. 2007) und Amerikas (Ruiz-Linares et al. 1999) verwendet werden, sowie für die angelsächsische Kolonisation Britanniens (Weale et al. 2002). Durch den Vergleich mit Ergebnissen aus mt-DNA Studien können geschlechtsspezifische Mobilitätsunterschiede nachgewiesen werden (z.B. Fagundes et al. 2002; Wilder et al. 2004). In Tabelle 6 werden noch einmal die verschiedenen vorgestellten molekulargenetischen Marker und ihre Anwendungsbereiche vorgestellt:

Tab. 6: Verschiedene molekulargenetische Marker und ihre Hauptanwendungsbereiche.

\begin{tabular}{|c|c|c|c|c|c|c|c|}
\hline Marker & Genort & 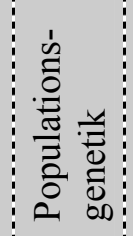 & 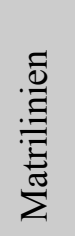 & & 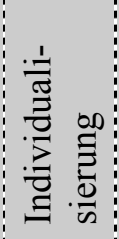 & 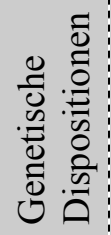 & 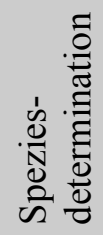 \\
\hline HVR I\&II & mtDNA & $\sqrt{ }$ & $\sqrt{ }$ & & & & $\sqrt{ }$ \\
\hline Cytochrom b & mtDNA & & & & & & $\sqrt{ }$ \\
\hline STRs & $\begin{array}{l}\text { ncDNA } \\
\text { (autosomal) }\end{array}$ & $\sqrt{ }$ & & & $\sqrt{ }$ & & \\
\hline STRs & $\begin{array}{l}\text { ncDNA (Y- } \\
\text { chromosomal) }\end{array}$ & $\sqrt{ }$ & & $\sqrt{ }$ & & & \\
\hline SNPs & mtDNA/ncDNA & $\sqrt{ }$ & $\sqrt{ }$ & $\sqrt{ }$ & & $\sqrt{ }$ & \\
\hline RFLPs & mtDNA/ncDNA & $\sqrt{ }$ & $\sqrt{ }$ & & & $\sqrt{ }$ & \\
\hline
\end{tabular}




\subsubsection{Alte DNA: Eigenschaften und Methoden}

Vor über 20 Jahren wurden die ersten Versuche unternommen, DNA aus alten tierlichen und menschlichen Geweben zu untersuchen (Higuchi et al. 1984; Paabo 1985). Auch wenn die zuerst verwendeten Methoden sich als ineffizient und sich im Verlauf der Zeit viele der frühen Ergebnisse als fehlerhaft oder falsch herausstellten, entwickelte sich dieser Forschungsbereich immer weiter und stellt mittlerweile ein wichtiges Werkzeug der Wissenschaft dar. Ein Werkzeug, um molekulare Archive aus historischen, prähistorischen und paläontologischen Materialien zu erschließen und damit archäologische, historische, populationsgenetische, phylogenetische und ökologische Fragen zu beantworten. Eng mit der regulären molekularen Genetik verbunden war es durch die besonderen Eigenschaften und Merkmale alter DNA (aDNA) notwendig, eigene Wege zu gehen und sich die Zugänge aus einem Disziplinen überspannenden Wissen zu erarbeiten. Das über die Jahre erarbeitete Wissen findet sich gut zusammengefasst in mehreren Review-Artikeln (Kaestle u. Horsburgh 2002; Paabo et al. 2004; Willerslev u. Cooper 2005) und methodisch umfangreicher z.B. in zwei Monographien aus der Historischen Anthropologie und Humanökologie in Göttingen (Herrmann u. Hummel 1995; Hummel 2003).

Der Begriff alte- oder ancient DNA (aDNA) beschreibt DNA im degradierten Zustand, die aus toten Organismen bzw. Geweben gewonnen wird. Es gibt keine einheitlichen Konventionen, ab welchem Zeitpunkt nach dem Tode eines Individuums von aDNA oder von Spuren-DNA zu sprechen ist. Dennoch kann man zumindest für DNA aus menschlichen Geweben sagen, dass aDNA da anfängt, wo der rechtspraktisch erhebliche Zeitraum aufhört. Der Untersuchungsbereich umfasst nicht nur Analysen an DANN, die direkt aus den erhaltenen Hartund Weichgeweben eines Menschen oder Tieres gewonnen wurde, sondern auch solche aus weiterverarbeiteten Geweben wie Pergament, Nahrungsresten (Burger et al. 2000), Ausscheidungsprodukten wie Koprolithen (Poinar et al. 2003), Sedimenten (Willerslev et al. 2003) oder auch Krankheitserregern (Bouwman u. Brown 2004).

Die Arbeit mit aDNA unterscheidet sich in vielen Aspekten von der Arbeit mit rezentem Erbgut. Die Degradierung von DNA beginnt unmittelbar nach dem Tod eines Organismus und bedingt durch diesen Prozess kommt es zu qualitativen und quantitativen Beeinträchtigungen. Während in lebenden Zellen enzymatische Reparaturprozesse auftretende Läsionen wieder ausgleichen und die Integrität der DNA Moleküle aufrechterhalten, ist nach dem Tod diese Funktion nicht mehr gegeben (Lindahl 1993). Es kommt zur Autolyse des Organismus durch lyosomale Enzyme, von denen einige, die Nukleasen, die DNA fragmentieren. Im Rahmen der weiterführenden Verwesung kann es dann durch eine Vielzahl von allochthonen 
Mikroorganismen und biochemischen Prozessen zu einer weiteren Fragmentierung der DNA in kurze Abschnitte, aber vor allem auch zu einer qualitativen Reduzierung des Erbgutes kommen (Eglinton u. Logan 1991). Die Konservierungswahrscheinlichkeit von DNA ist also maßgeblich vom Liegemilieu und den wirkenden Faktoren, wie Temperatur, Feuchtigkeit, pH-Wert, Anwesenheit von Mikroorganismen und Sauerstoff etc. abhängig (Burger et al. 1999). Die Lagerung in Permafrostböden führt z.B. zu sehr guten Erhaltungsbedingungen (Rompler et al. 2006). Auch die Lagerung in Höhlen mit kontinuierlich niedriger Temperatur kann sich sehr vorteilhaft auf die DNA-Erhaltung auswirken (Schilz 2006). Optimale Konservierungsbedingungen werden in der Regel durch die Kombination aus einer kühlen Temperatur, einem relativen $\mathrm{Ma} ß$ an Feuchtigkeit und die Abwesenheit von Mikroorganismen erreicht (Hummel 2003). Marota et al. (2002) führen an, dass sich DNA in hyperariden Wüstenumgebungen maximal über einen Zeitraum von ca. 700 Jahren erhalten kann. Diese Annahme basiert auf der Untersuchung von ägyptischen Papyri, die aus Grabkammern geborgen wurden (Marota et al. 2002). Dazu ist allerdings $\mathrm{zu}$ bemerken, dass das Niederlegen in Grabkammern nicht unbedingt die einzige Bestattungsmöglichkeit in einer Wüste ist und andere Liegebedingungen innerhalb dieser auch zu anderen Erhaltungszuständen führen können, wie es diese Arbeit beweisen wird. Weitere Überlegungen $\mathrm{zu}$ möglichen Halbwertszeiten und maximalen Erhaltungszeiten von aDNA (vgl. Hofreiter et al. 2001; Willerslev u. Cooper 2005) werden hier nicht weiter berücksichtigt, da bei der Vielzahl an Faktoren, die für die Konservierung von DNA relevant sind, keine allgemeingültigen Aussagen getroffen werden können.

Die chemischen Degradierungsprozesse der DNA sind Folgen von Oxidation und Hydrolyse. Letztere ist z.B. verantwortlich für Strangbrüche und damit die Fragmentierung der DNA. Die Brüche können entweder aus der direkten Spaltung des Phosphodiesterrückrats (Abb. 5 a-i) der DNA resultieren oder aus Depurinierungen. Diese beschreiben den Prozess des Verlustes einer Purinbase durch die Zerstörung der glykosidischen Bindung zwischen der Base und dem Zuckermolekül, wodurch es zu einer Destabilisierung des DNA-Stranges kommt (Abb. 5 a-ii) (Paabo et al. 2004).

Hydrolyse aber auch Oxidation können auch zur postmortalen Veränderung einzelner Basen in einer Basensequenz führen (Deaminierung / Abb. 5 - c). Diese Sequenzveränderungen führen zu Fehlbestimmungen, die z.B. im Falle der Untersuchung der HVR I, die Zuordnung zu einer falschen Haplogruppe bedingen können und damit in letzter Instanz zu einer falschen regionalen Zuordnung einer Probe führen können (Bandelt 2005). Deaminierung beschreibt die chemische Umwandlung einer Base in eine andere, die in der regulären Abfolge 


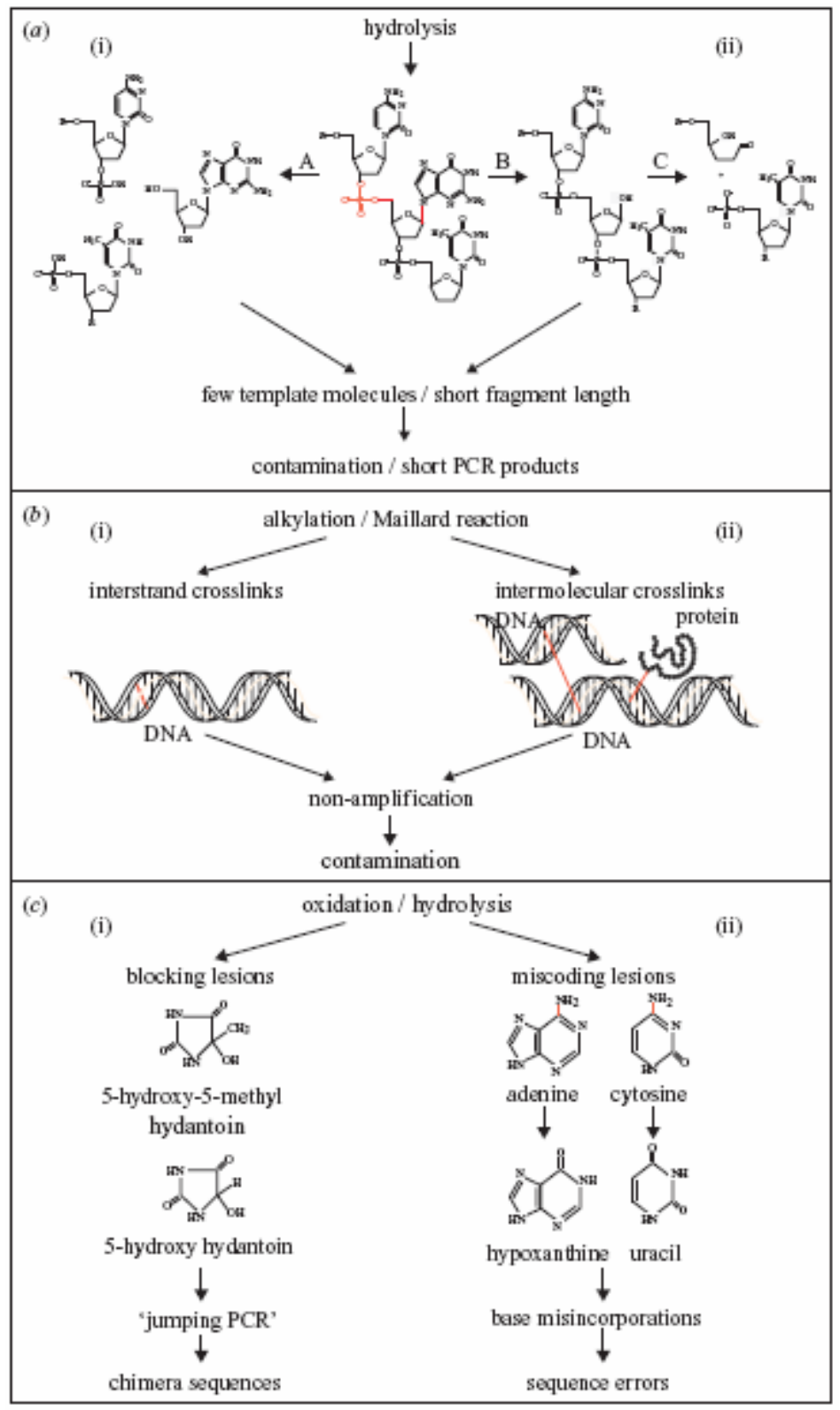

Abb. 5: Darstellung der postmortem wirkenden chemischen Prozesse, die zur Degradierung und Veränderung der DNA führen können (aus Willerslev u. Cooper 2005). Die Erklärung der Prozesse folgt im Text.

nicht vorkommt, z.B. Cytosin zu Uracil oder Guanin zu Xanthin. Diese deaminierten Basen paaren oft mit anderen komplementären Basen als im Ausgangszustand, z.B. Uracil mit Adenin statt Guanin. Bei der Amplifikation des betroffenen Sequenzabschnittes in der PCR wird dann die deaminierte Base entsprechend der neuen Paarung ausgetauscht und die ursprüngliche Sequenz ist verändert. Die häufigsten Deaminierungsergebnisse sind $\mathrm{C}>\mathrm{T}$ und $\mathrm{G}>\mathrm{A}$ Austausche (Stiller et al. 2006), wobei die Basenmodifikationen von Cytosin zu Uracil mit Abstand die häufigste Ursache von postmortalen Sequenzveränderungen sind (Brotherton et al. 2007). Eine Möglichkeit, aus diesem Phänomen resultierende Fehlbestimmungen zu vermeiden, ist der Einsatz von Uracil-N-glycosylase (UNG). Hierdurch werden alle zu Uracil umgewandelten Basen aus der Sequenz entfernt. Die DNA-Abschnitte werden dadurch weiter fragmentiert und können nicht mehr amplifiziert werden. Bei einer sowieso geringen Zahl an erhaltenen Zielsequenzen in einer Probe kann das allerdings dazu führen, dass keine positiven Ergebnisse 
mehr erzielt werden können. Deaminierungsphänomene kommen in mitochondrialer und nuklearer DNA gleich häufig vor (Binladen et al. 2006). Für das mitochondriale Genom lassen sich solche Phänomene am häufigsten in der nicht-codierenden Region beobachten, vor allem in der HVRI. Hier konnte festgestellt werden, dass die Nukleotidpositionen, die eine hohe in vivo Mutationsrate aufweisen (vgl. Kap. 2.2.1 / Mutational Hotspots), auch gleichzeitig am anfälligsten für postmortale Sequenzveränderungen sind (Gilbert et al. 2003).

Postmortale chemische Prozesse führen aber nicht ausschließlich zur Schädigung der DNA. Es gibt auch solche, die nur dazu führen, dass eine Amplifikation von DNA-Fragmenten verhindert oder erschwert wird. Um solche Prozesse handelt es sich bei der Alkylierung und der Maillard Reaktion (Abb. 5 - b). Diese führen zu starken „,crosslinks“, also Verknüpfungen von verschiedenen DNA-Abschnitten miteinander oder mit anderen Biomolekülen. Maillard Produkte können durch den Einsatz von N-Phenacylthiazolium-Bromid (PTB) aufgebrochen werden, wodurch eine Amplifikation wieder möglich ist (Poinar et al. 2003).

Alte DNA ist, außer durch das mögliche Vorkommen postmortaler Sequenzveränderungen, vor allem dadurch charakterisiert, dass sie in der Regel stark fragmentiert und in sehr geringer Menge vorliegt. Ältere Aussagen betreffend der maximalen Fragmentlänge von aDNA sprechen von 200-300bp, allerdings haben neuere Untersuchungen gezeigt, dass es durchaus möglich ist, in Abhängigkeit von den Lagerungsbedingungen und auch dem untersuchten DNA-Abschnitt längere Fragmente aus archäologischen Skelettfunden zu gewinnen (Hummel 2003). Trotz der geringen Zahl an erhaltenen Zielsequenzen ist es vor allem dank der Technik der Polymerase Kettenreaktion (PCR) möglich, DNA aus abgestorbenen Geweben zu untersuchen. Die PCR, in der Mitte der 1980er Jahre erfunden (Mullis et al. 1986), erlaubt spezifische DNA-Abschnitte millionenfach zu vervielfältigen (amplifizieren). Durch den paarweisen Einsatz so genannter Primer, in der Regel 20-30bp lange Oligonukleotide, kann eine gesuchte Zielsequenz zu beiden Seiten hin eingegrenzt und dann durch die mehrfache Wiederholung eines Zyklus, bestehend aus der Abfolge von Denaturierung, Hybridisierung und Elongation, selektiv vermehrt werden. Je nach DNA-Erhaltungsgrad muss dann die Zyklenzahl an die spezifischen Eigenschaften der untersuchten Proben angepasst werden, um eine detektierbare Menge an Zielsequenzen zu erhalten. Bezüglich der grundlegenden Parameter der PCR und der Diskussion über die nötige und mögliche Zahl an Zyklen sei an dieser Stelle auf die weiterführende Literatur verwiesen (z.B. Hummel 2003). PCRs können in Singelplex oder Multiplex Ansätzen durchgeführt werden. Das bedeutet, entweder mit einem Primerpaar oder mit mehreren, um gleichzeitig mehrere verschiedene Zielsequenzen zu amplifizieren. Durch den Einsatz von Multiplex-PCRs kann somit die verwendete Menge an sowieso meist rarem Probenmaterial für die Untersuchung 
reduziert werden, was einen enormen Vorteil für die Arbeitsökonomie bedeutet Gleichzeitig verlangt der Einsatz vorab aber auch ein sehr aufwendiges Design der Primer.

Quantitative Studien haben gezeigt, dass es in Abhängigkeit vom skelettanatomischen Beprobungsort und der topographischen Lage eines untersuchten Genortes auf einem Chromosom zu differenziellen Erhaltungsmustern von DNA kommen kann. Die meisten intakten Zielsequenzen und damit der quantitativ beste Erhaltungszustand der aDNA konnten im Pars Petrosum (Felsenbein) und Dens (Zahn) nachgewiesen werden (Abb. 6; Kleindorp et al. 2006). Für autosomale DNA konnten im Durchschitt 1-10 Zielsequenzen je $\mu$ l DNA-Extrakt nachgewiesen werden (Westenthanner 2007). Genorte, die im Centromer-nahen Chromosomenbereich liegen, erhalten sich darüber hinaus besser als solche, die telomer liegen (Adler 2007). Diese Erkenntnisse haben eine entscheidende Bedeutung für die Probenauswahl bei aDNA-Untersuchungen an menschlichem Skelettmaterial und für die Auswahl der für die aDNA-Analyse geeigneten genetischen Marker.

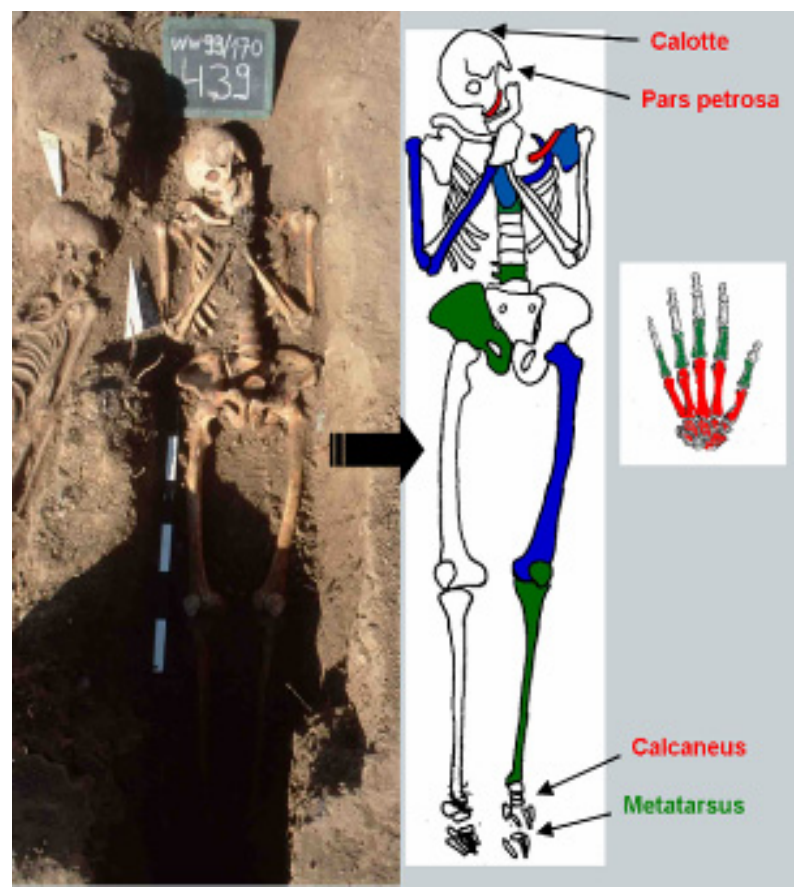

\begin{tabular}{|c|c|c|}
\hline Skelettelement & $\begin{array}{c}\text { authentische } \\
\text { STR Allele* }\end{array}$ & 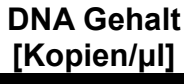 \\
\hline Dens & $81-100 \%$ & $2.5-3.5$ \\
\hline Pars petrosa & $30-100 \%$ & $0.2-8$ \\
\hline Carpus & $41-100 \%$ & $0.2-9$ \\
\hline Metacarpus & $6-100 \%$ & $0-6$ \\
\hline Calcaneus & $9-97 \%$ & $0-2.5$ \\
\hline Clavicula & $36-83 \%$ & $0-0.7$ \\
\hline Patella & $16-100 \%$ & $0-8$ \\
\hline Cervical vertebra & $2-67 \%$ & $0.1-1.2$ \\
\hline Phalanges & $0-75 \%$ & $0-2.5$ \\
\hline Metatarsus & $5-50 \%$ & $0-0.2$ \\
\hline Os coxa & $0-75 \%$ & $0-0.9$ \\
\hline Tibia & $6-54 \%$ & $0.2-0.4$ \\
\hline Femur & $6-61 \%$ & $0-0.7$ \\
\hline Lumbar vertebra & $9-38 \%$ & $0-0.2$ \\
\hline Costa & $6-50 \%$ & $0.2-0.3$ \\
\hline Humerus & $5-54 \%$ & $0-0.2$ \\
\hline Sternum & $3-39 \%$ & $0-4.9$ \\
\hline Scapula & $0-50 \%$ & $0-0.2$ \\
\hline Radius & $6-38 \%$ & $0.1-0.2$ \\
\hline Calvarium & $3-18 \%$ & $0-0.1$ \\
\hline
\end{tabular}

Abb. 6:Quantitativer DNA-Erhaltungszustand in verschiedenen Skelettelementen. In der Tabelle rechts sind die einzelnen Elemente unter Angabe der reproduziert nachweisbaren STR-Allele in Prozent angegeben und die absolute Zielsequenzenzahl gemessen mit der Real-Time PCR. Die Abbildung linkss zeigt die Lage der einzelnen Skelettelemente und den angetroffenen Erhaltungszustand am Beispiel eines Individuums. Rot= gute Erhaltung; Grün= mittlere Erhaltung; Blau= schlechte Erhaltung (nach Kleindorp at al mank

Das wohl größte Problem bei der Untersuchung von alter DNA sind Kontaminationen. Das Prinzip der PCR zeigt, dass, wenn es möglich ist aus einer Probe geringste Mengen DNA zu vermillionenfachen, dieses auch für kleinste Mengen an verunreinigender DNA gilt. Diese 
Kontaminationen können eine Vielzahl an Quellen haben. Bei fast jedem Bearbeitungsschritt einer Probe, von der Ausgrabung bis in das Labor, kann das zu untersuchende Material mit der DNA eines Bearbeiters verunreinigt werden. Dafür reicht eine Hautschuppe, ein wenig Tränenflüssigkeit oder Schweiß aus. Daraus resultiert, dass jede Probe vor der Weiterverarbeitung im Labor sorgfältigst, z.B. durch das Abtragen der Oberflächen, gereinigt werden muss. Kontaminationen können allerdings auch aus anderen Quellen wie Labormaterialien, anderen Proben oder Laborprozessen selbst resultieren. Um falsch-positive Ergebnisse zu vermeiden, müssen strikte Regeln eingehalten und Strategien angewendet werden.

Die beschriebenen Eigenschaften von aDNA und die Probleme, die mit der Analyse verbunden sind, zeigen, dass solche Untersuchungen weit von Trivialität entfernt sind. Es bedarf einer Menge an Lösungsstrategien, um die Authentizität der erwirtschafteten Ergebnisse sicher zu stellen. Es gibt eine Vielzahl von Vorschlägen in der Literatur, die diese gewährleisten sollen (vgl. Willerslev u. Cooper 2005), wobei nicht jeder dieser Vorschläge anstandslos zu akzeptieren oder tatsächlich notwendig ist. Generell kann behauptet werden, dass es, um die Authentizität von Ergebnissen zu sichern, notwendig ist, diese durch mehrfache Untersuchungen des gleichen DNA-Abschnittes zu bestätigen. Die Lösungsstrategien und Maßnahmen, die in dieser Arbeit verwendet wurden, werden ausführlich im Kap. 3.7 erläutert. Wenn Untersuchungen an alter DNA umsichtig und unter Berücksichtigung aller möglichen Fehlerquellen durchgeführt werden, ermöglichen sie den Zugang zu Archiven und die Beantwortung von Fragestellungen, die unter Anwendung aller möglichen anderen Methoden ansonsten verschlossen und unbeantwortet bleiben würden.

\subsubsection{Haplogruppen und Bevölkerungsbewegungen}

Der anatomisch moderne Mensch ist ein Kosmopolit und besiedelt eine Vielzahl unterschiedlichster Habitate. Generell ist die innerhalb unserer Spezies anzutreffende genetische Variabilität sehr gering und die Unterschiede innerhalb einer Population sind größer als die Interpopulationsunterschiede (Underhill u. Kivisild 2007). Trotzdem ist es möglich, anhand molekulargenetischer Untersuchungen zwischen Individuen verschiedener kontinentaler Herkunft und auch noch feiner auflösend zu unterscheiden. Haploide genetische Marker, wie die der mitochondrialen DNA und des nichtrekombinierenden Anteiles des Y-Chromosoms, haben sich als wertvoll für die Erforschung der Ausbreitung des Menschen über die Welt erwiesen. Durch ihre einzigartigen Vererbungswege und im Falle der mt-DNA die im Vergleich hohen Mutationsraten sind sie unersetzlich für Fragestellungen, die sich auf Langstreckenmigrationen, reziproken Genfluss oder die genetische Zusammensetzung von Populationen beziehen. 


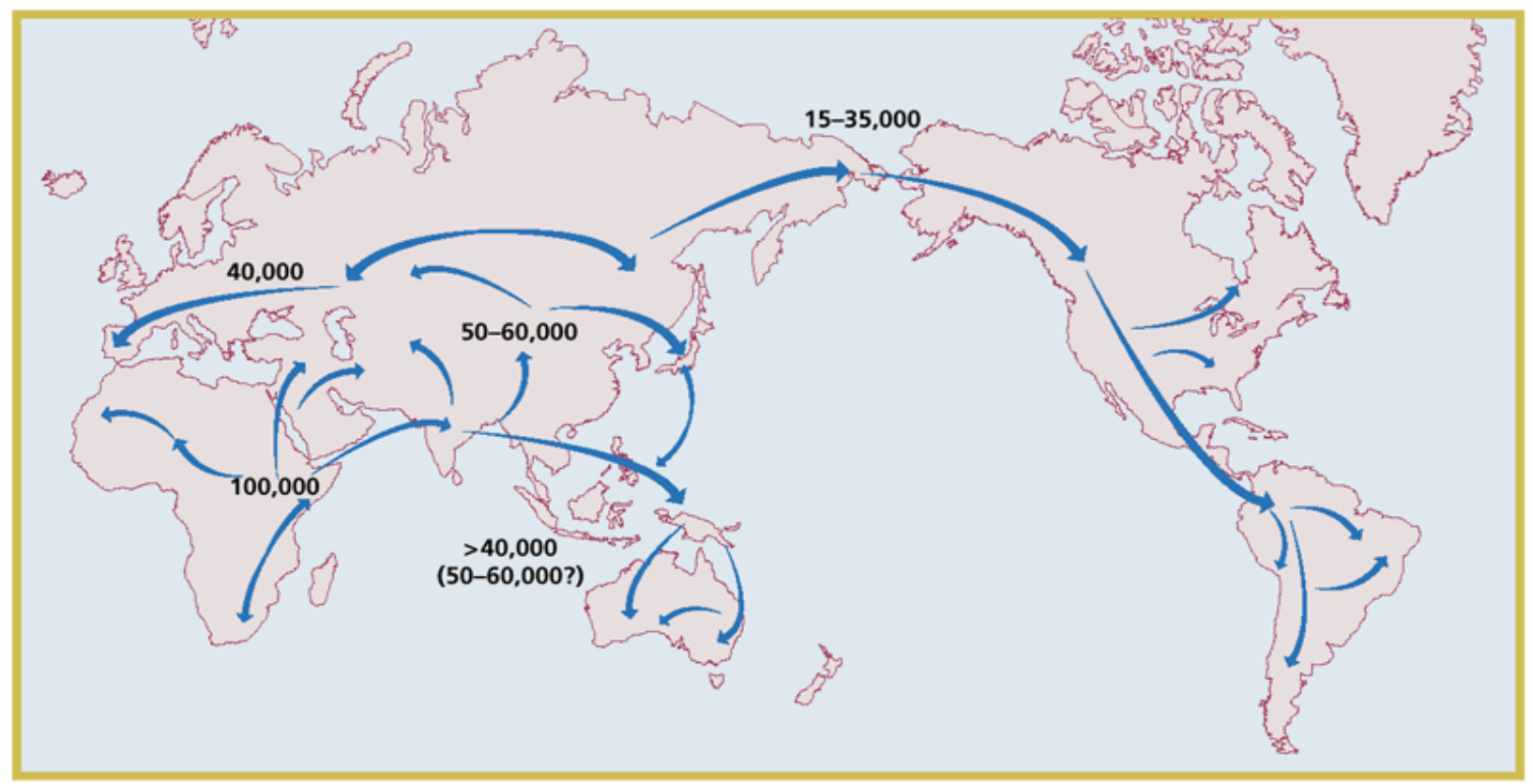

Abb. 7: Schematische Darstellung der Verbreitungswege des Homo Sapiens in der Welt auf Basis genetischer Daten (mt-DNA und Y-chromosomale DNA). Die angegebenen Werte geben ungefähre Zeiträume der Expansion an, resultierend aus molekular clock Berechnungen und 14C Daten. Die Daten sind allerdings mit Vorsicht zu betrachten (Cavalli-Sforza u. Feldman 2003).

Es ist möglich, anhand charakteristischer Sequenzpolymorphismen so genannte Haplogruppen zu definieren. Die Abhängigkeit dieser Haplogruppen voneinander wird kladistisch hierarchisch in einem System von Haupt- und Untergruppen notiert. Die Hierarchie ergibt sich aus komplexen Phylogenien, die auf Basis von Distanzberechnungen erstellt wurden (vgl. z.B. Richards u. Macaulay, V. 2001; Kong et al. 2003; Underhill et al. 1997; Y-Chromosome Consortium 2002). Die phylogenetische Analyse jedes einzelnen Genortes (locus) erlaubt die hierarchische Abstammungsreihenfolge der genetischen Varianten $\mathrm{zu}$ definieren. Anhand phylogenetischer Baumdiagramme kann der Grad genetischer Struktur in Populationen dargestellt, sowie die Reihenfolge und auch der Zeitpunkt ihrer Abstammung abgeleitet werden. Dabei muss bei der Rekonstruktion historischer Bevölkerungsprozesse aber auch berücksichtigt werden, dass diese Berechnungen auf genetischen Distanzen beruhen und damit auch durch Drift, Migration und Selektion beeinflusst wurden (Jobling et al. 2004).

Für das humane mitochondriale Genom liegt eine gut erforschte Phylogenie vor. Bis vor wenigen Jahren basierten die Daten hierfür auf der Untersuchung von spezifischen RFLPs des codierenden Abschnittes und der Sequenzierung der HVR I und II. Die ersten groß angelegten Populationsstudien wurden an der indigenen Bevölkerung Amerikas durchgeführt, mit dem Ziel ihre Herkunft und den Zeitpunkt der Einwanderung zu ergründen. In diesem Kontext wurde auch die bis heute gültige Nomenklatur für die Haplogruppen eingeführt (Torroni et al. 1993). Später wurden auch die Haplogruppenstrukturen der Populationen anderer Kontinente charakterisiert 
und die kladistischen Regeln für die hierarchische Ordnung der Gruppen etabliert (Richards et al. 1998). In den letzten Jahren ist man dazu übergegangen, die Struktur der mt-Phylogenie durch die Untersuchung kompletter mitochondrialer Genome zu erforschen (vgl. Ingman et al. 2000; Maca-Meyer et al. 2001; Kivisild et al. 2002; (Kong et al. 2003). Daraus resultiert eine höhere Auflösung der Phylogenie und ein besseres Verständnis der einzelnen Verzweigungen (Torroni et al. 2006). Allerdings ist zu bemerken, dass solche Untersuchungen an aDNA nicht möglich sind. Die neuen Daten sind allerdings hilfreich, um die Polymorphien kürzerer Sequenzabschnitte besser zu verstehen.

Die Mehrzahl der mt-Haplogruppen ist kontinentspezifisch (Abb. 8). Der Ursprung des Homo Sapiens lässt sich genetisch auf Afrika eingrenzen (Cann et al. 1987). Von dort aus lässt sich anhand der Mutationsereignisse der Weg des Menschen durch die Welt rekonstruieren. Ein Großteil der afrikanischen Bevölkerung lässt sich der mitochondrialen Makrohaplogruppe L zuordnen. Insgesamt ist jedoch in Afrika die höchste mitochochondriale Diversität zu beobachten (Bortolini et al. 2004). Alle mt-Haplogruppen außerhalb Afrikas lassen sich auf zwei Äste der Phylogenie zurückführen, die Makrohaplogruppen $\mathrm{M}$ und $\mathrm{N}$, die an der Wurzel der Haplogruppe L3 abzweigen (Torroni et al. 2006). Nach der in der Regel benutzen Nomenklatur leiten sich aus der Gruppe M die Haplogruppen C, D, E und G ab (Richards u. Macaulay, V. 2001). Von der Gruppe $\mathrm{N}$ leitet sich das Tochterkladon $\mathrm{R}$ ab, das auch eine Makrogruppe darstellt. Innerhalb der Gruppe R liegen die Haplogruppen B, F, H, V, T, J und K. Die übrigen Haplogruppen, die aus $\mathrm{N}$ entstehen, sind A, I, W und X (Jobling et al. 2004). M und die diversen Untergruppen sind hauptsächlich in Süd- und Ost-Asien, sowie den amerikanischen Kontinenten verbreitet (hier nur die Haplogruppen C und D). Aus der Gruppe N rekrutieren sich die einzelnen Haplogruppen, die hauptsächlich in West-Asien und Europa verbreitet sind, wobei sich die endemische westeuropäische Bevölkerung zu 95\% auf die Haplogruppen H, U, J, X, K, T und V eingrenzen lässt (Richards et al. 1998). Die Haplogruppen A (aus M) und B (aus R) gehören aber auch zu den vier typischen Haplogruppen der amerikanischen Kontinente und sind ansonsten nur in Ost-Asien verbreitet.

Die Makrogruppen M und N haben also einen gemeinsamen Ursprung (MRCA - Most recent common ancestor), der in Ost-Afrika zu suchen ist (Jobling et al. 2004). Anhand der Ableitung aus den angenommenen Substitutionsraten im mitochondrialen Genom (Molecular Clock) errechneten Ingman et al., auf Basis der Untersuchung kompletter Genome, einen Divergenzzeitpunkt für die beiden Gruppen von vor ca. $52 \pm 27,5$ tausend Jahren (Ingman et al. 2000). Es wird angenommen, dass innerhalb dieses Zeitraumes eine erste Migrationswelle 


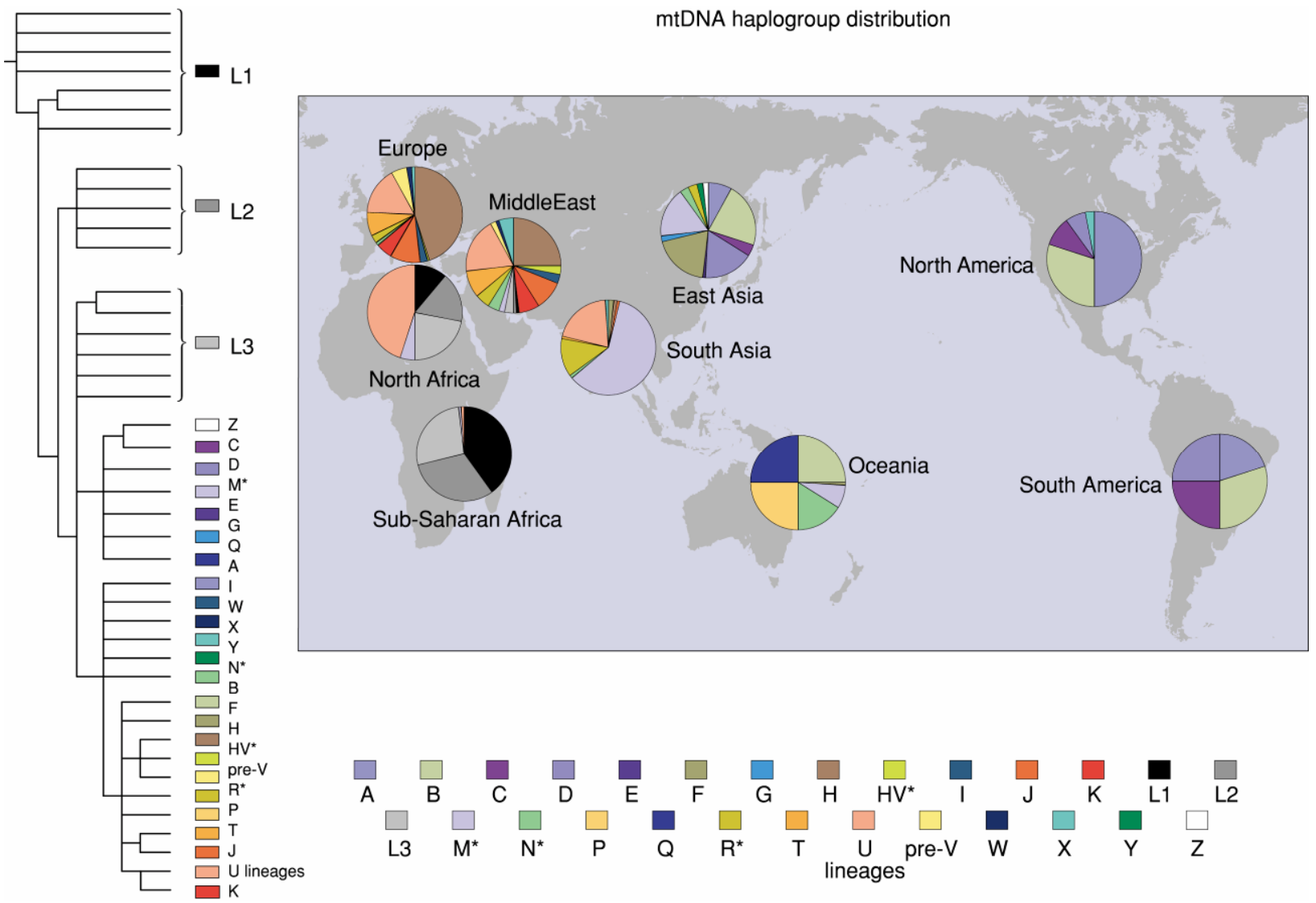

Abb. 8: Geographische Verteilung der Haupt- mt-Haplogruppen. Jeder Gruppe ist eine Farbe zugeordnet, anhand derer ihre Position in der Phylogenie nachzuvollziehen ist (links) und die relative Häufigkeit (Frequenz) in geographischen Großräumen (rechts). Die aufgeführte Phylogenie ist als sehr grob auflösend zu verstehen (Jobling 2004, Fig. 9.16).

stattfand, die, über den Weg durch Süd- und Südost-Asien, Australien und Ozeanien erreichte. Diese Annahmen stehen in Verbindung mit archäologischen Funden aus Australien, die Hinweise auf die Anwesenheit des Homo Sapiens vor ca. 50.000 Jahren liefern (Hudjashov et al. 2007). Aus der Verbreitung der Haplogruppen an dieser angenommenen Migrationsroute wird abgeleitet, dass sie sich zu einem großen Teil aus der Haplogruppe M zusammensetzte. Eine zweite Migrationswelle, die sich zu einem Hauptteil aus der Makrogruppe N zusammensetzte, korrespondiert mit der jung-paläolithischen Verbreitung der Menschen in West-Asien, Europa und Sibirien (Underhill u. Kivisild 2007). Es ist nicht sicher, ob der Ursprungsort der Wanderungen in Afrika oder z.B. auf der arabischen Halbinsel lag, genauso wenig wie gesichert ist, dass es sich wirklich um zwei Wellen handelte. Dies ist nur das Bild, das sich aus der Phylogenie des mitochondrialen Genoms und den Frequenzen der Haplogruppen in ihrer weltweiten Verteilung ableiten lässt. Es ist zu bedenken, dass diese Frequenzverteilung noch durch viele andere historische Ereignisse und genetisch wirksame Kräfte in den letzten 50.000 Jahren geprägt wurde (Cavalli-Sforza u. Feldman 2003). 


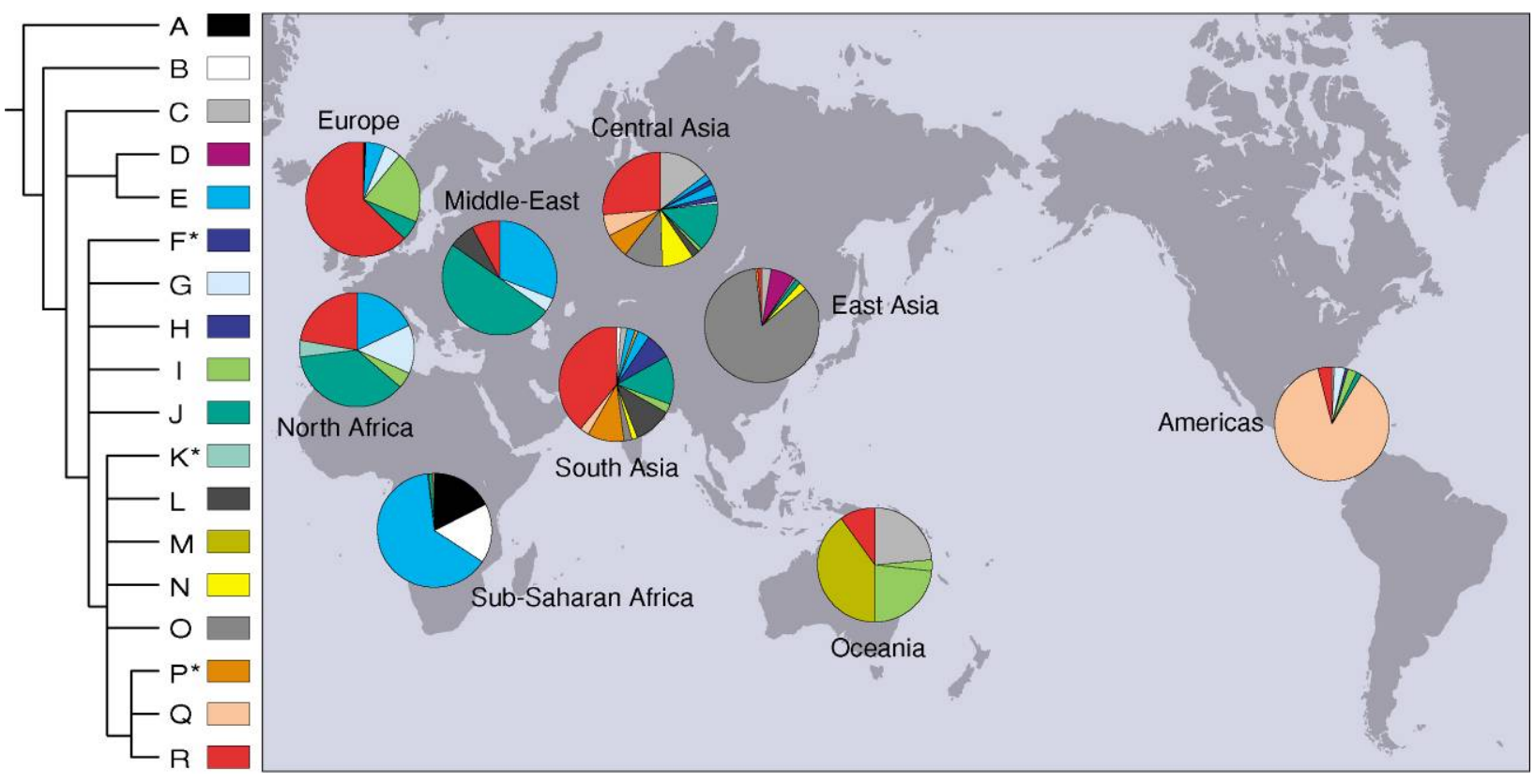

Abb. 9: Geographische Verteilung der Haupt- Y-chromosomalen Haplogruppen. Jeder Gruppe ist eine Farbe zugeordnet, anhand derer ihre Position in der Phylogenie nachzuvollziehen ist (links) und die relative Häufigkeit (Frequenz) in geographischen Großräumen (rechts) (aus Joblin 2004, Fig 9.18). Die YChromosomale Phylogenie ist mittlerweile weiter ausgearbeitet, für detaillierte Informationen wird auf Underhill et al. 2007 verwiesen.

Das Y-Chromosom bietet die größte phylogenetische Auflösung. Auf Basis binärer Marker (SNPs) des nichtrekombinierenden Anteils des Chromosoms (NRY) konnten ca. 150 Haplogruppen definiert werden (Y-Chromosome Consortium 2002). Die beiden Gruppen A und B und die jeweiligen Untergruppen sind in ihrer Verbreitung auf Afrika beschränkt. Alle anderen nicht-afrikanischen Haplogruppen, aber auch ein großer Teil der afrikanischen, zweigen an einem Knotenpunkt der Phylogenie ab, der durch die Mutation M168 definiert wird (Underhill et al. 2001). Daraus wird abgeleitet, dass der Y-chromosomale Vorfahre, der Afrika verließ, eben diese Mutation aufwies und es danach zur weiteren Differenzierung und Verbreitung über die Welt, aber auch zurück nach Afrika kam (Abb. 9). Alle nicht-afrikanischen Haplogruppen lassen sich den Makrogruppen $\mathrm{C}, \mathrm{D}$ und $\mathrm{F}$ zuordnen. Aus der Gruppe D leitet sich noch die Makrogruppe E und aus F die Makrogruppe $\mathrm{K}$ ab. Die Makrogruppen $\mathrm{C}$ und D lassen sich hauptsächlich dem ostasiatischen Raum zuordnen, E zu Europa, West-Asien und Afrika und die verschiedenen Tochterkladen der Gruppen $\mathrm{F}$ und $\mathrm{K}$ finden sich fast überall außerhalb Afrikas (Underhill u. Kivisild 2007) und repräsentieren dort häufig die dominanten Haplogruppen. So sind über 60\% der europäischen Y-Chromosome der Haplogruppe R, in Ost-Asien über $75 \%$ der Haplogruppe O und auf den amerikanischen Kontinenten ca. 75\% der Haplogruppe Q zuzuordnen, allesamt Subkladen der Makrogruppe K (Jobling et al. 2004). Der Mutationszeitpunkt der M168 Mutation wird auf ca. $69 \pm 13$ tausend Jahre datiert. 
Aus beiden hier vorgestellten Markern lässt sich ein nahezu ähnliches Bild der Ausbreitung des anatomisch modernen Menschen über die Welt ableiten. In beiden Fällen ist nur ein kleiner Teil der Phylogenie außerhalb Afrikas verbreitet. Jeweils drei Makrogruppen (Gründergruppen) umfassen die anzutreffende nicht-afrikanische Variabilität (Underhill u. Kivisild 2007). Das ist konsistent mit dem vermuteten Expansions-Bottelneck der „out-of-africa“ Hypothese. In geographisch peripheren Regionen wie Europa und Australien findet sich nur ein Teil dieser Gründergruppen, während sich in Asien alle der jeweils drei Gruppen erhalten haben, was für die zuvor beschriebenen Verbreitungsrouten spricht. Bei beiden Markern handelt es sich um uniparental vererbte Marker. Es zeigt sich, dass auf jeden Fall in der Makroebene der globalen Verbreitung die Daten der matri- und patrilinien konsistent sind. Es erscheint allerdings auch unplausibel, dass solche Expansionsprozesse nur von einem Geschlecht getragen, bzw. verschiedene Routen gewählt wurden (Wilder et al. 2004). Geschlechtsspezifische Unterschiede resultieren aus Matri- oder Patrilokalität, welche sich in der Mikroebene der genetischen Zusammensetzung einer Bevölkerung äußern (Hamilton et al. 2005) und auch eine gewisse räumliche Etablierung einer Gesellschaft voraussetzen (vgl. Kap. 2.1.4.).

Auf der Mikroebene werden Migrationsprozesse in der Populationsgenetik über die Frequenzen der Haplogruppen in jeweiligen Regionen und die Berechnung der Divergenzzeitpunkte über die molecular clock abgeleitet. Das Bild, was dadurch erzeugt wird, ist eine deduktive Interpretation rezent angetroffener Muster. aDNA Untersuchungen haben gezeigt, dass diese Rekonstruktionen gewisse Schwächen mit sich bringen. So wurde für die Besiedlungsgeschichte Europas das Auftauchen der jüngsten Haplogruppe J (ca. 8.500 Jahre v. Chr.) mit einer Verbreitungsroute an der mediterranen und atlantischen Küste und durch die Flusstäler Europas, mit der initialen Ausbreitung neolithischer Farmer gleich gesetzt (Sykes 1999). Neuere mtDNA-Analysen an Skeletten neolithischer Fundorte in Europa werfen Zweifel daran auf, ob die Vorfahren der heute lebenden Menschen tatsächlich Abkömmlinge der frühen neolithischen Farmer sein können. Bei 25\% der untersuchten Individuen konnte der Haplotyp N1a nachgewiesen werden, der heute kaum noch in Europa zu finden ist (Haak et al. 2005). Daraus lässt sich ableiten, dass die heute in Mitteleuropa anzutreffende Haplogruppenverteilung auch aus späteren Migrationsereignissen resultieren kann oder schon im Paläolithikum geformt wurde und die immigrierenden neolithischen Farmer keinen großen Einfluss auf die matrilineare Populationsdynamik Europas hatten.

Die zuvor bereits erwähnte molecular clock ist das grundlegende Datierungswerkzeug der molekularen Populationsgenetik. Die Anwendbarkeit bzw. die zu verwendenden Parameter werden allerdings kontrovers diskutiert. Grundlage dieses Verfahrens ist, dass ausgehend von 
bekannten Mutationsraten spezifischer Genorte, der Zeitraum errechnet wird, der benötigt werden würde, um eine bestimmte Mutation oder Kombination von Mutationen (Haplotyp) zu erreichen. Eine grundlegende Voraussetzung ist, dass der untersuchte Genort neutral ist, also keinem selektiven Druck unterliegt (Tajima 1989a) und damit eine konstante Mutationsrate hat. Dabei werden andere genetische Ereignisse wie Drift, aber auch Rückmutationen und Rekombination außer Acht gelassen, aber auch grundlegende Faktoren wie die Populationsgröße. Außerdem hat das Beispiel der HVR I gezeigt, dass auch innerhalb eines relativ kleinen Genomabschnittes die Mutationsraten abhängig von der Nukleotidposition unterschiedlich sein können (vgl. Kap 2.2.1). Die Kalibrierung der Uhr erfolgt über die Bestimmung der Divergenzzeitpunkte zweier Arten, für die Datierungsgrundlagen aus Fossilien vorliegen, aber bedingt durch die beschriebenen Faktoren wird die Kalibrierung der molekularen Uhr erschwert (Lowe et al. 2004). Neuere Ansätze schlagen molecular clock Modelle vor, die auf Basis unterschiedlich anzunehmender Mutationsraten kalibriert werden und nicht mehr auf einer globalen Ebene und erreichen damit konsistentere Daten (Douzery et al. 2004). Generell ist aber zu bemerken, dass diese Datierungsmethoden nur unter Berücksichtigung aller evolutiv wirkenden Kräfte anzuwenden ist.

Migration ist in der Populationsgenetik nur eine Größe, die den möglichen Genfluss zwischen Populationen beschreibt. Damit ist sie eher ein mathematisches, generalisierendes Modell, das keinen Anspruch auf die Kongruenz mit gesellschaftlichen Ereignissen hat (Fix 1999). Sie beschreibt die populationsgenetische Kraft, die gegen den genetische Drift, Homozygotie und die Fixierung von Mutationen in Bevölkerungen wirkt, die z.B. bei genetischer Isolation auftreten würde. Wenn die Populationsgenetik auch eher nur theoretische Modelle bietet, sind diese doch notwendig, um genetische Daten im Zusammenhang mit kulturhistorischen Daten in Prozesse der Populationsdynamik übersetzen zu können. Die direkte Ableitung auf gesellschaftliche Prozesse, z.B. aus dem Unterschied von Haplogruppen Frequenzen zwischen zwei Populationen, ist nicht möglich. So können spezifische Frequenzen durch isolation by distance geprägt sein (Wright 1943). Das bedeutet, dass die Frequenz innerhalb dieser Population durch Isolation und reduzierten Genfluss geformt wurde, schließt aber auch nicht aus, dass sie zu einem gewissen Zeitpunkt mit einer anderen Population verbunden war oder den gleichen Ursprung, die gleiche Abstammungslinie hat. Andererseits kann es gesellschaftliche Restriktionen geben, die den genetischen Austausch zwischen zwei Populationen vermindern, was von den Modellen der Populationsgenetik nicht erfasst werden kann. Eine weitere Grundlage vieler Berechnungen ist die Annahme des Hardy-WeinbergEquilibriums, das von einem genetischen Gleichgewicht innerhalb einer idealtypischen 
Population ausgeht. Ein grundlegender Faktor dieser Annahme ist, dass sich jedes Individuum einer Population mit einem beliebigen des anderen Geschlechtes mit gleicher Wahrscheinlichkeit paart, ein Phänomen, das in einer menschlichen Gesellschaft kaum anzutreffen sein wird. Die grundlegenden populationsgenetischen Berechnungen und Faktoren werden in Kap. 3.8 vorgestellt.

Abschließend kann gesagt werden, dass die molekulargenetische Anthropologie bei der Erforschung von prähistorischen Migrationsprozessen darauf angewiesen ist, das statistische Werkzeug der Populationsgenetik zu verwenden. Die so gewonnenen Daten sind unter Berücksichtigung evolutiver Kräfte, aber vor allem auch gesellschaftlich wirkender Faktoren zu verwenden. Die Ableitung von historischen Bevölkerungsprozessen aus rezenten Daten bietet häufig nur ein unilineares Bild, das durch Untersuchung an aDNA vervollständigt oder widerlegt werden kann. Die Verbindung von Kulturentwicklung, Migration und der Genetik wird im folgenden Kapitel (2.3) verdeutlicht werden. 


\subsection{Die Besiedlungs- und Kulturgeschichte Amerikas und des südlichen Perus}

\subsubsection{Die initiale Besiedlung Amerikas aus molekulargenetischer und archäologischer Perspektive}

Die Erforschung der initialen Besiedlungsgeschichte Amerikas ist seit langem ein gutes Beispiel für interdisziplinäre wissenschaftliche Zusammenarbeit. Anhand von Daten aus der Archäologie, Anthropologie, anderer Naturwissenschaften und nicht zuletzt der Linguistik werden die Fragen, wann die ersten Menschen einwanderten, woher sie kamen, wie viele es waren und wie viele Einwanderungswellen es gab, kontrovers diskutiert. Einigkeit herrscht darüber, dass die amerikanischen Kontinente die letzten Landmassen waren, die im Jungpleistozän von Menschen besiedelt wurden, und dass die Route über die- oder entlang der Bering-Landbrücke führte. Für andere Theorien, die z.B. eine Besiedlung von Europa oder Ozeanien aus annehmen, gibt es keine wissenschaftlichen Belege. Auch die neuesten aDNA Untersuchungen, die die Herkunft einiger Hühnerknochen in Chile von polynesischen Hühnerarten nachweisen, können keinen Gegenbeweis liefern (Storey et al. 2007). Der Befund beschreibt nur einen möglichen Austausch zwischen Polynesiern und den Inka, kurz vor dem ersten europäischen Kontakt.

Die ökologischen Bedingungen des für die Besiedlung in Betracht zu ziehenden Zeitraums sind geprägt durch das letzte glaziale Maximum des Pleistozäns. Zusätzlich zu den niedrigen Temperaturen und den Konsequenzen für Flora und Fauna führte dieses auch zu einem signifikanten Absinken des Meeresspiegels. Dadurch waren Sibirien und Alaska durch die so genannte Bering-Landbrücke verbunden. Diese Landbrücke bestand zwischen ca. 65.-36.000 Jahren cal. $\mathrm{BP}^{3}$ und wieder zwischen 30. -13.000 cal. BP (Jobling et al. 2004). Sie war nicht von Gletschern überdeckt, sondern eine Tundra, dominiert von Gräsern und Büschen mit einer relativ reichen Fauna. Der Weg in das Innere des nordamerikanischen Kontinents durch Alaska war allerdings nur in bestimmten Zeitfenstern möglich. Von 30.000 cal. BP bis ca.12.550 cal. BP war der Weg durch einen gewaltigen Eisschild, der sich aus dem Laurentidischen Eisschild und den Gletschern der Rocky Mountains zusammensetzte, versperrt (Jackson et al 1997). Erst gegen Ende des angegebenen Zeitraums bildete sich ein eisfreier Korridor zwischen den Eismassen (Abb. 10). Dieser Umstand bestimmt das frühstmögliche Datum einer Besiedlung Amerikas über den Inlandweg und ist konsistent mit der Clovis Hypothese. Clovis bezeichnet eine archäologische Kulturgruppe, charakterisiert durch spezifische bifaziale Speerspitzen, die sich in kürzester Zeit über weite Teile des eisfreien Nordamerikas verbreitete. Die frühesten mit Clovis`

\footnotetext{
${ }^{3}$ Die in der Literatur angegebenen Daten variieren zwischen cal. BP (Kalenderjahren vor Heute - kalibrierte 14CDaten) und BP (vor Heute - unkalibrierte 14C-Daten). Wenn möglich, werden kalibrierte Daten für diese Arbeit verwendet.
} 
Artefakten assoziierte 14C-Daten fallen mit dem Zeitraum der Bildung des eisfreien Korridors zusammen (Dixon 2001). Aus der häufigen Assoziation von Clovis-Speerspitzen mit Knochen von großen Säugetieren wie Mammuts wird abgeleitet, dass es sich um eine auf die Großtierjagd spezialisierte Jäger- und Sammler-Kultur handelte. Daraus wird auch abgeleitet, dass das Aussterben der amerikanischen Megafauna mit dem Erscheinen der Clovis-Kultur im Zusammenhang steht (Overkill-Szenario). Es ist aber unwahrscheinlich, dass dieses Ereignis alleine in dem Erscheinen der ersten Menschen auf dem Kontinent begründet liegt. Vielmehr ist davon auszugehen, dass auch andere Faktoren wie z.B. die klimatischen Veränderungen, die den Übergang zum Holozän begleiteten, ihren Anteil an diesem Phänomen hatten (Jobling et al. 2004). Es galt lange Zeit als gesichert, dass die Clovis-Kultur die initiale Besiedlungswelle der Kontinente repräsentiert. Dem widersprechen allerdings andere mit menschlichen Skelettfunden assoziierte 14C-Daten in Nordamerika, die zwischen 16.-14.000 cal BP liegen (Schurr 2004) und vor allem die Funde von Monte Verde aus Süd-Chile, die zumindest zeitgleich mit den frühen Clovis-Daten sind, wenn nicht sogar älter (Dillehay 1999). Selbst unter Berücksichtigung der schnellstmöglichen Ausbreitungsmodelle ist es nicht möglich, dass die Menschen im Falle einer initialen Besiedlung über den eisfreien Korridor so früh die südliche Hemisphäre, geschweige denn die Südspitze Südamerikas, erreichen konnten (Fix 2002). Es liegt also nahe, dass der früheste Besiedlungszeitpunkt Amerikas vor dem Auftreten der Clovis-Kultur lag. Die alternative Route $\mathrm{zu}$ dem eisfreien Korridor stellt eine Einwanderung entlang der Küsten der Bering-Landbrücke und der Pazifikküste Amerikas dar (Abb. 10; Dixon 2001; Malhi et al. 2002; Fix 2005; Smith et al. 2005). Die nordamerikanische Küste war ca. 2500 Jahre vor dem Inland eisfrei und passierbar. Funde aus anderen Regionen der Welt zeigen, dass es Navigation und Seefahrt in Küstennähe schon vor diesem Zeitpunkt gab und es ist anzunehmen, dass auch die ersten Siedler Amerikas diese Technologie beherrschten (Dixon 2001). Die Route entlang der Pazifikküste wäre konsistent mit den frühen Daten aus Südamerika. Demographische Modelle zeigen, dass es selbst für eine kleine Ausgangspopulation möglich gewesen wäre, auf diesem Wege die mehreren tausend Kilometer zwischen Alaska und dem südlichen Südamerika zu überwinden und tragende Populationsgrößen beizubehalten (Fix 2002; Hey 2005). Von den Küsten aus sollen dann kleine und damit sehr mobile Gruppen das Inland besiedelt haben. Neuere Erkenntnisse auf Basis genetischer Daten sprechen für ein etwas differenzierteres Szenario. Durch Ableitungen aus der in Amerika anzutreffenden genetischen Variabilität kommen Tamm et al. (2007) zu dem Schluss, dass eine kleine Ausgangspopulation die BehringLandbrücke besiedelte und dort für einen gewissen Zeitraum verweilte, bis sich dann ein Teil dieser Population auf dem schnellen Weg entlang der Pazifikküste nach Amerika ausbreitete (Tamm et al. 2007). 


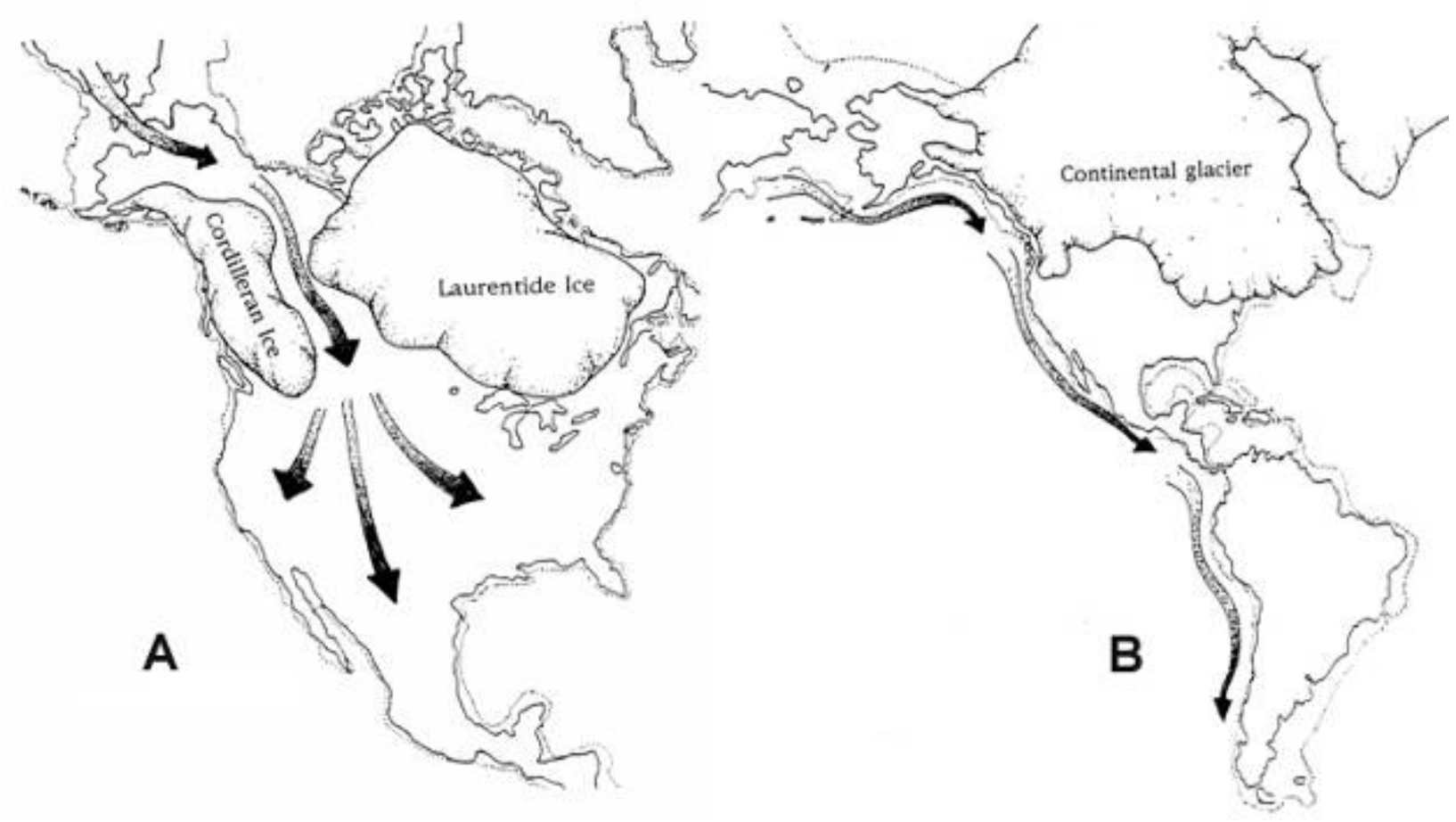

Abb. 10: Die möglichen Routen der initialen Besiedlung Amerikas. A: Die Besiedlung über den eisfreien Korridor. B: Besiedlung entlang der Küstenlinien. Die gepunkteten Umrisse der Landmassen zeichnen den möglichen Küstenverlauf zur Zeit der Besiedlung nach (nach Dixon 2001, Fig. 1 und 7).

Die Entscheidung für eine Besiedlungsroute ist abhängig vom Zeitpunkt. Diese Frage, aber auch die Frage nach der Zahl der Kolonisationsprozesse so wie der Herkunft der Quellpopulation der Besiedlung, findet Beantwortung in der Genetik. Die Basis dafür stellen die frühen Untersuchungen zu mitochondrialen Haplogruppen dar. Generell weisen die indigenen Bewohner Amerikas eine sehr geringe genetische Variabilität auf. Fast alle lassen sich in die mtHaplogruppen A, B, C und D einordnen (Schurr et al. 1990; Torroni et al. 1993). Eine fünfte Haplogruppe X findet sich nur mit geringen Frequenzen in Nordamerika (Dornelles et al. 2005). Diese Haplogruppen sind gekennzeichnet durch spezifische Polymorphismen in der HVR I und der codierenden Region des mitochondrialen Genoms (Tab. 7). Diese 5 Gruppen repräsentieren die Hauptmatrilinien der Gründerpopulation, die nach Amerika einwanderte. Lange Zeit wurde davon ausgegangen, dass jede dieser Haplogruppen zum Zeitpunkt der Besiedlung auch nur durch eine Subgruppe (ein spezifischer Haplotyp) repräsentiert wurde (Schurr u. Sherry 2004). aDNA Untersuchungen an Skeletten aus Nordamerika haben gezeigt, dass es durchaus möglich ist, dass die Zahl der initialen Haplotypen doch größer war. So konnte in British Columbia ein Haplotyp der Haplogruppe M (Smith et al. 2005) und in Alaska ein zusätzlicher Haplotyp der Gruppe D (Kemp et al. 2007) nachgewiesen werden. 
Tab. 7: Charakteristische mitochondriale Polymorphismen der in Amerika verbreiteten Haplogruppen/ typen. In der Spalte „Haplogruppe“ sind jeweils die asiatischen Hauptgruppen (A,B,C,D,X) angegeben. Eingerückt sind die amerikanischen Gründerhaplotypen (Fett= Haupthaplotypen; Kursiv= zusätzliche Gründerhaplotypen, die nur in Nordamerika vorkommen). Die angegebenen Nukleotidpositionen weichen, wenn nicht anders vermerkt, durch Transition von der rCRS ab. Fett gedruckte Nukleotidpositionen in der Spalte „codierende Region“ markieren die klassischen Polymorphismen zur Typisierung der Haplogruppen (nach Torroni et al. 1993; Merriwether et al. 1995; Shinoda et al. 2006; Tamm et al. 2007).

\begin{tabular}{|c|c|c|c|}
\hline $\begin{array}{l}\text { Haplo- } \\
\text { Gruppe }\end{array}$ & HVR I & HVR II & codierende Region \\
\hline A & $16223-16290-16319$ & $73-235-263$ & $\mathbf{6 6 3}, 1736,4248,4824,8794$ \\
\hline $\mathbf{A 2}$ & $16111-16223-16290-16319-16362$ & $64-73-146-153-235-263$ & 8027,12007 \\
\hline B & 16189 & $73-263$ & 8281 bis $8289 d e l$ \\
\hline B2 & $16189-16217$ & $73-263$ & $3547,4977,6473,9950,11177$ \\
\hline $\mathrm{C}$ & $16223-16298-16327$ & $73-249$ del-263 & $3552 \mathrm{~A}, 9545,11914,13263,14318$ \\
\hline C1 & $16223-16298-16325-16327$ & 73-249del-263-290-291del & - \\
\hline$C 4 c$ & $16223-16245-16298-16327$ & $73-263$ & $11440,13368,14433,15148$ \\
\hline $\mathrm{D}$ & $16223-16362$ & $73-263$ & $4883, \mathbf{5 1 7 8 A}$ \\
\hline D1 & $16223-16325-16362$ & $73-263$ & 2092 \\
\hline D2 & $16129-16223-16271-16362$ & $73-263$ & $3316,7493,8703,9536,11215$ \\
\hline$D 4 h 3$ & $16223-16241-16301-16342-16362$ & $73-263$ & $3336,3396,3644,5048,6285,9458$ \\
\hline D3 & $16223-16319-16362$ & $73-263$ & $951,8020,10181,15440,15951$ \\
\hline $\mathrm{X}$ & $16189-16223-16278$ & $73-153-263$ & $6221,6371,13966,14470$ \\
\hline $\mathbf{X} 2 \mathbf{a}$ & $16189-16213-16223-16278$ & $73-153-195-200-263$ & $1719,8913,12397,14502$ \\
\hline
\end{tabular}

Die jeweiligen Haplotypen haben ihre Hauptverbreitung in Amerika und kommen außerhalb, wenn überhaupt, nur selten vor. Als Herkunftsquelle der Haplogruppen und damit der ersten amerikanischen Siedler ist sicher Asien anzunehmen (Torroni et al. 1993; Kivisild et al. 2002). Allerdings ist der genaue Ursprungsort der Population schwerer zu lokalisieren. In rezenten sibirischen Populationen finden sich die mt-Haplogruppen A, C und D, aber keine Individuen mit der Haplogruppe B. Allerdings zeigen neuere archäologische Untersuchungen auch auf, dass die jetzige Bevölkerung des nordöstlichen Sibiriens erst nach der Zeit der amerikanischen Besiedlung in diese Region kam (Mulligan et al. 2004). Gemeinsam treten alle vier Haplogruppen und die Haplogruppe X nur in Ost-Zentralasien / Süd-Sibirien auf (Abb. 11). Es ist davon auszugehen, dass sich die matrilineare Stammpopulation von dort aus in einer Welle zur Bering-Landbrücke bewegte (Schurr 2004). 


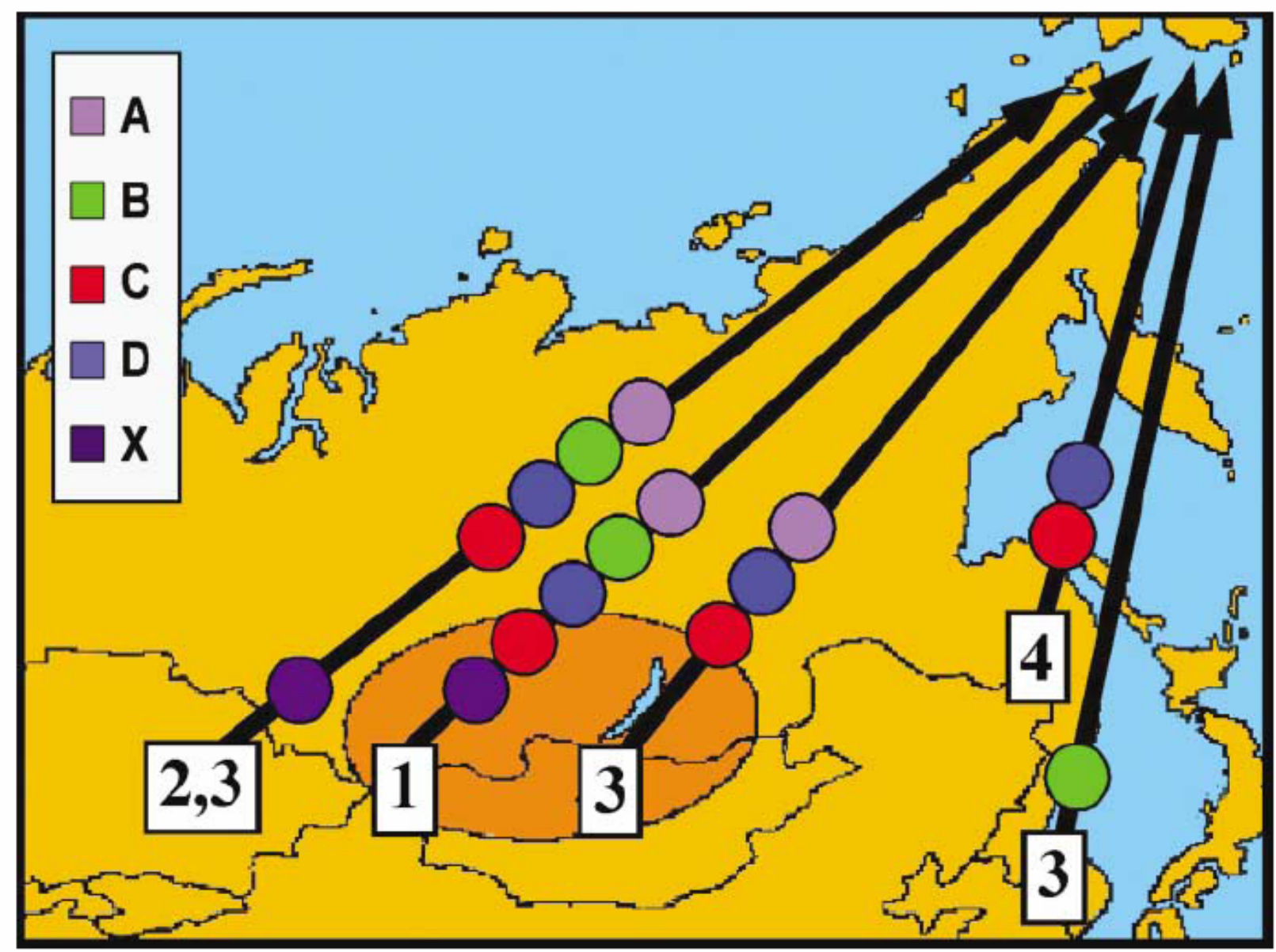

Abb. 11: Migrationsmodelle der möglichen asiatischen Quellpopulation für die amerikanische Gründerpopulation. (1): Alle fünf Haplogruppen stammen aus einer Region und die Migration erfolgt in einer Welle. (2) Die Haplogruppen A-D kamen in einer Welle und $X$ folgte in einer zweiten. (3) Die Haplogruppen A, C und D bilden die erste Besiedlungswelle und Haplogruppe $X$ und $B$ folgen in weiteren aus Sibirien und Ost-Asien. (4) Die Haplogruppen C und D folgen in einer späteren Migrationswelle auf das in Modell 3 vorgestellte Szenario. Der momentane Erkenntnisstand macht Modell 1 am wahrscheinlichsten (aus Schurr 2004, Fig. 5).

Durch die Berechnung der Divergenzzeitpunkte für die amerikaspezifischen Haplotypen über die molekular clock kann ein ungefährer Zeitraum für die Besiedlung Amerikas von 20.000 bis 15.000 cal. BP ermittelt werden (Silva et al. 2002). Die molekulare Datierung geht einher mit der Diskussion über die Zahl der Besiedlungswellen. Bis in die 1990er Jahre dominierte die DreiWellen Theorie. Diese Theorie wurde vor allem durch interdisziplinäre Untersuchungen zur linguistischen, dentalen und genetischen Variabilität in Amerika gestützt (Greenberg et al. 1986). Greenberg et al. stellten die Verbreitung von drei Sprachfamilien in Amerika fest: Amerind (Nord- und Südamerika), Na-Dene (nordwestliches Nordamerika) und Eskimo-Aleut (nördlichstes Nordamerika, Grönland, Sibirien). Diese Sprachfamilien wurden mit drei separaten Migrationswellen gleichgesetzt, die um ca. 11.000 BP, 9.000 BP und 4.000 BP stattfanden 
(Greenberg et al. 1986). Dieses Modell war kongruent mit der Clovis-Hypothese und wurde, obwohl die genetischen Daten auf Basis klassischer Marker beruhten und auch nur in sekundärer Verwendung für die Hypothesenfindung standen, lange Zeit als gültig betrachtet. Erste mt-Daten unterstützten die Hypothese, da unterschiedliche Haplogruppenfrequenzen zwischen den Sprachfamilien nachgewiesen werden konnten. So kommen in Amerind Populationen fast immer alle vier Haplogruppen vor, während in Na-Dene und Eskimo-Aleut Populationen Haplogruppe A dominiert und etwa B fast nie vorkommt (Torroni et al. 1993). Mit Zunahme der zur Verfügung stehenden Datensätze konnte allerdings belegt werden, dass diese strikten Trennungen nicht möglich sind, und die Haplogruppenfrequenzen unter den Sprachfamilien z.B. in direkter Nachbarschaft durchaus variieren. Die geringe genetische Diversität und die Verteilungsmuster der Haplogruppen über beide Kontinente lässt sich eher mit einem Modell erklären, das nur eine initiale Besiedlungswelle annimmt, die sich entlang der Küsten ausbreitete (Merriwether et al. 1995; Silva et al. 2002) und vielleicht noch durch eine zweite, kleinere Besiedlungswelle durch den eisfreien Korridor um ca. 12.550 cal. BP ergänzt wurde (Schurr u. Sherry 2004).

Dieses Modell wird gestützt durch die Daten, die aus der Untersuchung Y-chromosomaler Haplogruppen gewonnen werden konnten. Fast $90 \%$ aller indigenen amerikanischen patrilinearen Haplogruppen lassen sich den Hauptgruppen Q und C zuordnen, wobei die Gruppe Q mit ca. 75\% den größten Anteil ausmacht (Zegura et al. 2004). Die Haplogruppe C ist nur in Nordamerika verbreitet. Die Haplogruppe Q ist in phylogenetischer Reihenfolge der Mutationen in P-M45, Q-M242, Q-M3 und Q-M19 unterteilt, wobei die beiden letzteren nur in Amerika vorkommen (Underhill et al. 2001). Q-M19 und M3 leiten sich von Q-M242 ab, welche wiederum eine Untergruppe von P-M45 ist. Die jeweilige Angabe von M mit der folgenden Zahl bezeichnet die charakteristische Mutation der jeweiligen Gruppe nach der Nomenklatur des YChromosom Konsortiums (2002). Die M242 Mutation markiert den Zeitpunkt unmittelbar vor der Besiedlung Amerikas und charakterisiert den Gründerhaplotypen der rein amerikanischen QHaplotypen (Seielstad et al. 2003). Der Divergenzzeitpunkt dieser Linie beschreibt den frühest möglichen Zeitpunkt der Besiedlung. Bei bestmöglichster Kalibrierung der molecular clock und der Annahme einer kleinen effektiven Populationsgröße legen Seilestad et al. diesen Zeitpunkt mit 20.000 BP, eher 18.-15.000 BP fest. Dieser Zeitpunkt deckt sich mit den Daten aus den Analysen der mitochondrialen DNA. Die Frequenz der Haplogruppe Q-M3 nimmt in einem nord-süd Gradienten zu und Q-M19 tritt nur isoliert in Südamerika auf (Bortolini et al. 2003).

Auch wenn die Zahl an aDNA Untersuchungen an Individuen von den amerikanischen Kontinenten stetig steigt, ist sie dennoch gering, und die Untersuchungen sind häufig nur auf 
wenige Individuen beschränkt. Eine Ausnahme bildet in diesem Fall die Analyse an 108 Individuen von einem 700 Jahre alten Friedhof in Illinois (Stone u. Stoneking, M. 1993; Stone u. Stoneking 1999). Die meisten Untersuchungen konzentrieren sich auf die Bestimmung der mtHaplogruppe anhand der spezifischen RFLP Schnittstellen in der codierenden Region oder der Sequenzierung von Abschnitten der HVRI. Das Bild, das sich aus den aDNA Untersuchungen ergibt, bestätigt in der Regel die Annahme, dass sich die indigene Bevölkerung der amerikanischen Kontinente aus den 4 bzw. 5 Gründerhaplotypen rekrutiert. Bei einer Untersuchung an mehreren 500 - 4.000 Jahre alten Skeletten aus dem Amazonas Gebiet wurden bei 36\% der Individuen nichtamerikanische Haplotypen festgestellt (Ribetio-dos-Santos et al. 1996). Auch in anderen Untersuchungen wurden immer wieder Individuen mit nicht erwarteten Haplogruppen analysiert, wenn auch nicht mit so hohen Frequenzen. Viele dieser Typisierungsergebnisse konnten allerdings im Nachhinein als fehlerhaft identifiziert werden. Die Fehler resultierten entweder aus Kontaminationen, postmortalen Sequenzartefakten oder Analysefehlern (Bandelt et al. 2003). Darüber hinaus haben Untersuchungen an rezenter DNA gezeigt, dass es Haplotypen in Amerika gibt, die ihre gruppenspezifischen Restriktionsschnittstellen in der codierenden Region verloren haben (Torres et al. 2006), was bei Arbeiten, die sich nur auf diese Marker beschränken, zu einer fehlerhaften Typisierung führen kann. Die bereits erwähnten Arbeiten aus Nordamerika haben gezeigt, dass es durchaus möglich ist, dass es weitere mitochondriale Gründerhaplotypen gab, nur ist unklar, wie stark sie den amerikanischen Genpool beeinflussten.

Die indigene amerikanische Bevölkerung durchlief zwei Phasen massiver demographischer Reduzierung, die sich auch als genetischer Bottleneck auf die Variabilität auswirken konnten. Die erste Phase wird durch die initiale Besiedlung dargestellt und der Einfluss auf die genetische Variabilität ist nicht abzustreiten. Daten aus der Analyse mitochondrialer und Y-chromosomaler DNA zeigen eindeutig auf, dass Amerika von einer relativ kleinen Gründerpopulation besiedelt wurde, wenn auch die in einer neueren Arbeit erschienene Zahl von 80 Individuen (Hey 2005) kritisch zu betrachten ist. Die zweite Phase begann mit dem europäischen Kontakt. In Folge der europäischen Kolonisierung starben zwischen 50-90\% der amerikanischen Ureinwohner (Dobyns 1993). Sie wurden entweder durch Krieg oder von den Europäern eingeführten Krankheiten, dem ökologischen Imperialismus getötet (Crosby 2004). Dieser Prozess erstreckt sich allerdings zeitlich bis in das 19. Jahrhundert und äußerte sich in allen Teilen Amerikas unterschiedlich. Der intrakontinentale Vergleich ergibt, dass sich die geringe genetische Variabilität gleichmäßig verteilt. Darüber hinaus haben Untersuchungen autosomaler STRs an indigenen Populationen verschiedener Provenienz ergeben, dass in Amerika die weltweit 
niedrigste Heterozygotenrate anzutreffen ist. Es ist also davon auszugehen, dass der Genozid an der amerikanischen Urbevölkerung sich nicht maßgeblich auf die intrakontinentale genetische Variabilität ausgewirkt hat (Schurr u. Sherry 2004). Der größte Einfluss des europäischen Genpools auf die genetische Zusammensetzung der indigenen amerikanischen Bevölkerung ist patrilinear. Das liegt darin begründet, dass die ersten Phasen der europäischen Kolonisation Amerikas (vor allem Mittel- und Südamerikas) hauptsächlich von Männern getragen wurden (militärisches Personal, Missionare etc.). Diese zeugten Nachkommen mit indigenen amerikanischen Frauen. Die Verbindung von indigenen amerikanischen Männern mit europäischen Frauen ist als eher selten anzunehmen. Dieses Muster scheint sich konstant durch die neuere Geschichte Amerikas gezogen zu haben und äußert sich heute in einem minimalen Einfluss europäischer mt-Haplotypen in indigenen Bevölkerungen. (Mesa et al. 2000).

Auf der regionalen Ebene oder auf der Ebene geographischer Großräume lassen sich große Unterschiede in der genetischen Zusammensetzung der einzelnen Populationen, vor allem der mitochondrialen Haplogruppenfrequenzen beobachten. So ist z.B. in Mittelamerika die Haplogruppe A dominant, gefolgt von Haplogruppe B. Die Haplogruppen C und D sind stark unterrepräsentiert. In Südamerika dominiert die Haplogruppe B im zentralen Andenraum, während im äußeren Süden fast ausschließlich die Haplogruppen C und D auftreten (Jobling et al. 2004). Darüber hinaus ist festzustellen, dass einzelne Populationen sehr häufig spezifische (private) Haplotypen aufweisen, die nicht über diese Population hinaus verbreitet sind (Malhi et al. 2002). Diese Umstände begründen die besondere Eignung von Untersuchungen mitochondrialer DNA für die Rekonstruktion prähistorischer Populationsdynamik und Migrationsrouten in Amerika. Eine Ursache für die Verteilungsmuster ist in der initialen Besiedlung zu sehen. Die schnelle Verbreitung der Bevölkerung über die Kontinente, rasch gefolgt von Tribalisierungsprozessen ab dem Archaikum, führten zu Phasen starken genetischen Drifts und reduzierten Genflusses und damit zu spezifischen genetischen Frequenzen (Schurr 2004). Eine weitere Ursache für die Verteilungsmuster ist in den folgenden kulturellen und politischen Prozessen zu sehen, auch wenn diese von der Populationsgenetik, die sich überwiegend auf rezente Daten stützt, häufig vernachlässigt werden. Die Y-chromosomalen Daten unterstützen diese Beobachtungen, und es lassen sich kaum Unterschiede in der geschlechtsspezifischen Mobilität erkennen (Mesa et al. 2000).

Die geringe genetische Variabilität steht im Kontrast zu der großen Vielfalt an kulturellen Entwicklungen und Sprachen, die sich auf den amerikanischen Kontinenten in einer relativ kurzen Zeitspanne entwickelt haben. Diese Vielfalt entwickelte sich aus einer relativ kleinen Ausgangspopulation, die sich auf den Kontinenten über einen gewaltigen Raum mit nahezu allen 
möglichen ökologischen Zonen verbreitete. Die mögliche Ursache für diesen kulturellen Reichtum ist in der schnellen Verbreitung, dem schnellen demographischen Wachstum und der folgenden Anpassung an eine Vielzahl verschiedenster ökologischer Nischen zu suchen. Die Kulturentwicklung wird ihren maßgeblichen Teil an der Prägung der genetischen Verteilung gehabt haben. Prozesse geographischer Expansion, die Besiedlung neuer Nischen und die Entwicklung neuer Sprachen und Kulturen sind mögliche Ursachen für das Entstehen genetischer Unterschiede zwischen Bevölkerungen (Cavalli-Sforza et al. 1989).

\subsubsection{Besiedlung und genetische Struktur der indigenen Bevölkerung Südamerikas}

Die Erkenntnisse über die Besiedlungsgeschichte Südamerikas und die Ursachen und Umstände, unter denen es zur Sesshaftwerdung und der Entstehung komplexer Gesellschaften kam, sind äußerst lückenhaft. Die einzigartigen Verteilungsmuster genetischer Diversität erschweren die Rekonstruktion der initialen Besiedlung des Kontinentes (Lewis et al. 2007b), und auch die archäologischen Daten zu der frühen Besiedlungsphase sind spärlich. Die ersten gesicherten Spuren des Menschen datieren auf ca. 11.000 v. Chr., daraus wird eine Besiedlung des Kontinentes vor ca. 14.-13.000 Jahren abgeleitet (Dillehay 1999). Südamerika ist ein sehr großer Kontinent mit einer Fläche von ca. $17.870 .000 \mathrm{~km}^{2}$ und einer Vielzahl unterschiedlichster ökologischer Bedingungen. Diese reichen von den tropischen Klimaregionen der Nordhälfte bis zu den subpolaren Regionen an der Südspitze. Die verschiedenen Siedlungsräume umfassen den tropischen Regenwald des Amazonasbeckens, das Hochland der Anden, die hyperaride AtcamaWüste an der Pazifikküste oder die ausgeweiteten Parklandschaften wie das Gran Chaco. Auf Abbildung 12 ist die geläufigste Einteilung des Kontinentes in geographische und kulturelle Einheiten dargestellt (Stanish 2001), die im weiteren Verlauf der Arbeit auch als Grundlage des kontinentalen Vergleichs dienen soll.

Es ist davon auszugehen, dass die Menschen im späten Pleistozän andere ökologische Bedingungen antrafen als heute, die die Wahl ihrer Wege und der Orte, an denen sie sich niederließen, maßgeblich mit beeinflussten. Die starken und abrupten Klimaschwankungen des Holozäns (vgl. Abb. 1), in denen sich die gesellschaftliche Ausdifferenzierung und Kulturentwicklung vollzogen hat, werden ihren Anteil an diesem Prozess gehabt haben (Eitel 2007). Die westlichen Zentralanden und die anliegenden Küstenregionen stellen dabei unter dem Gesichtspunkt der kulturellen Entwicklung die dynamischste Region dar. In dieser haben sich in einem relativ kurzen Zeitraum früheste Formen der Sesshaftigkeit, Domestikation von Tieren, Anbau von Nutzpflanzen bis hin zu komplexen frühstaatlichen Gesellschaften entwickelt (Stanish 2001). 


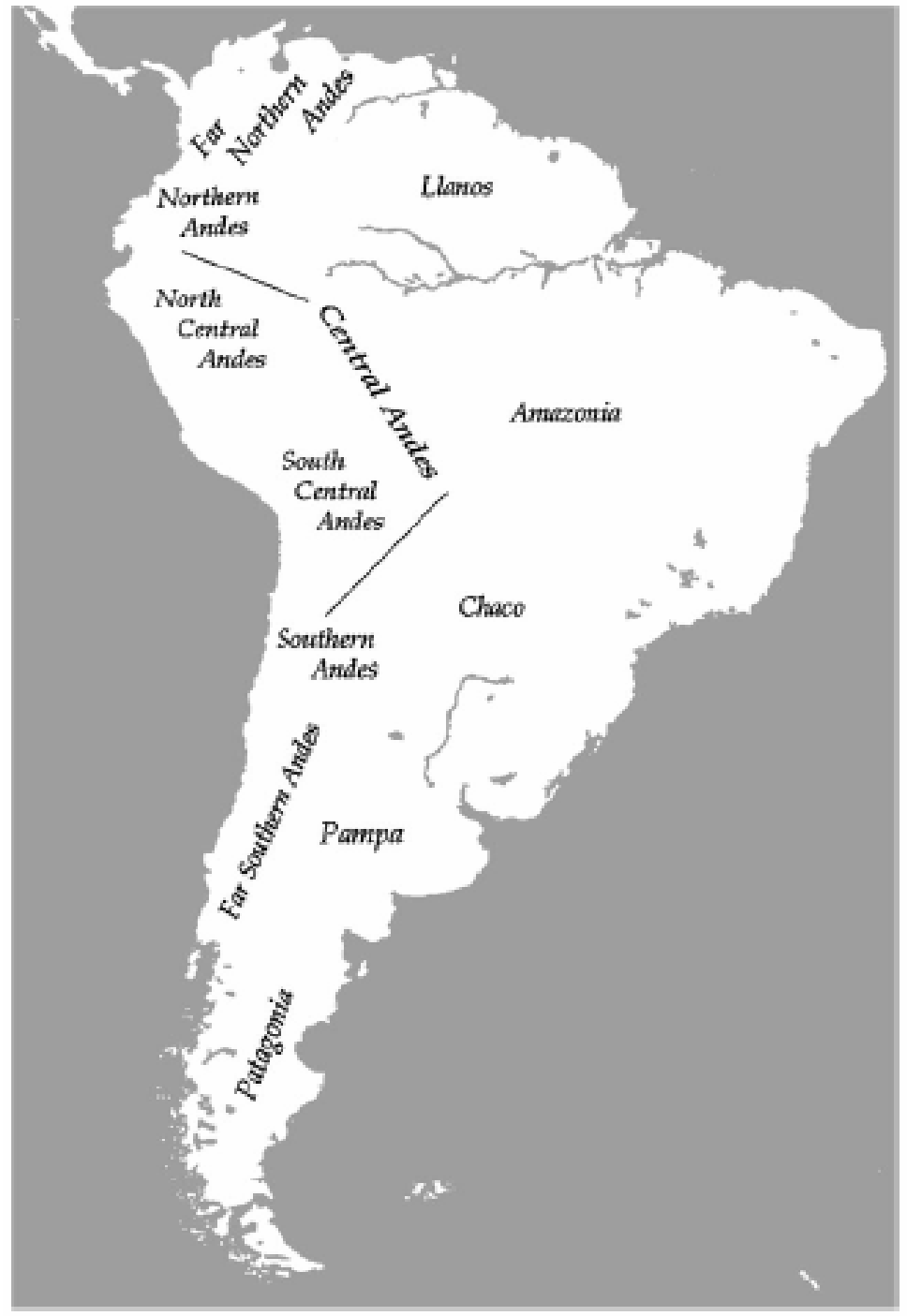

Abb. 12: Einteilung der kulturellen und geographischen Großräume Südamerikas nach Stanish 2001. Weitere Erläuterungen erfolgen bei der Beschreibung der verwendeten Referenzpopulationen für diese Arbeit (Kap. 3.1.3).

Als erste Indikatoren für Siedlungsplätze an der Westküste Südamerikas gelten Muschelhaufen, die von Küstenwildbeutern hinterlassen wurden. (Sandweiss et al. 1998). Der Reichtum an Fischen und Meeresfrüchten in den kalten Gewässern des Humboldt-Stromes ermöglichte es Fischern, Jägern und Sammlern, sich schon ab dem 8. Jt. v. Chr. in dauerhaften Siedlungen niederzulassen. In dem gleichen Zeitraum entwickelten sich auch erste Formen der Sesshaftigkeit im Andenhochland. Als Grundlage wird hier die Jagd auf Neuweltkamelidae (Guanakos und Vikunjas) angenommen, die als Standwild nur eine geringe Mobilität der Jäger verlangten. Diese Subsistenzgrundlage erlaubt das Leben in semipermanenten und permanenten Lagerstätten (Rick 1980). Zeitgleich finden sich auch die ersten Anzeichen von Pflanzendomestikation im Hochland (Lynch 1980). Das nur wenig zeitlich versetzte Auftreten von Hortikultur aber auch Obsidian an der Küste, sowie umgekehrt Muschelfunden im Hochland, deutet auf Kontakte zwischen den Bewohnern dieser Regionen hin. Im östlichen 
Südamerika lassen sich Sesshaftigkeit und Hortikultur im mittleren und oberen Amazonasgebiet ab ca. 4.-3.000 v. Chr. nachweisen (Haberland 1991). Es handelt sich dabei um Entwicklungen, die unabhängig von denen im westlichen Südamerika sind. Die Kamelidenjagd im andinen Hochland bildet die Grundlage für die Domestikation von Lamas und Alpakas ab dem 5. Jt. v. Chr.

Der Übergang von nomadisierenden zu sesshaften, Bodenbau und Viehzucht betreibenden Gesellschaften ereignete sich im zentralen Andenraum, im so genannten Archaikum. Im vergleich zum europäischen Neolithikum ist diese Entwicklung unabhängig von der Nutzung von Keramik, die erst ab ca. 4000 v. Chr. aufkommt (Dillehay 1999). Nach 6.000 v. Chr. setzte an der zentralandinen Küste eine rasche Entwicklung, ein und spätestens zum Beginn des 3. Jt. v. Chr. war die Sesshaftigkeit und der Anbau der meisten Nutzpflanzen etabliert (Stanish 2001). An der Küste Perus entstanden nun die ersten Monumentalanlagen mit Kultplätzen und ausgedehnten Siedlungen, wie z.B. Caral (2650 v. Chr.) 200 km nördlich von Lima (Solis et al. 2001). Sie sind Ausdruck großer, komplexer Gesellschaften, aus denen sich die späteren Hochkulturen im ganzen Andenraum entwickelten (Stanish 2001; Fuchs et al. 2006). Während der Ursprung von Monumentalität und Komplexität an der Küste zu vermuten ist, scheint die Domestikation von Tieren und die Kultivierung von Nahrungspflanzen vorwiegend im Hochland stattgefunden $\mathrm{zu}$ haben. Im Zuge dieser Entwicklungen bildete sich in den folgenden Jahrtausenden, bis zur Kolonisation durch die Europäer in der Region, eine Vielzahl von komplexen, großräumigen Kulturen und Staaten aus, wie Chavin, Moche, Huari (Wari), Tiahuanaco und zuletzt die Inka. Die letzten drei genannten Kulturgruppen, die ihren Ursprung im peruanischen bzw. bolivianischen Hochland hatten sind in Bezug auf die Bevölkerungsgeschichte besonders interessant, da sie allesamt stark expandierten und weite Gebiete unter ihren politischen Einfluss brachten. Das von den Inka beherrschte Gebiet reichte zum Zeitpunkt der Ankunft Francisco Pizarros 1526 n. Chr. von Quito im nördlichen Equador bis weit ins südliche Chile. Es ist anzunehmen, dass militärische Expansionen, aber auch die bekannten Zwangsumsiedlungen von Bevölkerungsgruppen einen Einfluss auf die genetischen Verteilungsmuster im westlichen Südamerika hatten.

Die beschriebenen Entwicklungen beziehen sich hauptsächlich auf den regionalen Fokus dieser Arbeit. Im südlichen Südamerika, Chile und Argentinien bestanden bis zum Kontakt mit den Europäern Kulturgruppen mit aneignender Lebensweise, wie die Mapuche in Chile oder in starker Abhängigkeit von marinen Ressourcen, wie die Yaghan auf Feuerland (Garcia-Bour et al. 2004; Garcia et al. 2006). An der Nordwestküste Südamerikas etablierten sich zwischen 1000 v. Chr. und 500 v. Chr. die Arawaken im Bereich des Deltas des Orinoco. Ihre Subsistenz beruhte 
auf einer Mischung aus Fischfang, Jagd und dem Anbau von Mais, Bohnen, Süßkartoffeln, Kürbissen und Maniok (Haberland 1991). Die Entwicklung frühstaatlicher und stark expandierender Gesellschaften zeichnet sich aber nur im zentralen Andenraum ab.

Auch wenn der Zeitpunkt der Besiedlung Südamerikas sich mittlerweile sehr gut eingrenzen lässt (s.o.), ist die Zahl der Besiedlungswellen sowie die Routen die die Menschen wählten, noch Gegenstand kontroverser Diskussionen. Wie bereits im Kapitel zuvor erwähnt, lassen sich regional spezifische Haplogruppenfrequenzen und auch Diversitätsunterschiede feststellen. Diese korrelieren aber nicht unbedingt mit den Verbreitungsmustern von Sprachfamilien, die als Indikator ethnischer Zuordnung verwendet werden, oder den heutigen Kulturräumen indigener Bevölkerungen. Eine Frage die aus dieser Beobachtung resultiert, ist, wie viel Anteil die initiale Besiedlung des Kontinentes an den heute anzutreffenden genetischen Mustern hatte. Vergleicht man den Westen Südamerikas (Zentralanden) mit dem Osten (Amazonas Region), so weisen andine Populationen eine hohe populationsinterne genetische Diversität, aber nur geringe genetische Distanzen zueinander auf. Amazonas Populationen haben zumeist eine geringere interne Diversität, aber große Distanzen zueinander (Luiselli et al. 2000; Tarazona-Santos et al. 2001; Fuselli et al. 2003; Lewis et al. 2005; Lewis et al. 2007b). Dieses Muster könnte z.B. aus separaten Einwanderungswellen resultieren, wobei die Besiedlung des andinen Raums dann die größere zeitliche Tiefe gehabt haben muss, um das höhere Maß an Diversität zu erlangen (Tarazona-Santos et al. 2001). Eine andere Ursache könnten aber auch unterschiedliche Populationsgrößen und Muster des Genflusses in Ost und West gewesen sein, was mit den Unterschieden in den gesellschaftlichen Entwicklungen der Regionen korrelieren würde (Fuselli et al. 2003). Beide Erklärungen sind aber nicht exklusiv. Ein Vergleich von HVR I Sequenzdaten aus andinen und amazonischen Populationen zeigte keine signifikanten Unterschiede auf, was bedeutet, dass entweder beide Gruppen aus der gleichen Gründerpopulation stammen oder über die Zeit ein konstanter Genfluss zwischen beiden Regionen bestand (Lewis et al. 2007b).

Betrachtet man die rezente mitochondriale Haplogruppenverteilung im westlichen Südamerika lässt sich ein nord-süd Gradient von Haplogruppe A zu D feststellen. Im nördlichen Kolumbien erreicht die Haplogruppe A eine Frequenz von über 50\%, während D so gut wie gar nicht nachgewiesen werden kann (Keyeux et al. 2002). Im südlichen Chile hingegen tritt die Haplogruppe A in den Hintergrund während Haplogruppe D dominant wird (Garcia et al. 2006). Die indigenen Bevölkerungen Feuerlands weisen nur noch die Haplotypen D und C auf (Moraga et al. 2000; Garcia-Bour et al. 2004). In den Zentralanden und Südanden, also den heutigen Landesgebieten von Equador, Peru, dem bolivianischen Hochland und dem nördlichen Chile, dominiert die Haplogruppe B mit Frequenzen von bis zu über 50\%. Stark repräsentiert ist auch 
die Haplogruppe C, während sich die Gruppen A und D unausgewogen verhalten, generell in der Frequenz aber viel geringer sind als B und C (Luiselli et al. 2000; Rodriguez-Delfin et al. 2001; Lewis et al. 2005). Die Dominanz der beiden Haplogruppen im Hochland lässt sich auch schon für die Inka-Zeit anhand von aDNA Untersuchungen bestätigen. Die genetischen Daten, die aus menschlichen Skeletten der mit Machu Picchu assoziierten Siedlungen Paucarcancha und Patallacta gewonnen werden konnten, zeigen eine klare Relation $\mathrm{zu}$ den heute in dem peruanischen und bolivianischen Hochland lebenden Menschen mit Quechua und Aymara Sprachtradition (Shinoda et al. 2006). Abweichend davon weisen aDNA Untersuchungen an Individuen des Fundplatzes Huaca-Loro an der norwestlichen peruanischen Küste einen sehr hohen Anteil der Haplogruppe D nach, während A und B in geringeren Frequenzen auftreten (Shimada et al. 2004). Der Fundplatz datiert in den Mittleren Horizont (ca. 650- 1000 n. Chr.) und ist damit weitaus älter als die inkazeitlichen Fundorte.

Die beschriebenen rezenten Frequenzunterschiede im westlichen Südamerika werden verschieden interpretiert. Das isolierte Aufkommen der Gruppen C und D im äußersten Süden und die zunehmende Frequenz von D entlang der Westküste könnte als Indiz für eine mehrwellige Besiedlung gesehen werden. Die erste Welle hätte sich in diesem Fall hauptsächlich aus Trägern dieser beiden Haplogruppen zusammengesetzt. Eine zweite folgende Besiedlung entlang der Küste hätte dann die Menschen der ersten weiter nach Süden verdrängt (Lalueza et al. 1997). Vergleichende Untersuchungen auf Ebene von HVRI-Haplotypen zwischen Populationen aus Feuerland und dem restlichen Chile haben allerdings gezeigt, dass die genetischen Unterschiede nicht signifikant sind, um diese Zwei-Wellen-Hypothese zu stützen (Moraga et al. 2000). Es ist eher zu vermuten, dass das angetroffene Muster aus einem isolation by distance Phänomen resultiert. Bei einer geringeren Ausgangsfrequenz der anderen beiden Haplogruppen und einer kleinen Grundbevölkerung kann es über die Zeit durch die relativ isolierte Lage des südlichen Südamerikas zu einer Fixierung der Gruppen C und D und dem Wegfallen der beiden anderen durch genetischen Drift gekommen sein. Die Dominanz der Haplogruppe A im äußersten Norden Südamerikas lässt sich auch durch einen ständigen genetischen Austausch mit Mittelamerika erklären, wo diese Gruppe ebenfalls dominiert (vgl. Kap. 2.3.1.). Da ähnliche Muster auch an der Nordküste Venezuelas zu beobachten sind (Vona et al. 2005), ist davon auszugehen, dass der hohe Anteil der Haplogruppe A aus späteren Immigrationsprozessen in das nördliche Südamerika resultiert, die im Zusammenhang mit der Ausbreitung der mittelamerikanischen Chibchan-Sprachfamilie stehen (Melton et al. 2007).

Rotthammer et al (2001) behaupten auf der Basis genetischer Distanzvergleiche, die auf den Frequenzen von mitochondrialen Haplogruppen beruhen, dass die rezente andine Bevölkerung 
aus dem Amazonasgebiet stammt. Die Distanzberechnungen gruppierten Aymara und Atacameno Populationen aus dem nördlichsten Chile näher zu amazonischen Populationen als zu mittel- und südchilenischen, wie den Pehuenche und Huichile. Diese Beobachtung wird unterstützt durch aDNA Untersuchungen an Individuen aus Arica (nördlichstes Chile) und Tiahuanaco (Bolivien). Beide prähistorischen Populationen weisen auch geringere genetische Distanzen zu amazonischen Populationen auf (Moraga et al. 2001; Rothhammer et al. 2003). Rotthammer erstellt auf Basis dieser Daten ein Modell, das zwei Besiedlungswellen nach Südamerika annimmt, bzw. eine Aufgabelung der Besiedlungsroute im äußersten Norden des Kontinentes. Eine Welle soll entlang der oder über die Anden Richtung Süden gezogen sein, dann die südlichen Anden überquert haben, um in die offenen Parklandschaften des Gran Chacos vorzudringen und von dort aus südwärts die Pampas und Patagonien zu besiedeln (vgl. Abb. 13). Während eine zweite Welle nach der Durchquerung des Isthmus von Panama entlang der Nordküste Südamerikas entlang zog und sich dann in das Amazonasbecken verbreitete. Ein Teil der zweiten Welle soll im Zuge von Raummangel, bedingt durch das Aufkommen der Landwirtschaft in der Region, entlang der Flussläufe nach Westen in die Anden gezogen sein (Rothhammer et al. 2001). Der Zeitpunkt dieser Westexpansion wird aber nicht genauer benannt. Neueste aDNA Untersuchungen des zur Tiahuanaco Kultur gehörenden Fundplatzes Chen Chen im südlichsten Peru (785-1000 n. Chr.) belegen allerdings eine genetische Kontinuität der Bevölkerung des südlichen zentralen Andenraums für zumindest die letzten 1000 Jahre (Lewis et al. 2007a). Nur Populationen aus der Aymara-Sprachtradition, die generell als die Nachfahren der Tiahuanaco Kultur angesehen werden, brechen aus diesem Bild aus, was aber auch aus rezenten Bevölkerungsrückgängen resultieren kann (Lewis et al. 2007b). Der Zeitpunkt der Immigration aus dem Osten müsste also vor die Tiahuanaco Kultur datieren. Die zuvor beschriebenen genetischen Diversitätsunterschiede zwischen West- und Ostsüdamerika korrelieren nicht mit dem Szenario von Rotthammer.

Auf Basis archäologischer Daten vertritt Dillehay (1999) die Hypothese, dass die Besiedlung Südamerikas entlang der Westküste stattfand. Von der Küste aus verbreiteten sich Gruppen schnell ins Inland, auch über die Anden. Dort teilten sie sich schnell in viele weiträumige und isolierte regionale Gruppen auf. Die zuvor beschriebenen kulturellen Entwicklungsprozesse im zentralen Andenraum sprechen für einen konstanten Austausch zwischen den ansässigen Kulturgruppen, was die genetische Nähe der Gruppen zueinander erklären könnte, während die Weitläufigkeit und naturräumlichen Gegebenheiten des Ostens mit einer stärkeren Fragmentierung der Bevölkerung und daraus resultierendem verminderten Genfluss korrelieren würden. 
Aus den genetischen und archäologischen Daten ergeben sich drei mögliche Modelle der Besiedlung Südamerikas, die in Abbildung 13 dargestellt werden. Die Datenlage lässt allerdings keine endgültige Entscheidung für eines dieser Modelle zu. Die Modelle variieren zwischen einer und zwei initialen Besiedlungswellen und verschiedenen Routen: entlang der Küste, durch die Anden oder vom Norden in das Amazonasbecken. In wie weit die angetroffenen genetischen Muster aber wirklich aus der initialen Besiedlung resultieren, bleibt an diesem Punkt ungeklärt. Untersuchungen an alter DNA haben sich als nützlich bewiesen, räumliche Kontinuität von Bevölkerungen zu belegen, können diese aber auch widerlegen. Generell ist die diachrone Entwicklung aber nur an eben solchen Daten zu erfassen. Nur liegen bislang aus Südamerika neben den hier erwähnten Studien kaum sichere aDNA Untersuchungen vor und sind wenn, chronologisch und geographisch, nur punktuell. Generell fehlen aDNA Untersuchungen, die große Stichproben beinhalten und diachrone Entwicklungen zwischen aufeinander folgenden Kulturgruppen in einer Region berücksichtigen. Die präkolumbische südamerikanische Geschichte weist viele dynamische Phasen der Kulturentwicklung und Ausbreitung auf, die sich bestimmt auch in den komplexen Mustern der genetischen Diversität widerspiegeln. Die bislang gegebenen genetischen Daten lassen vermuten, dass die Entwicklung kultureller Traditionen nicht nur aus der Akkulturation endogamer indigener Populationen resultiert, sondern diese auch stark durch Migrationen beeinflusst wurde. Genauere Zusammenhänge für den südlichen zentralandinen Raum und die Pazifikküste Südperus gilt es, in dieser Arbeit zu ergründen.

Die Ausführungen der letzten beiden Kapitel haben die Verbindung von Kulturgeschichte und Genetik am Beispiel der amerikanischen Besiedlungsgeschichte verdeutlicht. Die Entscheidung zugunsten verschiedener Szenarien von Kulturentwicklung und Bevölkerungsausbreitung wird durch das Erschließen des genetischen Archives möglich. Umgekehrt ermöglichen die kulturgeschichtlichen Kenntnisse, genetische Verteilungsmuster zu interpretieren. Um dieses auch für das Untersuchungsgebiet der vorliegenden Arbeit zu ermöglichen, folgt im nächsten Kapitel eine umfassende Beschreibung der kulturellen und umweltgeschichtlichen Entwicklungen in der Palpa-Region und dem südlichen Peru. 


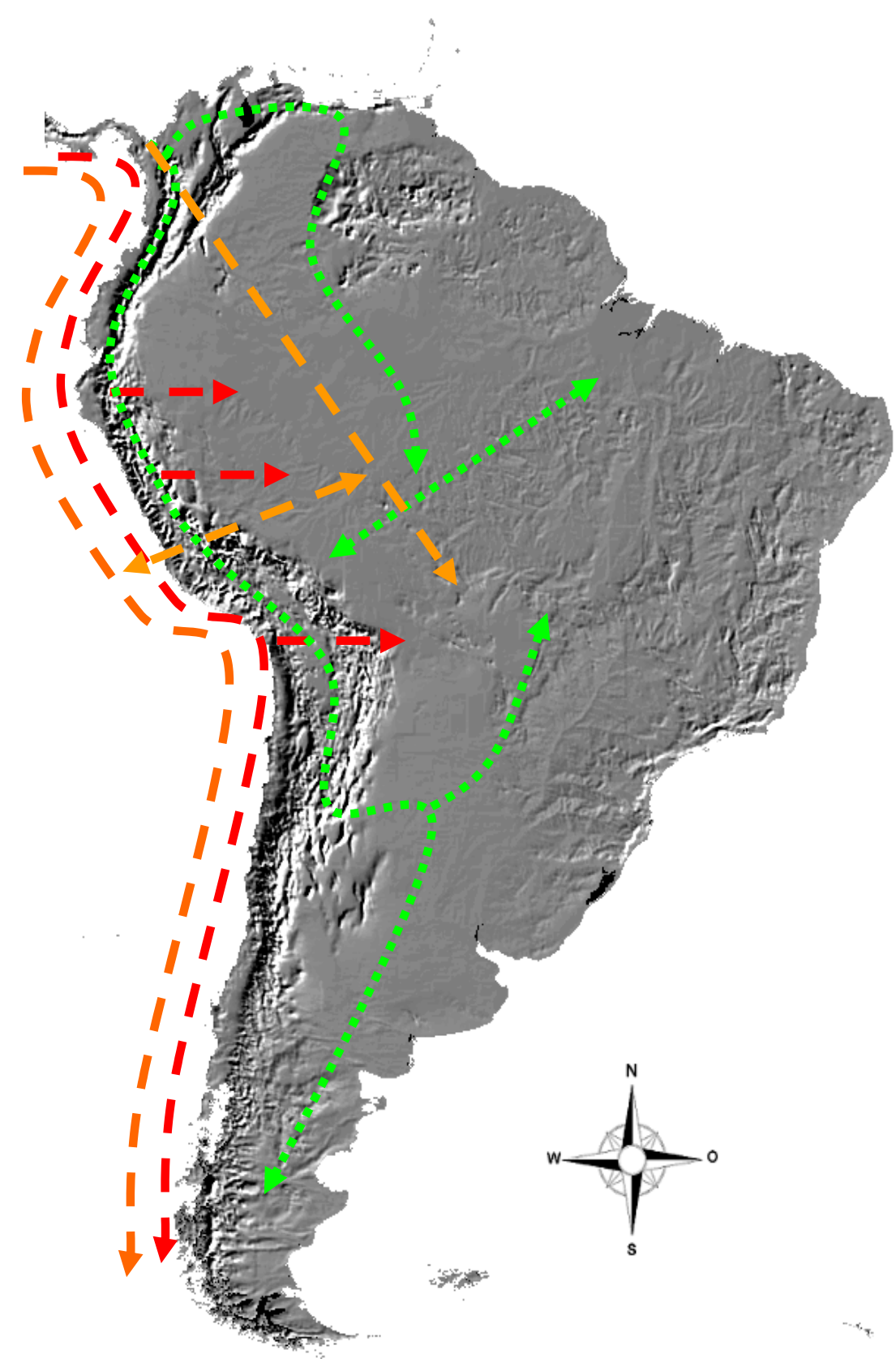

Abb. 13: Darstellung der möglichen Besiedlungsrouten Südamerikas. Rotes Modell: Die Siedler bewegen sich entlang der Pazifikküste und breiten sich von dort über die Anden in das restliche Südamerika aus. Oranges Modell: Zwei Besiedlungswellen breiten sich zeitgleich oder folgend entlang der Küste und in den Amazonasraum aus, bewahren aber einen kontinuierlichen Austausch (Genfluss) zueinander. Grüines Modell: Das im Text detailliert beschriebene Modell von Rotthammer et al. 2001. Quelle: Reliefkarte ETH-Zürich (www.ngdc.noaa.gov/seg/topo/img/sasm2.gif / Download: 01.02.2008) 


\subsubsection{Kultur- und Umweltgeschichte der Palpa Region und des südlichen Perus}

Das Landschaftsbild der südperuanischen Küste ist geprägt durch die hyperaride nördliche Atacama Wüste. Dieser Wüstenstreifen, der zu einer Seite vom Pazifik, zur anderen durch den westlichen Andenfuß eingefasst wird, erreicht in der Region um Ica, Palpa und Nasca seine maximale Breite mit ca. $60 \mathrm{~km}$. Der westliche Andenfuß ist zerschnitten von tiefen Kerbtälern, die durch die Flüsse erodiert wurden, durch die der Niederschlag des Andenhochlands in Richtung Pazifik abfließt. Ein Großteil dieser Flüsse führt nur temporär Wasser, direkter Niederschlag ist äußerst selten, so dass die hygrische Versorgung der unteren Talbereiche in direkter Abhängigkeit zu den Niederschlagsmengen des Hochlandes steht. Die nährstoffreichen Sedimente, die von den Flüssen mitgeführt werden, und natürlich das Wasser ermöglichen in den unteren Talbereichen, aber vor allem auf den breiten Schwemmebenen am Andenfuß, wie z.B. in der Umgebung des Städtchens Palpa, die Bildung fruchtbarer Oasen (Abb. 14). Diese Flussoasen bilden die räumlich eng begrenzten Siedlungskammern, in denen es schon früh zur Bevölkerungskonzentration kam.

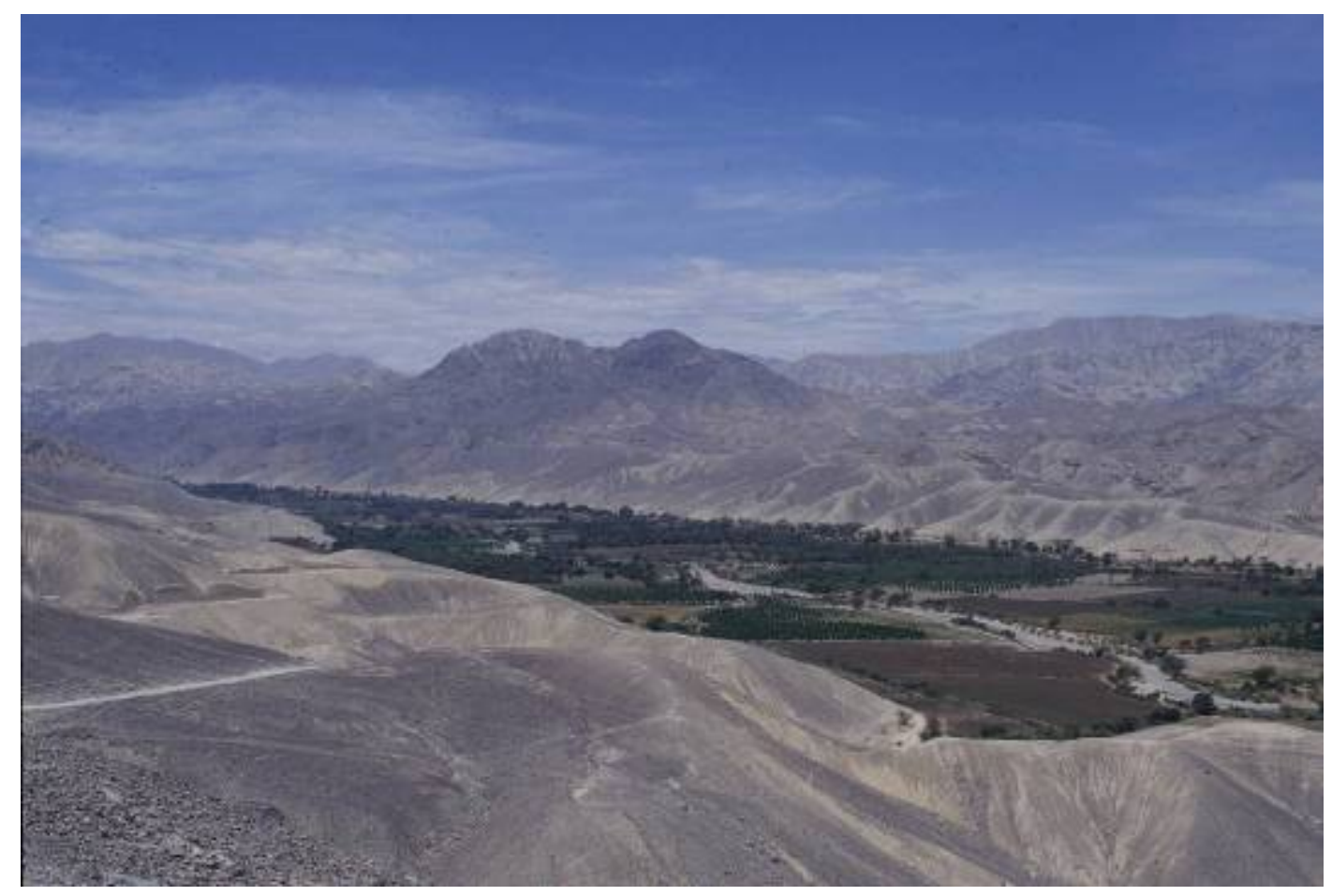

Abb. 14: Blick auf das Rio Palpa Tal (Quelle: KAAK-DAI)

Im Vergleich zur Nordküste Perus sind die Kenntnisse über die gesellschaftlichen Entwicklungen im Bereich der Südküste noch sehr rudimentär (Reindel u. Gruen 2006), auch wenn die Erforschung der Region schon am Anfang des 20. Jahrhunderts mit den Arbeiten von Max Uhle begann. Die archäologischen Untersuchungen konzentrierten sich vor allem auf die beiden bekanntesten Kulturgruppen der Region, die Paracas-Kultur (800-200 v. Chr.) und die 
Nasca-Kultur (200 v. Chr.- 600 n. Chr.). Im Rahmen des 1997 begonnenen Nasca-Palpa Projektes des Deutschen Archäologischen Institutes und des BMBF-Verbundprojektes „Nasca: Entwicklung und Adaptation archäometrischer Techniken zur Erforschung der Kulturgeschichte“ war es erstmalig möglich, die diachrone kultur- und umweltgeschichtliche Entwicklung einer solchen Siedlungskammer an der südperuanischen Küste $\mathrm{zu}$ rekonstruieren. Das Untersuchungsgebiet dieser Arbeit konzentriert sich auf die Region um die Stadt Palpa, ca. 400 $\mathrm{km}$ südlich von Lima und $40 \mathrm{~km}$ nördlich der Stadt Nasca (Abb. 15). In diesem Bereich verlaufen die drei Flusstäler des Rio Grande, Rio Palpa und Rio Viscas, und es finden sich eine Vielzahl prähistorischer Siedlungen in unmittelbarer Nähe der Nasca-zeitlichen Geoglyphen, die auf den Wüstenplateaus und Hängen zwischen den Tälern angelegt wurden (Reindel et al. 2002). Die erste dauerhafte Besiedlung dieser Region lässt sich in der Initialzeit durch den Fundort Pernil Alto (ab ca. 1300 v. Chr.) nachweisen, es gibt aber auch noch früher datierende Befunde. So wurden am gleichen Ort Gräber aus dem Mittleren Archaikum (ca. 3800-3000 v. Chr) entdeckt (Reindel u. Isla-Cuadrado 2001). Auf Basis der Untersuchungen des Projektes konnte eine umfassende Chronologie für das gesamte Nasca und Palpa Gebiet erstellt werden (Abb. 16).

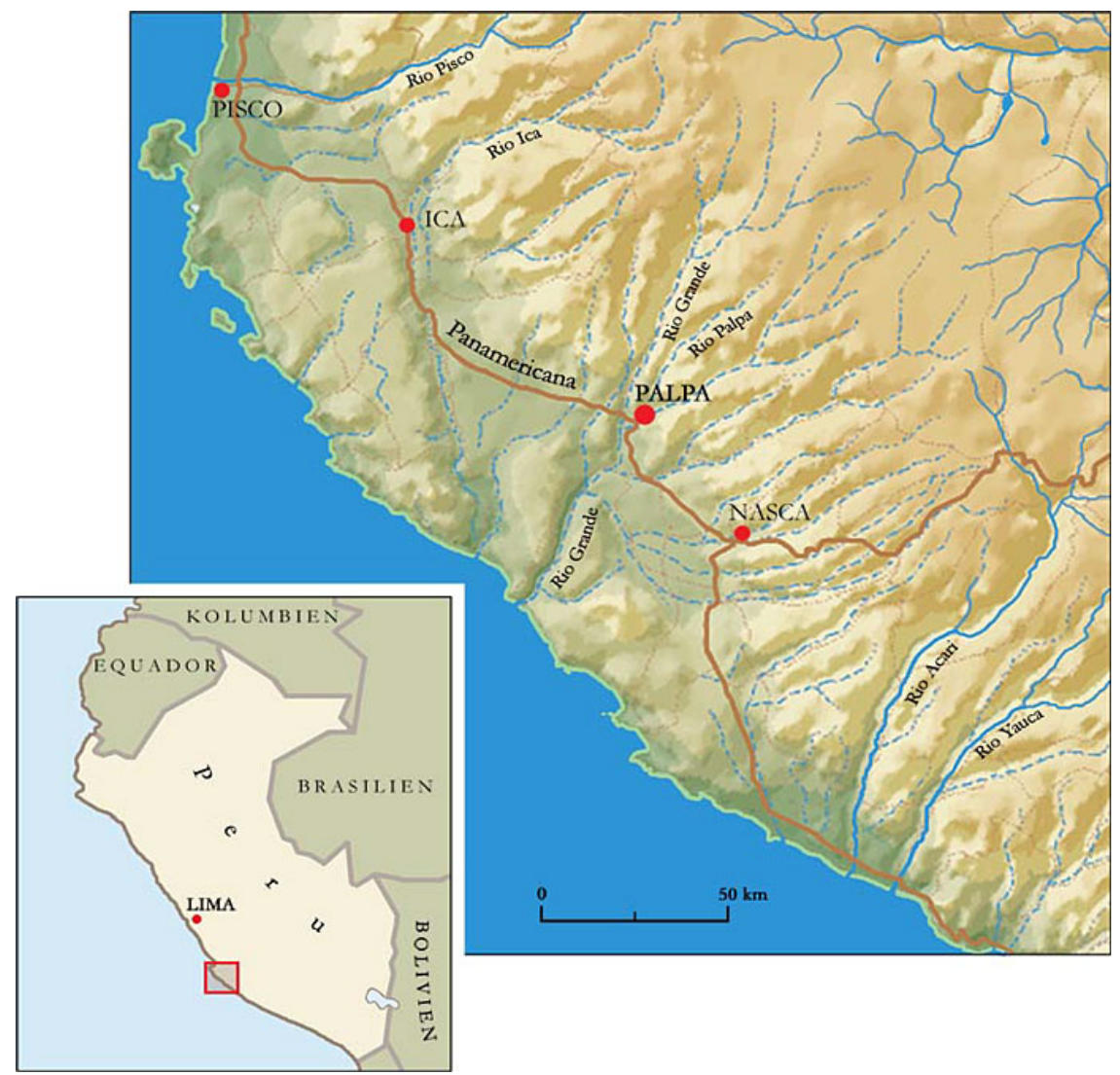

Abb. 15: Lage des Arbeitsgebietes Palpa an der Südküste Perus (Quelle: KAAK-DAI) 


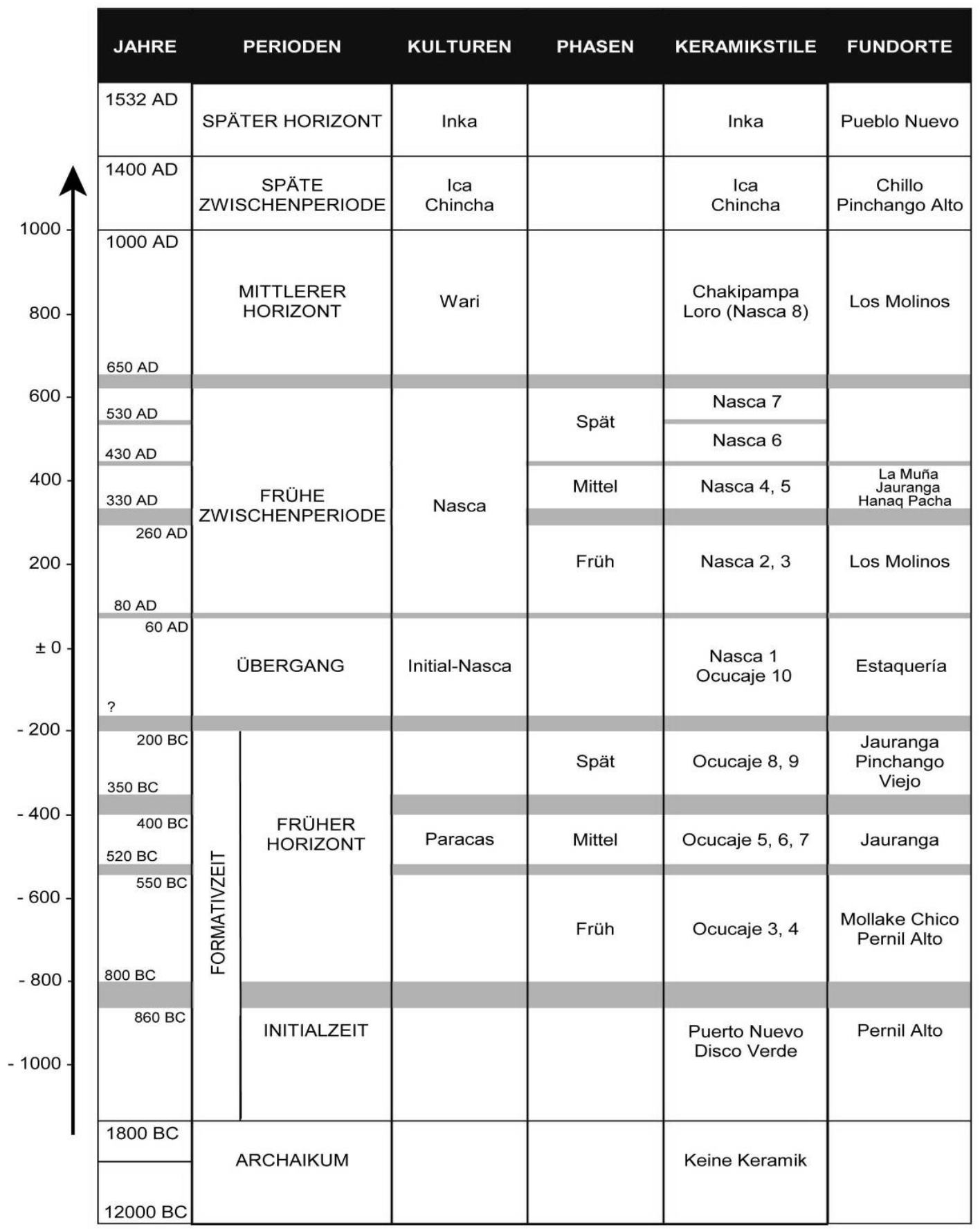

Abb. 16: Absolute und relative Chronologie des Nasca-Gebietes (Unkel 2006)

Im weiteren Verlauf des Kapitels sollen nun die kultur- und umweltgeschichtlich relevanten Informationen der einzelnen chronologischen Perioden für die Palpa-Region mit Bezug zu den anderen peruanischen Kulturräumen dargestellt werden.

Archaikum (bis 1800 v. Chr.)

Die gesellschaftlichen Entwicklungen des Archaikums sind bereits im vorherigen Kapitel geschildert worden. An der Nordküste Perus, aber auch im Andenhochland, kommt es zur 
Ausbildung von Sesshaftigkeit, Domestikation von Tieren und Pflanzen bis hin zur Bildung erster großer Siedlungszentren. Die Quellenlage für den südlichen peruanischen Küstenraum ist allerdings sehr schlecht, und es gibt wenige bekannte Fundorte. Dazu ist das Archaikum Perus akeramisch, was typolochronologische Zuordnungen schwer macht. Von der Paracas-Halbinsel in der Nähe der Stadt Pisco sind riesige Muschelhaufen bekannt, wie auch von der Nordküste (vgl. Kap. 2.3.2), die für die semipermanente Anwesenheit von Menschen in der Region sprechen, deren Lebensgrundlage marine Ressourcen waren (Haberland 1991). Im Rio Grande Tal konnten am Fundort Pernil Alto Bestattungen aber auch einige Gruben und Pfosten gefunden werden, die für eine zumindest temporäre Siedlungstätigkeit in der Region sprechen (M. Reindel KAAK-DAI, pers.. Mitteilung). Das Klima des Archaikums war feuchter als heute (vgl. Abb. 17), und der damalige Wüstenrand verlief ca. $50 \mathrm{~km}$ westlicher (Eitel et al. 2005). Die Landschaft bot also bessere Bedingungen für Jäger und Sammler, und es ist davon auszugehen, dass es in der Region eine größere Zahl semipermanenter Lager gab.

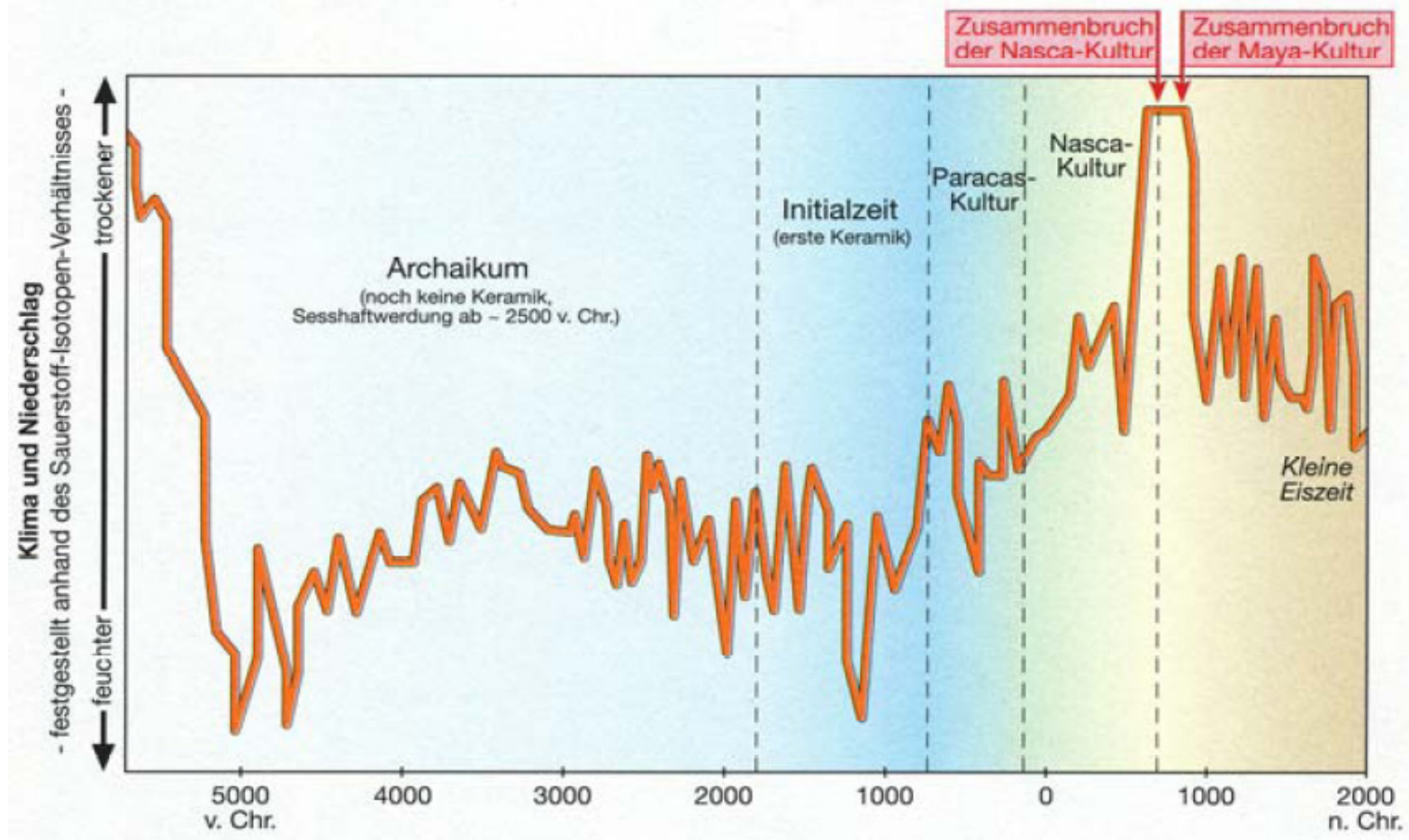

Abb. 17: Graphische Darstellung der diachronen Klima- und Niederschlagsentwicklung mit Bezug auf die Kulturentwicklung im südlichen Peru. Die Kurve ist abgeleitet von Sauerstoffisotopenverhältnissen, die im Grönlandeis gemessen wurden (aus Eitel u. Mächtle 2006; Abb. 4).

Initialzeit (1800-860 v. Chr.)

Die Initialzeit an der südlichen peruanischen Küste ist ebenfalls weitestgehend unerforscht. An der Nordküste ist die Phase gekennzeichnet durch ein rapides Wachstum der Siedlungen und der Weiterentwicklung architektonischer Komplexität. Auch im Hochland, vor allem im TiticacaBassin, bilden sich ab ca. 1300 v. Chr. komplexe Siedlungen aus. Chiripa, wohl ein 
zeremonielles Zentrum mit angegliederten Wohnkomplexen in Bolivien, erreicht gegen $900 \mathrm{v}$. Chr. eine Ausdehnung von über 7 Hektar (Stanish 2001). In der Initialzeit verbreitet sich im gesamten Raum die Herstellung und Nutzung von Keramik. Der Fundort Pernil Alto ist die erste flächig ergrabene dauerhafte Siedlung dieser Zeitstellung an der Südküste, weitere Kenntnisse über die Kulturgeschichte dieser Periode resultieren fast ausschließlich aus Lesefunden. Die Siedlung war am Fuße eines Talhanges angelegt, begleitet von weitläufigen Terassenanlagen. Die Gebäude der Siedlung waren Konstruktionen aus Lehmwänden und Holz. Der Nutzungszeitraum der Siedlung konnte anhand von 14C-Datierungen auf 1300-860 v. Chr. datiert werden (Reindel u. Isla-Cuadrado 2006). Die Formgebung der assoziierten Keramik gleicht der von anderen initialzeitlichen Fundplätzen an der Südküste wie Disco Verde und Hacha. Auffällig ist hier vor allem die nach dem Brennen aufgetragene Bemalung. In Chichictara am unteren östlichen Talrand des Rio Palpa konnte eine sehr hohe Konzentration Petroglyphen (Felsbilder) gefunden werden. Einige dieser in Felsblöcke eingepickten anthropomorphen, zoomorphen und geometrischen Felsbilder konnten aufgrund ikonographischer Vergleiche in die Initialzeit datiert werden (Fux 2006). Der Großteil datiert allerdings in den Frühen Horizont (s.u.). Dieser Befund ist in soweit interessant, da ein direkter Zusammenhang zwischen der Petroglyphentradition und der Entwicklung der späteren Paracas- und Nascazeitlichen Geoglyphen gesehen wird. Eine differenzierte Aufteilung in archäologische Kulturgruppen ist für die Periode in der Region nicht möglich. Die erste nachgewiesene permanente Besiedlung der Palpa Region fällt zusammen mit dem Beginn des Dessertifikationsprozesses. Das Klima ist noch weitaus humider als heute, aber der Wüstenrand wandert zunehmend in Richtung Osten (Eitel et al. 2005).

\section{Früher Horizont (800 - 200 v. Chr.)}

Die Kulturgeschichte des Frühen Horizontes ist an der Südküste Perus durch die Paracas Kultur geprägt. Der initiale und nahmengebende Fundort ist die Paracas-Halbinsel in der Nähe der Stadt Pisco (vgl. Abb. 15). Hier entdeckte Julio Tello zwei chronologisch diskrete Siedlungsgebiete und vier Gräberfelder. Er teilte die Kultur in zwei Phasen ein: Cavernas und Nekropolis. Die Cavernas-Phase wird charakterisiert durch polychrome Keramik und tiefe flaschenförmige Schachtgräber, in denen bis zu 40 Individuen bestattet wurden. Einige Gräber waren sehr reich ausgestattet, und fast alle Schädel wiesen artifizielle Deformationen auf (Silverman u. Proulx, 2002). Interessant ist auch, dass an einem großen Teil der Schädel Spuren von Trepanationen zu

erkennen sind (Abb. 18). Ein Zusammenhang mit den Prozessen oder Spätfolgen der intentionalen Deformationen ist zu vermuten. Die Nekropolis-Phase scheint chronologisch zu folgen. Die extrem dünnwandige und monochrome Keramik und die in brillanten Farben 
bestickten Textilien sind charakteristisch für diese Phase (Abb. 19). Die Bestattung der Toten erfolgte in unterirdischen Grabkammern mit ausgekleideten Wänden in einer Art Totenstadt (Silverman u. Proulx 2002). Aus diesen Gräbern stammen auch die bekannten südamerikanischen Mumienbündel, von denen einige Individuen mit bis zu 100 Lagen Textilien bestattet wurden. Die etablierte Keramik-Chronologie der Paracas-Kultur bezieht sich allerdings auf die Funde aus dem Ica-Tal und ist benannt nach dem Ort Ocucaje (Menzel 1964). Anhand der Keramik konnte die Kultur im Ica-Tal in zehn Phasen (Ocucaje 1-10) unterteilt werden. Diese Chronologie ist auch für die weiter südlichen Regionen gültig. Relativchronologisch lassen sich die Funde aus den Paracas-Cavernas in die späteren Phasen von Ica datieren.

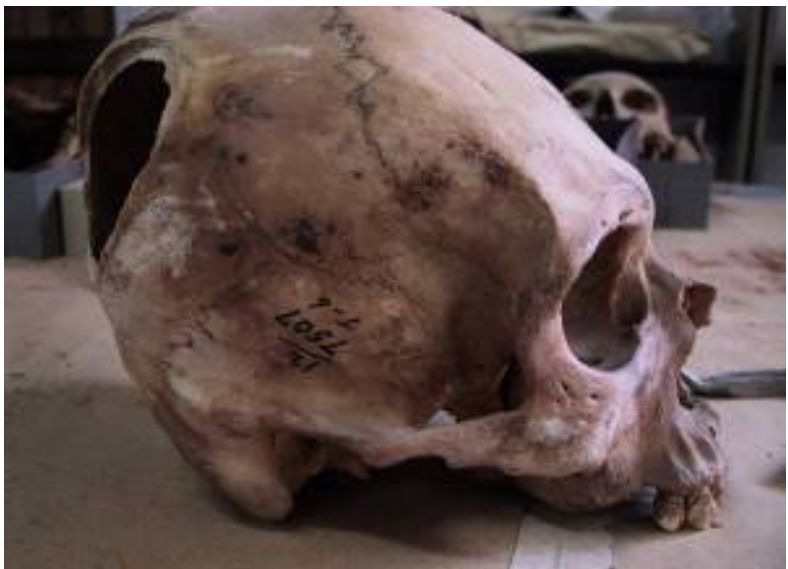

Abb. 19: Artifiziell deformierter Schädel eines Individuums aus der Paracas Caverna 6 (PC10) mit Trepanation.

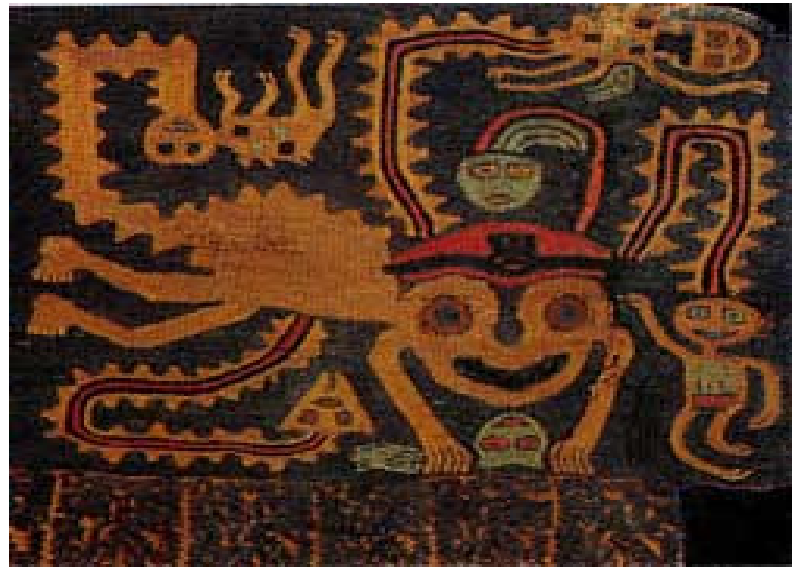

Abb. 18: Besticktes Gewebe der Paracas-Kultur (Quelle: KAAK-DAI)

In der Palpa- und Nasca-Region waren bis zu den Grabungen des DAI Projektes nur wenige Befunde bekannt, die der Paracas-Kultur zugerechnet wurden. Diese Tatsache führte zu der Annahme, dass die Kultur südlich von Ica nicht verbreitet war und sporadische Keramikfunde als Importe in die Region gelangt waren und dort von ortsansässigen Lokalgruppen vergesellschaftet worden sind (Silverman 1994). Hingegen wurde in der Region Ica eine keramische und bevölkerungsbiologische Kontinuität zu der folgenden Nasca-Kultur gesehen (s.u.):

„When the Nasca phase developed from the Paracas culture over a thousand year period, this cultural development did not result in a chance of blood groups. The Huari and Inca, however, were invaders who introduced genetic changes" (Allison 1979).

Dieses Zitat von Allison ist von besonderer Bedeutung für die Formulierung der Arbeitshypothesen dieser Arbeit. Die Untersuchungen in der Palpa Region erbrachten allerdings neben zahlreichen Oberflächenfunden auch Gräber (in Pernil Alto und Mollake Chico). Diese konnten anhand der Keramik und 14C-Daten eindeutig in die frühe Paracas Zeit (Ocucaje 3 \& 4, 
800-550 v. Chr.) datiert werden (Reindel et al. 2004). Flächengrabungen am Fundort Jauranga im mittleren Palpa-Tal erbrachten darüber hinaus den Nachweis einer paracaszeitlichen Siedlung mit Bauten aus Lehmziegeln und mehreren Gräbern, die anscheinend nach der Auflassung der jeweiligen Gebäude in die Siedlungsschichten eingetieft wurden. Der Ort war in dem Zeitraum von mindestens $600 \mathrm{v}$. Chr. bis etwa $200 \mathrm{v}$. Chr. durchgehend besiedelt. Darauf weist die Analyse des keramischen Fundmaterials hin, das den Stilphasen Ocucaje 5/6 bis 9 (550-200 v. Chr.) zuzuordnen ist. Die insgesamt 49 menschlichen Individuen, deren Überreste in Jauranga gefunden wurden, waren entweder in Einzel- oder Mehrfachbestattungen beigesetzt. Die meisten Einzelbestattungen umfassten infante Individuen, die in Vorratsgefäßen beigesetzt wurden. Jauranga ist aufgrund der Befundlage als ländliche Siedlung zu charakterisieren (Isla-Cuadrado u. Reindel 2003). Muschelfunde von der Küste und Obsidian aus dem Hochland belegen, dass Jauranga in ein weiträumiges Netzwerk zum Warenaustausch integriert war. Aufgrund der neuen Befundsituation im Palpa-Tal behaupten Reindel und Isla (2005), dass die Paracas-Kultur entgegen der bislang gültigen Lehrmeinung eine Verbreitung bis in die Palpa und Nasca Region hatte. Trotz des bereits erwähnten Aridisierungstrends, der ab der Initialzeit einsetzte, waren die grundlegenden klimatischen Konditionen noch weitaus günstiger für die Landwirtschaft als bereits wenige hundert Jahre später. Komplexe Irrigationssysteme waren noch nicht notwendig (Reindel u. Gruen 2006). Die Befundsituation deutet auf eine zunehmende Besiedlungsdichte und ein stetiges Bevölkerungswachstum in der Siedlungskammer hin. Neben den erwähnten Petroglyphen, z.B. in Chichictara, datieren auch die ersten Geoglyphen in der Palpa-Region bereits in den Frühen Horizont (ab ca. 400 v. Chr.) Diese in Hanglage angelegten Scharrbilder stellen fast ausschließlich anthropomorphe Figuren mit einer Größe von 2 bis $30 \mathrm{~m}$ dar. Der ikonographische Vergleich lässt vermuten, dass die Vorbilder dieser Bodenzeichnungen die Petroglyphen sind (Lambers 2006).

An der Mündung des Rio Grande, etwa 50 km von Palpa entfernt, konnte die bislang einzige bekannte Siedlung der Region in unmittelbarer Nähe zum Pazifik nachgewiesen werden. Durch die Lage und Einzigartigkeit des Ortes kann davon ausgegangen werden, dass dem Fundort Monte Grande eine zentrale Rolle in der Versorgung der Täler am Andenfuß mit marinen Ressourcen zukam.

Zum Beginn des Frühen Horizontes an der Nordküste ist ein allgemeiner Zusammenbruch der frühen Stadtstaaten $\mathrm{zu}$ beobachten. Es entwickelt sich eine Vielzahl kleinräumiger Lokalgruppen mit eigenen Keramik- und Architekturstilen. Diese Entwicklung steht im Kontrast zu den Entwicklungen im zentralen Hochland. Hier bildet sich mit Chavin der erste pan-andine Kunststil aus. Der namengebende Fundort Chavín de Huántar entwickelt sich in dieser Zeit zu 
einem großen Siedlungszentrum von ca. 42 ha Fläche und bis zu 3000 Einwohnern. Er liegt verkehrsgeographisch günstig an den Nord-Süd-Routen, die den Gebirgen folgten, und den OstWest-Routen, die vom Amazonasbecken bis zur Küste führten. Einige Autoren sehen eine Verbindung des Chavin-Stils zum Paracas-Stil (Silverman u. Proulx 2002).

Frühe Zwischenperiode (200 v. Chr. - 600 n. Chr.)

Im Untersuchungsgebiet schließt an den Frühen Horizont eine etwa 200 Jahre währende Übergangsphase an. Im Verlauf dieser Phase lässt sich der Wandel zu Stilelementen und der Technologie der Nasca Kultur verfolgen. Ikonographisch, wie auch formal, entwickelt sich die frühe Nasca Keramik aus dem späten Ocucaje Stil der Paracas Kultur (Silverman u. Proulx, D. A. 2002). Die Nasca-Kultur ist die prägende Kulturerscheinung der Frühen Zwischenperiode an der Südküste Perus. Das Kerngebiet bilden die Wüstenrandgebiete und Ausläufer der Flusstäler am Andenfuß vom Rio Ica im Norden bis ungefähr zum Rio Acari im Süden (vgl. Abb. 15). Der wohl bekannteste Fundort der Nasca Phase ist Cahuáchi. Dieser $28 \mathrm{~km}$ westlich von der Stadt Nasca gelegene Ort weist auf einer großen Fläche Gebäudestrukturen und Monumentalarchitektur in Form von Stufenpyramiden aus Lehmziegeln auf. Die Funktion dieses Ortes wird kontrovers diskutiert. Silverman et al. $(1995,2002)$ weisen dem Ort aufgrund der Befundlage eine Funktion als Kultzentrum der Nasca-Kultur zu. Die Gegenposition sieht in Cahuáchi eine urbane Siedlung mit einer Funktion als administratives Hauptzentrum des Nasca Gebietes (Isla-Cuadrado u. Reindel 2006). Die Hauptbelegungszeit des Ortes datiert in die frühen Nasca-Perioden.

In der Palpa Region konnte der Fundort Los Molinos als regionales Zentrum der frühen Nasca-Zeit (Nasca $2 \& 3 / 0-250$ n. Chr.) identifiziert werden. Grabungen erbrachten den Nachweis von monumentalen Terrassenanlagen, Höfen, Räumen, Säulenhallen und Korridoren. Im Vergleich zu den Paracas Siedlungen am Talboden (Jauranga) erstreckte sich diese frühurbane Siedlungstruktur entlang der Talhänge des auslaufenden Rio Grande Tals. Nahe dem Ort konnte ein assoziiertes Gräberfeld nachgewiesen werden. Nach der Auflassung der Siedlung wurden Gräber in die Gebäudestrukturen eingelassen (Reindel u. Isla-Cuadrado 2000). Neben Los Molinos finden sich zahlreiche Hinweise auf Siedlungen ruralen Charakters in der Region. $\mathrm{Ab} 200$ v. Chr. lassen sich auch die ersten Irrigationssysteme in den Talauenbereichen nachweisen. Es ist ein Zusammenhang mit der zunehmenden Trockenheit an der peruanischen Südküste zu sehen (vgl. Eitel et al. 2005). Reindel et al. (1999) sehen einen direkten Bezug zwischen der Einführung des Bewässerungsfeldbaus und der gesellschaftlichen Entwicklung in der Palpa-Region. Die Intensivierung der Landwirtschaft führt zur Erwirtschaftung eines Überschusses an Nahrungsressourcen, der einige Menschen von der Nahrungsproduktion 
freistellt und ihnen Zeit für andere Tätigkeiten lässt. Auf dieser Basis entwickeln sich Spezialisierungen, die wiederum die Entwicklung nicht agrarischer Siedlungsformen wie Los Molinos ermöglichen (vgl. auch Kap. 2.1.2). Die frühe Nasca-Kultur ist als eine komplexe Gesellschaft zu werten, deren kulturelles Zentrum in Cahuáchi lag (Isla-Cuadrado u. Reindel 2006).

In der mittleren Nasca-Zeit (Nasca 4 und 5 / 250-450 n. Chr.) verlagert sich das Siedlungszentrum der Region zu dem nahe liegenden Ort La Muña. Hier konnten weit reichende Siedlungsstrukturen und vor allem bislang für die Nasca-Kultur unbekannte monumentale Gräber aus Lehmziegeln dokumentiert werden. Diese Gräber bestehen aus bis zu $8 \mathrm{~m}$ tiefen Grabkammern mit verkleideten Wänden (Abb. 20) und sind an der Oberfläche durch Terassenstrukturen und Aufbauten aus Lehmziegeln gekennzeichnet. Funde von Opfergaben deuten darauf hin, dass diese oberirdischen Strukturen anscheinend auch noch nach der Anlage der Gräber, selbst nach dem Auflassen der Siedlung, für rituelle Zwecke genutzt wurden (IslaCuadrado u. Reindel 2006). Die Gräber selbst waren reich ausgestattet. Trotz vorhergegangener Plünderung der Gräber konnten noch prachtvoll verzierte Keramikgefäße und Schmuckstücke aus Stein, Spondylusmuschel und Gold geborgen werden. Auch in der mittleren Nasca Zeit lassen sich noch zahlreiche rurale Siedlungen im Untersuchungsgebiet belegen. Ab spätestens 430 n. Chr. lässt sich allerdings ein starker Rückgang der Besiedlungs- und Bevölkerungsdichte ausmachen (Reindel u. Isla-Cuadrado 2006). In der späten Nasca Zeit verschoben sich die Siedlungen immer weiter die Täler aufwärts, dem sich weiter nach Osten ausdehnenden Wüstenrand folgend. Ab ca. 600 n. Chr. ist die Palpa Region nur noch spärlich besiedelt.

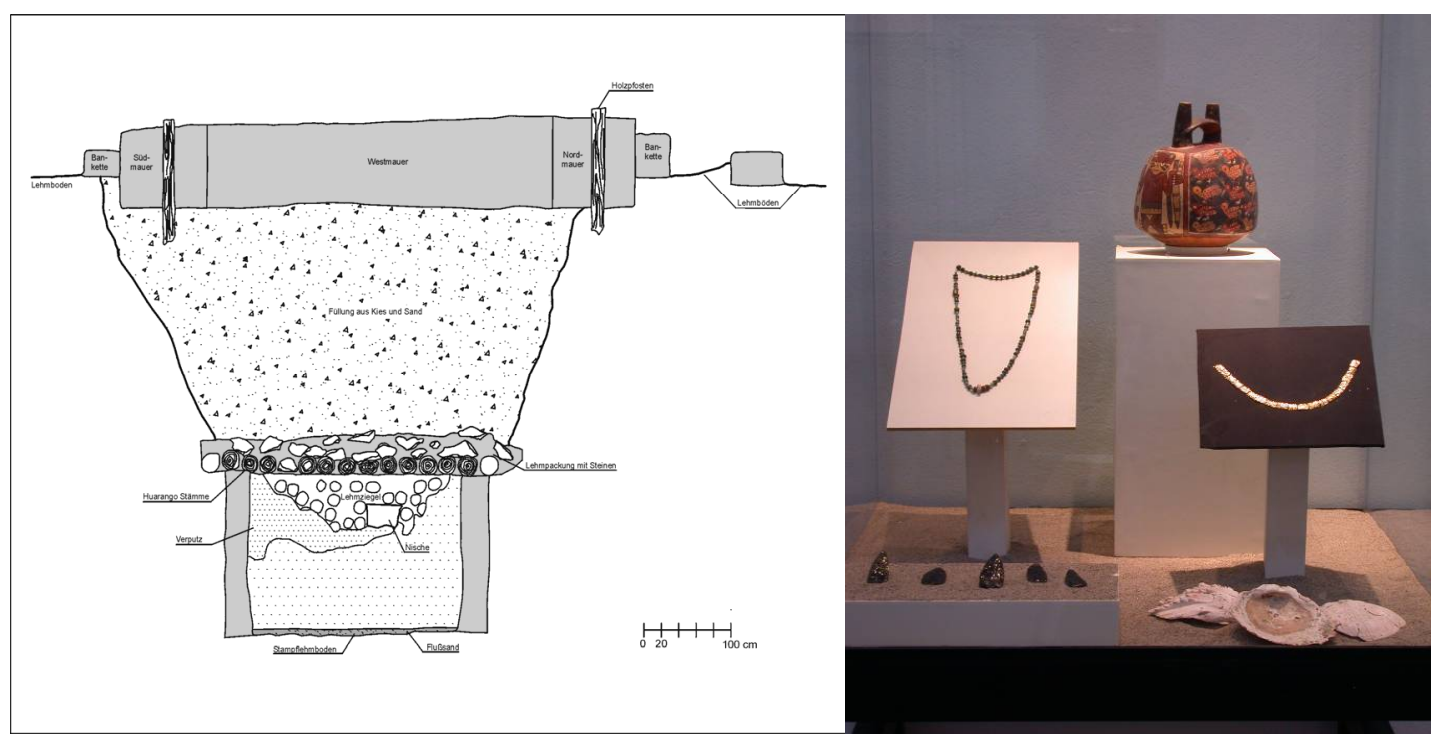

Abb. 20: Schematische Zeichnung eines der Elite-Gräber von La Muna (links) und die Grabbeigaben (rechts) (Quelle: KAAK-DAI). 
Isla-Curado und Reindel (2006) argumentieren aufgrund der Befunde der mittleren Nasca Zeit, dass die Nasca-Kultur in Phase 5 den Status einer frühstaatlichen Gesellschaft erreicht hatte. Es lassen sich mehrgliedrige Siedlungshierarchien nachweisen, und die in La Muña entdeckten Elite-Gräber deuten auf eine stratifizierte Gesellschaft hin. Das Zentrum dieses Staates sehen Isla-Curado und Reindel in La Muña. Diese Hypothese widerspricht der gängigen Lehrmeinung. So sehen z.B. Silmerman und Proulx (2002) die Sozialstruktur der Nasca als eine Ansammlung autonomer Häuptlingstümer, deren Einflussbereich in den jeweiligen Tälern liegt und nur über eine gemeinsame materielle und ideelle Kultur miteinander verbunden sind. Unabhängig von dieser Diskussion ist festzuhalten, dass die Nasca Kultur definitiv eine komplexe Gesellschaft war mit handwerklichen Spezialisierungen, einer redistributiven Ökonomie und Siedlungszentren mit urbanem Charakter. Funde von Nasca Keramik im Hochland belegen einen intensiven wirtschaftlichen Austausch zwischen den kulturellen Großräumen der Küste und des Hochlandes. Der Fundort Monte Grande behält auch in der Nasca Zeit seine vorherrschende Rolle in der Versorgung mit marinen Ressourcen bei.

Neben den in La Muña gefundenen Prunkgräbern sind noch zwei andere Bestattungstypen bekannt. Bestattungen in Vorratsgefäßen und in Grabgruben. Es lassen sich generell keine altersoder geschlechtsspezifischen Bestattungsmuster nachweisen. In der Regel werden Individuen einzeln bestattet. Die Bestattungen in Vorratsgefäßen finden sich vor allem in den frühen Nasca Phasen. Die Grabgruben stellen die Hauptbestattungsform da. In diesen Gruben wurden die Individuen meistens in sitzender Hockerposition beigesetzt. Es sind keine besonderen Formen der Totenbehandlung bekannt, wie z.B. intentionale Mumifikation. Wie auch in der Paracas Zeit weisen viele der Individuen artifiziell verformte Schädel auf (Isla-Cuadrado 2004).

Neben den prachtvoll verzierten Keramiken und Textilien ist die Nasca Kultur vor allem für ihre Geoglyphen bekannt. Metallurgie ist kaum entwickelt. Es findet sich zwar Schmuck aus Gold, aber eigenständige Kupferverarbeitung etc. konnten bislang nicht nachgewiesen werden. Die Geoglyphen sind gewaltige im Wüstenpflaster angelegte Scharrbilder, teilweise mit bis zu $20 \mathrm{~km}$ Länge, die in der Nasca Zeit vor allem zoomorphe und geographische Figuren darstellen. Im Rahmen des Nasca-Palpa Projektes konnte eine umfassende Typologie und Chronologie der Geoglyphen entwickelt werden (Lambers 2006). In unmittelbarer Nähe der Geoglyphen gefundene architektonische Strukturen und Opfergaben sprechen für einen rituellen Charakter dieser Gebilde. Wasserkulte spielten offensichtlich eine zentrale Rolle bei der Anlage dieser Bodenzeichnungen. Der monumentale und planvolle Charakter der Geoglyphen wird den Menschen ein hohes Maß an Arbeitsorganisation abverlangt haben und vereinte sie in der Ausübung gemeinschaftlicher religiöser Riten. 
Wie bereits erwähnt fällt das Ende der Nasca-Zeit mit einer Phase extremer Trockenheit zusammen (vgl. Abb. 17). Es ist davon auszugehen, dass diese ökologischen Veränderungen die ökonomische Grundlage für eine Kultur dieses gesellschaftlich hohen Entwicklungsgrades nahmen. Im archäologischen Fundgut lässt sich ab ca. 530 n. Chr. das Verschwinden vieler traditioneller Formen der Nasca fassen und ein zunehmender Fremdeinfluss aus dem Hochland beobachten (Silverman u. Proulx 2002).

Ungefähr zeitgleich zu den beschriebenen Entwicklungen an der Südküste existiert an der Nordküste die Moche-Kultur (ca. 100 - 800 n. Chr.). Diese Kultur ist vor allem für ihre Metallurgie bekannt. So findet sich neben kunstvoll angefertigten Gegenständen aus Gold und Silber auch Kupferverabeitung bis hin zur Anfertigung von Kupferlegierungen. Wie in früheren Phasen an der Nordküste finden sich auch hier große regionale Siedlungszentren. Die MocheKultur überspannte mehrere Täler und hatte eine staatliche Gesellschaftsstruktur mit einer Hauptstadt, die im Moche-Tal lag (Stanish 2001). Dieses urbane Zentrum ist charakterisiert von ausgedehnten Straßensystemen, Kanälen, Plätzen und Vierteln, in denen spezialisiertes Handwerk ausgeübt wurde. Dominiert wird die Stadt durch die Huaca del Sol Pyramide mit einem Ausmaß von 160 x 340 m und einer Höhe von 40 m, dem monumentalsten Bauwerk im präkolumbischen Südamerika. Im Hochland entwickeln sich gegen Ende der Frühen Zwischenperiode die Huari- (oder auch Wari-) und die Tihuanaco-Kultur.

\section{Mittlerer Horizont (650-1000 n. Chr.)}

Der Andenfuß des südlichen Perus ist in dieser Phase nur noch dünn besiedelt. Dieses gilt insbesondere auch für das Untersuchungsgebiet. Es finden sich nur wenige archäologische Hinweise einer Besiedlung, z.B. in den oberen Schichten des Fundortes Los Molinos (vgl. Abb. 16). Hier finden sich auch einige Gräber aus der Zeitstellung.

Das zentralandine Hochland dieser Zeit wird dominiert durch die staatlich organisierte HuariKultur. In seiner größten Ausbreitung reicht dieser expansive Staat von Cajamarka im Norden Perus bis nach Cusco im Süden (Stanish 2001). Das Zentrum findet sich mit der Hauptstadt Huari im Hochland nordöstlich der Ica-Nasca Region. Die Ausbildung der Kultur beginnt ab ca. 550 n. Chr. An der Nordküste finden sich archäologische Belege für militärische Eroberung weiter Gebiete durch die Huari. An der Südküste hatten sie entweder einen sehr starken kulturellen Einfluss auf die späte Nasca-Kultur oder eroberten deren Gebiete (Silverman u. Proulx 2002). Eine klare Aussage ist auf Grund der archäologischen Befunde nicht zu treffen. Es ist bekannt, dass die Huari, wie später auch die Inka, administrative Zentren in ihren tributpflichtigen Provinzen errichteten. In den Tälern der Region finden sich aber nur wenige 
Überreste von Siedlungs- oder Gebäudestrukturen, die für die Errichtung solcher Zentren sprechen. Ein mögliches Zentrum dieser Art findet sich im mittleren Tal des Rio Ingenio zwischen Palpa und Nasca (Silverman u. Proulx 2002). Die Hypothese der militärischen Expansion der Huari basiert vor allem auf der raschen Ablösung lokaler Keramikstile durch den typischen Huari (Chakipampa) Stil. In der Palpa-Nasca Region findet sich allerdings noch ein lokaler Keramikstil, der Loro bzw. Nasca 8 benannt wird. Beide Traditionen finden sich an der Südküste teilweise nebeneinander. Die Befunde der Palpa Region weisen nicht auf eine agressive Verdrängung der Menschen der Nasca-Kultur hin. Vielmehr lassen sie darauf schließen, dass sich die Menschen aufgrund der Aridisierung und der damit verbundenen Verschlechterung der Lebensbedingungen immer weiter in die Anden zurückgezogen haben (Reindel u. Gruen 2006). Sollte es zu einer Verdrängung lokaler Küstenpopulationen gekommen sein, so wäre nur ein Ausweichen in Richtung Süden möglich gewesen.

Zeitgleich zur Huari-Kultur entwickelt sich die Tiahuanaco Kultur im südlichen Titicaca Bassin zu einem Staat, dessen Einflussbereich das gesamte Gebiet der südlichen Zentralanden und südlichen Anden umfasst (vgl. Abb. 12). Zur Blütezeit der Kultur (ca. 800 - 900 n. Chr.) erreicht die Hauptstadt gewaltige Ausmaße mit einer Population von bis zu 60.000 Menschen (Stanish 2001). Tiahuanaco integrierte allerdings nicht, wie z.B. die Inka oder auch die Huari, weite Landstriche in das Staatsgebiet. Vielmehr wurde gezielt die Kontrolle über ökonomisch und strategisch wichtige Gebiete übernommen.

\section{Späte Zwischenperiode (1000 - 1400 n. Chr.)}

In dieser Phase blüht die Region am Andenfuß wieder auf. Der Zeitabschnitt fällt zusammen mit einer Feuchtphase (vgl. Abb. 17), in der sich der Wüstenrand wieder weit nach Westen verschiebt (Mächtle 2007). Es kommt zu einer enormen Zunahme der Besiedlungsdichte, die ähnliche Ausmaße wie in der frühen Nasca Zeit erreicht. Die Bevölkerung konzentriert sich in großen Siedlungen, die im Vergleich $\mathrm{zu}$ den vorhergehenden Phasen auch teilweise in Höhenlagen, bzw. Gipfelbereichen angelegt wurden. Die Hänge der Täler waren dicht terrassiert. Fundorte in der Palpa-Region sind z.B. Pinchango Alto und Chillo. Pinchango Alto ist ein typisches Beispiel einer großflächigen befestigten Höhensiedlung. Außerdem finden sich Werkzeuge, die für einen ausgeprägten Goldbergbau in der Region sprechen (Reindel 2002). Generell ist die Späte Zwischenperiode (bzw. LIP = Late Intermediate Period) an der Südküste geprägt von vielen kleinräumigen Kulturerscheinungen, die den großräumigen Kulturgruppen des Mittleren Horizontes folgen. An der Nordküste und in den angrenzenden Anden verbreitet sich mit den Chimu (850 - 1470 n. Chr.) die einzige großflächige Kultur der Periode. 
Später Horizont (1400 - 1532 n. Chr.)

Der Späte Horizont ist im gesamten Peru geprägt durch die Inka (vgl. Kap. 2.3.2.). Die Besiedlungsdichte im Untersuchungsgebiet geht wieder weit zurück. Gleichzeitig wird auch das Klima wieder trockener, und der Wüstenrand nimmt seine heutige Position ein. Siedlungsstrukturen wie Pernil Alto bestehen weiter. Zusätzlich finden sich wenige InkaSiedlungen, die wohl eine administrative Funktion hatten bzw. den Besitzanspruch der Inka über die Region sicherten, aber viele lokale Strukturen und Traditionen bleiben bestehen. Mit der Kolonisation durch die Europäer ab 1532 n. Chr. endet die präkolumbische Zeitstellung in Peru.

\subsection{Hypothesen und Ziele}

Grundlegendes Ziel dieser Arbeit ist es, anhand der Untersuchung von DNA prähistorischer menschlicher Individuen die diachrone bevölkerungsbiologische Entwicklung in der Palpa Region, im südlichen Peru, in einem Zeitraum von ca. 2000 Jahren (1000 v. Chr. - 1000 n. Chr) zu rekonstruieren. Dabei soll erfasst werden, in wie weit kultureller Wandel in der Region mit bevölkerungsbiologischem Wandel einhergeht. Unter Berücksichtigung der in Kapitel 2.1 beschriebenen Mechanismen kulturellen Wandels ergeben sich verschiedene mögliche Modelle von Fremdeinflussnahme und autochthonen Prozessen, die es anhand der genetischen Daten zu identifizieren und unterscheiden gilt. Außerdem soll untersucht werden, welchen Einfluss die Entwicklung gesellschaftlicher Komplexität, welche sich in der Nasca Zeit beobachten lässt, auf die genetische Zusammensetzung der Bevölkerung hat. So wäre es vorstellbar, dass es, mit Bezug auf die Push- und Pull-Modelle der Migrationstheorie, zu einer verstärken Einwanderung in das Gebiet kommt. Sollte dieses der Fall sein, ist zu klären, ob sich diese Kontribution zum lokalen Genpool eher in den urbanen ${ }^{4}$ oder ruralen Siedlungszusammenhängen niederschlägt. Daraus ergibt sich eine mögliche Unterscheidung der zugrunde liegenden Motivation der Immigrierenden. Der Zuzug von Spezialisten, aber auch die Kolonisation von Fremdmächten im Rahmen des „Elite Dominance“-Modelles sollten vor allem zu einer Veränderung der genetischen Zusammensetzung in den urbanen Siedlungen führen. Eine eher allgemeine Bevölkerungszunahme durch Immigration, bzw. die Rekrutierung von Produktionskräften von außerhalb sollte sich vor allem in Gräberfeldern der ruralen Siedlungen oder beider Siedlungsformen niederschlagen. Bevölkerungsverdrängungen durch Invasion sollten zu einem signifikanten Bruch in der genetischen Kontinuität führen, während andere Mechanismen

\footnotetext{
4 „Urban“ wird im Zusammenhang dieser Arbeit nicht im Sinne der juristischen neuzeitlichen Stadtdefinition verwendet. Vielmehr sind hier unter ,urbanen“ Siedlungen Zentralorte mit administrativem Charakter und einer vermutlich im Verhältnis großen Einwohnerzahl zu verstehen. Unter ,rural“ sind solche Siedlungen zu verstehen, die eher einen ländlichen Charakter haben und eine zahlenmäßig geringere Bevölkerung aufweisen.
} 
kultureller oder demischer Diffusion nur geringfügige Veränderungen im lokalen Genpool mit sich bringen würden.

Über die Palpa Region hinaus soll auf kontinentaler Ebene durch den Vergleich der genetischen Daten der prähistorischen Populationen mit den Daten rezenter, indigener südamerikanischer Populationen untersucht werden, ob die heute anzutreffenden Muster genetischer Verteilung und Diversität ein Produkt der initialen Besiedlung des Kontinentes sind. Die Alternative wäre, dass sie maßgeblich durch später folgende normative Prozesse beeinflusst wurden. Die beiden Möglichkeiten sollten sich auf Basis eines diachronen Vergleiches der genetischen Daten unterscheiden lassen. Sollte die initiale Besiedlung das Muster maßgeblich geprägt haben, würden die Populationen der verschiedenen Zeitstellungen keine signifikanten Unterschiede zu heute aufweisen. Eine spätere Beeinflussung der genetischen Verteilungsmuster sollte im diachronen Vergleich zu erfassen sein. Die weitere Diskussion dieser Frage erfolgt in Kap. 6. Diese Fragestellung knüpft direkt an die Diskussion an, in wie weit es möglich ist, ausschließlich anhand der Untersuchung rezenter Populationen Rückschlüsse auf prähistorische Migrationsprozesse zu ziehen. Außerdem soll so überprüft werden, ob es möglich ist, die Bevölkerungen der einzelnen kulturellen Großräume (hier vor allem Küste und Andenhochland) zu unterscheiden, um daraus neue Erkenntnisse zur Besiedlungsgeschichte des westlichen Südamerikas zu gewinnen.

Die Arbeitshypothesen ergeben sich aus den in den vorherigen Kapiteln beschriebenen Kenntnissen der Kulturgeschichte der Palpa-Region und des südlichen Perus (Kap. 2.3.3) und der für Südamerika zur Verfügung stehenden bevölkerungsbiologischen Daten (Kap. 2.3.2). Sie wurden in enger Zusammenarbeit mit den an der Erforschung der Palpa-Region beteiligten Forschern erstellt. Im Folgenden sollen einige der Hauptfragen der vorliegenden Arbeit formuliert werden, die ohne Rückgriff auf biologische Erkentnisse (genetische Befunde) nicht befriedigend beantwortet werden können.

\section{Bevölkerungs- und Kulturgeschichte der Palpa-Region und des südlichen Perus}

1. Bildet die Paracas-Kultur im südlichen Peru eine kulturelle und bevölkerungsbiologische Einheit oder handelt es sich um eine Ansammlung solitärer lokaler Gruppen?

2. Entwickelt sich die Nasca-Kultur bei bevölkerungsbiologischer Kontinuität aus der Paracas-Kultur oder wird sie von fremden Kulturträgern in die Region gebracht?

3. Stellt die Nasca-Kultur eine frühstaatliche Gesellschaft dar und haben zentrale Orte wie La Muña und Los Molinos einen realen urbanen Charakter? 
4. Resultiert der Niedergang der Nasca-Kultur aus der Invasion oder Kolonisation durch die Huari (vgl. Zitat von Allison in Kap. 2.3.3) oder liegt er in ökologischen Veränderungen bzw. internen Prozessen begründet?

5. In wie weit äußert sich der kulturelle Austausch zwischen der Palpa Region und dem Hochland auch in der Bevölkerungsbiologie?

Besiedlungsgeschichte des westlichen Südamerikas

6. Bilden die prähistorischen Bevölkerungen der beiden kulturellen Großräume des westlichen Südamerikas, der Küste und des Andenhochlandes, eine bevölkerungsbiologische Einheit?

7. Sind die rezenten genetischen Verteilungsmuster des westlichen Südamerikas maßgeblich durch spätere kulturhistorische Ereignisse beeinflusst worden oder spiegeln sie die initiale Besiedlung wieder?

8. Wie wurde das westliche Südamerika besiedelt? Lässt sich eines der drei zurzeit diskutierten Modelle (vgl. Kap. 2.3.2) bestätigen, oder gibt es alternative Möglichkeiten? 


\section{Material und Methoden}

\subsection{Fundorte und Proben}

\subsubsection{Die Beprobungsstrategie}

Die der Arbeit zugrunde liegenden Fragestellungen verlangten eine ausgearbeitete Beprobungsstrategie, die auf Basis der archäologischen Erkenntnisse über die Kulturgeschichte im Untersuchungsgebiet erarbeitet wurde. Die Probenakquisition wurde im Rahmen dreier Feldkampagnen in Peru (2004, 2005 und 2006) von dem Autor dieser Arbeit vorgenommen. Der chronologische Beprobungsschwerpunkt lag, bedingt durch die Fundsituation vor Ort, in einem Zeitfenster, das von der frühen Paracas-Zeit (ca. 800 v. Chr.) bis zum Ende des Mittleren Horizontes (ca. 1000 n. Chr.) reicht. Dieses Fenster umfasst einen projektrelevanten Zeitraum von ca. 1800-2000 Jahren, in den die Entwicklung von Paracas- und Nasca-Kultur an der südperuanischen Küste fallen, sowie der Zusammenbruch der Nasca-Kultur und die postulierten militärischen Expansionen der Huari-Kultur aus dem Hochland.

Die Beprobung umfasste menschliche Skelette und Mumien von mehreren mit Siedlungen assoziierten Gräberfeldern aus der Palpa-Region. Der Bezug zu Siedlungsfunden liefert eine zusätzliche Evidenz für die Residenz der Individuen in der Region bis zum Ende ihrer Lebenszeit. Die unterschiedlich datierenden Gräberfelder wurden so ausgewählt, dass ein möglichst lückenloser zeitlicher Überblick gewährleistet wird (Tab. 8). Darüber hinaus wurden mit Vorzug Bestattungsplätze in die Untersuchung integriert, die Gräber aus mehr als einer Kulturphase aufweisen. Dies ermöglicht einen besseren Einblick in lokale bevölkerungsbiologische Kontinuitäten oder Diskontinuitäten. Außerdem wurde für die NascaZeit drauf geachtet, Individuen aus ruralen und frühurbanen Siedlungszusammenhängen aufzunehmen, um eine mögliche Differenzierung in der Bevölkerungsstruktur darstellen zu können. Die Verteilung der Probenzahl über die einzelnen Zeitstufen ist so gewählt, dass das Besiedlungsgeschehen im Palpa-Tal innerhalb des erwähnten Zeitraumes von ca. 2000 Jahren statistisch relevant ausgewertet werden kann.

$\mathrm{Zu}$ den Proben aus dem Palpa-Tal wurden Zusätzlich Proben von prähistorischen Referenzpopulationen von der südperuanischen Küste und aus dem Hochland akquiriert. Bei diesen Referenzpopulationen handelt es sich zum einen um mehrere Individuen aus einem Paracas-Cavernas Grab (vgl. Kap. 2.3.3) von der Paracas-Halbinsel und zum anderen um mehrere Individuen aus Chullpas (Grabtürme) des Hochlandfundortes Pacapaccari in der Nähe des Ursprungs des Rio Palpa. Der Vergleich zwischen den Paracas-zeitlichen Individuen aus dem Palpa Tal und von der Paracas Halbinsel soll die Überprüfung ermöglichen, ob es sich bei 
den Trägern der Paracas Kultur um eine homogene Bevölkerung handelt. Anhand des Vergleiches der Individuen aus der Palpa-Region und der des Hochlandes soll die bevölkerungsbiologische Relation der beiden Hauptkulturräume zu einander beleuchtet werden. Zusätzlich $\mathrm{zu}$ den beiden Populationen wurden auch noch Proben von Individuen des Küstenfundortes Monte Grande an der Mündung des Rio Grande genommen, von dem aus die Palpa Region mit marinen Ressourcen versorgt wurde.

Tab. 8: Beprobte Gräberfelder und chronologische Zuordnung der akquirierten Proben. Die Balken beschreiben die genaue Zeitspanne, aus der die Proben stammen. In den Balken ist die jeweils aufgenommene Zahl an Proben aufgeführt.

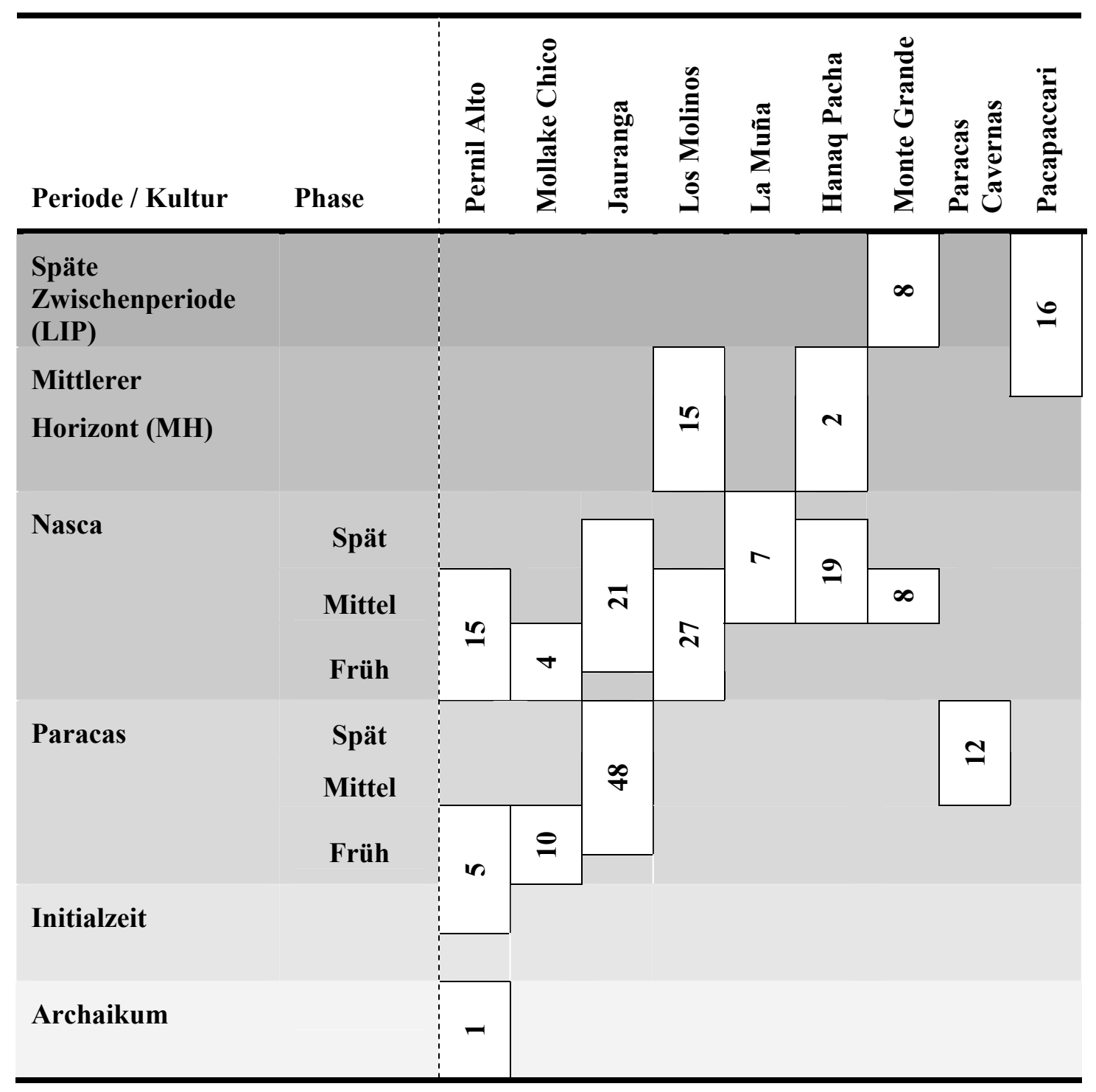

\subsubsection{Fundort- und Probenbeschreibung}

Insgesamt wurde Probenmaterial von 216 menschlichen Individuen aufgenommen. 172 Individuen (ca. 80\%) stammen von den verschiedenen Fundorten der Palpa-Region, die restlichen verteilen sich auf die Referenzpopulationen (vgl. Tab. 8). Aufgrund der Erkenntnisse zum differentiellen DNA-Erhalt in Skelettelementen (vgl. Kap. 2.2.2) wurden bevorzugt Zähne 
(hauptsächlich Molaren), Partes Petrosae oder Metatarsalia aufgenommen. In Ausnahmefällen musste von der Prozedur abgewichen werden, und es wurden andere postcraniale Skelettelemente entnommen (vgl. Fundkataloge im Anhang). Wenn möglich wurden die Individuen doppelt beprobt, jeweils zwei Zähne oder ein Zahn und ein Element des postcranialen Skelettes.

Der generelle makroskopische Erhaltungszustand der beprobten Individuen variiert nach Fundort. So finden sich einige mumifizierte Individuen mit fast vollständigem Erhalt der Weichgewebe und der Keratinen Anhangsgewebe. Andere hingegen sind vollständig skelettiert. Prozesse weiterführender diagenetischer Prozesse am Knochen wie z.B. Brushit-Bildung sind nicht zu beobachten. Wie bereits erwähnt, herrscht im Untersuchungsgebiet ein hyperarides Wüstenklima mit sehr hohen Durchschnittstemperaturen vor. Niederschlagsereignisse sind äußerst selten, und das Bodenbild wird von Sand und Gestein dominiert. Die Flussauen und Schwemmflächen weisen allerdings durchaus feuchte, nicht sanddominierte Böden auf. Bei Proben, die von bereits in vorhergehenden Kampagnen ergrabenen Skeletten stammen, wurden alle Personen, die mit der Bearbeitung beschäftigt waren, genauestens dokumentiert. Darüber hinaus wurden von den entsprechenden Personen die genetischen Daten bestimmt, um mögliche Kontaminationen durch diese aufdecken zu können. Alle Proben der prähistorischen Individuen wurden unter den für aDNA Arbeiten notwendigen Vorsichtsmaßnamen und Bedingungen (vgl. Hummel 2003) im Feldlabor in Palpa entnommen. Die entnommenen Proben wurden von der Anthropologin Elsa Tomasto (Universidad Católica del Perú, Lima) formal auf ihre Zugehörigkeit überprüft und die Ausführung der Proben nach Deutschland von der peruanischen Denkmalschutzbehörde autorisiert. In Folge sollen nun die jeweiligen Fundorte, die spezifischen Erhaltungszustände der bestatteten Individuen und die genaue Probenauswahl erläutert werden. Die Lage der Fundorte in der Palpa Region ist dem Fundplan (Abb. 21) zu entnehmen, der Laborcode, der den einzelnen Fundorten zugewiesen wurde, der Tab. 9.

Tab. 9: Beprobte Fundorte und der jeweils für die Laborarbeit zugewiesene Buchstabencode

\begin{tabular}{|c|c|}
\hline Fundort & Laborcode \\
\hline Pernil Alto & $\mathrm{AO}$ \\
\hline Mollake Chico & ME \\
\hline Jauranga & JA \\
\hline Los Molinos & MS \\
\hline La Muña & MA \\
\hline Hanaq Pacha & PA \\
\hline Monte Grande & GE \\
\hline Paracas Caverna VI & $\mathrm{PC}$ \\
\hline Pacapaccari (Buena Esperanza) & EA \\
\hline
\end{tabular}




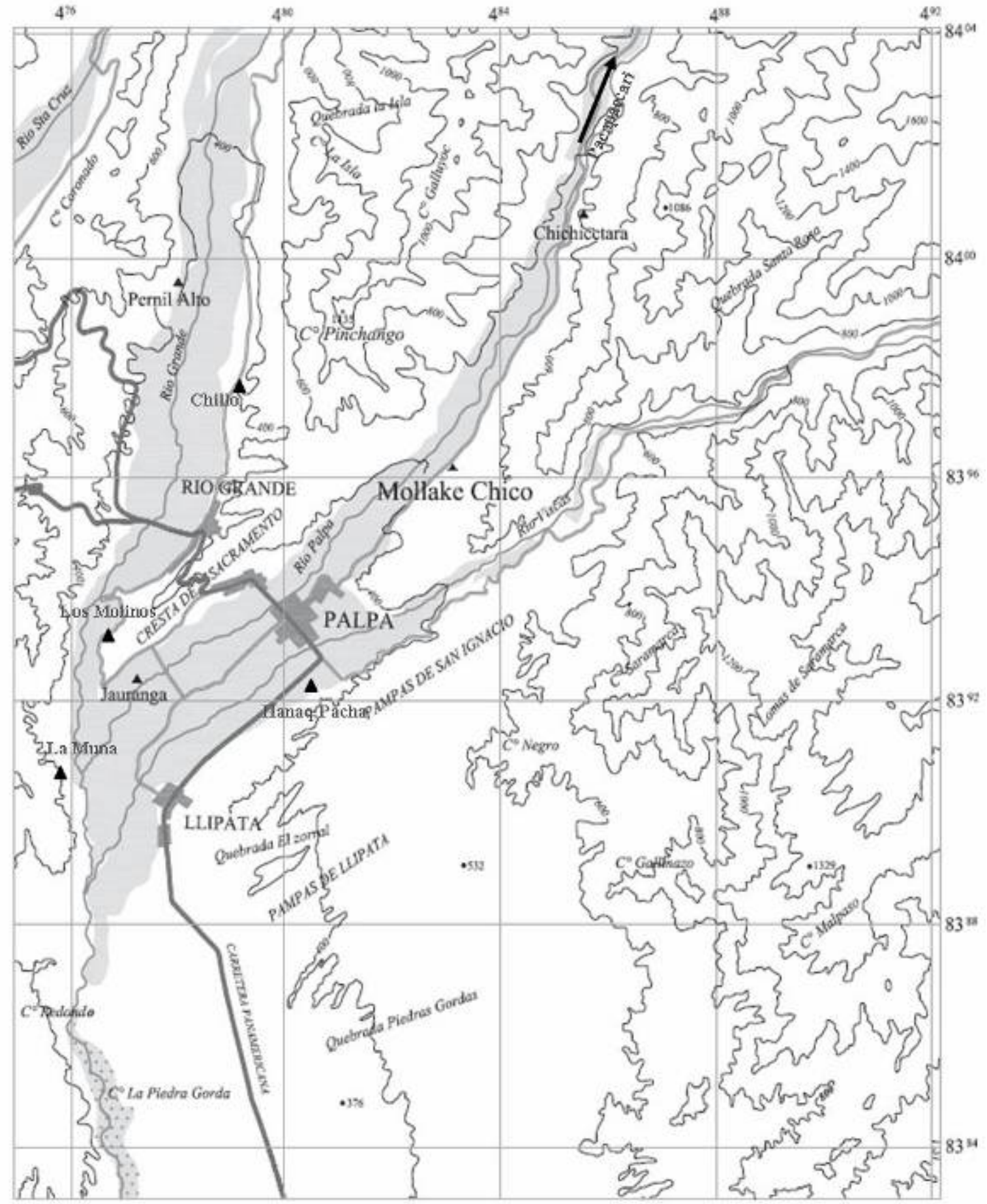

Abb. 21: Karte der Palpa Region. Die Dreiecke zeigen die einzelnen Fundorte (Isla u. Reindel 2006, Fig 2; erweitert vom Autor).

\section{Pernil Alto (AO)}

Der Fundort Pernil Alto liegt am rechten Talrand des Rio Grande an einem trockenen Hang. In zwei Grabungskampagnen (2004 u. 2005) konnten Siedlungsbefunde der Initialzeit und der frühen und mittleren Paracas-Zeit nachgewiesen werden. Die Hauptsiedlungstätigkeit und der Großteil der architektonischen Befunde konnten in die Initialzeit datiert werden. 14C Datierungen ergaben einen Nutzungszeitraum zwischen 1300 und 900 v. Chr. Neben den 
Besiedlungsstrukturen fanden sich insgesamt 23 Bestattungen (Reindel u. Isla-Cuadrado 2006). Drei der Bestattungen konnten mittlerweile in das mittlere Archaikum datiert werden. Die erwachsenen Toten waren in ovalen Gruben beigesetzt worden, zum Teil in Schilfmatten gehüllt (Abb. 22). In den Gruben fanden sich außerdem Beigaben aus Stein, Muscheln, Horn und Textilien, jedoch keine Keramikgefäße. Zusätzlich zu den Gräbern konnten auch noch Gruben gefunden werden, die auf eine Siedlungstätigkeit in dieser Zeitstellung hinweisen. Fünf weitere Bestattungen aus drei Gräbern konnten in die frühe Paracas-Zeit datiert werden (Ocucaje 3-4). Die Grabgruben waren in die initialzeitlichen Siedlungsstrukturen eingetieft. Die Toten waren in gestreckter Rückenlage oder seitlicher Hockerlage beigesetzt worden. Alle Individuen waren erwachsen, ein umfassender anthropologischer Befund durch die zuständige Anthropologin steht noch aus. An den Toten fanden sich noch Reste von Kleidungsstücken. Als Beigaben fanden sich Keramik, Muschelschalen und Werkzeuge aus Obsidian und Felsgestein. Anscheinend wurde der Ort aufgelassen, bis er in der mittleren Nasca-Zeit wieder für Bestattungen genutzt wurde. Insgesamt wurden 15 Gräber dieser Zeitstellung entdeckt. Die Gräber waren Schächte mit ovalem oder kreisförmigem Querschnitt, in denen die Toten in seitlicher Hockerlage beigesetzt wurden. Es finden sich Individuen aller Altersstufen (Reindel u. Isla-Cuadrado 2006).

Die Bestattungen waren allesamt in einen trockenen, sandigen Boden eingetieft. Einige Individuen sind teilweise mumifiziert, Reste der Gesichtshaut und Haare haben sich erhalten. Durch Grabplünderungen und andere Störungen weisen viele der Individuen postmortale Schädigungen auf. Es konnten 21 der Individuen beprobt werden, die genaue Zahl im Bezug auf die Datierung ist der Tab. 8 und dem Fundkatalog: Pernil Alto (10.3.1 - I) im Anhang zu entnehmen.
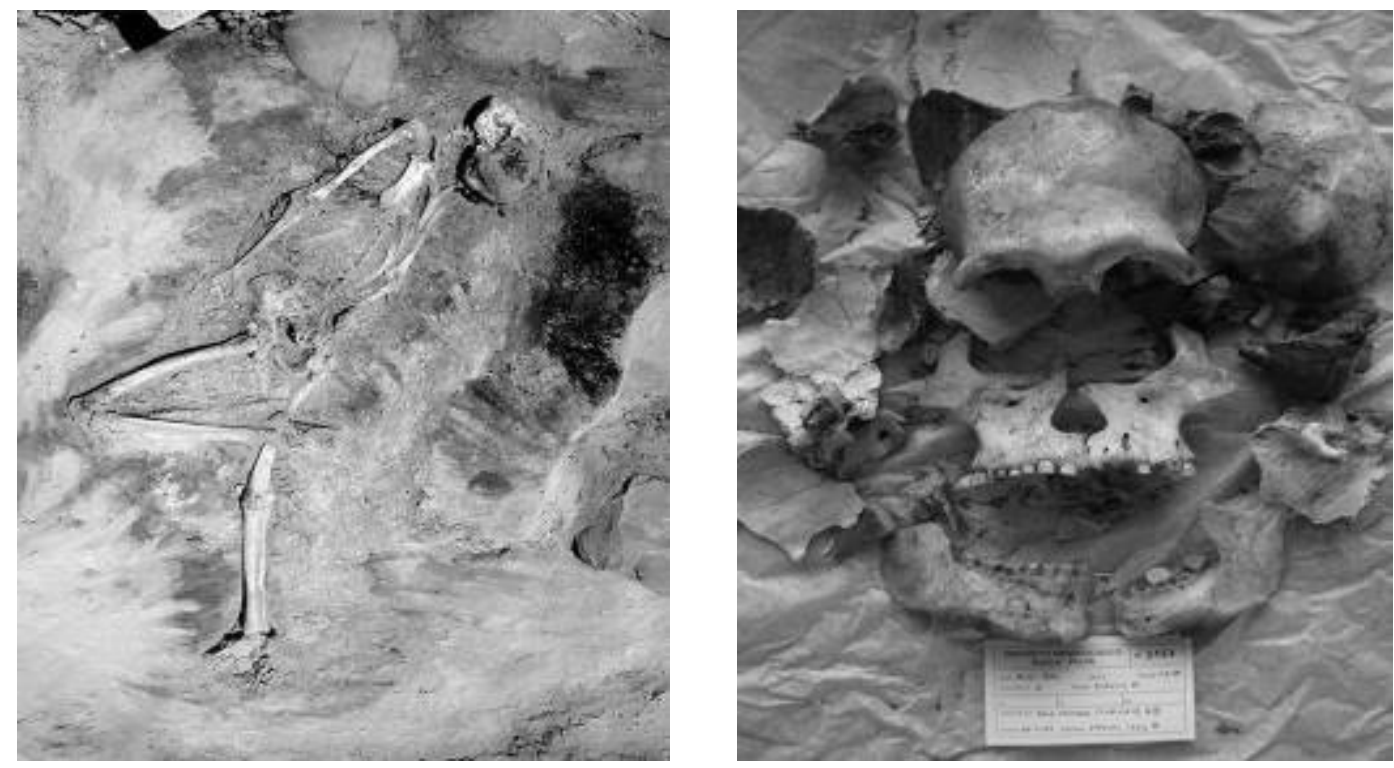

Abb. 22: Zwei Individuen aus Pernil Alto. Links: Ungestörte Bestattung aus dem Archaikum in situ (Individuum: AO 4) Rechts: Schädel des Individuums AO 9 (Nasca 3-4). 


\section{Mollake Chico (ME)}

Der Fundort Mollake Chico liegt am linken Rand des Palpa-Tals, nordöstlich der Stadt Palpa (vgl. Abb. 21). Durch Prospektion und einige Suchschnitte konnten Nasca-zeitliche Siedlungsspuren und Gräber der Phase Nasca 5 festgestellt werden. Einige Funde deuten auch auf eine Siedlungstätigkeit in der frühen Paracas-Zeit hin. In unmittelbarer Nähe zu den Siedlungsbefunden wurde eine mit Steinplatten verkleidete 1,8 x 2,5 m große Grabkammer gefunden. Innerhalb der Grabkammer fanden sich verstreut menschliche Knochen und Grabbeigaben. Anhand der Knochenfunde konnten 17 Individuen identifiziert werden, 12 Erwachsene und 5 Kinder. Anhand der beigefundenen Keramik, Obsidianwerkzeuge und eines Goldringes lässt sich das Grab eindeutig in die frühe Paracas Zeit (Ocucaje 3) datieren. Der disartikulierte und teilweise unvollständige Zustand der menschlichen Skelette deutet auf eine Sekundärbestattung hin. Anscheinend wurden erst die skelettierten Leichen der Kammer beigesetzt, über die vorhergehende Totenbehandlung ist nichts bekannt. Einige Skelettelemente wiesen Brandspuren auf. Der Knochen war geschwärzt und anscheinend nur einige ausgewählte Elemente niedrigeren Temperaturen ausgesetzt. Der Erhaltungszustand spricht gegen eine intentionale Kremation der Verstorbenen. Bei der Beprobung konnten Partes petrosae von zehn Individuen identifiziert und akquiriert werden. Da die Skelettelemente nach der Begutachtachtung durch die peruanischen Anthropologen anscheinend wieder zusammengeschüttet wurden, konnten die restlichen Individuen nicht sicher identifiziert werden und es wurde auf die Probenentnahme verzichtet, um die Ergebnislage nicht durch unbewusste Doppelbestimmungen zu verfälschen. Neben den 10 Paracas-zeitlichen Individuen konnten noch Proben von 4 Nasca-zeitlichen Individuen genommen werden (vgl. Tab. 8). Der allgemeine Erhaltungszustand aller Knochenelemente ist als schlecht $\mathrm{zu}$ beschreiben, weshalb auch die stabilen Partes petrosae aufgenommen wurden. Der Fundkatalog: Mollake Chico (10.3.1-II) mit den entsprechenden Zuweisungen der Befund- und Probennummern findet sich im Anhang.

\section{Jauranga (JA)}

Jauranga ist der bislang am Besten erforschte Siedlungsplatz der Paracas-Kultur im Untersuchungsgebiet. Abweichend von den meisten anderen hier vorgestellten Fundplätzen befindet sich der Ort nicht in Hanglage, sondern direkt auf der Schwemmfläche des Rio Palpa, südwestlich der Stadt (vgl. Abb. 21). In einer ausgedehnten Flächengrabung (2003) konnten Siedlungsreste, Gräber und Keramik geborgen werden, die den Fundplatz als Standort einer Paracas-zeitlichen Siedlung mit einfachen Lehmziegelbauten charakterisieren. Anhand des keramischen Fundmaterials lässt sich ein Nutzungszeitraum der Siedlung von ca. 600 - 200 v. 
Chr. (Ocucaje 5/6 - 9) belegen. Die architektonischen Befunde und die angetroffene Siedlungsstruktur geben Jauranga einen eindeutig ruralen Siedlungscharakter. In der Phase Ocucaje 9 wurde die Siedlung aufgelassen und noch als Bestattungsplatz weiter genutzt. Ingesamt konnten 80 bestattete Individuen geborgen werden. 49 der Bestattungen stammen aus der Paracas-Zeit und datieren zwischen Ocucaje 6 bis 9. Weitere 31 Bestattungen wurden in der Nasca-Zeit angelegt. Ungefähr die Hälfte der Paracas-zeitlichen Bestattungen und alle Nascazeitlichen wurden in die Siedlungsstrukturen eingetieft. Die Nasca-Gräber wiesen entweder Einfach- oder Mehrfachbestattungen auf. Bei den Einfachbestattungen handelte es sich in den meisten Fällen (83\%) um Kinder, die in Gefäßen beigesetzt wurden. In der Regel handelt es sich dabei um sekundär genutzte Vorratsgefäße. Die Mehrzahl der Paracas-Gräber waren Einfachbestattungen, die meist in einfachen Gruben und ohne Deckschicht bestattet waren (Abb. 23). Bei den Paracas-Bestattungen waren etwa gleiche Anteile Kinderbestattungen (49\%) und Erwachsene (51\%) zu finden. In der Paracas-Zeit wurden vergleichsweise wenige Tote in Gefäßen (33\%) beigesetzt, wobei dies auch für Kinderbestattungen gilt. Die übrigen Toten (67\%) wurden in einfachen Gruben mit einer Abdeckung aus Erde, mit einigen Steinen und Lehmziegeln bestattet (Reindel u. Isla-Cuadrado 2003).

Als besonderer Gräberkomplex ist eine Grabanlage mit vier rechteckigen Grabkammern hervorzuheben. Die vier Kammern waren durch dünne Mauern aus Lehm und Lehmziegeln voneinander getrennt. Kammer 1 enthielt drei Erwachsene und ein Kind mit 10 Keramikgefäßen. Kammer 2 einen Erwachsenen ohne Beigaben. Kammer 3 beinhaltete zwei Erwachsene und ein Kind mit 13 Keramikgefäßen. In Kammer 4 waren fünf Erwachsene und zwei Kinder mit 15 Keramikgefäßen beigesetzt. An allen Bestatteten fanden sich lokal begrenzte und auf wenige Körperbereiche begrenzte Brandstellen, die allerdings, wie im Falle von Mollake Chico, nicht auf eine vollständige Kremation der Leichname hinweisen. Die Brandeinwirkungen könnten ein Bestandteil eines bisher unbekannten Grabkultes sein (Isla Cuadrado u. Reindel 2003).

Von 48 der 49 Paracas-zeitlichen Individuen konnten Proben genommen werden und von 19 der Nasca-zeitlichen (vgl. Tab. 8). Die Individuen sind allesamt vollständig skelettiert. Der Erhaltungszustand variiert und ist weitestgehend als schlecht zu beschreiben, was auf das leicht feuchte Liegemilieu zurückzuführen ist (Abb. 23). Der pH-Wert des Bodens ist im Vergleich zu den Sandböden in Hanglage leicht alkalisch $(8,1)$ und nicht neutral (Los Molinos $=p H ~ 7,1)$. Der Fundkatalog für Jauranga (10.3.1-III) mit allen relevanten Daten ist dem Anhang zu entnehmen. 

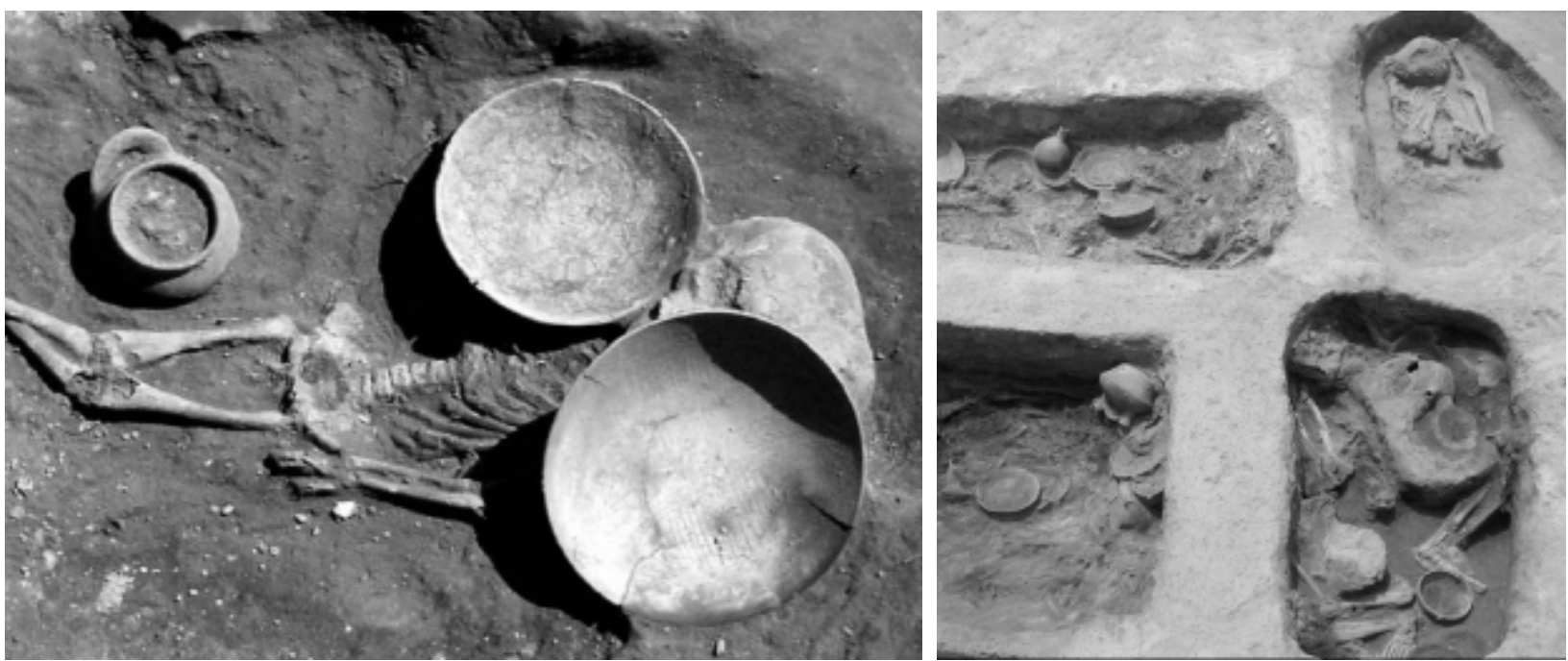

Abb. 23: Paracas Gräber aus Jauranga. Links: Bestattung eines Kindes (Infans I - JA 13). rechts: vier Gräber in situ (Quelle: Isla-Curado, Peru).

\section{Los Molinos (MS)}

Der Fundort Los Molinos liegt am südlichen Hang des unteren Talbereiches des Rio Grande (Abb. 21). Wie bereits in Kap. 2.3.3 beschrieben, erschloss sich bei mehreren großflächigen Grabungen (1997-1999) eine große Siedlung mit Resten von Monumentalarchitektur, Plattformen und großen Höfen, die sich entlang des Hanges über mehrere Terrassen zieht (Abb. 24). Die aufgedeckte Siedlungsstruktur spricht eindeutig für eine planmäßige Anlage des Ortes. Anhand der Funde und 14C-Daten konnte die Siedlung in die frühe Nasca-Zeit (ca. 0-250 n. Chr.) datiert werden. Der Nutzungszeitraum scheint bei ca. 100 Jahren zu liegen. Die Befunde deuten darauf hin, dass die Siedlung durch Starkregenfälle zerstört wurde. Los Molinos scheint das regionale Zentrum der Region in der frühen Nasca-Zeit gewesen zu sein, es werden zwar keine Ausmaße wie in Cahuáchi erreicht, aber die Siedlungsanlage spricht für einen frühurbanen Charakter des Ortes. Neben den Siedlungsbefunden konnten über 50 Gräber der Nasca-Zeit ergraben werden. Diese verteilen sich zum einen auf ein Gräberfeld in ummittelbarer Nähe der Siedlung, zum anderen wurden viele Gräber nach Aufgabe der Siedlung in die Baubefunde eingetieft. Die letzteren Gräber datieren hauptsächlich in die mittlere Nasca-Zeit. Die Toten waren in Schachtgräbern mit Balkendecke bestattet.

Zusätzlich zu den Nasca-zeitlichen Gräbern konnte etwas weiter westlich ein Gräberfeld des Mittleren Horizontes entdeckt werden. Das Gräberfeld umfasst 6 Gräber, in denen 15 Individuen bestattet wurden. Vier der Gräber sind einfache Gruben, die in den Boden eingetieft wurden. Die zwei anderen sind Schachtgräber im Stile der Nasca Gräber. Anhand der Grabbeigaben konnten die Bestattungen in einen Zeitraum von $600-800$ n. Chr. (MH 1) datiert werden. Es fanden sich 
sowohl der lokale Loro-Keramikstil, wie auch der mit den Huari assoziierte ChakipampaKeramikstil (Reindel u. Isla-Cuadrado 2000).

Die Bestattungen waren allesamt in den trockenen, steinigen, sandigen Boden eingetieft. Der makroskopische Erhaltungszustand der Individuen ist als gut zu beschreiben. Die meisten der Individuen weisen einen großflächigen Erhalt von Weichgewebe und Haaren auf (Abb. 24). Der Gesamtzustand deutet auf eine primäre Mumifikation hin (Auderheide 2003). Jedoch waren viele der Gräber beraubt, und die Mumien weisen postmortale Zerstörungen auf. Es konnten Proben von 27 Nasca-zeitlichen Individuen genommen werden. Individuen aus zerstörten Grabzusammenhängen wurden wegen der möglichen Kontamination nicht beprobt. Von allen 15 Individuen aus dem Mittleren Horizont wurden ebenfalls Proben genommen (Tab. 8 / Fundkatalog: Los Molinos im Anhang 10.3.1-IV).
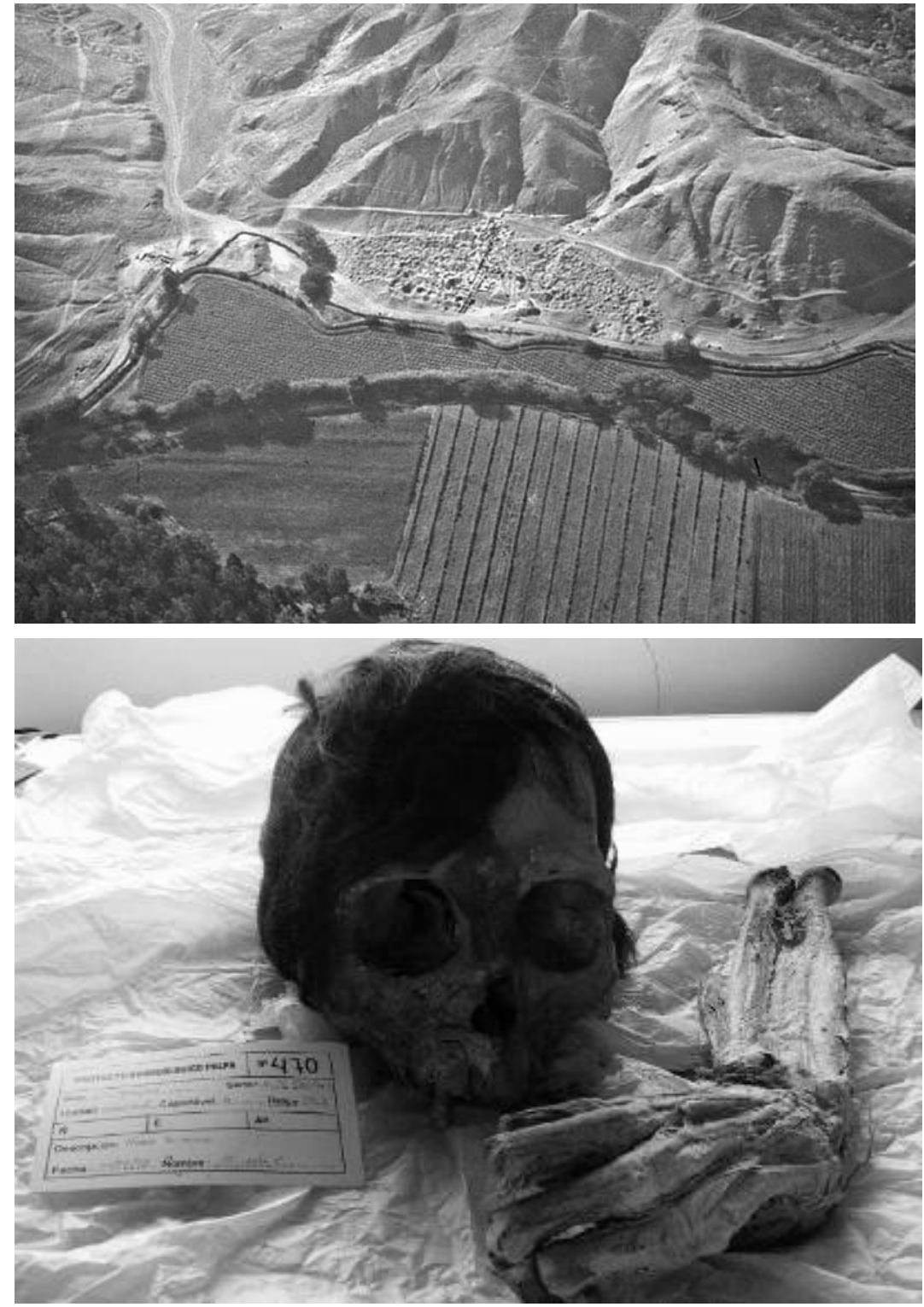

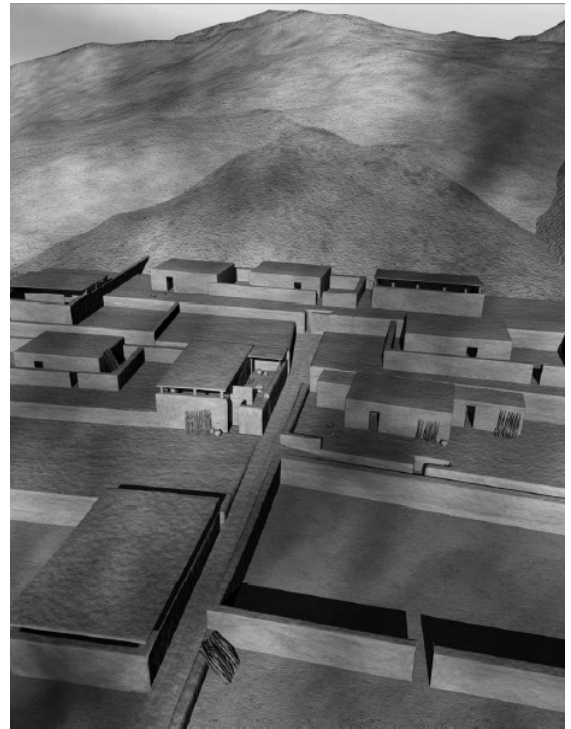

Abb. 24: Los Molinos. Oben links: Luftaufnahme des Fundortes (Quelle:KAAK-DAI); oben rechts: Digitale Rekonstruktion der Bebauung (Jens Tomkowitz - DAI), unten links: Schädel und Unterarm eines teilweise mumifizierten Nascazeitlichen Individuums (MS 2). 


\section{La Mũ̃a (MA)}

Der Fundort liegt nahe dem Zusammenfluss von Rio Grande und Rio Palpa am nördlichen Talrand, etwas südlich von Los Molinos. La Muña ist eine ausgedehnte Siedlung, die sich über mehrere hundert Meter an den Hängen der angrenzenden Berge entlang zieht. Siedlungsstruktur und Baubefunde (vgl. Kap. 2.3.3) charakterisieren den Ort als ein planmäßig angelegtes urbanes Siedlungszentrum. Wie bereits beschrieben, ist neben der herausragenden Siedlungsstruktur die monumentale Grabarchitektur von besonderem Interesse (Abb. 25). Die reich ausgestatteten „Elite“-Gräber wie auch die Siedlung datieren in die mittlere Nasca-Zeit, vor allem Nasca 5 (250-450 n. Chr.). Detailliertere Informationen zu diesem Fundort und seiner Bedeutung im Kontext der Nasca-Kultur und des Untersuchungsgebietes wurden bereits zuvor geschildert (Kap. 2.3.3). Es wurden insgesamt sieben Individuen aus den Grabkomplexen beprobt (Fundkatalog: La Muña 10.3.1-V im Anhang). Die Individuen befanden sich in einem schlechten Erhaltungszustand, die Skelette waren disartikuliert und viele Knochen zertrümmert. Dieser Zustand resultiert zum einen aus Plünderungen und zum anderen daraus, dass in einigen Gräbern die inneren Grababdeckungen zusammengestürzt waren und die Individuen unter sich begraben hatten. Neben den mechanischen Zerstörungen lassen sich allerdings keine fortgeschrittenen diagenetischen Zerfallserscheinungen nachweisen.

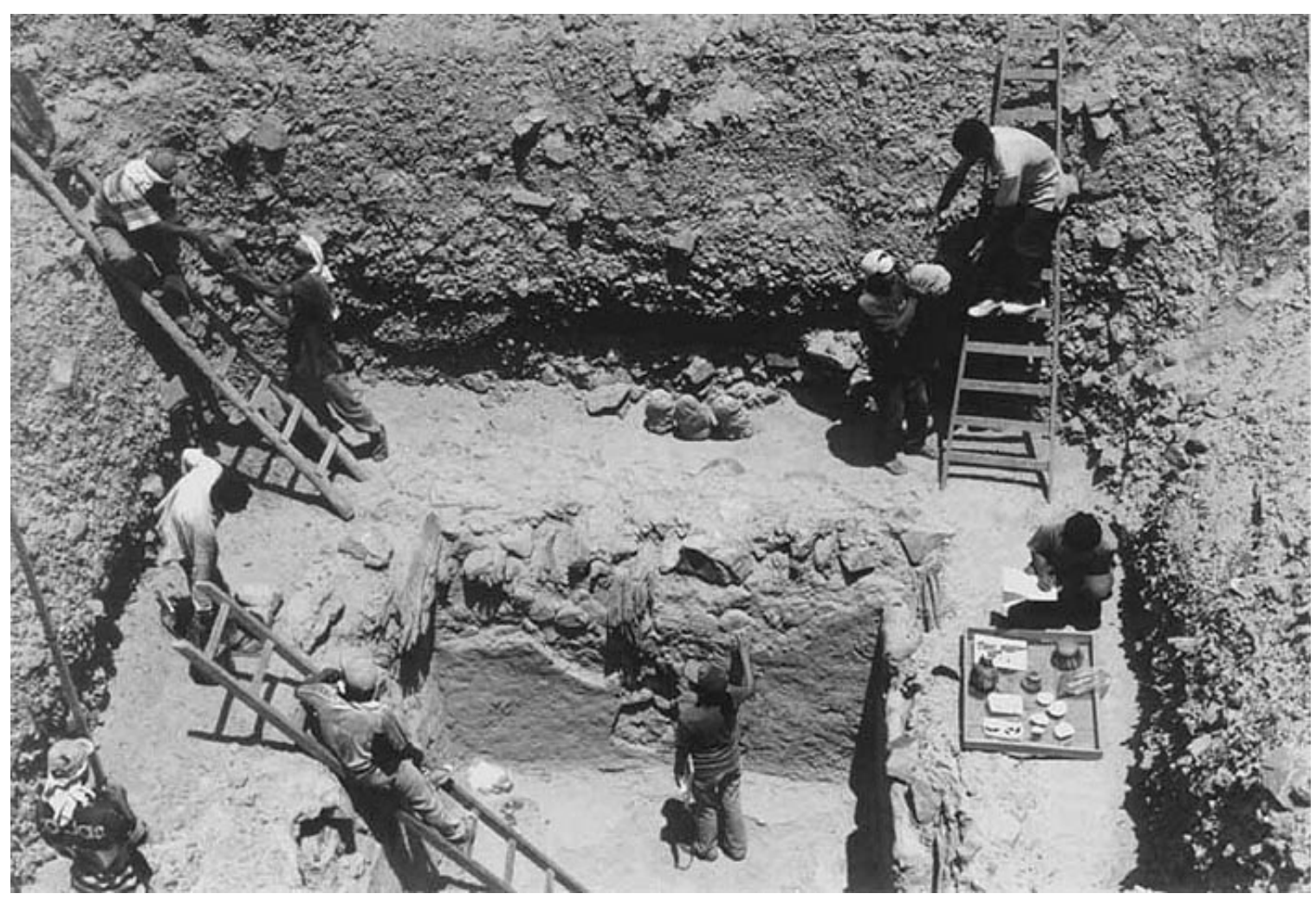

Abb. 25: Ausgrabung eines der Prunkgräber von La Muña (Quelle: KAAK-DAI). 


\section{Hanaq Pacha (PA)}

Im Zuge der Bauarbeiten des Grabungshauses, etwas südlich der Stadt Palpa (Abb. 21), wurde ein Gräberfeld der mittleren Nasca-Zeit entdeckt (vgl. Abb. 16). Ingesamt wurden 17 Gräber mit 19 bestatteten Individuen dokumentiert. Die Toten wurden in den für die Nasca-Kultur typischen Schachtgräbern beigesetzt. Darüber hinaus fanden sich auch drei Bestattungen aus dem Mittleren Horizont (Reindel et al. 2004). Alle aufgefundenen Individuen waren vollständig skelettiert. Der Erhaltungszustand der Knochen ist als gut zu beschreiben. Von allen Nasca-zeitlichen und zwei der aus dem Mittleren Horizont stammenden Individuen konnten Proben genommen werden (Fundkatalog 10.3.1-VI im Anhang).

\section{Monte Grande (ME)}

Monte Grande ist der einzig bekannte Fundort im Bereich des Untersuchungsgebietes, der in ummittelbarer Küstennähe liegt. Er erstreckt sich am südlichen Rand des Rio Grande an einem Talhang. Das Tal durchschneidet die an dieser Stelle recht hohe Küstenkordilliere. Es konnten Besiedlungsspuren aus der Paracas- und Nasca-Zeit gefunden werden, sowie aus der Späten Zwischenperiode (LIP). Dem Ort wird eine Zentrale Rolle in der Versorgung der Palpa-Region mit marinen Ressourcen zugesprochen (pers. Mitteilung M. Reindel 2007). Am Rande der Siedlungsfläche erstrecken sich zwei ausgedehnte Nasca- und LIP-zeitliche Nekropolen. Die meisten Gräber sind geplündert, Skelette und Mumienteile liegen über die Fläche verteilt (Abb. 26). Bei der Prospektion des Fundortes wurden jeweils acht Individuen der beiden Gräberfelder vom Autor beprobt (Fundkatalog: Monte Grande 10.3.1-VII). Die Individuen wurden so gewählt, dass sie zumindest noch zum Teil von Sediment bedeckt waren. Der größte Teil der zugänglichen Individuen war, dem Ausbleichungsgrad nach, schon längere Zeit der direkten Sonneneinstrahlung ausgesetzt. Es wurden nur Zähne direkt aus dem Kiefer genommen, um das Risiko von Kontaminationen durch Grabräuber zu minimieren.

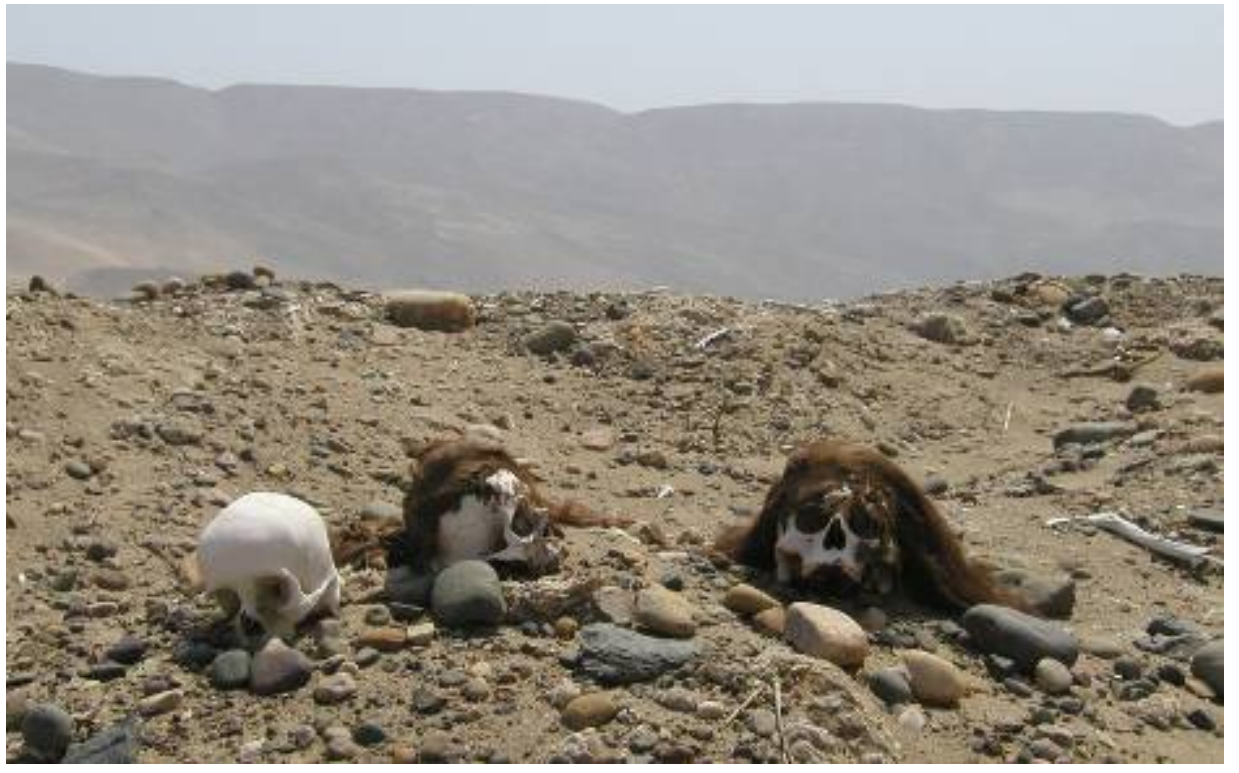

Abb. 26: Fundsituation in Monte Grande. 


\section{Paracas Caverna VI (PC)}

Die Paracas Cavernas stellen eine besondere Bestattungsform der Kultur auf der ParacasHalbinsel dar (vgl. Kap. 2.3.3). Das Museo Nacional de Arqueología, Antropología e Historia del Perú ermöglichte den Zugang zu einigen Individuen aus einem dieser Kammergräber. Es konnten insgesamt 12 Mumien aus dem Grab Caverna VI beprobt werden (Tab. 8). Das Grab datiert in die mittlere bis späte Paracas-Zeit (Ocucaje 7-8). Die Individuen befanden sich in einem durchschnittlichen bis guten makroskopischen Erhaltungszustand. Weite Teile der Weichgewebe waren mumifiziert erhalten. Es ist allerdings zu erwähnen, dass die Individuen aus Altgrabungen der 1920er Jahre stammen. Dem entsprechend wurden als Proben, wenn möglich, Zähne direkt aus dem Kiefer extrahiert. Die Probenentnahme geschah im Museum unter Laborbedingungen. Alle zehn erwachsenen Individuen wiesen artifizielle Schädelverformungen und Trepanationsöffnungen am Schädel auf (vgl. Abb. 18). In allen Fällen konnte Knochenneubildung beobachtet werden, die Schädeleingriffe wurden also überlebt. Der Fundkatalog: Caverna VI (10.3.1-VIII) mit den entsprechenden Zuweisungen der Befunde und Probennummern findet sich im Anhang.

\section{Pacapaccari - Buena Esperanza (EA)}

Der Fundort wurde bei Prospektionen in den Jahren 2005 und 2006 erschlossen. Es handelt sich um eine großflächige Hochlandsiedlung in Spornlage, von der das Tal des Rio Palpa weit zu überblicken ist. Der Fundort befindet sich in einer Höhe von ca. $2800 \mathrm{~m}$ über dem Meeresspiegel ca. $40 \mathrm{~km}$ andeneinwärts von Palpa. Die klimatischen Bedingungen unterscheiden sich maßgeblich vom restlichen Untersuchungsgebiet. Es ist feuchter und die Durchschnittstemperaturen liegen weitaus niedriger. Das gesamte Areal ist von einer dichten, aber niedrigen Vegetation umgeben. Auf der Siedlungsfläche befinden sich mehrere Chullpas, aus Felsstein aufgetürmte Grabtürme (Abb. 27). Innerhalb dieser Chullpas wurden mehrere Individuen beigesetzt. Zwei dieser Chullpas, die direkt nebeneinander stehen, wurden während der Prospektion vom Autor erschlossen und die bestatteten Individuen beprobt. Die Lage der Knochen innerhalb der Gräber, so wie das Fehlen vieler Skelettelemente deuten darauf hin, dass es sich um Sekundärbestattungen handelt (Abb. 27). Die Individuen waren vollständig skelettiert, die Knochen befanden sich aber in einem sehr guten Erhaltungszustand. In den Knochenakkumulationen beider Gräber konnten jeweils 8 Individuen anhand der Mandibulae sicher identifiziert und Zähne (Molaren) aus den Kiefern extrahiert werden (Fundkatalog: Pacapaccari 10.3.1-IX im Anhang). Es wurden nur erwachsene Individuen gefunden. Anhand der assoziierten Keramik und zweier 14C-Daten aus Oberschenkelknochen (pers. Mitteilung Bernd 
Kromer 2006) konnten die Gräber in den ausgehenden Mittleren Horizont bis in die Späte Zwischenperiode datiert werden (900-1100 n. Chr.).
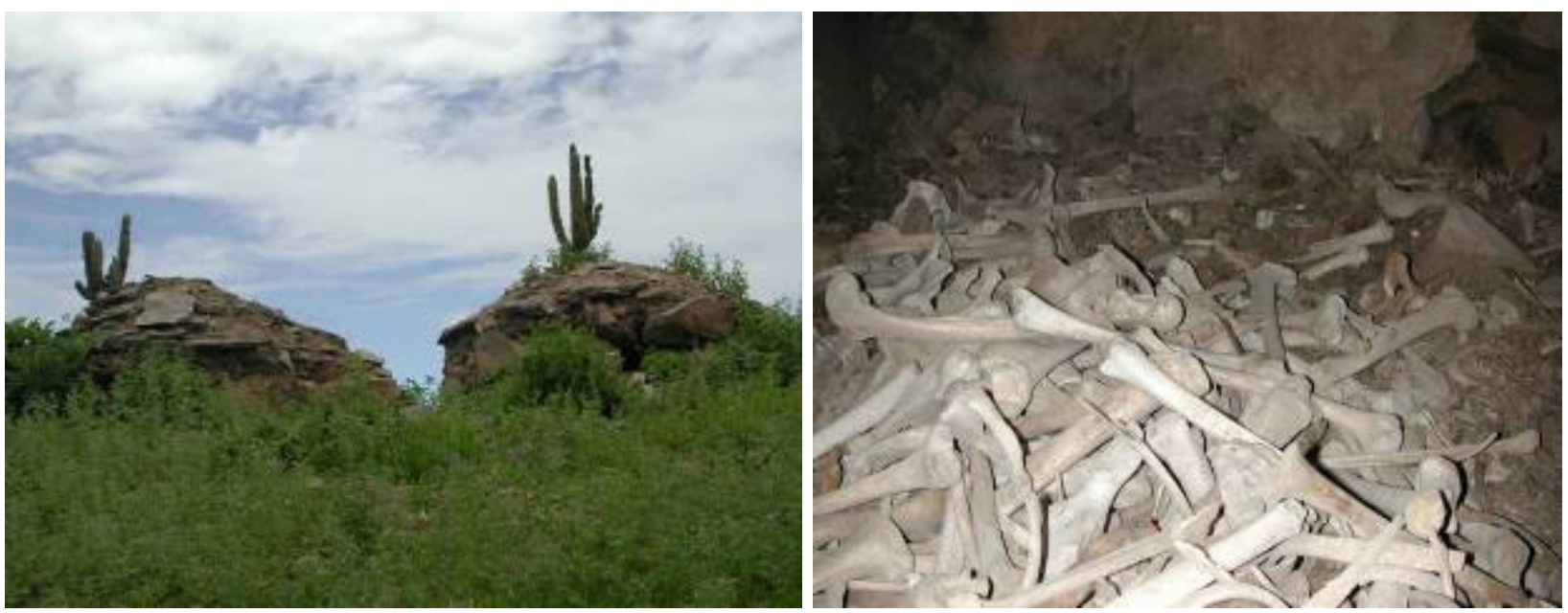

Abb. 27: Pacapaccari. Links: die beiden untersuchten Chullpas. Rechts: Auffindesituation der menschlichen Überreste in der rechten Chullpa.

\subsubsection{Die südamerikanischen Referenzpopulationen}

Um die genetischen Daten aus der Palpa-Region in einen kontinentalen Zusammenhang stellen zu können, wurden Referenzdaten aus der Literatur aufgenommen. Aufgrund der Quellenlage handelt es sich dabei ausschließlich um mitochondriale Daten. Die Referenzdaten lassen sich in zwei Gruppen gliedern: mt-Haplogruppen-Frequenzdaten und Sequenzdaten der mitochondrialen HVRI-Region. Bis heute werden in den populationsgenetischen Arbeiten zur Bevölkerungsgeschichte Südamerikas hauptsächlich Haplogruppen-Frequenzen publiziert, daraus resultiert ein gewisses Ungleichgewicht der verfügbaren Daten. Dazu sind viele HVRIDaten aus Arbeiten der 1990er Jahre kritisch zu betrachten (Bandelt et al. 2003), dementsprechend stehen dieser Arbeit auch mehr Frequenzdaten als Sequenzen für den Vergleich zur Verfügung. Es wurde versucht, alle publizierten Daten, die nicht offensichtlich fehlerbehaftet sind, in diese Arbeit aufzunehmen. Insgesamt wurden Haplogruppen-Daten von 60 rezenten indigenen südamerikanischen Populationen aufgenommen. Fünf dieser Populationen sind Pools, das bedeutet, dass es sich um mehrere kleine Populationen aus einer Publikation mit gleicher Provenienz handelt, die zusammengefasst wurden. Neun Populationen stammen aus aDNA-Arbeiten, die zeitlich vom Archaikum bis in die Frühe Neuzeit reichen. Die aufgenommenen Datensätze und die jeweiligen Quellen, so wie die prozentuale Verteilung der mitochondrialen Haplogruppen in den Populationen finden sich in Tabelle 10. Die geographische Herkunft der Populationen ist der Abbildung $28 \mathrm{zu}$ entnehmen. Insgesamt wurden mtHaplogruppen Daten von $\mathbf{4 3 2 0}$ indigenen südamerikanischen Individuen aufgenommen. 
Entscheidend für die Auswahl der HVR I-Sequenzdaten war die untersuchte Basenpaarlänge. Die für die Analyse notwendigen populationsgenetischen Berechnungen verlangen, dass die untersuchten Sequenzen gleich lang sind und die gleichen Nukleotidpositionen beinhalten. Je länger die Sequenz, desto höher ist auch die Auflösung der Daten, deshalb wurden nur Sequenzdaten aufgenommen, die von Position 16024 - 16400 der mitochondrialen HVR IRegion reichen. Die meisten aDNA-Daten erfüllen dieses Kriterium nicht, dementsprechend werden sie nicht berücksichtigt. Es wurden insgesamt Sequenzdaten von 984 Individuen aus 15 indigenen südamerikanischen Populationen aufgenommen. Die Quelle der Daten ist Tab. 11 zu entnehmen, ihre geographische Herkunft Abb. 29. Da zumeist nur die Polymorphismen, also die Abweichungen von der rCRS-Referenzsequenz (vgl. Kap. 2.2.1.) publiziert werden, mussten diese in eine Datenbank eingepflegt und anschließend mit der Software EditSeq ${ }^{\text {TM }}$ (DNAStar Inc., Madison USA) in vollständige Sequenzdaten umgewandelt werden. Um Übertragungsfehler zu vermeiden, wurden die Daten anschließend mehrmals unabhängig überprüft.

Um die Menge der mt-Haplogruppen Daten verwalten und die populationsgenetische Analyse gewährleisten zu können, erschien es sinnvoll, für diese Arbeit eine Einteilung in geographische und kulturelle Großräume nach dem Vorbild von Stanish (2001) vorzunehmen. Die Datensätze wurden jeweils in eine von 16 aus dem kulturellen- und geographischen Kontext heraus sinnvoll erscheinenden Gruppe zusammengefasst. Die genaue Einteilung ist Abb. $30 \mathrm{zu}$ entnehmen. In Tab. 12 findet sich eine genaue Beschreibung dieser Areale unter Angabe der jeweils gruppierenden Referenzpopulationen. In den Tabellen 10 und 11 findet sich in der Spalte „Reg“ (= Regionalcode) die Nennung der kulturellen und geographischen Großregion, aus der die Population stammt. 
Tab. 10: Auflistung der verwendeten südamerikanischen Referenzpopulationen und der jeweiligen prozentualen Anteile der mitochondrialen Haplogruppen [A, B, C, D und andere (N)]. Datensätze/ Populationen aus aDNA-Untersuchungen sind in Kursiv gedruckt, mit Angabe der chronologischen Einordnung in Klammern. Bei den zentralandinen Populationen (Reg. 4\&5) folgt außerdem die Zuweisung der Sprachfamilie in Klammern (Qechua / Aymara). No = Nummer zur Zuweisung der Population auf der Übersichtskarte - Abb. 28; Reg = zugewiesener Regionalcode - vgl. Abb. 30; n = Anzahl der Individuen)

\begin{tabular}{|c|c|c|c|c|c|c|c|c|c|}
\hline Population & No & $\operatorname{Reg}$ & n & $\mathbf{A}$ & B & C & D & $\mathbf{N}$ & Quelle \\
\hline \multicolumn{10}{|l|}{ Columbien } \\
\hline Columbien NW (Pool) & 1 & 1 & 335 & 56 & 13 & 24 & 1 & 0 & Keyeux et al. 2002 \\
\hline Ingano & 4 & 3 & 43 & 12 & 46 & 42 & 0 & 0 & Torres et al. 2006 \\
\hline Ticuna & 60 & 7 & 82 & 15 & 10 & 36 & 39 & 0 & Torroni 1993 / Mesa 2000 \\
\hline Columbien SE-1 (Pool) & 65 & 7 & 346 & 7 & 47 & 32 & 12 & 0 & Keyeux et al. 2002 \\
\hline Columbien SE-2 (Pool) & 66 & 7 & 92 & 24 & 9 & 59 & 9 & 0 & Torres et al. 2006 \\
\hline \multicolumn{10}{|l|}{ Venezuela } \\
\hline Guahibo & 2 & 2 & 59 & 47 & 3 & 49 & 0 & 0 & Vona et al. 2005 \\
\hline Yanomami-2 & 62 & 7 & 155 & 0 & 56 & 32 & 12 & 0 & Williams et al. 2002 \\
\hline \multicolumn{10}{|l|}{ Ecuador } \\
\hline Cayapa & 3 & 3 & 30 & 33 & 20 & 17 & 30 & 0 & Rickards et al. 1999 \\
\hline \multicolumn{10}{|l|}{ Brasilien } \\
\hline Yanomami-1 & 61 & 7 & 83 & 0 & 6 & 72 & 10 & 12 & Easton et al. 1996 \\
\hline Yanomami-3 & 63 & 7 & 24 & 0 & 17 & 54 & 29 & 0 & Torroni et al. 1993 \\
\hline Makiritari & 64 & 7 & 10 & 20 & 0 & 70 & 10 & 0 & Torroni et al. 1993 \\
\hline Wapishana & 59 & 7 & 12 & 0 & 25 & 8 & 67 & 0 & Torroni et al. 1993 \\
\hline Gaviao & 58 & 8 & 27 & 15 & 15 & 0 & 70 & 0 & Ward et al. 1996 \\
\hline Xavante & 56 & 8 & 28 & 16 & 84 & 0 & 0 & 0 & Ward et al. 1996 \\
\hline Zoro & 57 & 8 & 30 & 20 & 7 & 13 & 60 & 0 & Ward et al. 1996 \\
\hline Kraho & 55 & 8 & 14 & 29 & 57 & 14 & 0 & 0 & Torroni et al. 1993 \\
\hline Guarani & 53 & 12 & 200 & 84 & 0 & 10 & 7 & 0 & Marrero et al. 2007 \\
\hline Kaingang & 54 & 12 & 78 & 47 & 4 & 49 & 0 & 0 & Marrero et al. 2007 \\
\hline \multicolumn{10}{|l|}{ Peru } \\
\hline San Martin (Qechua) & 5 & 4 & 22 & 9 & 55 & 5 & 27 & 5 & Fuselli et al. 2003 \\
\hline Ancash (Qechua) & 7 & 4 & 33 & 9 & 52 & 18 & 21 & 0 & Lewis et al. 2004 \\
\hline Yungay (Qechua) & 8 & 4 & 36 & 3 & 47 & 36 & 14 & 0 & Lewis et al. 2007b \\
\hline Tupe & 9 & 4 & 16 & 0 & 69 & 31 & 0 & 0 & Lewis et al. 2007b \\
\hline Lima / Pasco (Qechua) & 6 & 4 & 52 & 4 & 54 & 17 & 19 & 6 & Rodriguez-Delfin et al. 2001 \\
\hline Tayacaja (Qechua) & 10 & 5 & 61 & 21 & 33 & 30 & 13 & 3 & Fuselli et al. 2003 \\
\hline Quechua-1 (Qechua) & 11 & 5 & 19 & 26 & 37 & 5 & 32 & 0 & Merriwether et al. 1995 \\
\hline Arequipa (Qechua) & 12 & 5 & 22 & 9 & 68 & 14 & 9 & 0 & Fuselli et al. 2003 \\
\hline Puno (Qechua) & 14 & 5 & 30 & 7 & 60 & 23 & 10 & 0 & Lewis et al. $2007 \mathrm{~b}$ \\
\hline Puno (Aymara) & 13 & 5 & 14 & 0 & 71 & 14 & 14 & 0 & Lewis et al. 2007b \\
\hline Huaca-Loro (Sican-MH) & 16 & 6 & 36 & 19 & 22 & 6 & 31 & 22 & Shimada et al. 2004 \\
\hline Paucarcancha (Inka-LH) & 17 & 5 & 35 & 9 & 66 & 23 & 3 & 0 & Shinoda et al. 2006 \\
\hline ChenChen (Tiwanaku-MH) & 15 & 5 & 23 & 39 & 39 & 17 & 4 & 0 & Lewis et al. 2007a \\
\hline \multicolumn{10}{|l|}{ Bolivien } \\
\hline Aymara-1 (Aymara) & 24 & 5 & 172 & 7 & 68 & 12 & 13 & 0 & Merriwether et al. 1995 \\
\hline Aymara-3 (Aymara) & 25 & 5 & 33 & 0 & 94 & 3 & 3 & 0 & Bert et al. 2001 \\
\hline Quechua-2 (Qechua) & 27 & 5 & 32 & 16 & 75 & 9 & 0 & 0 & Bert et al. 2001 \\
\hline Chimane & 18 & 9 & 41 & 39 & 54 & 5 & 0 & 2 & Bert et al. 2001 \\
\hline Moseten & 19 & 9 & 20 & 40 & 55 & 0 & 0 & 1 & Bert et al. 2001 \\
\hline Yuracare & 20 & 9 & 28 & 39 & 32 & 21 & 4 & 4 & Bert et al. 2001 \\
\hline Ignaciano & 21 & 8 & 22 & 18 & 36 & 41 & 0 & 5 & Bert et al. 2001 \\
\hline Trinitario & 22 & 8 & 35 & 14 & 40 & 37 & 3 & 6 & Bert et al. 2001 \\
\hline
\end{tabular}




\begin{tabular}{|c|c|c|c|c|c|c|c|c|c|}
\hline Population & No & Reg & n & A & B & C & D & $\mathbf{N}$ & Quelle \\
\hline Movima & 23 & 8 & 22 & 9 & 9 & 64 & 18 & 0 & Bert et al. 2001 \\
\hline Bolivien-Tiefland (Pool) & 26 & 8 & 54 & 19 & 24 & 50 & 6 & 1 & Bert et al. 2004 \\
\hline Tiwanaku $(M H)$ & 68 & 5 & 13 & 8 & 15 & 23 & 23 & 31 & Rothhammer et al. 2003 \\
\hline \multicolumn{10}{|l|}{ Paraguay } \\
\hline Ayoreo & 50 & 11 & 91 & 0 & 0 & 84 & 16 & 0 & Dornelles et al. 2004 \\
\hline Ache & 52 & 12 & 63 & 10 & 90 & 0 & 0 & 0 & Schmitt et al. 2004 \\
\hline \multicolumn{10}{|l|}{ Chile } \\
\hline Aymara-2 (Aymara) & 67 & 5 & 120 & 7 & 57 & 18 & 16 & 2 & Rocco et al. 2002 \\
\hline Atacameno-1 & 30 & 10 & 50 & 11 & 72 & 11 & 6 & 0 & Merriwether et al. 1995 \\
\hline Atacameno-2 & 31 & 10 & 23 & 9 & 61 & 26 & 4 & 0 & Rocco et al. 2002 \\
\hline Pehuenche-1 & 32 & 13 & 100 & 2 & 9 & 37 & 52 & 0 & Merriwether et al. 1995 \\
\hline Pehuenche-2 & 33 & 13 & 105 & 3 & 11 & 41 & 46 & 0 & Moraga et al. 2000 \\
\hline Mapuche-2 & 34 & 13 & 111 & 0 & 7 & 44 & 49 & 0 & Moraga et al. 2000 \\
\hline Huilliche & 35 & 13 & 80 & 4 & 29 & 19 & 49 & 0 & Merriwether et al. 1995 \\
\hline Carelmapu & 36 & 13 & 47 & 4 & 30 & 38 & 26 & 2 & Garcia et al. 2006 \\
\hline Quetal.mahue & 37 & 15 & 42 & 0 & 31 & 36 & 26 & 7 & Garcia et al. 2006 \\
\hline Detif & 38 & 15 & 27 & 11 & 22 & 37 & 30 & 0 & Garcia et al. 2006 \\
\hline Laitec & 39 & 15 & 42 & 0 & 0 & 36 & 57 & 7 & Garcia et al. 2006 \\
\hline Yaghan & 41 & 16 & 21 & 0 & 0 & 52 & 48 & 0 & Moraga et al. 2000 \\
\hline Chile-Coast (Archaikum) & 27 & 5 & 14 & 50 & 36 & 7 & 7 & 0 & Moraga et al. 2005 \\
\hline Chile-Coast (MH) & 28 & 5 & 19 & 32 & 42 & 26 & 0 & 0 & Moraga et al. 2005 \\
\hline Chile-Coast (LIP/Inca) & 29 & 5 & 15 & 20 & 53 & 20 & 7 & 0 & Moraga et al. 2005 \\
\hline Tierra del Fuego-2 (19. Jh.) & 40 & 16 & 24 & 0 & 0 & 58 & 42 & 0 & Garcia-Bour et al. 2004 \\
\hline \multicolumn{10}{|l|}{ Argentinen } \\
\hline Punenos & 46 & 10 & 65 & 12 & 65 & 8 & 15 & 0 & Dipierri et al. 1998 \\
\hline Wichi & 47 & 11 & 99 & 16 & 46 & 13 & 24 & 0 & Cabana et al. 2006 \\
\hline Pilaga & 48 & 11 & 38 & 11 & 32 & 29 & 29 & 0 & Cabana et al. 2006 \\
\hline Toba & 49 & 11 & 67 & 18 & 43 & 4 & 34 & 0 & Cabana et al. 2006 \\
\hline Gran Chaco (Pool) & 51 & 11 & 240 & 11 & 48 & 11 & 28 & 2 & Torroni 1993/ Bianchi 1995/ Demarchi 2001 \\
\hline Mapuche-1 & 44 & 14 & 58 & 5 & 31 & 21 & 30 & 13 & Ginther et al. 1993 \\
\hline Mapuche-3 & 45 & 14 & 97 & 8 & 34 & 22 & 29 & 7 & Goicoeohea et al. 2001 \\
\hline Tehuelche & 43 & 17 & 29 & 0 & 21 & 24 & 55 & 0 & Goicoeohea et al. 2001 \\
\hline Tierra del Fuego-1(19. Jh.) & 42 & 16 & 45 & 0 & 0 & 42 & 56 & 2 & Lalueza et al. 1997 \\
\hline
\end{tabular}


Tab. 11: Verwendete Referenzpopulationen mit Daten aus der HVR I Region des mitochondrialen Genoms (No = Nummer der Referenzpopulation vgl. Abb. 29 / Reg = Regionalgruppe vgl. Abb. 30/ $\mathbf{n}=$ Anzahl der Individuen)

\begin{tabular}{l|ccc:l}
\hline \multicolumn{1}{c}{ Population } & No & Reg & n & \multicolumn{1}{c}{ Quelle } \\
\hline Yanomami & 1 & 7 & 155 & Williams et al. 2002 \\
Gaviao & 6 & 8 & 5 & Ward et al. 1996 \\
Zoro & 7 & 8 & 29 & Ward et al. 1996 \\
Xavante & 8 & 8 & 25 & Ward et al. 1996 \\
San Martin & 2 & 4 & 22 & Fuselli et al. 2003 \\
Ancash & 3 & 4 & 34 & Lewis et al. 2005 \\
Tayacaja & 4 & 5 & 60 & Fuselli et al. 2003 \\
Arequipa & 5 & 5 & 22 & Fuselli et al. 2003 \\
Bolivien Tiefland (Pool) & 9 & 8 & 53 & Bert et al. 2004 \\
Gran Chaco (Pool) & 10 & 11 & 169 & Cabana et al. 2006 \\
Ache & 11 & 12 & 63 & Schmitt et al. 2004 \\
Guarani & 12 & 12 & 200 & Marrero et al. 2007 \\
Kaingang & 13 & 12 & 74 & Marrero et al. 2007 \\
Pehuenche & 14 & 13 & 24 & Moraga et al. 2000 \\
Mapuche & 15 & 13 & 34 & Moraga et al. 2000 \\
Yaghan & 16 & 16 & 15 & Moraga et al. 2000 \\
\hline
\end{tabular}

Tab. 12: Einteilung und Beschreibung der in dieser Arbeit festgelegten kulturellen Großräume (Region 1-17 / vgl. auch Abb. 30) unter Angabe der sich in diesen Regionen gruppierenden mt-Haplogruppen Referenzpopulationen ( $\mathbf{n}=$ Anzahl der Individuen in der jeweiligen Regionalgruppe / rezente Populationen: in der Gruppe integrierte Populationen - vgl. Tab. 10/ aDNA-Datensätze: vgl. Tab. 10). Die Regionalgruppe 5 wurde in Qechua und Aymara sprechende Referenzpopulationen aufgeteilt.

\begin{tabular}{|c|c|c|c|c|c|}
\hline Region & & $\mathbf{n}$ & Beschreibung & $\begin{array}{c}\text { rezente } \\
\text { Populationen }\end{array}$ & $\begin{array}{c}\text { aDNA } \\
\text { Datensätze }\end{array}$ \\
\hline 1 & & 335 & nordwestliches Kolumbien, Übergangsbereich zu Mittelamerika & 1 & \\
\hline 2 & & 59 & südamerikanische Nordküste & 2 & \\
\hline 3 & & 73 & nördliche Anden & $3 ; 4$ & \\
\hline 4 & Qechua & 159 & nördlicher Zenralandenraum & $5-9$ & \\
\hline 5 & Qechua & 164 & südlicher Zentralandenraum (Qechua-Sprecher) & $10-12 ; 14 ; 27$ & $15 ; 17 ; 27-29$ \\
\hline 5 & Aymara & 339 & südlicher Zentralandenraum (Aymara-Sprecher) & $13 ; 24 ; 25 ; 67$ & \\
\hline 6 & & - & Peru Westküste & - & 16 \\
\hline 7 & & 804 & Llanos; nördliche Amazonasregion & $59-66$ & \\
\hline 8 & & 232 & Amazonia; südliche Amazonasregion & $21-23 ; 26 ; 55-58$ & \\
\hline 9 & & 89 & östlicher Andenfuß (Bolivien) & $18-20$ & \\
\hline 10 & & 138 & südliche Anden (Nord-Chile, -Argentinien) & $30-31 ; 46$ & \\
\hline 11 & & 535 & Gran Chaco Region & $47-51$ & \\
\hline 12 & & 341 & südliches brasilianisches Hochland & $52-54$ & \\
\hline 13 & & 443 & südlichster Andenraum / mittleres Chile & $32-36$ & \\
\hline 14 & & 155 & Pampa & $44-45$ & \\
\hline 15 & & 111 & westliches Patagonien (Chile) & $37-39$ & \\
\hline 16 & & 90 & Feuerland / südamerikanische Südspitze & $40-42$ & \\
\hline 17 & & 29 & östliches Patagonien (Argentinien) & 43 & \\
\hline
\end{tabular}




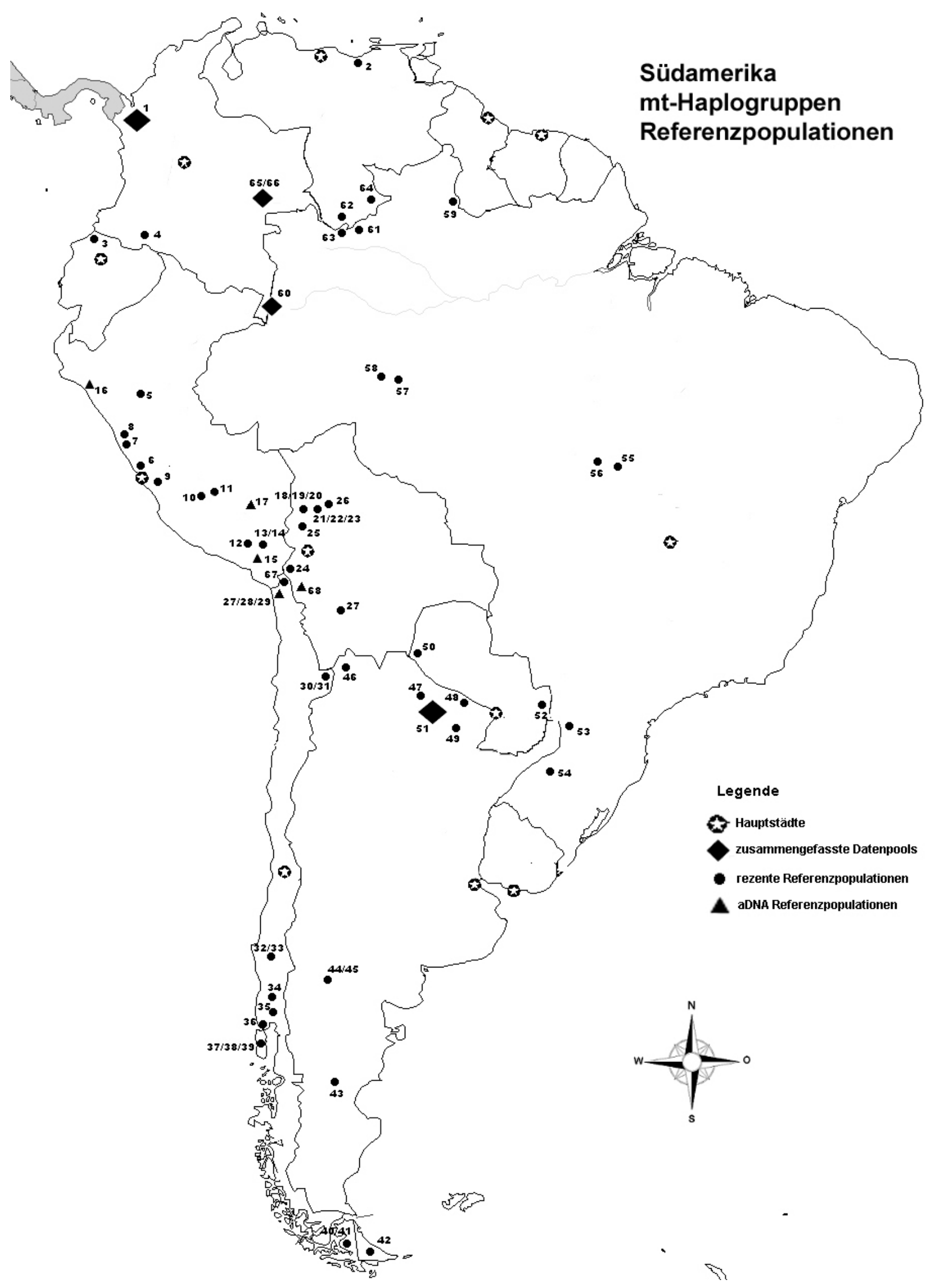

Abb. 28: Kartierung der südamerikanischen indigenen mt-Haplogruppen Referenzpopulationen (vgl. Tab. 10 für die Zuweisung der Populationen zu den Nummern). 


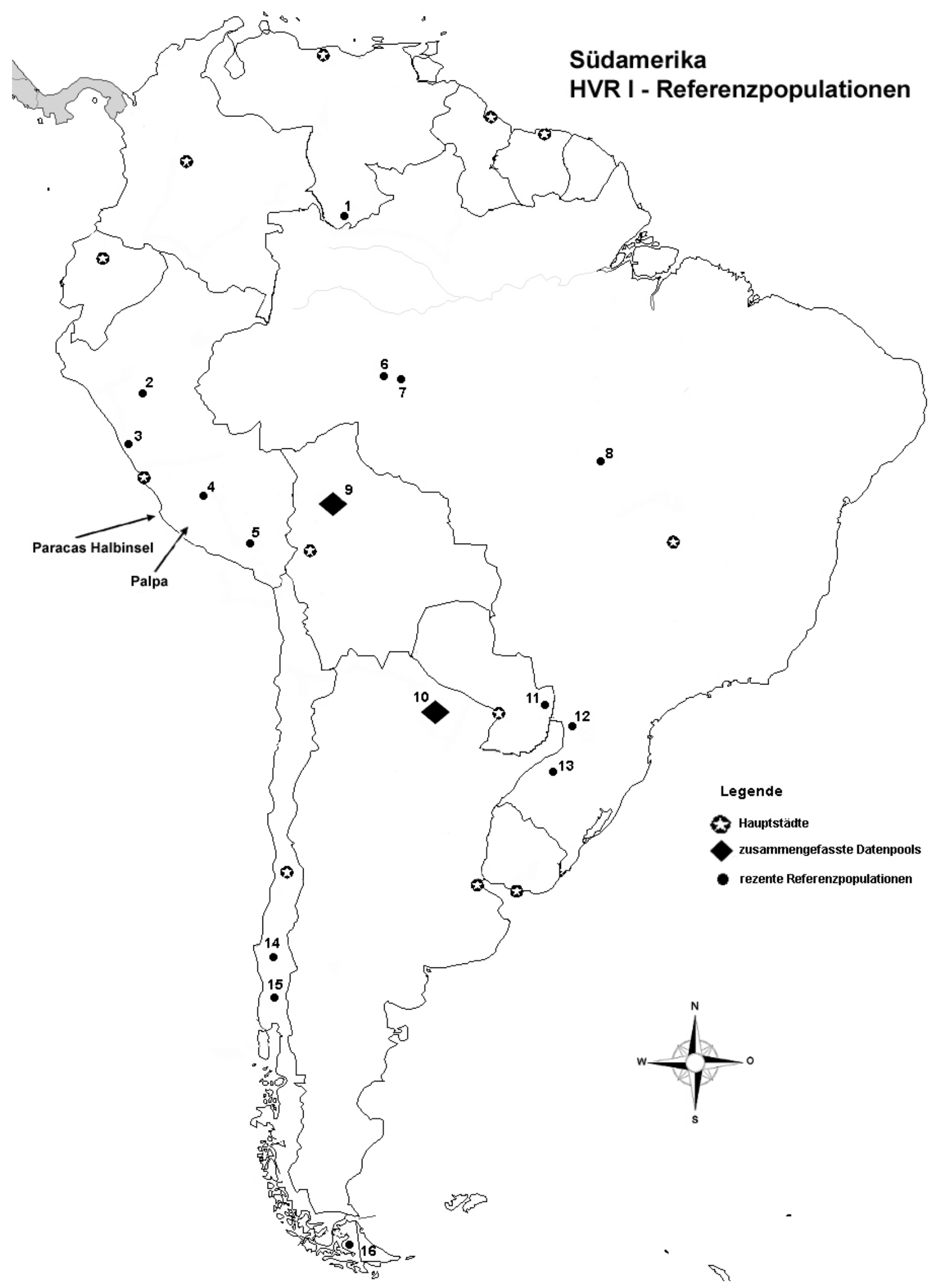

Abb. 29: Kartierung der südamerikanischen indigenen HVR I-Sequenzdaten Referenzpopulationen (vgl. Tab. 11 für die Zuweisung der Populationen zu den Nummern). 


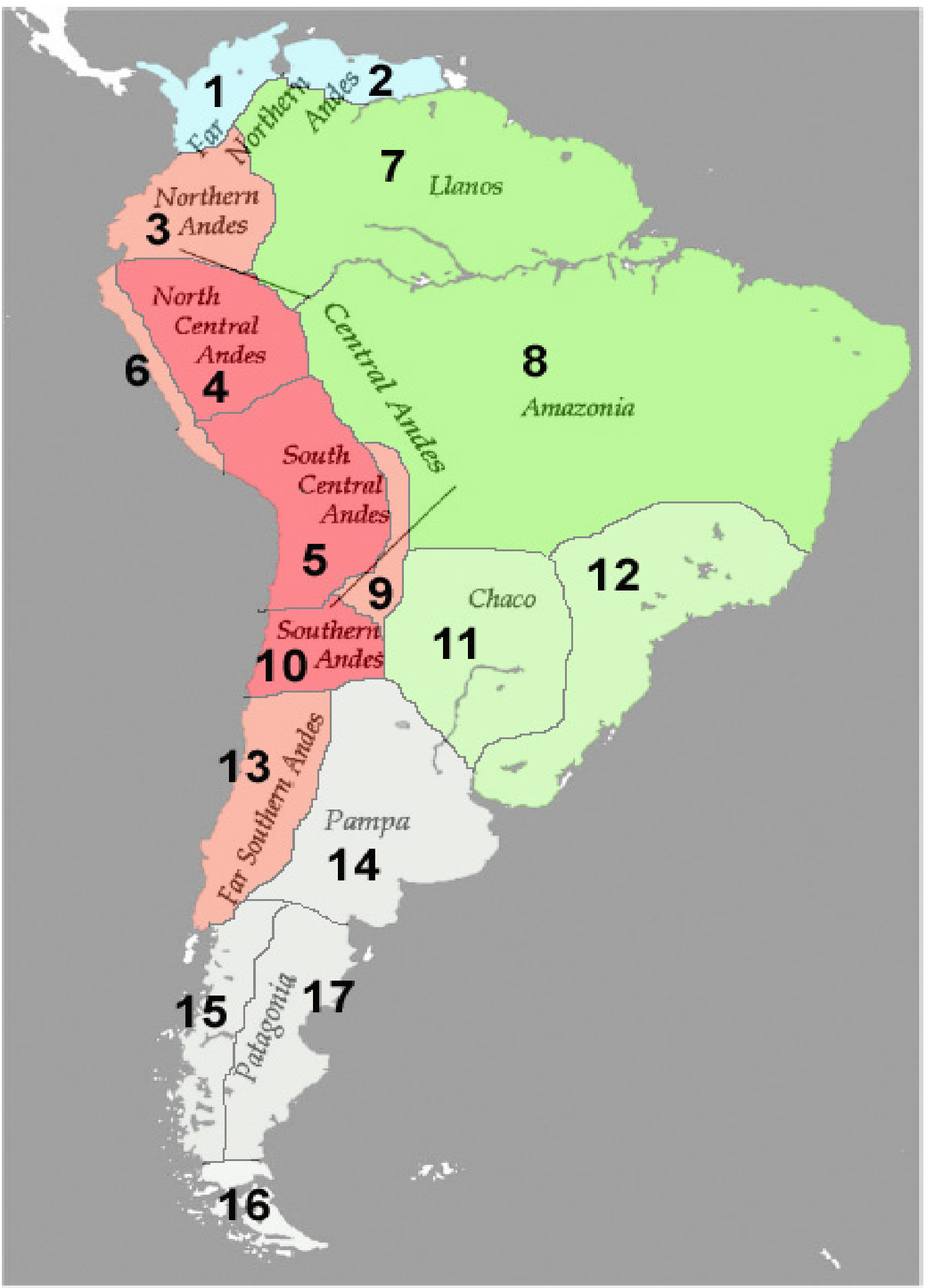

Abb. 30: Geographische und kulturelle Großräume Südamerikas. Die Zuweisung und Entschlüsselung der Regionalcodes (Reg.) sind Tab. 12 zu entnehmen. Die Farbgebungen beschreiben kulturelle Einflusssphären. Rot $=$ Hauptausbreitung der Inka, Hellrot = Peripherie; Dunkelgrün: Oberes und unteres Amazonasgebiet $/$ kulturen. Hellgrün: Parklandschaften in Peripherie der Amazonaskulturen; Grau: Südlicher südamerikanischer Kulturraum; Hellblau: Karibisch- / mesoamerikanischer Kontaktbereich (Karte nach Stanish 2001; Fig. 1) 


\subsection{Untersuchte Genorte}

In den folgenden Kapiteln sollen kurz die in dieser Arbeit untersuchten Genorte beschrieben werden. Detaillierte Informationen $\mathrm{zu}$ den genetischen Typisierungsmarkern und den spezifischen Eigenschaften bzw. möglichen Analyseschwierigkeiten sind dem Kapitel $2.2 \mathrm{zu}$ entnehmen.

\subsubsection{Mitochondriale Genorte}

Der Schwerpunkt dieser Arbeit liegt auf der Untersuchung mitochondrialer Genorte. Ziel ist die Determinierung der mitochondrialen Haplogruppen und Haplotypen der untersuchten Individuen zur Rekonstruktion der maternalen Populationsdynamik im Untersuchungsgebiet. Aufgrund der maternalen Vererbung und der ausbleibenden Rekombination können mitochondriale Linien nahezu unverändert über viele Generationen nachvollzogen werden und ermöglichen so eine Studie von Genealogien, die über lange Zeitspannen verlaufen. Ein weiterer Vorteil der Untersuchung mitochondrialer DNA aus prähistorischem Probenmaterial ist die hohe Kopienzahl in Zellen, welche die Wahrscheinlichkeit erhöht, dass genügend amplifizierbare Moleküle in den beprobten Knochen erhalten sind.

Die Bestimmung der Haplotypen erfolgt über die Untersuchung von Sequenzabschnitten der mitochondrialen Control-Region bzw. Kontrollregion. Die Kontrollregion ist ein nichtcodierender Abschnitt. Damit ist er für populationsgenetische Studien sehr geeignet, da bei Regionen, auf denen ein Funktionsdruck liegt, die Gefahr besteht, dass sich in den Sequenzen eher die Folgen der Selektion als die Genealogie einer Population widerspiegeln. Eine Beschreibung der möglichen Analyseprobleme, die bei der Untersuchung dieses Genortes auftreten können, sind Kapitel 2.2.1 und 2.2.2 zu entnehmen. In der vorliegenden Arbeit wird für die Bestimmung der Haplotypen ausschließlich die hypervariable Region I (HVR I) und nicht die hypervariable Region II (HVR II) untersucht. Diese Entscheidung resultiert zum einen daraus, dass für Südamerika so gut wie keine Vergleichsdaten der HVRII vorliegen und zum anderen daraus, dass der zusätzliche Informationsgewinn aus der Untersuchung dieser Region für die spezifische Fragestellung als gering anzusehen ist. Konkret erfolgt die Analyse eines 388bp langen Sequenzabschnittes der HVRI (np 16021-16408). Mögliche Polymorphismen beschreiben Abweichungen in der Sequenzabfolge von der allgemein anerkannten revised Cambridge-Reference-Sequence ( $r C R S$ ) nach Anderson et al. 1981, überarbeitet von Andrews et al. 1999 mit der GenBank-Accession Number AC_000021.2. Die Benennung der Polymorphismen erfolgt nach der von Bandelt und Parson (2006) vorgeschlagenen Nomenklatur für die mitochondriale Kontrollregion. 
Die Bestimmung der mitochondrialen Haplogruppen erfolgt zum einen über die charakteristischen Polymorphismen in der HVRI (vgl. Tab. 7 / Kap. 2.3.2) und zum anderen über die spezifischen, im codierenden Abschnitt des mitochondrialen Genoms liegenden Polymorphismen der vier indigenen amerikanischen mt-Haplogruppen (A, B, C und D). Die Gruppen A, C und D werden hier jeweils durch einen SNP charakterisiert (vgl. Abb. 31) und B durch eine 9 bp Deletion der Nukleotidpositionen 8272 - 8280 (Merriwether et al. 1995; Herrnstadt et al. 2002). Die zusätzliche Bestimmung der Haplogruppen über die Polymorphismen der codierenden Region erfolgt zur Authentifizierung der Ergebnisse aus der HVR I, da die schnell evolvierenden mutational Hotspots in der Kontrollregion und möglichen postmortalen Sequenzveränderungen ein Risiko für Fehlbestimmungen darstellen (vgl. Kap. 2.2.1).

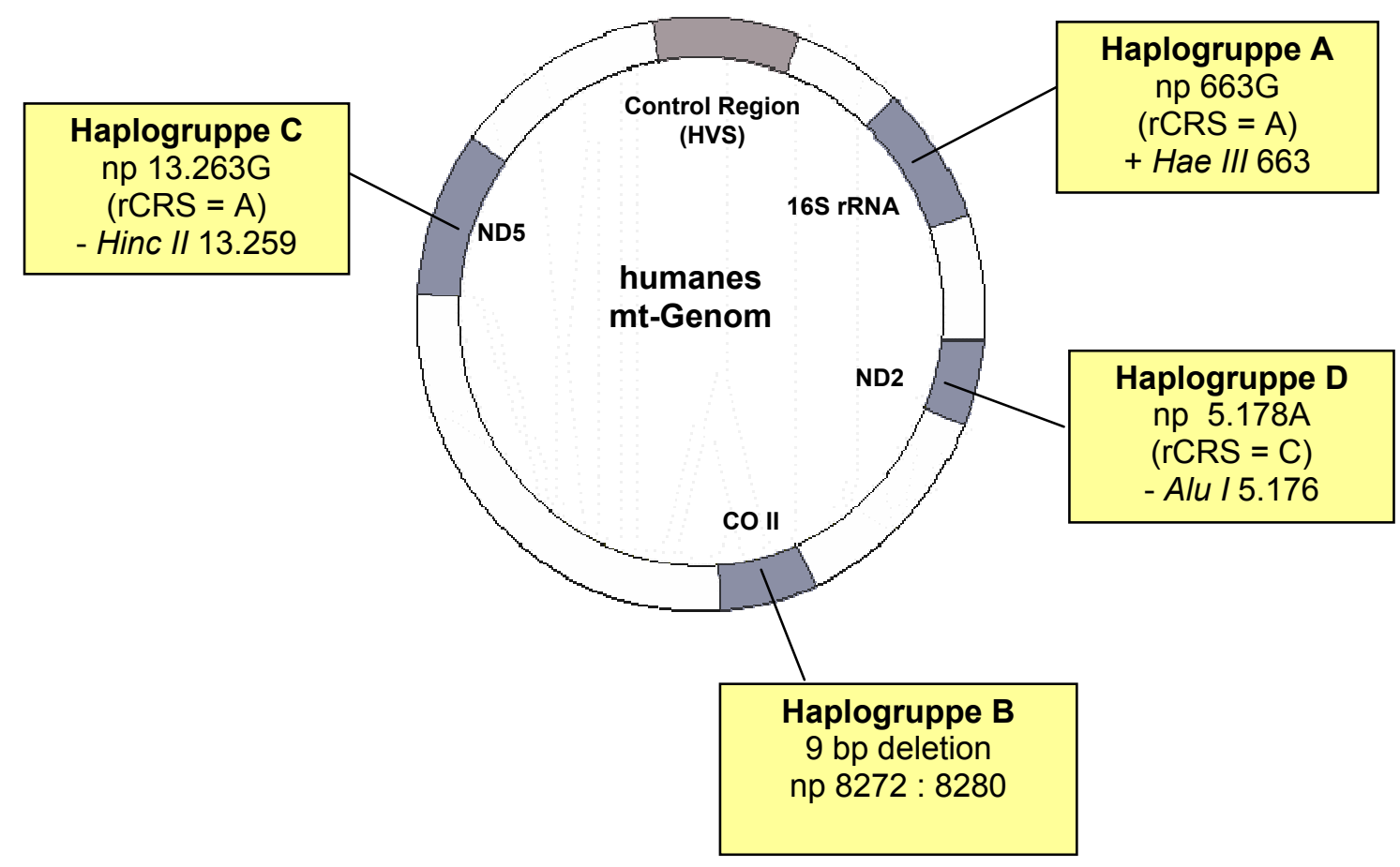

Abb. 31: Lage und Ausprägung der haplogruppendeterminierenden Polymorphismen in der codierenden Region des mitochondrialen Genoms. In den Kästen findet sich die Haplogruppe und die untersuchte Nukleotidposition unter Angabe der für die Gruppe charakteristischen Base (Bsp. 663G). Die unterste Zeile beschreibt die mit dem Polymorphismus verbundene RFLP-Schnittstelle (vgl. Torroni et al. 1993).

\subsubsection{Chromosomale Genorte}

Im Rahmen dieser Arbeit werden außer mitochondrialen Markern auch Y-chromosomale SNPs und STRs und autosomale STRs untersucht. Aus Gründen der Arbeitsökonomie werden diese nuklearen Marker lediglich an solchen Proben untersucht, welche durch die erfolgreiche Amplifikation mitochondrialer Abschnitte auch einen möglichen Erhalt nuklearer DNA in 
Aussicht stellen. Die Untersuchung der Y-chromosomalen Marker erfolgt zur Rekonstruktion der paternalen Populationsdynamik im Untersuchungsgebiet. Die autosomalen STRs dienen der Erstellung eines genetischen Fingerabdruckes. Durch den hohen individualspezifischen Charakter und den Vererbungsweg der autosomalen STRs ist es möglich, genealogische Beziehungen z.B. von Individuen aus einem Grabzusammenhang zu rekonstruieren und damit Aussagen über Bestattungssitten (z.B. Familiengräber) aber auch den Erbcharakter von Prestige (z.B. mögliche Verwandtschaft der Individuen aus den Großgräbern in La Muña) zu treffen.

Die Y-chromosomalen Haplogruppen werden durch die Analyse von binären Markern (SNPs) des nichtrekombinierenden Anteils des Chromosoms (NRY) bestimmt (vgl. Kap. 2.2.3). In dieser Arbeit werden die vier SNPs untersucht, welche die in indigenen amerikanischen Populationen anzutreffenden Haplogruppen determinieren. Dabei handelt es sich um die Gruppen C (Bergen et al. 1999), P (Karafet et al. 1997) und die sich daraus ableitenden Haplogruppen Q (Seielstad et al. 2003) und Q3 (Karafet et al. 1997). In Abbildung 32 findet sich der phylogenetische Baum der Y-chromosomalen Haplogruppen und die determinierenden Polymorphismen. Die Benennung erfolgt nach der Nomenklatur des Y-Chromosome Consortiums (2002).

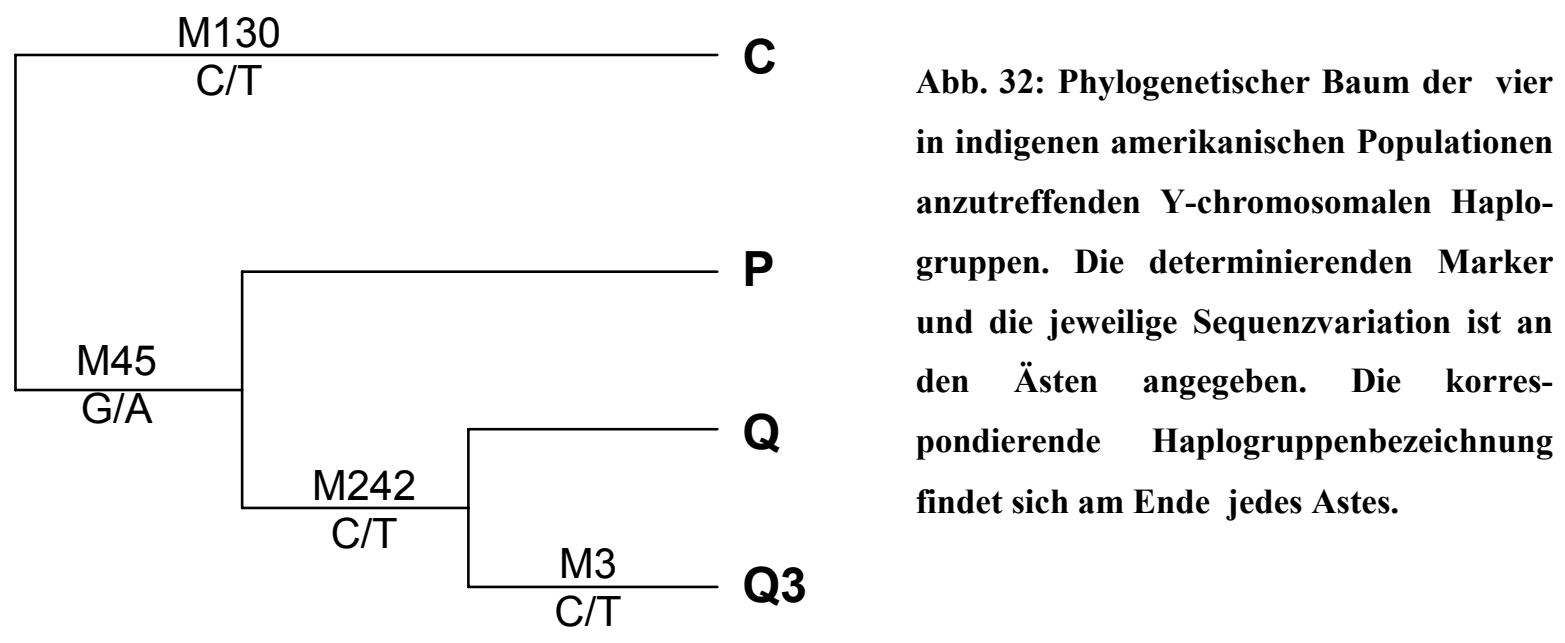

Die Bestimmung des Y-chromosomalen Haplotyps erfolgt über die Analyse von Y-STRs. Aufgrund der geringen Aussagekraft nur eines dieser Systeme sollten zur Bestimmung von Haplotypen möglichst viele polymorphe Loci gleichzeitig untersucht werden (Buttler 2005). Die internationale Konvention benennt neun Y-STRs, die vorwiegend für die Y-Haplotypisierung analysiert werden sollen (DYS19, DYS389I, DYS389II, DYS390, DYS391, DYS392, DYS393, DYS385 a und b). Diese STRs bilden den minimal haplotype und sind allesamt hoch oder mäßig polymorph (Roewer et al. 2001). Diese Konvention erlaubt den Abgleich internationaler Ergebnisse für vergleichende populationsgenetische Analysen. Als Vergleichsgrundlage für die 
Allelfrequenzen der STRs in verschiedenen Populationen dient die Y Chromosome Haplotype Reference Database (Abk. YHRD, http://www.yhrd.org/index.html, 19.01.08). Dieser Quelle sind auch weitere Informationen zu den verschiedenen STRs zu entnehmen. Die Haplotypen bieten, wie auch bei der mitochondrialen DNA, eine höhere Auflösung der Daten als die Haplogruppen. Im Falle der Y-chromosomalen Marker ist allerdings zu bemerken, dass die SNPs durch die Möglichkeit der Analyse kurzer Amplifikationsprodukte (120-140bp) bei der Anwendung auf prähistorisches degradiertes Probenmaterial eine höhere Erfolgsaussicht bieten als die bis zu 250bp langen Wiederholungseinheiten der STRs (Bouakaze et al. 2007). Für Südamerika liegen auch nur sehr wenige Vergleichsdaten zu Y-STRs vor. Dementsprechend haben Y-STRs in der vorliegenden Arbeit auch nur einen unterstützenden Charakter.

Die Klärung direkter verwandtschaftlicher Verhältnisse der untersuchten Individuen untereinander über die Analyse autosomaler STRs hat hier nur eine untergeordnete Bedeutung. Durch den individualisierenden Charakter des genetischen Fingerabdrucks ist allerdings auch eine Authentifizierung von DNA-Extrakten und damit Typisierungsergebnissen aus diesen Extrakten möglich (vgl. Kap. 3.7) Einige der untersuchten STRs weisen darüber hinaus populationsspezifische Allelfrequenzen auf, womit sie ein zusätzliches Werkzeug für die populationsgenetische Analyse sind. Allelfrequenzen, Nomenklatur und alle weiteren wichtigen Daten zu den autosomalen STRs können der Short Tandem Repeat DNA Internet DataBase (Abk.: STRbase; http://www.cstl.nist.gov/div831/strbase/; Ruitberg et al. 2001) entnommen werden. In der vorliegenden Arbeit werden sieben STRs untersucht (D3S1358, D5S818, D13S317, D21S11, CSF1PO, FGA, VWA). Die zu amplifizierenden Fragmentlängen und weitere Amplifikationsparameter für die Analyse dieser Systeme wurden in vorhergehenden Arbeiten der Paläogenetik-Arbeitsgruppe in der Abteilung für Historische Anthropologie und Humanökologie, Göttingen, auf die spezifischen Eigenschaften von aDNA angepasst (Schilz 2006). Zusätzlich wird der geschlechtsspezifische Längenpolymorphismus im Amelogenin-Gen, das auf dem X- und dem Y-Chromosom liegt, untersucht (Sullivan et al. 1993). Hierdurch wird eine molekulare Geschlechtsbestimmung ermöglicht.

\subsection{Probenvorbereitung und DNA-Extraktion}

Die DNA-Extraktion nimmt in der aDNA-Analytik eine Schlüsselstellung ein. Die geringe Zahl analysierbarer Zielsequenzen und andere Degradierungserscheinungen alter DNA, aber auch die häufig gegebene Limitierung des verfügbaren Probenmaterials und potentiell enthaltene PCRInhibitoren machen effiziente und materialsparende Extraktionsmethoden notwendig. Der Extraktionserfolg und die Qualität der Extrakte determinieren die Möglichkeit, weiterführende molekulargenetische Untersuchungen durchzuführen. 
Die Probenaufnahme und Dokumentation erfolgte in Peru (vgl. Kap. 3.1.2). Nach der Ankunft des Probenmaterials in Deutschland wurde es umgehend in einer Kühlkammer bei einer Temperatur von $-20^{\circ} \mathrm{C}$ eingelagert. Für die DNA-Extraktion muss ein Teil des Probenmaterials pulverisiert werden. Für eine erfolgreiche DNA-Extraktion aus Knochen- und Zahnmehl sind ca. 100 bis 300 mg Pulver notwendig (Hummel 2003).

Die Knochenelemente oder Zähne wurden mit einer Dentalbohrmaschine (Typ K10, KaVo) mit Diamantsägeblattaufsatz in die gewünschte Größe zersägt bzw. im Falle von Zähnen, die Wurzel von der Krone getrennt. Anschließend wurden mit dem Diamantsägeblatt die Oberflächen des Probenmaterials großzügig abgetragen, um Verunreinigungen bzw. eventuell anhaftende Kontaminationen zu entfernen. Da bei Zähnen die für eine DNA-Extraktion wichtigen Zellen im Wesentlichen in den Wurzeln vorliegen, wurden nur diese für die Weiterverarbeitung verwendet. Die Zahnkronen wurden für die Untersuchung schwerer Isotopen an die Arbeitsgruppe Hölzl und Horn der Universität München weitergegeben. Die Weiterverarbeitung der Probenmaterialien bis zum Zahn- bzw. Knochenmehl erfolgte wie bei Hummel (2003) beschrieben.

Vor dem eigentlichen Extraktionsprozess wurde das homogenisierte Knochen- und Zahnmehl vorbereitenden Schritten zur Dekalzifizierung und Zelllyse unterzogen. Dafür wurden 100-200 mg Pulver mit einer Feinwaage in ein $2 \mathrm{ml}$ Reaktionsgefäß (SafeLock, Eppendorf) abgewogen und mit $500 \mu \mathrm{l}$ des Komplexbildners EDTA (0,5M; pH8) versetzt. Anschließend erfolgte eine Inkubation des Gemisches für $18 \mathrm{Std}$. bei $37^{\circ} \mathrm{C}$ unter permanenter Invertierung in einem Rotator (ST-1, Steward). Zur Zelllyse wurde das Gemisch dann mit $20 \mu 1$ Proteinase K $(20 \mathrm{mg} / \mathrm{ml}$, Qiagen) versetzt und weitere $2 \mathrm{Std}$. bei $56^{\circ} \mathrm{C}$ in einem Thermomixer (Eppendorf) inkubiert. Nach abschließender Zentrifugation für 4min bei $6000 \mathrm{U} / \mathrm{min}$ (Minispin, Eppendorf) wurden $200 \mu 1$ vom flüssigen Überstand abgenommen und in die automatisierte DNA-Extraktion eingesetzt.

Die eigentliche Extraktion erfolgte automatisiert in einem Biorobot EZ1 (Qiagen). Der Vorteil dieses automatisierten Verfahrens gegenüber z.B. der häufig in der aDNA-Analytik eingesetzten manuellen Phenol-Chloroform-Extraktion liegt in der verminderten Möglichkeit zur Fremd-Kontamination während des Extraktionsprozesses. Darüber hinaus ermöglicht der Extraktionsroboter einen hohen Probendurchsatz in geringer Zeit und erstellt dabei Extrakte mit einem hohen Reinheitsgrad fast ohne PCR- Inhibitoren (Westenthanner 2007). Trotz der geringeren DNA-Ausbeute im Vergleich zur Phenol-Chloroform-Extraktion überwiegen die beschriebenen Vorteile und machen dieses Verfahren für die aDNA-Analytik besonders geeignet (Montpetit et al. 2005). Das Prinzip der EZ1-DNA-Extraktion basiert auf einer Guanidiumthiocyanat/ Guanidiumhydrochlorid-Extraktion, in der die DNA an silikatbeschichtete 
Magnetpartikel (magnetic beads) gebunden wird (Fa. Qiagen). Nähere Information zur genauen Funktionsweise dieser Extraktionsmethode sind in der Arbeit von Schmidt (2004) aufgeführt. Für die DNA-Extraktion wurde das forensic Protokoll für trace samples genutzt. Das endgültige Elutionsvolumen des Extraktes betrug $50 \mu \mathrm{l}$. Das Eluat wurde anschließend bei $-20^{\circ} \mathrm{C}$ eingefroren.

Zur Kontrolle möglicher Kontamination wurden von allen peruanischen Bearbeitern, sowie von allen Mitarbeitern des Göttinger Labors, die Kontakt zu dem Probenmaterial hatten, Mundschleimhautabstriche genommen. Die DNA aus den Abstrichen wurde mit der Chelex ${ }^{\circledR}$ 100-Methode (Biorad) extrahiert (Walsh et al. 1991).

\subsection{Amplifikationssysteme und Parameter für die Endpunkt PCR}

\subsubsection{HVR I -Analyse}

Um einen möglichst hohen Informationsgewinn zur populationsgenetischen Differenzierung der mitochondrialen Haplotypen zu erhalten, wurde ein 388bp langer Abschnitt der HVR I untersucht (np16021-16408). Hierfür wurde ein neues Analysesystem mit überlappenden PCRProdukten erstellt. Die insgesamt acht Primer des Systems wurden modular entwickelt, so dass durch die unterschiedliche Kombination der Primer entweder lange (434bp) mittlere (236 261bp) oder kurze (157-180bp) Amplifikationsprodukte generiert werden können (Abb. 33). Damit ist eine Anpassung an den spezifischen Fragmentierungsgrad der DNA in einer Probe möglich.

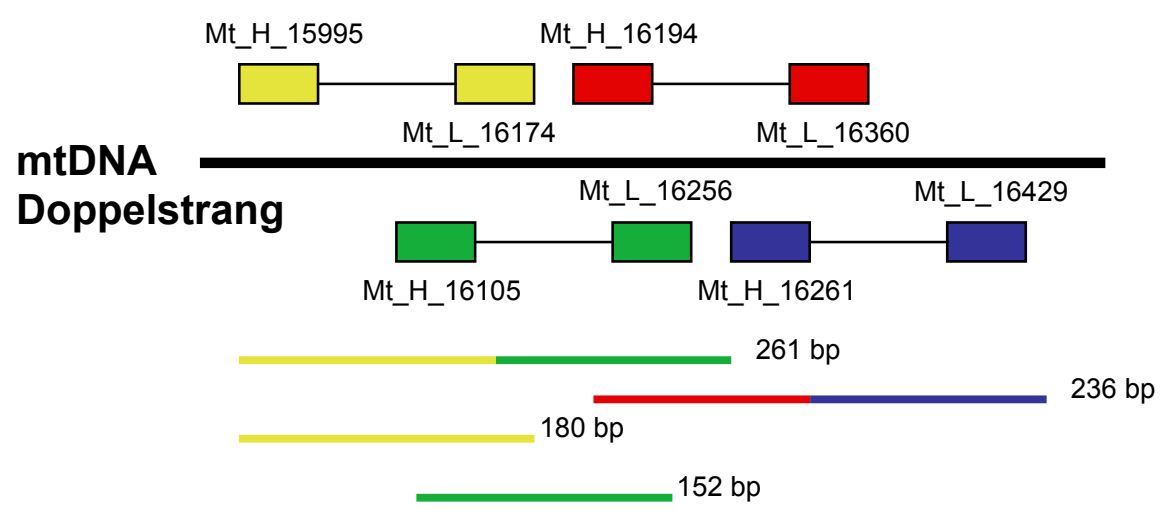

167 bp 169 bp

Abb. 33: Modulares Primerdesign und daraus resultierende Amplifikationsmöglichkeiten für die HVRI-Analyse. Durch verschiedene Kombinationen der acht Primer können Amplifikationsprodukte mit unterschiedlichen Fragmentlängen generiert werden. Auf diese Weise kann flexibel auf die sehr unterschiedliche DNA-Erhaltung des Probenmaterials reagiert werden. 
Das Primerdesign erfolgte nach der in Hummel (2003) beschriebenen Vorgehensweisen. Für die Erstellung der Primer wurde das Programm PrimerSelect (Lasergene Software Package, DNAStar) verwendet. Um nichtintentionale Primerfehlbindungen $\mathrm{zu}$ vermeiden, wurden die Bindungsbereiche der Primer so ausgewählt, dass sie weder für asiatische Populationen spezifische Mutationen aufweisen noch so genannte mutational hotspots enthalten (vgl. Kap. 2.2.1). In Tab. 13 finden sich die jeweiligen Primersequenzen. Die Produktlängen, die aus der Kombination der Primer entstehen, sind der Abbildung $33 \mathrm{zu}$ entnehmen, die Farben der Striche geben an, aus welchen Primerkombinationen sich die Produkte ergeben.

Tab. 13: Primer des HVR I -Analysesystems. Der Name der Primer setzt sich folgendermaßen zusammen: mt = mitochondrial, $\mathrm{H}$ = heavy chain, $\mathrm{L}$ = light chain, und einer Zahl, die das jeweilige 5 '-Ende des Primers nach der Nomenklatur von Anderson (1981) angibt.

\begin{tabular}{l|l|l}
\hline Primername & Primersequenz $\left(5^{\prime}\right.$-> 3') & Primerlänge \\
\hline mt_H_15995 & GCTAAGATTCTAATTTAAACTATTCT & $26 \mathrm{bp}$ \\
mt_L_16174 & GGATTGGGTTTTTATGTACTAC & $22 \mathrm{bp}$ \\
mt_H_16105 & TGCCAGCCACCATGAATATTGTAC & $24 \mathrm{bp}$ \\
mt_L_16256 & GCTTTGGAGTTGCAGTTGATGTGT & $24 \mathrm{bp}$ \\
mt_H_16194 & ATGCTTACAAGCAAGTACAGCAA & $23 \mathrm{bp}$ \\
mt_L_16360 & GAGAAGGGATTTGACTGTAATGTG & $24 \mathrm{bp}$ \\
mt_H_16261 & CCTCACCCACTAGGATACCAACAA & $24 \mathrm{bp}$ \\
mt_L_16429 & GCGGGATATTGATTTCACGGA & $21 \mathrm{bp}$ \\
\hline
\end{tabular}

Die Amplifikationen mit den verschiedenen Primerkombinationen erfolgten jeweils in Singleplex Ansätzen in einem Reaktionsvolumen von $50 \mu \mathrm{l}$ mit folgenden Komponenten und Konzentrationen:

- 10x Buffer II (50 mM KCl, 10 mM Tris-HCl; PE Applied Biosystems)

- $2 \mathrm{mM} \mathrm{MgCl} 2$ (PE Applied Biosystems)

- $175 \mu \mathrm{M}$ dNTPs (Sigma-Aldrich)

- 2,5 U AmpliTaqGold ${ }^{\mathrm{TM} D N A}$ Polymerase (PE Applied Biosytems)

- $\quad 0,2 \mu \mathrm{M}$ upper Primer (Operon)

- $\quad 0,2 \mu \mathrm{M}$ lower Primer (Operon)

- $1 \mu 1 \mathrm{BSA} 20 \mathrm{mg} / \mathrm{ml}$ (Roche)

- $5-15 \mu \mathrm{l}$ DNA-Extrakt (1 $\mu$ l für rezente Kontrollproben)

- HPLC $\mathrm{H}_{2} \mathrm{O}$ (Merck) zum Auffüllen des Reaktionsmixes auf das Endvolumen von $50 \mu \mathrm{l}$ 
Die PCR erfolgte in einem automatischen Thermocycler (Eppendorf - Mastercycler ${ }^{\mathrm{TM}}$ ) unter den in Tab. 14 angegebenen Bedingungen. Die weiterführende Analyse der Amplifikationsprodukte erfolgte durch Direktsequenzierung (Kap. 3.6.2).

Tab. 14: Amplifikationsparameter der HVR I - Amplifikationssysteme

\begin{tabular}{ccc} 
& Temperatur & Dauer \\
\hline Initiale Aktivierung & $94^{\circ} \mathrm{C}$ & $11 \mathrm{~min}$ \\
\hline Denaturierung & $94^{\circ} \mathrm{C}$ & $1 \mathrm{~min}$ \\
Hybridisierung & $57^{\circ} \mathrm{C}$ & $1 \mathrm{~min}$ \\
Elongation & $72^{\circ} \mathrm{C}$ & $1 \mathrm{~min}$ \\
& $35-45 \mathrm{Zyklen}$ & \\
\hline Soak & $10^{\circ} \mathrm{C}$ & $10 \mathrm{~min}$ \\
\hline
\end{tabular}

\subsubsection{Y-STRs}

Für die Analyse der Y-chromosomalen Haplotypen wurden sieben auf dem Y-Chromosom gelegene Systeme koamplifiziert. Hierfür wurde eine im Hause entwickelte Multiplex-PCR verwendet (Müller 2002). Die Primer für DYS389 amplifizieren zwei Systeme und der Marker DYS385 ist biallelisch, deshalb ermöglichen in diesem Fall sieben Primerpaare die Analyse von neun STRs (vgl. Kap. 3.2.2.). Die amplifizierten Fragmentlängen und die jeweiligen Primer des Systems wurden an die speziellen Anforderungen der aDNA-Analyse angepasst. Primersequenzen, Allele, Produktlängen etc. sind Müller (2002) und Hummel (2003) zu entnehmen. Die Angabe der analysierten STRs findet sich in Kapitel 3.2.2.

Die PCR-Reaktion erfolgte in einem $25 \mu$ Ansatz und setzte sich aus folgenden Komponenten zusammen:

- $\quad$ 12,5 $\mu$ l Qiagen ${ }^{\circledR}$ Multiplex PCR Kit

- $6 \mu 1$ Primerset (Primerkonzentrationen siehe Müller 2002)

- $6,5 \mu 1$ DNA-Extrakt

Die Amplifikation erfolgte in einem automatischen Thermocycler (Eppendorf - Mastercycler ${ }^{\mathrm{TM}}$ ), die Parameter sind Tab. 15 zu entnehmen. Die Y-PCR wurde mit Dreifarb-Fluoreszenztechnik analysiert. Dafür wurde je System einer der Primer mit einem Fluoreszenzfarbstoff markiert (6FAM, HEX, NED). 
Tab. 15: Amplifikationsparameter der Y-STR Nonaplex-PCR

\begin{tabular}{ccc} 
& Temperatur & Dauer \\
\hline Initiale Aktivierung & $95^{\circ} \mathrm{C}$ & $15 \mathrm{~min}$ \\
\hline Denaturierung & $94^{\circ} \mathrm{C}$ & $1 \mathrm{~min}$ \\
Hybridisierung & $53^{\circ} \mathrm{C}$ & $1 \mathrm{~min}$ \\
Elongation & $72^{\circ} \mathrm{C}$ & $1 \mathrm{~min}$ \\
& $45 \mathrm{Zyklen}$ & \\
\hline Finale Elongation & $60^{\circ} \mathrm{C}$ & $30 \mathrm{~min}$ \\
Soak & $10^{\circ} \mathrm{C}$ & $10 \mathrm{~min}$ \\
\hline
\end{tabular}

\subsubsection{Autosomale STRs und Amelogenin}

Die Analyse der autosomalen STRs (Kap. 3.2.2) und des längenpolymorphen Bereichs im Intron 1 des Amelogenin-Gens erfolgte mit einer Oktaplex-PCR. Dieses Analysesystem wurde von Schilz (2006) speziell für die Anwendung auf aDNA einwickelt. Primersequenzen, konzentrationen, Allele und Produktlängen sind der Arbeit von Schilz zu entnehmen. Die PCRReaktion erfolgte in einem $25 \mu 1$ Ansatz mit folgenden Komponenten:

- $\quad$ 12,5 $\mu$ l Qiagen ${ }^{\circledR}$ Multiplex PCR Kit

- 3,8 $\mu 1$ Primerset (Primerkonzentrationen siehe Schilz 2006)

- $5-8,7 \mu 1$ DNA-Extrakt

- HPLC $\mathrm{H}_{2} \mathrm{O}$ (Merck) zum Auffüllen des Reaktionsmixes auf das Endvolumen von $25 \mu 1$

Für die Amplifikation wurde ein automatischer Thermocycler (Eppendorf - Mastercycler ${ }^{\mathrm{TM}}$ ) und die in Tab. 16 angegebenen Parameter verwendet. Die Oktaplex-PCR wurde wie die YMulitplex-PCR mit Dreifarb-Fluoreszenztechnik analysiert (Fluoressenzmarkierungen: 6-FAM, HEX, NED). 
Tab. 16: Amplifikationsparameter der Oktaplex-PCR

\begin{tabular}{ccc} 
& Temperatur & Dauer \\
\hline Initiale Aktivierung & $95^{\circ} \mathrm{C}$ & $15 \mathrm{~min}$ \\
\hline Denaturierung & $94^{\circ} \mathrm{C}$ & $1 \mathrm{~min}$ \\
Hybridisierung & $53^{\circ} \mathrm{C}$ & $1 \mathrm{~min}$ \\
Elongation & $72^{\circ} \mathrm{C}$ & $1 \mathrm{~min}$ \\
& $45 \mathrm{Zyklen}$ & \\
\hline Finale Elongation & $60^{\circ} \mathrm{C}$ & $30 \mathrm{~min}$ \\
Soak & $10^{\circ} \mathrm{C}$ & $10 \mathrm{~min}$ \\
\hline
\end{tabular}

\subsection{Amplifikation und SNP-Analysen mit der Real-Time PCR}

\subsubsection{Real-Time PCR}

Das generelle Prinzip der Amplifikation mit der Real-Time PCR unterscheidet sich nicht von der konventionellen (Endpunkt) PCR. Die Real-Time PCR oder kurz qRT-PCR (quantitative RealTime PCR) bietet darüber hinaus aber die Möglichkeit der Echtzeitbeobachtung des Amplifikationsprozesses und der abschließenden Quantifizierung. Dieses wird durch den Einsatz mit DNA interkalierender Farbstoffe wie Ethidiumbromid oder SYBR $^{\circledR}$ Green oder sequenzspezifischer molekularer Sonden möglich. Die Emmissionsfluoreszenz dieser Farbstoffe bzw. Sonden verstärkt sich proportional zur Menge der akkumulierten PCR-Produkte. Die eingesetzten Real-Time Cycler detektieren das Fluoreszenzsignal in verschiedenen zeitlichen und prozessualen Abständen und wandeln es über eine Software in Amplifikationskurven um, die den Vermehrungsprozess der DNA bildlich festhalten (Wittwer et al. 1997). Am Ende des PCR-Prozesses wird anhand der in der exponentiellen Phase der PCR gemessenen Fluoreszenzdaten die Ausgangskopienzahl der Probe quantifiziert. Für detaillierte Informationen über die Quantifizierung mit der qRT-PCR sei an dieser Stelle auf Westenthanner (2007) und Adler (2007) verwiesen. Durch den Einsatz von sequenzspezifischen molekularen Sonden in der Amplifikation ist es außerdem möglich, anhand von Schmelzkurvenanalysen Mutationen bzw. SNPs mit der qRT-PCR zu typisieren. In der vorliegenden Arbeit wurde dieses Prinzip genutzt, um mitochondriale und y-chromosomale SNPs zu analysieren (vgl. Kap 3.2). In den folgenden Kapiteln sollen das grundlegende Verfahren, die Funktionsweise der verwendeten Hybridisierungssonden und die entwickelten Analyseassays vorgestellt werden. 


\subsubsection{Genotypisierung mit Hybridisierungssonden für die qRT-PCR}

Die Funktion der hier verwendeten molekularen Sonden basiert auf dem Prinzip des Fluoreszenz Resonanz Energietransfer (kurz: FRET). Hierbei gibt ein durch eine Lichtquelle angeregter Donor Energie an einen sich in der Nähe befindenden Akzeptor ab, der dadurch beginnt, selber ein Fluoreszenzsignal zu emittieren. Nimmt der Abstand zwischen Akzeptor und Donor zu, verringert sich die Intensität des Fluoreszenzsignals des Akzeptors, während das des Donors zunimmt.

Das Hybridisierungssonden Format $\left(\mathrm{HybProbe}^{\mathrm{TM}}\right)$, das speziell für die Anwendung auf dem LightCycler ® System für Real-Time PCR (Roche) entwickelt wurde, nutzt das FRET-Prinzip, in dem zwei Oligonukleotide, die nebeneinander binden können, an den jeweiligen aufeinander gerichteten Enden mit Fluophoren versehen werden. Eines der Oligonukleotide wird mit dem kurzwelligen Farbstoff Fluorescein, das andere mit dem langwelligeren Farbstoff LightCycler ${ }^{\circledR}$ Red versehen. Das Fluorescein wird mittels blauen Lichts angeregt, seine Energie strahlungslos an den langwelligeren Farbstoff abzugeben, der dadurch ein rotes Licht emittiert. Dieses Signal kommt nur zustande, wenn beide Sonden in räumlicher Nähe binden. Das verwendete LightCycler® 2.0 System (Roche) erlaubt die gleichzeitige Detektion von vier LightCycler ${ }^{\circledR}$ Red Farbstoffen, die unterschiedliche Wellenlängen haben: 610, 640, 670 und 705 nm. Die genaue Funktion und Detektion der Sonden während der Amplifikation wird in Abbildung 34 schematisch dargestellt.

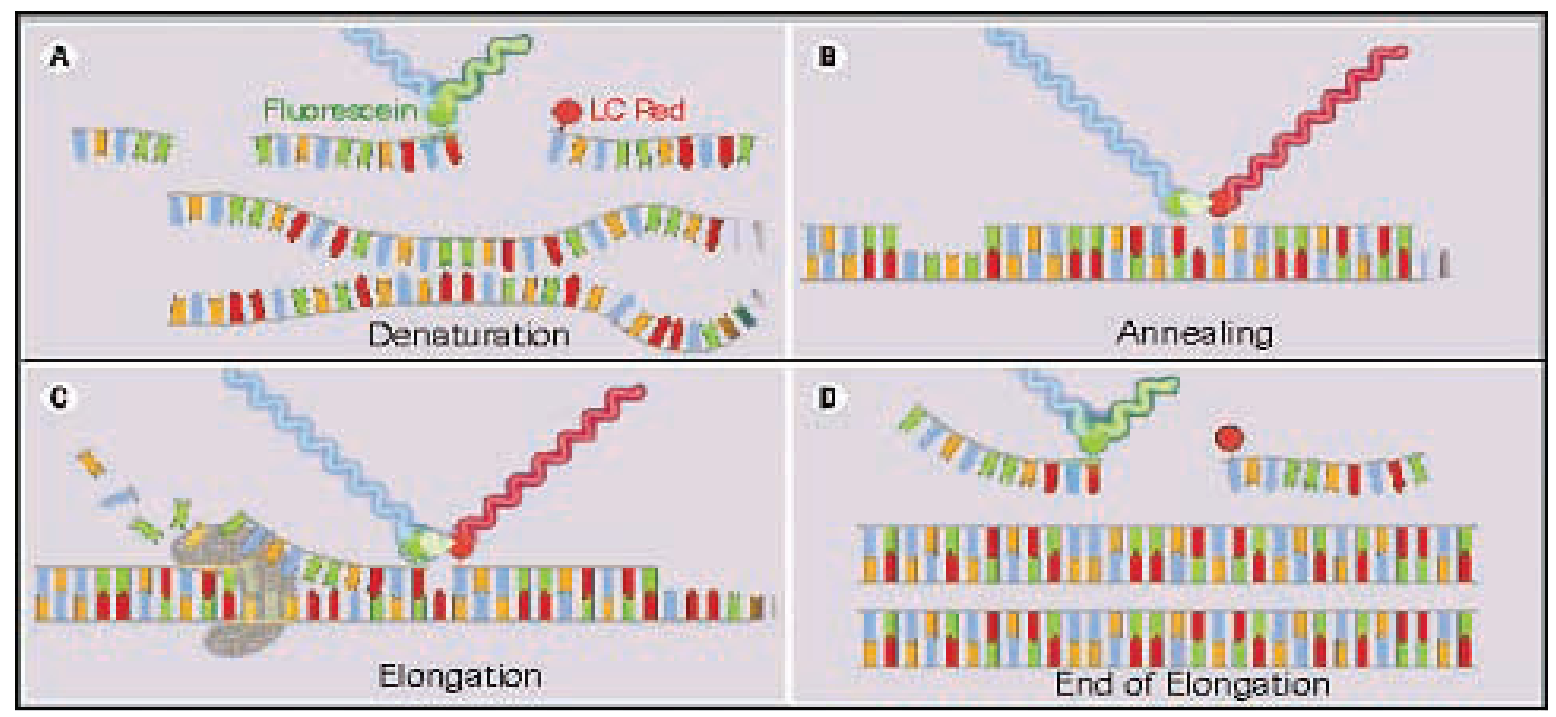

Abb. 34: Funktionsweise der Hybridisierungssonden: Die Sonden binden an die, nach der Denaturierung (A), einzelsträngig vorliegende Ziel-DNA. Hierdurch kommt es zum FRET und der rote Farbstoff beginnt zu fluoreszieren (B). Während der Elongation werden die Sonden wieder verdrängt $(C)$ und der Energietransfer zwischen ihnen wird beendet. Die zuvor eingebundenen Sonden stehen jetzt im Reaktionsmix wieder frei zur Verfügung. Das System misst das jeweilige Fluoreszenzsignal am Ende der Annealingphase. Die gemessene Signalintensität steigt proportional zur Menge der vorliegenden Zielsequenzen. 
Ein HybProbe-System besteht aus zwei Primern, die die Zielsequenz flankieren und den zwei Sonden (Sensor und Anchor), die innerhalb dieses Bereiches liegen. Die Sonden binden wie die Primer an einzelsträngiger DNA. Beide Sonden müssen für den FRET an den gleichen Strang und nicht mehr als 5bp voneinander entfernt binden (Roche 2004). Darüber hinaus ist es bei der Anwendung der Sonden für die Analyse von Mutationen wichtig, dass eine der Sonden - die Sensor-Probe - die variable Sequenz überdeckt (Abb. 35). Es ist dabei egal, welche der beiden Sonden mit dem Fluorescein und welche mit dem LightCycler® Red Farbstoff markiert ist. $\mathrm{Zu}$ beachten ist allerdings, dass der Schmelzpunkt der Sonden über dem der Primer liegt und dass die Anchor-Sonde einen höheren Schmelzpunkt hat als die Sensor-Sonde, somit werden Messartefakte vermieden. Die Entwicklung der Sonden und der zugehörigen Primer erfolgt mittels der LightCycler® Probe Design Software 2.0 (Roche)

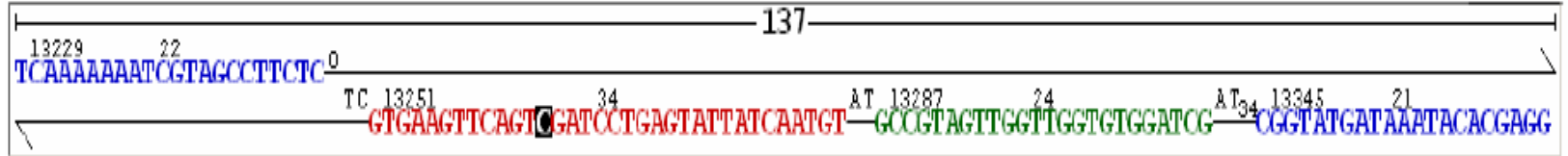

Abb. 35: Design eines HybProbe Systems: Ein Primerpaar flankiert die zu analysierende Region (blau / 137 bp Amplicon). Eine Sensor-Sonde (rot) bindet über dem zu analysierenden SNP (schwarz markiert). Zwei Basenpaare weiter bindet die Anchor-Sonde (grün).

Die Typisierung von Sequenzvariationen (SNPs, Deletionen etc.) in den amplifizierten Produkten erfolgt über das Schmelzkurvenverfahren im direkten Anschluss an die PCR. Dabei wird ausgenutzt, dass jede Veränderung in der Zielsequenz der Sensor-Sonde zu einer Erniedrigung des Schmelzpunktes $(\Delta \mathrm{Tm})$ führt, also der Temperatur, bei der sich die Sonde von dem DNA-Strang löst. Ein Basenaustausch alleine verursacht dabei eine Änderung von 2-10 $\mathrm{C}$, abhängig von der Art des Austausches und den Nachbarsequenzen dieser Base. Die amplifizierten Produkte werden für diesen Vorgang denaturiert und dann die Temperatur gesenkt, so dass die Sonden an die einzelsträngige DNA binden können. Dann wird der Reaktionsmix unter stetiger Messung der Fluoreszenz erhitzt. Durch das Erhitzen lösen sich die Sonden wieder, was zur Abnahme des gemessenen Fluoreszenzsignals führt. Dieser Prozess wird in Form einer Schmelzkurve von der Software dargestellt. Die Morphologie der Schmelzkurve und die Temperatur, bei der genau die Hälfte der Sonden abgeschmolzen ist, definieren den spezifischen Schmelzpunkt (melting peak) des Produktes. Eine Probe ohne Sequenzabweichung ergibt einen definierten Schmelzpunkt, eine heterozygote Probe zwei Schmelzpunkte und eine homozygot veränderte, mutierte Probe einen einheitlichen Schmelzpunkt bei einer niedrigeren Temperatur (Abb. 36). 
GGTACCAGCTCTTCCTAATTGTCAGTCCCAGAGGTGACCC

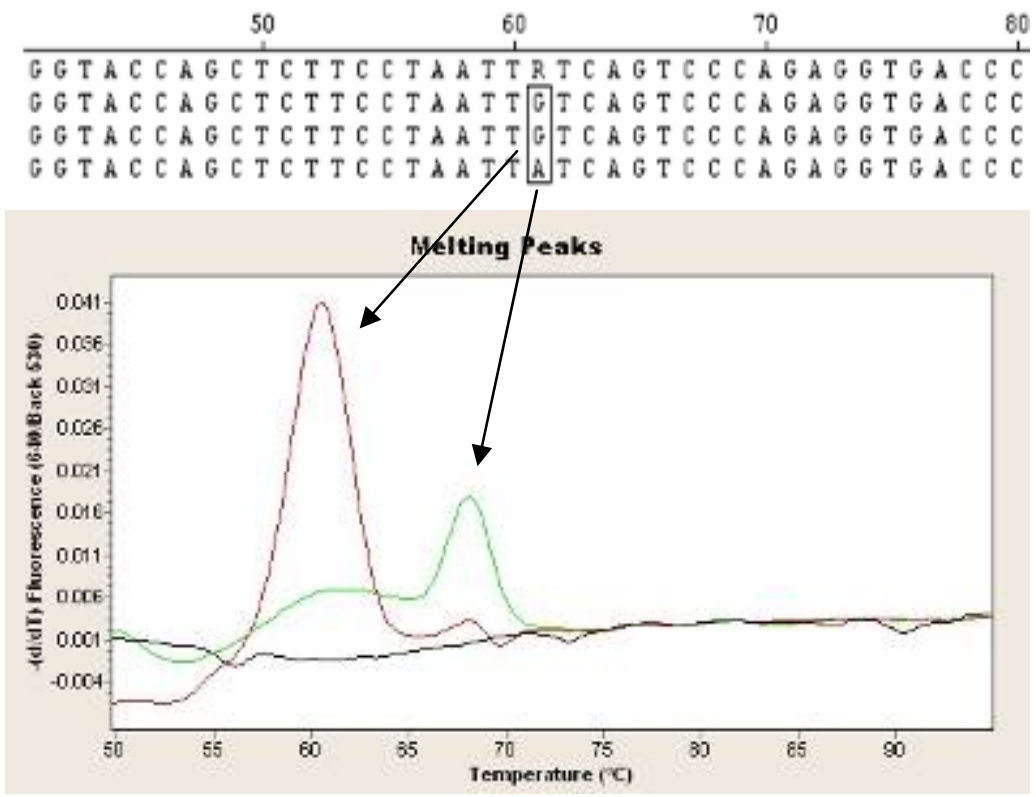

Abb. 36: Beispiel für eine Schmelzkurvenanalyse: Die markierten

Basen in der Sequenz geben die untersuchte Nukleotidposition an.

Je nach Base, die an dieser Position realisiert ist, variiert der zu messende Schmelzpunkt.

\subsubsection{HybProbe Assay für mitochondriale SNPs und die 9bp Deletion}

Zur Typisierung der vier indigenen amerikanischen mt-Haplogruppen A, B, C und D wurden drei gruppenspezifische SNPs (für A, C und D) und eine 9bp Deletion in der COII/tRNA Region des mitochondrialen Genoms (für B) untersucht (vgl. Abb. 31). Für jeden dieser genetischen Marker wurde ein HybProbe-System entwickelt, das den spezifischen Anforderungen der aDNAAnalytik gerecht wird (Amplikonlängen zwischen 130 u. 144bp). Das Design wurde darauf ausgerichtet, dass alle vier Systeme zusammen in einer Quadruplex-Reaktion amplifiziert und analysiert werden können und erfolgte nach den in Kap. 3.5.2 beschriebenen Richtlinien. Weitere Informationen zur Erstellung von HybProbe-Sonden und Primern sind dem Handbuch der LightCycler ${ }^{\circledR}$ Probe Design Software $2.0 \mathrm{zu}$ entnehmen. Als Sequenz-Matrize für das Design der Primer und Sonden wurde die rCRS (Andrews et al. 1999) verwendet. Die Primerund Sondensequenzen, die Amplikonlänge der Systeme und die jeweiligen Fluoreszenzmarkierungen sind Tab. $17 \mathrm{zu}$ entnehmen. 
Tab. 17: Primer und Sonden der HybProbe-Systeme (mt-SNPs und die 9bp Deletion / HG= Haplogruppe).

\begin{tabular}{|c|c|c|c|}
\hline System & $\begin{array}{l}\text { Primer } \\
\text { Sonde }\end{array}$ & $\begin{array}{l}\text { Primer- / Sondensequenz }\left(5^{\prime}-3^{\prime}\right) \text { und Fluoreszenzfarbstoffe } \\
\text { (Fluorescein und LightCycler }{ }^{\circledR R e d ~ 610-705) ~}\end{array}$ & $\begin{array}{l}\text { PCR- } \\
\text { Produkt }\end{array}$ \\
\hline \multirow[t]{2}{*}{ HG A } & Upper & AATACACTGAAAATGTTTAGACG & \multirow{4}{*}{$135 \mathrm{bp}$} \\
\hline & Lower & GGTGATTTAGAGGGTGAAC & \\
\hline np 663 & Sensor & LC Red 610-GGCCAGGACCAAACCTATT & \\
\hline $\mathrm{A} / \mathrm{G}$ & Anchor & GCTTGCATGTGTAATCTTACTAAGAGCTAATAGA-Fluorescein & \\
\hline HG B & Upper & TAATTCCCCTAAAAATCTTTGAAATAG & \multirow{4}{*}{$130 \mathrm{bp}$} \\
\hline \multirow{3}{*}{ 9bp del } & Lower & GGTGTTGGTTCTCTTAATCT & \\
\hline & Sensor & ATAGCACCCCСТCTACCCCCTC-Fluorescein & \\
\hline & Anchor & LC Red 705-GAGCCCACTGTAAAGCTAACTTAGCATTAACCTTT & \\
\hline $\mathrm{HG} \mathrm{C}$ & Upper & TCAAAAAAATCGTAGCCTTCTC & \multirow{4}{*}{$137 \mathrm{bp}$} \\
\hline \multirow{3}{*}{ np 13.263} & Lower & GGAGCACATAAATAGTATGGC & \\
\hline & Sensor & LC Red 670-TGTAACTATTATGAGTCCTAGCTGACTTGAAGTG & \\
\hline & Anchor & GCTAGGTGTGGTTGGTTGATGCCG-Fluorescein & \\
\hline HG D & Upper & TTAAACTCCAGCACCACGA & \multirow{4}{*}{$144 b p$} \\
\hline \multirow{3}{*}{$\begin{array}{l}\text { np } 5.178 \\
\text { C/A }\end{array}$} & Lower & TTCGATAATGGCCCATTTG & \\
\hline & Sensor & AAGCTAACATGACTAACACCCTTAATTCC-Fluorescein & \\
\hline & Anchor & LC Red 640-CCACССТССТСТСССТAGGAG & \\
\hline
\end{tabular}

Die Amplifikation und Analyse erfolgte in einem LightCycler ${ }^{\circledR} 2.0$ (Roche) in den dafür vorgesehenen Glaskapillaren mit einem Reaktionsvolumen von $20 \mu$. Primer und Sonden wurden jeweils zu einem Set zusammengefügt. Die eingesetzten Konzentrationen sind Tab. 18 zu entnehmen. Der Reaktionsmix setzte sich aus folgenden Komponenten zusammen:

- $4 \mu 1$ LightCycler ${ }^{\circledR}$ Multiplex DNA Mastermix - HybProbe (Roche)

- 3,6 $\mu 1$ Primerset (Konzentrationen siehe Tab. 18)

- $6 \mu 1$ Sondenset (Konzentrationen siehe Tab. 18)

- $3-5 \mu 1$ DNA-Extrakt

- $\mathrm{H}_{2} \mathrm{O}$ PCR-Grade (Roche) zum Auffüllen des Mixes auf das Endvolumen von $20 \mu \mathrm{l}$ 
Tab. 18: Zusammensetzung des Primer- und Sondensets ( $\mathrm{SP}=$ Sensor Sonde / AP = Anchor Sonde).

\begin{tabular}{ccc|ccc}
\hline & Primerset & & \multicolumn{3}{c}{ Sondenset } \\
\hline Primer & $\begin{array}{c}\text { Arbeitskonz. } \\
{[\mathrm{pmol} / \mu \mathrm{l}]}\end{array}$ & $\begin{array}{c}\text { Primerset } \\
{[\mu \mathrm{M}]}\end{array}$ & Sonden & $\begin{array}{c}\text { Arbeitskonz. } \\
{[\mathrm{pmol} / \mu \mathrm{l}]}\end{array}$ & $\begin{array}{c}\text { Sondenset } \\
{[\mu \mathrm{M}]}\end{array}$ \\
HG-A upper & 20 & 0,6 & HG-A SP & 8 & 0,4 \\
HG-A lower & 20 & 0,3 & HG-A AP & 8 & 0,2 \\
HG-B upper & 20 & 0,3 & HG-B SP & 8 & 0,2 \\
HG-B lower & 20 & 0,6 & HG-B AP & 8 & 0,4 \\
HG-C upper & 20 & 0,6 & HG-C SP & 8 & 0,4 \\
HG-C lower & 20 & 0,3 & HG-C AP & 8 & 0,2 \\
HG-D upper & 20 & 0,3 & HG-D SP & 8 & 0,2 \\
HG-D lower & 20 & 0,6 & HG-D AP & 8 & 0,4 \\
\hline
\end{tabular}

Die PCR- und Schmelzkurvenanalysen-Parameter sind in Tab. 19 aufgelistet. Die in der letzten Spalte angegebenen Slope und Aquisition Werte sind spezifische Einstellungen für den LightCycler ${ }^{\circledR}$. Der Slope Wert beschreibt die Heizgeschwindigkeit des Cyclers und der Aquisition Modus die Art der Datendetektion (single= Punktmessung; continuous= durchgehende Messung)

Tab. 19: Parameter für die mt-Haplogruppen Quadruplex PCR und Schmelzkurvenanalyse

\begin{tabular}{|c|c|c|c|c|}
\hline & & Temperatur & Dauer & $\begin{array}{c}\text { Slope / } \\
\text { Aquisition }\end{array}$ \\
\hline \multirow{5}{*}{ PCR } & Initiale Aktivierung & $95^{\circ} \mathrm{C}$ & $10 \mathrm{~min}$ & - \\
\hline & Denaturierung & $95^{\circ} \mathrm{C}$ & 10 sek & - \\
\hline & Hybridisierung & $55^{\circ} \mathrm{C}$ & 15 sek & single \\
\hline & Elongation & $72^{\circ} \mathrm{C}$ & 10 sek & - \\
\hline & \multicolumn{4}{|c|}{50 Zyklen } \\
\hline \multirow{3}{*}{$\begin{array}{c}\text { Schmelzkurven- } \\
\text { Analyse }\end{array}$} & Denaturierung & $95^{\circ} \mathrm{C}$ & 5 sek & \\
\hline & Hybridisierung & $45^{\circ} \mathrm{C}$ & 40 sek & \\
\hline & Schmelzen & $95^{\circ} \mathrm{C}$ & & $\begin{array}{l}0,1^{\circ} \mathrm{C} / \text { sek } \\
\text { continuous }\end{array}$ \\
\hline & Soak & $30^{\circ} \mathrm{C}$ & $30 \mathrm{sek}$ & \\
\hline
\end{tabular}




\subsubsection{HybProbe Assay für Y-chromosomale SNPs}

Für die Typisierung der indigenen amerikanischen Y-chromosomalen Haplogruppen $(\mathrm{C}, \mathrm{P}, \mathrm{Q}$, Q3) wurde ebenfalls ein Quadruplex-HybProbe-System entwickelt. Das Primer und Sonden Design erfolgte nach den für das mitochondriale Typisierungssystem beschriebenen Vorgaben (s.o.). Für die Entwicklung wurden die publizierten Sequenzmatrizen der NRY-Marker M3, M45, M130 und M242 verwendet (Underhill et al. 2000). Die Primer- und Sondensequenzen der vier HybProbe Systeme sowie die Amplikonlänge und die jeweiligen Fluoreszenz-markierungen sind Tab. $20 \mathrm{zu}$ entnehmen.

Tab. 20: Primer und Sonden der Y-HybProbe-Quadruplex PCR

\begin{tabular}{|c|c|c|c|}
\hline System & $\begin{array}{l}\text { Primer } \\
\text { Sonde }\end{array}$ & $\begin{array}{l}\text { Primer- / Sondensequenz }\left(5^{\prime}-3^{\prime}\right) \text { und Fluoreszenzfarbstoffe } \\
\text { (Fluorescein und LightCycler®Red 610-705) }\end{array}$ & Amplikon \\
\hline $\mathrm{HG} \mathrm{C}$ & Upper & TGTGTGTTTTGGTGGGATGT & \multirow{4}{*}{$145 \mathrm{bp}$} \\
\hline M130 & Lower & ТСТСТСТСТTCAGCAACAGTAAGTC & \\
\hline \multirow[t]{2}{*}{$\mathrm{C} / \mathrm{T}$} & Sensor & LC Red 705-TTTCCCTGCCCAGGGGAAAGGG & \\
\hline & Anchor & TCСТСТTСТАTTGCAGGGCAATAAACCTTG-Fluorescein & \\
\hline HG P & Upper & TTTAACAGTAACTCTAGGAGAGAGG & \multirow{4}{*}{$148 \mathrm{bp}$} \\
\hline M45 & Lower & GGCACCAAAGGTCATTTGTG & \\
\hline \multirow[t]{2}{*}{$\mathrm{G} / \mathrm{A}$} & Sensor & LC Red 640-TTTGCCTATCTATAATTTTTCACTGCCAAT & \\
\hline & Anchor & CTCCTGGCCTGGACCTCAGAAGGAGC-Fluorescein & \\
\hline HG Q & Upper & TAAGCTTTCTACGGCATAGAAAGT & \multirow{4}{*}{$148 b p$} \\
\hline M242 & Lower & TACCTAGAACAACTCTGAAGCG & \\
\hline \multirow[t]{2}{*}{$\mathrm{C} / \mathrm{T}$} & Sensor & AAGGTGCTCTTGGCATTGGTCTTA-Fluorescein & \\
\hline & Anchor & LC Red 670-GTGTTTTTTGAAAAAAATCTATTTTAACGT & \\
\hline $\mathrm{HG} \mathrm{Q3}$ & Upper & CTGAAATTTAAGGGCATCTTTCAT & \multirow{4}{*}{$130 \mathrm{bp}$} \\
\hline M3 & Lower & CGGGATAAATGTGGCCAAG & \\
\hline \multirow[t]{2}{*}{$\mathrm{C} / \mathrm{T}$} & Sensor & LC Red 610-GACTGACAATTAGGAAGAGCTGGTACCTAA & \\
\hline & Anchor & AGGTTGACCTGACAATGGGTCACCTCT-Fluorescein & \\
\hline
\end{tabular}

Die Amplifikation und Analyse erfolgte in einem LightCycler ${ }^{\circledR} 2.0$ (Roche) in den dafür vorgesehenen Glaskapillaren mit einem Reaktionsvolumen von $20 \mu 1$. Primer und Sonden wurden jeweils zu einem Set zusammengefügt. Die eingesetzten Konzentrationen finden sich in Tab. 21. Der PCR-Reaktionsmix setzte sich aus folgenden Komponenten zusammen:

- $4 \mu 1$ LightCycler ${ }^{\circledR}$ Multiplex DNA Mastermix - HybProbe (Roche) 
- $4 \mu 1$ Primerset (Konzentrationen siehe Tab. 21)

- $4 \mu \mathrm{l}$ Sondenset (Konzentrationen siehe Tab. 21)

- $\quad$ 5-8 $\mu 1$ DNA-Extrakt

- $\quad \mathrm{H}_{2} \mathrm{O}$ PCR-Grade (Roche) zum Auffüllen des Mixes auf das Endvolumen von $20 \mu \mathrm{l}$

Tab. 21: Zusammensetzung des Primer- und Sondensets für die Y-HybProbe-Quadruplex PCR.

\begin{tabular}{ccc|ccc}
\hline & Primerset & & Sondenset & \\
\hline Primer & $\begin{array}{c}\text { Arbeitskonz. } \\
{[\mathrm{pmol} / \mu \mathrm{l}]}\end{array}$ & $\begin{array}{c}\text { Primerset } \\
{[\mu \mathrm{M}]}\end{array}$ & Sonden & $\begin{array}{c}\text { Arbeitskonz. } \\
{[\mathrm{pmol} / \mu 1]}\end{array}$ & $\begin{array}{c}\text { Sondenset } \\
{[\mu \mathrm{M}]}\end{array}$ \\
M130 upper & 20 & 0,5 & M130 SP & 8 & 0,2 \\
M130 lower & 20 & 0,5 & M130 AP & 8 & 0,2 \\
M45 upper & 20 & 0,5 & M45 SP & 8 & 0,2 \\
M45 lower & 20 & 0,5 & M45 AP & 8 & 0,2 \\
M242 upper & 20 & 0,5 & M242 SP & 8 & 0,2 \\
M242 lower & 20 & 0,5 & M242 AP & 8 & 0,2 \\
M3 upper & 20 & 0,5 & M3 SP & 8 & 0,2 \\
M3 lower & 20 & 0,5 & M3 AP & 8 & 0,2 \\
\hline
\end{tabular}

Die Parameter für die PCR und die Schmelzkurvenanalyse finden sich in Tab. 22. Die mit der Real-Time PCR amplifizierten PCR Produkte mussten nicht zur Überprüfung des Amplifikationserfolges auf ein Agarosegel aufgetragen werden (vgl. Kap. 3.6.1).

Tab. 22: Parameter für die Y-HybProbe-Quadruplex PCR und Schmelzkurvenanalyse

\begin{tabular}{|c|c|c|c|c|}
\hline & & Temperatur & Dauer & $\begin{array}{c}\text { Slope / } \\
\text { Aquisition }\end{array}$ \\
\hline \multirow{5}{*}{ PCR } & Initiale Aktivierung & $95^{\circ} \mathrm{C}$ & $10 \mathrm{~min}$ & - \\
\hline & Denaturierung & $95^{\circ} \mathrm{C}$ & $10 \mathrm{sek}$ & - \\
\hline & Hybridisierung & $56^{\circ} \mathrm{C}$ & $15 \mathrm{sek}$ & single \\
\hline & Elongation & $72^{\circ} \mathrm{C}$ & $15 \mathrm{sek}$ & - \\
\hline & \multicolumn{4}{|c|}{55 Zyklen } \\
\hline \multirow{4}{*}{$\begin{array}{c}\text { Schmelzkurven- } \\
\text { Analyse }\end{array}$} & Denaturierung & $95^{\circ} \mathrm{C}$ & 5 sek & \\
\hline & Hybridisierung & $42^{\circ} \mathrm{C}$ & 40 sek & \\
\hline & Schmelzen & $95^{\circ} \mathrm{C}$ & & $\begin{array}{l}0,1^{\circ} \mathrm{C} / \mathrm{sek} \\
\text { continuous }\end{array}$ \\
\hline & Soak & $30^{\circ} \mathrm{C}$ & 30 sek & \\
\hline
\end{tabular}




\subsection{Auswertung}

\subsubsection{Agarosegelelektrophorese}

Der Amplifikationserfolg aller Endpunkt-PCR-Reaktionen wurde durch die elektrophoretische Auftrennung auf 2,5\%-Agarosegelen überprüft. Es wurden standardgemäß $\quad 10 \quad \mu 1$ Amplifikationsprodukt aufgetragen. Die Kontrolle der amplifizierten Produktlänge und Produktstärke erfolgte über den Vergleich mit einer 1KB-Leiter $(1 \mu \mathrm{g} / \mu 1$ Stammkonzentration; Invitrogen), die als Längenstandard auf jedem Agarosegel mitgeführt wurde. Das Verfahren der Agarosegelelektrophorese und die chemische Zusammensetzung werden z.B. in Hummel (2003) beschrieben. Die Dokumentation der Gele erfolgte auf dem Digitalen Geldokumentationssystem GelJet-Imager 2004 (Intas).

\subsubsection{Sequenzierung und Kapillarelektrophorese}

Um die HVR I zu analysieren, muss die jeweilige mtDNA-Sequenzabfolge der Proben bestimmt werden. Dafür wurden die Amplifikationsprodukte nach dem Prinzip der Cycle Sequencing Reaktion (Sanger et al. 1977) direktsequenziert. Für alle amplifizierten Produkte wurden forward-Sequenzierungen (H-Strang) angewendet. Bei vorzeitigem Abbruch der Reaktion z.B. durch homopolymere Regionen in den Sequenzen, aber auch bei scheinbarer Heteroplasmie von Sequenzabschnitten wurden auch reverse-Sequenzierungen (L-Strang) durchgeführt. Detaillierte Beschreibungen der Funktionsweise des Cycle-Sequencing und der Sequenzdetektion finden sich z.B. in Hummel (2003).

Vorbereitend zur Sequenzierreaktion müssen die PCR-Produkte von überschüssigen Reaktionskomponenten wie dNTPs, Polymerase, Primern, Primerdimeren und Puffersalzen bereinigt werden. Dieser Aufreinigungsvorgang wurde mit dem MinElute ${ }^{\circledR}$ PCR Purification Kit (Qiagen) vorgenommen. Die Durchführung erfolgte nach den Angaben des Herstellers.

Die Taq Cycle-Sequencing Reaktion wurde in einem Reaktionsvolumen von $20 \mu 1$ durchgeführt und beinhaltete die im Folgenden aufgelisteten Komponenten. Die einzusetzende DNA-Menge wurde über das Agarosegelbild abgeschätzt (vgl. Kap. 3.6.1). Für die Sequenzierreaktion wurden HPLC-aufgereinigte Primer verwendet.

- $2 \mu 1$ BigDye Terminator V1.1 (PE Applied Biosystems)

- $3 \mu 1$ XX Sequencing Buffer (PE Applied Biosystems)

- $0,6 \mu \mathrm{l}$ Primer $(\mathrm{AK} 5 \mathrm{pmol} / \mu \mathrm{l}=3,2 \mathrm{pmol})$

- 1-5 $\mu 1$ aufgereinigtes PCR-Produkt

- HPLC-H2O (Merck) zum Auffüllen des Reaktionsvolumens auf 20 $\mu 1$ 
Die Sequenzierreaktion erfolgte in einem DNA Thermal Cycler Typ TC1 (Perkin Elmer Cetus). Da dieser Cycler über keine Deckelheizung verfügt, musste jede Probe mit einem Tropfen Mineralöl (NUJOL, Perkin Elmer Cetus) überschichtet werden. Die Reaktionsparameter lauteten wie folgt:

- Initiale Denaturierung: $10 \mathrm{~min} / 96^{\circ} \mathrm{C}$

- Cycling: $10 \mathrm{sec} / 96^{\circ} \mathrm{C} ; 5 \mathrm{sec} / 50^{\circ} \mathrm{C}, 4 \mathrm{~min} / 60^{\circ} \mathrm{C}(25$ Zyklen $)$

Die Sequenzierprodukte müssen ebenfalls aufgereinigt werden, um überschüssige fluoreszenzmarkierte ddNTPS, Nukleotide und Polymerase zu entfernen, die ansonsten zu einem starken „Hintergrundrauschen“, bzw. eingeschränkter Analysierbarkeit der Produkte führen würden. Hierfür wurde das NucleoSeq Kit (Macherey-Nagel) eingesetzt, dessen Funktionsweise auf der Methode der Gelfiltration beruht. Die Vorbereitung der Trennmatrix in den Spincolumns und die Filtrierung durch Zentrifugation wurden nach Angaben des Herstellers vorgenommen.

Die Sequenzanalyse selbst erfolgte auf einem DNA-Sequenzer Modell ABI Prism ® 310 Genetic Analyser (PE Applied Biosystems). Hierfür wurde der gesamte Überstand aus der Aufreinigung in die entsprechenden sample tubes überführt und in den Sequenzierer gebracht. Die elektrophoretische Auftrennung erfolgte unter Verwendung des Polymer POP-6®) (PE Applied Biosystems). Abschließend wurden die ermittelten Signaldaten mit Hilfe der AnalyseSoftware ABI Prism ${ }^{\circledR}$ Sequencing Analysis (PE Applied Biosystems) ausgewertet. Die Datendarstellung erfolgt hier in Form eines Elektropherogrammes. Dieses ist eine Aneinanderreihung von Peaks mit basenspezifischer Farbgebung. Den vier Basen werden folgende Farben zugeordnet: Adenin = grün, Cytosin = blau, Guanin = schwarz und Thymin $=$ rot. Die ermittelte Abfolge der Basen stellt die DNA-Sequenz dar.

Die ermittelten Sequenzdaten wurden abschließend mit der SeqMan Software (Lasergene Software Paket, DNAStar) überprüft und von Analyse- bzw. Lesefehlern der SequenzerSoftware bereinigt (vgl. Salas et al. 2005). Für Nukleotidpositionen, an denen mehr als eine Base realisiert war, wurde der entsprechende IUB-Code eingesetzt. Die abschließende Auswertung und der Abgleich mit der universalen mitochondrialen Referenzsequenz ( $r C R S$ ) erfolgte über die MegAlign Software (Lasergene Software Paket, DNAStar).

\subsubsection{Fragmentlängenanalyse und Alleldetermination}

Die Auftrennung der Amplifikationsprodukte, sowohl der Y-STRs als auch der autosomalen STRs, erfolgte ebenfalls mittels der Kapillarelektrophorese auf einem ABI Prism ${ }^{\circledR} 310$ Genetic Analyser (PE Applied Biosystems). Als Medium für die elektrophoretische Auftrennung wurde hier das Polymer POP-4® (PE Applied Biosystems) verwendet. Eine Aufreinigung der PCR- 
Produkte für die Fragmentlängenanalyse ist nicht notwendig. Für die Analyse wurden je nach Signalintensität auf dem Agarosegel 0,5-1 $\mu$ PCR-Produkt aus der Oktaplex-PCR oder der YMultiplex-PCR in einen Mastermix aus 0,25 $\mu 1$ spurinternem Standart GeneScan ${ }^{\mathrm{TM}} 500 \mathrm{ROX}^{\mathrm{TM}}$

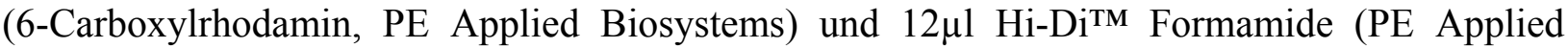
Biosystems) gegeben. Der Mix wurde für 5 min bei $95^{\circ} \mathrm{C}$ zur Denaturierung der DNADoppelstränge inkubiert, auf Eis gekühlt und anschließend vollständig in die sample tubes für die Analyse im ABI Prism ${ }^{\circledR} 310$ Genetic Analyser (PE Applied Biosystems) überführt. Die Daten werden während des Prozesses von der ABI Prism ${ }^{\circledR}$ Data Collection Software auf den Steuerrechner übertragen und dann mittels der GeneScan ${ }^{\mathrm{TM}}$ Analysis Software weiterverarbeitet. Die Fragmentlängenbestimmung wurde mit Hilfe des spurinternen Längenstandards vorgenommen. Für das size calling wurde die Local Southern Methode gewählt. Die analysierten Fragmente werden in Form von Peaks in einem Elektropherogramm dargestellt. Über den Vergleich mit einer spezifischen selbstgenerierten Allelleiter für die Oktaplex- (Schilz 2006) und die Y-Multiplex-PCR (Müller 2002) wurden die jeweiligen Allele determiniert. Für genauere Information zu möglichen Analyseproblemen wie Stotterbanden (vgl. Kap. 2.2.1) und der Funktionsweise der automatisierten Fragmentlängenbestimmung sei an dieser Stelle auf weiterführende Literatur wie z.B. Hummel (2003) und Schilz (2006) verwiesen.

\subsection{Kontaminationsprävention und Authentizitätssicherung}

\subsubsection{Maßnahmen zur Kontaminationsprävention}

Der Überlieferungszustand alter DNA (vgl. Kap. 2.2.2), vor allem die geringe Zahl an erhaltenen Zielsequenzen (targets) bedingt, dass die Analyse genetischer Marker aus prähistorischem Probenmaterial besonders sensibel gegenüber Kontaminationen mit exogener DNA ist. Das bedeutet, dass Vorkehrungen getroffen werden müssen, um die Generierung falsch-positiver Ergebnisse $\mathrm{zu}$ verhindern. Als Kontaminationsarten und -quellen sind carry over Kontaminationen (Longo et al. 1990), Kreuzkontaminationen zwischen Proben (Kitchin et al. 1990), mit DNA kontaminierte Reagenzien und Einwegmaterialien (Schmidt et al. 1995; Tamariz et al. 2006) und natürlich der Eintrag von menschlicher DNA durch somatische Zellen, z.B. durch die Bearbeiter (Kitchin et al. 1990) zu nennen. Im Folgenden soll geschildert werden, welche Laborstandards und Präventionsmaßnahmen eingehalten wurden.

Zur Vermeidung von carry over Kontaminationen, also dem Verschleppen und Einbringen von PCR-Produkten, besteht in der Abteilung eine strikte Trennung von Prä- und Post-PCRBereichen. Das bedeutet, dass zum einen eine räumliche Trennung und zum anderen, dass eine Einbahnstraßenregelung für die Benutzungsreihenfolge der Laborbereiche besteht. Weder 
Material, noch Personen (nur geduscht und mit neuer Kleidung) dürfen nach dem Aufenthalt im Post-PCR-Bereich zurück in den Prä-PCR-Bereich.

Zur Verhinderung von Kreuzkontaminationen wurden alle mehrmals verwendeten Arbeitsgeräte nach Probenkontakt mit Seife (Alconox ${ }^{\text {TM }}$ Detergent, Alconox Inc.), bidestiliertem Wasser und Ethanol gereinigt. Pipettenspitzen und andere Einwegmaterialien mit Probenkontakt wurden nach Gebrauch gewechselt.

Alle Bearbeiter trugen bei Kontakt mit dem Probenmaterial stets Schutzkleidung (Einmalhandschuhe aus Latex, Haarhaube, Mundschutz, OP-Kittel und Schutzbrillen), um die Kontamination mit Körperzellen zu vermeiden. Die Probenoberflächen wurden großzügig abgetragen (vgl. Kap. 3.3).

Einwegmaterialien, Pipettenspitzen und Einweg-Reaktionsgefäße wurden aus kurzer Distanz mit UV-Licht $(254 \mathrm{~nm})$ bestrahlt. Zur Verstärkung des Bestrahlungserfolges wurden die bestrahlten Bereiche mit Aluminiumfolie umgeben (Tamariz et al. 2006). Auch PCRKomponenten wie Puffer, $\mathrm{MgCl}_{2}$ und $\mathrm{H}_{2} \mathrm{O}$ wurden für ca. 1 Std. aus kürzester Distanz bestrahlt. Polymerasen, Primer und dNTPS wurden nicht bestrahlt, da sie unter Einfluss von UV-Licht entweder degradieren oder inhibierende Wirkungen entwickeln (Ou et al. 1991).

\subsubsection{Strategien zur Authentizitätssicherung}

Es gibt zwei Hauptfehlerquellen, die beachtet werden müssen, um die Generierung falscher Ergebnisse zu vermeiden bzw. solche zu identifizieren. Zum einen besteht die Möglichkeit, dass Kontaminationen das authentische Signal überdecken (Kap. 3.7.1), zum anderen können authentische Signale durch postmortale Degradierungserscheinungen der DNA (Kap. 2.2.2) fehlerhaft verändert werden.

Trotz der Vorkehrungen gegen Kontaminationen ist es nicht möglich, diese $100 \%$ ig zu vermeiden. Deshalb muss durch gezielte Typisierungsstrategien die Authentizität der Ergebnisse gesichert werden. Sollte die DNA-Erhaltung des Probenmaterials die Analyse von chromosomaler DNA erlauben, empfiehlt sich zur Authentizitätssicherung die Analyse von individualspezifischen Markern, wie sie z.B. der genetische Fingerabdruck beinhaltet (Hummel et al. 1999). Diese Technik erlaubt, dass die aus einem aDNA-Extrakt generierten Daten mit den genetischen Fingerabdrücken aller an den Untersuchungen beteiligten Personen abgeglichen werden kann. Historische Kontaminationen können hierdurch nicht aufgedeckt werden, das würde aber auch nicht durch die Involvierung eines zweiten unabhängigen Labors ermöglicht, wie es häufig in der Literatur gefordert wird (Cooper et al. 2001). Der sicherste Nachweis solcher Kontaminationen ist die Mehrfachamplifikation aus unabhängigen DNA-Extrakten, die 
am besten aus verschiedenen Skelettelementen des Individuums erstellt wurden (Montiel et al. 2001). Mitochondriale DNA-Daten haben nicht den individualisierenden Charakter wie der genetische Fingerabdruck. Doch ist es durch den häufig regionalspezifischen Charakter mitochondrialer Haplogruppen und -typen möglich, Kontaminationen zu identifizieren. In der vorliegenden Arbeit wurden ausschließlich Proben von präkolumbischen indigenen amerikanischen Individuen untersucht, die nach dem Wissensstand zur Besiedlungsgeschichte der amerikanischen Kontinente nur asiatisch/amerikanische mt-Haplogruppen /-typen aufweisen sollten. Alle Mitarbeiter im Labor und die Archäologen weisen einen europäischen Haplotypen auf, der sich von den erwarteten Ergebnissen aus dem Probenmaterial unterscheiden lässt. Darüber hinaus wurde für alle Personen in Peru, die Kontakt zu den Proben hatten, der mitochondriale Haplotyp, Y-chromosomale Haplotyp und genetische Fingerabdruck generiert. Genetische Daten von prähistorischen Individuen, die sich nicht sicher gegen die Daten der Bearbeiter abgrenzen ließen, wurden als potentiell kontaminiert eingestuft und in der abschließenden Auswertung nicht berücksichtigt. Für alle Proben wurden mindestens zwei unabhängige DNA-Extrakte hergestellt und wenn möglich zwei unterschiedliche Skelettelemente pro Individuum untersucht. Gerade für die Untersuchung der mitochondrialen HVR I wurde jeder untersuchte Locus (vgl. 3.4.1.) mehrmals aus einem Extrakt amplifiziert. Durch die Amplifikation überlappender Sequenzabschnitte erfolgte eine zusätzliche Authentizitätssicherung. Bei stark inkonsistenten Ergebnissen wurden die Proben als potentiell kontaminiert verworfen. Bei punktuellen Abweichungen an wenigen Nukleotidpositionen wurde eine Sequenzveränderung durch postmortale Deaminierungsprozesse angenommen (vgl. Kap. 2.2.2). Für die mtDNA-Analysen wurden außerdem zusätzlich Leerkontrollen mitgeführt. Diese können einen Hinweis auf die herstellerabhängige Kontaminationsrate der Reaktionsgefäße, aber auch auf Kontaminationen während des Ansetzens der PCR geben.

Auch für Sequenzveränderungen durch Deaminierungseffekte ist zur Überprüfung die mehrfache Amplifikation des Abschnittes empfohlen. Darüber hinaus sollten der H- und LStrang sequenziert werden (Paabo et al. 2004). Beides wurde befolgt. Zur Absicherung gegen Fehltypisierungen von mitochondrialen Haplogruppen durch postmortale Sequenzveränderungen in der HVR I (vgl. Kap. 2.2.2) wurden darüber hinaus diese durch die Analyse der haplogruppenspezifischen Polymorphismen der codierenden Region des mt-Genoms überprüft (Fehren-Schmitz et al. 2006).

Auch für die Überprüfung von falsch-homozygoten STR-Typisierungen, bedingt durch allelic dropout Phänome, ist die Mehrfachamplifikation empfohlen (Hummel 2003). Gerade bei stark degradierter DNA und geringen DNA-Mengen $(<0,05 \mathrm{ng} / 10 \mu \mathrm{l})$ ist die Wahrscheinlichkeit 
sehr hoch, dass es zu solchen Analyseartefakten kommt. Generell wurde zur Überprüfung der STR-Typisierungsergebnisse nach dem von Schultes (1997, 2000) empfohlenen Handlungskatalog verfahren.

Alle Genotypen und Sequenzdaten, die in der vorliegenden Arbeit präsentiert werden, stellen einen Konsensus aus mehreren, sich gegenseitig bestätigenden Daten aus unabhängigen Analysen dar.

\subsection{Populationsgenetische Datenauswertung}

Zur Untersuchung der Populationsdynamik im Untersuchungsgebiet und auf kontinentaler Ebene wurden populationsgenetische Parameter wie die Intrapopulations-Diversität, die Interpopulations-Distanz berechnet, die phylogentische Relation der ermittelten Haplotypen zueinander analysiert, sowie mehrere Berechnungen zur Überprüfung räumlicher Expansionen angestellt. Die populationsgenetischen Vergleiche wurden auf zwei Ebenen vorgenommen: Haplogruppen und Haplotypen. Für HVR I-Sequenzdaten aus der vorliegenden Arbeit mussten Konsenssequenzen gebildet werden. Hierfür wurden für jede Probe und jedes Primersystem (vgl. Kap. 3.4.1) die reproduzierten Sequenzen verglichen und bei eindeutiger Bestimmung des Haplotypen zusammengefügt. Die Bearbeitung und ggf. Korrektur der Daten wurde mit dem Lasergene Softwarepaket (Version 4.05, DNAStar) vorgenommen. Die Alignments für Stammbaum-, Netzwerk- und einige Diversitäts- und Distanzanalysen wurden mit MEGA 4.0 (Tamura et al. 2007) erstellt. Ein grundlegendes Kriterium für die Wahl der einzelnen Analysemethoden war die Vergleichbarkeit mit den publizierten populationsgenetischen Daten zur südamerikanischen Besiedlungsgeschichte. Im Folgenden sollen die angewendeten populationsgenetischen Analysemethoden beschrieben werden.

\subsubsection{Diversitäts Indices}

Zur Darstellung der genetischen Diversität innerhalb der Populationen wurden zum einen die Haplotypen- /Haplogruppen-Diversität (gene diversity $=h$ ) und zum anderen die NukleotidDiversität (nucleotide diversity $=\pi$ ) ermittelt.

Haplotypen und Haplogrupen Diversität $(\mathrm{Hd})$ sind direkte Ableitungen aus Nei's gene diversity (h):

$$
h=\left[\frac{n}{n-1}\right] \ldots\left[1-\sum_{i} p_{i}^{2}\right]
$$


$\mathrm{p}_{\mathrm{i}}$ beschreibt hier die Frequenz des $i$-ten Haplotypen und $\mathrm{n}$ ist die Zahl der untersuchten Individuen (Nei 1987). Der ermittelte Wert beschreibt die Quantität der angetroffenen genetischen Diversität in einer Population und kann auf diploide und haploide Genorte angewendet werden. Für die statistische Analyse der Haplogruppenfrequenzen und der Ermittlung der Haplogruppen Diversität $(\mathrm{Hd})$ wurden die vier indigenen amerikanischen Haplogruppen (A, B, C und D) als vier Allele eines einzelnen haploiden Locus betrachtet (Demarchi et al. 2001).

Der zweite berechnete Diversitätsindex, die Nukleotid-Diversität, konnte nur auf die Sequenzdaten (Haplotypen) angewendet werden. Dieser Wert beschreibt die Wahrscheinlichkeit, dass zwei Kopien eines gleichen Nukleotids, die zufällig aus den Sequenzen einer Population gewählt wurden, sich voneinander unterscheiden. Angegeben wird daraus die durchschnittliche Zahl an Unterschieden über $L$ loci zwischen allen Haplotyppaaren in der Population $(\pi)$ :

$$
\pi=\frac{\sum_{i=1}^{k} \sum_{j<1} p_{i} p_{j} \hat{d}_{i j}}{L}
$$

$\hat{d}_{i j}$ ist die Schätzung der Zahl an Mutationen, die seit der Differenzierung der Haplotypen $i$ und $j$ voneinander aufgetreten ist, $k$ beschreibt die Zahl der Haplotypen, während $p$ die Frequenz des jeweiligen Haplotypen beschreibt. Die Populationsgröße wird mit $n$ angegeben. L beschreibt die Anzahl der untersuchten Nukleotidpositionen/ Loci, also die Länge der Sequenzdaten (Tajima 1983; Nei 1987).

Nukleotid-Diversität und Haplogruppen /-typen Diversität wurden mit der Software Arlequin Vers. 3.1(Excoffier u. Schneider 2005) und DnaSP 4.20.2 (Rozas et al. 2003) berechnet. Zum Vergleich von beiden Diversitäts-Indices wurden für die Sequenzdaten der HVR I Scatterplots mit Statistica 6.0 (StatSoft) angefertigt. Der Vergleich der Unterschiede beider Werte erlaubt Aussagen über die demographische Geschichte von Populationen (Lowe et al. 2004).

\subsubsection{Genetische Distanzen}

Die Berechnungen der genetischen Distanz unter den hier untersuchten Populationen beruht auf zwei verschiedenen, paarweisen Distanzmaßen. Für die mt-Haplogruppen Frequenzen und die Sequenzdaten der mt-Haplotypen wurden paarweise $F_{S T}$ Distanzen und Nei's genetische Distanz $D$ ermittelt. Darüber hinaus wurde für die Sequenzdaten die evolutionäre Divergenz basierend auf dem paarweisen Vergleich der Basensubstitutionen zwischen den Haplotypen und den Populationen berechnet. Die Erläuterung hierzu findet sich im nächsten Kapitel. 
Der $\mathrm{F}_{\mathrm{ST}}$-Wert (fixation index) ist in seiner ursprünglichen Anwendung Teil von Wrights FStatistik und beschreibt die Reduktion der Heterozygotie innerhalb einer Population relativ zur totalen Population, bedingt durch Selektion oder genetische Drift. Er kann in dieser Form also nur auf diploide Genome angewendet werden (Wright 1950). Durch Modifikation der Formeln eignet sich der Wert aber auch als Distanzmaß für haploide Genome. Der paarweise Vergleich der so ermittelten $\mathrm{F}_{\mathrm{ST}}$ Werte eignet sich besonders zur Berechnung von genetischen Distanzen zwischen Populationen mit einer geringen Divergenzzeit (Slatkin 1995). Die paarweisen F $_{\mathrm{ST}}-$ Werte wurden mit Arlequin Vers. 3.1(Excoffier u. Schneider 2005) berechnet. Es wurde Reynolds (1983) Algorithmus für den Vergleich stationärer haploider Populationen verwendet. Die Werte variieren zwischen 0 für identische Populationen und 1 für sich absolut unterscheidende Populationen.

In seiner ursprünglichen Anwendung definiert Nei's genetische Distanz (Nei D od. D) die Wahrscheinlichkeit, mit der innerhalb und zwischen Populationen Allele geteilt werden. Auch die diesem Distanzwert zugrunde liegende Formel kann für die Anwendung auf haploide Nukleotiddaten transformiert werden. $D$ beschreibt dann die Zahl der Nukleotidunterschiede zwischen Populationen (Nei u. Li 1979). Auch die Nei D Werte wurden mit Arlequin Vers. 3.1(Excoffier u. Schneider 2005) berechnet. Die zugrunde liegenden Formeln sind der genannten Quelle zu entnehmen.

Alle Berechnungen wurden standardgemäß mit 100.000 Permutationen durchgeführt. Die ermittelten paarweisen Distanzen wurden in Form von Matrices dargestellt. Für die neutrale graphische Darstellung der Distanzmatrices und der Beziehung der Populationen zueinander wurde die multidimensionale Skalierung (MDS) genutzt. Bei der multidimensionalen Skalierung (MDS) werden die Abstände der Datenpunkte gemäß den Abständen in der Distanzmatrix umgesetzt. Im Vergleich zu anderen Methoden wie der principal components analysis (PCA) wird hier allen Komponenten bzw. Dimensionen die gleiche Bedeutung zugesprochen, wodurch eine getreuere Abbildung der Distanzen ermöglicht wird. Der MDS-Plot wurde mit Statistica 6.0 (StatSoft) berechnet und erstellt. Zur Darstellung der phylogenetischen Beziehungen der Populationen wurden außerdem Neighbour Joining Stammbäume aus den Distanzmatrices erzeugt (s.u.).

\subsubsection{Phylogenetische Bäume}

Phylogenetische Stammbäume sind eine intuitive Möglichkeit, die Beziehungen zwischen verschiedensten Wesenheiten, z.B. Haplotypen, Spezies oder Populationen darzustellen. In der vorliegenden Arbeit sollen sie vor allem dazu dienen, die Beziehung zwischen verschiedenen 
Populationen und mt-Haplotypen darzustellen und nicht verschiedene Spezies voneinander zu unterscheiden und ihre Divergenzzeitpunkte zu ermitteln. Dementsprechend wurden nur auf Distanz-Methoden basierende Baumdiagramme erstellt, die aber auch diskrete Daten (Nukleotid Daten) verarbeiten können. Grundlage hierfür sind paarweise Distanz-Matrices, die aus Sequenzdaten erstellt und dann über ein Vergleichsverfahren bzw. Clusterverfahren in Bäume umgewandelt werden. Die beiden verwendeten Methoden sind zum einen die Methode der ungewichteten Paar-Gruppierung mit arithmetischen Mitteln (UPGMA; Sneath u. Sokal 1973) und zum anderen die neighbour-joining Methode (NJ; Saitou u. Nei 1987). Die den Berechnungen $\mathrm{zu}$ Grunde liegenden Datenmengen machten eine Anwendung von alleine auf diskreten Daten basierenden Methoden, wie maximum parsimony, unmöglich.

Über die UPGMA-Methode wird ein ultrametrischer Baum erstellt. Hierfür wird die geringste Distanz zwischen zwei Individuen (oder Populationen) ermittelt, und davon ausgehend werden alle weiteren Individuen nach dem Grad ihrer Distanz hinzugefügt. Die Methode basiert auf der Annahme einer molekularen Uhr, das bedeutet, dass eine gleiche Evolutionsrate für alle Taxa angenommen wird, was besonders bei dem Vergleich von Taxa mit unterschiedlichen Raten oder verschiedener Spezies zu topologischen Fehlern führen kann (Sneath u. Sokal. 1973). Die Anwendung auf eine Zahl von Populationen der gleichen Spezies, die eine gemeinsame geschichtliche Entwicklung durchlaufen haben, bzw. auf Populationsdistanzen ist aber unproblematisch.

Bei der NJ-Methode wird nicht nur ein Ausgangspunkt für alle untersuchten Individuen berechnet, sondern auch die genaue Beziehung der Individuen zueinander. Neighbour-joining basiert auf dem minimum evolution Kriterium (Cavalli-Sforza u. Edwards 1967). Ausgehend von einem zunächst sternförmigen Baum, in dem alle Taxa mit einem Zentrum verbunden sind, werden paarweise die Individuen oder Populationen mit der geringsten genetischen Distanz ausgewählt und zu einem Ast des Baumes vereinigt. Die genetischen Distanzen der Sequenzen werden neu berechnet und wieder die nächstverwandten zu einem Ast mit zwei Taxa zusammengefügt. Dies erfolgt solange, bis alle Taxa in dem Baum eingefügt und die Sternstruktur des Baumes völlig aufgelöst wurde. Endgültig dargestellt wird die BaumTopologie mit der geringsten Verzweigungslänge. Im Vergleich zu anderen Verfahren werden aber nicht alle möglichen Bäume errechnet, woraus resultieren kann, dass nicht die optimale Baum-Topologie gefunden wird. Die NJ-Methode beruht nicht auf der Annahme einer molekularen Uhr und erzeugt infolgedessen einen unbalancierten Baum.

Schwachpunkte und Unsicherheiten eines Baumes können mit der Berechnung der bootstrapWerte sichtbar gemacht werden. Aus den Datensätzen werden dabei zufällig neue 
Kombinationen gebildet und eine alternative Stichprobenverteilung simuliert. Die BaumTopologien aus jeder Simulation werden untereinander verglichen und die Häufigkeiten der berechneten Abzweigungen ermittelt. Der so ermittelte bootstrap-Wert gibt also an, bei wieviel Prozent der Bäume eine bestimmte Abzweigung vorkommt. Ein geringer Wert bedeutet nicht unbedingt, dass eine Abzweigung falsch ist, sondern dass die Daten nicht erlauben, die Unsicherheiten vollständig aufzulösen. Da die bootstrap-Werte dem Mittelwert einer Vielzahl von Bäumen entsprechen, werden sie in separaten Konsensbäumen dargestellt. Die Werte können nicht für die Bäume ermittelt werden, die alleine aus Distanz-Matrices berechnet werden (vgl. Kap. 3.8.3).

Beide verwendete Verfahren gehören zu den expliziten Methoden. Die Berechnungen der genetischen Distanzen können über verschiedene Evolutionsmodelle, d. h. unter der Annahme verschiedener Nukleotidsubstitutionsmuster erfolgen. Für die Distanzberechnungen wurde das für Sequenzdaten aus der mitochondrialen Kontrollregion empfohlene Tamura-Nei Distanzmodell mit Gamma-Korrektur gewählt (Tamura u. Nei 1993). Dieses Modell berücksichtigt die von Position zu Position unterschiedlichen Substitutionsraten unter Nukleotiden (vgl. Kap 2.2.1) und die Ungleichheit von Nukleotidfrequenzen. Die GammaVerteilung beschreibt die Form der Verteilung der Substitutionsunterschiede. Als GammaParameter wurde der für die HVR I von Meyer et al. vorgeschlagene Wert von 0,26 verwendet (Meyer et al. 1999). Die Berechnung der Distanzen und Erstellung der Stammbäume, sowie die Berechnung der bootstrap-Werte erfolgte mit MEGA 4.0 (Tamura et al. 2007).

\subsubsection{Netzwerke}

Ergänzend zu den phylogenetischen Bäumen wurden für die HVR1 Sequenzdaten bzw. für die mt-Haplotypen Netzwerke erstellt. Hierfür wurde die median joining-Methode genutzt (Bandelt et al. 1999). Netzwerke haben den Vorteil gegenüber Bäumen, dass alle möglichen Beziehungen zwischen Sequenzen und alternative Wege dargestellt werden, während bei den Bäumen durch vorgegebene Kriterien (z.B. Parsimonie) selbst bei konflikthaften Situationen scheinbar eindeutige Abzweigungen dargestellt werden. Ein Netzwerk vereint also gleichzeitig mehrere Bäume. Es ermöglicht darüber hinaus auch die Darstellung weiterführender Informationen. So wird über die Größe der Kreise (nodes), die jeweils einen Haplotypen repräsentieren, die Häufigkeit dieser angegeben. Aus der Topographie des Netzwerkes können Informationen zur Entwicklung einer Population abgeleitet werden, so reflektiert ein sternförmiges Muster eine Populations-Expansion. Für die Erstellung des Netwerkes wurden die charakteristischen Polymorphismen aller Haplotypen in die Software Network (Fluxus-Engineering) eingegeben und über die median joining-Methode weiterverarbeitet (Bandelt et al. 1999). Hochpolymorphe 
Nukleotidpositionen (die z.B. in vielen unabhängigen Haplotypen nachgewiesen wurden) wurden für die Analyse geringer gewichtet.

\subsubsection{Tajima D-Statistik und Mismatch Distribution}

Tajimas Test auf selektive Neutralität (Tajima D) und die mismatch distribution sind zwei grundlegend verschiedene populationsgenetische Werkzeuge. Aus beiden können allerdings Informationen über demographische und räumliche Expansionen von Populationen abgeleitet werden.

Die mismatch distribution ist ein häufig eingesetztes Mittel zur Darstellung von Diversität in molekularen Daten. Sie beschreibt die Verteilung der beobachteten Zahl an Unterschieden zwischen Paaren von Haplotypen (distribution of pairwise difference). Die Darstellung erfolgt in der Regel in Form eines Histogrammes. Die hieraus abzulesende Form der Verteilung kann durch Episoden von Bevölkerungsexpansionen beeinflusst werden. Unimodale, glockenförmige mismatch distributions sind Indikatoren für ein schnelles Populationswachstum aus einem einzigen oder wenigen Haplotypen, während zerklüftete, multimodale Verteilungen auf eine über einen langen Zeitraum konstante Populationsgröße hindeuten (Rogers u. Harpending, H. 1992). Räumliche Expansionen mit einem starken Austausch zwischen den benachbarten Populationen können auch zu einer unimodalen Verteilung führen (Excoffier 2004). Bei einem unimodalen Verlauf kann aus dem Abstand des höchsten Peaks zur Y-Achse des Histogramms auf den Zeitpunkt der Bevölkerungsexpansion geschlossen werden, bzw. über die entsprechenden Formeln der Expansionszeitpunkt $(\tau)$ ermittelt werden (Schneider u. Excoffier, L. 1999). Die mismatch distribution und die Tests auf demographische oder räumliche Expansion wurden für die Sequenzdaten aus der HVRI mit der Software DnaSP 4.20.2 (Rozas et al. 2003) und Arlequin Vers. 3.1(Excoffier u. Schneider 2005) berechnet.

Die D-Statistik von Tajima ist ein Test auf neutrale Evolution (Tajima 1989a), was bedeutet, dass die Veränderung einer Sequenz nur auf der Mutationsrate beruht und keine Selektion auf einen betrachteten Genort wirkt. Die grundlegende Annahme, auf der der Test basiert, ist, dass sich unter Selektion die Anzahl der polymorphen Stellen (S) anders entwickelt als die Häufigkeit einer bestimmten Mutation $(\pi)$ innerhalb einer Population. Aus beiden Werten kann die erwartete Anzahl der genetischen Variation jedes Nukleotids $(\theta)$ abgeleitet werden. Bei einer neutralen Evolution sollten die aus S und aus $\pi$ ermittelten $\theta$-Werte identisch sein. Die Differenz D ist also gleich Null. Liegt der Wert signifikant über Null, bedeutet das entweder, dass sich die Population verkleinert, oder dass eine positive Selektion auf den benachbarten Genort wirkt. Signifikant negative Werte deuten auf eine negative Selektion, die Expansion einer Population oder ihre 
Vermischung mit anderen Populationen hin (Tajima 1993; Harpending u. Rogers 2000). Die Tajima-D Werte für die HVRI-Sequenzdaten wurden mit Arlequin Vers. 3.1(Excoffier u. Schneider 2005) berechnet.

\subsubsection{AMOVA}

Das Verfahren der Analyse Molekularer Varianz (AMOVA) erlaubt die Untersuchung der in einer Population und unter Populationen angetroffenen Variation der genetischen Struktur auf molekularer Ebene (Excoffier et al. 1992). Diese Methode berücksichtigt dabei nicht nur die Frequenz von Variationen, sondern auch ihre molekulare Beziehung. Hierfür werden DistanzMatrices berechnet, über die die Varianz innerhalb von und unter vordefinierten Gruppen abgeschätzt wird. Insgesamt werden die Varianz-Korrelationen für drei Ebenen ermittelt:

- Die Varianz innerhalb einer definierten Gruppe relativ zum Gesamtdatensatz $\left(\Phi_{\mathrm{ST}}\right)$

- Die Korrelation der Varianz unter den Populationen einer definierten Gruppe relativ zum Gesamtdatensatz $\left(\Phi_{\mathrm{CT}}\right)$.

- Die Korrelation der Varianz von Populationen relativ zu der Varianz der vordefinierten Gruppen, bzw. die Varianz zwischen den definierten Gruppen $\left(\Phi_{\mathrm{SC}}\right)$

Die Analyse ermöglicht das freie Gruppieren aller Populationen des Gesamtdatensatzes und damit den Vergleich aller möglichen Beziehungsebenen. Die AMOVA wurde mit der von Excoffier et al. (1992) für mitochondriale Sequenzdatensätze entworfenen Methode in Arlequin 3.1 (Excoffier u. Schneider 2005) durchgeführt. Die ermittelten Varianz-Korrelationen werden als Prozentwerte angegeben. In die Analyse wurden alle in dieser Arbeit typisierten HVR I Datensätze und die Referenzpopulations-Daten (vgl. Kap. 3.1.3) eingegeben. Die Gruppierungen der jeweiligen Populationen, unter denen die Vergleiche angestellt wurden, basierten auf verschiedenen möglichen kulturgeschichtlichen oder geographischen Relationen. Zur Absicherung der Daten wurden die jeweiligen Berechnungen mit 100.000 Permutationen durchgeführt. 


\section{Ergebnisse der molekulargenetischen Untersuchungen}

\subsection{Proben und Erhaltung}

Insgesamt wurden 254 Proben von 216 Individuen von 9 Fundorten untersucht. Eine Auflistung aller bearbeiteten Proben findet sich nach Fundorten sortiert im Fundkatalog (Anhang 10.3.1). Tab. 23 gibt, nach Fundort und Zeitstellung sortiert, einen Überblick über den Typisierungserfolg bezüglich der verschiedenen untersuchten genetischen Marker. Für 64\% der untersuchten Individuen konnte die mitochondriale Haplogruppe bestimmt und für immerhin 48\% reproduzierbar die gesamte 388bp umspannende HVR I -Sequenz zur Bestimmung der mtHaplotypen amplifiziert und sequenziert werden. Diese Erfolgsquote für die Typisierung der mitochondrialen Marker ist vergleichbar mit derer anderer aDNA-Studien aus Peru (Shinoda et al. 2006; Lewis et al. 2007a). Trotz der relativ hohen Zahl an erfolgreichen Typisierungen muss der DNA-Erhaltungszustand als eher mittelmäßig bis schlecht eingestuft werden. Die DNA in den meisten Proben lag stark fragmentiert vor, und ein Amplifikationserfolg konnte zumeist nur bei der Analyse der mittleren und kurzen Zielsequenzen für die mitochondrialen Marker erreicht werden. Dieser Umstand äußert sich auch darin, dass mehr mt-Haplogruppen bestimmt werden konnten als mt-Haplotypen. Der Amplifikationserfolg für nukleare DNA ist verschwindend gering (vgl. Tab 23). Die angetroffene DNA-Erhaltung in den Proben variiert stark in Abhängigkeit vom Fundort. Während für alle Individuen des Hochlandfundortes Pacapaccari (EA) die mt-Haplotypen bestimmt werden konnten und sogar für fünf Individuen reproduzierbar einige autosomale STRs, konnte aus den Proben vom Wüstenfundort Monte Grande (GE) weder mitochondriale noch nukleare DNA amplifiziert werden. Eine Abhängigkeit des DNA-Erhaltes vom Liegemilieu der Proben ist nur bedingt nachzuweisen. So konnten bei $85 \%$ der Individuen vom Fundort Los Molinos (MS) die mt-Haplogruppen bestimmt werden. Die Bodenbeschaffenheit (Sandboden, trocken) und der makroskopische Erhaltungszustand der beprobten Individuen (teilweise Mumifikation) sind hier identisch zu Monte Grande. Allerdings stammen die meisten Proben aus Los Molinos von Individuen, die in Schachtgräbern aufgefunden wurden, während die Individuen aus Monte Grande zumeist aus gestörten Bestattungszusammenhängen stammen und zum Zeitpunkt der Auffindung nur unter wenigen Zentimetern Sand begraben lagen. Der schlechte DNA-Erhaltungszustand, der in den Proben aus Monte Grande angetroffen wurde, kann also auch auf die stärkere Exposition des Materials gegenüber UV-Strahlung (Sonnenlicht) zurückzuführen sein (vgl. Kap. 3.1.2). Das Probenmaterial aus den feuchten Böden, wie z.B. aus Jauranga (JA), weist eine schlechtere DNA-Erhaltung auf (49 \% bestimmbare mt-Haplogruppen) als das Material aus den trockenen Sandböden der Palpa-Region. Die Lagerung bei konstanter Temperatur und Feuchtigkeit in einer 
höhlenartigen Fundsituation, wie sie in den Hochland-Chullpas von Pacapaccari anzutreffen ist, bietet anscheinend die günstigsten Erhaltungsbedingungen für DNA. Diese Beobachtung korreliert mit den Ergebnissen anderer Untersuchungen zur Abhängigkeit der DNA-Erhaltung vom Lagerungsmilieu (Burger et al. 1999).

Tab. 23: Typisierungserfolge der analysierten genetischen Marker für die untersuchten Individuen der verschiedenen Fundorte (HG= Haplogruppen; HT=Haplotypen; Auto= autosomale).

\begin{tabular}{|c|c|c|c|c|c|c|c|c|}
\hline \multirow[b]{2}{*}{ Fundort } & \multirow[b]{2}{*}{ Zeitstellung } & \multirow[b]{2}{*}{ Individuen } & \multirow[b]{2}{*}{ Proben } & \multicolumn{5}{|c|}{ Typisierungserfolg (Zahl der Individuen) } \\
\hline & & & & $\mathrm{mt}-\mathrm{HG}$ & $\mathrm{mt}-\mathrm{HT}$ & Y-HG & $\begin{array}{c}\text { Y- } \\
\text { STRs }\end{array}$ & $\begin{array}{l}\text { Auto- } \\
\text { STRs }\end{array}$ \\
\hline \multirow[t]{3}{*}{$\mathrm{AO}$} & Archaikum & 1 & 1 & 1 & 1 & 0 & 0 & 0 \\
\hline & Paracas & 5 & 7 & 4 & 3 & 0 & 0 & 0 \\
\hline & Nasca & 15 & 20 & 10 & 7 & 0 & 0 & 0 \\
\hline \multirow[t]{2}{*}{$\mathrm{ME}$} & Paracas & 8 & 9 & 3 & 2 & 0 & 0 & 0 \\
\hline & Nasca & 4 & 5 & 2 & 1 & 0 & 0 & 0 \\
\hline \multirow[t]{2}{*}{ JA } & Paracas & 48 & 58 & 21 & 20 & 0 & 0 & 1 \\
\hline & Nasca & 21 & 27 & 13 & 12 & 0 & 0 & 0 \\
\hline \multirow[t]{2}{*}{ MS } & Nasca & 27 & 33 & 23 & 22 & 0 & 0 & 0 \\
\hline & MH & 15 & 15 & 10 & 5 & 0 & 0 & 0 \\
\hline MA & Nasca & 7 & 8 & 5 & 3 & 0 & 0 & 0 \\
\hline \multirow[t]{2}{*}{ PA } & Nasca & 19 & 22 & 12 & 10 & 0 & 0 & 0 \\
\hline & $\mathrm{MH}$ & 2 & 2 & 1 & 1 & 0 & 0 & 0 \\
\hline \multirow[t]{2}{*}{ GE } & Nasca & 8 & 8 & 0 & 0 & 0 & 0 & 0 \\
\hline & LIP & 8 & 8 & 0 & 0 & 0 & 0 & 0 \\
\hline $\mathrm{PC}$ & Paracas & 12 & 15 & 10 & 6 & 0 & 0 & 0 \\
\hline EA & MH/LIP & 16 & 16 & 16 & 12 & 4 & 0 & 5 \\
\hline \multirow{2}{*}{\multicolumn{2}{|c|}{$\begin{array}{c}\text { Gesamt } \\
\text { in } \%\end{array}$}} & 216 & 254 & 131 & 105 & 4 & 0 & 6 \\
\hline & & - & - & $61 \%$ & $48 \%$ & $2 \%$ & $0 \%$ & $3 \%$ \\
\hline
\end{tabular}

\subsection{Typisierungsergebnisse der mitochondrialen Marker und Ableitungen}

\subsubsection{Analyse der HVR I}

In Vorversuchen an rezenter DNA aus Chelex-Extrakten wurden die in Kapitel 3.4.1 beschriebenen Primersysteme /-kombinationen für die HVRI-Analyse getestet. Dabei konnten für alle Kombinationen, bei gleich bleibenden Amplifikationsparametern, sehr gute Ergebnisse erzielt werden. Die Amplifikationsprodukte wiesen die jeweiligen theoretisch berechneten 
Fragmentlängen auf, und es wurden keine störenden unspezifischen Produkte generiert (vgl. Abb. 37).

Alle akquirierten Proben wurden einer mtDNA-Analyse ihrer HVRI unterzogen. Es wurde zuerst versucht, das längste aus den Primerkombinationen mögliche Amplifikationsprodukt von 434bp Länge zu generieren (für die amplifizierten Produktlängen und jeweiligen Primerkombinationen vgl. Kap. 3.4.1). Bei DNA-Extrakten von 15 Individuen war die Amplifikation erfolgreich. Für alle anderen Proben wurde als nächstes versucht, das mittellange Amplifikationsprodukt, das den hinteren Bereich der untersuchten HVRI-Sequenz abdeckt (np16194 - np16429 / 236 bp), zu generieren. Dieser Abschnitt beinhaltet alle charakteristischen HVRI-Polymorphismen der amerikanischen mt-Haplogruppen (vgl. Tab. 7), deshalb wurde er zuerst untersucht. Der Amplifikationserfolg für das mittellange Produkt war weitaus höher. Insgesamt war es möglich, aus Extrakten von 70 Individuen PCR-Produkte zu generieren, die eine für die folgende Sequenzierreaktion ausreichende Produktstärke aufwiesen (vgl. Abb. 37). Bei erfolgreicher Amplifikation des ersten mittellangen PCR-Produktes wurde versucht, das zweite mittellange Produkt (np15995-np16256) aus denselben Extrakten zu generieren. In der Regel gelang diese auch erfolgreich.

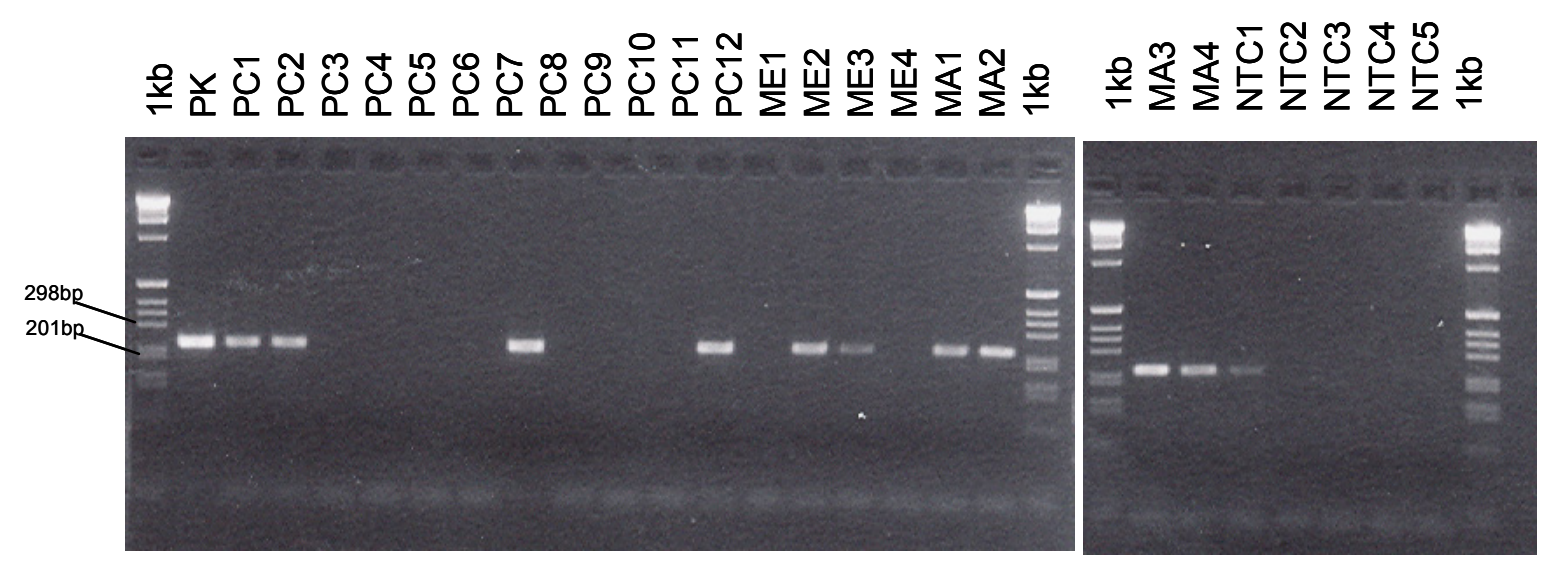

Abb. 37: Das Agarosegelbild zeigt den Amplifikationserfolg der HVRI-PCR 91 (Primer: mt_H_16194 /mt_L_16429 - Produktlänge: 236 bp) für prähistorische Proben aus Peru (PC, ME und MA), einer Positivkontrolle (PK) und fünf Leerkontrollen (NTC 1-5). NTC 1 weist ein spezifisches Produkt auf, bei dem es sich wahrscheinlich um eine Kontamination aus einem Reaktionsgefäß handelt. Unter $75 \mathrm{bp}$ befinden sich unspezifische Produkte und freie Primer. Als Längenstandard diente die 1KB-Leiter.

Für DNA-Extrakte, aus denen die Amplifikation der mittellangen PCR-Produkte nicht möglich war, wurde dann versucht, eines der vier aus den Primerkombinationen möglichen, kurzen Fragmente zu generieren. Es wurde zuerst das Fragment mit den meisten diagnostisch relevanten Nukleotidpositionen (np16194-np16360) gewählt, um überprüfen zu können, ob wirklich DNA 
von indigenen amerikanischen Individuen amplifiziert wurde, oder ob die Produkte aus europäischen Kontaminationen resultieren. Extrakte, die auch hier keinen Amplifikationserfolg erbrachten, wurden danach von weiteren Untersuchungen ausgenommen. Bei Amplifikationserfolg wurden aus demselben Extrakt die anderen drei kurzen DNA-Fragmente amplifiziert. Für alle Individuen, bei denen die Amplifikation des langen, der mittleren oder der kurzen DNA-Fragmente aus einem Extrakt erfolgreich war, wurden weitere Amplifikationen vorgenommen. Es folgten so viele Analysen, dass aus mindestens zwei DNA-Extrakten des Individuums reproduzierte Typisierungsergebnisse für den gesamten untersuchten Abschnitt der HVRI vorlagen. Individuen, bei denen es nicht möglich war, die Ergebnisse zu reproduzieren oder nur einzelne unzusammenhängende Abschnitte der HVR I amplifiziert werden konnten, wurden von der weiteren Auswertung der Ergebnisse ausgenommen.

Bei allen PCRs zur Amplifikation der HVRI Fragmente wurden Leerkontrollen mitgeführt. Diese wiesen bei der Amplifikation der langen DNA-Fragmente (434bp) nie spezifische Amplifikationsprodukte auf. Bei den PCRs für die mittleren (236-261bp) und kurzen Fragmente (152-180bp) konnten sporadisch Kontaminationen in den Leerkontrollen nachgewiesen werden. Frühere Untersuchungen zu Kontaminationen in Reaktionsgefäßen konnten bereits zeigen, dass die Nachweisrate von Kontaminationen in Reaktionsgefäßen mit der Abnahme der Fragmentlänge eines Amplifikats und einer gleichzeitigen Erhöhung der Zyklenzahlen zunimmt (Schmidt et al. 1995; Hummel 2003). Die höchsten Kontaminationsraten treten bei der Untersuchung mitochondrialer DNA ab einer Fragmentlänge unter 200bp auf. Um das Risiko falsch-positiver Ergebnisse zu verringern, wurden alle PCRs zur Amplifikation der kurzen HVRI-Fragmente mit maximal 40 Zyklen durchgeführt. Es ist davon auszugehen, dass die in den Leerkontrollen nachgewiesenen PCR-Produkte auch auf Gefäßkontaminationen zurückzuführen sind (vgl. Abb. 37). Zum Ausschluss anderer Quellen wurden die Produkte aus den Leerkontrollen mitsequenziert und anschließend mit den übrigen Ergebnissen verglichen. Darüber hinaus wurden reproduzierte Analysen durchgeführt, um Kontaminationsereignisse aufzudecken.

Alle generierten PCR-Produkte ließen sich in der Regel problemlos sequenzieren (Abb. 38). $\mathrm{Zu}$ vorzeitigen Abbrüchen der Sequenzauswertung kam es nur, wenn an der Position np16189 in dem so genannten C-Stretch (np16184-16193), einer homopolymeren Region in der HVRI, Cytosin als Base realisiert war und nicht Thymin. Durch diese Transition kommt es zu einer Basenabfolge von zehn C. Homopolymere Abschnitte dieser Länge führen regelmäßig zu Analysefehlern der von den Sequenzierern verwendeten Auswertungssoftware (Abb. 38). Dieses Phänomen ist aus der Literatur bekannt (Buttler 2005), aber selbst die Hersteller der 
Sequenzierer räumen ein, dass es keine Lösung für dieses Problem gibt. Für betroffene PCRProdukte wurde in diesem Fall ergänzend revers sequenziert (d.h. der L-Strang untersucht), um die Sequenzdaten zu komplettieren. Bei Sequenzabschnitten, die unsichere Nukleotidpositionen aufwiesen, z.B. zwei realisierte Basen oder unterschiedliche Basen in unabhängigen Analysen, wurde durch wiederholtes Amplifizieren und Sequenzieren versucht, einen sicheren Konsens zu finden (Abb. 39). War dieses, z.B. durch die zu starke Degradierung bzw. Deaminierung der DNA nicht möglich (vgl. Kap. 2.2.2), wurden die Proben von der weiteren Analyse ausgeschlossen. Die vollständigen Einzeltypisierungsergebnisse der HVRI Analysen für alle Individuen finden sich im Anhang (10.4.4).

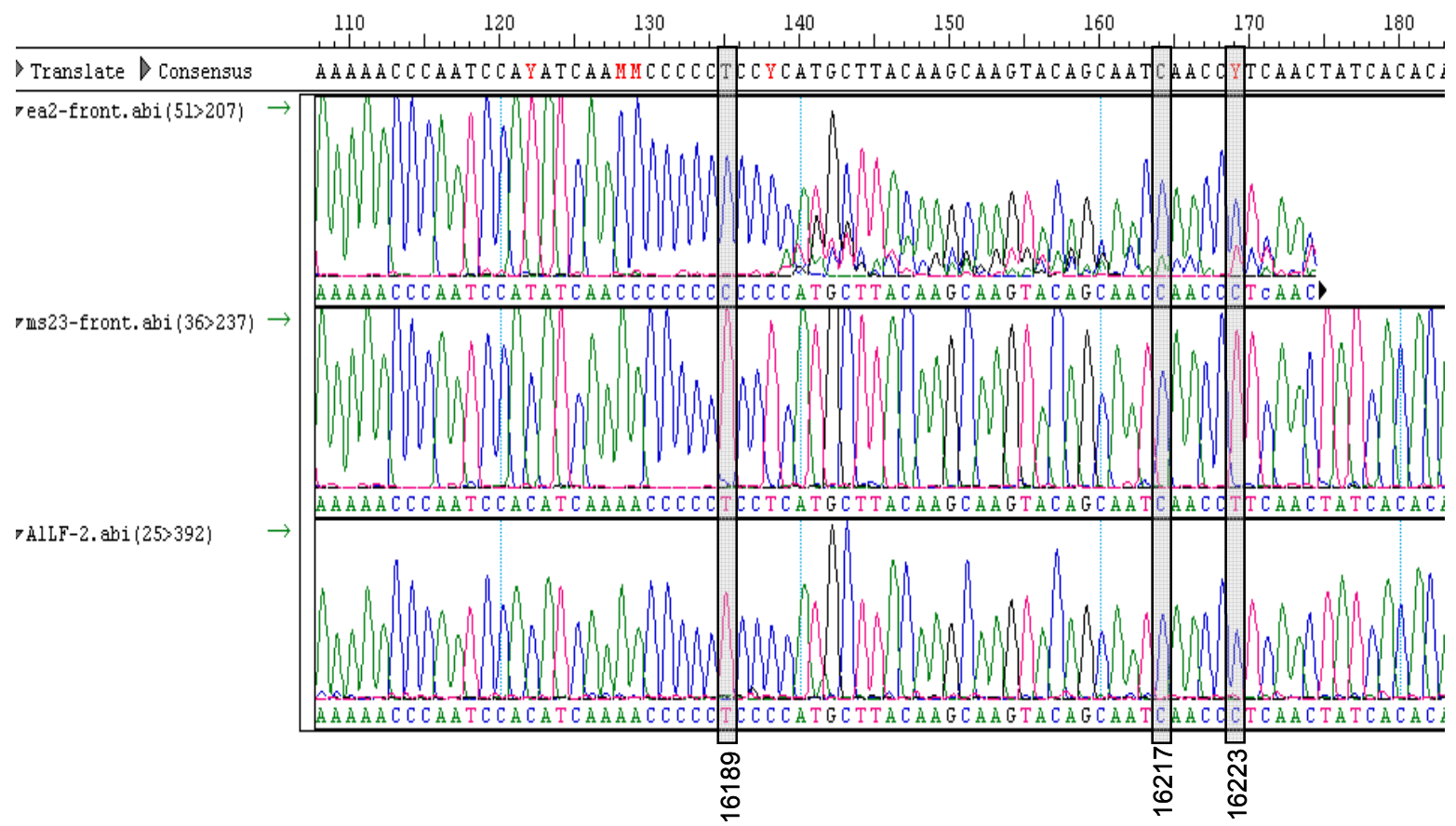

Abb. 38: Elektropherogramm eines Sequenzausschnittes der HVRI zweier prähistorischer peruanischer Individuen und einer rezenten europäischen Kontrollprobe (Haplogruppe H). Die Gegenüberstellung der Sequenzen erlaubt die Aufklärung von Sequenzpolymorphismen. Bei dem Individuum EA2 (Haplogruppe B) ist der C-Stretch durch eine Transversion zu C an Position 16189 realisiert. Dadurch kommt es zu einer Art slippage Phänomen, das die weitere Sequenzauswertung unmöglich macht. Es ist allerdings noch zu sehen, dass das Individuum die für HG B charakteristische Transversion zu C an Position 16217 aufweist. Die beiden anderen Sequenzen weisen an Position 16189 ein $T$ auf, wodurch die Sequenz nicht abbricht. Das Individuum MS23 (Haplogruppe D) weist darüber hinaus noch die für Haplogruppe D charakteristische Transversion zu T an Position 16223 auf. 


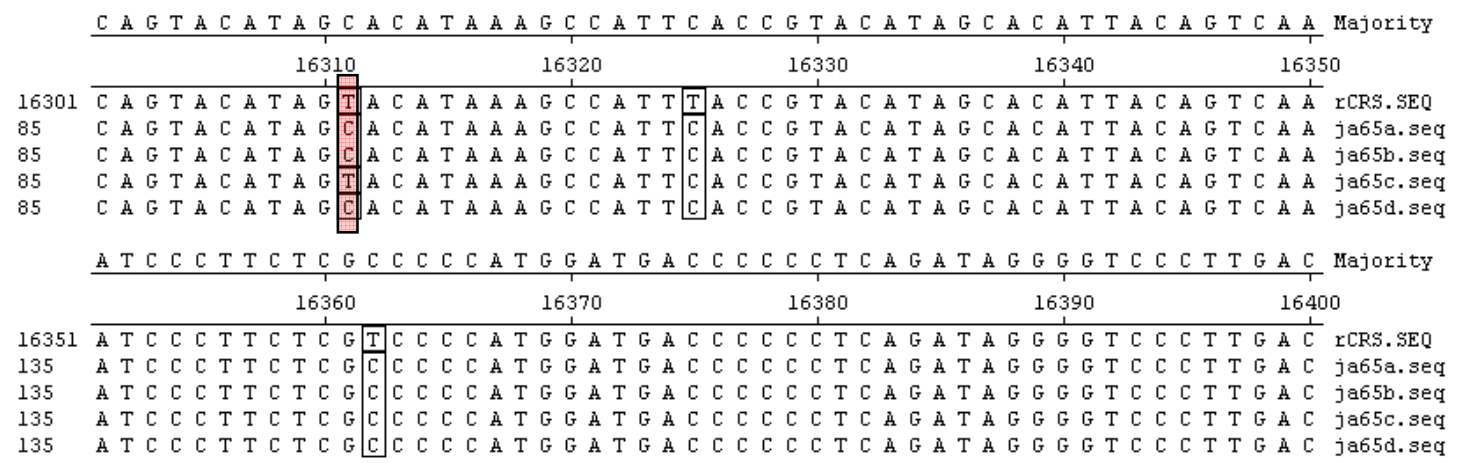

Abb. 39: Sequenzallignment für einen vier Mal unabhängig amplifizierten Sequenzabschnitt eines Individuums (JA65). Die oberste Sequenz ist die Referenzsequenz (rCRS), mit der die anderen Sequenzdaten aligniert wurden. An np 16311 ist bei der Sequenz JA65c ein $T$ statt einem $C$ wie bei den anderen drei Sequenzen des gleichen Individuums realisiert. Dieser Basenunterschied ist wahrscheinlich ein Deaminierungsartefakt. Da die Sequenz von JA65c nur an einer Position den anderen Sequenzen widerspricht und durch die mehrfache Replikation der Analyse drei mal für diese Basenposition für dieses Individuum ein $C$ nachgewiesen wurde, wird für die Konsenssequenz (nicht abgebildet) entschieden, dass an np16311 der HVRI-Sequenz des Individuums JA65 ein C realisiert ist.

\subsubsection{Analyse der mitochondrialen SNPs und der 9bp-Deletion}

Auch das HybProbe-Multiplex Analysesystem zur Untersuchung der drei die mt-Haplogruppen determinierenden SNPs und der 9bp-Deletion (vgl. Abb. 31) wurde in Vorversuchen an rezenter DNA getestet. Für alle vier Systeme wurden zuerst in Singleplex-Reaktionen die Amplifikationsund Schmelzkurvenanalyseparameter optimiert und aneinander angepasst. Danach erfolgte die Kombination der einzelnen Systeme zu einer Multiplex-Reaktion. Hierfür war es nötig, die Konzentrationen der Sonden so aufeinander abzustimmen, dass eine optimale Detektion der jeweiligen Fluoreszenzen möglich war (vgl. Tab. 18). Anschließend wurden mit rezenten peruanischen und europäischen Kontrollproben die jeweils spezifischen Schmelzpunkte der Sondensyteme in Abhängigkeit von den realisierten Basen in den untersuchten Abschnitten determiniert. Damit wurde eine Schmelzkurven-Matrize für die Genotypisierung der aDNAProben generiert. Alle vier HybProbe-Systeme ließen sich erfolgreich einzeln, aber auch in der Muliplex amplifizieren. Für jedes System konnte darüber hinaus eine Schmelzkurvenanlyse mit distinkten Temperaturen zur Typisierung der untersuchten Mutationen etabliert werden. Die jeweiligen Schmelzpunkte (Tm) für die Systeme sind Abb. 40 zu entnehmen.

Alle akquirierten Proben wurden einer mtDNA-Analyse mit dem HybProbe Multiplex System für die charakteristischen Polymorphismen der codierenden-Region der mtDNA unterzogen. Für Proben von 130 Individuen war es möglich, reproduziert alle vier Systeme zu typisieren (vgl. Tab. 23). Diese 130 Individuen beinhalten auch alle Proben, für die die Analyse 
der HVRI erfolgreich war. Zur Authentifizierung der Ergebnisse wurde für jedes Individuum jeweils eine Amplifikation und Analyse aus zwei DNA-Extrakten vorgenommen.

LC 610 System: np 663 A / G

$\mathrm{A}=53^{\circ} \mathrm{C} / \mathrm{G}=57^{\circ} \mathrm{C}$

Haplogroup $\mathbf{A}=\mathbf{G}$
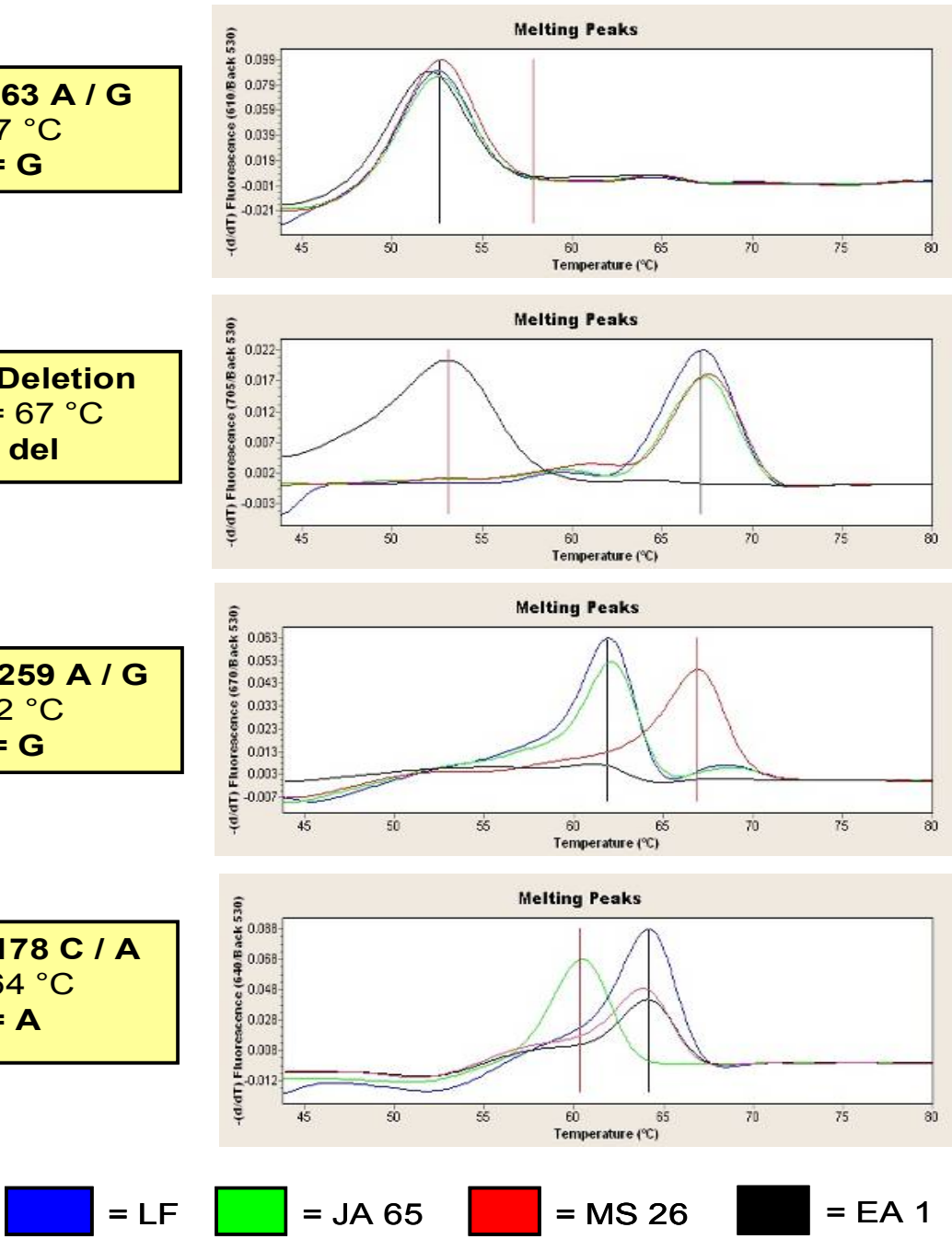

LC 640 System: np 5178 C / A

$\mathrm{A}=60,5^{\circ} \mathrm{C} / \mathrm{C}=64^{\circ} \mathrm{C}$

Haplogroup D = A

Abb. 40: Schmelzpunktauswertung an drei prähistorischen peruanischen Proben und einer rezenten europäischen Kontrollprobe (LF), analysiert mit dem HybProbe Multiplex PCR System. Für die Analyse der vier Proben ist jedes der vier Sondensysteme (vgl. Tab 17) einzeln aufgeführt. Den Kästen auf der linken Seite sind die mutationsspezifischen Schmelzpunkte (Tm) für jedes System zu entnehmen. Die Schmelzkurvendiagramme auf der rechten Seite zeigen die jeweilige Analyse und ermöglichen die Bestimmung der Haplogruppe bei Kenntnis der mutationsspezifischen Schmelzpunkte.

Typisierungsergebnisse: JA $65=$ D $/$ MS $26=$ C $/$ EA $1=$ B $/$ LF $=$ weder A, B, C od. D (HG = J).

Das hier entwickelte Real-Time PCR Analysesystem hat sich als erfolgreich auch für die Anwendung auf aDNA bewiesen. Auch wenn die Entwicklung dieses Systems und die Anpassung der Konzentrationen der insgesamt acht Primer und acht Sonden aufeinander sehr zeitaufwendig war, ermöglicht das etablierte System eine sehr schnelle und effiziente Analyse 
solcher populationsgenetisch relevanter Polymorphismen und zeigt sich der klassischen RFLPMethode überlegen. Alle der untersuchten vier Haplogruppen lassen sich sicher bestimmen und durch die Kombination der vier Systeme ist es darüber hinaus möglich, andere Haplogruppen zwar nicht zu bestimmen, aber als anders zu identifizieren. Die Haplogruppen der jeweiligen Individuen und die Einzeltypisierungsergebnisse finden sich im Anhang (10.3.2 u. 10.4.3), die Auswertung der Haploguppenbestimmung für die untersuchten Proben in Kap. 4.2.4.

\subsubsection{Bestimmung der mitochondrialen Haplotypen}

Es konnten für insgesamt 105 der untersuchten Individuen reproduzierte Sequenzdaten des gesamten untersuchten Abschnittes der HVR I generiert werden. Diese Sequenzen sind Konsenssequenzen, die sich aus den Ergebnissen der einzelnen Amplifikationen und Sequenzierungen, wie in Kap. 3.8 beschrieben, zusammensetzen.

Insgesamt konnten 44 variable Nukleotidpositionen (segregating sites $=\mathrm{S}$ ) in dem 388bp langen untersuchten Abschnitt der HVR I nachgewiesen werden. Anhand dieser Polymorphismen war es möglich, 57 mitochondriale Haplotypen $(\mathrm{H})$ für die 105 Individuen zu unterscheiden (Abb. 41). Alle Haplotypen lassen sich den vier indigenen amerikanischen Haplogruppen (A, B, C und D) zuordnen (vgl. Kap. 4.2.2). Für die Benennung der Typen wurde eine Kombination aus dem Namen des Untersuchungsgebietes (Palpa-Region: PA), der Haplogruppe, in die der Typ gruppiert (Bsp.: A), und einer fortlaufenden Nummerierung gewählt (Bsp.: PA-A1). Die Sortierung der einzelnen Haplotypen wurde unter Berücksichtigung der phylogenetischen Beziehungen der Typen zueinander vorgenommen (vgl. Abb. 42). Alle analysierten Haplotypen und die zeitliche und räumliche Herkunft der Individuen sind Abb. 41 zu entnehmen (Auflistung pro Individuum im Anhang: 10.3.3).

32 Haplotypen (57\%) konnten für nur jeweils ein Individuum und 25 Haplotypen (43 \%) für mehrere Individuen nachgewiesen werden. Elf der von mehreren Individuen geteilten Typen traten nur an einem einzigen Fundort mit gleicher Zeitstellung auf. Die übrigen 14 mehrfach bestimmten Haplotypen verteilen sich entweder über verschiedene zeitgleiche Fundorte des Untersuchungsgebietes (insgesamt: $4 \mathrm{H}$ ) oder treten auch zeitübergreifend (insgesamt: $10 \mathrm{H}$ ) auf. Der Tab. 24 sind diese Typen und ihre zeitliche und räumliche Verteilung zu entnehmen.

Abb. 41: (nächste Seite) Zusammenfassung aller in den Proben nachgewiesenen HVRI-Haplotypen unter Angabe des Herkunftsortes, der Zeitstellung und der jeweiligen Zahl an Individuen pro Fundort, die den Haplotypen aufweisen. Unter den Nukleotidpositionen ist die in der rCRS realisierte Base angegeben. Für die jeweiligen Haplotypen werden die variablen Positionen genannt. 


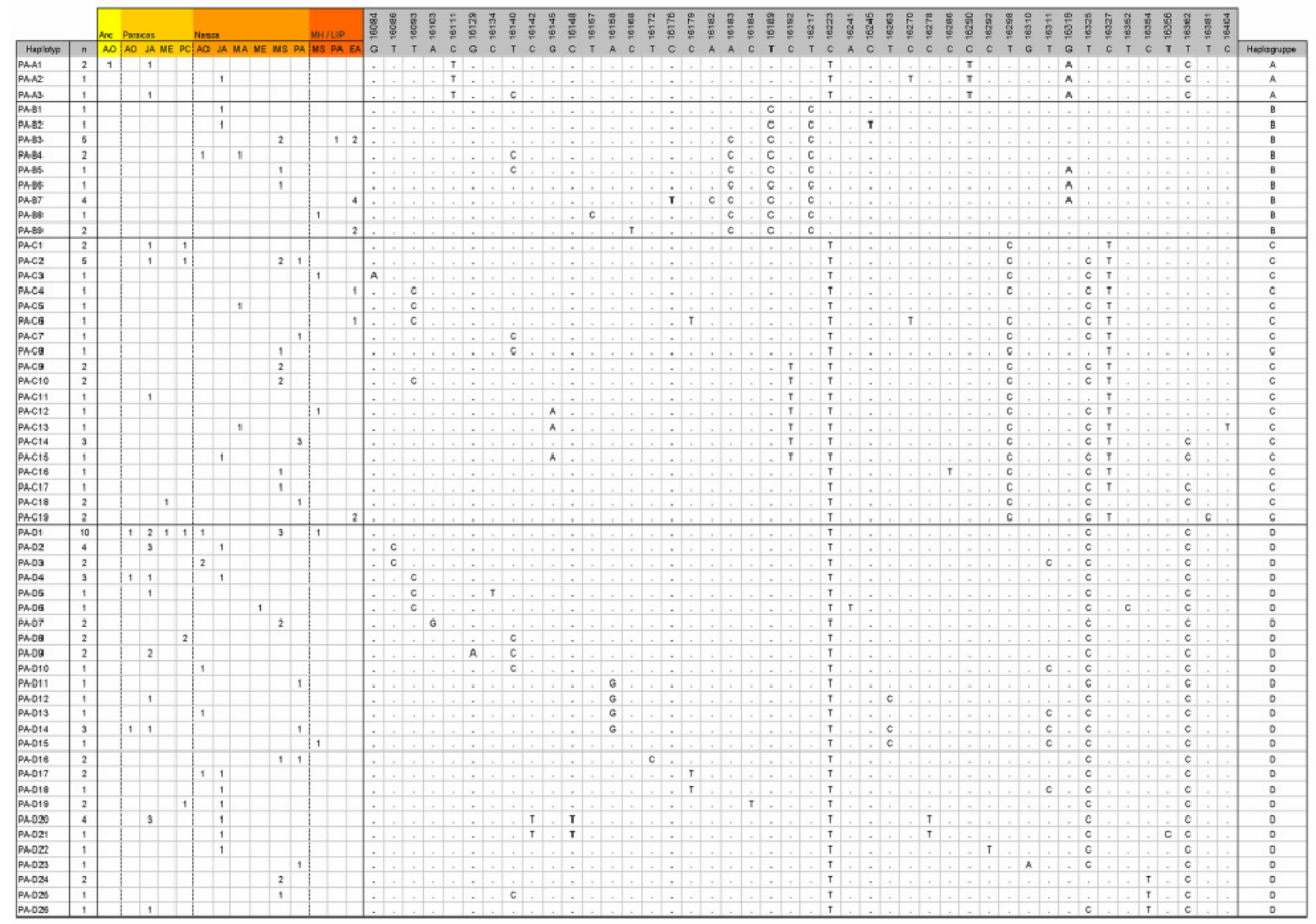


Tab. 24: Zeitliche und räumliche Verteilung der bei mehreren Individuen nachgewiesenen mt-Haplotypen. In den Spalten ist die jew. Zahl der Individuen des Haplotyps aus den verschiedenen Orten und Phasen angegeben. (Blaue Kästchen = Haplotypen, die in der gleichen Zeitstellung an verschiedenen Fundorten auftreten; grüne Kästchen = Haplotypen, die zeitübergreifend und an verschiedenen Fundorten nachgewiesen wurden)

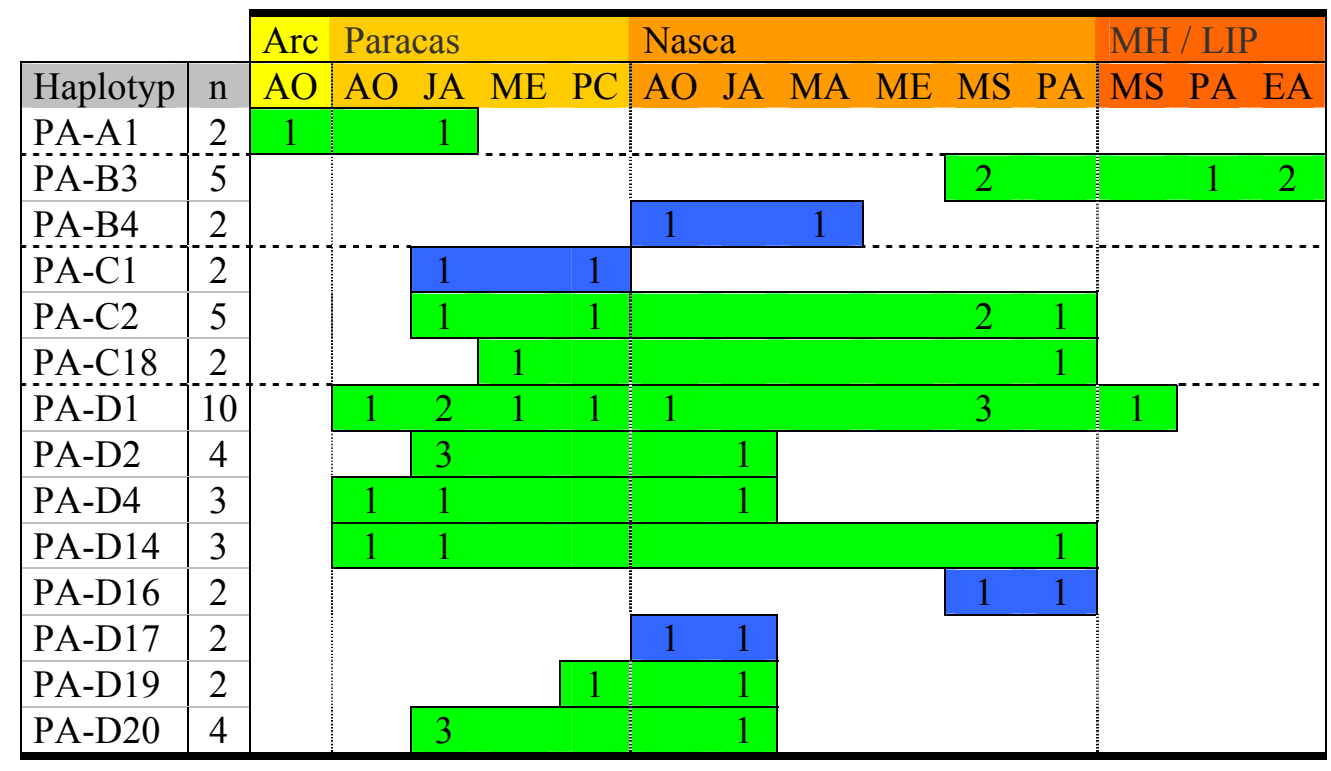

Die Haplotypen PA-A1 $(n=2)$, PA-C2 $(n=5)$ und PA-D1 $(n=10)$ entsprechen den Gründerhaplotypen der indigenen amerikanischen Bevölkerung (vgl. Tab 7). Sie sind auch die am häufigsten nachgewiesenen Typen der jeweiligen Haplogruppen. Der Gründerhaplotyp der Haplogruppe B wird hier durch die Haplotypen PA-B1 $(n=1)$ und B3 $(n=5)$ repräsentiert. Die Aufteilung in zwei separate Haplotypen resultiert aus dem Umstand, dass die für die Haplogruppe charakteristische Transition von T zu C an np16189 häufig von Transversionen (A zu C) an den Positionen 16182 und 16183 begleitet wird (Bandelt u. Parson 2007). Wird also durch den Basenaustausch zu C an der Position 16189 der homopolymeren C-Stretch in diesem Abschnitt der HVR I gebildet, variiert dieser in seiner Länge zwischen 10 bis 12 CytosinWiederholungen. Die hohe Variabilität der Positionen 16182 und 16183 in Abhängigkeit von der jeweils realisierten Base an Position 16189 führt dazu, dass viele Autoren diese nicht berücksichtigen. So auch nicht bei der Bestimmung des Gründerhaplotypen für die Gruppe B (vgl. Merriwether et al. 1995). Der Haplotyp PA-B3, charakterisiert durch die Polymorphismen 16183C-16189C-16217C, konnte in den untersuchten Populationen aus der Palpa-Region am häufigsten von den beiden potentiellen B-Gründertypen nachgewiesen werden. Ein 12-C CStretch fand sich nur in den HVRI-Sequenzen vierer Individuen aus Pacapaccari (EA) mit dem Haplotypen PA-B7 (16176T-16182C-16183C-16189C-16217C-16319A). 


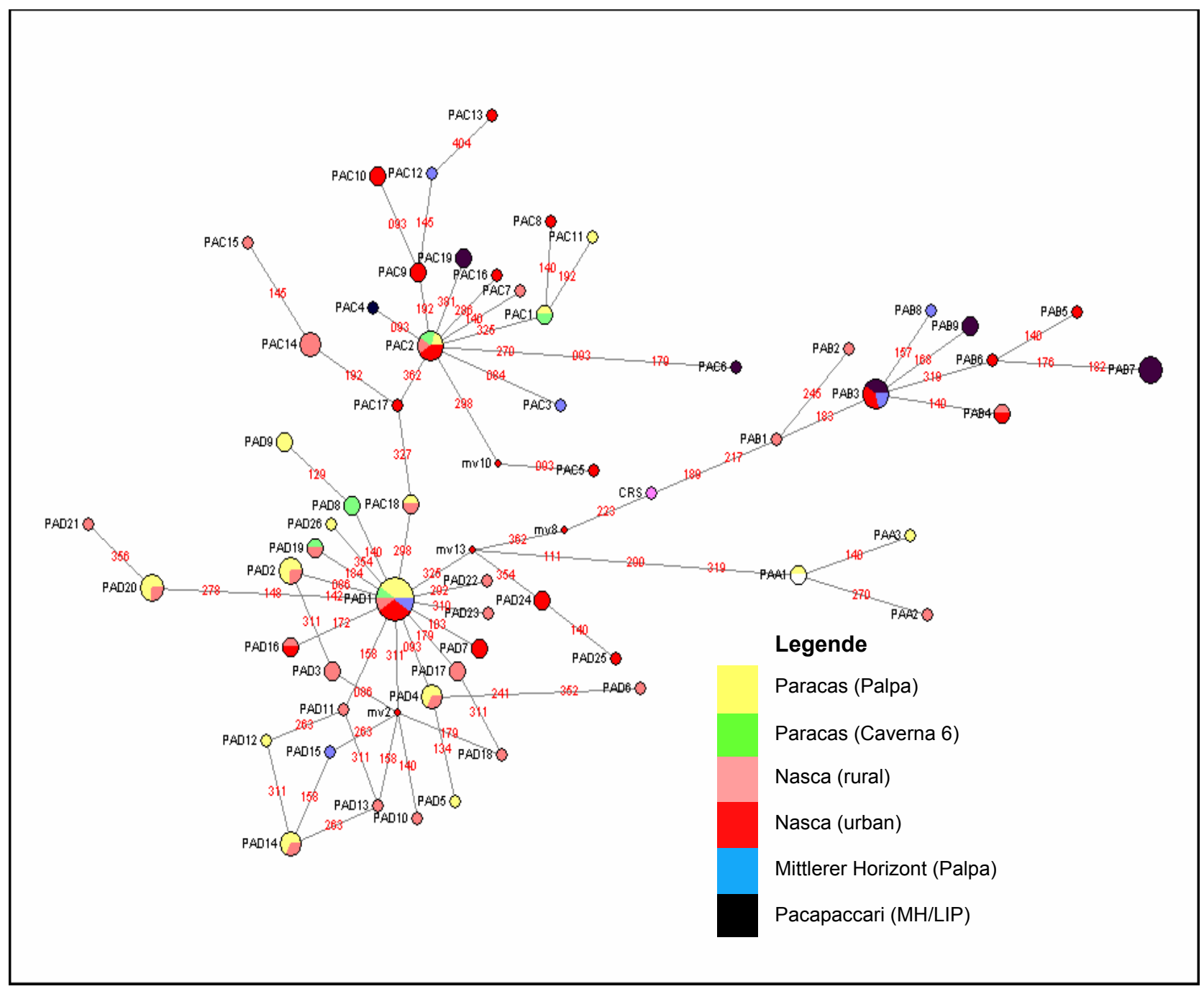

Abb. 42: Median-Joining-Netzwerk der 105 HVRI-Sequenzen. Die Größe der Kreise ist proportional zur Häufigkeit der jeweiligen Haplotypen in den untersuchten Proben. Die Zahlen (rot) an den Verbindungen bezeichnen die Position der Mutation (16.xxx) gemäß der Referenzsequenz (rCRS). Die Farben der Knoten beschreiben die räumliche und zeitliche Herkunft der Individuen mit den entsprechenden Haplotypen (vgl. Legende) und die Häufigkeit des jew. Haplotypen pro Zeitstellung.

Der Gründerstatus der Haplotypen PA-A1, C2, D1 und B3 wird auch in der Netzwerk-Analyse deutlich (Abb. 38). Sie bilden die jeweiligen zentralen Knoten, von denen aus sich die anderen Haplotypen der gleichen Haplogruppe sternförmig ableiten. Diese Topographie des Netzwerkes deutet darauf hin, dass es zu einer demographischen Expansion kam, ausgehend von einer Stammpopulation, die sich aus den vier zentralen Knotenpunkten / Haplotypen zusammensetzte (Bandelt et al. 1995). Der Beginn dieser Expansion beschreibt in diesem Fall die initiale Besiedlung der amerikanischen Kontinente (vgl. Silva et al. 2002; Salzano 2002; Smith et al. 2005). Insgesamt bilden sich vier Cluster im Netzwerk, die den vier Haplogruppen entsprechen. Die geringe Distanz zwischen dem C und D Cluster resultiert aus der phylogenetischen Verbindung der beiden Gruppen zueinander. Beide Haplogruppen leiten sich aus der 
Makrohaplogruppe M ab und haben die gleiche zeitliche Entwicklungstiefe (Starikovskaya et al. 2005). Die Lage der Haplotypen PA-C17 und der sich daraus ableitenden Typen C14, C15 und C18 zwischen den Clustern der Haplogruppe D und C im Netzwerk resultiert vor allem aus der $\mathrm{T}>\mathrm{C}$ Transition an der Position 16362. Diese Mutation ist charakteristisch für die indigenen amerikanischen Haplotypen der Gruppen A und D (vgl. Tab 7). Dementsprechend werden die vier C-Haplotypen näher an das D-Cluster gruppiert. Allerdings handelt es sich bei der Nukleotidposition 16362 um einen mutational hotspot mit einer sehr hohen Substitutionsrate. Mutationen an dieser Position sind aus allen mitochondrialen Haplogruppen bekannt (Behar et al. 2007). Damit ist der diagnostische Charakter dieser Nukleotidposition zur Bestimmung von Haplogruppen als sehr gering einzuordnen.

Es konnten insgesamt acht hochvariable Nukleotidpositionen identifiziert werden, die Basensubstitutionen in mehreren Haplotypen der vier Haplogruppen aufwiesen (vgl. Abb. 43). Vier dieser Positionen sind charakteristisch für mindestens eine der Haplogruppen (16223 $\mathrm{A} / \mathrm{C} / \mathrm{D} ; 16225$ - C/D; $16319-\mathrm{A} ; 16362$ - A/D), und das Auftreten in mehreren Haplogruppen resultiert zumeist aus der phylogenetischen Verbindung dieser Gruppen zueinander. So ist z.B. die $\mathrm{C}>\mathrm{T}$ Transition an np16223 charakteristisch für alle Haplogruppen außer denen, die sich aus der Makrohaplogruppe R ableiten (vgl. Kap. 2.2.3). Die Nukleotidposition 16140 stellt dagegen einen realen mutational hotspot dar. In verschiedenen Haplotypen aller vier Haplogruppen konnte hier eine Substitution nachgewiesen werden, ohne dass eine direkte phylogenetische Beziehung, bzw. Abstammung der Typen voneinander besteht (vgl. Abb. 42). Dieses Bild bestätigt sich auch durch den weltweiten Vergleich mit anderen Haplogruppen (Behar et al. 2007).

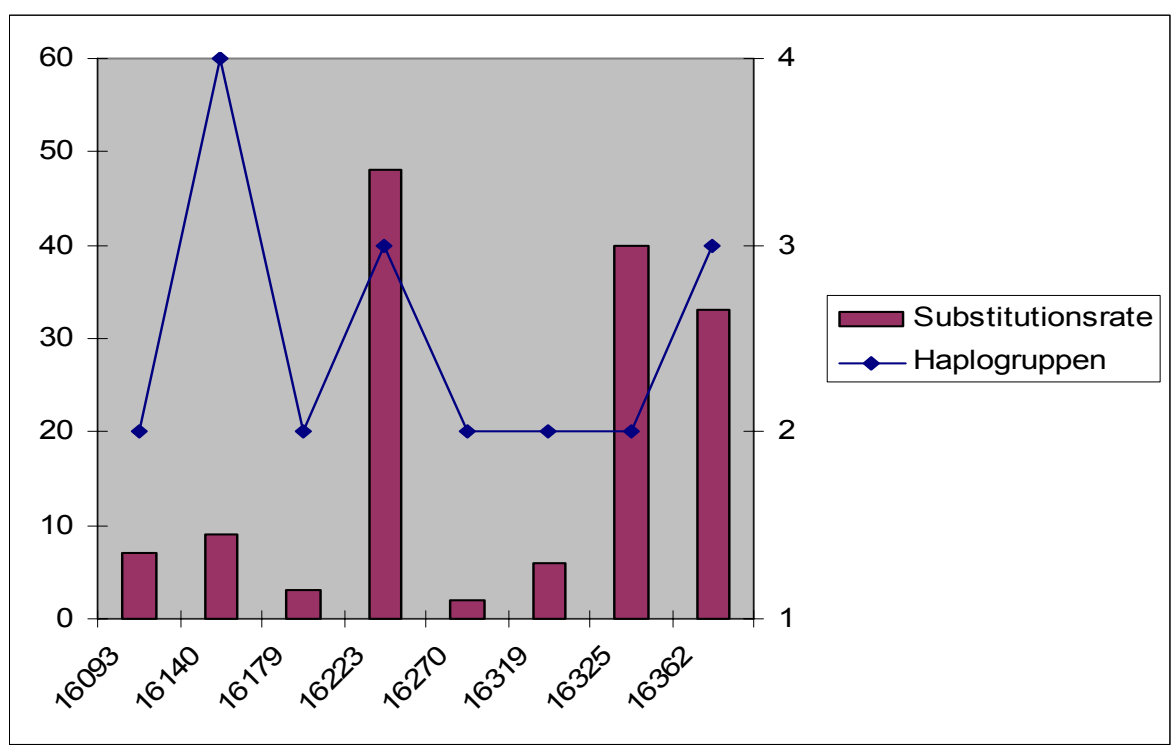

Abb. 43: Hochvariable Nukleotidpositionen. In der $x$-Achse findet sich die jeweilige Position. Die linke y-Achse gibt die Substitutionsrate (Häufigkeit von Mutationen an der Position im Datensatz) an. Die rechte $y$-Achse beschreibt die Zahl der Haplogruppen, in denen für die Position ein Mutationsereignis nachgewiesen werden konnte. 
Die weitere Beurteilung der phylogenetischen Relationen der Haplotypen zueinander erfolgt im nächsten Kapitel. Die populationsgenetische Auswertung der Haplotypen-Daten erfolgt in Kapitel 5.2.

\subsubsection{Bestimmung der mitochondrialen Haplogruppen}

Durch die Analyse der Polymorphismen der Codierenden-Region der mtDNA und der HVR I konnten für 131 Individuen die mitochondrialen Haplogruppen bestimmt werden. Für 26 Individuen war diese Bestimmung nur durch die Untersuchung der Polymorphismen in dem codierenden Anteil des mt-Genoms möglich, während für 105 Individuen eine zusätzliche Bestimmung der Haplogruppe über die HVRI-Sequenzen erfolgte. (vgl. Kap. 4.2.3). Die jeweiligen Sequenzdaten der 105 Individuen gruppieren sich in der phylogenetischen Analyse über einen NJ-Baum (Abb. 44) und in einem Netzwerk aller 57 Haplotypen (Abb. 42) in vier distinkte Cluster, die den vier indigenen amerikanischen Haplogruppen entsprechen. In den untersuchten Proben wurden nur die Haplotypen A, B, C und D nachgewiesen. Weder aus den HVRI-Sequenzdaten, noch aus den Polymorphismen der codierenden Region ergibt sich die Zuordnung $\mathrm{zu}$ einer anderen asiatischen Haplogruppe. Dieses Bild bestätigt für das Untersuchungsgebiet die Annahme, dass sich die amerikanische Urbevölkerung aus vier Gründerhaplogruppen rekrutiert (Torroni et al. 1993).

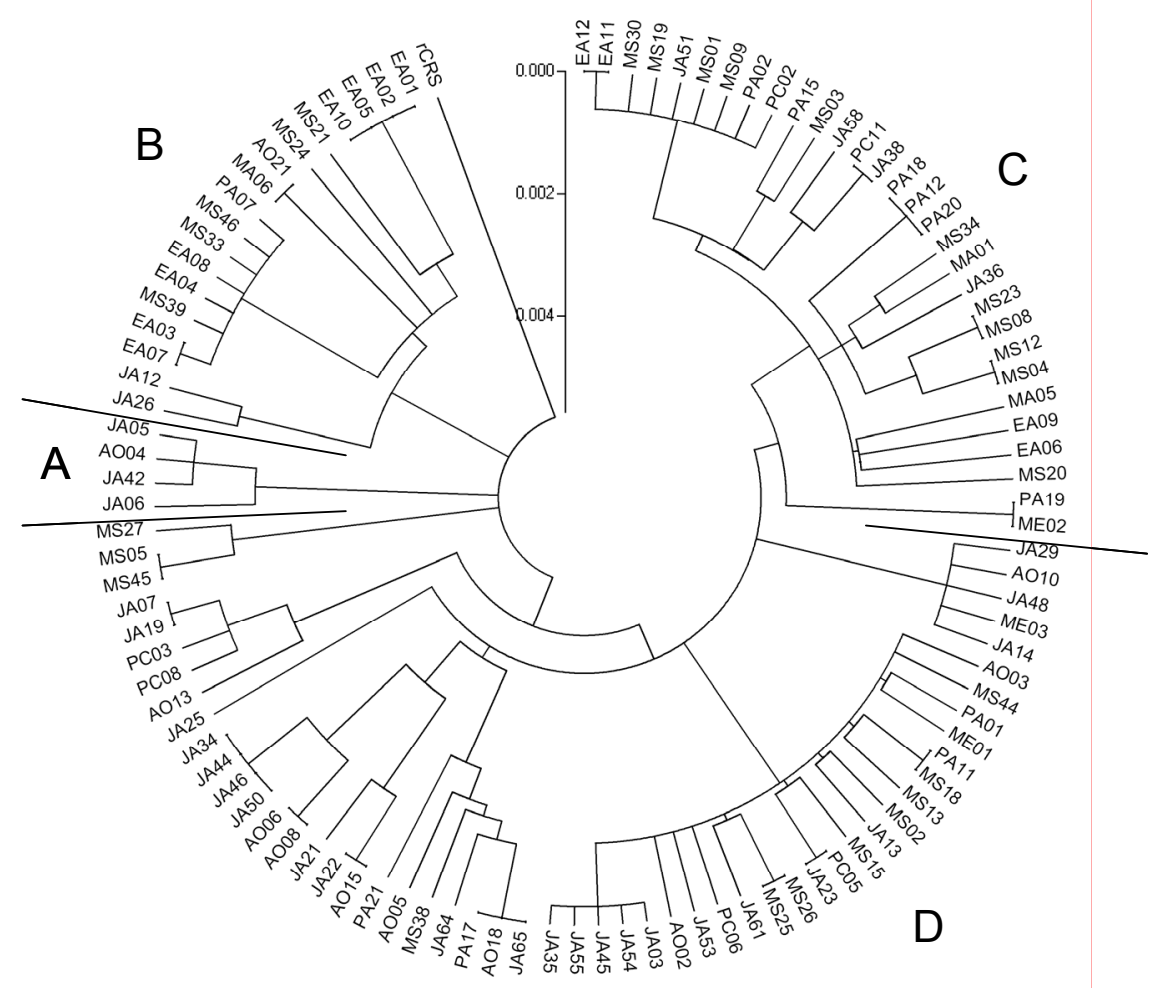

Abb. 44: Linearisierter NJ-Baum der 105 ermittelten HVRI-Sequenzen und der rCRS. Der Baum ist skaliert mit Astlängen, die die jeweiligen berechneten Distanzen (vgl. Kap. 3.8.2) wiedergeben. Die Zuweisung der Sequenzen zu den jeweiligen Haplogruppen (außen angegeben) erfolgte über die Ergebnisse aus der Untersuchung der mitochondrialen Kontrollregion. 
Insgesamt konnten 4 Individuen der Haplogruppe A (2\%), 23 der Haplogruppe B (18\%), 36 der Haplogruppe C (28\%) und 68 der Haplogruppe D (52\%) zugeordnet werden. Die genaue Verteilung - nach Fundort und Zeitstellung - der Individuen aus den untersuchten Populationen, für die eine Haplogruppe bestimmt werden konnte, und der jeweilige prozentuale Anteil der Gruppen in den Populationen ist Tab. $25 \mathrm{zu}$ entnehmen. Die Analyse der Haplogruppenverteilung erfolgt in Kapitel 5.1.

Tab. 25: Ergebnisse der Haploguppenbestimmung und Verteilung der 131 typisierten Individuen über die Fundorte und Zeitstellungen. Die Angabe der bestimmten HG's erfolgt in absoluten Zahlen und prozentualen Anteilen bezogen auf die jeweilige Population (in Klammern).

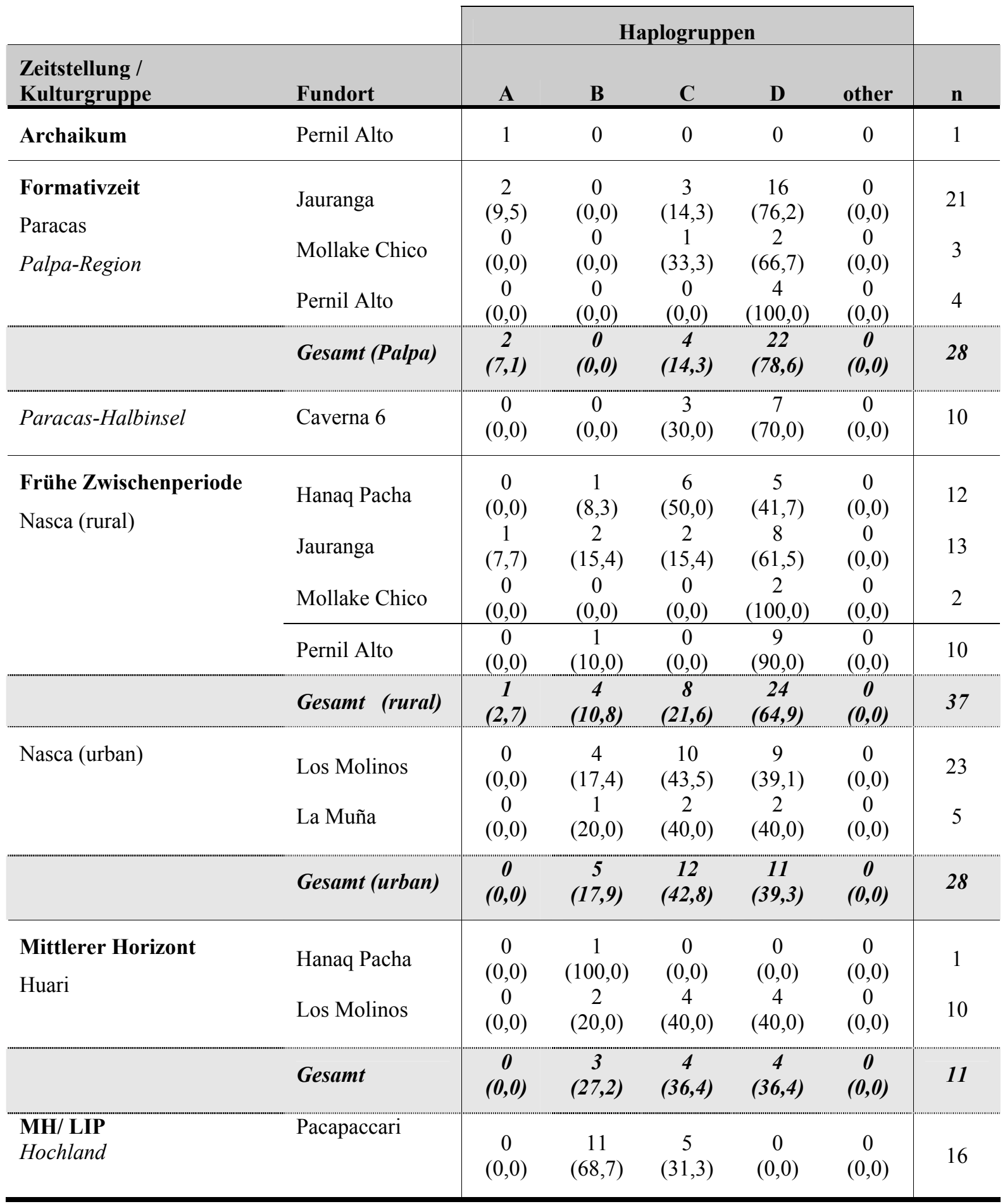




\subsection{Typisierungsergebnisse der nuklearen Marker}

\subsubsection{Autosomale STRs und Amelogenin}

Wie bereits in Kapitel 4.1 beschrieben, ließ der in den Proben angetroffene DNAErhaltungszustand in nur sehr wenigen Fällen die erfolgreiche Amplifikation nuklearer DNA zu. Alle Individuen, aus deren DNA-Extrakten mindestens eines der mittellangen HVRI-Produkte amplifiziert werden konnte, wurden einer Untersuchung mit dem Oktaplex-Analysesystem für die autosomalen STRs und Amelogenin unterzogen (vgl. Kap 3.4.3). Proben, bei denen nur die kurzen HVRI-Produkte amplifiziert werden konnten, wurden aufgrund des daraus abzuleitenden Grades der DNA-Degradierung nicht weiter auf den Erhalt von nuklearer DNA untersucht.

Insgesamt konnten für sechs Individuen reproduziert einige Allele amplifiziert werden. Vollständige genetische Fingerabdrücke konnten nicht generiert werden (Abb. 26). Reproduzierte Allelbestimmungen bzw. Typisierungen aus den sechs Individuen liegen vor allem für Amelogenin (6) und D13S317 (5) vor (vgl. Tab. 26). Es handelt sich bei beiden um die kürzesten der untersuchten Systeme $(\mathrm{D} 13=103-131 \mathrm{bp}$; Amelogenin = 107 od. 113bp). Diese Tatsache unterstützt die Annahme, dass der geringe Amplifikationserfolg auf den DNA-Erhalt und den Degradierungsgrad der Proben und nicht auf mögliche Fehler des Analysesystems zurückzuführen ist. In Tab. 26 finden sich die aus den einzelnen Amplifikationen zusammengefassten Konsens-Genotypen der sechs Individuen. Die Einzeltypisierungsergebnisse sind dem Anhang (10.4.1) zu entnehmen.

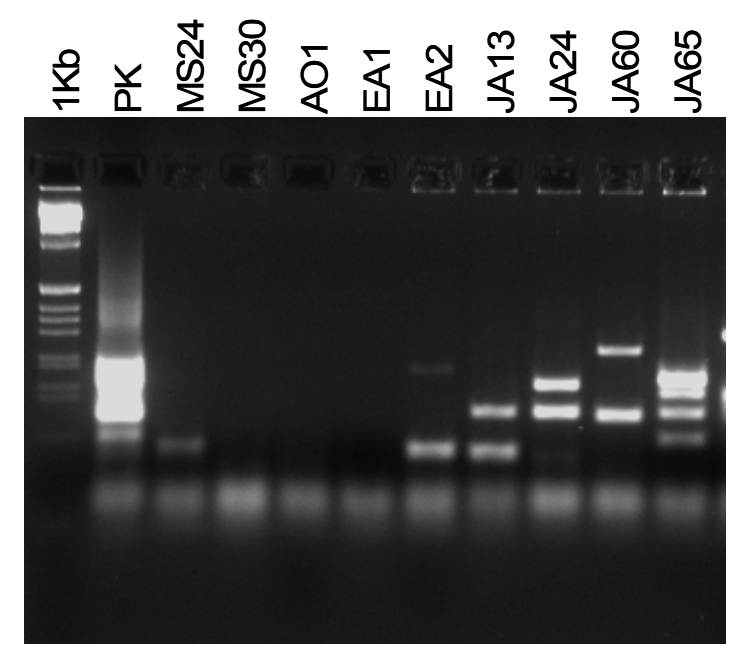

Abb. 45: Das Agarosegelbild zeigt den Amplifikationserfolg der Oktaplex-PCR (Okta1) für einige präkolumbische Proben aus der Palpa-Region. Die Positivkontrolle (PK) amplifiziert alle untersuchten Systeme, während für die meisten aDNA Proben kein Amplifikationserfolg nachzuweisen ist oder nur wenige Produkte gebildet werden. Eine Ausnahme macht in diesem Fall nur die Probe JA65. Im unteren Bereich des Gelbildes befinden sich Primerdimere und freie Primer. Es werden ansonsten keine unspezifischen Nebenprodukte gebildet. Als Längenstandard diente die 1KB-Leiter. 
Tab. 26: Reproduzierte Genotypen der Analyse der autosomalen STRs und Amelogenin

\begin{tabular}{l:cccccccc}
\hline Individuum & D13S317 & CSF1PO & FGA & Amelo & VWA & D5S818 & D3S1358 & D21S11 \\
\hline EA 1 & $(8) / 9$ & - & - & X/Y & - & - & 17 & - \\
EA 2 & - & - & - & X/Y & 16 & - & - & - \\
EA 4 & 9 & - & - & $\mathrm{X} / \mathrm{Y}$ & $16 / 17$ & - & - & - \\
EA 10 & 10 & - & - & $\mathrm{X} / \mathrm{Y}$ & - & - & 16 & - \\
EA 12 & $8 / 11$ & $11 /(14)$ & - & $\mathrm{X}$ & - & - & - & - \\
JA 65 & $9 / 10$ & - & $23 / 25$ & $\mathrm{X}$ & - & 11 & $14 / 15$ & - \\
\hline
\end{tabular}

\subsubsection{Y-SNPs und Y-chromosomale Haplogruppen}

Das Vorgehen zur Etablierung des HybProbe-Analysesystem zur Bestimmung der Ychromosomalen Haplogruppen gleicht dem für das mitochondriale Analysesystem (vgl. Kap 4.2.2). Die einzelnen Sondensysteme wurden zuerst in Singleplex-Reaktionen mit rezenter DNA eingestellt und dann zu einer Multiplex-PCR zusammengeführt und optimiert. Auch für die YSNPs konnte eine Schmelzkurvenanalyse mit distinkten Temperaturen zur Typisierung der untersuchten Mutationen etabliert werden. Die jeweiligen Schmelzpunkte (Tm) für die einzelnen Systeme sind Tab. 27 zu entnehmen.

Tab. 27: Schmelzpunkte (Tm) für die vier HybProbe-Systeme zur Analyse der Y-chromosomalen SNPs

\begin{tabular}{ccc|ccc|ccc|ccc}
\hline \multicolumn{10}{c}{ Schmelzpunkte Y-SNP HybProbe Multiplex } \\
\hline System & Tm & Base & System & Tm & Base & System & Tm & Base & System & Tm & Base \\
\hline \multirow{2}{*}{ M3 } & $66^{\circ} \mathrm{C}$ & $\mathrm{C}$ & \multirow{2}{*}{$\mathbf{M 4 5}$} & $60^{\circ} \mathrm{C}$ & $\mathrm{G}$ & \multirow{2}{*}{$\mathbf{3 1 3 0}$} & $64^{\circ} \mathrm{C}$ & $\mathrm{C}$ & \multirow{2}{*}{$\mathbf{M 2 4 2}$} & $59^{\circ} \mathrm{C}$ & $\mathrm{C}$ \\
& $60^{\circ} \mathrm{C}$ & $\mathrm{T}$ & & $56^{\circ} \mathrm{C}$ & $\mathrm{A}$ & & $59^{\circ} \mathrm{C}$ & $\mathrm{T}$ & & $56^{\circ} \mathrm{C}$ & $\mathrm{T}$ \\
\hline
\end{tabular}

Alle Proben, die mit der Oktaplex-PCR für die autosomalen STRs untersucht wurden, sind auch der Analyse mit dem HybProbe-System für die Y-SNPs unterzogen worden. Für 4 Individuen vom Fundort Pacapaccari konnten alle vier untersuchten Systeme reproduziert amplifiziert und durch die Schmelzkurvenanalyse typisiert werden (Einzeltypisierungsergebnisse: 10.4.2). Die Individuen gruppieren alle in die Y-chromosomale Haplogruppe Q3, der am häufigsten auftretenden Haplogruppe im rezenten Südamerika (Bortolini et al. 2002). In Tab. 28 sind die Typisierungsergebnisse aufgeführt. Die geringe Zahl an erwirtschafteten Daten macht eine weiterführende Auswertung für die Y-chromosomalen Haplogruppen unnötig. Sie bestätigen aber erstmals, dass die Haplogruppe Q3 auch wirklich in präkolumbischen Populationen Südamerikas auftrat. Weitere Daten zu Y-chromosomalen Haplotypen aus aDNAUntersuchungen liegen bislang nicht vor. 
Tab. 28: Typisierungsergebnisse der Y-chromosomalen SNPs

\begin{tabular}{l|ccccc|c}
\hline \multicolumn{7}{c}{ Y-chromosomale SNPs (realisierte Base) } \\
Individuum & M3 & M45 & M130 & M242 & Haplogruppe \\
\hline EA 1 & T & A & C & T & Q3 \\
\hline EA 2 & T & T & A & C & T & Q3 \\
\hline EA 4 & A & C & T & Q3 \\
\hline EA 10 & T & A & C & T & Q3 \\
\hline
\end{tabular}

\subsubsection{Y-STRs und Y-chromosomale Haplotypen}

Die Untersuchung der Y-STRs erfolgte mit einem bereits etablierten Multiplex-Analysesystem (vgl. Kap. 3.4.2). Es wurden nur die DNA-Extrakte von Individuen, bei denen auch Amplifikationserfolge für eines oder mehrere der Y-SNP Systeme erzielt wurden, der Y-STR Analyse unterzogen. Die Analysen erbrachten keine reproduzierten Ergebnisse. 


\section{Auswertung der genetischen Daten für die Palpa-Region}

Die weitere populationsgenetische und bevölkerungsgeschichtliche Beurteilung und Auswertung der Daten erfolgt nur für die mitochondrialen Daten. Die wenigen Ergebnisse aus den Untersuchungen der nuklearen DNA eignen sich nicht für solche Analysen. Im Folgenden werden die Daten zuerst in zwei Ebenen betrachtet: Haplogruppen und Haplotypen. Diese Unterteilung ergibt sich aus der jeweiligen Auflösung der Daten und dem Aussagecharakter. Abschließend werden die Ergebnisse der Betrachtung beider Ebenen zusammengeführt.

\subsection{Mitochondriale Haplogruppen}

\subsubsection{Haplogruppen Verteilung}

$\mathrm{Zu}$ Beurteilung der prozentualen Haplogruppenverteilung (Abb. 46) wurde eine Gruppierung der untersuchten Populationen in die jeweiligen Zeitstellungen vorgenommen (Tab. 29). Diese Gruppierung ist notwendig, da ansonsten für einige Fundorte $\mathrm{zu}$ wenige Ergebnisse für eine populationsgenetische Auswertung vorliegen (vgl. Tab 25). Die Paracas-zeitlichen Populationen wurden ergänzend nach ihrer regionalen Herkunft unterteilt (Palpa-Region u. Paracas-Halbinsel / Caverna 6). Für die Nasca-zeitlichen Proben wurde zwischen Individuen aus ruralen oder urbanen Siedlungszusammenhängen unterschieden. Alle untersuchten Proben dieser Zeitstellung kommen aus der Palpa-Region. Dasselbe gilt für die Individuen aus dem Mittleren Horizont (MH). Die Individuen aus Pacapaccari stellen eine eigene Gruppe dar. Sie unterscheiden sich von den anderen untersuchten Populationen durch ihre Herkunft aus dem andinen Hochland.

Tab. 29: Gruppierung der untersuchten Populationen

\begin{tabular}{|c|c|c|}
\hline Datierung / Phase & Fundorte / Populationen & Gruppe \\
\hline \multirow[t]{4}{*}{ Formativzeit / Paracas } & Jauranga (JA) & Paracas (Palpa) \\
\hline & Mollake Chico (ME) & \\
\hline & Pernil Alto (AO) & \\
\hline & Caverna 6 (PC) / Paracas-Halbinsel & Paracas (Caverna 6) \\
\hline \multirow{6}{*}{$\begin{array}{l}\text { Frühe Zwischenperiode / } \\
\text { Nasca }\end{array}$} & Hanaq Pacha (PA) & Nasca (rural) \\
\hline & Jauranga (JA) & \\
\hline & Mollake Chico (ME) & \\
\hline & Pernil Alto (AO) & \\
\hline & Los Molinos (MS) & Nasca (urban) \\
\hline & La Muña (MA) & \\
\hline \multirow[t]{2}{*}{ Mittlerer Horizont / Huari } & Hanaq Pacha & MH/Huari (Palpa) \\
\hline & Los Molinos & \\
\hline $\begin{array}{l}\text { Mittl. Horizont (MH) - } \\
\text { Späte Zwischenp. (LIP) }\end{array}$ & Pacapaccari (EA) & Pacapaccari \\
\hline
\end{tabular}


In beiden Paracas-zeitlichen Populationen dominiert die Haplogruppe D (Palpa $=78 \%$; ParacasHalbinsel $=70 \%)$. Die zweithäufigste Haplogruppe ist jeweils $\mathrm{C}$ (Palpa $=14 \%$; ParacasHalbinsel $=30 \%$ ). Haplogruppe A konnte in der Paracas-Zeit nur in der Palpa-Region nachgewiesen werden. Es ist dabei zu beachten, dass die Stichprobe für die Paracas-Halbinsel relativ klein ist $(\mathrm{n}=10)$.

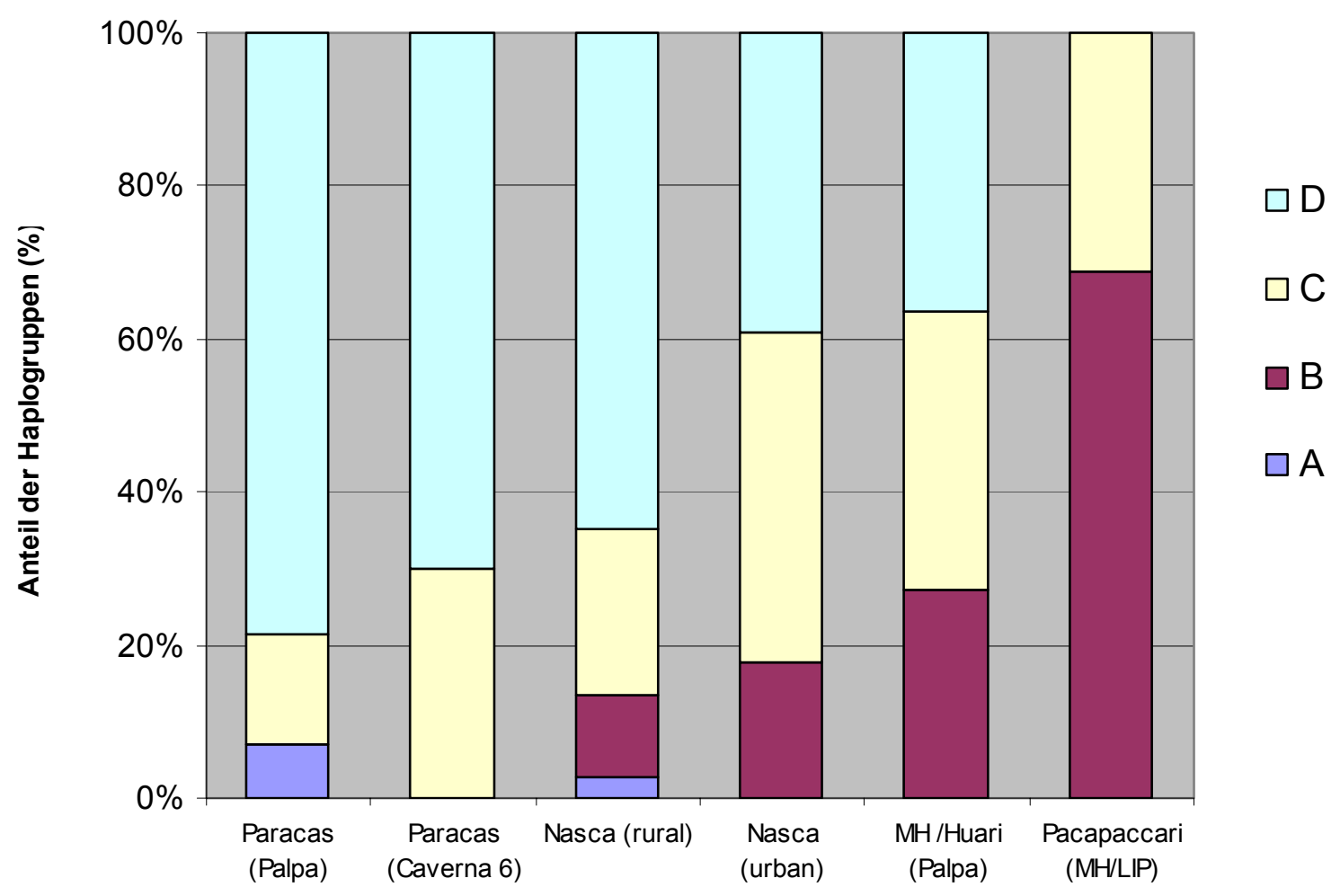

Abb. 46: Prozentuale Verteilung der mt-Haplogruppen der untersuchten Individuen in den verschiedenen Zeitstellungen (Erläuterung der Gruppierungen erfolgt im Text).

Ab der Nasca-Zeit kann auch Haplogruppe B im Untersuchungsgebiet nachgewiesen werden. Die Haplogruppen D und C sind allerdings weiterhin am stärksten repräsentiert. Unterscheidet man zwischen den Individuen, die von mit ruralen und urbanen Siedlungen (Definition vgl. Kap. 2.4) assoziierten Gräberfeldern stammen, zeigt sich, dass in der ruralen Gruppe noch eindeutig die Haplogruppe D dominiert (65\%). In der urbanen Gruppe hingegen sind die Haplogruppen C und $\mathrm{D}$ ungefähr gleichstark vertreten $(C=43 \% ; D=40 \%)$. Die in der Paracas-Zeit im Untersuchungsgebiet noch nicht nachgewiesene Haplogruppe B erreicht einen Anteil von 10,8\% im ruralen und von 17,9\% im urbanen Zusammenhang. Das Verteilungsbild der Haplogruppen für den Mittleren Horizont im Untersuchungsgebiet gleicht ungefähr dem in der Nasca-zeitlichen urbanen Gruppe.

Die Haplogruppenverteilung, die für den Fundort Pacapaccari aus dem Hochland nachgewiesen werden konnte, unterscheidet sich maßgeblich von allen anderen untersuchten 
Gruppen und Populationen. Hier dominiert eindeutig die Haplogruppe B (69\%). Neben B konnte nur die Haplogruppe C nachgewiesen werden (31\%). Die beiden anderen Haplogruppen treten in der untersuchten Stichprobe nicht auf.

\subsubsection{Genetische Diversität und Distanz}

Zur Beurteilung der Haplogruppen-Diversität $(\mathrm{Hd})$ wurden die in Kap. 3.8.1 erläuterten Berechnungen vorgenommen. Die Ergebnisse aus jeder der Gruppen und die jeweiligen Haplogruppen-Frequenzen sind Tab. $30 \mathrm{zu}$ entnehmen.

Tab. 30: Haplogruppen-Frequenzen und Haplogruppen-Diversität (Hd) der Gruppen aus der Palpa-Region und den beiden Referenzpopulationen.

\begin{tabular}{l|c|c|cccc|c}
\hline \multicolumn{1}{c}{ Gruppe } & n & \multicolumn{5}{c|}{ Haplogruppen-Frequenz } & \multirow{2}{*}{ A } \\
\hline Paracas (Palpa) & 28 & 0,07 & 0,00 & 0,14 & 0,79 & 0,37 \\
Paracas (Caverna 6) & 10 & 0,00 & 0,00 & 0,30 & 0,70 & 0,47 \\
Nasca (rural) & 37 & 0,02 & 0,11 & 0,22 & 0,65 & 0,53 \\
Nasca (urban) & 28 & 0,00 & 0,18 & 0,43 & 0,39 & 0,65 \\
MH/Huari & 11 & 0,00 & 0,27 & 0,36 & 0,36 & 0,72 \\
Pacapaccari & 16 & 0,00 & 0,69 & 0,31 & 0,00 & 0,46 \\
\hline
\end{tabular}

Die beiden Paracas-zeitlichen Gruppen und Pacapaccari weisen die geringsten Diversitätswerte auf (Hd: 0,37-0,47). Der niedrige Wert für die Paracas-zeitliche Gruppe aus der Palpa-Region resultiert aus der sehr hohen Frequenz der Haplogruppe D $(0,79)$. Auch bei den beiden anderen Gruppen resultiert der Hd-Wert aus der eindeutigen Dominanz einer Haplogruppe im Verhältnis zu den anderen drei. Der Wert für die rurale Nasca-Gruppe liegt nur leicht über denen der anderen drei zuvor besprochenen Gruppen (Hd: 0,53). Obwohl eindeutig die Frequenz für Haplogruppe D am höchsten ist $(0,65)$, konnten alle vier Haplogruppen nachgewiesen werden. Dementsprechend ist auch die angetroffene Diversität höher. Das ausgewogene Frequenzverhältnis der Haplogruppen C und D und die relativ hohe Frequenz der Gruppe B in der urbanen Nasca-Gruppe führt zu einer im Vergleich hohen Haplogruppen-Diversität (Hd: 0,65). Ähnliches gilt in verstärkter Form für die MH/Huari-Gruppe (Hd: 0,72). Hier ist allerdings zu bemerken, dass dem sehr hohen Wert bedingt nur eine kleine Stichprobe $(n=11)$ zugrunde liegt.

Die Beurteilung der genetischen Distanz unter den Gruppen erfolgte wie in Kap. 3.8.2 beschrieben. Die paarweisen $\mathrm{F}_{\mathrm{ST}}$-Distanzen (nach Reynolds 1983) sind der Distanzmatrix zu entnehmen (Tab. 31). Zur Darstellung der Distanz unter den untersuchten Populationen wurde 
über die Distanzmatrix ein NJ-Baum berechnet (Abb. 47). Als Berechnungsgrundlage für die genetische Distanz dienten die Haplogruppen-Frequenzen. Ein Wert von 0,000 in der paarweisen Distanzberechnung (vgl. Tab. 31) bedeutet nicht, dass beide Populationen identisch sind. Sehr geringe Distanzen können $\mathrm{zu}$ leicht negativen $\mathrm{F}_{\mathrm{ST}}$-Werten führen. Der $\mathrm{p}$-Wert (Irrtumswahrscheinlichkeit) der Berechnung liegt in dem Fall so hoch, dass die Nullhypothese nicht verworfen werden kann. Die Unterscheidung zwischen den beiden Gruppen ist damit nicht signifikant, und der Wert wird von dem der Software zugrunde liegenden Algorithmus auf 0 gesetzt. Dadurch wird das endgültige Gesamtbild der Distanzberechnung unter allen Gruppen aber nicht maßgeblich verzerrt (Lowe et al. 2004).

Tab. 31: Distanzmatrix auf Basis der paarweisen $F_{\mathrm{ST}}$-Werte für die Haplogruppen-Frequenzen der untersuchten Gruppen aus der Palpa-Region und der beiden prähistorischen peruanischen Referenzgruppen.

\begin{tabular}{lcccccc}
\hline \multicolumn{7}{c}{ Distanzmatrix (paarweise F ST-Distanzen nach Reynolds) } \\
& 1 & 2 & 3 & 4 & 5 & 6 \\
1: Paracas (Caverna 6) & 0,000 & & & & & \\
2: Paracas (Palpa) & 0,000 & 0,000 & & & & \\
3: Nasca (rural) & 0,000 & 0,009 & 0,000 & & & \\
4: Nasca (urban) & 0,050 & 0,231 & 0,068 & 0,000 & & \\
5: MH/Huari & 0,063 & 0,265 & 0,054 & 0,000 & 0,000 & \\
\hline 6: Pacapaccari & 0,962 & 1,350 & 0,704 & 0,316 & 0,194 & 0,000 \\
\hline
\end{tabular}

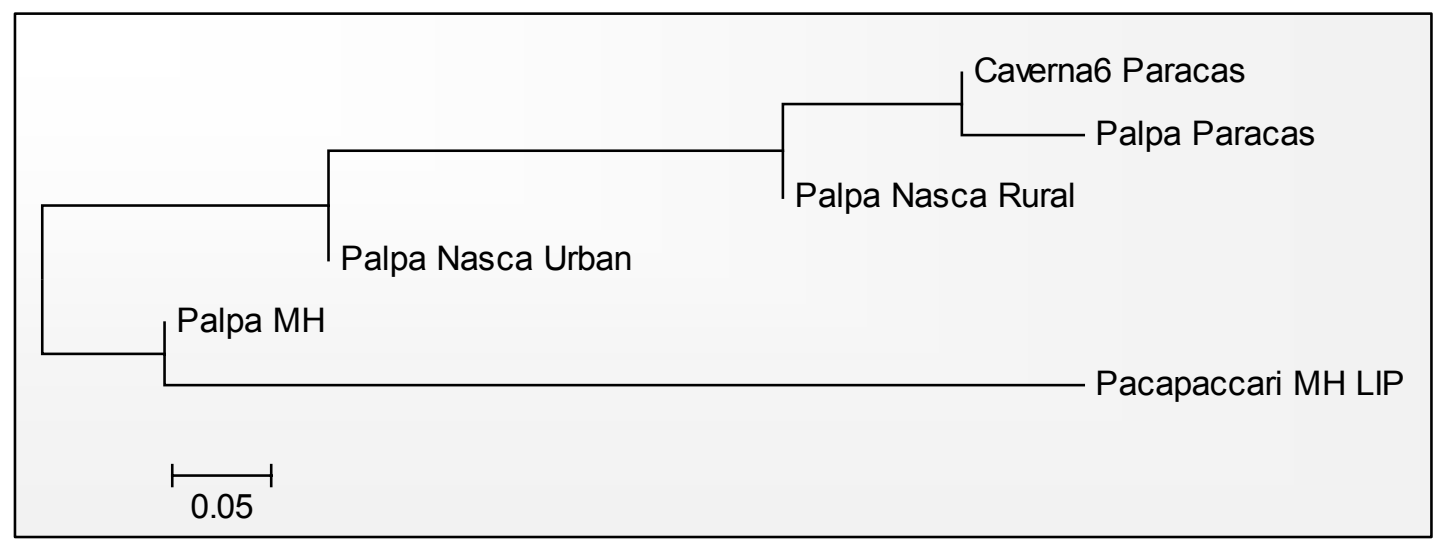

Abb. 47: Skalierter NJ-Baum zur Darstellung der genetischen Distanz unter den untersuchten Gruppen. Als Datengrundlage für die Erstellung des Baumes wurde die Distanzmatrix in Tab. 31 verwendet. Die Astlängen des Baumes geben die ermittelten paarweisen Distanzen wieder.

Die Distanzberechnungen geben das Bild wieder, das auch schon aus den Haplogruppenfrequenzen abzuleiten war. Beide Paracas-zeitlichen Gruppen weisen, trotz der hohen geographischen Distanz der beiden Fundorte zueinander (rund 150km Luftlinie), eine minimale genetische Distanz auf. Die ruralen Nasca-zeitlichen Populationen gruppieren sich im NJ-Baum nahe an die Paracas-zeitlichen Gruppen. Es besteht keine signifikante Distanz unter 
den drei Gruppen $(\mathrm{p}=0,005)$. Zwischen den urbanen Nasca-Populationen und der Gruppe aus dem Mittleren Horizont ist ebenfalls keine signifikante Unterscheidung anzutreffen. Sie setzen sich klar von den drei zuvor besprochenen Gruppen ab. Die geringste Distanz besteht zu der ruralen Nasca-Gruppe (0,068). Die fünf besprochenen Gruppen aus dem südperuanischen Küstenraum (Palpa-Region und Paracas-Halbinsel) weisen zueinander allerdings geringere Distanzen auf als zu der Hochland-Population Pacapaccari. Mit einem Wert von 1,350 besteht die größte genetische Distanz zwischen der Paracas-zeitlichen Population der Palpa-Region und der Population aus Pacapaccari. Die urbane Nasca-Population und die des Mittleren Horizontes weisen die geringste, aber dennoch hohe Distanz zu der Hochlandbevölkerung auf (Urban zu Pacapaccari: 0,316). Geographisch ist die Distanz von Pacapaccari zu der Palpa-Region geringer (ca. 50km) als zwischen dieser und der Paracas-Halbinsel. Allerdings trennen die beiden Regionen ca. 2000 Höhenmeter und die angetroffenen ökologischen Bedingungen.

\subsubsection{Zusammenfassende Auswertung der mt-Haplogruppen Daten für die Palpa-Region}

Die ermittelten mitochondrialen Haplogruppen-Daten weisen auf eine diachrone Veränderung der Bevölkerungszusammensetzung im Untersuchungsgebiet hin. Während in der Paracas-Zeit eindeutig die Haplogruppe D dominiert, verschiebt sich in der Nasca-Zeit das Verhältnis zugunsten der anderen Haplogruppen, vor allem C. Allgemein nimmt die HaplogruppenVariabilität zu. Dieses resultiert unter anderem aus dem Auftreten der zuvor nicht nachgewiesenen Haplogruppe B in den Nasca-zeitlichen Populationen. Die Veränderung schlägt sich vor allem in den Daten der aus dem urbanen Kontext stammenden Populationen nieder. Auch wenn sich die Frequenz der Haplogruppe D in den ruralen Populationen zugunsten der Gruppen C und B verringert und die Diversität zunimmt, ist keine signifikante Distanz zu den Paracas-zeitlichen Populationen nachzuweisen. Die in dem urbanen Zusammenhang beobachtete Veränderung in der genetischen Zusammensetzung der Bevölkerung des Untersuchungsgebietes zeichnet sich auch in den ruralen Bevölkerungen ab, jedoch nicht mit der gleichen Intensität.

Im Mittleren Horizont zeigt sich in den Daten ein noch etwas ausgewogeneres Verhältnis der drei Haplogruppen, B, C und D zueinander als in der Nasca-Zeit. Es kommt aber zu keiner maßgeblichen Veränderung gegenüber den urbanen Nasca-zeitlichen Populationen, was sich auch in der geringen genetischen Distanz der Gruppen zueinander niederschlägt. Betrachtet man die Haplogruppen-Daten aller drei Zeitstufen für die Populationen aus dem direkten Untersuchungsgebiet zeigt sich ein diachroner Trend, der sich in der Zunahme der genetischen Diversität und einer geringer werdenden Frequenz der Haplogruppe D äußert. 
Die untersuchte Bevölkerung des andinen Hochlandes unterscheidet sich in der Haplogruppenzusammensetzung, trotz der geringen geographischen Distanz, maßgeblich von den Populationen in der Palpa-Region. Die geringste Distanz besteht zu der Bevölkerung des Mittleren Horizontes und der urbanen Nasca-zeitlichen Gruppe. Der Grund hiefür ist in den ebenfalls hohen Anteilen der Haplogruppen B und C in diesen beiden Gruppen zu sehen. Während allerdings der Haplogruppe C in allen drei Gruppen ungefähr der gleiche Anteil an der Bevölkerung zukommt, dominiert in Pacapaccari eindeutig die Haplogruppe B. Der räumliche Vergleich zwischen den Küstenpopulationen (Palpa-Region u. Paracas-Halbinsel) und der Hochlandpopulation lässt einen Gradienten von Haplogruppe D zu B erkennen.

Da beide Paracas-zeitlichen Populationen trotz einer hohen räumlichen Distanz ein homogenes Bild der genetischen Zusammensetzung der Bevölkerung (auf Haplogruppen-Ebene) aufweisen, ergibt sich die Schlussfolgerung, dass die Dominanz der Haplogruppe D und das Fehlen der Haplogruppe B charakteristisch für die Paracas-zeitliche Bevölkerung der Ica-NascaKüstenregion ist. Die Beobachtung spricht gegen eine Fixierung der Haplogruppe D durch genetischen Drift, der aus der Isolierung der Bevölkerung resultiert (isolation by distance, Wright 1943). Diese Behauptung ist allerdings nicht anhand von Haplogruppen-Daten endgültig zu validieren. Die genetische Homogenität der Küstenbevölkerung lässt darüber hinaus vermuten, dass die Kontribution der Haplogruppe B zu dem Genpool der Palpa-Region aus dem Hochland hervorgehen muss. Andere Quellen sind allerdings anhand der präsentierten Daten auch nicht auszuschließen. Die abschließende Interpretation der Haplogruppen-Daten erfolgt unter Einbeziehung einer großen Zahl an Referenzdaten (vgl. Kap. 3.1.3) in einem späteren Kapitel (Kap. 6.1).

\subsection{Mitochondriale Haplotypen}

\subsubsection{Räumliche und zeitliche Verteilung der Haplotypen}

Auf die angetroffene räumliche und zeitliche Verteilung der mitochondrialen Haplotypen in den untersuchten Populationen wurde schon weitestgehend in Kap. 4.2.3 eingegangen (vgl. Abb. 41 u. Tab. 21). Darüber hinaus sind auch dem Median-Joining-Netzwerk (Abb. 42), das aus den Sequenzdaten der 105 typisierten Individuen erstellt wurde, Informationen über die Verteilung zu entnehmen.

Von besonderer Bedeutung für die Beurteilung der bevölkerungsbiologischen Entwicklung in der Palpa-Region sind die Haplotypen, die von mehreren Individuen im Datensatz geteilt werden und vor allem die, die in mehreren Zeitstufen auftreten. Die Haplotypen PA-A1, B3, C2 und 
$\mathrm{D} 1^{5}$, die den postulierten Gründerhaplotypen der indigenen amerikanischen Bevölkerung entsprechen (Merriwether et al. 1995; Starikovskaya et al. 2005), sind, wie zu erwarten, auch am stärksten im Datensatz repräsentiert. Ableitungen aus der Häufigkeit und dem Auftreten dieser Typen in den verschiedenen Zeitstellungen und Fundorten erscheinen dementsprechend nicht sinnvoll, da diese Haplotypen in allen süd- und nordamerikanischen Populationen nachgewiesen werden können. Hingegen haben alle anderen Linien einen hohen diagnostischen Wert, da sie selten unter indigenen amerikanischen Populationen aus verschiedenen geographischen Großräumen geteilt werden (Malhi et al. 2002). Dieser Umstand resultiert aus der initialen Besiedlungsgeschichte der amerikanischen Kontinente (vgl. Kap. 2.3.1-2). Fünf Haplotypen (PA-C18, D2, D4, D14 und D20) konnten jeweils in der Paracas-Zeit und der Nasca-Zeit im Untersuchungsgebiet nachgewiesen werden. In der Nasca-Zeit treten diese Typen in den ruralen Siedlungszusammenhängen auf. PA-C18, D2 und D20 finden sich in beiden Zeiten nur in Jauranga. Der Haplotyp PA-D19 konnte jeweils in einem Individuum aus der Paracas-zeitlichen Population von der Paracas-Halbinsel (PC) und dem Nasca-zeitlichen Jauranga (Palpa-Region) bestimmt werden. Ein weiterer Haplotyp, der in beiden Regionen nachgewiesen werden konnte, ist PA-C1. In der Palpa-Region findet er sich in der Paracas-zeitlichen Population von Jauranga (vgl. Tab. 21 / Kap. 4.2.3).

Die ruralen und urbanen Populationen der Nasca-Zeit teilen sich nur zwei Haplotypen. PAB4 konnte in jeweils einem Individuum aus La Muña (MA) und Pernil Alto (AO) nachgewiesen werden. Mit dem Haplotypen PA-D16 findet sich jeweils ein Individuum in Los Molinos (MS) und eines in Hanaq Pacha (PA). Die Bevölkerung der Palpa-Region und die des Hochlandfundortes Pacapaccari teilen sich nur einen Haplotypen. Der Gründerhaplotyp PA-B3 konnte für zwei Individuen aus Pacapaccari (EA), ein Individuum aus dem Mittleren Horizont in Hanaq Pacha (PA) und zwei aus dem Nasca-zeitlichen Los Molinos (MS) bestimmt werden.

\subsubsection{Populationsgenetische Berechnungen}

Für die populationsgenetischen Berechnungen wurde bei den HVRI-Sequenzdaten die gleiche Einteilung in Gruppen vorgenommen wie für die Haplogruppen-Daten (vgl. Tab. 29). Anschließend wurden die Haplotypen-Diversität (Hd) und die Nukleotiddiversität $(\pi)$ berechnet (vgl. Kap. 3.8.1). Die Ergebnisse sind Tab. 32 zu entnehmen. Neben diesen Werten sind in der Tabelle die pro Gruppe nachgewiesene Zahl an verschiedenen Haplotypen (H), die Zahl der variablen Nukleotidpositionen $(\mathrm{S}=$ segregating sites) und die durchschnittliche Zahl der Nukleotidunterschiede (K) angegeben.

\footnotetext{
${ }^{5}$ Der jeweilige Genotyp der mt-Haplotypen, die in diesem Kapitel beschrieben werden, ist Abb. 41 zu entnehmen.
} 
Tab. 32: Genetische Diversität der Populationen aus der Palpa-Region, Pacapaccari und der ParacasHalbinsel auf Basis der mt-Haplotypendaten (Erläuterung der Zeichen und Gruppierung erfolgt im Text).

\begin{tabular}{lcccccc} 
Population/ Gruppe & n & H & S & Hd & K & $\boldsymbol{\pi}$ \\
\hline Paracas (Caverna 6) & 6 & 5 & 6 & 0,9333 & 2,8000 & 0,0078 \\
Paracas (Palpa) & 25 & 15 & 21 & 0,9500 & 3,7884 & 0,0105 \\
Nasca (rural) & 30 & 26 & 31 & 0,9885 & 4,6020 & 0,0130 \\
Nasca (urban) & 25 & 17 & 18 & 0,9700 & 4,9267 & 0,0137 \\
MH/Huari (Palpa) & 6 & 6 & 15 & 1,0000 & 6,2667 & 0,0174 \\
Pacapaccari & 12 & 6 & 15 & 0,8636 & 6,0909 & 0,0169 \\
\hline
\end{tabular}

Alle sechs Gruppen weisen eine hohe Haplotypen-Diversität auf (Hd: 0,86 - 1,00). In Pacapaccari wurde der geringste Hd-Wert $(0,8636)$ ermittelt. Dieser Wert resultiert aus dem Verhältnis der Größe der Stichprobe $(\mathrm{n}=12)$ zu der Zahl der nachgewiesenen Haplotypen $(\mathrm{H}=6)$. Alle anderen fünf Gruppen weisen mehr Haplotypen im Verhältnis zur Zahl der Individuen auf als Pacapaccari

Auch die $\pi$-Werte der untersuchten Populationen unterscheiden sich nicht signifikant. Nur in der Paracas-zeitlichen Bevölkerung der Paracas-Halbinsel (PC) lässt sich eine, im Verhältnis zu den anderen fünf Gruppen, geringe Nukleotiddiversität nachweisen $(\pi=0,0078)$. Dieser Wert erklärt sich aus der geringen Zahl an variablen Nukleotidpositionen $(S=6)$ im Vergleich zur Größe der Stichprobe $(n=6)$ und Zahl der verschiedenen Haplotypen $(\mathrm{H}=5)$.

Insgesamt entsprechen die in den untersuchten Gruppen angetroffenen Diversitätswerte dem Bild, das auch aus den Untersuchungen der HVRI an rezenten Populationen des zentralen Andenraums bekannt ist (Lewis et al. 2007b). Die Diversitätswerte sind vor allem für den später angestrebten interkontinentalen Vergleich von Bedeutung (Kap. 6).

Zur Ermittlung der genetischen Distanz wurden die paarweisen $\mathrm{F}_{\mathrm{ST}}$-Distanzen unter den Gruppen ermittelt (vgl. Kap. 3.8.2) und aus der Distanz-Matrix ein NJ-Baum generiert. Außerdem wurden für die sequenzbasierenden durchschnittlichen Distanzen unter den Gruppen phylogenetische Bäume unter Verwendung der NJ- und UPGMA-Methode (vgl. Kap. 3.8.3) erstellt. Der Vergleich des UPGMA-Baumes mit dem NJ-Baum aus den beiden letztgenannten Berechnungen erbrachte ein identisches Bild. Dementsprechend werden im Folgenden nur die beiden NJ-Bäume dargestellt (Abb. 48). Für den Vergleich mit der heute anzutreffenden genetischen Zusammensetzung in Peru wurde eine rezente Vergleichspopulation aus Ancash (HVR-Referenzpopulation No. 3 / vgl. Abb. 29) in die Berechnungen integriert. 

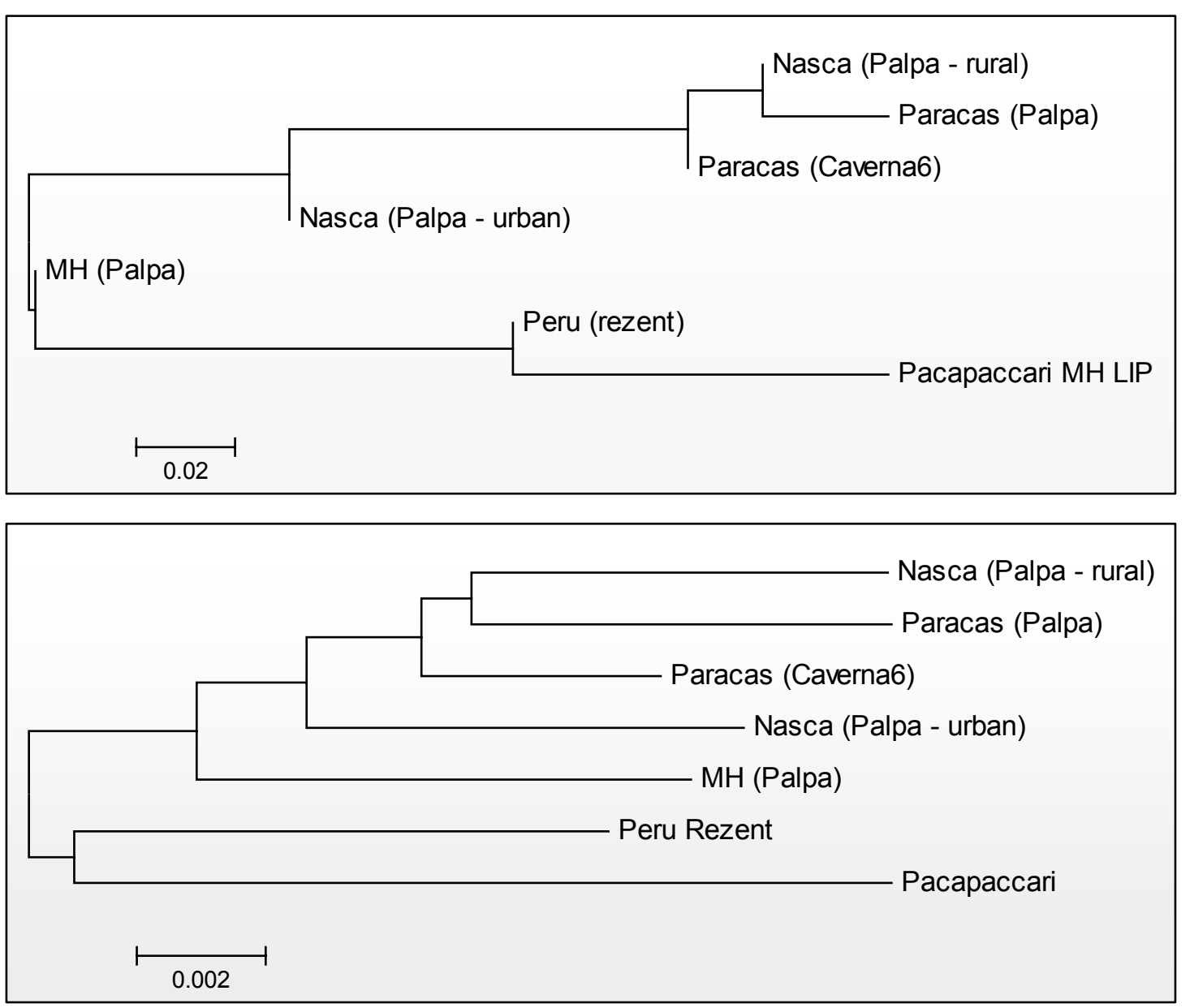

Abb. 48: NJ-Bäume für die paarweisen $\mathrm{F}_{\mathrm{ST}}$-Distanzen (oben) und der durchschnittlichen sequenzbasierten Distanz unter den Gruppen (unten). Den Berechnungen liegen die HVRI-Daten, die im Rahmen der vorliegenden Arbeit ermittelt wurden, und die der rezenten peruanischen Population aus Ancash (Lewis et al. 2005) zu Grunde. Die Bäume sind skaliert und die Länge der Äste gibt die ermittelten Distanzen unter den Gruppen wieder (weitere Erläuterungen im Text).

Tab. 33: NJ Distanz-Matrix für den NJ-Baum (Abb. 47 unten)

\begin{tabular}{lccccccc}
\hline Distanzmatrix (zu Abb. 47 unten) & 1 & 2 & 3 & 4 & 5 & 6 & 7 \\
1: Paracas (Caverna6) & 0,000 & & & & & & \\
2: Paracas (Palpa) & 0,011 & 0,000 & & & & & \\
3: Nasca (rural) & 0,011 & 0,013 & 0,000 & & & & \\
4: Nasca (urban) & 0,012 & 0,016 & 0,016 & 0,000 & & & \\
5: MH/Huari & 0,015 & 0,018 & 0,018 & 0,017 & 0,000 & & 0,000 \\
\hline 6: Pacapaccari & 0,024 & 0,028 & 0,027 & 0,023 & 0,023 & 0,000 & \\
7. Peru (rezent) & 0,019 & 0,022 & 0,022 & 0,020 & 0,020 & 0,021 & 0,020 \\
\hline
\end{tabular}


Beide Distanzberechnungen führen zu einem ähnlichen Bild. Die Paracas-zeitliche und die rurale Nasca-zeitliche Population gruppieren sich in den Bäumen zusammen mit der Paracas-zeitlichen Population von der Paracas-Halbinsel. In geringer Distanz zu dieser Gruppe finden sich die urbane Nasca-zeitliche Population und die des Mittleren Horizontes. Pacapaccari bildet eine monophyletische Gruppe mit der rezenten peruanischen Population. Die größte genetische Distanz besteht in beiden Berechnungen zwischen der Paracas-zeitlichen Population aus der Palpa-Region und der Hochlandpopulation vom Fundort Pacapaccari. Generell bilden sich zwei Hauptcluster aus den Distanzberechnungen. Eines umfasst die Gruppen aus der Palpa-Region und der Paracas-Halbinsel und das andere die präkolumbische Hochlandpopulation und die rezente peruanische Bevölkerung.
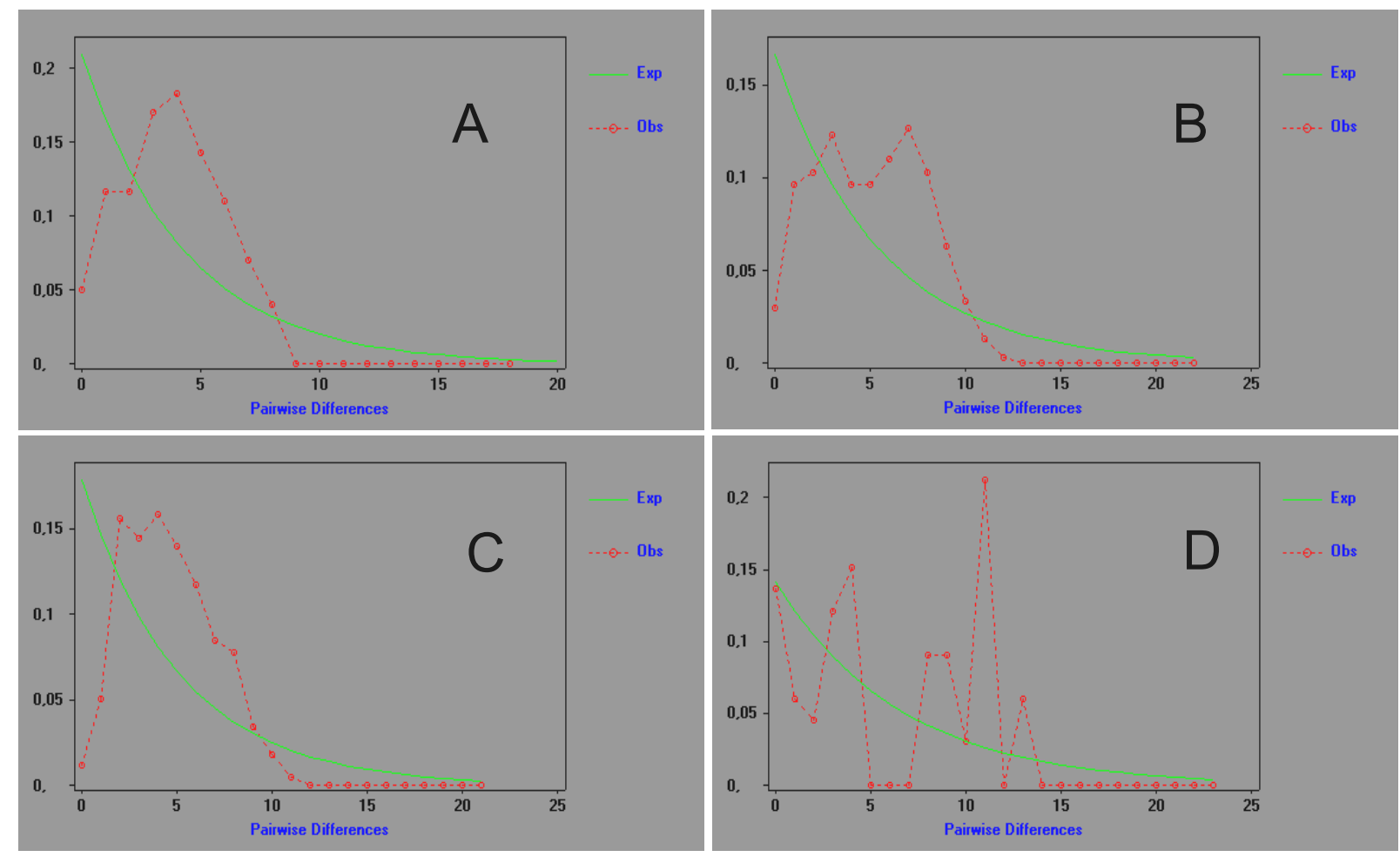

Abb. 49: Missmatch Distribution der HVRI-Daten. Der rote Graph beschreibt die beobachteten Frequenzen in der jeweiligen Population, der grüne gibt die erwartete Frequenz für eine konstante Populationsgröße an. A: Paracas (Palpa); B: Nasca (rural); C: Nasca (urban); D: Pacapaccari.

In Abb. 49 findet sich die graphische Auswertung der missmatch distribution (vgl. Kap. 3.8.5) für vier der sechs Gruppen. Die geringe Zahl der HVRI-Daten, die jeweils für die Paracas (Caverna 6) und die MH/Huari (Palpa) Gruppe erwirtschaftet werden konnte, lässt keine solche Auswertung zu. In der Anwendung auf Sequenzdaten gibt die missmatch distribution die Verteilung der Nukleotiddiversität $(\pi)$ in der Population wieder. Alle drei Gruppen aus der Palpa-Region (Abb. 49: A, B und C) weisen einen unimodalen Kurvenverlauf in der missmatch 
distribution auf. Dieses Muster der paarweisen Nukleotidunterschiede kann als Hinweis auf eine demographische Populationsexpansion (reine Bevölkerungszunahme ohne räumliche Ausbreitung) ausgehend von wenigen Gründerhaplotypen (Rogers u. Harpending 1992) oder eine hohe Migrationsrate bzw. räumliche Expansion der Population gedeutet werden (Excoffier 2004). Der Peak der Kurvenverläufe entspricht der durchschnittlichen Zahl der Nukleotidunterschiede (K) in der jeweiligen Population (vgl. Tab 23). Alle drei Populationen haben einen K-Wert von ca. vier. Das bedeutet, dass sich alle Sequenzen in den jeweiligen Datensätzen im Durchschnitt um vier Mutationen unterscheiden. Die missmatch distribution für die Sequenzdaten aus Pacapaccari (Abb. 49 - D) weist einen multimodalen Verlauf auf. Generell wird ein solcher Verlauf als Hinweis auf eine über längere Zeiträume konstante Populationsgröße gewertet (Rogers u. Harpending 1992).

Tab. 34: Tajima-D Statistik für die HVRI-Sequenzdaten der präkolumbischen peruanischen Populationen.

\begin{tabular}{ccccccc}
\hline & $\begin{array}{c}\text { Paracas } \\
(\text { Palpa })\end{array}$ & $\begin{array}{c}\text { Paracas } \\
(\text { Caverna 6) }\end{array}$ & $\begin{array}{c}\text { Nasca } \\
\text { (rural) }\end{array}$ & $\begin{array}{c}\text { Nasca } \\
\text { (urban) }\end{array}$ & $\begin{array}{c}\text { MH/Huari } \\
\text { (Palpa) }\end{array}$ & Pacapaccari \\
\hline $\mathrm{n}$ & 25 & 6 & 30 & 25 & 6 & 12 \\
Tajima's D & -1.16337 & 0.37522 & -1.49178 & 0.17977 & 0.13548 & 0.97142 \\
\hline
\end{tabular}

Die Berechnung der Tajima-D Statistik (Tab. 34) erbrachte für keine der sechs Gruppen eine signifikante Abweichung von 0 bei einem Konfidenzintervall von 90\% (-1,6 1,7; Tajima 1989, Tab. 2). Es kann also kein signifikanter demographischer Einfluss auf die genetische Zusammensetzung der Bevölkerungen nachgewiesen werden. Die D-Werte für die Paracas (Caverna 6) und die MH/Huari (Palpa) Gruppen können allerdings auch durch die geringe Stichprobengröße beeinflusst sein $(n=6)$. Auch wenn die D-Werte für die Paracas (Palpa) und Nasca (rural) keinen signifikant negativen Wert über $D=-1,6$ erreichen, sind sie doch annähernd signifikant (vgl. Tab. 34). Daraus lässt sich ableiten, dass das Wachstum beider Populationen nicht stagnierte und ein relativ hoher Genfluss bestand (Tajima 1989b). Die leicht positiven Werte der Gruppen Nasca (urban) und Pacapaccari sind zu gering $(<1,7)$, um als Anzeichen für einen Bevölkerungsrückgang gedeutet zu werden. Sie könnten allerdings auf eine stärkere Untergliederung der Bevölkerung im Vergleich zu der Paracas-zeitlichen und ruralen Nascazeitlichen Bevölkerung hindeuten (Jobling et al. 2004).

\subsubsection{Zusammenfassende Auswertung der mt-Haplotypen Daten für die Palpa-Region}

Die Persistenz einiger komplexer ${ }^{6}$ mitochondrialer Haplotypen von der Paracas-Zeit in die Nasca-Zeit spricht gegen einen umfassenden Populationswechsel im Untersuchungsgebiet (vgl.

\footnotetext{
6 Komplex bedeutet in diesem Zusammenhang, dass die Haplotypen besondere, bzw. viele zusätzliche Polymorphismen im Vergleich zu den Gründerhaplotypen der jeweiligen Haplogruppe aufweisen.
} 
Tab. 24 / Kap. 4.2.3). Das Auftreten dieser Matrilinien in den Gräberfeldern der gleichen Fundorte in verschiedenen Zeitstellungen kann eher als ein Anzeichen für eine zeitlich stabile (weibliche) Grundbevölkerung in der Region gesehen werden. Diese Annahme wird durch die geringe genetische Distanz der Paracas-zeitlichen zu der ruralen Nasca-zeitlichen Bevölkerung unterstützt (vgl. Abb. 48). Die Haplotypen-Diversität aller untersuchten Populationen zeigt, dass es zu keinem Zeitpunkt zu einer Isolation der Bevölkerungen gekommen ist, sondern in allen untersuchten Zeitstellungen ein hoher Genfluss in der südperuanischen Küstenregion bestand (vgl. Tab. 32). Die Distanzberechnungen zeigen eine klare Unterscheidung der präkolumbischen Bevölkerung der Palpa-Region und der Paracas-Halbinsel zu der prähistorischen Hochlandpopulation von Pacapaccari und der rezenten indigenen Bevölkerung Perus. Unter den beiden letztgenannten besteht eine relativ geringe genetische Distanz. Von den untersuchten Küstenpopulationen weisen die Gruppen Nasca (urban) und MH/Huari (Palpa) die geringste Distanz zu der Hochland- und rezenten Bevölkerung auf.

Die Paracas Population der Paracas-Halbinsel gruppiert sich in den NJ-Bäumen zu den Bevölkerungen aus der Palpa-Region. Sie weist vor allem eine sehr geringe genetische Distanz zu den Paracas-zeitlichen und ruralen Nasca-zeitlichen Bevölkerungen auf. Darüber hinaus teilen sich beide Populationen komplexe Haplotypen und zeigen eine klare genetische Differenzierung zum Hochland. Die mitochondrialen Haplotypen-Daten deuten damit auf eine einheitliche Bevölkerung des Ica-Nasca Küstengebietes hin, bzw. auf einen konstanten Bevölkerungsaustausch untereinander. Diese Annahme wird durch die hohe genetische Diversität, die in den untersuchten präkolumbischen Küstenpopulationen anzutreffen, ist unterstützt.

Missmatch Analyse und Tajima-D Statistik ergeben kein einheitliches Bild. Es ist keine eindeutige Phase signifikanten Bevölkerungswachstums nachzuweisen. Im Zusammenhang mit den Diversitäts-Werten bestätigen beide Analysen aber einen konstanten Genfluss in der Region. Das aus den Missmatch-Graphen abzulesende Bild deutet auf eine demographische Expansion nach dem Durchlaufen eines genetischen Bottleneck hin. Ein ähnliches Bild ist aus vielen anderen indigenen amerikanischen Populationen bekannt und wird in der Regel auf die initiale Kolonisation der Kontinente zurückgeführt (Tarazona-Santos et al. 2001; Fix 2002; Mulligan et al. 2004; Smith et al. 2005).

\subsection{Zusammenführung der mitochondrialen Haplotypen- und Haplogruppendaten}

Die Ergebnisse der beiden Analyseebenen für die matrilineare Populationsdynamik sind konsistent. Der höher auflösende Datencharakter der mitochondrialen Haplotypen gibt zwar ein 
etwas differenzierteres Bild der Bevölkerungsentwicklung wieder, aber weitestgehend werden die Ableitungen aus den Haplogruppen-Daten unterstützt.

Die hohen Frequenzen der Haplogruppe D in den Paracas-zeitlichen Populationen resultieren nicht aus einer Reduzierung der genetischen Variabilität durch genetischen Drift. Das wird durch die angetroffene hohe Haplotypen-Diversität (Tab. 32) bestätigt. Die Bevölkerungen rekrutieren sich also nicht nur aus der direkten Umgebung, sondern es muss ein konstanter Genfluss bestanden haben. Das gleiche gilt für die anderen untersuchten Zeitstellungen.

Die Distanzberechnungen beider Analyseebenen führen zu einem ähnlichen Ergebnis (vgl. Abb. 47 u. 48). Die Paracas-zeitlichen Populationen aus der Palpa-Region und der ParacasHalbinsel, sowie die ruralen Nasca-zeitlichen Populationen gruppieren in den jeweiligen NJBäumen nahe beieinander. Die Gruppen des Mittleren Horizontes und der urbanen Nascazeitlichen Populationen weisen ein gewisses Maß an genetischer Distanz zu den drei zuvor beschriebenen Gruppen auf, bilden aber noch ein gemeinsames Cluster mit diesen. Alle drei Berechnungen ergeben eine hohe genetische Distanz zwischen der Hochlandbevölkerung von Pacapaccari und den Küstenbevölkerungen, die im Kontrast zu der geringen geographischen Distanz der Regionen steht (ca. $50 \mathrm{~km}$ ). Insgesamt lassen sich die Beobachtungen aus den Distanzberechnungen mit dem Trend zur Veränderung der Haplogruppenfrequenzen parallelisieren. Die drei Populationen mit dem höchsten D-Anteil weisen auch die geringste Distanz zueinander auf. Mit Zunahme der Frequenzen von Haplogruppe B und C in der PalpaRegion ab der Nasca-Zeit verringert sich auch die Distanz zu der Hochlandbevölkerung von Pacapaccari, wo eine eindeutige Dominanz der Haplogruppe B nachgewiesen werden konnte und eine hohe Frequenz der Haplogruppe C (Abb. 50).

Es ist eine gleich bleibend hohe Haplotypen-Diversität bei diachroner Zunahme der Haplogruppen-Diversität in der Palpa-Region zu beobachten. Daraus ist abzuleiten, dass es nicht $\mathrm{zu}$ einer quantitativen Veränderung des Genflusses gekommen ist, sondern zu einer Vergrößerung oder Verschiebung des Einflussbereiches des Genflusses. Haplogruppe B kommt in der Paracas-Zeit weder in der Palpa-Region noch auf der Paracas-Halbinsel vor. Die beiden regionalen Gruppen stellen im Endeffekt die nördliche und südliche Verbreitungsgrenze der archäologischen Kultur-Gruppe dar. Es ist damit wahrscheinlich, dass in der Nasca-Zeit eine Kontribution zum Genpool stattgefunden hat, deren Quelle außerhalb des beschrieben Gebietes liegt. Darüber hinaus ist zu bemerken, dass in der urbanen Nasca-zeitlichen Gruppe die Haplogruppen-Diversität höher ist als in der ruralen Gruppe, während das Verhältnis für die Haplotypen-Diversität umgekehrt ist. Die abschließende Interpretation der hier beschriebenen Analyseergebnisse erfolgt in Kap. 7.2. 


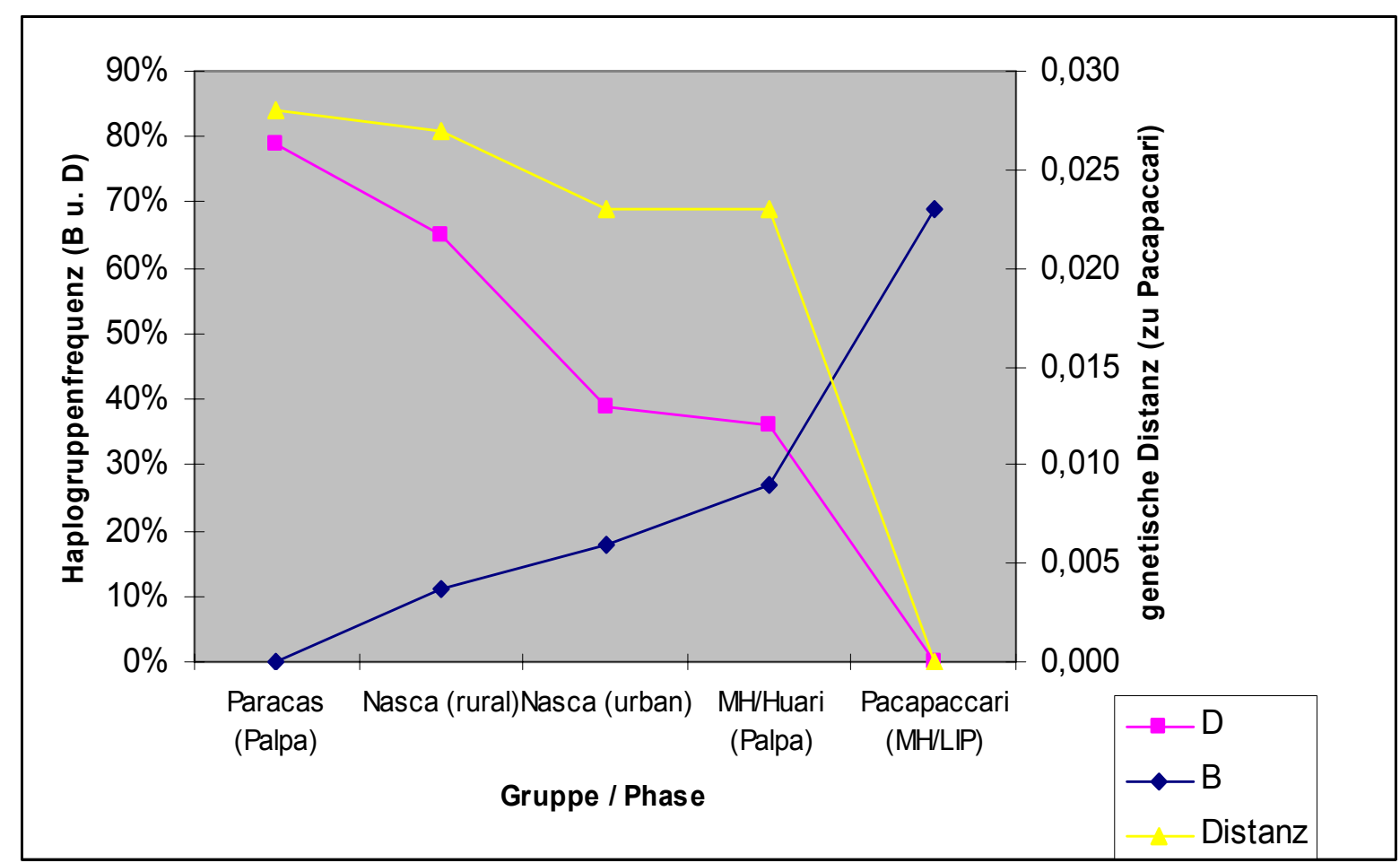

Abb. 50: Entwicklung der Haplogruppen-Frequenzen von D und B über die Zeitphasen/ Gruppen im Verhältnis zur genetischen Distanz der jeweiligen Gruppen zu Pacapaccari. 


\section{Auswertung der genetischen Daten im kontinentalen Vergleich}

Für den Vergleich der in der vorliegenden Arbeit ermittelten genetischen Daten mit den südamerikanischen Referenzpopulationen (vgl. Kap. 3.1.3) erfolgt zuerst eine Betrachtung auf zwei Ebenen: mt-Haplogruppen und mt-Haplotypen. Abschließend werden die Daten beider Ebenen verglichen.

\subsection{Mitochondriale Haplogruppen}

\subsubsection{Haplogruppenverteilung und-Frequenzen}

Für den kontinentalen Vergleich der mitochondrialen Haplogruppenfrequenzen wurden Daten von 4320 Individuen aus 69 Populationen aus der Literatur aufgenommen (vgl. Tab. 10 / Kap. 3.1.3). Sieben dieser Populationen sind aDNA-Datensätze, die in präkolumbische Zeitstellungen datieren. Drei andere Datensätze von Feuerland stammen zwar auch aus aDNA-Untersuchungen, datieren aber ins ausgehende 19. Jhd. und werden im Folgenden mit den rezenten Populationen gleichgestellt. Die rezenten indigenen südamerikanischen Populationen wurden in geographisch / kulturelle Großräume zusammengefasst (vgl. Kap. 3.1.3), um die Datenmenge handhaben zu können. Eine Beschreibung der Regionen findet sich in Tab. 12 und ihre Kartierung in Abb. $30 / 51$.

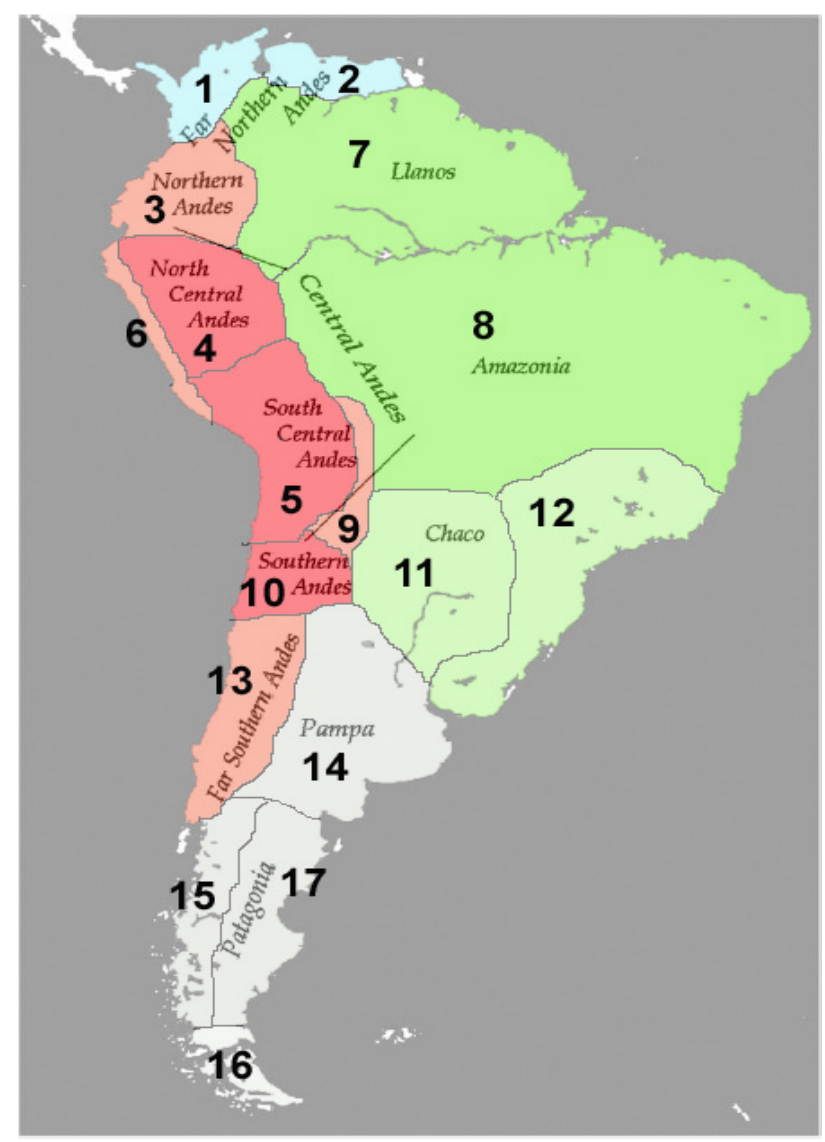

Abb. 51: Geographisch-/kulturelle Regionalgruppen für die Auswertung der mt- 
Für die Gruppen wurden die Haplogruppenfrequenzen und die Haplogruppen-Diversität berechnet (vgl. Kap. 3.8.1). Die Ergebnisse der Berechnungen finden sich in Tab. 35. Die Frequenzen werden zusätzlich in Histogrammen, eines für die rezenten Populationen (Abb. 52) und ein anderes für die prähistorischen Populationen (Abb. 53), dargestellt.

Tab. 35: Haplogruppenfrequenzen (A, B, C, D und andere) und Haplogruppen-Diversität (Hd) der in Regional-Gruppen (Reg.) zusammengefassten rezenten Referenzpopulationen und aDNA-Daten.

\begin{tabular}{|c|c|c|c|c|c|c|c|c|c|}
\hline \multirow[b]{2}{*}{ Reg. } & & & \multicolumn{7}{|c|}{ Haplogruppenfrequenzen } \\
\hline & & & $\mathbf{n}$ & $\mathbf{A}$ & B & C & D & other & Hd \\
\hline 1 & & & 335 & 0,591 & 0,138 & 0,258 & 0,013 & 0,000 & 0.566 \\
\hline 2 & & & 59 & 0,475 & 0,034 & 0,492 & 0,000 & 0,000 & 0.541 \\
\hline 3 & & & 73 & 0,205 & 0,356 & 0,315 & 0,123 & 0,000 & 0.726 \\
\hline 4 & Qechua & & 159 & 0,052 & 0,548 & 0,219 & 0,181 & 0,026 & 0.619 \\
\hline 5 & Qechua & & 164 & 0,060 & 0,673 & 0,134 & 0,134 & 0,006 & 0.654 \\
\hline 5 & Aymara & & 339 & 0,167 & 0,519 & 0,198 & 0,117 & 0,012 & 0.509 \\
\hline 7 & & & 804 & 0,077 & 0,353 & 0,413 & 0,157 & 0,013 & 0.675 \\
\hline 8 & & & 232 & 0,171 & 0,329 & 0,303 & 0,197 & 0,018 & 0.735 \\
\hline 9 & & & 89 & 0,407 & 0,488 & 0,093 & 0,012 & 0,023 & 0.593 \\
\hline 10 & & & 138 & 0,115 & 0,662 & 0,122 & 0,101 & 0,000 & 0.522 \\
\hline 11 & & & 535 & 0,109 & 0,381 & 0,245 & 0,264 & 0,009 & 0.714 \\
\hline 12 & & & 341 & 0,619 & 0,176 & 0,167 & 0,038 & 0,000 & 0.558 \\
\hline 13 & & & 443 & 0,023 & 0,147 & 0,367 & 0,464 & 0,002 & 0.629 \\
\hline 14 & & & 155 & 0,079 & 0,364 & 0,236 & 0,321 & 0,107 & 0.707 \\
\hline 15 & & & 111 & 0,029 & 0,181 & 0,381 & 0,410 & 0,057 & 0.659 \\
\hline 16 & & & 90 & 0,000 & 0,000 & 0,494 & 0,506 & 0,011 & 0.505 \\
\hline 17 & & & 29 & 0,000 & 0,207 & 0,241 & 0,552 & 0,000 & 0.615 \\
\hline \multicolumn{10}{|c|}{ aDNA-Populationen } \\
\hline 6 & Huaca-Loro & $\mathrm{MH}$ & 36 & 0,190 & 0,220 & 0,060 & 0,310 & 0,220 & 0,722 \\
\hline 5 & Paucarraca & Inka & 35 & 0,086 & 0,657 & 0,229 & 0,029 & 0,000 & 0.522 \\
\hline 5 & ChenChen & $\mathrm{MH}$ & 23 & 0,391 & 0,391 & 0,174 & 0,043 & 0,000 & 0.691 \\
\hline 5 & Tiwanaku & $\mathrm{MH}$ & 13 & 0,080 & 0,150 & 0,230 & 0,230 & 0,310 & 0.805 \\
\hline 5 & Chile-Coast & Arch & 14 & 0,500 & 0,357 & 0,071 & 0,071 & 0,000 & 0.659 \\
\hline 5 & Chile-Coast & $\mathrm{MH}$ & 19 & 0,200 & 0,533 & 0,200 & 0,067 & 0,000 & 0.690 \\
\hline 5 & Chile-Coast & Inka & 15 & 0,316 & 0,421 & 0,263 & 0,000 & 0,000 & 0.676 \\
\hline & Palpa & Paracas & 28 & 0,070 & 0,000 & 0,140 & 0,790 & 0,000 & 0,370 \\
\hline & Caverna 6 & Paracas & 10 & 0,000 & 0,000 & 0,300 & 0,700 & 0,000 & 0,470 \\
\hline & Palpa (rural) & Nasca & 37 & 0,020 & 0,110 & 0,220 & 0,650 & 0,000 & 0,530 \\
\hline & Palpa (urban) & Nasca & 28 & 0,000 & 0,180 & 0,430 & 0,390 & 0,000 & 0,650 \\
\hline & Palpa & $\mathrm{MH}$ & 11 & 0,000 & 0,270 & 0,360 & 0,360 & 0,000 & 0,720 \\
\hline 5 & Pacapaccari & MH/LIP & 16 & 0,000 & 0,690 & 0,310 & 0,000 & 0,000 & 0,370 \\
\hline
\end{tabular}




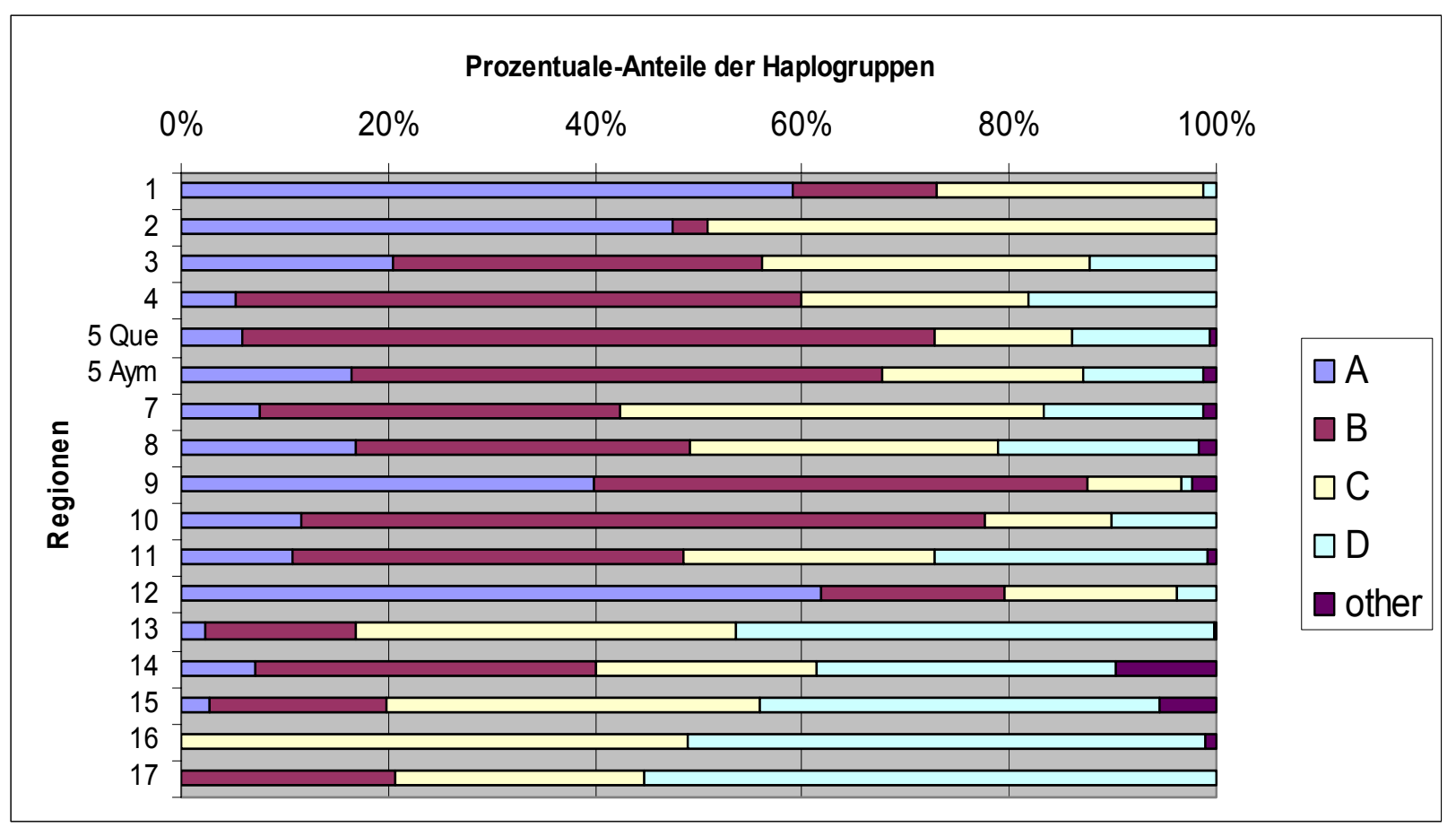

Abb. 52: Häufigkeitsverteilung der mt-Haplogruppen in den einzelnen regionalen Großgruppen. Die Gruppe 5 (südlicher Zentralandenraum) wurde bezüglich der Zugehörigkeit zu einer Sprachfamilie (Quechua u. Aymara) unterteilt. Die x-Achse gibt den prozentualen Anteil der Haplogruppen an der Bevölkerung an.

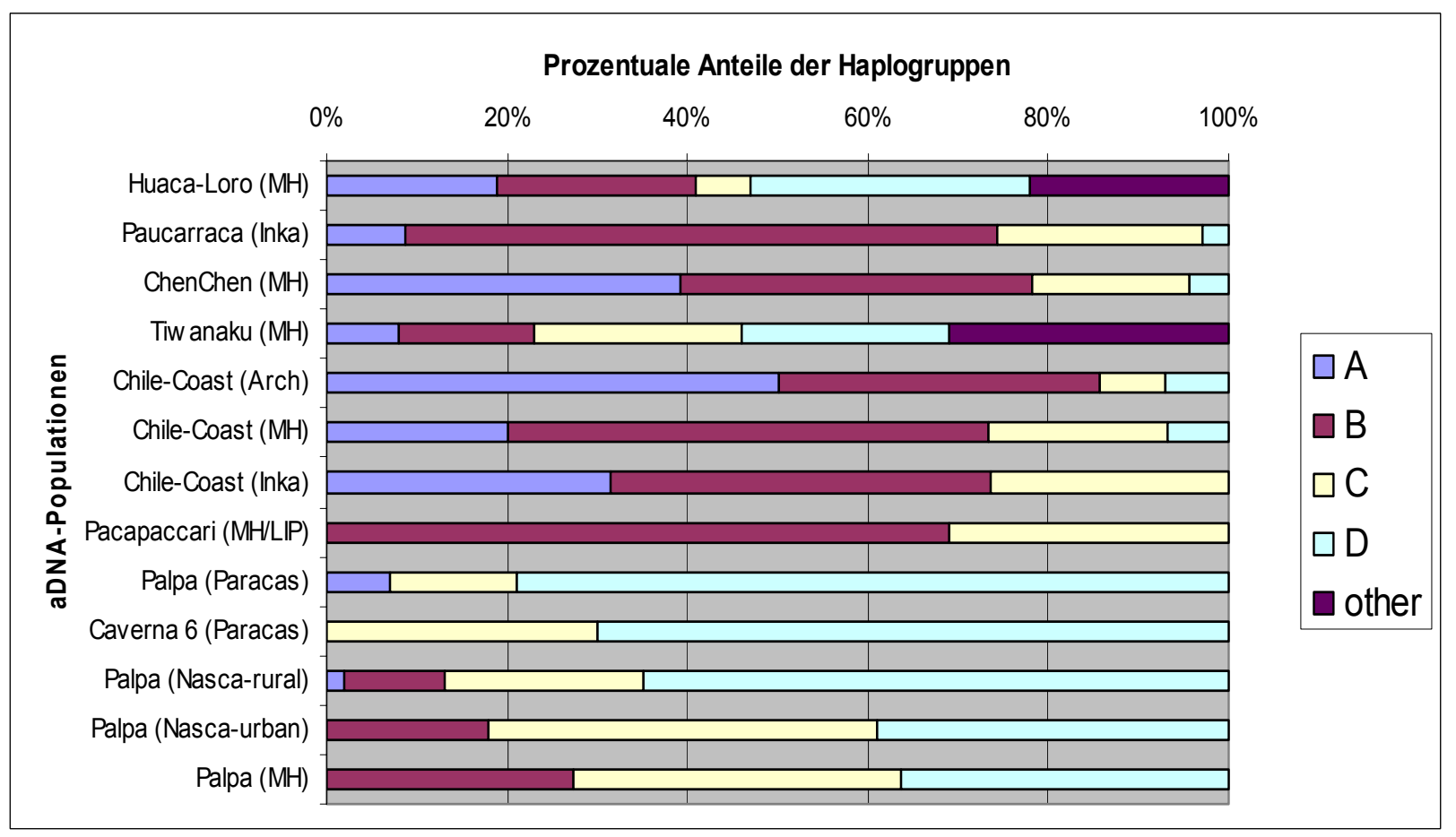

Abb. 53: Häufigkeitsverteilung der mt-Haplogruppen in den aus der Literatur bekannten aDNA-Daten aus präkolumbischen Populationen und der in der vorliegenden Arbeit untersuchten Populationen. In Klammern hinter den Namen findet sich die jeweilige Phase, aus der die Daten stammen. Bis auf Huaca-Loro (PeruNordküste Reg. 6) stammen die aDNA-Populationen alle aus der Region 5 (südlicher Zentralandenraum). Die x-Achse gibt den prozentualen Anteil der Haplogruppen an der Bevölkerung an. 
Wie bereits in Kap. 2.3.2 beschrieben, weisen die indigenen südamerikanischen Bevölkerungen im äußersten Norden des Kontinentes (Reg. 1 u. 2; Abb. 51) sehr hohe Frequenzen der Haplogruppe A auf (48-60\%). Im weiteren Verlauf der Anden und der Pazifikküste in Richtung Süden nimmt dieser Anteil stetig ab. Nur in Region 9 am östlichen Andenfuß der südlichen Zentralanden und im südlichen brasilianischen Hochland (Reg. 12) finden sich ähnlich hohe Frequenzen der Haplogruppe A (41\% u. 62\%) wie an der Nordküste. Ein regionaler oder kultureller Zusammenhang unter diesen vier Regionen ist nicht bekannt. In einem Raum, der von den nördlichen Zentralanden (Reg. 3) über die Zentralanden (Reg. 4 u. 5) bis in die südlichen Anden (Reg. 10) reicht, wird Haplogruppe A in der Dominanz von Haplogruppe B abgelöst (Abb. 54). Die Bevölkerungen des zentralen Andenraums (Reg. 4 u. 5) und der südlichen Anden (10) weisen Anteile von 52\%-67\% der Haplogruppe B auf. Haplogruppe C stellt in den Regionen jeweils den zweitgrößten Anteil an der Bevölkerung mit 12\%-20\%. Die Haplogruppen D und A sind jeweils nur schwach repräsentiert (vgl. Abb. 52). Weiter südwärts entlang der Pazifikküste und der südlichsten Anden (Reg. 13, 15 u. 16) nimmt der Anteil von Haplogruppe B ab (vgl. Abb. 54). Auf Feuerland (Reg. 16) konnte Haplogruppe B bislang nicht nachgewiesen werden. Gleichzeitig steigt die Häufigkeit der Haplogruppe D in der Bevölkerung in den drei Regionen auf $46-51 \%$ an. Haplogruppe C ist, wie auch in den Zentralanden und den Südanden, die am zweitstärksten repräsentierte Gruppe, allerdings mit einem viel höheren prozentualen Anteil von 37-49\%. Im Osten der südlichsten Anden, in der argentinischen Pampa (Reg. 14), ist eine sehr homogene Verteilung der Haplogruppen B, C und D anzutreffen. Patagonien (Reg. 17) ähnelt in der Haplogruppenverteilung den südchilenischen Bevölkerungen (Reg. 15).

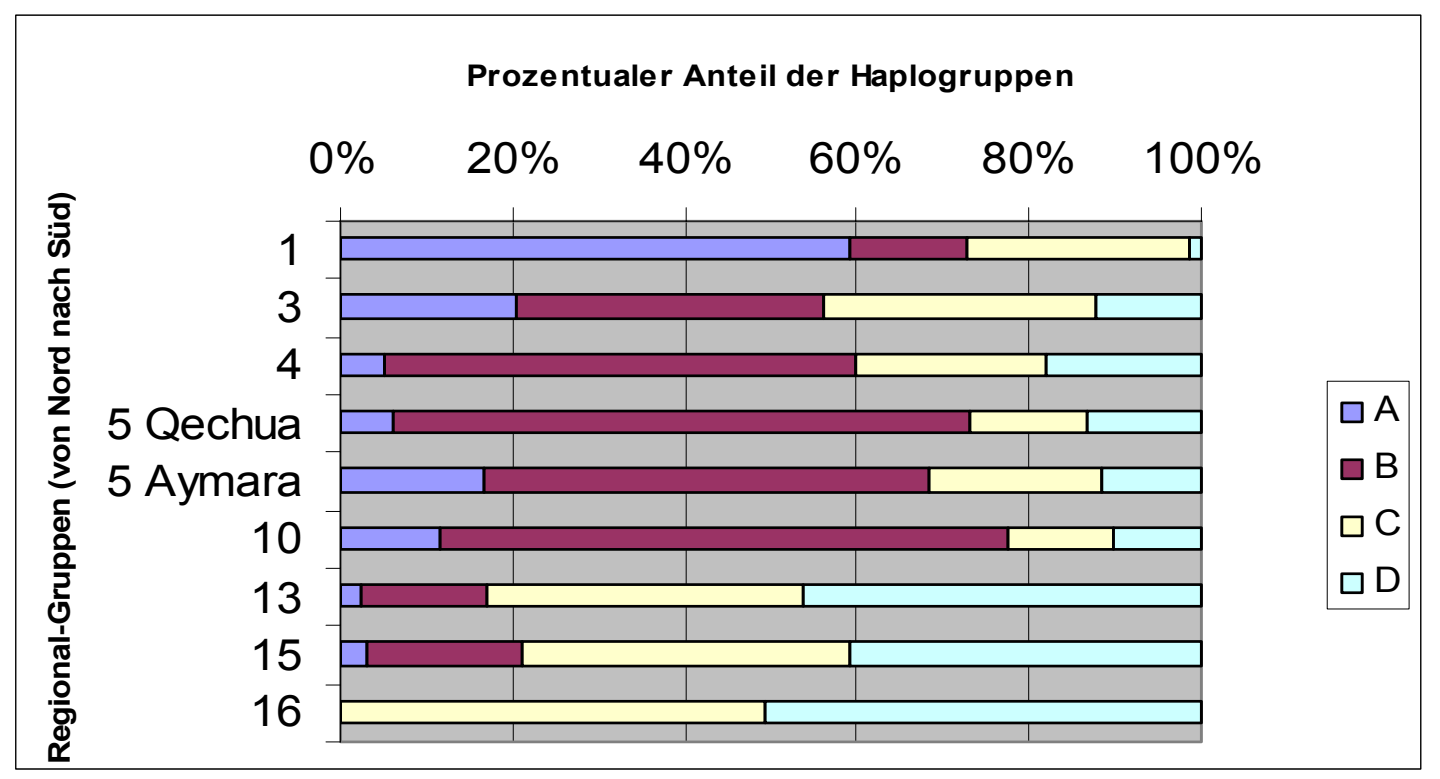

Abb. 54: Veränderung der Haplogruppen-Frequenzen entlang der südamerikanischen Westküste und der Anden von Nord nach Süd (das Diagramm umfasst nur die Regionalgruppen der Westküste: Reg. 1, 3, 4, 5, 10, 13, 15, 16; vgl. Abb. 51) 
In den Bevölkerungen der nördlichen und südlichen Amazonasregion ist ein viel homogeneres Verhältnis der vier mt-Haplogruppen zueinander anzutreffen. Keine Haplogruppe ist so eindeutig dominant, wie es im westlichen Südamerika der Fall ist. B und C sind jeweils mit $30-40 \%$ am stärksten repräsentiert. In der Gran Chaco Region (11) ist ein ähnliches Verteilungsbild anzutreffen.

Vergleicht man die aDNA-Daten mit den rezenten Daten ist festzustellen, dass die Populationen aus dem südlichsten Peru (Chen Chen - Lewis et al. 2007a) und Nord-Chile (Chile Coast - Moraga et al. 2005) viel höhere Anteile an Haplogruppe A aufweisen, als heute anzutreffen sind (Reg. 5 Aymara u. 10). Die Haplogruppenfrequenzen finden am ehesten in den Bevölkerungen des östlichen Andenfußes der südlichen Zentralanden (Reg. 9) eine Entsprechung. Die Inka-zeitliche Bevölkerung Paucarracas (Shinoda et al. 2006) und auch des in der vorliegenden Arbeit untersuchten Fundortes Pacapaccari, der 400-600 Jahre früher datiert, weisen ein sehr ähnliches Verteilungsbild auf. Beide Populationen stammen aus dem andinen Hochland. Der Vergleich mit der Haplogruppenverteilung in den rezenten Bevölkerungen der Zentralanden (Reg. 4 u. 5) und der Südanden (Reg. 9) zeigt auf, dass trotz der zeitlichen Distanz von ca. 600-1200 Jahren ein fast einheitliches Bild anzutreffen ist wie in den präkolumbischen Populationen. Ein geringer Unterschied ergibt sich nur aus den etwas höheren Frequenzen der Haplogruppen A und D (vgl. Tab. 35).

Die in den Mittleren Horizont datierende Population von Huaca-Loro von der Nordküste Perus (Shimada et al. 2004) weicht in ihren Haplogruppenfrequenzen von der rezenten Bevölkerung der Region (Reg. 4) ab. Haplogruppe D ist hier am stärksten vertreten (31\%). Es ist allerdings zu bemerken, dass $22 \%$ der in Huaca-Loro typisierten Individuen den Autoren nach einer Haplogruppe zugehörig waren, die nicht den vier indigenen amerikanischen Gründerhaplogruppen entspricht. Es ist nicht abzuschätzen, ob es sich bei diesen anderen Haplogruppen nicht vielleicht auch um rezente Kontaminationen handelt, bzw. wie authentisch die anderen Daten sind (Bandelt et al. 2003; Bandelt 2005). Reduziert man die Daten aus HuacaLoro auf die vier Haplogruppen A, B, C und D, ist eine Entsprechung des Frequenzmusters am ehesten in den Nasca-zeitlichen Populationen aus der Palpa-Region zu finden. Die hohen prozentualen Anteile an Haplogruppe $\mathrm{C}$ und $\mathrm{D}$ in den hier untersuchten Populationen der südperuanischen Küste sind in dieser Verteilung in den rezenten Populationen nur im südlichen Südamerika (Reg. 13-17) nachzuweisen. Dabei entsprechen die in der urbanen Nasca-zeitlichen Population angetroffenen Haplogruppenfrequenzen denen des heutigen mittleren Chile (Reg. 13). Die beiden Paracas-zeitlichen und die rurale Nasca-zeitliche Population weisen hingegen 
eher eine Haplogruppenverteilung auf wie die rezenten Bevölkerungen der Regionen 15-17, also dem südlichen Chile und Argentinien.

In den Haplogruppen-Diversitätswerten (Tab. 35) ist kein übergeordnetes, regional abhängiges Muster zu erkennen. Sehr hohe Werte weisen die südlichen Amazonasregion (Reg. 8), das Gran Chaco (Reg. 11), die argentinische Pampa (Reg. 14) und die nördlichen Zentralanden (Reg. 3) auf. Die niedrigste Haplogruppen-Diversität wurde für die Paracaszeitliche Population aus der Palpa-Region und Pacapaccari ermittelt.

\subsubsection{Genetische Distanzen}

Wie bereits für die Palpa-Region beschrieben (Kap. 5.1.2), wurden auch für die gesamten Haplogruppen-Daten aus Südamerika Distanzberechnungen angestellt. Die Berechnungen beinhalten die zuvor beschriebenen Regionalgruppen und die aDNA-Daten. Aus den Berechnungen der paarweisen $\mathrm{F}_{\mathrm{ST}}$-Distanzen und der Nei-D (vgl. 3.8.2) ergibt sich ein vergleichbares Bild. Als Grundlage für die graphische Darstellung der Daten wurden die F $_{\mathrm{ST}^{-}}$ Distanzwerte gewählt. Für die Darstellung wurden drei verschiedene Methoden gewählt. Da phylogenetische Bäume durch die Verbindung der Taxa eindeutige Abstammungslinien suggerieren, wurde für eine neutrale Darstellungsform eine multidimensionale Skalierung mit den Daten aus der Distanzmatrix durchgeführt und in einen MDS-Plot umgesetzt (Abb. 55). Zusätzlich wurden auch ein UPGMA- und NJ-Baum berechnet (vgl. Kap 3.8.3). Beide Bäume ergeben ein nahezu identisches Bild. Im Folgenden wird der UPGMA-Baum (Abb. 56) dargestellt.

Der MDS-Plot und auch der UPGMA-Baum verdeutlichen das Bild, das sich bereits aus den Frequenzverteilungen ergeben hat. Die Paracas- und Nasca-zeitlichen Populationen aus dem Palpa-Tal und der Paracas-Halbinsel clustern zusammen mit den Regionen 13, 15, 16 und 17, also den rezenten Populationen des mittleren und südlichen Chiles und dem argentinischen Patagonien. Ein zweites Cluster wird von den zentral- und südandinen Gruppen und den präkolumbischen Populationen von Paucarraca und Pacapaccari gebildet. Die in den Mittleren Horizont datierenden Populationen aus Chen Chen und dem nördlichen Chile gruppieren zusammen mit der rezenten Bevölkerung des östlichen Fußes der südlichen Zentralanden. 


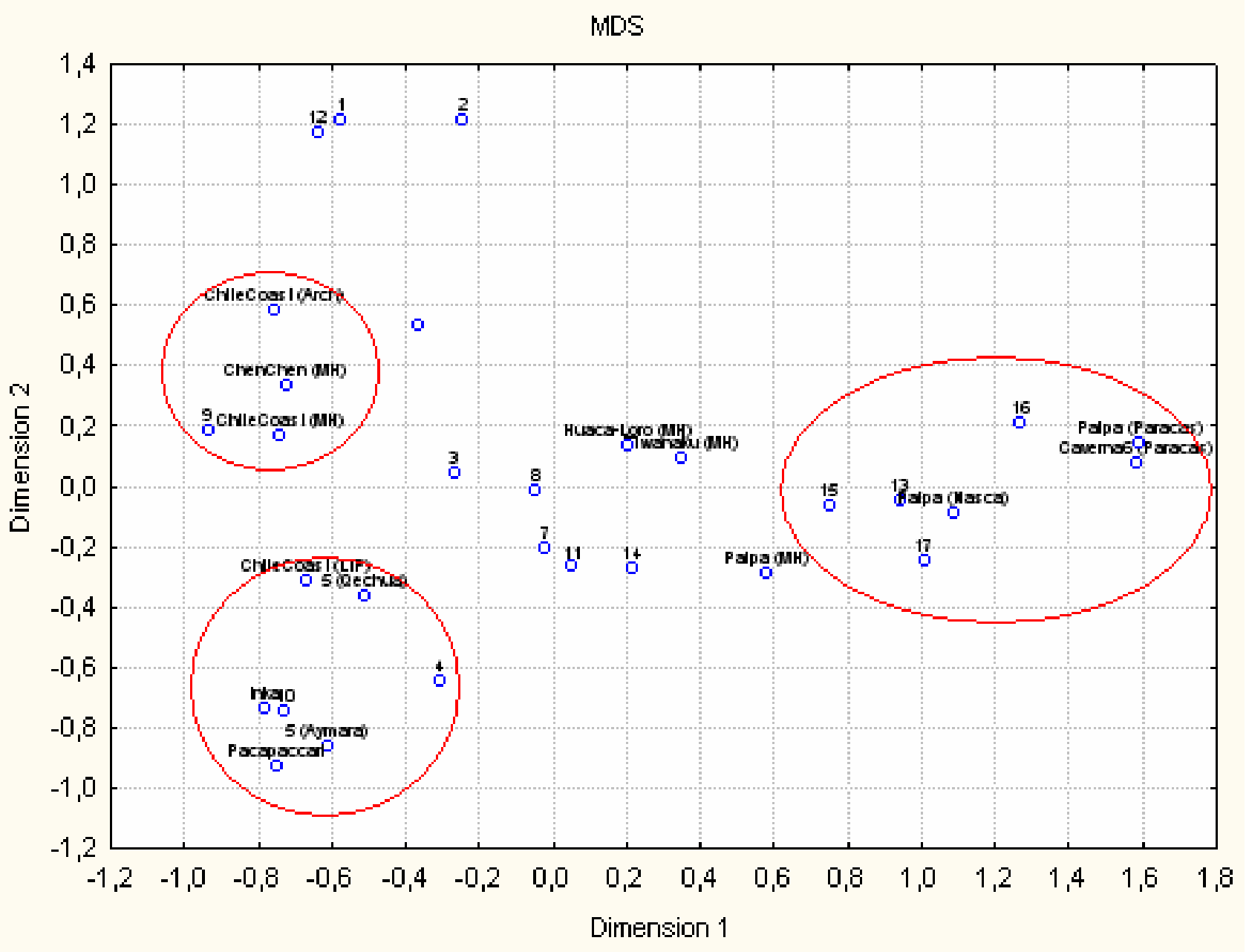

Abb. 55: MDS-Plot der paarweisen $F_{\mathrm{ST}}$-Distanzen für die rezenten und präkolumbischen Haplogruppen-Daten aus Südamerika. Aus Platzgünden ist der Fundort Paucarraca mit „Inka“ beschriftet.

Die drei Cluster aus dem MDS-Plot zeichnen sich auch in dem UPGMA-Baum ab (Abb. 56). Die Populationen aus der Palpa-Region und des südlichen Südamerika gruppieren zusammen in einem distinkten Ast des Baumes und weisen eine hohe Distanz gegenüber allen anderen Regionen auf. Die Astlängen innerhalb der Gruppe der anderen Populationen weisen auf relativ geringe Distanzen zueinander hin. Innerhalb dieser Gruppe bilden, wie auch im Plot, die rezenten und präkolumbischen Populationen der zentralen und südlichen Anden ein distinktes Cluster. Auch die Gruppe aus Region 9 und den präkolumbischen Populationen der nördlichen chilenischen Küste bildet sich in dem Baum ab. Dieses Cluster gruppiert im Baum zusammen mit den Populationen aus dem östlichen Südamerika. 


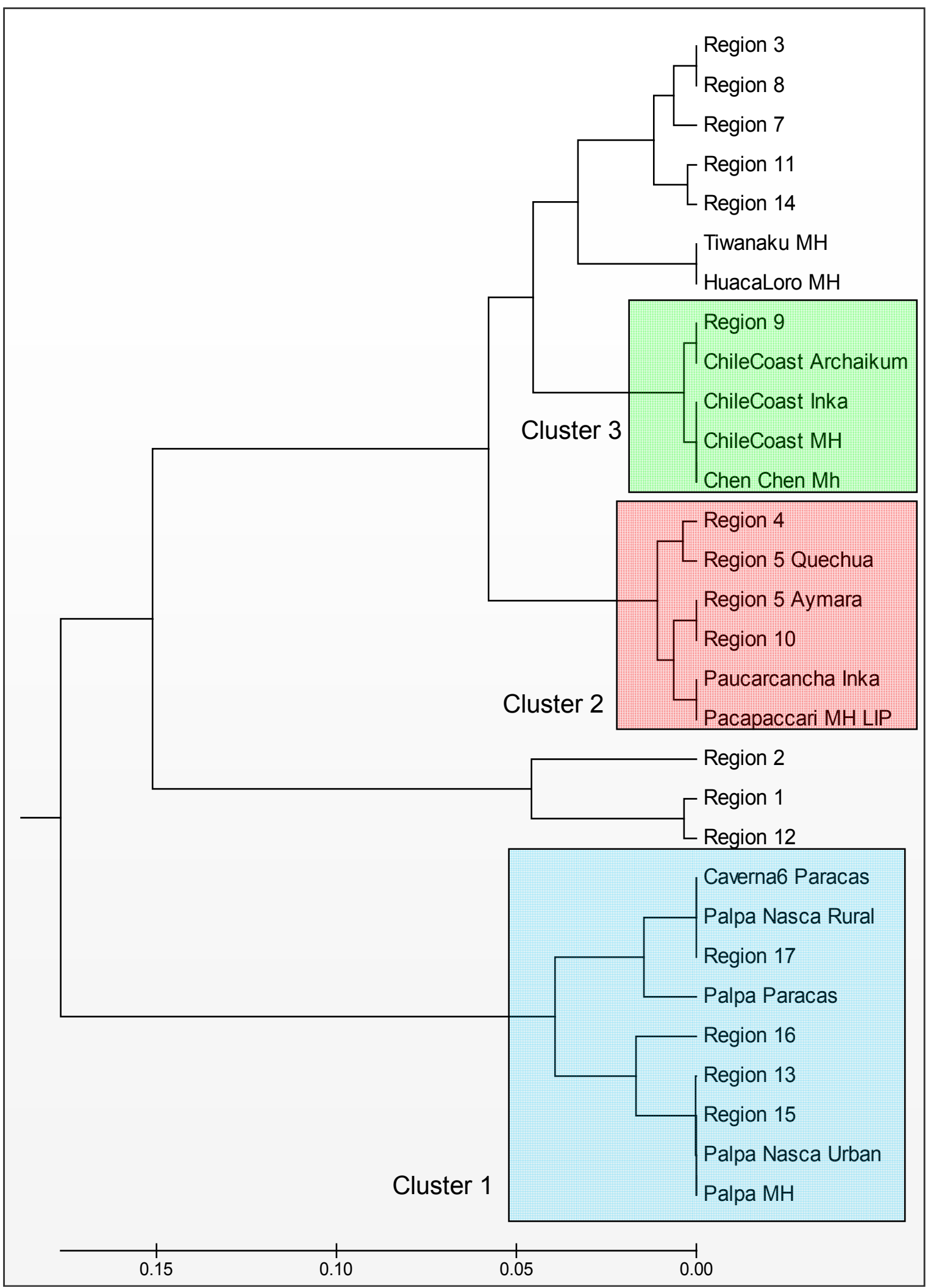

Abb. 56: UPGMA-Baum, erstellt aus den paarweisen $F_{\mathrm{ST}}$-Distanzen für die rezenten und präkolumbischen Haplogruppen-Daten aus Südamerika. Der Baum ist skaliert. Die Astlängen geben die zugrunde liegenden paarweisen Distanzwerte wieder. Die Kästen kennzeichnen die drei Cluster aus dem MDS-Plot. 1 = Palpa u. Süd-Südamerika; 2 = Hochland u. rezentes Peru; $3=$ östlicher Andenfuß und präkolumbische, chilenische Nordküste. 


\subsection{Mitochondriale Haplotypen}

\subsubsection{Intrakontinentaler Vergleich der Haplotypen aus dem Untersuchungsgebiet}

Um die mitochondrialen Haplotypen-Daten aus dem Untersuchungsgebiet mit dem restlichen Südamerika zu kontextualisieren, wurden sie mit den genetischen Daten von 984 Individuen aus 15 indigenen südamerikanischen Populationen verglichen (vgl. Abb. 29; Tab. 11 / Kap. 3.1.3). In Tab. 36 sind alle im Rahmen der vorliegenden Arbeit ermittelten Haplotypen aufgeführt, die auch in den Referenzpopulationen nachgewiesen wurden. Insgesamt teilen sich die Populationen nur sehr wenige Haplotypen, mit Ausnahme der indigenen amerikanischen Gründerhaplotypen PA-A1, B1, B3, C2 und D1. Darüber hinaus kommen nur die drei Haplotypen PA-A3, C4 und C10 (vgl. Abb. 41) ebenfalls in den rezenten indigenen Bevölkerungsgruppen vor. Überraschenderweise teilt sich die präkolumbische Bevölkerung der Palpa-Region diese Haplotypen mit Populationen aus dem östlichen Südamerika, dem Gran Chaco (Reg. 11) und dem angrenzenden südlichsten Brasilien (Reg. 12). Der Vergleich bestätigt das Bild, dass die meisten indigenen amerikanischen Populationen einen sehr hohen Anteil diskreter Haplotypen aufweisen (Malhi et al. 2002), die meist nur in begrenzten geographischen Räumen verbreitet sind.

Tab. 36: Haplotypen aus der Palpa-Region, die in mehreren Populationen nachgewiesen werden konnten.

\begin{tabular}{l|cccccccc}
\hline & \multicolumn{7}{|c}{ mt-Haplotypen Palpa-Region } \\
& PA-A1 & PA-A3 & PA-B1 & PA-B3 & PA-C2 & PA-C4 & PA-C10 & PA-D1 \\
\hline Yanomami & 0 & 0 & 0 & $\mathbf{7 5}$ & $\mathbf{4 9}$ & 0 & 0 & 0 \\
Zoro & 0 & 0 & 0 & 0 & 0 & $\mathbf{3}$ & 0 & $\mathbf{1 3}$ \\
Xavante & $\mathbf{4}$ & 0 & $\mathbf{1 1}$ & 0 & 0 & 0 & 0 & 0 \\
Ancash & 0 & 0 & $\mathbf{4}$ & 0 & $\mathbf{3}$ & 0 & 0 & $\mathbf{1}$ \\
Bolivien Tiefland & $\mathbf{5}$ & 0 & $\mathbf{3}$ & 0 & $\mathbf{6}$ & 0 & 0 & $\mathbf{3}$ \\
Gran Chaco & 0 & 0 & 0 & $\mathbf{9}$ & $\mathbf{1 0}$ & 0 & $\mathbf{1}$ & $\mathbf{1 1}$ \\
Guarani & $\mathbf{7 9}$ & $\mathbf{1}$ & 0 & 0 & 0 & 0 & 0 & $\mathbf{1 3}$ \\
Kaingang & $\mathbf{3 0}$ & 0 & 0 & 0 & $\mathbf{1 2}$ & 0 & 0 & 0 \\
Pehuenche & 0 & 0 & $\mathbf{2}$ & 0 & $\mathbf{7}$ & 0 & 0 & 0 \\
Mapuche & 0 & 0 & 0 & 0 & $\mathbf{1 2}$ & 0 & 0 & 0 \\
\hline Yaghan & 0 & 0 & 0 & 0 & $\mathbf{3}$ & 0 & 0 & $\mathbf{2}$ \\
\hline
\end{tabular}

\subsubsection{Populationsgenetische Berechnungen}

Für alle aufgenommenen HVRI-Daten aus den rezenten Referenzpopulationen wurden genetische Diversitäts- und Distanzberechnungen durchgeführt (vgl. Kap. 3.8.1), um die 
bevölkerungsbiologischen Relationen der präkolumbischen Palpa-Region zum restlichen Südamerika zu beleuchten. In Tab. 37 finden sich die Ergebnisse der Diversitätsberechnungen. Wie für die Populationen aus dem Untersuchungsgebiet (vgl. Kap. 5.2.2) wurden auch für die rezenten Referenzpopulationen Haplotypen- $(\mathrm{Hd})$ und Nukleotid-Diversität $(\pi)$ ermittelt. Neben diesen Werten sind in Tab. 37 die pro Gruppe nachgewiesene Zahl an verschiedenen Haplotypen (h), die Zahl der variablen Nukleotidpositionen ( $\mathrm{S}=$ segregating sites) und die durchschnittliche Zahl der Nukleotidunterschiede (K) angegeben.

Tab. 37: Genetische Diversität der rezenten indigenen südamerikanischen Referenzpopulationen und den präkolumbischen Populationen aus dem Untersuchungsgebiet (für die geographische Zuordnung der Populationen vgl. Abb. 29)

\begin{tabular}{lccccccc}
\multicolumn{1}{c}{ Population } & n & h & S & Hd & K & $\boldsymbol{\pi}$ & Quelle \\
\hline Ache & 63 & 3 & 7 & 0,2038 & 1,0824 & 0,0030 & Schmitt et al. 2004 \\
\hline Guarani & 200 & 9 & 13 & 0,7635 & 2,4970 & 0,0070 & Marrero et al. 2007 \\
\hline Xavante & 25 & 4 & 10 & 0,6767 & 3,0000 & 0,0083 & Ward et al. 1996 \\
\hline Zoro & 29 & 8 & 16 & 0,7586 & 3,7783 & 0,0106 & Ward et al. 1996 \\
\hline Gaviao & 5 & 2 & 10 & 0,4000 & 4,0000 & 0,0111 & Ward et al. 1996 \\
\hline Yanomami & 155 & 6 & 16 & 0,6566 & 4,4226 & 0,0123 & Williams et al. 2002 \\
\hline Arequipa & 22 & 18 & 25 & 0,9784 & 5,0476 & 0,0140 & Fuselli et al. 2003 \\
\hline San Martin & 22 & 15 & 22 & 0,9394 & 5,1429 & 0,0143 & Fuselli et al. 2003 \\
\hline Yaghan & 15 & 7 & 15 & 0,8857 & 5,2952 & 0,0147 & Moraga et al. 2000 \\
\hline Mapuche & 34 & 9 & 17 & 0,8378 & 5,5350 & 0,0156 & Moraga et al. 2000 \\
\hline Kaingang & 74 & 10 & 19 & 0,7486 & 5,6594 & 0,0157 & Marrero et al. 2007 \\
\hline Pehuenche & 24 & 13 & 22 & 0,9022 & 5,8370 & 0,0162 & Moraga et al. 2000 \\
\hline Ancash & 34 & 27 & 42 & 0,9768 & 5,9893 & 0,0162 & Lewis et al. 2005 \\
\hline Bolivien Tiefland & 53 & 31 & 36 & 0,9666 & 5,8578 & 0,0163 & Bert et al. 2004 \\
\hline Tayacaja & 60 & 42 & 48 & 0,9672 & 5,9571 & 0,0166 & Fuselli et al. 2003 \\
\hline Gran Chaco & 169 & 45 & 55 & 0,9552 & 6,8872 & 0,0191 & Cabana et al. 2006 \\
\hline Palpa (Paracas) & 25 & 15 & 21 & 0,9500 & 3,7884 & 0,0105 & diese Arbeit \\
\hline Caverna6 (Paracas) & 6 & 5 & 6 & 0,9333 & 2,8000 & 0,0078 & diese Arbeit \\
\hline Palpa (Nasca-Rural) & 30 & 26 & 31 & 0,9885 & 4,6020 & 0,0130 & diese Arbeit \\
\hline Palpa (Nasca-Urban) & 25 & 17 & 18 & 0,9700 & 4,9267 & 0,0137 & diese Arbeit \\
\hline Palpa (MH) & 6 & 6 & 15 & 1,0000 & 6,2667 & 0,0174 & diese Arbeit \\
\hline Pacapaccari & 12 & 6 & 15 & 0,8636 & 6,0909 & 0,0169 & diese Arbeit \\
\hline & & & & & & \\
\hline
\end{tabular}

Die rezenten Populationen des westlichen Südamerika (Anden, Pazifikküste) weisen, wie auch die präkolumbische Bevölkerung der südlichen peruanischen Küste, sehr hohe HaplotypenDiversitätswerte auf (Hd: 0,84-1,00). Ähnlich hohe Werte sind östlich der Anden nur in den 
Bevölkerungen des Gran Chaco und des bolivianischen Tieflandes zu finden. Alle anderen Populationen des östlichen Südamerika, vor allem in den nördlichen und südlichen Amazonasgebieten, weisen geringere Werte in einem Bereich von $\mathrm{Hd}=0,20-0,75$ auf. Das Gran Chaco verbindet seit präkolumbischer Zeit den Westen und Osten Südamerikas, als eines der Hauptdurchgangsgebiete für Handel und Menschen (Cabana et al. 2006). Dieser Umstand erklärt wahrscheinlich auch die, im Vergleich zu den anderen ost-südamerikanischen Populationen, hohe Haplotypen-Diversität. Die aus den Hd-Werten abzuleitende eindeutige Unterscheidung der östlichen und westlichen Populationen Südamerikas ist nicht aus den $\pi$-Werten zu ersehen. Die in den Gruppen der Palpa-Region anzutreffende Nukleotid-Diversität fügt sich in die Variationsbreite der rezenten Populationen ein. Das Verhältnis von beiden genetischen Diversitäten zueinander in den untersuchten Populationen ist in Abb. 57 dargestellt.

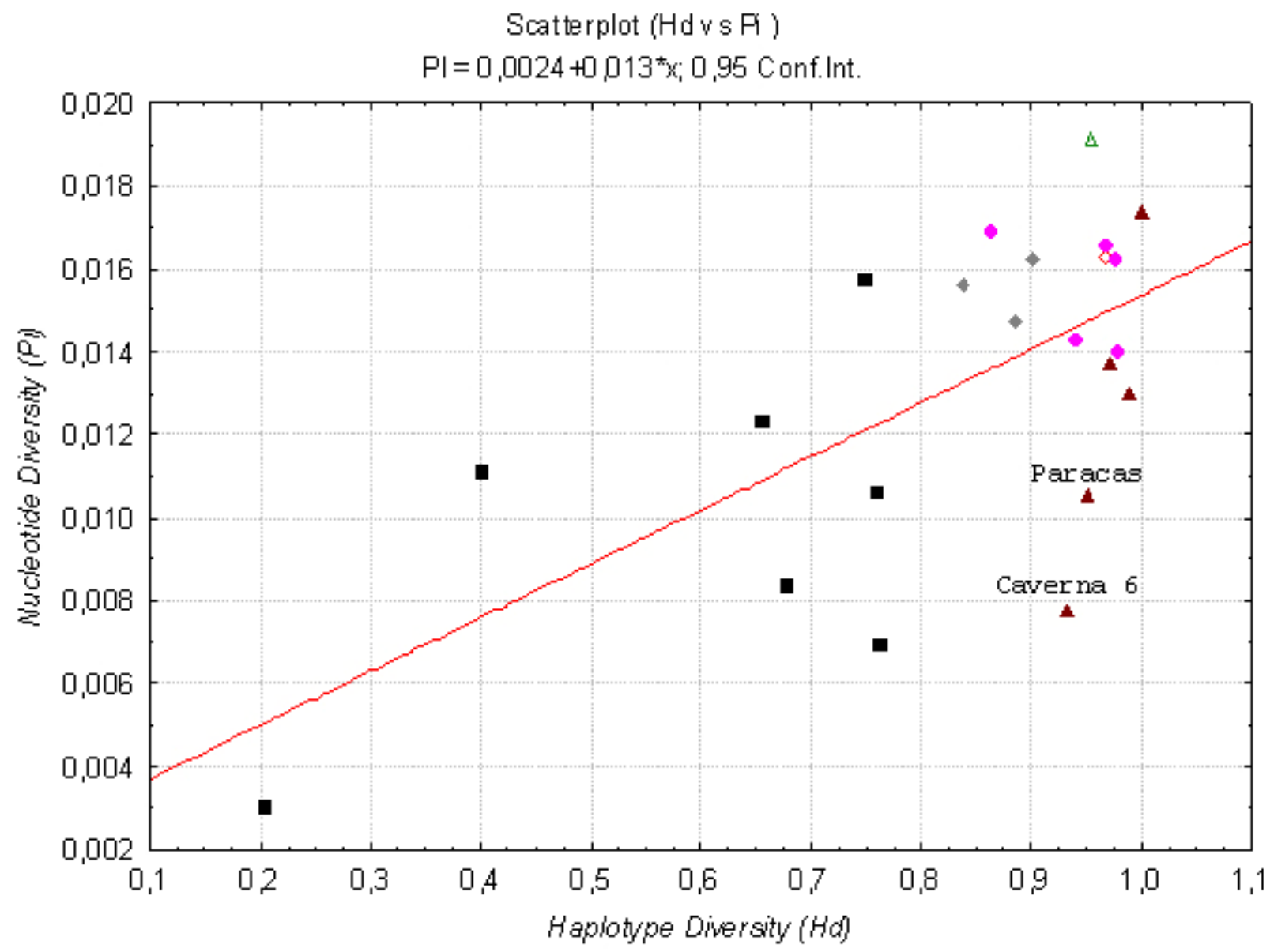

Abb. 57: Haplotypen- vs. Nukleotid-Diversität. In dem Plot sind die beiden Diversitätswerte der südamerikanischen Populationen gegeneinander aufgetragen (schwarze Rechtecke: Populationen der Amazonasregion und des südöstlichen Südamerika; graue Rauten: chilenische Populationen; rosa Punkte: rezente zentralandine Populationen und Pacapaccari; grünes Dreieck: Gran Chaco; rote Dreiecke: präkolumbische Populationen aus der Palpa-Region und der Paracas-Halbinsel. 
Der Plot verdeutlicht den Unterschied der genetischen Diversität in den ost- und westsüdamerikanischen Bevölkerungen. Es fällt auf, dass die west-südamerikanischen Populationen in dem Plot sehr nahe zusammen gruppieren (Abb. 57). Die hohen Diversitätswerte weisen darauf hin, dass der Genfluss im andinen, bzw. west-südamerikanischen Raum über die Zeit hinweg stabil hoch war, während die Bevölkerungsgruppen im Osten einer stärkeren Isolation unterlagen (vgl. Lewis et al. 2007b). Die hohen Hd-Werte und die dazu im Verhältnis geringen $\pi$-Werte der beiden Paracas-zeitlichen Populationen könnten auf ein Bottleneck-Ereignis hinweisen, auf das ein schnelles Bevölkerungswachstum folgte (Lowe et al. 2004). Das Diversitätsverhältnis der anderen rezenten und präkolumbischen west-südamerikanischen Populationen deutet auf eine relativ stabile und große Bevölkerung mit einem konstanten genetischen Austausch hin.

Zur Ermittlung der genetischen Distanz wurden die 15 Referenzpopulationen in Abhängigkeit von ihrer regionalen Herkunft (vgl. Abb. 51) in Gruppen zusammengefasst. Für diese Gruppen wurde auf Basis der Sequenzdaten die durchschnittliche genetische Distanz zwischen den Gruppen berechnet und mit der UPGMA-Methode (vgl. Kap. 3.8.3) in einen phylogenetischen Baum umgewandelt (Abb. 58).

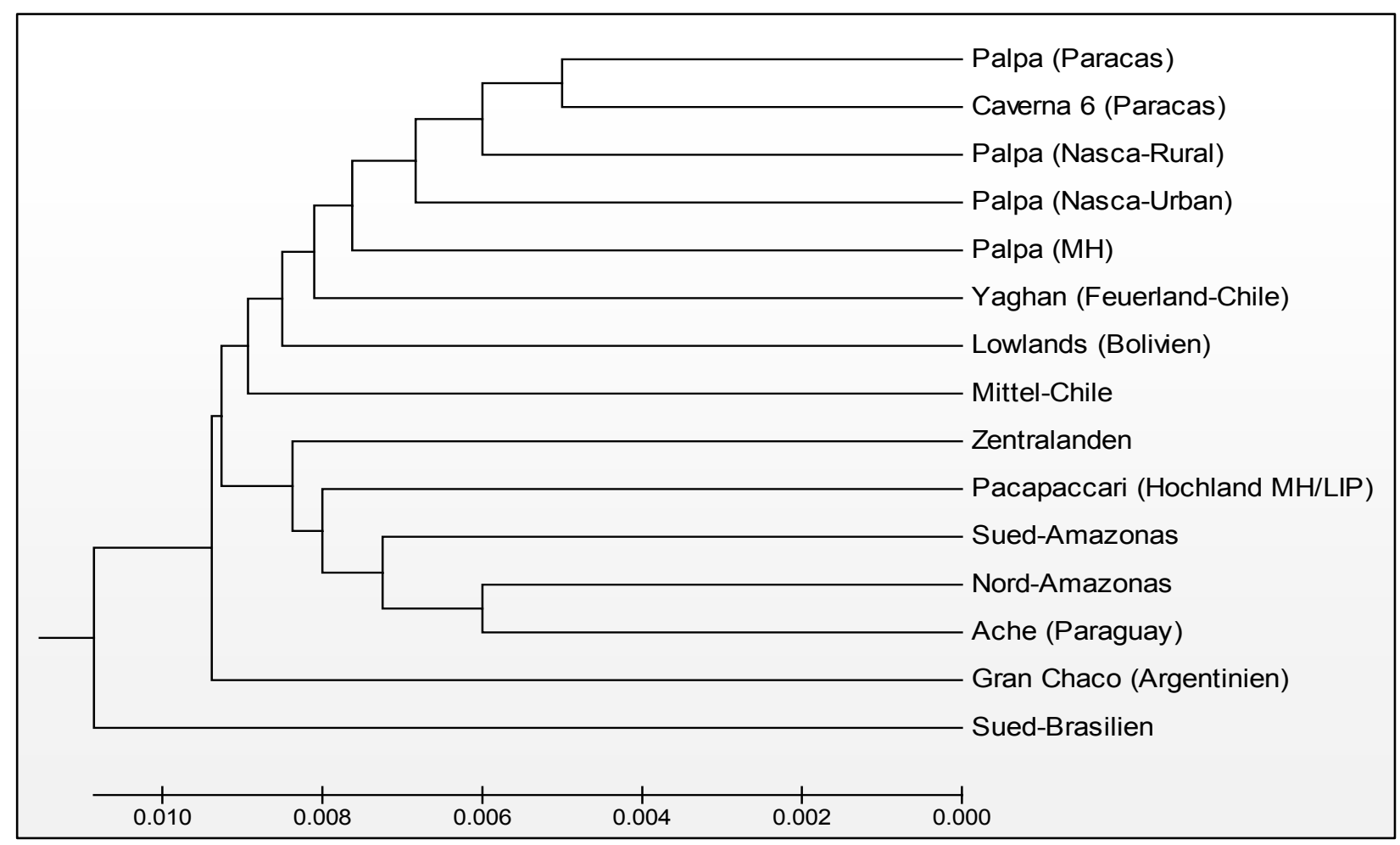

Abb. 58: UPGMA-Baum der durchschnittlichen genetischen Distanzen zwischen den verschiedenen rezenten und präkolumbischen Bevölkerungsgruppen Südamerikas. Der Baum ist skaliert und die Astlängen geben die ermittelten paarweisen Distanzwerte wieder. 
Die Sequenzdaten bieten ein etwas differenzierteres Bild als die Haplogruppen-Daten (vgl. Kap. 6.1.2). Es bilden sich zwei Hauptmonophyla (Abb. 58). Das eine umfasst die südbrasilianischen Populationen (Guarani u. Kaingang) und das andere die restlichen rezenten Populationen und die präkolumbische Bevölkerung der Palpa-Region. Dieses zweite Monophylum lässt sich in drei Cluster unterteilen. Cluster eins bildet für sich das Gran Chaco. Die zentralandinen Populationen und das präkolumbische Pacapaccari gruppieren zusammen mit den nord- und südamazonischen Populationen, wobei letztere eine geringere Distanz zueinander aufweisen als zu den andinen Gruppen. Auffällig ist, dass die Ache aus den Galeriewäldern Paraguays eine geringere Distanz zu der nordamazonischen Bevölkerung aufweisen als zu der südamazonischen. Das dritte Cluster wird von den präkolumbischen Populationen der Palpa-Region und den südwestlichen südamerikanischen rezenten Populationen gebildet (Mapuche, Pehuenche, Yaghan). In dieses Cluster fällt außerdem die Bevölkerung des bolivianischen Tieflandes. Die präkolumbischen Populationen der Palpa-Region und der Paracas-Halbinsel gruppieren in relativ geringer Distanz zueinander. In geringer Distanz dazu findet sich die rezente Bevölkerung Feuerlands (Yaghan).

Um die genetischen Beziehungen der prähistorischen Gruppen zu der rezenten Bevölkerung des westlichen Südamerikas zu verdeutlichen, wurden zusätzlich Distanzberechnungen vorgenommen, die nur die einzelnen Populationen dieser Regionen umfassen (nicht in Gruppen zusammengefasst). Zur Darstellung der Beziehungen wurde ein NJ-Baum gewählt, der aus den paarweisen $\mathrm{F}_{\mathrm{ST}}$-Distanzen ermittelt wurde (Abb. 59). Alle anderen Distanzberechnungen (vgl. Kap. 3.8.2) ergeben ein ähnliches Bild.

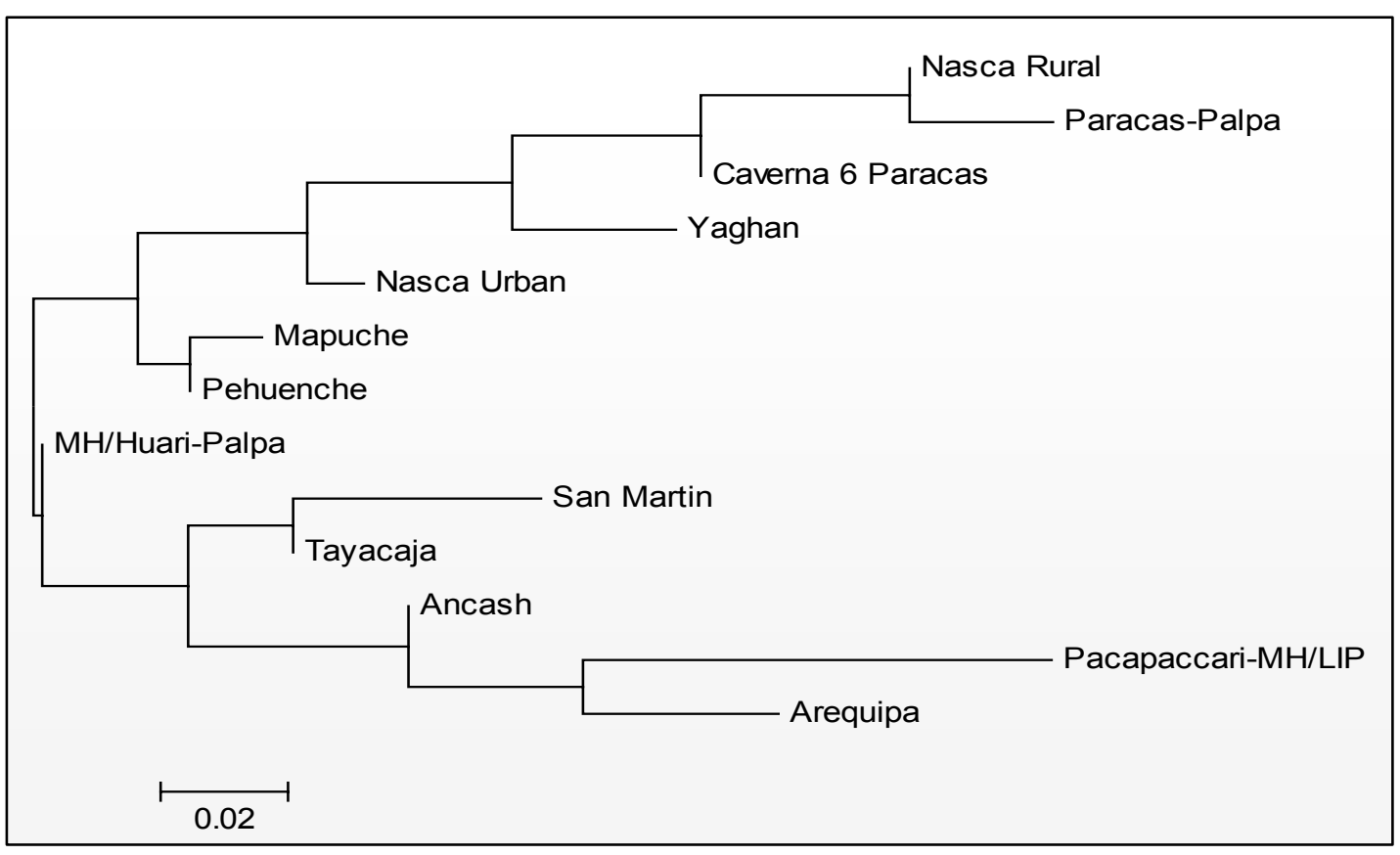

Abb. 59: NJ-Baum der paarweisen $F_{S T}$-Distanzen zwischen den west-südamerikanischen Populationen. Der Baum ist skaliert und die Astlängen geben die ermittelten DistanzVerhältnisse wieder. 
Der NJ-Baum (Abb. 59) weist zwei eindeutige Cluster auf. Das eine umfasst die präkolumbischen Populationen der Palpa-Region und die rezenten chilenischen Populationen, das andere die rezenten peruanischen Populationen und das präkolumbische Pacapaccari. Die in den Mittleren Horizont datierende Bevölkerung der Palpa-Region gruppiert sich zwischen die beiden Cluster. Mapuche, Pehuenche (mittleres bis südliches Chile) und die rurale Nascazeitliche Population der Palpa-Region weisen geringe Distanzen zueinander auf. Die Yaghan (Feuerland) gruppieren sich zwischen die urbane Nasca-zeitliche Bevölkerung und die anderen drei Gruppen aus der Palpa-Region.

Zum Vergleich der genetischen Strukturen der einzelnen Regionen und Gruppen zueinander wurde eine AMOVA-Analyse durchgeführt (vgl. Kap. 3.8.6). Die Ergebnisse der Analyse finden sich in Tab. 38. Für die AMOVA werden Gruppen gebildet, die mehrere Populationen umfassen. Diese Gruppen können miteinander verglichen werden. Die hier vorgenommene Gruppenbildung versucht verschiedene Relationen und Oppositionen unter Bevölkerungsgruppen in Abhängigkeit von kulturellen und geographischen Faktoren zu erfassen. So werden das östliche und westliche Südamerika ebenso miteinander verglichen, wie die präkolumbischen Populationen der PalpaRegion mit den rezenten Populationen aus Peru. Die jeweiligen Vergleichsszenarien sind der ersten Spalte in Tab. 38 zu entnehmen.

Die AMOVA-Analysen, die sich jeweils nur auf eine Gruppe beziehen (Zeile: 1-6; Tab. 38), zeigen, dass die Bevölkerungsgruppen des westlichen Südamerika den größten Anteil molekularer Variationen innerhalb der einzelnen Populationen aufweisen (93-100\%), aber nur eine geringe genetische Differenzierung zwischen den Populationen besteht (3-6\%). Im Kontrast dazu steht die Bevölkerung des östlichen Südamerika, wo nur 66\% der Variationen innerhalb der Populationen auftreten und 34 \% unter verschiedenen Populationen. Dieses Bild zeigten bereits die ermittelten Haplotypen-Diversitätswerte (s.o.) und bestätigen die Annahme, dass im Andenraum und an der Pazifikküste zu allen Zeiten ein höherer und konstanter genetischer Austausch unter den Bevölkerungen bestand als östlich der Anden. Der Vergleich zwischen allen westlichen und östlichen Gruppen (Tab. 38, Zeile 8) ergibt allerdings keine signifikante Unterscheidung. Diese Beobachtung wurde bereits in früheren Arbeiten gemacht (Luiselli et al. 2000; Tarazona-Santos et al. 2001; Lewis et al. 2005). 


\begin{tabular}{|c|c|c|c|c|c|c|c|c|c|c|}
\hline \multirow[b]{2}{*}{ Vergleich } & \multirow[b]{2}{*}{$\begin{array}{c}\text { Anzahl } \\
\text { Gruppen }\end{array}$} & \multicolumn{3}{|c|}{ Molekulare Variation (in \%) } & \multicolumn{3}{|c|}{ Fixation Index } & \multicolumn{3}{|c|}{ Verglichene Populationen } \\
\hline & & $\begin{array}{l}\text { Variation } \\
\text { zwischen } \\
\text { Gruppen }\end{array}$ & $\begin{array}{c}\text { Variation unter } \\
\text { den } \\
\text { Populationen } \\
\text { in den Gruppen }\end{array}$ & $\begin{array}{c}\text { Variation } \\
\text { innerhalb } \\
\text { der } \\
\text { Populationen }\end{array}$ & ФSC & ФST & ФCT & Gruppe 1 & Gruppe 2 & Gruppe 3 \\
\hline Peru (rezent) & 1 & n.d. & 3,89 & 96,11 & n.d. & 0,03886 & n.d. & $2-5$ & & \\
\hline Chile (rezent) & 1 & n.d. & 4,02 & 95,98 & n.d. & 0,04017 & n.d. & $14-16$ & & \\
\hline Osten (gesamt) & 1 & n.d. & 33,51 & 66,49 & n.d. & 0,33505 & n.d. & $1 ; 6-13$ & & \\
\hline aDNA (Küste / ohne Paccapacari) & 1 & n.d. & 4,94 & 95,06 & n.d. & 0,04940 & n.d. & & & \\
\hline Paracas (Palpa \& Caverna6) & 1 & n.d. & $-0,58$ & 100,58 & n.d. & $-0,00576$ & n.d. & & & \\
\hline Nasca (Palpa) & 1 & n.d. & 6,73 & 93,27 & n.d. & 0,06732 & n.d. & & & \\
\hline Gran Chaco zu Südost & 2 & $-10,17$ & 44,72 & 65,45 & 0,04059 & 0,34549 & $-0,1018$ & 10 & $11-13$ & \\
\hline Ost zu West & 2 & $-1,53$ & 28,97 & 72,56 & 0,28531 & 0,27436 & $-0,0153$ & $2-5 ; 14-16$ & $1 ; 6-13$ & \\
\hline Gran Chaco zu Peru & 2 & 2,94 & 3,25 & 93,81 & 0,03344 & 0,06190 & 0,0295 & 10 & $2-5$ & \\
\hline Chile zu Nasca (Palpa) & 2 & 3,81 & 4,91 & 91,28 & 0,05103 & 0,08721 & 0,0381 & $14-16$ & & \\
\hline Chile zu Peru & 2 & 5,82 & 3,69 & 90,49 & 0,03923 & 0,09514 & 0,0582 & $14-16$ & $2-5$ & \\
\hline Chile (rezent) zu aDNA (Küste) & 2 & 6,41 & 4,04 & 89,54 & 0,04319 & 0,10455 & 0,0641 & $14-16$ & & \\
\hline Gran Chaco zu Chile & 2 & 7,39 & 2,76 & 89,85 & 0,02975 & 0,10148 & 0,0739 & 10 & $14-16$ & \\
\hline Peru \& Hochland zu Nasca \& MH Küste & 2 & 8,76 & 5,56 & 85,68 & 0,06095 & 0,14323 & 0,8762 & $2-5$ & & \\
\hline Peru zu Nasca & 2 & 8,90 & 4,04 & 87,05 & 0,04440 & 0,12947 & $\mathbf{0 , 0 8 9 0}$ & $2-5$ & & \\
\hline Chile zu Paracas & 2 & 10,30 & 3,28 & 86,41 & 0,03661 & $\mathbf{0 , 1 3 5 8 7}$ & 0,1030 & $14-16$ & & \\
\hline Peru zu Hochland & 2 & 11,24 & 3,43 & 85,34 & 0,03859 & 0,14661 & 0,1124 & $2-5$ & & \\
\hline Peru (rezent) zu aDNA (Küste) & 2 & 12,02 & 5,02 & 82,97 & 0,05701 & 0,17034 & 1,1202 & $2-5$ & & \\
\hline Peru zu Paracas & 2 & 15,71 & 3,10 & 81,19 & 0,03676 & 0,18813 & 0,1572 & $2-5$ & & \\
\hline Nordost zu Südost & 2 & 16,62 & 32,61 & 50,77 & 0,39113 & 0,49233 & 0,1662 & 1 & $6-8 ; 11-13$ & \\
\hline Nasca zu Hochland & 2 & 24,55 & 5,08 & 70,37 & 0,06734 & 0,29628 & 0,2455 & & & \\
\hline aDNA Küste zu Hochland & 2 & 30,70 & 3,10 & 66,21 & 0,04467 & 0,33793 & 0,3070 & & & \\
\hline Paracas zu Hochland & 2 & 43,55 & $-1,37$ & 57,82 & $-0,02424$ & $\mathbf{0 , 4 2 1 7 7}$ & 0,4355 & & & \\
\hline Paracas zu Nasca zu Mittl. Horizont & 3 & $-0,73$ & 5,47 & 95,26 & 0,05429 & 0,04741 & $-0,0073$ & & & \\
\hline Ost zu West zu aDNA Daten & 3 & 0,95 & 27,02 & 72,03 & 0,27280 & 0,27972 & 0,0095 & $1 ; 6-13$ & $2-5 ; 14-16$ & \\
\hline Nordost zu Mitteost zu Südost & 3 & 1,93 & 46,35 & 51,72 & 0,47263 & 0,48281 & 0,0193 & 1 & $6-9$ & $11-13$ \\
\hline Regionalgruppen \& Chrono zueinander & 9 & 1,10 & 26,34 & 72,56 & 0,26635 & 0,27442 & 0,0110 & & & \\
\hline
\end{tabular}

Tab. 38: AMOVA-Analyse der HVRI-Daten aus allen rezenten und präkolumbischen Populationen. Die linke Spalte gibt das Vergleichsszenario an. Die Spalte daneben die Zahl an Gruppen, die gebildet wurden. Variationen zwischen Gruppen (ISC) können nur ermittelt werden, wenn mehrere gebildet wurden. Fettgedruckte Werte sind signifikant. Die letzten drei Spalten geben die jeweiligen integrierten rezenten Populationen an (vgl. Tab. 11). 
Den höchsten Variationswert unter Gruppen ergibt der Vergleich zwischen den Paracaszeitlichen Populationen und dem präkolumbischen Hochland (Pacapaccari) und auch aller Daten aus der Palpa-Region zum Hochland (40\% bzw. 30 \%). Der Vergleich zwischen der Paracas-Zeit und dem rezenten Peru ergibt ebenfalls eine signifikante Unterscheidung zwischen den beiden Gruppen. Die Variation zwischen der rezenten chilenischen und der Paracas-zeitlichen Bevölkerung ist niedriger. Der Vergleich aller chilenischen Populationen zu den Nascazeitlichen zeigt, dass nur 3,8\% der angetroffenen genetischen Variation unter den beiden Gruppen besteht. Die rezente peruanische Bevölkerung unterscheidet sich im Gruppenvergleich deutlich mehr von den präkolumbischen Populationen der Palpa-Region. Allerdings erreichen die Werte keine eindeutige Signifikanz.

Die AMOVA-Analysen bestätigen das Bild, welches aus den Diversitäts- und DistanzAnalysen entstanden ist. Das westliche Südamerika (Anden und Pazifikküste) weist eine höhere Diversität auf, und alle Daten deuten auf einen konstanten Genfluss unter den Populationen hin. Die präkolumbischen Populationen aus der Palpa-Region zeigen eine höhere Affinität zu den rezenten mittel- und südchilenischen Populationen als zu der rezenten Bevölkerung Perus. Der Hochlandfundort Pacapaccari zeigt hingegen in allen Untersuchungen eine hohe Korrelation zu den Bevölkerungen des heutigen Perus.

\subsection{Zusammenfassende Betrachtung des kontinentalen genetischen Vergleichs}

Der Vergleich der genetischen Daten aus der Palpa-Region mit anderen präkolumbischen aber auch rezenten südamerikanischen Populationen ermöglicht es, die bevölkerungsbiologischen Verbindungen und Entwicklungen der südperuanischen Küste zu beleuchten. Die Ableitungen, die aus beiden Analyseebenen - mitochondriale Haplogruppen und Haplotypen - gemacht werden können, sind weitestgehend kongruent.

Bezüglich der genetischen Diversität und damit verbunden dem regionalen Genfluss zeigt sich eine Unterscheidung zwischen dem westlichen und dem östlich der Anden gelegenen Südamerika. Generell ist die genetische Differenzierung unter den Gemeinschaften im Westen geringer. Es bestand über die Zeiten hinweg immer ein starker genetischer Austausch unter den Gruppen. Die trotzdem zu erkennende regionale Differenzierung der Bevölkerungszusammensetzung und die Tatsache, dass unter den verschiedenen Regionen nur wenige Haplotypen geteilt werden, deuten allerdings darauf hin, dass der Genfluss hauptsächlich innerhalb bestimmter geographischer oder kultureller Grenzen stattgefunden hat. Diese Aussage wird auch durch die Variationen in der Verteilung der Haplogruppenfrequenzen entlang der Anden und Pazifikküste bestärkt (vgl. Abb. 54). Anhand dieser lassen sich in der rezenten 
Bevölkerung drei Hauptgruppen festlegen. In der Bevölkerung des äußersten Nordens Südamerikas dominiert die Haplogruppe A. Diese wird in dem zentral- und südandinen Raum durch die Haplogruppe B in der Bedeutung abgelöst. Im südlichen Südamerika treten die Haplogruppen D und C am häufigsten auf. Die aus den Haplogruppenfrequenzen abzulesende Unterscheidung spiegelt sich auch in den verschiedenen genetischen Distanzberechnungen auf Haplogruppen- und Sequenzebene wider. Auch hier bilden sich jeweils für die Populationen des zentralen und südlichen Andenraums und des südlichen Südamerikas relativ distinkte Cluster. Frequenz- und Distanzdaten sprechen aber nicht für abrupte Brüche zwischen den Regionen, sondern deuten eher auf mehr oder weniger sanfte Übergänge in den postulierten Grenzbereichen der Verbreitung hin.

Die genetischen Daten der Bevölkerung der Palpa-Region und der Paracas-Halbinsel zeigen, trotz der gewaltigen geographischen Distanz von über $2000 \mathrm{~km}$, eine höhere Affinität zu den rezenten mittel- und südchilenischen und argentinischen Populationen als zum heutigen Peru. Nur die präkolumbische Hochlandbevölkerung Pacapaccaris und des Inka-zeitlichen Paucarraca weisen eine hohe Ähnlichkeit zu den rezenten peruanischen Populationen auf. Es ist allerdings zu ergänzen, dass die beiden präkolumbischen Populationen geringere HaplogruppenDiversitätswerte aufweisen, als sie in der heutigen indigenen Bevölkerung anzutreffen sind. 


\section{Interpretation, Diskussion und Kontextualisierung der genetischen Daten}

\subsection{DNA-Erhaltung in Wüstenfunden}

Die von Marota et al. (2002) aufgestellte Hypothese, dass DNA in organischen Fundstücken, die in einem hyperariden Wüstenmilieu gelagert wurden, eine maximale Erhaltungsdauer von 700 Jahren hat, kann durch die vorliegenden Untersuchungen widerlegt werden. Es konnte mitochondriale DNA aus einer großen Zahl von 1500-2500 Jahre alten menschlichen Skelettelementen extrahiert und amplifiziert werden. Darüber hinaus gelang es auch, in einem ca. 6000 Jahre alten Individuum des peruanischen Archaikums (Individuum: AO4) den Erhalt von mt-DNA nachzuweisen. Die DNA lag zwar stark fragmentiert vor, doch unterscheidet sich der Typisierungserfolg nicht von anderen aDNA-Studien, die erdgelagerte menschliche Skelettfunde aus Südamerika (z.B. Shinoda et al. 2006) oder Nordamerika (z.B. Stone u. Stoneking 1999) untersuchten. Es kann keine generalisierende Behauptung bezüglich der maximalen Erhaltung von DNA aufgestellt werden. Die Erhaltungsqualität und -quantität ist in erster Linie abhängig von den individuellen Lagerungsbedingungen des Probenmaterials (vgl. Burger et al. 1999; Hummel 2003). Die vorliegende Arbeit, aber auch die über viele Jahre gesammelte Erfahrung der Arbeitsgruppe Paläogenetik zeigt auf, dass nur eine praktische Überprüfung Hinweis darauf geben kann, ob aDNA erhalten ist oder nicht.

\subsection{Bevölkerungs- und Kulturgeschichte der Palpa-Region und Südamerikas}

\subsubsection{Verbreitung der Paracas-Kultur an der südperuanischen Küste}

Es galt lange als Lehrmeinung, dass die Paracas-Kultur hauptsächlich in der Umgebung von Ica verbreitet war (Silverman 1994). Das Auftreten der wenigen mit der Paracas-Kultur zu assoziierenden Funde südlich von Ica wurde durch Handel bzw. kulturelle Diffusion erklärt. Archäologische Grabungen in der Palpa-Region erbrachten erstmals den Nachweis für ParacasSiedlungen außerhalb der Ica-Region (vgl. Kap. 2.3.3). Auf Basis dieser Funde behaupten Reindel und Isla (2006), dass die Paracas-Kultur eine weitaus größere Verbreitung hatte, als zuvor angenommen. Die paläogenetischen Untersuchungen an den Skeletten der Paracaszeitlichen Populationen der Palpa-Region (Jauranga, Mollake Chico, Pernil Alto) und der Paracas-Halbinsel (Paracas-Caverna 6) zeigen, dass zwischen beiden Regionen keine signifikante genetische Distanz besteht (vgl. Kap. 5). Trotz der ca. 100 Kilometer, die beide Orte voneinander trennen, weisen die untersuchten Populationen eine fast identische Haplogruppenzusammensetzung auf. Darüber hinaus finden sich identische mitochondriale Haplotypen. Genetische Untersuchungen haben gezeigt, dass sich die verschiedenen indigenen amerikanischen Populationen in der Regel hauptsächlich die Gründerhaplotypen teilen. Die 
Verbreitung anderer distinkter Haplotypen ist zumeist auf Kulturen bzw. geographische Räume begrenzt (Malhi et al. 2002).

Die Dominanz der Haplogruppe D unterscheidet die Paracas-zeitlichen Populationen klar von bekannten aDNA-Datensätzen aus dem peruanischen Hochland (Shinoda et al. 2006) und der rezenten Bevölkerung des südlichen Peru (Rodriguez-Delfin et al. 2001; Lewis et al. 2005). Es ist allerdings zu bemerken, dass aus Südamerika keine anderen zeitgleichen aDNA-Datensätze bekannt sind. Auch die erwähnten Individuen aus dem Hochland datieren ca. 1600 Jahre später. Die genetischen Diversitätsberechnungen zeigen, dass in der Palpa-Region und auf der ParacasHalbinsel ein konstanter Genfluss bestand.

Die aufgeführten Beobachtungen und Ergebnisse der paläogenetischen Untersuchungen führen $\mathrm{zu}$ dem Schluss, dass die Paracas-Kultur in der Ica-Nasca Region eine bevölkerungsbiologische Einheit bildete (Kap. 2.4 - Frage 1). Die Funde der Paracas-Kultur in der Palpa-Region sowie der Nasca-Region sind nicht auf die kulturelle Adaption lokal ansässiger Gruppen bzw. Handel mit der Ica-Region zurückzuführen. Vielmehr ist in Anlehnung an Reindel und Isla (2006) davon auszugehen, dass es sich bei der Paracas-Kultur um eine regional verbreitete einheitliche Kulturerscheinung handelt. Die genetischen Ähnlichkeiten unter den Individuen von der Paracas-Halbinsel (nahe Ica) und der Palpa-Region sind zu groß, als dass sie aus der Immigration weniger Kulturträger resultieren könnten. Die hohe genetische Diversität, die geringe genetische Distanz und die Unterscheidung der genetischen Zusammensetzung zu anderen rezenten und präkolumbischen Populationen deuten darauf hin, dass eine hohe Migrationstendenz innerhalb der Verbreitungsgrenzen der Kultur bestand, aber nicht über den Raum hinaus (Abb. 60-A). Daraus ist abzuleiten, dass es eine gewisse raumbezogene Wahrnehmung kultureller Identität gab. Die Schlussfolgerung bedeutet allerdings nicht, dass es in der Paracas-Kultur - im Sinne der diffusionistischen kulturhistorischen Schule der Archäologie (vgl. Kap. 2.1.3) - die Wahrnehmung einer ausgeprägten ethnischen Identität gab.

\subsubsection{Die Entwicklung der Nasca-Kultur aus genetischer und archäologischer Perspektive}

Ähnlichkeiten in Ikonographie und Formengebung der Keramik und Textilien führen zu der archäologischen Hypothese, dass die Nasca-Kultur aus der Paracas-Kultur hervorgeht (Silverman u. Proulx 2002). Das Auftreten Paracas-zeitlicher Geoglyphen in der Palpa-Region, die eine Vorform der Nasca-zeitlichen darstellen, unterstützt diese Annahme (vgl. Kap. 2.3.3) und deutet darüber hinaus darauf hin, dass es auch in dieser Region eine kontinuierliche Entwicklung gab, die mit einer persistierenden Bevölkerung einher ging (Reindel 2004; Lambers 2006). 
Die geringe genetische Distanz zwischen der Nasca-zeitlichen Population in der PalpaRegion und der Paracas-zeitlichen und die Persistenz einiger mitochondrialen Haplotypen bestätigen die archäologische Hypothese (Kap. 2.4 - Frage 2). Vor allem die genetischen Daten der Individuen von Gräberfeldern, die mit ruralen Siedlungszusammenhängen assoziiert sind, weisen auf eine bevölkerungsbiologische Konstanz in der Region hin (vgl. Kap. 5.3). Das Auftreten neuer mitochondrialer Haplogruppen und -typen in der Palpa-Region bei gleich bleibender genetischer Diversität ist aber ein Hinweis darauf, dass sich in der Nasca-Zeit der bevölkerungsbiologische Einflussbereich verändert. Es findet eine Immigration von außerhalb in den für die Paracas-Zeit postulierten Kulturraum statt (Abb. 60-B). Diese Kontribution zum lokalen Genpool schlägt sich vor allem in der urbanen Nasca-zeitlichen Bevölkerung nieder. Die Veränderung der genetischen Zusammensetzung der Bevölkerung äußert sich auf der Haplogruppen-Ebene vor allem durch das Auftreten der Haplogruppe B und die im Vergleich zur Paracas-Zeit erhöhten Frequenzen der Haplogruppe C. Vor allem Haplogruppe B ist dominant im präkolumbischen peruanischen Hochland. Die Fundorte Pacapaccari (vorliegende Arbeit) und Paucaracca (Shinoda et al. 2006) datieren zwar in jüngere Phasen, dennoch deuten die genetischen Daten - geringere genetische Distanz und Auftreten der Haplogruppe B - darauf hin, dass in der Nasca-Zeit ein vermehrter biologischer Austausch mit dem Hochland bestand (Kap. 2.4 - Frage 5). Diese Annahme wird durch die archäologischen Befunde unterstützt. Funde von Nasca-Keramik im Hochland verdeutlichen die interkulturelle Beziehung zwischen der Küstenregion und dem Hochland (Reindel u. Gruen 2006).

Die Tatsache, dass die mit urbanen Siedlungszusammenhängen assoziierten Populationen (Los Molinos, La Muña) eine geringere genetische Ähnlichkeit (und höhere genetische Distanz) zur Paracas-zeitlichen Bevölkerung aufweisen als die mit ruralen Siedlungszusammenhängen assoziierten (Jauranga, Pernil Alto, Hanaq Pacha, Mollake Chico) lässt sich durch zwei mögliche Szenarien erklären:

1. Mit der Zunahme an gesellschaftlicher Komplexität der Nasca-Kultur erhöht sich der Pull-Faktor (vgl. Kap. 2.1.4) der Region. Handwerkliche und vielleicht auch administrative Spezialisierung erhöhen den Bedarf an Immigranten, bzw. die Attraktivität zu immigrieren. Möglicherweise etablieren sich Personen in den urbanen Siedlungen, die Stoffströme mit anderen Regionen koordinieren (Handelsmigration). Eine verstärkte Immigration von Produktionskräften (Arbeitsmigration) würde sich eher in den ruralen Siedlungszusammenhängen niederschlagen und ist in dieser Form nicht nachzuweisen.

2. Fremde Kulturträger, bzw. eine nicht aus der Region stammende Macht, etablieren ihren Einfluss durch die Errichtung administrativer Zentren (Elite Dominance / Kolonisation, 
vgl. Kap.2.1.4). Der bevölkerungsbiologische Einfluss ist eher gering und äußert sich vor allem in den Zentren und weniger in den versorgenden Siedlungen.

Die archäologischen Befunde weisen eher auf einen Übergang der Paracas- zur Nasca-Kultur hin, nicht auf ein plötzliches Auftauchen oder einen kulturellen Bruch (Silverman u. Proulx 2002). Es gibt keine Hinweise auf eine kulturelle Fremdbeeinflussung. Die postulierte zentrale kulturelle und ideologische Bedeutung der Geoglyphen für die Nasca-Kultur und die Belege für ihre Entwicklung aus Paracas-zeitlichen Vorformen (Lambers 2006) sprechen gegen die Etablierung einer fremden Kultur mit anderer Superstruktur (Harris 1968). Bis auf die EliteGräber von La Muña gibt es keine signifikante Unterscheidung zwischen den Bestattungen, aus denen die untersuchten Individuen stammen (Isla-Cuadrado 2004). Für den Fall, dass eine fremde Elite Orte wie Los Molinos als administratives Zentrum genutzt hätte, wäre zu erwarten, dass es einen geringen Genfluss zwischen der lokalen Stammpopulation und den Usurpatoren gegeben hätte. Die genetischen Daten deuten allerdings auf einen hohen Genfluss in ruralen und urbanen Populationen hin. Das Elite-Dominance Modell würde einen vermehrten Nachzug aus dem Ausgangsgebiet der Migration erwarten lassen (Kettenmigration; vgl. Anthony 1997), der letztendlich zu einer immer höher werdenden genetischen Distanz zwischen den Bewohnern der administrativen Zentren und des Umlandes führen müsste. Die ermittelten genetischen Distanzen sind allerdings nicht so hoch, als dass sie eine solche Entwicklung validieren könnten. Die gemeinsame Betrachtung der kulturwissenschaftlichen und molekularanthropologischen Daten lässt nur Szenario 1 als Möglichkeit zu. Die Ausbildung sozialer Stratifikation, Ansiedlung lokaler Eliten in Siedlungszentren und tätigkeitsbedingte Differenzierung von Bevölkerungsteilen (z.B. durch Spezialisierung) kann am ehesten die Unterscheidung zwischen den Populationen aus ruralen und urbanen Siedlungszusammenhängen erklären (Kap. 2.4 Frage 3).

\subsubsection{Der Untergang der Nasca: Invasion vs. ökologische Krise}

Gegen Ende der Nasca-Zeit lässt sich ein massiver Rückgang der Besiedlungsdichte in der Palpa-Region verzeichnen (vgl. Kap. 2.3.3), der mit einer zunehmenden Aridisierung der Region zusammenfällt (Eitel u. Mächtle 2006). Am Übergang der Frühen Zwischenperiode zum Mittleren Horizont (ca. 600-650 n. Chr.; vgl. Abb. 16) kommt es zudem zu massiven, vielleicht auch militärischen Expansionen der Huari-Kultur aus dem Hochland (Allison 1979; Silverman u. Proulx 2002). Hieraus ergeben sich zwei mögliche Gründe für den Untergang der Nasca-Kultur. Einer, der dem diffusionistischen Gedanken der Invasion entspricht und einer, der die ökologische Beeinflussung der Kulturentwicklung hervorhebt (vgl. Kap. 2.1.1). Die genetische 
Zusammensetzung der wenigen Individuen aus dem Mittleren Horizont, die im Rahmen der vorliegenden Arbeit untersucht werden konnte, unterscheidet sich nicht maßgeblich von der Bevölkerung der Nasca-Zeit. Die genetische Distanz zu den bekannten Hochlandpopulationen ist weitaus höher (vgl. Kap. 5). Im archäologischen Befund lassen sich für die Palpa-Region auch keine massiven Fremdeinflüsse festmachen oder gar Anzeichen für eine Invasion. Vielmehr ist der Mittlere Horizont durch eine minimale Besiedlungsdichte gekennzeichnet, und es gibt keinen Beleg für zentrale, große Siedlungen (Reindel u. Gruen 2006). Im Falle einer Invasion aus dem Hochland wäre ein Wandel in der genetischen Zusammensetzung der Bevölkerung zu erwarten gewesen. Haplogruppe B sollte in einer höheren Frequenz vorliegen. Allerdings ist zu bemerken, dass die in der vorliegenden Arbeit dargestellten Daten nur die matrilineare Populationsdynamik wiedergeben. Ein Kolonisationsprozess (vgl. Kap. 2.1.4) wird in der Regel nur von wenigen Personen getragen. Dieses militärische und administrative Personal ist vorwiegend männlich (Sanjek 2003). Das bedeutet, dass sich ein solcher Migrationsprozess vor allem auf die Ychromosomale Zusammensetzung der Bevölkerung auswirken würde. Allein aufgrund der vorliegenden genetischen Daten ist also eine definitive Entscheidung für eines der Szenarien nicht möglich.

Die untersuchte Population aus dem Mittleren Horizont weist sehr hohe Diversitätswerte auf. Es muss also noch ein konstanter Genfluss bestanden haben, da ansonsten bei einer geringen Bevölkerungsgröße eher eine Verarmung der genetischen Diversität durch Drift zu erwarten wäre (Wright 1950).

Auch wenn eine Validierung durch die genetischen Daten nicht möglich ist, scheint unter Einbeziehung der interdisziplinären Erkenntnisse am plausibelsten, dass sich die Bewohner der Palpa-Region, bedingt durch die ökologischen Veränderungen, weiter in die Anden-Täler zurückgezogen haben (Abb. 60-C), dem Wüstenrand folgend (Eitel et al. 2005). Die zunehmende Trockenheit bedingt, dass die Siedlungskammer nicht mehr eine so große Bevölkerung wie in den vorhergehenden Zeitphasen tragen kann. Dabei kommt es aber nicht zu einer maßgeblichen Veränderung der genetischen Zusammensetzung der Bevölkerung, sondern nur zu einer Reduktion der Bevölkerungsgröße in der Palpa-Region. Da keine Veränderung nachzuweisen ist, aber hohe Diversitätswerte vorliegen, ist $\mathrm{zu}$ vermuten, dass ein konstanter bevölkerungsbiologischer Austausch mit den abwandernden Gruppen bestand (Kap. 2.4 - Frage 4). 


\subsubsection{Bevölkerungswandel vom präkolumbischen zum rezenten südlichen Peru}

Die Ausführungen der letzten drei Kapitel zeigen, dass eine genetische Unterscheidung der präkolumbischen Bewohner der beiden kulturellen Großräume des südwestlichen Peru - Küste und Hochland - möglich ist. Der einzig andere bekannte präkolumbische Küstenfundort, von dem aDNA-Daten menschlicher Individuen existieren, ist Huaca-Loro an der Nordküste Perus (Shimada et al. 2004). Dieser Fundort datiert in den Mittleren Horizont und die untersuchte Population weist, wie die Bevölkerung der Palpa-Region, hohe Frequenzen der Haplogruppe D auf. Die prozentuale Verteilung der Haplogruppe gleicht insgesamt eher den präkolumbischen südperuanischen Küstenpopulationen, als der im Hochland angetroffenen. Aus dieser Tatsache lässt sich ableiten, dass sich die genetische Unterscheidung zwischen Küste und Hochland nicht nur auf die Palpa-Region beschränkt, sondern ein Phänomen ist, das sich auf das gesamte westliche präkolumbische Peru - auf jeden Fall bis zum Mittleren Horizont - beziehen lässt.

Vergleicht man die präkolumbischen Daten mit der rezenten genetischen Zusammensetzung Perus, fällt auf, dass eine Unterscheidung, wie zuvor beschrieben, nicht mehr möglich ist (vgl. Kap. 5 u. 6). Vielmehr gleicht sie der im präkolumbischen Hochland angetroffenen Struktur (vgl. (Luiselli et al. 2000; Rodriguez-Delfin et al. 2001; Lewis et al. 2005; Shinoda et al. 2006). Die heute anzutreffende genetische Zusammensetzung der peruanischen Bevölkerung muss also ein Produkt von Prozessen sein, die nach dem in der vorliegenden Arbeit untersuchten Zeitraum stattfinden. Sie resultiert nicht aus der initialen Besiedlung des Kontinentes (Kap. 2.4 - Frage 7). Die Landflucht des 20. Jhd. kommt als Erklärung nicht in Frage, da die rezenten Daten bewusst in ruralen Siedlungen erhoben wurden.

Aus den genetischen Daten und den Kenntnissen der peruanischen Kulturgeschichte ergeben sich folgende mögliche Szenarien:

1. In Folge der kurzeitigen klimatischen Verbesserungen an der peruanischen Küste in der Späten Zwischenperiode (Mächtle 2007) kommt es zu einer, vom Hochland ausgehenden Wiederbesiedlung der Region. Die einwandernde Bevölkerung importiert gleichzeitig die genetische Struktur der Hochlandbevölkerung.

2. Die großräumig expandierenden Hochlandkulturen der späten präkolumbischen Phasen, vor allem die Inka, überprägen oder verdrängen die Küstenbevölkerung.

Beide Szenarien sind nicht exklusiv zu verstehen. Szenario 1 bezieht sich vornehmlich auf die südliche Küste Perus. Die archäologischen Befunde zeigen eine gewaltige Zunahme der Besiedlungsdichte in den Andenfußtälern in der Späten Zwischenperiode (vgl. Kap. 2.3.3). Der daraus abzuleitende Bevölkerungszuwachs in der Region lässt sich dadurch erklären, dass die 
Menschen dem in dieser Zeit nach Westen wandernden Wüstenrand folgen. Demographisches Wachstum der kleinen zurückgebliebenen Bevölkerung in der Küstenregion alleine kann einen solchen Bevölkerungsanstieg in so kurzer Zeit nicht erklären. Die rezenten peruanischen Populationen weisen eine geringere genetische Distanz zu der Bevölkerung im präkolumbischen Hochland als zu der Küstenbevölkerung auf. Allerdings finden sich in der rezenten Bevölkerung höhere Anteile der Haplogruppen D und A und ebenso eine höhere Haplogruppen-Diversität als im präkolumbischen Hochland (vgl. Kap. 6.1). Dieser Umstand deutet auf eine stärkere Durchmischung der Bevölkerungen aus beiden kulturellen Großräumen hin. Die auf den genetischen Daten basierende These ist konsistent mit der Annahme einer Bevölkerung, die sich erst weiter in Richtung Hochland zurückzieht und ca. 400 Jahre später wieder zurückkehrt (Abb. 60-D). Der Zeitraum ist groß genug, um eine solche Durchmischung zu ermöglichen.

Szenario 2 würde aber ein ähnliches Bild der genetischen Zusammensetzung erwarten lassen. Die diachronen klimatischen Veränderungen und der damit verbundene Bevölkerungsrückgang am Ende der Nasca-Zeit, sowie die massive Wiederbesiedlung in der Späten Zwischenperiode lassen sich nur auf das südliche Peru beziehen (vgl. Kap. 2.3.3). Das Beispiel von Huaca-Loro an der peruanischen Nordküste zeigt aber, dass der genetisch festzumachende Bevölkerungswandel, von Damals zu Heute, sich nicht nur auf den Süden begrenzen lässt. Die Ausbreitung der InkaKultur wurde auch maßgeblich von intentionalen (Expansion) und erzwungenen (Deportation) Bevölkerungsbewegungen getragen. Die Infrastruktur erlaubte eine hohe Mobilität, und die staatliche Struktur bedingte einen hohen Waren- und Informationsaustausch unter einzelnen Regionen (vgl. Kap. 2.1.2). Ein komplexes Gefüge von Push- und Pull-Faktoren, welches aus der politischen Situation resultiert, führt zu einem Migrationsverhalten, das sich nicht alleine anhand eines Typen (vgl. Migrationstypologie; Kap. 2.2.4) festmachen lässt. Die mögliche Auswirkung auf die Bevölkerungszusammensetzung im westlichen Südamerika lässt sich am besten im kontinentalen Zusammenhang verdeutlichen (Kap. 7.2.5).

Die rezente mitochondriale genetische Zusammensetzung der peruanischen Bevölkerung lässt sich nur durch eine maßgebliche Prägung aus dem andinen Hochland erklären (Abb. 60-D). Dieser Prozess beginnt - unter Berücksichtigung der in der vorliegenden Arbeit ermittelten genetischen Daten - mit der Nasca-Zeit. Der endgültige Prozess, der die Homogenisierung der Küsten- und Hochlandbevölkerung bewirkt, muss allerdings nach der Nasca-Zeit stattgefunden haben. 

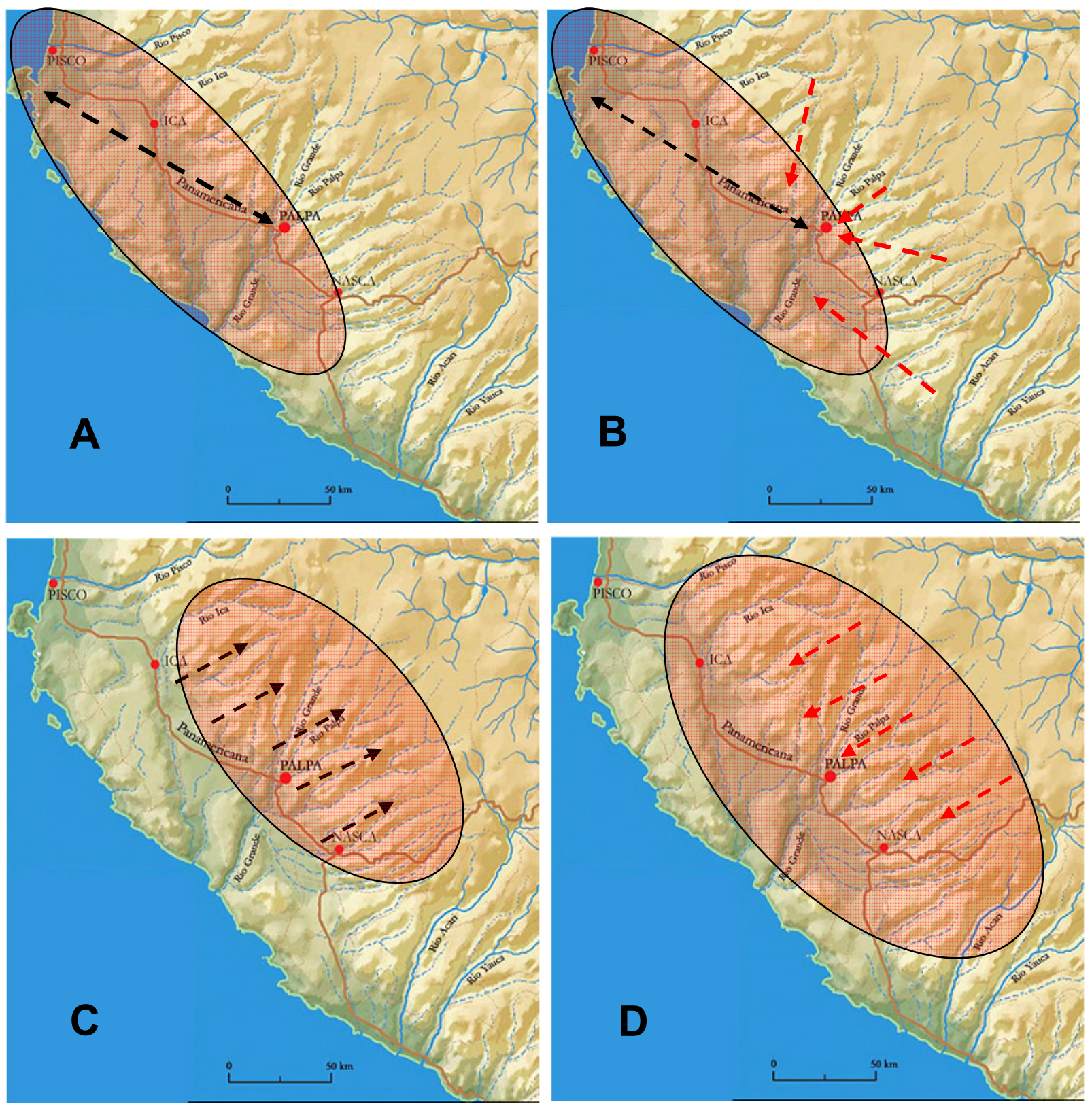

Abb. 60: Modelle der diachronen Bevölkerungsentwicklung in der Ica-Palpa-Nasca Region.

A - Paracas-Zeit: Die Paracas-Kultur bildet in der Region eine bevölkerungsbiologische Einheit (Oval). Genetischer Austausch findet vor allem unter den Populationen innerhalb der Küstenregion statt (Pfeil). B - Nasca-Zeit: Der bevölkerungsbiologische Einflussbereich bleibt weitestgehend gleich (Oval u. schwarzer Pfeil). Es kommt aber vermehrt zur Immigration von außerhalb, vor allem aus dem angrenzenden Hochland. C - Ende der Nasca-Zeit / Mittlerer Horizont. Große Teile der Bevölkerung der Palpa-Region ziehen sich weiter ins Hochland zurück. Der bevölkerungsbiologische Einflussbereich verschiebt sich nach Westen (Oval).

D - Späte Zwischenperiode bis Heute. Bevölkerungen aus dem Hochland verbreiten sich über weite Regionen und bilden neue bevölkerungsbiologische Einflussbereiche aus (Oval), die in enger Verbindung zur Hochlandbevölkerung stehen (rote Pfeile) 


\subsubsection{Migration und Bevölkerungsentwicklung im westlichen Südamerika}

Wie bereits in den Kapiteln zuvor ausführlich besprochen, unterscheidet sich die präkolumbische Bevölkerung der Palpa-Region, bzw. der peruanischen Pazifikküste, genetisch von der prähistorischen Hochlandbevölkerung und der rezenten Bevölkerung Perus. Die kontinentalen Vergleiche (Kap. 6) haben gezeigt, dass die rezente mittel- und südchilenische Bevölkerung die größte genetische Ähnlichkeit zu den prähistorischen Bewohnern der peruanischen Küstenregionen aufweist. Die Verbreitung der genetisch relativ homogenen, durch Haplogruppe B dominierten rezenten Bevölkerung von den nördlichen Zentralanden bis in die südlichen Anden (vgl. Abb. 50; Kap. 5.3) ist annähernd deckungsgleich mit der maximalen Verbreitung der Inka-Kultur (Abb. 61). Die zuvor erwähnten Gebiete mit indigenen Bevölkerungen, die den prähistorischen Bewohnern der Palpa-Region (genetisch) ähneln, liegen südlich von der Verbreitungsgrenze der Inka. Die südlichsten Anden im mittleren Chile (Reg. 13; Abb. 61) liegen in der Peripherie der Inka-Verbreitung. Die mitochondriale genetische Struktur der rezenten indigenen Bevölkerung dieser Region weist eine hohe Ähnlichkeit zu der urbanen Nasca-zeitlichen Population auf.

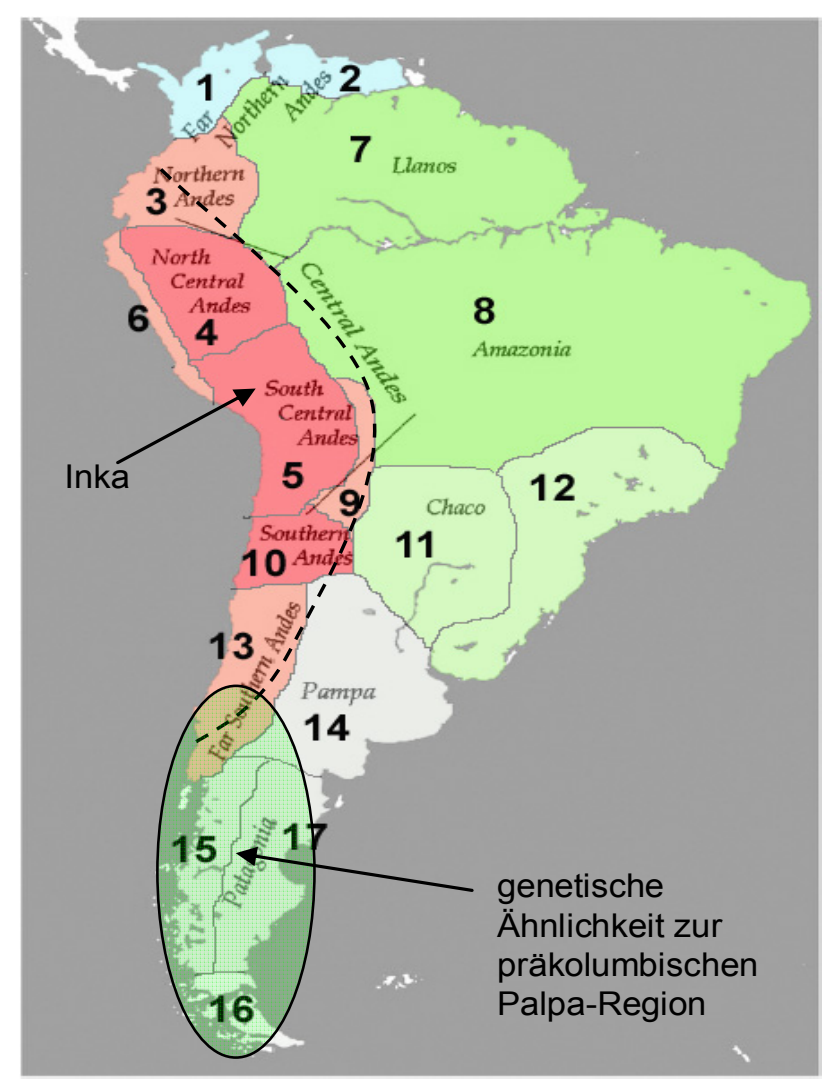

Abb. 61: Karte der kulturellen und geographischen Großräume in Südamerika (vgl. Tab 12 / Kap. 3.1.3). Die gestrichelte Linie markiert die maximale Verbreitung der Inka-Kultur. 
Die präkolumbischen und rezenten genetischen Daten deuten darauf hin, dass die genetische Struktur der Bevölkerung von den nördlichen bis zu den südlichen Anden maßgeblich durch die Verbreitung der Inka-Kultur und politische Prozesse innerhalb des Inka-Staates geprägt wurde (Kap. 2.4 - Frage 7). In diesem Bereich wird eine Vielzahl an verschiedenen Migrationsprozessen stattgefunden haben: Expansion, Kolonisation, Deportation, Arbeits- und Handelsmigration (vgl. Kap. 2.1.4). Die kulturgeschichtlichen Kenntnisse der Inka-Kultur und auch die genetischen Daten deuten nicht auf eine reine Verdrängung der ansässigen Bevölkerungen durch eine Expansion hin, sondern eher auf eine Überprägung (vgl. Kap. 2.1.4).

Die von Lalueza et al. (1997) postulierte Besiedlung des westlichen Südamerika in zwei Wellen, bei der die Siedler der ersten Welle kurze Zeit später durch eine zweite in den Süden Chiles verdrängt wurden (vgl. Kap. 2.3.2), lässt sich durch die neuen genetischen Daten nicht stützen. Auch andere Besiedlungstheorien, welche die mitochondriale Haplogruppenverteilung in Südamerika durch separate, aufeinander folgende Wellen erklären (Torroni et al. 1993; Forster et al. 1996), sind nicht konsistent mit den Ergebnissen der vorliegenden Arbeit ${ }^{7}$. Die genetischen Daten weisen aber auf eine separate Besiedlung der Pazifik-Küste und der Anden hin. Statt einer zweiten frühen Besiedlungswelle entlang der Küste (Lalueza et al. 1997) kam es zu einer viel später datierenden genetischen Überprägung des mittleren westlichen Südamerikas durch kulturelle und politische Prozesse (vgl. Abb. 61-B) und nicht zu einer massiven Verdrängung der Bevölkerung (Südspitzenverdrängung). Das mittlere und südliche Chile und Argentinien liegen außerhalb des Wirkungsbereiches dieser Prozesse. Deshalb ist in der rezenten indigenen Bevölkerung dieser Region die genetische Zusammensetzung der Besiedlungswelle entlang der Küste konserviert (vgl. auch Garcia et al. 2006).

Die initiale Besiedlung entlang der Küste ist konsistent mit der Theorie von Dillehay (1999), erklärt aber nicht die Besiedlung des östlichen Südamerika und der Anden. Genetische Vergleiche der Bevölkerung des östlichen und westlichen Südamerika auf Basis der HVRI zeigen, dass die Besiedlung des gesamten Kontinents von einer Gründerpopulation ausgegangen sein muss (Fuselli et al. 2003; Lewis et al. 2007b). Rothhammer et al. (2001) gehen davon aus, dass sich diese Gründerpopulation im nördlichsten Südamerika in zwei Routen aufteilt (vgl. Melton et al. 2007), eine in Richtung Süden über die oder entlang der Anden und eine entlang der Nordküste und dann in das Amazonasbecken. Die spätere Besiedlung der Anden erfolgt nach dieser Theorie aus der Amazonas-Region. Dieses Besiedlungsmodell erscheint auch mit den in der vorliegenden Arbeit ermittelten genetischen Daten weitestgehend plausibel (Kap. 2.4 - Frage 8). Allerdings weisen die Daten darauf hin, dass die westliche Route nicht über die Anden,

\footnotetext{
${ }^{7}$ Hierzu ist zu bemerken, dass dieser Arbeit eine viel größere Zahl an Daten zugrunde liegt als den aufgeführten Studien.
} 
sondern entlang der Küste verlief (vgl. Abb. 61-A). Eine Besiedlung der Anden von Osten her ist auf Basis der genetischen Daten möglich, aber nicht zu validieren. Die vorliegenden Daten könnten genauso als Hinweis auf eine dritte initiale Besiedlungsroute über die Anden interpretiert werden (vgl. Abb. 61-A). Für ein differenzierteres Bild der Besiedlung der Anden müssten mehr aDNA-Untersuchungen an prä-inkazeitlichen Populationen des andinen Hochlands durchgeführt werden.
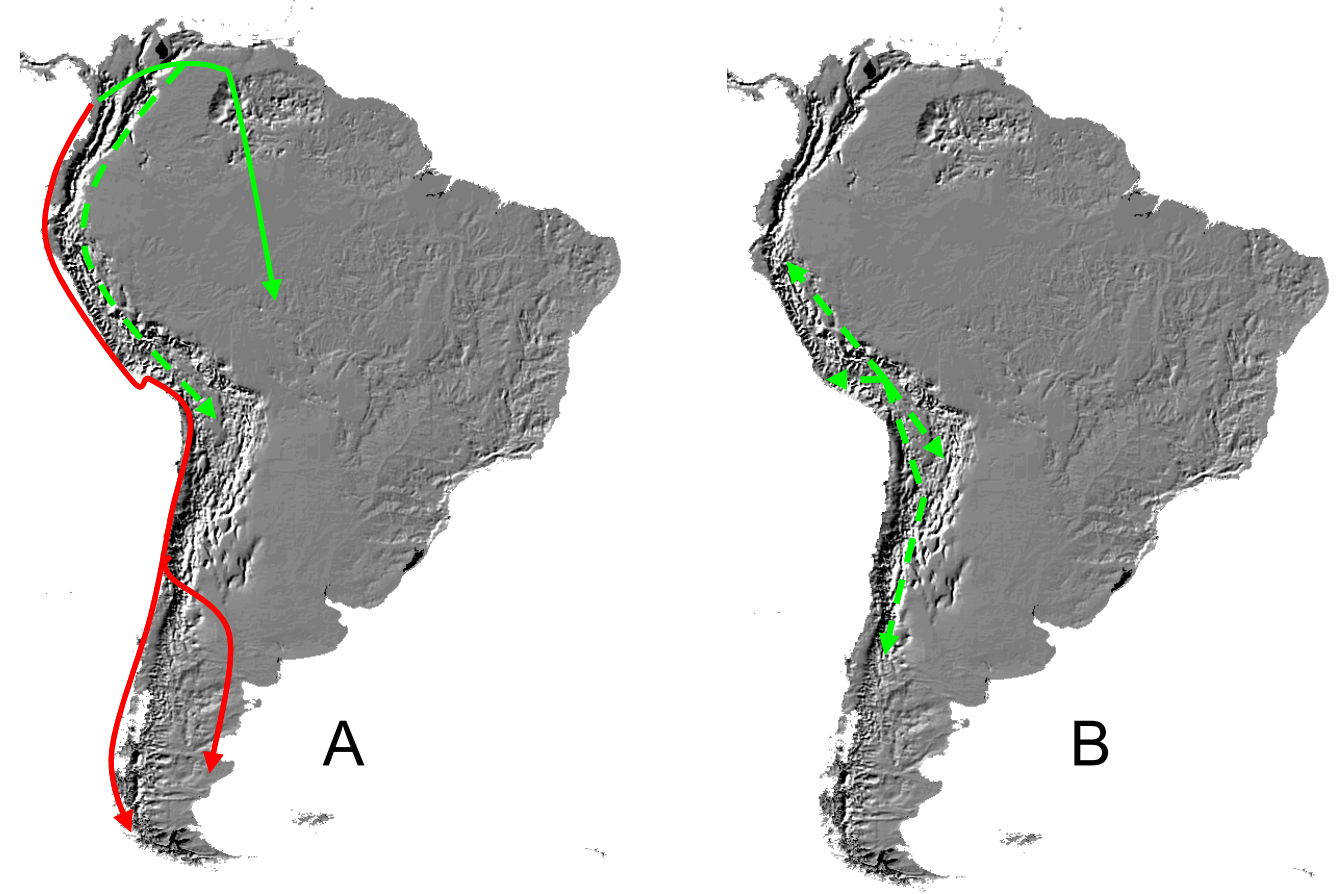

Abb. 62: Besiedlungsmodell Südamerikas auf Basis der genetischen Daten.

A: Die initiale Besiedlung des Kontinentes durch eine Gründerpopulation, die sich an den nördlichsten Anden in zwei bis drei Routen aufteilt. Eine Route verläuft entlang der Westküste bis ins mittlere Chile, wo sich die Besiedlungsroute teilt und weiter durch das südliche Chile und das argentinische Patagonien verläuft (rote Pfeile). Eine weitere Route führt entlang der Nordküste Südamerikas und dann in das Amazonasbecken (grüner Pfeil). Eine dritte mögliche Route mit Siedlern, die sich von Route 2 abspalten und dann über die Anden in Richtung Süden ziehen, bis sie das Altiplano erreichen (grüner gestrichelter Pfeil).

B: Die sich ab dem Mittleren Horizont ausbreitenden andinen Hochkulturen, vor allem die Inka, überprägen die genetische Struktur der Bevölkerung der westlichen Küste von den nördlichen Anden bis ins mittlere Chile (grüne gestrichelte Pfeile). 


\subsubsection{Adaptation an das andine Hochland und genetische Selektion: Eine alternative Hypothese zum Ursprung der genetischen Bevölkerungsstruktur im südamerikanischen Hochland.}

Die Verbreitung genetischer Strukturen, vor allem der mitochondrialen Haplogruppen, wurde in dem vorherigen Kapitel hauptsächlich durch Migrationsprozesse erklärt. Für die Besiedlung der südamerikanischen Pazifikküste und das östliche Südamerika lassen sich solche Prozesse anhand der genetischen und kulturhistorischen Daten validieren. $\mathrm{Ob}$ das zentralandine Hochland nun aber über eine separate Route über die Anden oder vom Osten aus besiedelt wurde, bleibt weitestgehend spekulativ (vgl. Kap. 7.2.5). Die Haplogruppen-Verteilung in der präkolumbischen, aber auch rezenten Hochland Bevölkerung unterscheidet sich signifikant von umliegenden Regionen (vgl. Kap. 6.1). Dennoch ist ein stetiger Genfluss nachzuweisen (Fuselli et al. 2003), und die genetischen Daten weisen auf eine einheitliche Gründerpopulation Südamerikas hin (Moraga et al. 2000; Lewis et al. 2007). Die spätere Verbreitung der mitochondrialen Hochlandsignaturen, auch über den zentralen Andenraum hinaus, lässt sich durch kulturell und politisch bedingte Migrationsprozesse erklären (vgl. Kap. 7.2.5). Es ergibt sich aber die Frage, ob die grundlegende Prägung der genetischen Struktur in den Anden nicht vielleicht auch aus anderen Prozessen als Migration resultieren kann.

Hochlandbewohner (über 2500 m N.N.) unterliegen einem kontinuierlichen physischen Stress, z.B. durch Hypoxie, Kälte und Strahlung, der adaptiv kompensiert werden muss (für die Anden: Moran 2000). Die Adaptation betrifft auch den menschlichen Reproduktionserfolg. Im Hochland aufgewachsene Frauen bringen dort einen erheblich höheren Anteil an Lebendgeburten zur Welt als nicht-angepasste Frauen (Moore et al. 2004)(historisches Beispiel: Quito-Lima). Das Geburtsgewicht wird offenbar direkt durch genetische Faktoren beeinflusst (Petry et al. 2005), und die perinatale Überlebenswahrscheinlichkeit in der Höhe wird mit einem geringeren Geburtsgewicht in Zusammenhang gebracht (Giussani 2007).

Genetische Marker, die mit fötalem Wachstum und Geburtsgewicht in Zusammenhang gebracht werden, sind unter anderem das exklusiv matrilinear exprimierte Gen H19 und die Nukleotidposition 16189 der mitochondrialen HVRI. Die Ausprägung von Cytosin an der zuletzt genannten Position wird mit einem geringeren Geburtsgewicht bei folgender schneller postnataler Wachstumszunahme (catch-up-growth) assoziiert (Dunger et al. 2006) Eine Ausprägung der Base C an np16189 ist auch charakteristisch für die mt-Haplogruppe B (vgl. Kap. 2.3.2). B ist die dominante Haplogruppe im andinen Hochland (vgl. Kap. 5 u. 6).

Weibliche Individuen der Haplogruppe B haben also in Hochlandhabitaten theoretisch durch ein geringeres Geburtsgewicht ihrer Nachkommen eine höhere Aussicht auf Lebendgeburten. Dieser adaptiv beeinflusste Reproduktionsvorteil gegenüber den anderen mt-Haplogruppen 
könnte bedeuten, dass die Dominanz der Haplogruppe B im Hochland nicht Produkt von Bevölkerungsbewegungen ist, sondern von genetischer Selektion. Als initiale Quellpopulation würden in diesem Fall trotzdem die Bevölkerungen der Amazonas-Region in Frage kommen (postulierte Amazonasroute / Abb. 62-A, grüner Pfeil), da hier grundlegend höhere Anteile an Haplogruppe B nachzuweisen sind als an der Pazifikküste (postulierte Küstenroute / Abb. 62-A; roter Pfeil).

Sollte wirklich durch intensive Studien nachgewiesen werden können, dass Selektion einen maßgeblichen Einfluss auf die Verteilung mitochondrialer Haplogruppen und -typen hat, würde dies die bislang postulierte selektive Neutralität der mitochondrialen Kontrollregion (Tajima 1989a) in Frage stellen. Das hätte maßgebliche Folgen für die Rekonstruktion der Besiedlungswege des anatomisch modernen Menschen anhand mitochondrialer DNA. Alle populationsgenetischen Berechnungen und die darauf basierenden Verbreitungsmodelle gehen von der Neutralität des mt-Genoms und vor allem der HVR aus. Dass es zur selektiven Beeinflussung der Evolution des menschlichen mitochondrialen Genoms kommen kann, zeigt sich bereits in anderen Studien (Kivisild et al. 2006). Diese Erkenntnisse beziehen sich allerdings auf den codierenden Abschnitt des Genoms. Es wurde aber bislang kein endgültiger Beweis erbracht. Der Einfluss der Genetik auf Adaptationsprozesse in Hochlandhabitaten ist bislang noch unzureichend erforscht (Rupert u. Hochachka 2001). Trotz der bislang noch fehlenden Evidenz sollte das hier beschriebene Selektions-Modell als alternative Hypothese zur Prägung der genetischen Struktur Südamerikas durch Migration bedacht werden. 


\section{Zusammenfassung}

Eine der Grundfragen, die die wissenschaftliche Archäologie seit dem 19. Jahrhundert begleitet, ist, ob und in welcher Dimension kultureller Wandel durch bevölkerungsbiologischen Wandel bedingt oder begleitet wird. Trotz des mittlerweile existierenden theoretischen Überbaus bezüglich der möglichen Auswirkungen von Bevölkerungsbewegungen auf den archäologischen Befund, ist diese Frage, anhand der materiellen Hinterlassenschaften prähistorischer Kulturen, nicht endgültig entscheidbar. Die physische Anthropologie verfügt über analytische Werkzeuge, die den Zugang zu dem einzigen Archiv ermöglichen, das Informationen über die biologische Zusammensetzung einer Bevölkerung enthält: den Menschen. Durch die Aufnahme von ancientDNA Analysen in die anthropologischen Arbeitsmethoden sind diachrone Vergleiche genetischer Bevölkerungsstrukturen und die Klärung der verwandtschaftlichen Beziehungen unter prähistorischen Populationen möglich. Die so zugänglich gemachten Daten erlauben die Existenz von Migrationen und Bevölkerungsveränderungen in Kulturräumen zu bestätigen oder zu widerlegen und können im transdisziplinären Dialog mit anderen archäologisch arbeitenden Wissenschaften in Kulturgeschichte übersetzt werden.

Die Palpa-Region an der Südküste Perus ist eine kulturell dynamische Siedlungskammer, in der in einem Zeitraum von ca. 6000 Jahren die Sesshaftwerdung menschlicher Gruppen bis hin zur Entwicklung und dem Untergang komplexer frühstaatlicher Gesellschaften zu beobachten ist. Die archäologischen Befunde zeigen, dass die Region seit spätestens 1800 v. Chr. bis heute durchgängig besiedelt war. In der präkolumbischen Zeit sind vor allem die Paracas-Kultur (800200 v. Chr.) und die Nasca-Kultur (200 v. Chr.- 600 n. Chr.) als prägende Kulturerscheinungen hervorzuheben.

Ziel dieser Studie war es, durch die Untersuchung mitochondrialer genetischer Marker an menschlichen Skelettelementen die diachrone Entwicklung der matrilinearen Populationsdynamik in der Palpa-Region zu rekonstruieren. Hierbei waren vor allem die bevölkerungsbiologischen Anteile an oder Konsequenzen aus der Entwicklung und dem Untergang der Paracas- und Nasca-Kultur von Interesse. Darüber hinaus sollte, durch den Vergleich mit genetischen Daten von präkolumbischen und rezenten indigenen südamerikanischen Populationen, die Bevölkerungsgeschichte der Palpa-Region mit der kontinentalen Kolonisationsgeschichte und Bevölkerungsentwicklung Südamerikas kontextualisiert werden. Hierfür wurden Proben von 216 präkolumbischen Individuen, hauptsächliche Zähne und Fußknochen, aus der Palpa-Region akquiriert. Die Individuen stammen von mehreren, mit präkolumbischen Siedlungen assoziierten Nekropolen, die in verschiedene Zeitstufen datieren. Insgesamt wurden die Fundorte so gewählt, dass anhand der 
Proben die Bevölkerungsentwicklung in einem Zeitraum von 2000 Jahren (1000 v. Chr. - 1000 n. Chr.) beleuchtet werden kann.

Für 131 Individuen konnte die mitochondriale Haplogruppe und für 105 Individuen der mitochondriale Haplotyp bestimmt werden. Die DNA-Typisierung erfolgte mit selbst generierten Analysesystemen, für die mitochondriale HVRI und verschiedene SNPs in der codierenden Region, des mitochondrialen Genoms. Darüber hinaus wurden auch Analysesysteme für Ychromosomale und autosomale Marker entwickelt und angewendet. Der DNA-Erhaltungszustand erlaubte aber nur bei sehr wenigen Individuen die Amplifikation und Analyse nuklearer DNA. Dementsprechend flossen diese Ergebnisse auch nicht in die weitere Beurteilung der genetischen Daten ein. Die aus den präkolumbischen Individuen erwirtschafteten mitochondrialen Daten wurden genutzt, um populationsgenetische Berechnungen zur Intrapopulations-Diversität und Interpopulations-Distanz durchzuführen und mit aus der Literatur gesammelten genetischen Daten von über 4000 indigenen südamerikanischen Individuen verglichen.

Die Ergebnisse der aDNA-Untersuchungen erlauben eine Rekonstruktion der Bevölkerungsgeschichte des südlichen Perus. Es konnte nachgewiesen werden, dass die ParacasKultur an der südperuanischen Küste eine bevölkerungsbiologische Einheit bildete und nicht, wie von einigen Archäologen postuliert, eine Ansammlung unabhängiger lokaler Gruppen war. Die Nasca-Kultur entwickelte sich bei bevölkerungsbiologischer Kontinuität in der Region. Es lassen sich keine signifikanten allochthonen Bevölkerungseinflüsse, wie z.B. durch Kolonisations- oder Invasionsprozesse nachweisen. Der Vergleich mit anderen genetischen Daten zeigt, dass die Bewohner der präkolumbischen Küste eine homogene Bevölkerung bildeten, die sich genetisch eindeutig vom angrenzenden andinen Hochland und anderen Regionen unterschied. Innerhalb der Küstenregion bestand aber ein konstanter Genfluss. Mit dem Wandel von einer reinen Subsistenzwirtschaft zu einer komplexeren Wirtschaftsform und der Ausbildung autarker regionaler (urbaner) Zentren in der Nasca-Zeit kommt es zu einem vermehrten genetischen Einfluss von außen. Dieser schlägt sich vor allem in dem Auftreten, vorher nicht nachgewiesener, mitochondrialer Haplogruppen nieder. Der Wandel in der sozialen Struktur hat gleichzeitig einen höheren Attraktionswert für Migranten. Die Ansiedlung von Spezialisten, Populationszuwachs und der verstärkte Handel mit anderen Kulturgruppen können die beobachtete Veränderung der genetischen Struktur in der Palpa-Region erklären.

Die archäologische Hypothese, dass der Untergang der Nasca-Kultur durch die militärischen Expansionen der Huari-Kultur um ca. 600 n. Chr. ausgelöst wurde, kann für die Palpa-Region anhand der genetischen Daten widerlegt werden. Ein Szenario, das die fast vollständige Aufgabe der Siedlungskammer und damit auch das Ende der Nasca-Kultur, bedingt durch negative 
Veränderungen der ökologischen Rahmenbedingungen erklärt, erscheint plausibler. Es kommt zu keiner signifikanten Veränderung der genetischen Struktur in der Bevölkerung am Ende der Nasca-Zeit.

Die heute in Peru angetroffene mitochondriale genetische Struktur unterscheidet sich maßgeblich von der, die in der präkolumbischen Palpa-Region nachgewiesen werden konnte. Dieser Unterschied ist durch Expansionen und politische Prozesse späterer andiner Hochkulturen, vor allem der Inka-Kultur, zu erklären, die zu einer genetischen Überprägung weiter Bereiche des westlichen Südamerikas führten. Die heutige genetische Struktur Perus ist kein Produkt der initialen Besiedlung des Kontinentes, wie häufig aus der Untersuchung rezenter indigener Populationen abgeleitet. Anhand der in dieser Studie ermittelten genetischen Daten und dem Vergleich mit rezenten Verteilungen kann ein erneuertes Szenario der initialen Kolonisation Südamerikas entworfen werden. Dieses Szenario nimmt separate Routen einer einheitlichen Gründerpopulation für die Besiedlung der Pazifikküste und des andinen Hochlands an. Die indigene Bevölkerung des südlichen Südamerika repräsentiert noch heute die genetische Struktur der Siedler, die entlang der Pazifikküste nach Südamerika vordrangen. Sie liegen außerhalb des Expansionsbereiches der andinen Hochkulturen und wurden dementsprechend nicht überprägt. Die genetischen Daten weisen aber nicht auf eine Verdrängung der prähistorischen Küstenpopulationen in den Süden hin.

Die vorliegende Arbeit zeigt, dass anhand der Untersuchung alter DNA die Erstellung eines differenzierteren Bildes von Bevölkerungsentwicklungen und prähistorischen Migrationen möglich ist als durch die Analyse rezenter genetischer Daten. Nur durch die Erschließung der historischen genetischen Archive können durch diachrone Vergleiche kulturgeschichtlich beeinflusste Bevölkerungsveränderungen aufgedeckt und beurteilt werden. Darüber hinaus konnte am Beispiel der Bevölkerungs- und Kulturentwicklung der Palpa-Region gezeigt werden, dass kultureller Wandel zu Veränderungen im Migrationsverhalten führen kann. Eine endgültige Entscheidung zwischen verschiedenen kulturellen Diffusionsmechanismen und Migrationsprozessen wird durch die Anwendung paläogenetischer Werkzeuge möglich. 


\section{Literatur}

Adler M (2007) Degradierungsmuster alter DNA - Quantifizierung von DNA Erhaltung unterschiedlicher chromosomaler Lokalisation durch Real-Time-PCR. Diplomarbeit Biol. Fak. Univ. Göttingen / Jena, Göttingen

Allison MJ (1979) Paleopathology in Peru. Nat Hist 88 [2]: 74-82

Ammerman A, Cavalli-Sforza L (1984) The Neolithic Transition and the Genetics of Populations in Europe. Princeton Univ. Press, New Jersey

Andelinovic S, Sutlovic D, Erceg I, I, Skaro V, Ivkosic A, Paic F, Rezic B, Definis-Gojanovic M, Primorac D (2005) Twelve-year experience in identification of skeletal remains from mass graves. Croat Med J 46 [4]: 530-539

Andrews RM, Kubacka I, Chinnery PF, Lightowlers RN, Turnbull DM, Howell N (1999) Reanalysis and revision of the Cambridge reference sequence for human mitochondrial DNA. Nat Genet 23 [2]: 147-

Anthony DW (1990) Migration in Archaeology: The Baby and the Bathwater. American Anthropologist 92: 895-914

Anthony DW (1992) The Bath refilled: Migration in archaeology again. American Anthropologist 94: 174-176

Anthony DW (1997) Prehistoric migration as a social process. In: Chapman J, Hamerow H (Hrsg.) Migrations and invasions in archaeological explanation. Archaeopress, Oxford

Arnold C (1994) From Roman Britain to Saxon England. Croom Helm, London

Auderheide AC (2003) The scientific Study of Mummies. Cambridge

Bandelt HJ (2005) Mosaics of ancient mitochondrial DNA: positive indicators of nonauthenticity. Eur J Hum Genet 13 [10]: 1106-1112

Bandelt HJ, Forster P, Rohl A (1999) Median-joining networks for inferring intraspecific phylogenies. Mol Biol Evol 16 [1]: 37-48

Bandelt HJ, Forster P, Sykes BC, Richards MB (1995) Mitochondrial portraits of human populations using median networks. Genetics 141 [2]: 743-753

Bandelt HJ, Herrnstadt C, Yao YG, Kong QP, Kivisild T, Rengo C, Scozzari R, Richards M, Villems R, Macaulay V, Howell N, Torroni A, Zhang YP (2003) Identification of Native American founder mtDNAs through the analysis of complete mtDNA sequences: some caveats. Ann Hum Genet 67 [6]: 512-524

Bandelt HJ, Parson W (2007) Consistent treatment of length variants in the human mtDNA control region: a reappraisal. Int J Legal Med 122 [1]: 11-21

Bargatzky T (1986) Einführung in die Kulturökologie. Umwelt, Kultur und Gesellschaft. Reimer, Berlin

Barnard A (2000) History and Theory in Anthropology. University Press, Cambridge 
Bayer K (1994) Evolution - Kultur - Sprache: Eine Einführung. Brockmeyer, Bochum

Behar DM, Rosset S, Blue-Smith J, Balanovsky O, Tzur S, Comas D, Mitchell RJ, QuintanaMurci L, Tyler-Smith C, Wells RS (2007) The Genographic Project public participation mitochondrial DNA database. PLoS Genet. 3 [6]: 104-130

Bergen AW, Wang CY, Tsai J, Jefferson K, Dey C, Smith KD, Park SC, Tsai SJ, Goldman D (1999) An Asian-Native American paternal lineage identified by RPS4Y resequencing and by microsatellite haplotyping. Ann Hum Genet 63 [1]: 63-80

Bernbeck R (1997) Theorien in der Archäologie. UTB, Stuttgart

Bert F, Corella A, Gene M, Perez-Perez A, Turbon D (2001) Major mitochondrial DNA haplotype heterogeneity in highland and lowland Amerindian populations from Bolivia. Hum Biol 73 [1]: 1-16

Bert F, Corella A, Gene M, Perez-Perez A, Turbon D (2004) Mitochondrial DNA diversity in the Llanos de Moxos: Moxo, Movima and Yuracare Amerindian populations from Bolivia lowlands. Ann Hum Biol 31 [1]: 9-28

Binford LR (1962) Archaeology as Anthropology. American Antiquity 28: 217-225

Binford SR, Binford LR (1968) New Pespectives in Archaeology. Aldine Press, Chicago

Binladen J, Wiuf C, Gilbert MT, Bunce M, Barnett R, Larson G, Greenwood AD, Haile J, Ho SY, Hansen AJ, Willerslev E (2006) Assessing the fidelity of ancient DNA sequences amplified from nuclear genes. Genetics 172 [2]: 733-741

Bogenhagen D, Clayton DA (1974) The number of mitochondrial deoxyribonucleic acid genomes in mouse $\mathrm{L}$ and human HeLa cells. Quantitative isolation of mitochondrial deoxyribonucleic acid. J Biol Chem. 249 [24]: 7991-7995

Bortolini MC, Da SW, Jr., Zago MA, Elion J, Krishnamoorthy R, Goncalves VF, Pena SD (2004) The phylogeography of mitochondrial DNA haplogroup L3g in Africa and the Atlantic slave trade. Am J Hum Genet 75 [3]: 522-524

Bortolini MC, Salzano FM, Bau CH, Layrisse Z, Petzl-Erler ML, Tsuneto LT, Hill K, Hurtado AM, Castro-De-Guerra D, Bedoya G, Ruiz-Linares A (2002) Y-chromosome biallelic polymorphisms and Native American population structure. Ann Hum Genet 66 [4]: 255259

Bortolini MC, Salzano FM, Thomas MG, Stuart S, Nasanen SP, Bau CH, Hutz MH, Layrisse Z, Petzl-Erler ML, Tsuneto LT, Hill K, Hurtado AM, Castro-De-Guerra D, Torres MM, Groot H, Michalski R, Nymadawa P, Bedoya G, Bradman N, Labuda D, Ruiz-Linares A (2003) Y-chromosome evidence for differing ancient demographic histories in the Americas. Am J Hum Genet 73 [3]: 524-539

Bouakaze C, Keyser C, Amory S, Crubezy E, Ludes B (2007) First successful assay of Y-SNP typing by SNaPshot minisequencing on ancient DNA. Int J Legal Med 121 [6]: 493-499

Bouwman AS Brown TA (2004) The limits of biomolecular palaeopathology: ancient DNA cannot be used to study venereal syphilis. J Arch Sci 32: 703-715 
Brooks N (2006) Cultural responses to aridity in the Middle Holocene and increased social complexity. Quaternary International 151: 29-49

Brotherton P, Endicott P, Sanchez JJ, Beaumont M, Barnett R, Austin J, Cooper A (2007) Novel high-resolution characterization of ancient DNA reveals $\mathrm{C}>\mathrm{U}$-type base modification events as the sole cause of post mortem miscoding lesions. Nucleic Acids Res 35 [17]: $5717-5728$

Burger J, Hummel S, Hermann B, Henke W (1999) DNA preservation: a microsatellite-DNA study on ancient skeletal remains. Electrophoresis 20 [8]: 1722-1728

Burger J, Hummel S, Pfeifer I, Herrmann B (2000) Palaeogenetic analysis of (pre)historic artifacts and its significance for anthropology. Anthropol Anz 58 [1]: 69-76

Burmeister S (2000) Archaeology and Migration. Current Anthropology 41 [4]: 539-567

Butler JM (2005) Forensic DNA Typing. 2nd Edition. Elsevier Academic Press, Burlington

Buttler JM (2005) Forensic DNA Typing. Biology and Technology Behind STR Markers: Biology, Technology, and Genetics of STR Markers. 2nd. Edition. Academic Press, London

Cabana GS, Merriwether DA, Hunley K, Demarchi DA (2006) Is the genetic structure of Gran Chaco populations unique? Interregional perspectives on native South American mitochondrial DNA variation. Am J Phys Anthropol. 131 [1]: 108-119

Cann RL, Stoneking M, Wilson AC (1987) Mitochondrial DNA and human evolution. Nature 325 [6099]: 31-36

Capelle, T (1990) Archäologie der Angelsachsen. Eigenständigkeit und kontinentale Bindung vom 5. bis 9. Jahrhundert. Wiss. Buchges., Darmstadt

Carniero R (1970) A Theory of the Origin of the State. Science 169: 733-738

Cavalli-Sforza L Edwards AW (1967) Phylogenetic analysis. Models and estimation procedures. Am.J.Hum.Genet. 19 [3]: 233-257

Cavalli-Sforza L, Feldman M, Dornbusch S, Chen KH (1983) Cultural evolution. Anthropology and cultural transmission. Nature 304 [5922]: 124-140

Cavalli-Sforza L Feldman MW (2003) The application of molecular genetic approaches to the study of human evolution. Nat Genet 33: 266-275

Cavalli-Sforza L, Piazza A, Menozzi P, Mountain J (1989) Genetic and linguistic evolution. Science 244 [4909]: 1128-1129

Chamberlain AT (2006) Demography in Archeology. University Press, Cambridge

Childe VG (1925) The Dawn of European Civilization. Alfred Knopf, New York

Childe VG (1950) Prehistoric Migrations in Europe. Harvard Univ. Press, Cambridge

Childe VG (2001) The urban Revolution. In: Pacione M (Hrsg.) The City: Critical Concepts in the Social Sciences. Routledge, London 
Chinnery PF (2006) Transmission and Segregation of Mitochondrial DNA in Homo Sapiens. In: Bandelt HJ, Macaulay V, Richards M (Hrsg.) Human Mitochondrial DNA and the Evolution of Homo sapiens. Spinger, Berlin-Heidelberg-New York

Cooper A, Rambaut A, Macaulay V, Willerslev E, Hansen AJ, Stringer C (2001) Human origins and ancient human DNA. Science 292 [5522]: 1655-1656

Crosby AW (2004) Ecological Imperialism: The biological exoansion of Europe. 2nd. Edition. Cambridge University Press, New York

Demarchi DA, Panzetta-Dutari GM, Motran CC, Lopez de Basualdo MA, Marcellino AJ (2001) Mitochondrial DNA haplogroups in Amerindian populations from the Gran Chaco. Am J Phys Anthropol 115 [3]: 199-203

Diamond J (2000) Guns, Germs and Steel: The Fate of Human Societies. Econo-Clad, New York

Diamond J (2005) Collapse. How Societies Choose to Fail or Succeed. Viking, New York

Dillehay TD (1999) The Late Pleistocene cultures of South America. Evolutionary Anthropology 7 [6]: 206-216

Dingle H (1996) Migration: The Biology of Life on the Move. Oxford University Press, Oxford

Dipierri JE, Alfaro E, Martinez-Marignac VL, Bailliet G, Bravi CM, Cejas S, Bianchi NO (1998) Paternal directional mating in two Amerindian subpopulations located at different altitudes in northwestern Argentina. Hum Biol 70 [6]: 1001-1010

Dixon EJ (2001) Human colonization of the Americas: timing, technology and process. Quaternary Science Reviews 20 [1]: 277-299

Dobyns HF (1993) Disease Transfer at Contact. Annu Rev Anthropol 22: 273-291

Dornelles CL, Battilana J, Fagundes NJ, Freitas LB, Bonatto SL, Salzano FM (2004) Mitochondrial DNA and Alu insertions in a genetically peculiar population: the Ayoreo Indians of Bolivia and Paraguay. Am J Hum Biol 16 [4]: 479-488

Dornelles CL, Bonatto SL, De Freitas LB, Salzano FM (2005) Is haplogroup X present in extant South American Indians? Am J Phys Anthropol 127 [4]: 439-448

Douzery EJ, Snell EA, Bapteste E, Delsuc F, Philippe H (2004) The timing of eukaryotic evolution: does a relaxed molecular clock reconcile proteins and fossils? Proc Natl Acad Sci USA 101 [43]: 15386-15391

Dunger DB, Petry CJ, Ong KK (2006) Genetic variations and normal fetal growth. Horm Res 65 Suppl 3: 34-40

Durham W (1976) The Adaptive Significance of Cultural Behaviour. Hum Ecol 4: 89-121

Düvell F (2006) Europäische und internationale Migration: Einführung in historische, soziologische und politische Analysen. Lit Verlag, Münster

Edwards A, Civitello A, Hammond HA, Caskey CT (1991) DNA typing and genetic mapping with trimeric and tetrameric tandem repeats. Am J Hum Genet 49 [4]: 746-756 
Eggert MKH (2005) Prähistorische Archäologie - Konzepte und Methoden. 2. Ausgabe. UTB, Stuttgart

Eglinton G, Logan GA (1991) Molecular preservation. Philos Trans R Soc Lond B Biol Sci 333 [1268]: $315-327$

Eitel B (2007) Kulturentwicklung am Wüstenrand: Aridisierung als Anstoß für frühgeschichtliche Innovation und Migration. In: Wagner G (Hrsg.) Einführung in die Archäometrie. Springer, Berlin-Heidelberg-New York

Eitel B, Hecht S, Mächtle B, Kadereit A, Wagner G, Kromer B, Unkel I, Reindel M (2005) Geoarchaeological evidence from desert loess in the Nazca-Palpa region, Southern Peru: Paleoenvironmental Changes and their impact on the Pre-Columbian cultures. Archaeometry 47 [1]: 137-158

Eitel B, Mächtle B (2006) Holozäner Umweltwandel in der nördlichen Atacama und sein Einfluss auf die Nasca-Kultur (Südperu). Geographische Rundschau 58 [4]: 30-36

Excoffier L (2004) Patterns of DNA sequence diversity and genetic structure after a range expansion: lessons from the infinite-island model. Mol Ecol 13 [4]: 853-864

Excoffier L Schneider S (2005) Arlequin ver. 3.0: An integrated software package for population genetics data analysis. Evol Bioinformatics Online 1: 47-50

Excoffier L, Smouse PE, Quattro JM (1992) Analysis of molecular variance inferred from metric distances among DNA haplotypes: application to human mitochondrial DNA restriction data. Genetics 131 [2]: 479-491

Fagundes NJ, Bonatto SL, Callegari-Jacques SM, Salzano FM (2002) Genetic, geographic, and linguistic variation among South American Indians: possible sex influence. Am J Phys Anthropol 117 [1]: 68-78

Fehren-Schmitz L, Liebert A, Hummel S (2006) Determination of Native American Haplogroups: Alternative approaches for the analysis of the mitochondrial coding region polymorphisms (Poster). 8th International Conference on Ancient DNA \& Associated Biomolecules: 16 - 20 October 2006, Lodz (Poland)

Fix AG (1999) Migration and Colonization in Human Microevolution. Cambridge University Press, Cambridge

Fix AG (2002) Colonization models and initial genetic diversity in the Americas. Hum.Biol. 74 [1]: $1-10$

Fix AG (2005) Rapid deployment of the five founding Amerind mtDNA haplogroups via coastal and riverine colonization. Am J Phys Anthropol 128 [2]: 430-436

Flannery KV (1972) The Cultural Evolution of Civilizations. Annu Rev Ecol Syst 3: 399-426

Forster P, Harding R, Torroni A, Bandelt HJ (1996) Origin and evolution of Native American mtDNA variation: a reappraisal. Am J Hum Genet 59 [4]: 935-945

Friedlaender JS, Gentz F, Green K, Merriwether DA (2002) A Cautionary Tale on Ancient Migration Detection: Mitochondrial DNA Variation in Santa Cruz Island, Solomon Islands. Hum Biol 74 [3]: 453-471 
Fuselli S, Tarazona-Santos E, Dupanloup I, Soto A, Luiselli D, Pettener D (2003) Mitochondrial DNA diversity in South America and the genetic history of Andean highlanders. Mol Biol Evol 20 [10]: 1682-1691

Fux P (2006) Das Petroglyphen-Projekt «Chichictara» in Palpa, Peru. Jahresbericht der SLSA 2006: $189-205$

Garcia F, Moraga M, Vera S, Henriquez H, Llop E, Aspillaga E, Rothhammer F (2006) mtDNA microevolution in Southern Chile's archipelagos. Am J Phys Anthropol 129 [3]: 473-481

Garcia-Bour J, Perez-Perez A, Alvarez S, Fernandez E, Lopez-Parra AM, Arroyo-Pardo E, Turbon D (2004) Early population differentiation in extinct aborigines from Tierra del Fuego-Patagonia: ancient mtDNA sequences and Y-chromosome STR characterization. Am J Phys Anthropol 123 [4]: 361-370

Gilbert MT, Hansen AJ, Willerslev E, Rudbeck L, Barnes I, Lynnerup N, Cooper A (2003) Characterization of genetic miscoding lesions caused by postmortem damage. Am J Hum Genet 72 [1]: 48-61

Gimbutas M (1994) Das Ende Alteuropas. Der Einfall von Steppennomaden aus Südrussland und die Indogermanisierung Mitteleuropas. Innsbruck

Giussani DA (2007) Hypoxia, fetal growth and early origins of disease: The Andean curse on the Conquistadors. J Physiol 582: 472-480

Gould SJ, Eldredge N (1977) Punctuated equilibria: The tempo and mode of evolution reconsidered. Paleobiology 3: 115-151

Gramsch A (2006) Eine kurze Geschichte des archäologischen Denkens in Deutschland. Universität Leipzig, Leipzig

Greenberg JA, Turner CG, Zegura SL (1986) The Settlement of the Americas: A Comparsion of the Linguistic, Dental, and Genetic Evidence. Current Anthropology 27 [5]: 477-497

Grupe G, Christiansen K, Schröder I, Wittwer-Backofen U (2005) Anthropologie: Ein einführendes Lehrbuch. Springer-Verlag, Heidelberg

Haak W, Forster P, Bramanti B, Matsumura S, Brandt G, Tanzer M, Villems R, Renfrew C, Gronenborn D, Alt KW, Burger J (2005) Ancient DNA from the first European farmers in 7500-year-old Neolithic sites. Science 310 [5750]: 1016-1018

Haberland W (1991) Amerikanische Archäologie: Geschichte, Theorie, Kulturentwicklung. Wiss Buchgeselschaft, Darmstadt

Hamerow H (1997) Migration theory and the Anglo-Saxon "identity crisis". In: Chapman J, Hamerow $\mathrm{H}$ (Hrsg.) Migrations and invasions in archaeological explanation. Archaeopress, Oxford

Hamilton G, Stoneking M, Excoffier L (2005) Molecular analysis reveals tighter social regulation of immigration in patrilocal populations than in matrilocal populations. Proc Natl Acad Sci USA 102 [21]: 7476-7480

Han P (2006) Theorien zur internationalen Migration. UTB, Stuttgart 
Härke H (1998) Archaeologists and Migrations. Current Anthropology 39 [1]: 19-45

Harpending H, Rogers A (2000) Genetic perspectives on human origins and differentiation. Annu Rev Genomics Hum Genet 1: 361-385

Harris M (1968) The Rise of Anthropological Theory. A History of Theories of Culture. Crowell, New York

Herrmann, B. (2008) Innerfachliches und Fächerübergreifendes aus einer anthropologischen Sicht und historische Mensch-Umwelt-Beziehungen. Symposium Frauenchiemsee 2008 (im Druck).

Herrmann B, Grosskopf B, Fehren-Schmitz L, Schoon R (2007) Knochen als Spurenträger. In: Herrmann B, Saternus K-S (Hrsg.) Biologische Spurenkunde: Kriminalbiologie. Springer, Berlin-Heidelberg-New York

Herrmann B, Grupe G, Hummel S, Piepenbrink H, Schutkowski H (1990) Prähistorische Anthropologie: Leitfaden der Feld- und Labormethoden. Springer, Berlin-HeidelbergNew York

Herrmann B, Hummel S (1995) Ancient DNA: Recovery and Analysis of Genetic Material from Paleontological, Archaeological, Museum, Medical and Forensic Specimens. Springer, Berlin-Heidelberg-New York

Herrnstadt C, Elson JL, Fahy E, Preston G, Turnbull DM, Anderson C, Ghosh SS, Olefsky JM, Beal MF, Davis RE, Howell N (2002) Reduced-median-network analysis of complete mitochondrial DNA coding-region sequences for the major African, Asian, and European haplogroups. Am J Hum Genet 70 [5]: 1152-1171

Hey J (2005) On the number of New World founders: a population genetic portrait of the peopling of the Americas. PLoS Biol 3 [6]: e193-

Higuchi R, Bowman B, Freiberger M, Ryder OA, Wilson AC (1984) DNA sequences from the quagga, an extinct member of the horse family. Nature 312 [5991]: 282-284

Hodder I (1982) The Present Past: An Introduction to Anthropology for Archaeologists. Batsford Ltd., London

Hofreiter M, Serre D, Poinar HN, Kuch M, Paabo S (2001) Ancient DNA. Nat Rev Genet 2 [5]: 353-359

Horn, P (2005) Isotopensignaturen schwerer Elemente in der ökologischen Forschung und Praxis. Rundgespräche der Kommission für Ökologie 30: 131-152

Hudjashov G, Kivisild T, Underhill PA, Endicott P, Sanchez JJ, Lin AA, Shen P, Oefner P, Renfrew C, Villems R, Forster P (2007) Revealing the prehistoric settlement of Australia by Y chromosome and mtDNA analysis. Proc Natl Acad Sci USA 104 [21]: 8726-8730

Hummel S (2003) Ancient DNA Typing: Methods, Strategies and Applications. Springer, Berlin-Heidelberg-New York

Hummel S, Schultes T, Bramanti B, Herrmann B (1999) Ancient DNA profiling by megaplex amplications. Electrophoresis 20 [8]: 1717-1721 
Ingman M, Kaessmann H, Paabo S, Gyllensten U (2000) Mitochondrial genome variation and the origin of modern humans. Nature 408 [6813]: 708-713

Isla-Cuadrado J, Reindel M (2003) Jauranga: un sitio Paracas en el valle de palpa, costa sur del Peru. Beiträge zur allgemeinen und vergleichenden Archäologie 23: 227-274

Isla-Cuadrado J (2004) Grabsitten an der Südküste Perus: Neue Befunde von der Paracas-, Nasca- und Wari-Kultur. Archäologischer Anzeiger 2004 [2]: 96-98

Isla-Cuadrado J, Reindel M (2006) Burial Patterns and Sociopolitical Organization in Nasca 5 Society. In: Isbell WH, S (Hrsg.) Andean Archaeology III. North and South., New York

Issar A, Zohar M (2004) Climate Change - Environment and Civilization in the Middle East. Springer, Berlin

Jobling MA, Hurles ME, Tyler-Smith C (2004) Human Evolutionary Genetics: Origins, Peoples and Disease. Garland Science, New York

Kaestle FA, Horsburgh KA (2002) Ancient DNA in anthropology: methods, applications, and ethics. Am J Phys Anthropol Suppl 35: 92-130

Karafet T, Zegura SL, Vuturo-Brady J, Posukh O, Osipova L, Wiebe V, Romero F, Long JC, Harihara S, Jin F, Dashnyam B, Gerelsaikhan T, Omoto K, Hammer MF (1997) Y chromosome markers and Trans-Bering Strait dispersals. Am J Phys Anthropol 102 [3]: 301-314

Kemp BM, Malhi RS, McDonough J, Bolnick DA, Eshleman JA, Rickards O, Martinez-Labarga C, Johnson JR, Lorenz JG, Dixon EJ, Fifield TE, Heaton TH, Worl R, Smith DG (2007) Genetic analysis of early holocene skeletal remains from Alaska and its implications for the settlement of the Americas. Am J Phys Anthropol 132 [4]: 605-621

Keyeux G, Rodas C, Gelvez N, Carter D (2002) Possible migration routes into South America deduced from mitochondrial DNA studies in Colombian Amerindian populations. Hum Biol 74 [2]: 211-233

Kitchin PA, Szotyori Z, Fromholc C, Almond N (1990) Avoidance of PCR false positives [corrected]. Nature 344 [6263]: 201-220

Kivisild T, Shen P, Wall DP, Do B, Sung R, Davis K, Passarino G, Underhill PA, Scharfe C, Torroni A, Scozzari R, Modiano D, Coppa A, de Knijff P, Feldman M, Cavalli-Sforza LL, Oefner PJ (2006) The role of selection in the evolution of human mitochondrial genomes. Genetics 172 [1]: 373-387

Kivisild T, Tolk HV, Parik J, Wang Y, Papiha SS, Bandelt HJ, Villems R (2002) The emerging limbs and twigs of the East Asian mtDNA tree. Mol.Biol.Evol. 19 [10]: 1737-1751

Kleindorp R, Westenthanner M, Adler M, Hummel S (2006) aDNA preservation patterns within different human skeletal elements and in dependance on different chromosomal locations (Poster). 8th International Conference on Ancient DNA \& Associated Biomolecules: 16 20 October 2006, Lodz (Poland)

Knox PL, Marston SA (2001) Humangeographie. Spektrum, Heidelberg 
Knudson KJ, Price TD, Buikstra JE, Blom DE (2004) The use of strontium isotope analysis to investigate Tiwanaku migration and mortuary ritual in Bolivia and Peru. Archaeometry 46 [1]: $5-18$

Kong QP, Yao YG, Sun C, Bandelt HJ, Zhu CL, Zhang YP (2003) Phylogeny of east Asian mitochondrial DNA lineages inferred from complete sequences. Am J Hum Genet 73 [3]: 671-676

Kossina G (1912) Die deutsche Vorgeschichte, eine hervorragend nationale Wissenschaft. Curt Kabitzsch Verlag, Leipzig

Kuhn T (1976) Die Struktur wissenschaftlicher Revolutionen. Suhrkamp, Frankfurt a.M.

Lalueza C, Perez-Perez A, Prats E, Cornudella L, Turbon D (1997) Lack of founding Amerindian mitochondrial DNA lineages in extinct aborigines from Tierra del FuegoPatagonia. Hum Mol Genet 6 [1]: 41-46

Lambers K (2006) The Geoglyphs of Palpa, Peru: Documentation, Analysis, and Interpretation. LINDEN SOFT, Bonn

Lee ES (1972) Eine Theorie der Wanderung. In: Szell G (Hrsg.) Regionale Mobilität. Nymphenburger Verlag, München

Lehmkühler S (1991) Heiratskreise in der Vorgeschichte. Archäologische Informationen 14: 155-159

Lewis CM, Tito RY, Lizarraga B, Stone AC (2005) Land, language, and loci: mtDNA in Native Americans and the genetic history of Peru. Am J Phys Anthropol 127 [3]: 351-360

Lewis CM, Buikstra JE, Stone AC (2007a) Ancient DNA and Genetic Continuity in the South Central Andes. Latin American Antiquity 18 [2]: 145-160

Lewis CM, Lizarraga B, Tito RY, Medina A, Martinez R, Polo S, Caceres AM, Stone AC (2007b) Mitochondrial DNA and the Peopling of South America. Hum Biol 79 [2]: 159178

Lindahl T (1993) Instability and decay of the primary structure of DNA. Nature 362 [6422]: 709715

Longo MC, Berninger MS, Hartley JL (1990) Use of uracil DNA glycosylase to control carryover contamination in polymerase chain reactions. Gene 93 [1]: 125-128

Lowe A, Harris S, Ashton P (2004) Ecological Genetics: Design, Analysis and Application. Blackwell Publishing, Oxford

Luiselli D, Simoni L, Tarazona-Santos E, Pastor S, Pettener D (2000) Genetic structure of Quechua-speakers of the Central Andes and geographic patterns of gene frequencies in South Amerindian populations. Am J Phys Anthropol 113 [1]: 5-17

Maca-Meyer N, Gonzalez AM, Larruga JM, Flores C, Cabrera VM (2001) Major genomic mitochondrial lineages delineate early human expansions. BMC Genet 2: 13-

Macaulay V, Hill C, Achilli A, Rengo C, Clarke D, Meehan W, Blackburn J, Semino O, Scozzari R, Cruciani F, Taha A, Shaari NK, Raja JM, Ismail P, Zainuddin Z, Goodwin 
W, Bulbeck D, Bandelt HJ, Oppenheimer S, Torroni A, Richards M (2005) Single, rapid coastal settlement of Asia revealed by analysis of complete mitochondrial genomes. Science 308 [5724]: 1034-1036

Mächtle B (2007) Geomorphologische-bodenkundliche Untersuchungen zur Rekonstruktion der holozänen Umweltgeschichte in der nördlichen Atacam im Raum Palpa. Universität Heidelberg, Heidelberg

Malhi RS, Eshleman JA, Greenberg JA, Weiss DA, Schultz Shook BA, Kaestle FA, Lorenz JG, Kemp BM, Johnson JR, Smith DG (2002) The structure of diversity within New World mitochondrial DNA haplogroups: implications for the prehistory of North America. Am J Hum Genet 70 [4]: 905-919

Marota I, Basile C, Ubaldi M, Rollo F (2002) DNA decay rate in papyri and human remains from Egyptian archaeological sites. Am J Phys Anthropol 117 [4]: 310-318

Marrero AR, Bravi C, Stuart S, Long JC, Pereira das Neves LF, Kommers T, Carvalho CM, Pena SD, Ruiz-Linares A, Salzano FM, Catira BM (2007a) Pre- and Post-Columbian Gene and Cultural Continuity: The Case of the Gaucho from Southern Brazil. Hum Hered 64 [3]: 160-171

Marrero AR, Silva-Junior WA, Bravi CM, Hutz MH, Petzl-Erler ML, Ruiz-Linares A, Salzano FM, Bortolini MC (2007b) Demographic and evolutionary trajectories of the Guarani and Kaingang natives of Brazil. Am J Phys Anthropol 132 [2]: 301-310

Melton PE, Briceno I, Gomez A, Devor EJ, Bernal JE, Crawford MH (2007) Biological relationship between central and South American Chibchan speaking populations: Evidence from mtDNA. Am J Phys Anthropol 133 [1]: 753-770

Menzel D (1964) Style and time in the Middle Horizon. Nawpa Pacha 2: 1-105

Merriwether DA, Rothhammer F, Ferrell RE (1995) Distribution of the four founding lineage haplotypes in Native Americans suggests a single wave of migration for the New World. Am J Phys Anthropol 98 [4]: 411-430

Mesa NR, Mondragon MC, Soto ID, Parra MV, Duque C, Ortiz-Barrientos D, Garcia LF, Velez ID, Bravo ML, Munera JG, Bedoya G, Bortolini MC, Ruiz-Linares A (2000) Autosomal, mtDNA, and Y-chromosome diversity in Amerinds: pre- and post-Columbian patterns of gene flow in South America. Am.J.Hum.Genet. 67 [5]: 1277-1286

Meyer S, Weiss G, von Haeseler A (1999) Pattern of nucleotide substitution and rate heterogeneity in the hypervariable regions I and II of human mtDNA. Genetics 152 [3]: $1103-1110$

Montgomery J, Evans JA, Powlesland D, Roberts CA (2005) Continuity or colonization in Anglo-Saxon England? Isotope evidence for mobility, subsistence practice, and status at West Heslerton. Am J Phys Anthropol 126 [2]: 123-138

Montiel R, Malgosa A, Francalacci P (2001) Authenticating ancient human mitochondrial DNA. Hum Biol 73 [5]: 689-713

Montpetit SA, Fitch IT, O'Donnell PT (2005) A simple automated instrument for DNA extraction in forensic casework. J Forensic Sci 50 [3]: 555-563 
Moore LG, Shriver M, Bemis L, Hickler B, Wilson M, Brutsaert T, Parra E, Vargas E (2004) Maternal adaptation to high-altitude pregnancy: an experiment of nature--a review. Placenta 25 Suppl A: S60-S71

Moraga M, Rocco P, Miquel JF, Nervi F, Llop E, Chakraborty R, Rothhammer F, Carvallo P (2000) Mitochondrial DNA polymorphisms in Chilean aboriginal populations: implications for the peopling of the southern cone of the continent. Am J Phys Anthropol 113 [1]: 19-29

Moraga M, Aspillaga E, Santoro CM, Standen VG, Carvallo P, Rothhammer F (2001) Analisis de ADN mitocondrial en momias del norte de Chile avala hipotesis de origen amazonico de poblaciones andinas. Rev Chil Hist Nat 74: 719-726

Moraga M, Santoro CM, Standen VG, Carvallo P, Rothhammer F (2005) Microevolution in prehistoric Andean populations: chronologic mtDNA variation in the desert valleys of northern Chile. Am J Phys Anthropol 127 [2]: 170-181

Moran EF (2000) Human Adaptability: An Introduction to Ecological Anthropology. 2nd. Westview Press, Oxford

Müller B (2002) Design einer Multiplex-PCR zur Typisierung von Y-STR Haplotypen aus degradierter DNA. Diplomarbeit Biol. Fak. Univ. Göttingen, Göttingen

Mulligan CJ, Hunley K, Cole S, Long JC (2004) Population genetics, history, and health patterns in native americans. Annu Rev Genomics Hum Genet 5: 295-315

Mullis K, Faloona F, Scharf S, Saiki R, Horn G, Erlich H (1986) Specific enzymatic amplification of DNA in vitro: the polymerase chain reaction. Cold Spring Harb.Symp. Quant Biol 51: 263-273

Nei M (1987) Molecular Evolutionary Genetics. Columbia University Press, New York

Nei M, Li WH (1979) Mathematical model for studying genetic variation in terms of restriction endonucleases. Proc Natl Acad Sci USA 76 [10]: 5269-5273

Neustupny E (1982) Prehistoric migration by infiltration. Archeologické Rozhledy 34: 278-293

Ou CY, Moore JL, Schochetman G (1991) Use of UV irradiation to reduce false positivity in polymerase chain reaction. Biotechniques 10 [4]: 442, 444, 446-

Paabo S (1985) Molecular cloning of Ancient Egyptian mummy DNA. Nature 314 [6012]: 644645

Paabo S, Poinar H, Serre D, Jaenicke-Despres V, Hebler J, Rohland N, Kuch M, Krause J, Vigilant L, Hofreiter M (2004) Genetic analyses from ancient DNA. Annu Rev Genet 38: 645-679

Pakendorf B Stoneking M (2005) Mitochondrial DNA and human evolution. Annu Rev Genomics Hum Genet 6: 165-183

Perez SI, Bernal V, Gonzalez PN (2007a) Evolutionary Relationships among prehistoric Human Populations: An evaluation of relatedness patterns based on Facial Morphometric Data using Molecular Data. Hum Biol 79 [1]: 25-50 
Perez SI, Bernal V, Gonzalez PN (2007b) Morphological differentiation of aboriginal human populations from Tierra del Fuego (Patagonia): implications for South American peopling. Am J Phys Anthropol 133 [4]: 1067-1079

Petry CJ, Ong KK, Barratt BJ, Wingate D, Cordell HJ, Ring SM, Pembrey ME, Reik W, Todd JA, Dunger DB (2005) Common polymorphism in H19 associated with birthweight and cord blood IGF-II levels in humans. BMC Genet 6 [1]: 22-

Poinar H, Kuch M, McDonald G, Martin P, Paabo S (2003) Nuclear gene sequences from a late pleistocene sloth coprolite. Curr Biol 13 [13]: 1150-1152

Prentiss WC, Chatter JC (2003) Cultural Diversification and Decimation in the Prehistoric Record. Current Anthropology 44 [1]: 33-58

Primorac D, Andelinovic S, Definis-Gojanovic M, Drmic I, Rezic B, Baden MM, Kennedy MA, Schanfield MS, Skakel SB, Lee HC (1996) Identification of war victims from mass graves in Croatia, Bosnia, and Herzegovina by use of standard forensic methods and DNA typing. J Forensic Sci 41 [5]: 891-894

Pucciarelli HM, Neves WA, Gonzalez-Jose R, Sardi ML, Rozzi FR, Struck A, Bonilla MY (2006) East-West cranial differentiation in pre-Columbian human populations of South America. Homo. 57 [2]: 133-150

Reindel M (2002) Pinchango Alto: A Gold Miners Settlement in Palpa, Southern Peru. In: Eeckhout P, Le Fort G (Hrsg.) Wars and Conflicts in Prehispanic Mesoamerica and the Andes. BAR, Oxford

Reindel M (2004) Landschafts- und Siedlungsgeschichte im Gebiet der Nasca-Kultur /Peru. Geographische Rundschau 56 [3]: 22-29

Reindel M, Gruen A (2006) The Nasca-Palpa Projekt: a cooperative approach of photogrammetry, archaeometry and archaeology. In: Baltsavias E, Gruen A (Hrsg.) Recording, Modeling and Visualization of Cultural Heritage. Taylor \& Francis, London

Reindel M, Isla-Cuadrado J (2000) Ausgrabungen in Los Molinos und La Muña. Ergebnisse der Grabungskampagne 1999 des Archäologischen Projektes Nasca-Palpa, Süd-Peru. Jahresbericht der SLSA: 3-31

Reindel M, Isla-Cuadrado J (2001) Los Molinos und La Muña. Zwei Siedlungszentren der Nasca-Kultur in Palpa, Südperu. Beiträge zur allgemeinen und vergleichenden Archäologie 21: 241-319

Reindel M, Isla-Cuadrado J (2003) Archäologisches Projekt "Paracas in Palpa", Peru: Bericht über die Grabungskampagne 2003. Jahresbericht der SLSA 2003: 137-156

Reindel M, Isla-Cuadrado J (2006) Archäologisches Projekt "Paracas in Palpa", Peru Ausgrabungen und Forschungen im Jahr 2005. Jahresbericht der SLSA 2005: 30-59

Reindel M, Isla-Cuadrado J, Lambers K (2002) Abschließende Untersuchungen zu Geoglyphen und Siedlungen in Palpa, Südperu. Ergebnisse der Feldkampagne 2001 des Archäologischen Projektes Nasca-Palpa. Jahresbericht der SLSA : 57-74 
Reindel M, Isla-Cuadrado J, Lambers K (2004) Archäologisches Projekt "Paracas in Palpa", Peru - Ausgrabungen und Forschungen 2004. SLSA-Jahresbericht 2004

Renfrew C (1973) Before Civilisation, the Radiocarbon Revolution and Prehistoric Europe. Pimlico, London

Renfrew C (1987) Archaeology and Language. Cambridge University Press, Cambridge

Renfrew C, Bahn PG (2004) Archaeology: Theories, Methods and Practice. 4th. Thames \& Hudson, London

Ribetio-dos-Santos AK, Santos SE, Machado AL, Guapindaia V, Zago MA (1996) Heterogeneity of mitochondrial DNA haplotypes in Pre-Columbian Natives of the Amazon region. Am J Phys Anthropol 101 [1]: 29-37

Richards M, Macaulay V (2001) The mitochondrial gene tree comes of age. Am.J.Hum.Genet. 68 [6]: 1315-1320

Richards MB, Macaulay VA, Bandelt HJ, Sykes BC (1998) Phylogeography of mitochondrial DNA in western Europe. Ann Hum Genet 62 [Pt 3]: 241-260

Rick JW (1980) Prehistoric Hunters of the High Andes. Academic Press, New York

Rickards O, Martinez-Labarga C, Lum JK, De Stefano GF, Cann RL (1999) mtDNA history of the Cayapa Amerinds of Ecuador: detection of additional founding lineages for the Native American populations. Am J Hum Genet 65 [2]: 519-530

Rodriguez-Delfin LA, Rubin-de-Celis VE, Zago MA (2001) Genetic diversity in an Andean population from Peru and regional migration patterns of Amerindians in South America: data from Y chromosome and mitochondrial DNA. Hum Hered 51 [1-2]: 97-106

Roewer L, Krawczak M, Willuweit S, Nagy M, Alves C, Amorim A, Anslinger K, Augustin C, Betz A, Bosch E, Caglia A, Carracedo A, Corach D, Dekairelle AF, Dobosz T, Dupuy BM, Furedi S, Gehrig C, Gusmao L, Henke J, Henke L, Hidding M, Hohoff C, Hoste B, Jobling MA, Kargel HJ, de Knijff P, Lessig R, Liebeherr E, Lorente M, Martinez-Jarreta B, Nievas P, Nowak M, Parson W, Pascali VL, Penacino G, Ploski R, Rolf B, Sala A, Schmidt U, Schmitt C, Schneider PM, Szibor R, Teifel-Greding J, Kayser M (2001) Online reference database of European Y-chromosomal short tandem repeat (STR) haplotypes. Forensic Sci Int 118 [2-3]: 106-113

Rogers AR, Harpending H (1992) Population growth makes waves in the distribution of pairwise genetic differences. Mol Biol Evol 9 [3]: 552-569

Rompler H, Rohland N, Lalueza-Fox C, Willerslev E, Kuznetsova T, Rabeder G, Bertranpetit J, Schoneberg T, Hofreiter M (2006) Nuclear gene indicates coat-color polymorphism in mammoths. Science 313 [5783]: 62-72

Rosenberg M (1994) Pattern, process, and hierarchy in the evolution of culture. J Anth Arch 13: 307-340

Rössler M (2007) Die deutschprachige Ethnologie bis ca. 1960: Ein historischer Abriss. DBV, Köln 
Rothhammer F, Llop E, Carvallo P, Moraga M (2001) Origin and evolutionary relationships of native Andean populations. High Alt Med Biol 2 [2]: 227-233

Rothhammer F, Moraga M, Rivera M, Standen VG, Garcia F, Carvallo P (2003) Analisis de ADNmt de restos esqueletales del sitio arqueologico de tiwanaku y su relacion con el origen de sus constructores. Chungara 35 [2]: 269-274

Rothhammer F, Silva C (1989) Peopling of Andean South America. Am J Phys Anthropol 78 [3]: 403-410

Rozas J, Sanchez-DelBarrio JC, Messeguer X, Rozas R (2003) DnaSP, DNA polymorphism analyses by the coalescent and other methods. Bioinformatics 19 [18]: 2496-2497

Ruiz-Linares A, Ortiz-Barrientos D, Figueroa M, Mesa N, Munera JG, Bedoya G, Velez ID, Garcia LF, Perez-Lezaun A, Bertranpetit J, Feldman MW, Goldstein DB (1999) Microsatellites provide evidence for Y chromosome diversity among the founders of the New World. Proc Natl Acad Sci USA 96 [11]: 6312-6317

Rummel S, Hölzl S, Horn P (2007) Isotopensignaturen von Bio- und Geoelementen in der Forensik. In: Herrmann B, Saternus K-S (Hrsg.) Biologische Spurenkunde: Kriminalbiologie. Springer, Berlin-Heidelberg-New York

Rupert JL, Hochachka PW (2001) Genetic approaches to understanding human adaptation to altitude in the Andes. J Exp Biol 204 [Pt 18]: 3151-3160

Sahlins M (1972) Stone Age Economics. Aldine Transaction, New York

Sahlins M (1977) Culture and Practical Reason. University of Chicago Press, Chicago

Sahlins M, Service E (1960) Evolution and Culture. University of Michigan Press, Ann Arbor

Saitou N, Nei M (1987) The neighbor-joining method: a new method for reconstructing phylogenetic trees. Mol Biol Evol 4 [4]: 406-425

Salas A, Carracedo A, Macaulay V, Richards M, Bandelt HJ (2005) A practical guide to mitochondrial DNA error prevention in clinical, forensic, and population genetics. Biochem Biophys Res Commun 335 [3]: 891-899

Salzano FM (2002) Molecular variability in Amerindians: widespread but uneven information. An Acad Bras Cienc 74 [2]: 223-263

Sanderson SK (1999) Social Transformations: A General Theory of Historical Development. Rowman \& Littlefield Inc., Lanham

Sandweiss DH, McInnis H, Burger RL, Cano A, Ojeda B, Paredes R, Sandweiss MC, Glascock MD (1998) Quebrada jaguay: early south american maritime adaptations. Science 281 [5384]: 1830-1832

Sanger F, Nicklen S, Coulson AR (1977) DNA sequencing with chain-terminating inhibitors. Proc Natl Acad Sci USA 74 [12]: 5463-5467

Sanjek R (2003) Rethinking migration, ancient to future. Global Networks 3 [3]: 315-336 
Schilz F (2006) Molekulargenetische Verwandtschaftsanalysen am prähistorischen Skelettkollektiv der Lichtensteinhöhle. Dissertation Mathematisch-Naturwissenschaftliche Fakultät, Universität Göttingen

Schmidt T, Hummel S, Herrmann B (1995) Evidence of contamination in PCR laboratory disposables. Naturwissenschaften 82 [9]: 423-431

Schmitt R, Bonatto SL, Freitas LB, Muschner VC, Hill K, Hurtado AM, Salzano FM (2004) Extremely limited mitochondrial DNA variability among the Ache Natives of Paraguay. Ann Hum Biol 31 [1]: 87-94

Schneider S, Excoffier L (1999) Estimation of past demographic parameters from the distribution of pairwise differences when the mutation rates vary among sites: application to human mitochondrial DNA. Genetics 152 [3]: 1079-1089

Schurr TG (2004) The Peopling of the New World: Perspectives from Molecular Anthropology. Annu Rev Anthropol 33: 551-583

Schurr TG, Ballinger SW, Gan YY, Hodge JA, Merriwether DA, Lawrence DN, Knowler WC, Weiss KM, Wallace DC (1990) Amerindian mitochondrial DNAs have rare Asian mutations at high frequencies, suggesting they derived from four primary maternal lineages. Am J Hum Genet 46 [3]: 613-623

Schurr TG, Sherry ST (2004) Mitochondrial DNA and Y chromosome diversity and the peopling of the Americas: evolutionary and demographic evidence. Am J Hum Biol 16 [4]: 420439

Schutkowski H (1994) Isotopenanalysen in der Archäometrie. Teil B: Analyse Stabiler Isotope. In: Herrmann B (Hrsg.) Archäometrie: Naturwissenschaftliche Analyse von Sachüberresten. Springer, Berlin-Heidelberg-New York

Schutkowski H (1998) Biokulturelle Anpassungen in menschlichen Bevölkerungen : Beiträge zu einer Humanökologie . Univ. Habil.-Schr., Göttingen

Schwartz M Vissing J (2002) Paternal inheritance of mitochondrial DNA. N Engl J Med 347 [8]: $576-580$

Scott JP (1989) The Evolution of Social Systems. Routledge, Oxford

Seielstad M, Yuldasheva N, Singh N, Underhill P, Oefner P, Shen P, Wells RS (2003) A novel $\mathrm{Y}$-chromosome variant puts an upper limit on the timing of first entry into the Americas. Am J Hum Genet 73 [3]: 700-705

Service E (1962) Primitive Social Organisation. Random House, New York

Shennan S (2000) Population, Culture History, and the Dynamics of Culture Change. Current Anthropology 41 [5]: 811-835

Shimada I, Shinoda K, Farnum J, Corruccini R, Watanabe H (2004) An integrated analysis of pre-Hispanic mortuary practices. Current Anthropology 45 [3]: 369-390

Shinoda K, Adachi N, Guillen S, Shimada I (2006) Mitochondrial DNA analysis of ancient Peruvian highlanders. Am J Phys Anthropol 131 [1]: 98-107 
Silva WA, Jr., Bonatto SL, Holanda AJ, Ribeiro-dos-Santos AK, Paixao BM, Goldman GH, Abe-Sandes K, Rodriguez-Delfin L, Barbosa M, Paco-Larson ML, Petzl-Erler ML, Valente V, Santos SE, Zago MA (2002) Mitochondrial genome diversity of Native Americans supports a single early entry of founder populations into America. Am J Hum Genet 71 [1]: 187-192

Silverman H (1994) Paracas in Nazca: new data on the Early Horizon occupation of the Rio Grande de Nazca Drainage, Peru. Latin American Antiquity 5 [4]: 359-382

Silverman H, Proulx DA (2002) The Nasca. Blackwell, Oxford

Slatkin M (1995) A measure of population subdivision based on microsatellite allele frequencies. Genetics 139 [1]: 457-462

Smith DG, Malhi RS, Eshleman JA, Kaestle FA, Kemp BM (2005) Mitochondrial DNA Haplogroups of Paleoamericans in North America. In: Bonnichsen R, Lepper BT, Stanford D (Hrsg.) Paleoamerican Origins: Beyond Clovis. Texas A\&M University Press, College Station

Sneath PHA, Sokal RR (1973) Numerical Taxonomy. W.H. Freeman, San Francisco

Solis RS, Haas J, Creamer W (2001) Dating Caral, a preceramic site in the Supe Valley on the central coast of Peru. Science 292 [5517]: 723-726

Stanish C (2001) The Origin of State Societies in South America. Annu Rev Anthropol 30: 4164

Starikovskaya EB, Sukernik RI, Derbeneva OA, Volodko NV, Ruiz-Pesini E, Torroni A, Brown MD, Lott MT, Hosseini SH, Huoponen K, Wallace DC (2005) Mitochondrial DNA diversity in indigenous populations of the southern extent of Siberia, and the origins of Native American haplogroups. Ann Hum Genet 69 [1]: 67-89

Steward JH (1948) Handbook of South American Indians. Vol. 1-7. US Government Printing, Washington, D.C.

Steward JH (1955) Theory of culture change. University of Illinois Press, Urbana

Stiller M, Green RE, Ronan M, Simons JF, Du L, He W, Egholm M, Rothberg JM, Keates SG, Ovodov ND, Antipina EE, Baryshnikov GF, Kuzmin YV, Vasilevski AA, Wuenschell GE, Termini J, Hofreiter M, Jaenicke-Despres V, Paabo S (2006) Patterns of nucleotide misincorporations during enzymatic amplification and direct large-scale sequencing of ancient DNA. Proc Natl Acad Sci USA 103 [37]: 13578-13584

Stone AC, Stoneking M (1993) Ancient DNA from a pre-Columbian Amerindian population. Am J Phys Anthropol 92 [4]: 463-471

Stone AC, Stoneking M (1999) Analysis of ancient DNA from a prehistoric Amerindian cemetery. Philos Trans R Soc Lond B Biol Sci 354 [1379]: 153-159

Stoneking M (2000) Hypervariable sites in the mtDNA control region are mutational hotspots. Am J Hum Genet 67 [4]: 1029-1032

Storey AA, Ramirez JM, Quiroz D, Burley DV, Addison DJ, Walter R, Anderson AJ, Hunt TL, Athens JS, Huynen L, Matisoo-Smith EA (2007) Radiocarbon and DNA evidence for a 
pre-Columbian introduction of Polynesian chickens to Chile. Proc Natl Acad Sci USA 104 [25]: 10335-10339

Straubhaar T (1993) Ursachen der Migration aus ökonomischer Sicht. In: Kälin W, Moser R (Hrsg.) Migrationen aus der Dritten Welt: Ursachen-Wirkungen und Handlungsmöglichkeiten. Haupt, Bern

Sullivan KM, Mannucci A, Kimpton CP, Gill P (1993) A rapid and quantitative DNA sex test: fluorescence-based PCR analysis of X-Y homologous gene amelogenin. Biotechniques 15 [4]: 636-1

Swallow DM (2003) Genetics of lactase persistence and lactose intolerance. Annu Rev Genet 37: 197-219

Sykes B (1999) The molecular genetics of European ancestry. Philos Trans R Soc Lond B Biol Sci 354 [1379]: 131-138

Tajima F (1983) Evolutionary relationship of DNA sequences in finite populations. Genetics 105 [2]: 437-460

Tajima F (1989a) Statistical method for testing the neutral mutation hypothesis by DNA polymorphism. Genetics 123 [3]: 585-595

Tajima F (1989b) The effect of change in population size on DNA polymorphism. Genetics 123 [3]: 597-601

Tajima F (1993) Statistical analysis of DNA polymorphism. Jpn J Genet 68 [6]: 567-595

Tamariz J, Voynarovska K, Prinz M, Caragine T (2006) The application of ultraviolet irradiation to exogenous sources of DNA in plasticware and water for the amplification of low copy number DNA. J Forensic Sci 51 [4]: 790-794

Tamm E, Kivisild T, Reidla M, Metspalu M, Smith DG, Mulligan CJ, Bravi CM, Rickards O, Martinez-Labarga C, Khusnutdinova EK, Fedorova SA, Golubenko MV, Stepanov VA, Gubina MA, Zhadanov SI, Ossipova LP, Damba L, Voevoda MI, Dipierri JE, Villems R, Malhi RS (2007) Beringian standstill and spread of Native American founders. PLoS ONE 2 [9]: 829-835

Tamura K, Dudley J, Nei M, Kumar S (2007) MEGA4: Molecular Evolutionary Genetics Analysis (MEGA) software version 4.0. Mol Biol Evol 24 [8]: 1596-1599

Tamura K Nei M (1993) Estimation of the number of nucleotide substitutions in the control region of mitochondrial DNA in humans and chimpanzees. Mol Biol Evol 10 [3]: 512526

Tarazona-Santos E, Carvalho-Silva DR, Pettener D, Luiselli D, De Stefano GF, Labarga CM, Rickards O, Tyler-Smith C, Pena SD, Santos FR (2001) Genetic differentiation in South Amerindians is related to environmental and cultural diversity: evidence from the $\mathrm{Y}$ chromosome. Am J Hum Genet 68 [6]: 1485-1496

Torres MM, Bravi CM, Bortolini MC, Duque C, Callegari-Jacques S, Ortiz D, Bedoya G, Groot dR, Ruiz-Linares A (2006) A revertant of the major founder Native American haplogroup $\mathrm{C}$ common in populations from northern South America. Am J Hum Biol 18 [1]: 59-65 
Torroni A, Achilli A, Macaulay V, Richards M, Bandelt HJ (2006) Harvesting the fruit of the human mtDNA tree. Trends Genet 22 [6]: 339-345

Torroni A, Schurr TG, Cabell MF, Brown MD, Neel JV, Larsen M, Smith DG, Vullo CM, Wallace DC (1993) Asian affinities and continental radiation of the four founding Native American mtDNAs. Am J Hum Genet 53 [3]: 563-590

Underhill PA, Jin L, Lin AA, Mehdi SQ, Jenkins T, Vollrath D, Davis RW, Cavalli-Sforza LL, Oefner PJ (1997) Detection of numerous Y chromosome biallelic polymorphisms by denaturing high-performance liquid chromatography. Genome Res 7 [10]: 996-1005

Underhill PA, Kivisild T (2007) Use of Y Chromosome and Mitochondrial DNA Population Structure in Tracing Human Migrations. Annu Rev Genet 41: 539-564

Underhill PA, Passarino G, Lin AA, Shen P, Mirazon LM, Foley RA, Oefner PJ, Cavalli-Sforza LL (2001) The phylogeography of Y chromosome binary haplotypes and the origins of modern human populations. Ann Hum Genet 65 [1]: 43-62

Underhill PA, Shen P, Lin AA, Jin L, Passarino G, Yang WH, Kauffman E, Bonne-Tamir B, Bertranpetit J, Francalacci P, Ibrahim M, Jenkins T, Kidd JR, Mehdi SQ, Seielstad MT, Wells RS, Piazza A, Davis RW, Feldman MW, Cavalli-Sforza LL, Oefner PJ (2000) Y chromosome sequence variation and the history of human populations. Nat Genet 26 [3]: 358-361

Unkel I (2006) AMS- ${ }^{14}$ C-Analysen zur Rekonstruktion der Landschafts- und Kulturgeschichte in der Region Palpa. Universität Heidelberg, Heidelberg

Vona G, Falchi A, Moral P, Calo CM, Varesi L (2005) Mitochondrial sequence variation in the Guahibo Amerindian population from Venezuela. Am J Phys Anthropol 127 [3]: 361-369

Walsh PS, Fildes NJ, Reynolds R (1996) Sequence analysis and characterization of stutter products at the tetranucleotide repeat locus vWA. Nucleic Acids Res 24 [14]: 2807-2812

Walsh PS, Metzger DA, Higuchi R (1991) Chelex 100 as a medium for simple extraction of DNA for PCR-based typing from forensic material. Biotechniques 10 [4]: 506-513

Ward RH, Salzano FM, Bonatto SL, Hutz MH, Coimbra CEA, Santos R (1996) Mitochondrial DNA Polymorphism in Three Brazilian Indian Tribes. Am J Hum Biol 8: 317-323

Weale ME, Weiss DA, Jager RF, Bradman N, Thomas MG (2002) Y chromosome evidence for Anglo-Saxon mass migration. Mol Biol Evol 19 [7]: 1008-1021

Westenthanner M (2007) Optimierung der Real Time PCR zur Charakterisierung der Degradation von ancient DNA (aDNA) in ausgewählten Skelettelementen. Diplomarb. Biol. Fak. Univ. Göttingen / Jena, Göttingen

White LA (1959) The Evolution of Culture; The Development of Civilization to the Fall of Rome. Mcgraw-Hill, Toronto

Wilder JA, Kingan SB, Mobasher Z, Pilkington MM, Hammer MF (2004) Global patterns of human mitochondrial DNA and Y-chromosome structure are not influenced by higher migration rates of females versus males. Nat Genet 36 [10]: 1122-1125

Willerslev E, Cooper A (2005) Ancient DNA. Proc Biol Sci 272 [1558]: 3-16 
Willerslev E, Hansen AJ, Binladen J, Brand TB, Gilbert MT, Shapiro B, Bunce M, Wiuf C, Gilichinsky DA, Cooper A (2003) Diverse plant and animal genetic records from Holocene and Pleistocene sediments. Science 300 [5620]: 791-795

Williams SR, Chagnon NA, Spielman RS (2002) Nuclear and mitochondrial genetic variation in the Yanomamo: a test case for ancient DNA studies of prehistoric populations. Am J Phys Anthropol 117 [3]: 246-259

Wittfogel K (1957) Oriental Despotism. Yale University Press, New Haven

Wittwer CT, Herrmann MG, Moss AA, Rasmussen RP (1997) Continuous fluorescence monitoring of rapid cycle DNA amplification. Biotechniques 22 [1]: 130-138

Wright S (1931) Evolution in Mendelian Populations. Genetics 16 [2]: 97-159

Wright S (1943) Isolation by Distance. Genetics 28 [2]: 114-138

Wright S (1950) Genetic structure of populations. Br Med J 2 [4669]: 36-

Y-Chromosome Consortium (2002) A nomenclature system for the tree of human Ychromosomal binary haplogroups. Genome Res 12 [2]: 339-348

Zegura SL, Karafet TM, Zhivotovsky LA, Hammer MF (2004) High-resolution SNPs and microsatellite haplotypes point to a single, recent entry of Native American Y chromosomes into the Americas. Mol Biol Evol 21 [1]: 164-175

Zsurka G, Kraytsberg Y, Kudina T, Kornblum C, Elger CE, Khrapko K, Kunz WS (2005) Recombination of mitochondrial DNA in skeletal muscle of individuals with multiple mitochondrial DNA heteroplasmy. Nat Genet 37 [8]: 873-877 


\section{Anhang}

\subsection{Abkürzungsverzeichnis}

\begin{tabular}{|c|c|}
\hline Abb. & Abbildung \\
\hline Abk. & Abkürzung \\
\hline aDNA & ancient DNA \\
\hline $\mathrm{bp}$ & Basenpaare \\
\hline bidest bidestillata, & zweifach destilliert \\
\hline bzw. & beziehungsweise \\
\hline${ }^{\circ} \mathrm{C}$ & Grad-Celsius \\
\hline ca. & Circa \\
\hline $\mathrm{cm}$ & Zentimeter \\
\hline CODIS & engl. Combined DNA Index system \\
\hline DNA & engl. deoxyribonucleic acid \\
\hline dATP & Desoxyadenintriphosphat \\
\hline $\mathrm{dCTP}$ & Desoxycytidintriphosphat \\
\hline d.h. & das heißt \\
\hline dGTP & Deoxyguanosintriphosphat \\
\hline dNTP & Desoxynucleotidtriphosphat \\
\hline dTTP & Desoxythymidintriphosphat \\
\hline eds. & engl. editor(s), Herausgeber \\
\hline EDTA & Ethylendiamintetraacetat \\
\hline engl. & englisch \\
\hline et al. & et alii, und Weitere \\
\hline event. & eventuell \\
\hline 6-FAM & 6-Carbofluorescein \\
\hline g & Gramm \\
\hline ggf. & gegebenenfalls \\
\hline h & Stunde(n) \\
\hline $\mathrm{H}$ & Haplotypen (im statistischen Gebrauch) \\
\hline Hd & Haplotypen-; Haplogruppen-Diversität \\
\hline HEX & 6-Carboxyl-2', $4^{\prime}, 7^{\prime}, 4,7-$ Hexachlorofluorescein $^{\prime}$ \\
\hline $\mathrm{HG}$ & Haplogruppe \\
\hline Hrsg. & Herausgeber \\
\hline $\mathrm{HT}$ & Haplotyp \\
\hline i.d.R. & in der Regel \\
\hline Jhd.(s) & Jahrhundert(s) \\
\hline JOE & 6-carboxy-4',5'-dichloro-2',7'-dimethoxy-fluorescein \\
\hline Kap. & Kapitel \\
\hline $\mathrm{Kb}$ & Kilobasenpaare \\
\hline 1 & Liter \\
\hline LC & Light Cycler \\
\hline LIP & engl. Late Intermediate Period, Späte Zwischenperiode \\
\hline M & Molar, mol/l \\
\hline $\mathrm{mA}$ & Milliampère, $10^{-3} \mathrm{~A}$ \\
\hline $\mathrm{MgCl} 2$ & Magnesiumchlorid \\
\hline $\mathrm{MH}$ & Mittlerer Horizont \\
\hline $\min$ & Minute(n) \\
\hline $\mathrm{ml}$ & Milliliter \\
\hline $\mathrm{mM}$ & millimolar, mmol/1 \\
\hline
\end{tabular}




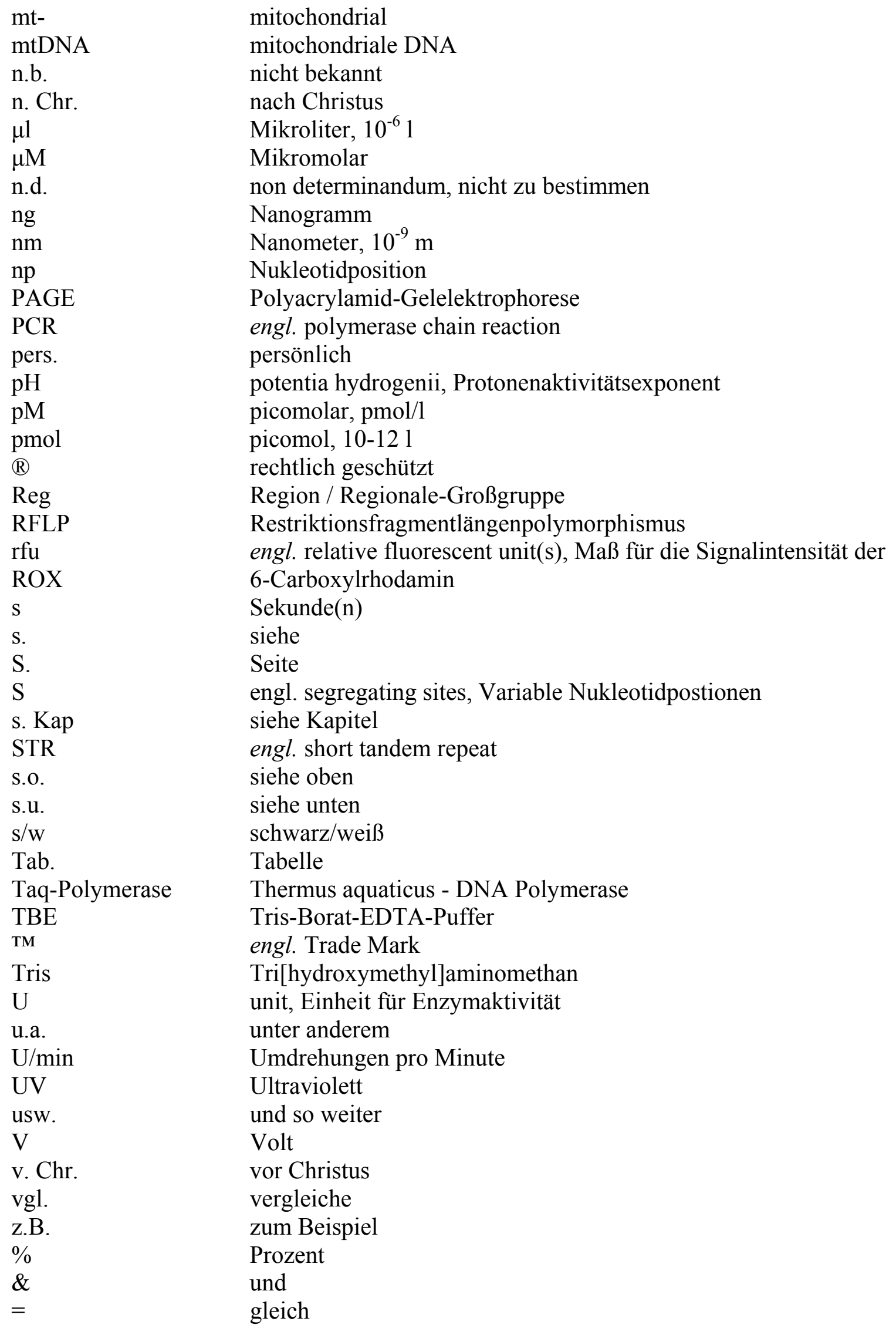




\subsection{Verwendete Geräte, Chemikalien, Hilfsmittel und Einwegmaterialien}

Geräte

Demineralisationsanlage Typ LAB-UPW, TKA Wasseraufbereitungsanlage GmbH

DNA-Extraktor Biorobot ${ }^{\circledR}$ EZ1, Qiagen

DNA-Sequenzer Modell 310, PE Applied Biosystems

DNA Thermal Cycler Typ TC1, Perkin Elmer Cetus

DNA Thermal Cycler Typ Mastercycler ${ }^{\circledR}$ gradient, Eppendorf

DNA Thermal Cycler Typ Mastercycler ${ }^{\circledR}$ personal, Eppendorf

Dremel ${ }^{\circledR}$ Multi ${ }^{\mathrm{TM}}$ Handbohrer 395 mit 3,2mm Hochgeschwindigkeitsfräser-Aufsatz

Elektrophoresekammern Horizon ${ }^{\mathrm{TM}} 1060$ BD 58 (5x8 cm), Gibco BRL

Elektrophoresekammern Horizon ${ }^{\mathrm{TM}} 1060$ BD 11-14 (11x14 cm), Gibco BRL

Glaskapillaren, 310Capillaries 47-cm x 50 um 5/pkg, PE Applied Biosystems

Kugelschwingmühle Typ MM 2, mit Zirkonium-Mahlbechern, Retsch

LightCycler 2.0 ${ }^{\mathrm{TM}}$ Real-Time PCR System, Roche

Magnetrührer Ikamag® RET, Ikamag® MTC. Ikamag ${ }^{\circledR}$ RH, Janke \& Kunkel Ika-Werk

Power Macintosh 7100/66, Apple Computer Inc.

Power Macintosh G3, Apple Computer Inc.

Präzisionswaage excellence Typ E 1200 S, Sartorius

Quadra 650, Apple Computer Inc.

Rotator LC-1, Steward

Stromversorgung Typ ST606 Electrophoresis Power Supply, Gibco BRL

Thermomixer Typ 5437, Eppendorf

Varipetten ${ }^{\circledR}$ Typ 4810, Satz: 0,5-10 $\mu 1,10-100 \mu 1,100-1000 \mu 1$, Eppendorf

Wasser-Destilliergerät Typ Muldestor, Wagner \& Munz

Zentrifuge Typ 5402, Eppendorf

Zentrifuge Typ 5415C, Eppendorf

Zentrifuge Typ 5415R, Eppendorf

Chemikalien und Kits

1Kb DNA-Leiter (Molekulargewichtsstandard); Life Technologies

310 10X Buffer with EDTA, PE Applied Biosystems

310 POP-6 ${ }^{\mathrm{TM}}$ Polymer, PE Applied Biosystems

ABI Prism ${ }^{\circledR}$ BigDye ${ }^{\circledR}$ Terminator v1.1 Cycle Sequencing Kit, PE Applied Biosystems

Acrylamid / Bisacrylamid 29:1, 40\% w/v, Rotiphorese ${ }^{\circledR}$, Roth

Agarose Roti®Agarose, Roth 
Albunin (BSA), molecular biology quality, Roche

Alconox (Detergenz), Aldrich

Ammoniumpersulfat 98+\% ACS grade, Aldrich

AmpliTaq-Gold ${ }^{\mathrm{TM}}$ DNA-Polymerase (5U/ $\left.\mu \mathrm{l}\right)$, Perkin Elmer Cetus

Ampuwa ${ }^{\circledR}$ (steriles Wasser), Fresenius

Aqua bidestillata, eigene Herstellung

Borsäure, p.a., Merck

Bromphenolblau, p.a., Serva

Chelex®100 Resin, BioRad

dATP,dCTP,dGTP,dTTP, Sigma

Dextran-Blau, Fluka

DNA Molecular Weight Marker V, Roche

EDTA (Ethylendinitrotetraacetat Dinatriumsalz-Dihydrat):Titriplex ${ }^{\circledR I I I, ~ M e r c k ~}$

Ethanol absolut, p.a., Abgabestelle der Bundesmonopolverwaltung: Zander-Göttingen,

Nordbrand-Nordhausen (Abfüllung Universitätsklinikumsapotheke Göttingen)

Ethidiumbromid, wässrige Lösung 1\% (w/v), $10 \mathrm{mg} / \mathrm{ml}$, Serva

EZ1 DNA Tissue Kit, Qiagen

Formamid, Fluka

GeneAmp® 10x PCR Buffer II \& MgCl2 Solution 25 mM, Perkin Elmer Cetus

Genescan-500 ${ }^{\mathrm{TM}}$ ROX-Kit (spurinterner Standard, loading buffer), PE Applied

Biosystems

Harnstoff, Rotiphorese ${ }^{\circledR}$, Roth

Internal Lane Standard 600 (spurinterner Standard, loading buffer), Promega

Isopropanol p.a.,. Merck

LiChrosolv ${ }^{\circledR}$, HPLC-Wasser zur Chromatographie, Merck

LightCycler ${ }^{\circledR}$ Multiplex DNA Master HybProbe, Roche

MinElute ${ }^{\mathrm{TM}}$ PCR Purification Kit, Qiagen

Mineralöl NUJOL, Perkin Elmer Cetus

NucleoSeq Kit Dye Terminator Removal, Macherey-Nagel

Qiagen ${ }^{\circledR}$ Multiplex PCR Kit, Qiagen

PowerPlexÒ Y System, Promega

Proteinase K (Qiagen)

TEMED (Tetramethylethylendiamin), Bio-Rad

Tris (Tri[hydroxymethyl]aminoethan), Trizma ${ }^{\mathrm{TM}}$ Base, p.a., Sigma 


\section{Längenstandards}

$1 \mathrm{~Kb}$ Leiter (Größen in bp)

75134154201220298344396506517101816362036

3054407250906108712681449162101801119812216

GS-500 ROX (Größen in bp)

355075100139150160200250300340350400

450490500

\section{Einwegmaterialien und Hilfsmittel}

Dental-Diamantsägeblätter Typ Diaflex-T H 350 220, Horico

Einmaluntersuchungshandschuhe Safeskin Satin Plus Powder-free, Kimberley-Clark ${ }^{\circledR}$

Eppendorf Reaktionsgefäße (0,5 ml) safe-lock, Eppendorf

Eppendorf Reaktionsgefäße (2,0 ml) safe-lock, Eppendorf

Gesichtsmasken: Surgine face mask, Johnson + Johnson

Kimwipes ${ }^{\circledR}$ Lite, Kinberley Clark ${ }^{\circledR}$

OP-Haube Astronautenform Surgine ${ }^{\circledR}$, Mölnlycke Health Care, Inc.

Parafilm ${ }^{\circledR}$ M, American National Clan ${ }^{\mathrm{TM}}$

PE-Zentrifugationsgefäße, Blue Max ${ }^{\mathrm{TM}} 50 \mathrm{ml}$ Conical Tubes 2070, Falcon ${ }^{\circledR}$

Pipettenspitzen: blaue Spitzen 1ml, Sarstedt

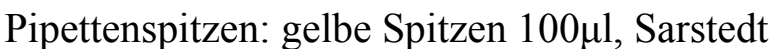

Pipettenspitzen: Standardtips 10 $\mu 1$, Eppendorf 


\subsection{Tabellen}

\subsubsection{Fundkataloge}

\begin{tabular}{|c|c|c|c|c|}
\hline \multicolumn{5}{|c|}{ Fundkatalog I: Pernil Alto (AO) } \\
\hline Individuum & Befundnr. & $\begin{array}{l}\text { Probenmaterial und } \\
\text { Unternummer }\end{array}$ & $\begin{array}{l}\text { Proben Nr. } \\
\text { (KAAK) }\end{array}$ & Datierung \\
\hline \multirow[t]{2}{*}{$\mathrm{AO} 1$} & \multirow[t]{2}{*}{2911} & A: Molar (1/7) & 392 & \multirow[t]{2}{*}{ Nasca (Nasca 4-6) } \\
\hline & & B: Metacarpus V links & 394 & \\
\hline $\mathrm{AO} 2$ & 3153 & Pars Petrosa & 870 & Nasca (Nasca 4-6) \\
\hline $\mathrm{AO} 3$ & 3155 & Metatarsus I rechts & 871 & Paracas (Ocucaje 3-4) \\
\hline $\mathrm{AO} 4$ & 3167 & Pars Petrosa & 872 & Archaikum (ca. 3800 v. Chr) \\
\hline \multirow[t]{2}{*}{ AO 5} & \multirow[t]{2}{*}{3108} & A: Prämolar (1/5) & 874 & \multirow[t]{2}{*}{ Nasca (Nasca 4-6) } \\
\hline & & B: Incisivus (2/1) & 875 & \\
\hline \multirow[t]{2}{*}{$\mathrm{AO} 6$} & \multirow[t]{2}{*}{3105} & A: Molar (Maxilla) & 876 & \multirow[t]{2}{*}{ Nasca (Nasca 4-6) } \\
\hline & & B: Metacarpus II rechts & 877 & \\
\hline $\mathrm{AO} 7$ & 3216 & Molar (4/6) & 878 & $? ? ?$ \\
\hline $\mathrm{AO} 8$ & 3226 & Molar (3/7) & 879 & Nasca (Nasca 4-6) \\
\hline AO 9 & 3226 & Molar (4/7) & 880 & Nasca (Nasca 4-6) \\
\hline \multirow[t]{2}{*}{ AO 10} & \multirow[t]{2}{*}{3141} & A: Molar 2/7 & 881 & \multirow[t]{2}{*}{ Paracas (Ocucaje 3-4) } \\
\hline & & B: Caninus $4 / 3$ & 882 & \\
\hline \multirow[t]{2}{*}{ AO 11} & \multirow[t]{2}{*}{3126} & A: Pars Petrosa & 883 & \multirow[t]{2}{*}{ Nasca (Nasca 4-6) } \\
\hline & & B: Molar (Mandibula) & 884 & \\
\hline $\mathrm{AO} 12$ & 3114 & Pars Petrosa & 885 & Nasca (Nasca 1-3) \\
\hline $\mathrm{AO} 13$ & 3110 & Molar (Mandibula) & 885 & Nasca (Nasca 4-6) \\
\hline AO 14 & 3228 & Molar (1/6) & 888 & Nasca (Nasca 1-3) \\
\hline \multirow[t]{2}{*}{ AO 15} & \multirow[t]{2}{*}{3227} & A: Caninus (1/3) & 890 & \multirow[t]{2}{*}{ Nasca (Nasca 4-6) } \\
\hline & & B: Incisivus (1/2) & 891 & \\
\hline AO 16 & 3148 & Molar (1/7) & 892 & Paracas (Ocucaje 3-4) \\
\hline AO 17 & 3148 & Molar (Maxilla) & 893 & Paracas (Ocucaje 3-4) \\
\hline
\end{tabular}




\begin{tabular}{|l|c|l|c|c|}
\hline Individuum & Befundnr. & $\begin{array}{c}\text { Probenmaterial und } \\
\text { Unternummer }\end{array}$ & $\begin{array}{c}\text { Proben Nr. } \\
\text { (KAAK) }\end{array}$ & \multicolumn{1}{c|}{ Datierung } \\
\hline \hline AO 18 & 3230 & Pars Petrosa & 895 & Nasca (Nasca 4-6) \\
\hdashline AO 19 & 3232 & Pars Petrosa & 896 & Paracas (Ocucaje 3-4) \\
\hdashline AO 20 & 3229 & Pars Petrosa & 897 & Nasca (Nasca 4-6) \\
\hdashline AO 21 & 3361 & Pars Petrosa & 898 & Nasca (Nasca 4-6) \\
\hline
\end{tabular}

Fundkatalog II: Mollake Chico (ME)

\begin{tabular}{|c|c|c|c|c|}
\hline Individuum & Befundnr. & $\begin{array}{l}\text { Probenmaterial und } \\
\text { Unternummer }\end{array}$ & $\begin{array}{l}\text { Proben Nr. } \\
\text { (KAAK) }\end{array}$ & Datierung \\
\hline ME 1 & 1802 & $\begin{array}{l}\text { A: Incisivus }(2 / 1) \\
\text { B: Metacarpus IV rechts }\end{array}$ & $\begin{array}{l}599 \\
600\end{array}$ & Paracas (Ocucaje 3-4) \\
\hline ME 2 & 1802 & Phalange & 595 & Paracas (Ocucaje 3-4) \\
\hline ME 3 & 1817 & $\begin{array}{l}\text { A: Molar }(3 / 8) \\
\text { B: Metacarpus V rechts }\end{array}$ & $\begin{array}{l}591 \\
592\end{array}$ & Nasca (Nasca 4-5) \\
\hline ME 4 & 1802 & Metacarpus & 596 & Paracas (Ocucaje 3-4) \\
\hline ME 5 & 1802 & Pars Petrosa links & 903 & Paracas (Ocucaje 3-4) \\
\hline ME 6 & 1802 & Pars Petrosa links & 904 & Paracas (Ocucaje 3-4) \\
\hline ME 7 & 1802 & Pars Petrosa links & 905 & Paracas (Ocucaje 3-4) \\
\hline ME 8 & 1802 & Pars Petrosa links & 906 & Paracas (Ocucaje 3-4) \\
\hline ME 9 & 1802 & Pars Petrosa links & 907 & Paracas (Ocucaje 3-4) \\
\hline ME 10 & 1802 & Pars Petrosa links & 908 & Paracas (Ocucaje 3-4) \\
\hline ME 11 & 1802 & Pars Petrosa links & 909 & Paracas (Ocucaje 3-4) \\
\hline ME 12 & 1816 & Pars Petrosa & 912 & Nasca (Nasca 4-5) \\
\hline ME 13 & 1817 & Pars Petrosa rechts & 910 & Nasca (Nasca 4-5) \\
\hline ME 14 & 1818 & Pars Petrosa links & 911 & Nasca (Nasca 4-5) \\
\hline
\end{tabular}




\begin{tabular}{|c|c|c|c|c|}
\hline \multicolumn{5}{|c|}{ Fundkatalog III: Jauranga (JA) } \\
\hline Individuum & Befundnr. & $\begin{array}{l}\text { Probenmaterial und } \\
\text { Unternummer }\end{array}$ & $\begin{array}{c}\text { Proben Nr. } \\
\text { (KAAK) }\end{array}$ & Datierung \\
\hline \multirow[t]{2}{*}{ JA 1} & \multirow[t]{2}{*}{1776} & A: Incisivus (2/2) & 466 & \multirow[t]{2}{*}{ Paracas (Ocucaje 8) } \\
\hline & & B: Metatarsus III links & 467 & \\
\hline JA 2 & 1906 & Metacarpus I & 489 & Paracas (Ocucaje 9) \\
\hline JA 3 & 1908 & Metatarsus I rechts & 487 & Paracas (Ocucaje 9) \\
\hline JA 4 & 1915 & Phalange & 471 & Paracas (Ocucaje 9) \\
\hline JA 5 & 1916 & Phalange & 470 & Paracas (Ocucaje 9) \\
\hline \multirow[t]{2}{*}{ JA 6} & \multirow{2}{*}{1919} & A: Molar (1/7) & 473 & \multirow[t]{2}{*}{ Nasca (Nasca 5) } \\
\hline & & B: Incisivus (2/2) & 474 & \\
\hline JA 7 & 1920 & Phalange & 468 & Paracas (Ocucaje 9) \\
\hline JA 8 & 1921 & Incisivus $(4 / 2)$ & 486 & Paracas \\
\hline JA 9 & 1927 & Phalange & 485 & Paracas (Ocucaje 9) \\
\hline JA 10 & 1945 & Phalange & 462 & Paracas (Ocucaje 8) \\
\hline \multirow[t]{2}{*}{ JA 11} & \multirow{2}{*}{1992} & A: Molar (Maxilla) & 492 & \multirow[t]{2}{*}{ Paracas (Ocucaje 8) } \\
\hline & & B: Metacarpus I & 493 & \\
\hline JA 12 & 2201 & Costa & 553 & Nasca \\
\hline JA 13 & 2207 & Tibia rechts (Inf I ) & 554 & Nasca \\
\hline JA 14 & 2208 & A: Molar (2/7) & 548 & n.d. \\
\hline JA 15 & 2210 & Costa & 551 & Nasca \\
\hline \multirow[t]{2}{*}{ JA 16} & \multirow{2}{*}{2211} & A: Molar $(1 / 8)$ & 569 & \multirow[t]{2}{*}{ Paracas (Ocucaje 9) } \\
\hline & & B: Caninus $(1 / 3)$ & 570 & \\
\hline JA 17 & 2215 & Praemolar $(3 / 5)$ & 567 & Nasca (Nasca 5) \\
\hline JA 18 & 2217 & Caninus $(3 / 3)$ & 565 & Paracas \\
\hline \multirow[t]{2}{*}{ JA 19} & \multirow{2}{*}{2218} & A: Praemolar (3/4) & 572 & \multirow[t]{2}{*}{ Paracas (Ocucaje 9) } \\
\hline & & B: Metatarsus V rechts & 573 & \\
\hline
\end{tabular}




\begin{tabular}{|c|c|c|c|c|}
\hline Individuum & Befundnr. & $\begin{array}{l}\text { Probenmaterial und } \\
\text { Unternummer }\end{array}$ & $\begin{array}{l}\text { Proben Nr. } \\
\text { (KAAK) }\end{array}$ & Datierung \\
\hline JA 20 & 2221 & $\begin{array}{l}\text { A: Molar (Maxilla) } \\
\text { B: Incisivus (1/1) }\end{array}$ & $\begin{array}{l}535 \\
536\end{array}$ & Nasca \\
\hline JA 21 & 2235 & Costa & 537 & Nasca \\
\hline JA 22 & 2239 & Metacarpus & 534 & Nasca (Nasca 5) \\
\hline JA 23 & 2244 & Metacarpus & 540 & Nasca (Nasca 5) \\
\hline JA 24 & 2245 & Costa & 543 & Nasca (Nasca 5) \\
\hline JA 25 & 2246 & $\begin{array}{l}\text { A: Molar }(7 / 5) \\
\text { B: Costa }\end{array}$ & $\begin{array}{l}541 \\
542\end{array}$ & Paracas (Ocucaje 9) \\
\hline JA 26 & 2253 & $\begin{array}{l}\text { A: Molar (1/6) } \\
\text { B: Metatarsus IV rechts }\end{array}$ & $\begin{array}{l}562 \\
563\end{array}$ & Nasca (Nasca 5) \\
\hline JA 27 & 2254 & $\begin{array}{l}\text { A: Caninus }(7 / 3) \\
\text { B: Incisivus }(6 / 2)\end{array}$ & $\begin{array}{l}547 \\
546\end{array}$ & Nasca (Nasca 5) \\
\hline JA 28 & 2255 & $\begin{array}{l}\text { A: Molar }(1 / 7) \\
\text { B: Metatarsus III }\end{array}$ & $\begin{array}{l}544 \\
545\end{array}$ & Nasca (Nasca 5) \\
\hline JA 29 & 2256 & $\begin{array}{l}\text { A: Incisivus (2/1) } \\
\text { B: Metacarpus }\end{array}$ & $\begin{array}{l}531 \\
532\end{array}$ & Paracas (Ocucaje 9) \\
\hline JA 30 & 2257 & Caninus (1/3) & 518 & Paracas (Ocucaje 9) \\
\hline JA 31 & 2258 & $\begin{array}{l}\text { A: Molar (4/8) } \\
\text { B: Molar (2/8) }\end{array}$ & $\begin{array}{l}576 \\
578\end{array}$ & Paracas \\
\hline JA 32 & 2261 & Metacarpus & 520 & Paracas (Ocucaje 9) \\
\hline JA 33 & 2263 & Phalange & 523 & Paracas (Ocucaje 9) \\
\hline JA 34 & 2264 & Costa & 524 & Nasca (Nasca 5) \\
\hline JA 35 & 2266 & Molar (1/7) & 507 & Nasca \\
\hline JA 36 & 2267 & Costa & 510 & Nasca (Nasca 5) \\
\hline JA 37 & 2278 & $\begin{array}{l}\text { A: Praemolar (3/5) } \\
\text { B: Incisivus (2/1) }\end{array}$ & $\begin{array}{l}555 \\
556\end{array}$ & Paracas (Ocucaje 9) \\
\hline
\end{tabular}




\begin{tabular}{|c|c|c|c|c|}
\hline Individuum & Befundnr. & $\begin{array}{l}\text { Probenmaterial und } \\
\text { Unternummer }\end{array}$ & $\begin{array}{l}\text { Proben Nr. } \\
\text { (KAAK) }\end{array}$ & Datierung \\
\hline JA 38 & 2278 & Metacarpus & 557 & Paracas (Ocucaje 9) \\
\hline JA 39 & 2288 & Diaphysenfragment & 579 & Paracas (Ocucaje 8) \\
\hline JA 40 & 2288 & Diaphysenfragment & 580 & Paracas (Ocucaje 8) \\
\hline JA 41 & 2288 & Metacarpus & 581 & Paracas (Ocucaje 8) \\
\hline JA 42 & 2288 & Metacarpus & 582 & Paracas (Ocucaje 8) \\
\hline JA 43 & 2289 & Caninus (4/3) & 561 & Paracas (Ocucaje 8) \\
\hline JA 44 & 2290 & Metacarpus II links & 525 & Paracas (Ocucaje 8) \\
\hline \multirow[t]{2}{*}{ JA 45} & \multirow[t]{2}{*}{2290} & A: Incisivus (1/1) & 527 & \multirow[t]{2}{*}{ Paracas (Ocucaje 8) } \\
\hline & & B: Metatarsus IV links & 528 & \\
\hline JA 46 & 2290 & Praemolar (2/4) & 529 & Paracas (Ocucaje 8) \\
\hline JA 47 & 2291 & Metacarpus III links & 494 & Paracas (Ocucaje 8) \\
\hline JA 48 & 2291 & Molar (3/7) & 497 & Paracas (Ocucaje 8) \\
\hline JA 49 & 2291 & Metacarpus V links & 495 & Paracas (Ocucaje 8) \\
\hline JA 50 & 2291 & Metacarpus III rechts & 498 & Paracas (Ocucaje 8) \\
\hline JA 51 & 2291 & Phalange & 511 & Paracas (Ocucaje 8) \\
\hline JA 52 & 2291 & Costa & 500 & Paracas (Ocucaje 8) \\
\hline JA 53 & 2291 & Diaphysenfragment & 499 & Paracas (Ocucaje 8) \\
\hline \multirow[t]{2}{*}{ JA 54} & \multirow[t]{2}{*}{2300} & A: Praemolar (4/4) & 513 & \multirow[t]{2}{*}{ Paracas (Ocucaje 8) } \\
\hline & & B: Metacarpus II rechts & 514 & \\
\hline JA 55 & 2305 & Costa & 517 & Nasca (Nasca 5) \\
\hline JA 56 & 2316 & Molar (2/6) & 515 & Nasca (Nasca 5) \\
\hline \multirow[t]{2}{*}{ JA 57} & \multirow[t]{2}{*}{2318} & A: Caninus (1/3) & 584 & \multirow[t]{2}{*}{ Nasca } \\
\hline & & B: Metatarsus IV links & 586 & \\
\hline JA 58 & 2337 & Molar (5/4) & 587 & Paracas (Ocucaje 8) \\
\hline JA 59 & 2339 & Molar (2/7) & 478 & Paracas (Ocucaje 7) \\
\hline JA 60 & 2342 & Molar (1/7) & 475 & Paracas (Ocucaje 7) \\
\hline
\end{tabular}




\begin{tabular}{|c|c|c|c|c|}
\hline Individuum & Befundnr. & $\begin{array}{l}\text { Probenmaterial und } \\
\text { Unternummer }\end{array}$ & $\begin{array}{l}\text { Proben Nr. } \\
\text { (KAAK) }\end{array}$ & Datierung \\
\hline JA 61 & 2346 & Caninus $(3 / 3)$ & 502 & Paracas (Ocucaje 6/7) \\
\hline JA 62 & 2351 & Tibia rechts (Inf. I) & 575 & Paracas \\
\hline JA 63 & 2354 & Molar (5/5) & 504 & Paracas (Ocucaje5/6) \\
\hline JA 64 & 2409 & Metacarpus I rechts? & 484 & Paracas (Ocucaje 8) \\
\hline JA 65 & 2419 & Metatarsus II links & 483 & Paracas (Ocucaje 8) \\
\hline JA 66 & 2428 & Molar (3/7) & 481 & Paracas (Ocucaje 8) \\
\hline JA 67 & 2715 & Metatarsus I rechts & 459 & Paracas (Ocucaje 9) \\
\hline JA 68 & 2722 & Metatarsus V links & 490 & Paracas (Ocucaje 8/9) \\
\hline JA 69 & 2744 & Incisivus $(5 / 2)$ & 765 & n.d. \\
\hline
\end{tabular}

\section{Fundkatalog IV: Los Molinos (MS)}

\begin{tabular}{|c|c|c|c|c|}
\hline Individuum & Befundnr. & $\begin{array}{l}\text { Probenmaterial und } \\
\text { Unternummer }\end{array}$ & $\begin{array}{l}\text { Proben Nr. } \\
\text { (KAAK) }\end{array}$ & Datierung \\
\hline MS 1 & 460 & $\begin{array}{l}\text { A: Molar (4/8) } \\
\text { B: Metatarsus links }\end{array}$ & $\begin{array}{l}442 \\
443\end{array}$ & Nasca \\
\hline MS 2 & 260 & $\begin{array}{l}\text { A: Caninus (1/3) } \\
\text { B: Metatarsus III links }\end{array}$ & $\begin{array}{l}452 \\
453\end{array}$ & Nasca \\
\hline MS 3 & 274 & Caninus $(3 / 3)$ & 448 & Nasca \\
\hline MS 4 & 910 & $\begin{array}{l}\text { A: Molar }(1 / 6) \\
\text { B: Metatarsus III rechts }\end{array}$ & $\begin{array}{l}654 \\
655\end{array}$ & Nasca (Nasca 5) \\
\hline MS 5 & 1063 & Metacarpus III links & 426 & Nasca \\
\hline MS 6 & 1135 & Molar (3/7) & 431 & Mittlerer Horizont (MH1) \\
\hline MS 8 & 1166 & Praemolar (1/4) & 422 & Nasca (Nasca 3) \\
\hline MS 9 & 1045 & Metacarpus IV links & 425 & Nasca \\
\hline MS 12 & 909 & Metacarpus IV rechts & 401 & Nasca (Nasca 5) \\
\hline MS 13 & 869 & $\begin{array}{l}\text { A: Incisivus (1/1) } \\
\text { B: Metacarpus II links }\end{array}$ & $\begin{array}{l}399 \\
400\end{array}$ & Nasca \\
\hline
\end{tabular}




\begin{tabular}{|c|c|c|c|c|}
\hline Individuum & Befundnr. & $\begin{array}{l}\text { Probenmaterial und } \\
\text { Unternummer }\end{array}$ & $\begin{array}{l}\text { Proben Nr. } \\
\text { (KAAK) }\end{array}$ & Datierung \\
\hline MS 15 & 910 & Molar (3/8) & 656 & Nasca (Nasca 5) \\
\hline MS 17 & 254 & Clavicula rechts & 458 & Nasca \\
\hline \multirow[t]{2}{*}{ MS 18} & \multirow[t]{2}{*}{265} & A: Caninus $(1 / 3)$ & 427 & \multirow[t]{2}{*}{ Nasca } \\
\hline & & B: Metacarpus III links & 428 & \\
\hline MS 19 & 462 & Phalange & 451 & Nasca \\
\hline MS 20 & 466 & Metatarsus II rechts & 450 & Nasca \\
\hline MS 21 & 470 & Molar (2/7) & 444 & Nasca \\
\hline MS 22 & 476 & Molar (2/6) & 429 & Nasca \\
\hline MS 23 & 476 & Molar (1/6) & 430 & Nasca \\
\hline MS 24 & 478 & Metacarpus III links & 449 & Nasca \\
\hline MS 25 & 1103 & Molar (4/6) & 454 & Nasca \\
\hline MS 26 & 1104 & Metatarsus I links & 441 & Nasca (Nasca 5) \\
\hline MS 27 & 1120 & Molar (3/8) & 439 & Nasca (Nasca 5) \\
\hline MS 28 & 1124 & A: Molar (8/5) & 420 & Nasca (Nasca 5) \\
\hline & & B: Metatarsus I rechts & 421 & \\
\hline MS 29 & 1132 & Radius rechts (Inf. I) & 436 & Mittlerer Horizont (MH1) \\
\hline MS 30 & 1133 & Praemolar (1/5) & 414 & Mittlerer Horizont (MH1) \\
\hline MS 31 & 1134 & Metatarsus III rechts & 434 & Mittlerer Horizont (MH1) \\
\hline MS 32 & 1135 & Metatarsus & 433 & Mittlerer Horizont (MH1) \\
\hline MS 33 & 1145 & Clavicula rechts & 438 & Nasca (Nasca 5) \\
\hline MS 34 & 1147 & Costa & 435 & Mittlerer Horizont (MH1) \\
\hline MS 35 & 1151 & Caninus $(3 / 4)$ & 419 & Mittlerer Horizont (MH1) \\
\hline MS 36 & 1151 & Molar (3/6) & 418 & Mittlerer Horizont (MH1) \\
\hline MS 37 & 1151 & Metacarpus III rechts & 417 & Mittlerer Horizont (MH1) \\
\hline MS 38 & 1151 & Costa & 416 & Mittlerer Horizont (MH1) \\
\hline MS 39 & 1158 & Metatarsus I rechts & 437 & Mittlerer Horizont (MH1) \\
\hline
\end{tabular}




\begin{tabular}{|l|c|l|c|l|}
\hline Individuum & Befundnr. & $\begin{array}{c}\text { Probenmaterial und } \\
\text { Unternummer }\end{array}$ & $\begin{array}{c}\text { Proben Nr. } \\
\text { (KAAK) }\end{array}$ & \multicolumn{1}{c|}{ Datierung } \\
\hline \hline MS 40 & 1163 & Molar (2/6) & 402 & Mittlerer Horizont (MH1) \\
\hline MS 41 & 1163 & Molar (1/7) & 404 & Mittlerer Horizont (MH1) \\
\hdashline MS 42 & 1163 & Molar (1/7) & 407 & Mittlerer Horizont (MH1) \\
\hline MS 43 & 1163 & Molar (3/8) & 409 & Mittlerer Horizont (MH1) \\
\hdashline MS 44 & 1164 & Molar (8/5) & 410 & Mittlerer Horizont (MH1) \\
\hline MS 45 & 1165 & Costa (Inf. I) & 457 & Nasca (Nasca 3) \\
\hdashline MS 46 & 1167 & Radius rechts (Inf. I) & 456 & Nasca (Nasca 3) \\
\hdashline MS 47 & 1177 & Ulna rechts (Inf. I) & 440 & Nasca (Nasca 3) \\
\hline
\end{tabular}

\begin{tabular}{|c|c|c|c|c|}
\hline \multicolumn{5}{|c|}{ Fundkatalog V: La Muña (MA) } \\
\hline Individuum & Befundnr. & $\begin{array}{l}\text { Probenmaterial und } \\
\text { Unternummer }\end{array}$ & $\begin{array}{l}\text { Proben Nr. } \\
\text { (KAAK) }\end{array}$ & Datierung \\
\hline MA 1 & 636 & Metacarous II links & 395 & Nasca (Nasca 5) \\
\hline MA 2 & 1275 & A: Metatarsus I links & 396 & Nasca (Nasca 5) \\
\hline & & B: Phalange & 397 & \\
\hline MA 3 & 1276 & Metacarpus II links & 398 & Nasca (Nasca 5) \\
\hline MA 4 & 636 & Diaphysenfragment & 900 & Nasca (Nasca 5) \\
\hline MA 5 & 1275 & Molar (2/5) & 899 & Nasca (Nasca 5) \\
\hline MA 6 & 1276 & Metacarpus II links & 901 & Nasca (Nasca 5) \\
\hline MA 7 & 1666 & Pars Petrosa & 902 & Nasca (Nasca 5) \\
\hline
\end{tabular}

\section{Fundkatalog VI: Hanaq Pacha (PA)}

\begin{tabular}{|l|c|l|c|l|}
\hline \multirow{2}{*}{ Individuum } & Befundnr. & $\begin{array}{c}\text { Probenmaterial und } \\
\text { Unternummer }\end{array}$ & $\begin{array}{c}\text { Proben Nr. } \\
\text { (KAAK) }\end{array}$ & \multicolumn{1}{c|}{ Datierung } \\
\hline \hline PA 1 & 2801 & Metacarpus & 639 & Nasca (Nasca 5) \\
\hdashline PA 2 & 2801 & A: Molar (3/6) & 640 & Nasca (Nasca 5) \\
& & B: Phalange & 641 & \\
\hline
\end{tabular}




\begin{tabular}{|c|c|c|c|c|}
\hline Individuum & Befundnr. & $\begin{array}{l}\text { Probenmaterial und } \\
\text { Unternummer }\end{array}$ & $\begin{array}{c}\text { Proben Nr. } \\
\text { (KAAK) }\end{array}$ & Datierung \\
\hline PA 3 & 2802 & $\begin{array}{l}\text { A: Incisivus }(2 / 1) \\
\text { B: Metatarsus IV rechts }\end{array}$ & $\begin{array}{l}637 \\
638\end{array}$ & Nasca (Nasca 5) \\
\hline PA 4 & 2803 & Incisivus $(2 / 1)$ & 635 & Nasca (Nasca 5) \\
\hline PA 5 & 2803 & Molar (1/7) & 631 & Nasca (Nasca 5) \\
\hline PA 6 & 2803 & Metatarsus III rechts & 630 & Nasca (Nasca 5) \\
\hline PA 7 & 2805 & Praemolar $(2 / 4)$ & 625 & Mittlerer Horizont (MH1) \\
\hline PA 8 & 2806 & Molar (1/8) & 627 & Mittlerer Horizont (MH1) \\
\hline PA 9 & 2807 & Molar (1/7) & 622 & Nasca (Nasca 5) \\
\hline PA 10 & 2808 & $\operatorname{Molar}(8 / 4)$ & 620 & Nasca (Nasca 5) \\
\hline PA 11 & 2809 & Molar (3/8) & 617 & Nasca (Nasca 5) \\
\hline PA 12 & 2813 & Metatarsus I links & 608 & Nasca (Nasca 5) \\
\hline PA 13 & 2815 & Molar (3/5) & 612 & Nasca (Nasca 5) \\
\hline PA 14 & 2816 & Molar (6/5) & 605 & Nasca (Nasca 5) \\
\hline PA 15 & 2820 & Metatarsus I links & 611 & Nasca (Nasca 5) \\
\hline PA 16 & 2821 & Molar (1/7) & 609 & Nasca (Nasca 5) \\
\hline PA 17 & 2823 & Metatarsus III links & 604 & Nasca (Nasca 5) \\
\hline PA 18 & 2825 & Phalange & 607 & Nasca (Nasca 5) \\
\hline PA 19 & 2829 & Costa & 603 & Nasca (Nasca 5) \\
\hline PA 20 & 2830 & Metatarsus V rechts & 601 & Nasca (Nasca 5) \\
\hline PA 21 & 2831 & $\begin{array}{l}\text { A: Molar }(2 / 7) \\
\text { B: Metacarpus }\end{array}$ & $\begin{array}{l}615 \\
616\end{array}$ & Nasca (Nasca 5) \\
\hline
\end{tabular}

\section{Fundkatalog: Monte Grande VII (GE)}

\begin{tabular}{|l|c|l|l|l|}
\hline Individuum & Befundnr. & $\begin{array}{c}\text { Probenmaterial und } \\
\text { Unternummer }\end{array}$ & $\begin{array}{c}\text { Proben Nr. } \\
\text { (KAAK) }\end{array}$ & \multicolumn{1}{c|}{ Datierung } \\
\hline \hline GE 1 & - & Molar (3/7) & 657 & Nasca \\
\hdashline GE 2 & - & Molar (4/8) & 658 & Nasca \\
\hline
\end{tabular}




\begin{tabular}{|c|c|c|c|c|}
\hline Individuum & Befundnr. & $\begin{array}{l}\text { Probenmaterial und } \\
\text { Unternummer }\end{array}$ & $\begin{array}{l}\text { Proben Nr. } \\
\text { (KAAK) }\end{array}$ & Datierung \\
\hline GE 3 & - & Molar (3/7) & 659 & Nasca \\
\hline GE 4 & - & Molar (1/8) & 660 & Nasca \\
\hline GE 5 & - & Molar (1/7) & 661 & Nasca \\
\hline GE 6 & - & Molar (2/7) & 662 & Nasca \\
\hline GE 7 & - & Molar (2/7) & 663 & Nasca \\
\hline GE 8 & - & Molar (3/7) & 664 & LIP \\
\hline GE 9 & - & Molar (1/7) & 665 & LIP \\
\hline GE 10 & - & Molar (1/6) & 666 & LIP \\
\hline GE 11 & - & Molar (2/6) & 667 & LIP \\
\hline GE 12 & - & Molar (2/6) & 668 & LIP \\
\hline GE 13 & - & Molar (3/7) & 669 & LIP \\
\hline GE 14 & - & Molar (1/6) & 670 & LIP \\
\hline GE 15 & - & Molar (2/7) & 671 & LIP \\
\hline GE 16 & - & Molar (1/8) & 672 & Nasca \\
\hline
\end{tabular}

\begin{tabular}{|c|c|c|c|c|}
\hline \multicolumn{5}{|c|}{ Fundkatalog VIII: Paracas Caverna VI (PC) } \\
\hline Individuum & Befundnr. & $\begin{array}{l}\text { Probenmaterial und } \\
\text { Unternummer }\end{array}$ & $\begin{array}{l}\text { Proben Nr. } \\
\text { (KAAK) }\end{array}$ & Datierung \\
\hline PC 1 & Mumie 266 & Clavicula links (Inf. I) & 792 & Paracas (Ocucaje 7-8) \\
\hline \multirow[t]{2}{*}{ PC 2} & Mumie 267 & A: Molar (3/7) & 796 & Paracas (Ocucaje 7-8) \\
\hline & & B: Metacarpus III links & 797 & \\
\hline \multirow[t]{2}{*}{ PC 3} & Mumie 268 & A: Molar (4/7) & 798 & Paracas (Ocucaje 7-8) \\
\hline & & B: Metacarpus II links & 799 & \\
\hline PC 4 & Mumie 273 & Caninus $(4 / 3)$ & 789 & Paracas (Ocucaje 7-8) \\
\hline PC 5 & Mumie 274 & Molar (1/7) & 793 & Paracas (Ocucaje 7-8) \\
\hline PC 6 & Mumie 275 & Molar (2/7) & 790 & Paracas (Ocucaje 7-8) \\
\hline
\end{tabular}




\begin{tabular}{|l|l|l|c|c|}
\hline Individuum & Befundnr. & $\begin{array}{c}\text { Probenmaterial und } \\
\text { Unternummer }\end{array}$ & $\begin{array}{c}\text { Proben Nr. } \\
\text { (KAAK) }\end{array}$ & \multicolumn{1}{c|}{ Datierung } \\
\hline \hline PC 7 & Mumie 276 & A: Praemolar (2/4) & 800 & Paracas (Ocucaje 7-8) \\
& & B: Metatarsus I rechts & 801 & \\
\hdashline PC 8 & Mumie 277 & Praemolar (2/5) & 787 & Paracas (Ocucaje 7-8) \\
\hdashline PC 9 & Mumie 278 & Molar (1/7) & 788 & Paracas (Ocucaje 7-8) \\
\hdashline PC 10 & Mumie 162 & Molar (2/7) & 794 & Paracas (Ocucaje 7-8) \\
\hdashline PC 11 & Schädel 7 & Molar (1/7) & 795 & Paracas (Ocucaje 7-8) \\
\hdashline PC 12 & - & Molar (3/6) & 802 & Paracas (Ocucaje 7-8) \\
\hline
\end{tabular}

Fundkatalog IX: Pacapaccari (EA)

\begin{tabular}{|c|c|c|c|c|}
\hline Individuum & Befundnr. & $\begin{array}{l}\text { Probenmaterial und } \\
\text { Unternummer }\end{array}$ & $\begin{array}{l}\text { Proben Nr. } \\
\text { (KAAK) }\end{array}$ & Datierung \\
\hline EA 1 & Chullpa 1 & Molar (3/7) & 744 & Mittlerer Horizont - LIP \\
\hline EA 2 & Chullpa 1 & Molar (4/7) & 745 & Mittlerer Horizont - LIP \\
\hline EA 3 & Chullpa 1 & Molar (4/7) & 1091 & Mittlerer Horizont - LIP \\
\hline EA 4 & Chullpa 1 & Molar (3/6) & 1092 & Mittlerer Horizont - LIP \\
\hline EA 5 & Chullpa 1 & Molar (3/7) & 1093 & Mittlerer Horizont - LIP \\
\hline EA 6 & Chullpa 1 & Molar (3/7) & 1094 & Mittlerer Horizont - LIP \\
\hline EA 7 & Chullpa 1 & Molar (4/6) & 1095 & Mittlerer Horizont - LIP \\
\hline EA 8 & Chullpa 1 & Molar (3/7) & 1096 & Mittlerer Horizont - LIP \\
\hline EA 9 & Chullpa 1 & Molar (3/7) & 1097 & Mittlerer Horizont - LIP \\
\hline EA 10 & Chullpa 2 & Molar (4/7) & 1098 & Mittlerer Horizont - LIP \\
\hline EA 11 & Chullpa 2 & Molar (3/6) & 1099 & Mittlerer Horizont - LIP \\
\hline EA 12 & Chullpa 2 & Molar (3/6) & 1100 & Mittlerer Horizont - LIP \\
\hline EA 13 & Chullpa 2 & Molar (4/7) & 1101 & Mittlerer Horizont - LIP \\
\hline EA 14 & Chullpa 2 & Molar (3/6) & 1102 & Mittlerer Horizont - LIP \\
\hline EA 15 & Chullpa 2 & Pars Petrosa & 1103 & Mittlerer Horizont - LIP \\
\hline Ea 16 & Chullpa 2 & Pars Petrosa & 1104 & Mittlerer Horizont - LIP \\
\hline
\end{tabular}




\subsubsection{Haplogruppen-Typisierungsergebnisse}

Tab. 39: Typisierungsergebnisse der untersuchten Individuen aus der HybProbe-Multiplex Analyse für die Polymorphismen der codierenden-Region des mitochondrialen Genoms (Kap. 4.2.4).

\begin{tabular}{|c|c|c|c|c|c|c|c|}
\hline Ind. & Kulturgruppe & Phase & mt_663 & $\begin{array}{c}\text { 9_bp_- } \\
\text { Deletion }\end{array}$ & $\begin{array}{c}\mathrm{mt}_{-} \\
132 \overline{6} 3\end{array}$ & mt_ & HG \\
\hline $\mathrm{AO} 2$ & Nasca & Nasca 4-7 & A & Nein & A & A & $\mathrm{D}$ \\
\hline $\mathrm{AO} 3$ & Paracas & Ocucaje 3-4 & A & Nein & A & A & D \\
\hline $\mathrm{AO} 4$ & Praekeramisch & Archaikum & G & Nein & A & $\mathrm{C}$ & A \\
\hline AO 5 & Nasca & Nasca 4-7 & A & Nein & A & A & $\mathrm{D}$ \\
\hline $\mathrm{AO} 6$ & Nasca & Nasca 4-7 & A & Nein & A & A & $\mathrm{D}$ \\
\hline $\mathrm{AO} 8$ & Nasca & - & A & Nein & A & A & $\mathrm{D}$ \\
\hline AO 10 & Paracas & Ocucaje 3-4 & A & Nein & A & A & $\mathrm{D}$ \\
\hline AO 12 & Nasca & Nasca 2-3 & A & Nein & A & A & $\mathrm{D}$ \\
\hline AO 13 & Nasca & Nasca 2-3 & A & Nein & A & A & $\mathrm{D}$ \\
\hline AO 14 & Nasca & Nasca 1-3 & A & Nein & A & A & $\mathrm{D}$ \\
\hline Ao 15 & Nasca & Nasca 4-7 & A & Nein & A & A & $\mathrm{D}$ \\
\hline AO 18 & Paracas & Ocucaje 3-4 & A & Nein & A & A & $\mathrm{D}$ \\
\hline AO 19 & Paracas & Ocucaje 3-4 & A & Nein & A & $\mathrm{A}$ & $\mathrm{D}$ \\
\hline AO 20 & Nasca & Nasca 4-7 & A & Nein & A & A & D \\
\hline AO 21 & Nasca & Nasca 4-7 & A & $\mathrm{Ja}$ & A & $\mathrm{C}$ & B \\
\hline EA 1 & Hochland & MH/LIP & A & $\mathrm{Ja}$ & A & $\mathrm{C}$ & B \\
\hline EA 2 & Hochland & MH/LIP & A & $\mathrm{Ja}$ & G & $\mathrm{C}$ & B \\
\hline EA 3 & Hochland & MH/LIP & A & $\mathrm{Ja}$ & A & $\mathrm{C}$ & B \\
\hline EA 4 & Hochland & MH/LIP & A & $\mathrm{Ja}$ & A & $\mathrm{C}$ & B \\
\hline EA 5 & Hochland & MH/LIP & A & $\mathrm{Ja}$ & A & $\mathrm{C}$ & B \\
\hline EA 6 & Hochland & MH/LIP & A & Nein & G & $\mathrm{C}$ & $\mathrm{C}$ \\
\hline EA 7 & Hochland & MH/LIP & A & $\mathrm{Ja}$ & A & $\mathrm{C}$ & B \\
\hline EA 8 & Hochland & MH/LIP & A & $\mathrm{Ja}$ & A & $\mathrm{C}$ & B \\
\hline EA 9 & Hochland & MH/LIP & A & Nein & G & $\mathrm{C}$ & $\mathrm{C}$ \\
\hline EA 10 & Hochland & MH/LIP & A & $\mathrm{Ja}$ & A & $\mathrm{C}$ & B \\
\hline EA 11 & Hochland & MH/LIP & A & Nein & G & $\mathrm{C}$ & $\mathrm{C}$ \\
\hline EA 12 & Hochland & MH/LIP & A & Nein & G & $\mathrm{C}$ & $\mathrm{C}$ \\
\hline EA 13 & Hochland & MH/LIP & A & Nein & G & $\mathrm{C}$ & $\mathrm{C}$ \\
\hline EA 14 & Hochland & MH/LIP & A & $\mathrm{Ja}$ & A & $\mathrm{C}$ & B \\
\hline EA 15 & Hochland & MH/LIP & A & $\mathrm{Ja}$ & A & $\mathrm{C}$ & B \\
\hline EA 16 & Hochland & MH/LIP & A & $\mathrm{Ja}$ & A & $\mathrm{C}$ & B \\
\hline Ja 3 & Paracas & Ocucaje 9 & A & Nein & A & A & D \\
\hline Ja 5 & Paracas & Ocucaje 9 & $\mathrm{G}$ & Nein & A & $\mathrm{C}$ & A \\
\hline Ja 6 & Nasca & Nasca 5 & $\mathrm{G}$ & Nein & A & $\mathrm{C}$ & A \\
\hline Ja 7 & Paracas & Ocucaje 9 & A & Nein & A & A & D \\
\hline Ja 12 & Nasca & - & A & $\mathrm{Ja}$ & A & $\mathrm{C}$ & B \\
\hline Ja 13 & Nasca & - & A & Nein & A & A & $\mathrm{D}$ \\
\hline Ja 14 & - & - & A & Nein & A & A & D \\
\hline Ja 19 & Paracas & Ocucaje 9 & A & Nein & A & A & D \\
\hline Ja 21 & Nasca & - & A & Nein & A & A & D \\
\hline Ja 22 & Nasca & - & A & Nein & A & A & $\mathrm{D}$ \\
\hline Ja 23 & Nasca & Nasca 5 & A & Nein & A & A & D \\
\hline Ja 25 & Paracas & Ocucaje 9 & A & Nein & A & A & D \\
\hline Ja 26 & Nasca & Nasca 5 & A & $\mathrm{Ja}$ & A & $\mathrm{C}$ & B \\
\hline Ja 29 & Paracas & Ocucaje 9 & $\mathrm{~A}$ & Nein & A & A & $\mathrm{D}$ \\
\hline
\end{tabular}




\begin{tabular}{|c|c|c|c|c|c|c|c|}
\hline Ind. & Kulturgruppe & Phase & mt_663 & $\begin{array}{c}\text { 9_bp_- } \\
\text { Deletion }\end{array}$ & ${ }_{13263}$ & $\begin{array}{l}\text { mt } \\
5178 \\
\end{array}$ & HG \\
\hline Ja 34 & Nasca & Nasca 5 & $\mathrm{~A}$ & Nein & A & $\mathrm{A}$ & $\mathrm{D}$ \\
\hline Ja 35 & Nasca & - & A & Nein & A & A & D \\
\hline Ja 36 & Nasca & Nasca 5 & A & Nein & G & $\mathrm{C}$ & $\mathrm{C}$ \\
\hline Ja 38 & Paracas & Ocucaje 9 & A & Nein & G & $\mathrm{C}$ & $\mathrm{C}$ \\
\hline Ja 42 & Paracas & Ocucaje 8 & G & Nein & A & $\mathrm{C}$ & A \\
\hline Ja 44 & Paracas & Ocucaje 8 & A & Nein & A & A & D \\
\hline Ja 45 & Paracas & Ocucaje 8 & A & Nein & A & A & D \\
\hline Ja 46 & Paracas & Ocucaje 8 & A & Nein & A & A & D \\
\hline Ja 48 & Paracas & Ocucaje 8 & A & Nein & A & A & D \\
\hline Ja 49 & Paracas & Ocucaje 8 & A & Nein & A & A & $\mathrm{D}$ \\
\hline Ja 50 & Paracas & Ocucaje 8 & A & Nein & A & A & D \\
\hline Ja 51 & Paracas & Ocucaje 8 & A & Nein & G & $\mathrm{C}$ & $\mathrm{C}$ \\
\hline Ja 53 & Paracas & Ocucaje 8 & A & Nein & A & A & $\mathrm{D}$ \\
\hline Ja 54 & Paracas & Ocucaje 8 & A & Nein & A & A & D \\
\hline Ja 55 & Nasca & Nasca 5 & A & Nein & A & A & D \\
\hline Ja 56 & Nasca & Nasca 5 & A & Nein & G & $\mathrm{C}$ & $\mathrm{C}$ \\
\hline Ja 58 & Paracas & Ocucaje 8 & A & Nein & G & $\mathrm{C}$ & $\mathrm{C}$ \\
\hline Ja 61 & Paracas & Ocucaje 6/7 & A & Nein & A & A & $\mathrm{D}$ \\
\hline Ja 64 & Paracas & Ocucaje 8 & A & Nein & A & A & D \\
\hline Ja 65 & Paracas & Ocucaje 8 & A & Nein & A & A & $\mathrm{D}$ \\
\hline MA 1 & Nasca & Nasca 5 & A & Nein & G & $\mathrm{C}$ & $\mathrm{C}$ \\
\hline MA 2 & Nasca & Nasca 5 & A & Nein & A & A & D \\
\hline MA 3 & Nasca & Nasca 5 & A & Nein & A & A & $\mathrm{D}$ \\
\hline MA 5 & Nasca & Nasca 5 & A & Nein & G & $\mathrm{C}$ & $\mathrm{C}$ \\
\hline MA 6 & Nasca & Nasca 5 & A & $\mathrm{Ja}$ & A & $\mathrm{C}$ & B \\
\hline ME 1 & Paracas & Ocucaje 3-4 & A & Nein & A & A & D \\
\hline ME 2 & Paracas & Ocucaje 3-4 & A & Nein & G & $\mathrm{C}$ & $\mathrm{C}$ \\
\hline ME 3 & Nasca & Nasca 4-5 & A & Nein & A & A & D \\
\hline ME 9 & Paracas & Ocucaje 3-4 & A & Nein & A & A & $\mathrm{D}$ \\
\hline ME 13 & Nasca & Nasca 4-5 & A & Nein & A & A & $\mathrm{D}$ \\
\hline MS 1 & Nasca & - & A & Nein & G & $\mathrm{C}$ & $\mathrm{C}$ \\
\hline MS 2 & Nasca & - & A & Nein & A & A & $\mathrm{D}$ \\
\hline MS 3 & Nasca & - & A & Nein & G & $\mathrm{C}$ & $\mathrm{C}$ \\
\hline MS 4 & Nasca & Nasca 5 & A & Nein & G & $\mathrm{C}$ & $\mathrm{C}$ \\
\hline MS 5 & Nasca & - & A & Nein & A & A & $\mathrm{D}$ \\
\hline MS 6 & Huari / Local & HM 1 & A & Nein & G & $\mathrm{C}$ & $\mathrm{C}$ \\
\hline MS 8 & Nasca & Nasca 3 & A & Nein & G & $\mathrm{C}$ & $\mathrm{C}$ \\
\hline MS 9 & Nasca & - & A & Nein & G & $\mathrm{C}$ & $\mathrm{C}$ \\
\hline MS 12 & Nasca & Nasca 5 & A & Nein & G & $\mathrm{C}$ & $\mathrm{C}$ \\
\hline MS 13 & Nasca & - & A & Nein & A & A & $\mathrm{D}$ \\
\hline MS 14 & Nasca & Nasca 5 & A & Nein & G & $\mathrm{C}$ & $\mathrm{C}$ \\
\hline MS 15 & Nasca & Nasca 5 & A & Nein & A & A & D \\
\hline MS 18 & Nasca & - & A & Nein & A & A & $\mathrm{D}$ \\
\hline MS 19 & Nasca & - & A & Nein & G & $\mathrm{C}$ & $\mathrm{C}$ \\
\hline MS 20 & Nasca & - & A & Nein & G & $\mathrm{C}$ & $\mathrm{C}$ \\
\hline MS 21 & Nasca & - & A & $\mathrm{Ja}$ & A & $\mathrm{C}$ & B \\
\hline MS 23 & - & - & A & Nein & G & $\mathrm{C}$ & $\mathrm{C}$ \\
\hline MS 23 & Nasca & - & A & Nein & G & $\mathrm{C}$ & $\mathrm{C}$ \\
\hline MS 24 & Nasca & - & A & $\mathrm{Ja}$ & A & $\mathrm{C}$ & B \\
\hline
\end{tabular}




\begin{tabular}{|c|c|c|c|c|c|c|c|}
\hline Ind. & Kulturgruppe & Phase & mt_663 & $\begin{array}{c}\text { 9_bp_- } \\
\text { Deletion }\end{array}$ & $\begin{array}{c}\mathrm{mt}_{-} \\
13263 \\
\end{array}$ & $\begin{array}{l}\text { mt } \\
5178 \\
\end{array}$ & HG \\
\hline MS 25 & Nasca & - & $\mathrm{A}$ & Nein & A & A & $\mathrm{D}$ \\
\hline MS 26 & Nasca & Nasca 5 & A & Nein & A & A & $\mathrm{D}$ \\
\hline MS 27 & Nasca & Nasca 5 & A & Nein & A & A & D \\
\hline MS 30 & Huari / Local & HM 1 & A & Nein & G & $\mathrm{C}$ & $\mathrm{C}$ \\
\hline MS 33 & Nasca & Nasca 5 & A & $\mathrm{Ja}$ & A & $\mathrm{C}$ & B \\
\hline MS 34 & Huari / Local & HM 1 & A & Nein & G & $\mathrm{C}$ & $\mathrm{C}$ \\
\hline MS 35 & Huari / Local & HM 1 & A & Nein & A & A & $\mathrm{D}$ \\
\hline MS 36 & Huari / Local & HM 1 & A & Nein & A & A & $\mathrm{D}$ \\
\hline MS 37 & Huari / Local & HM 1 & A & Nein & G & $\mathrm{C}$ & $\mathrm{C}$ \\
\hline MS 38 & Huari / Local & HM 1 & A & Nein & A & A & $\mathrm{D}$ \\
\hline MS 39 & Huari / Local & HM 1 & A & $\mathrm{Ja}$ & A & $\mathrm{C}$ & B \\
\hline MS 41 & Huari / Local & HM 1 & A & $\mathrm{Ja}$ & A & $\mathrm{C}$ & B \\
\hline MS 44 & Huari / Local & HM 1 & A & Nein & A & A & $\mathrm{D}$ \\
\hline MS 45 & Nasca & Nasca 3 & A & Nein & A & A & D \\
\hline MS 46 & Nasca & Nasca 3 & A & $\mathrm{Ja}$ & A & $\mathrm{C}$ & B \\
\hline PA 1 & Nasca & Nasca 5 & A & Nein & A & A & $\mathrm{D}$ \\
\hline PA 2 & Nasca & Nasca 5 & A & Nein & G & $\mathrm{C}$ & $\mathrm{C}$ \\
\hline PA 7 & Huari / Local & HM 1 & A & $\mathrm{Ja}$ & A & $\mathrm{C}$ & B \\
\hline PA 10 & Nasca & Nasca 5 & A & $\mathrm{Ja}$ & A & $\mathrm{C}$ & B \\
\hline PA 11 & Nasca & Nasca 5 & A & Nein & A & A & $\mathrm{D}$ \\
\hline PA 12 & Nasca & Nasca 5 & A & Nein & G & $\mathrm{C}$ & $\mathrm{C}$ \\
\hline PA 15 & Nasca & Nasca 5 & A & Nein & G & $\mathrm{C}$ & $\mathrm{C}$ \\
\hline PA 16 & Nasca & Nasca 5 & A & Nein & A & A & $\mathrm{D}$ \\
\hline PA 17 & Nasca & Nasca 5 & A & Nein & A & A & $\mathrm{D}$ \\
\hline PA 18 & Nasca & Nasca 5 & A & Nein & G & $\mathrm{C}$ & $\mathrm{C}$ \\
\hline PA 19 & Nasca & Nasca 5 & A & Nein & G & $\mathrm{C}$ & $\mathrm{C}$ \\
\hline PA 20 & Nasca & Nasca 5 & A & Nein & G & $\mathrm{C}$ & $\mathrm{C}$ \\
\hline PA 21 & Nasca & Nasca 5 & A & Nein & A & A & $\mathrm{D}$ \\
\hline PC 1 & Paracas & - & A & Nein & A & A & D \\
\hline PC 2 & Paracas & - & A & Nein & G & $\mathrm{C}$ & $\mathrm{C}$ \\
\hline PC 3 & Paracas & - & A & Nein & A & A & $\mathrm{D}$ \\
\hline PC 4 & Paracas & - & A & Nein & A & A & $\mathrm{D}$ \\
\hline PC 5 & Paracas & - & A & Nein & A & A & $\mathrm{D}$ \\
\hline PC 6 & Paracas & - & A & Nein & A & A & $\mathrm{D}$ \\
\hline PC 8 & Paracas & - & A & Nein & A & A & $\mathrm{D}$ \\
\hline PC 10 & Paracas & - & A & Nein & A & A & $\mathrm{D}$ \\
\hline PC 11 & Paracas & - & A & Nein & $\mathrm{G}$ & $\mathrm{C}$ & $\mathrm{C}$ \\
\hline PC 12 & Paracas & - & A & Nein & $\mathrm{G}$ & $\mathrm{C}$ & $\mathrm{C}$ \\
\hline
\end{tabular}

\subsubsection{Haplotypen-Typisierungsergebnisse}

Tab. 40: Auf den nächsten drei Seiten finden sich die mt-Haplotypen der einzelnen untersuchten Individuen. Die angegebenen Basen sind Abweichungen von der rCRS. Die Nummerierung der Nukleotidpositionen erfolgt nach der rCRS.

Legende: HG= Haplogruppe; HT= Haplotyp; . = Nukleotidposition entspricht der rCRS 


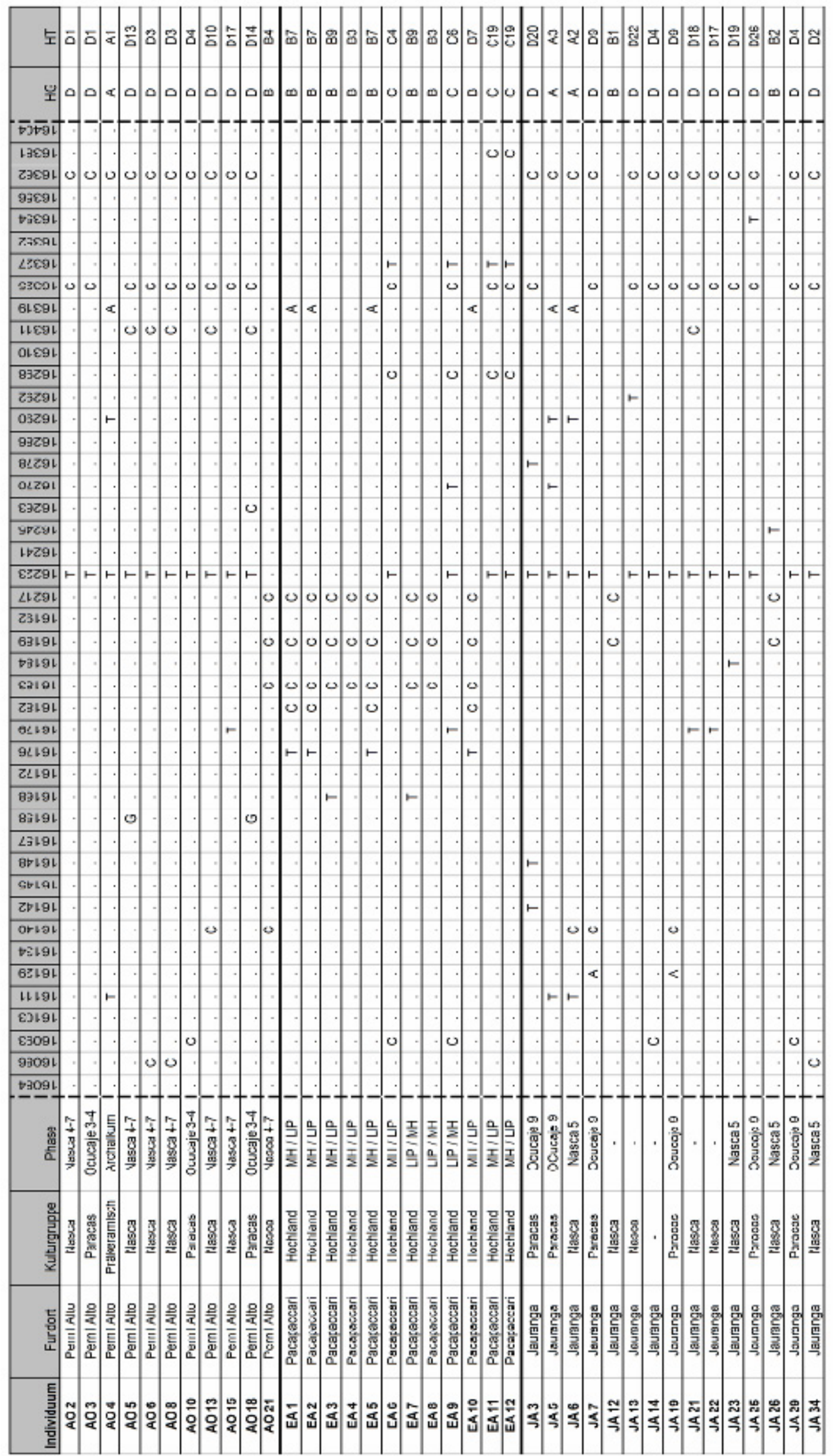




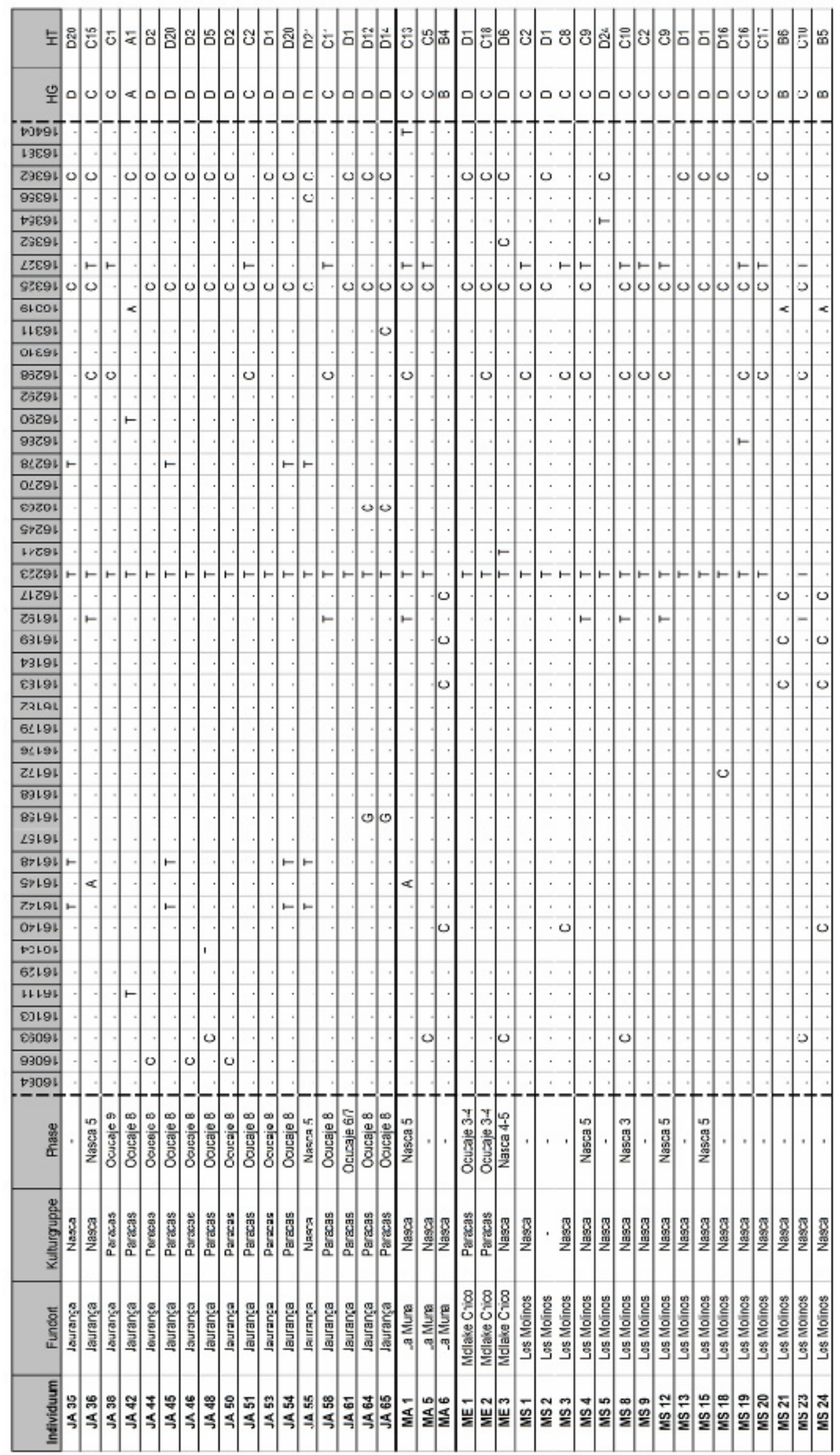




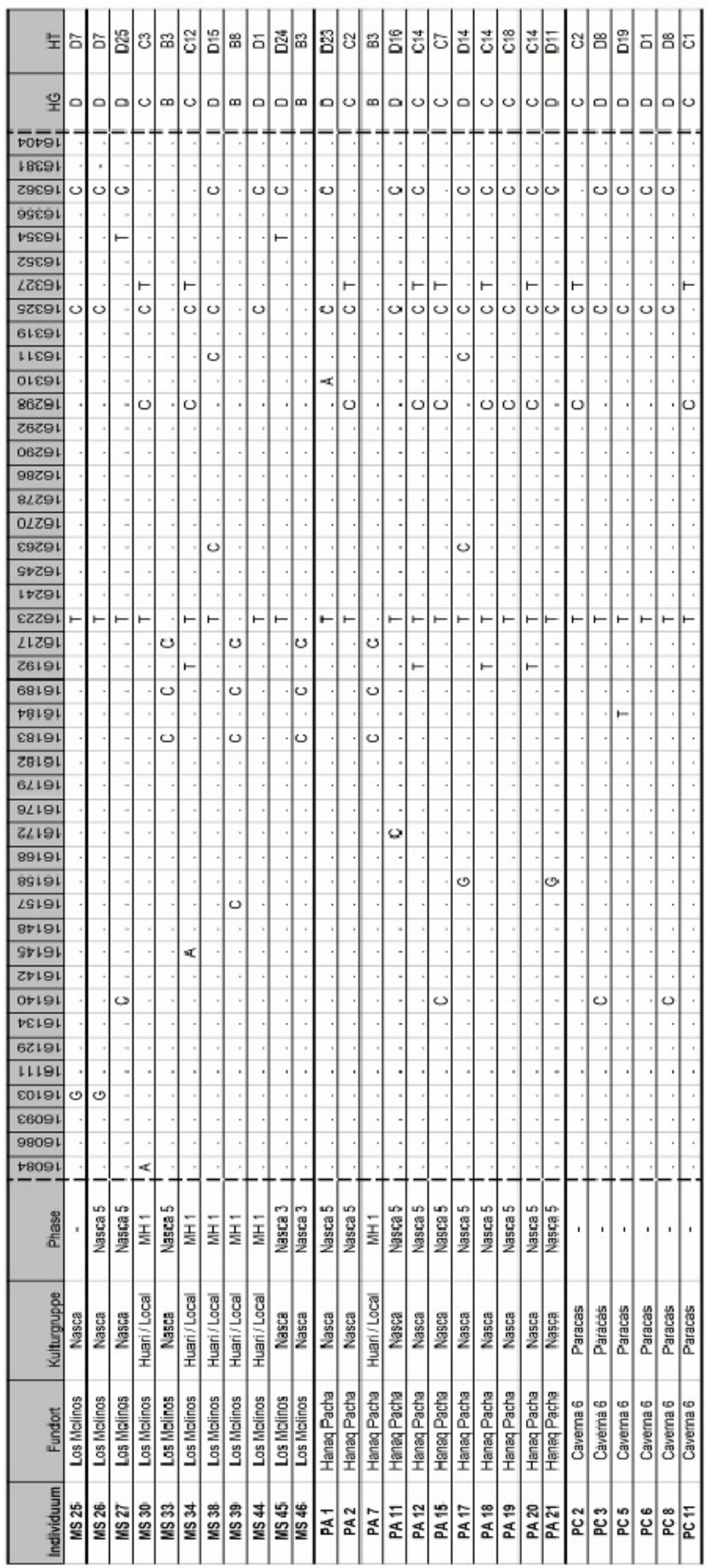




\subsection{Einzeltypisierungsergebnisse}

\subsubsection{Einzeltypisierungsergebnisse der autosomalen STRs}

Tab. 41: Einzeltypisierungsergebnisse der autosomalen STRs.

Legend: $0=$ unsicheres Allel; - = Allel konnte nicht bestimmt werden

\begin{tabular}{|c|c|c|c|c|c|c|c|c|c|}
\hline \multicolumn{10}{|c|}{ EA 1} \\
\hline Extrakt & PCR & D13S377 & CSF1PO & FGA & Amelo & VWA & D5S878 & D3S1418 & D21S71 \\
\hline 18 & 66 & 9 & - & - & $\mathrm{Y}$ & - & 12 & 17 & 35 \\
\hline 38 & Okta2 & 9 & - & - & $\mathrm{X} / \mathrm{Y}$ & 17 & - & 17 & - \\
\hline 38 & Okta4 & $8 / 9$ & - & 20 & $\mathrm{X}$ & 16 & - & - & - \\
\hline \multicolumn{2}{|c|}{ Genotyp } & $(8) / 9$ & - & - & $\mathrm{X} / \mathrm{Y}$ & - & - & 17 & - \\
\hline \multicolumn{10}{|c|}{ EA 2} \\
\hline Extrakt & PCR & D13S377 & CSF1PO & FGA & Amelo & VWA & D5S878 & D3S1418 & D21S71 \\
\hline 18 & 66 & 9 & - & - & $\mathrm{X} / \mathrm{Y}$ & 16 & - & - & 35 \\
\hline 38 & Okta2 & - & 10 & - & $\mathrm{X} / \mathrm{Y}$ & $16 / 20$ & - & - & - \\
\hline 38 & Okta4 & 11 & 12 & - & $\mathrm{Y}$ & 16 & - & - & - \\
\hline \multicolumn{2}{|c|}{ Genotyp } & - & - & - & $\mathrm{X} / \mathrm{Y}$ & 16 & - & - & - \\
\hline \multicolumn{10}{|c|}{ EA 4} \\
\hline Extrakt & PCR & D13S377 & CSF1PO & FGA & Amelo & VWA & D5S878 & D3S1418 & D21S71 \\
\hline 18 & 66 & 10 & - & - & $\mathrm{X} / \mathrm{Y}$ & $16 / 17$ & - & - & - \\
\hline 38 & Okta2 & - & - & 18 & $\mathrm{Y}$ & 17 & - & 15 & - \\
\hline 38 & Okta4 & 10 & - & - & $\mathrm{X} / \mathrm{Y}$ & 16 & - & - & - \\
\hline \multicolumn{2}{|c|}{ Genotyp } & 10 & - & - & $\mathrm{X} / \mathrm{Y}$ & $16 / 17$ & - & - & - \\
\hline \multicolumn{10}{|c|}{ EA 10} \\
\hline Extrakt & PCR & D13S377 & CSF1PO & FGA & Amelo & VWA & D5S878 & \begin{tabular}{|l|l|} 
D3S1418 \\
\end{tabular} & D21S71 \\
\hline 18 & 66 & 9 & - & - & $\mathrm{X} / \mathrm{Y}$ & - & - & 16 & - \\
\hline 38 & Okta2 & $9 / 12$ & 10 & 23 & $\mathrm{X} / \mathrm{Y}$ & $(12)$ & 11 & 16 & 30 \\
\hline 38 & Okta4 & - & - & 23 & $\mathrm{X}$ & 16 & - & 16 & - \\
\hline \multicolumn{2}{|c|}{ Genotyp } & 9 & - & - & $\mathrm{X} / \mathrm{Y}$ & - & - & 16 & - \\
\hline \multicolumn{10}{|c|}{ EA 12} \\
\hline Extrakt & PCR & D13S377 & CSF1PO & FGA & Amelo & VWA & D5S878 & D3S1418 & D21S71 \\
\hline 18 & 66 & $8 / 11$ & 11 & 18 & $\mathrm{X}$ & - & 11 & - & - \\
\hline 38 & Okta2 & 11 & 11 & - & $\mathrm{X}$ & - & - & 15 & - \\
\hline 38 & Okta4 & $8 / 11$ & 14 & - & $X$ & 17 & - & - & - \\
\hline \multicolumn{2}{|c|}{ Genotyp } & $8 / 11$ & $11 /(14)$ & - & $X$ & - & - & - & - \\
\hline \multicolumn{10}{|c|}{ JA 65} \\
\hline Extrakt & PCR & D13S377 & CSF1PO & FGA & Amelo & VWA & D5S878 & D3S1418 & D21S71 \\
\hline 13 & 66 & 9 & - & - & $\mathrm{X}$ & 16 & - & - & - \\
\hline ptb1 & $\mathrm{XX}$ & 10 & - & 23 & $\mathrm{X}$ & $16 / 19$ & $9 / 11$ & $14 / 15$ & 30 \\
\hline ptb1 & duis-1 & - & - & $23 / 25$ & $X$ & - & 11 & $14 / 15$ & 31.2 \\
\hline 38 & 17.08 .07 & $9 / 10$ & 11 & $23 / 25$ & $X$ & - & 11 & 14 & - \\
\hline \multicolumn{2}{|c|}{ Genotyp } & $9 / 10$ & - & $23 / 25$ & $\mathrm{X}$ & - & 11 & $14 / 15$ & - \\
\hline
\end{tabular}




\subsubsection{Einzeltypisierungsergebnisse der Y-HybProbe-Multiplex}

Tab. 42: Einzeltypisierungsergebnisse der Y-HybProbe-Multiplex zur Bestimmung der Y-chromosomalen Haplogruppen.

Legende: n.d. $=$ nicht determiniert

\begin{tabular}{|c|c|c|c|c|c|c|c|}
\hline Individuum & Extrakt & PCR & M3 & M45 & M130 & M242 & Haplogruppe \\
\hline \multirow[t]{2}{*}{ EA 1} & 33 & Y1 & $\mathrm{T}$ & $\mathrm{A}$ & $\mathrm{C}$ & $\mathrm{T}$ & \\
\hline & 37 & Y2 & $\mathrm{T}$ & n.d. & $\mathrm{C}$ & $\mathrm{T}$ & \\
\hline \multicolumn{3}{|c|}{ Genotyp } & $\mathrm{T}$ & A & $\mathrm{C}$ & $\mathrm{T}$ & Q3 \\
\hline \multirow[t]{2}{*}{ EA 2} & 33 & Y1 & $\mathrm{T}$ & A & $\mathrm{C}$ & $\mathrm{T}$ & \\
\hline & 37 & $\mathrm{Y} 2$ & $\mathrm{~T}$ & $\mathrm{~A}$ & $\mathrm{C}$ & $\mathrm{T}$ & \\
\hline \multicolumn{3}{|c|}{ Genotyp } & $\mathrm{T}$ & A & $\mathrm{C}$ & $\mathrm{T}$ & Q3 \\
\hline \multirow[t]{2}{*}{ EA 4} & 33 & Y1 & $\mathrm{T}$ & A & $\mathrm{C}$ & $\mathrm{T}$ & \\
\hline & 37 & Y2 & n.d. & A & $\mathrm{C}$ & $\mathrm{T}$ & \\
\hline \multicolumn{3}{|c|}{ Genotyp } & $\mathrm{T}$ & A & $\mathrm{C}$ & $\mathrm{T}$ & Q3 \\
\hline \multirow[t]{2}{*}{ EA 10} & 33 & Y1 & $\mathrm{T}$ & A & $\mathrm{C}$ & $\mathrm{T}$ & \\
\hline & 37 & $\mathrm{Y} 2$ & $\mathrm{~T}$ & A & n.d. & n.d. & \\
\hline \multicolumn{3}{|c|}{ Genotyp } & $\mathrm{T}$ & A & $\mathrm{C}$ & $\mathrm{T}$ & Q3 \\
\hline
\end{tabular}




\subsubsection{Einzeltypisierungsergebnisse der HybProbe-Multiplex für die mt-Haplogruppen}

Tab. 43: Einzeltypisierungsergebnisse der HybProbe-Multiplex Anaylsen zur bestimmung der Mitochondrialen Haplogruppen. Es wird für jedes System die realisierte Base genannt.

Legende: n.d. $=$ Position konnte nicht bestimmt werden; $\mathbf{x} / \mathbf{x}=$ uneindeutiges Typisierungsergebniss; Ind.= Individuum; HG= Haplogruppe

\begin{tabular}{|c|c|c|c|c|c|c|c|}
\hline Ind. & PCR & Extrakt & $\mathrm{mt}_{-}$ & $\begin{array}{c}\text { 9_bp } \\
\text { Deletion }\end{array}$ & $\mathrm{mt}_{-\overline{6}}$ & $\mathrm{mt}_{5178}$ & HG \\
\hline \multirow[t]{2}{*}{$\mathrm{AO} 2$} & HaploMult 1 & 33 & $\mathrm{~A}$ & Nein & $\mathrm{A}$ & $\mathrm{A}$ & $\mathrm{D}$ \\
\hline & HaploMult 5 & 37 & A & Nein & A & A & \\
\hline \multirow[t]{2}{*}{$\mathrm{AO} 3$} & HaploMult 1 & 33 & A & Nein & A & A & $\mathrm{D}$ \\
\hline & HaploMult 5 & 37 & $\mathrm{~A}$ & Nein & $\mathrm{A}$ & $\mathrm{A}$ & \\
\hline \multirow[t]{2}{*}{$\mathrm{AO} 4$} & HaploMult 1 & 37 & G & Nein & A & $\mathrm{C}$ & A \\
\hline & HaploMult 5 & 33 & $\mathrm{G}$ & Nein & A & $\mathrm{C}$ & \\
\hline \multirow[t]{2}{*}{$\mathrm{AO} 5$} & HaploMult 1 & 33 & A & Nein & $\mathrm{A}$ & A & $\mathrm{D}$ \\
\hline & HaploMult 5 & 37 & $\mathrm{~A}$ & Nein & n.d. & $\mathrm{A}$ & \\
\hline \multirow[t]{2}{*}{$\mathrm{AO} 6$} & HaploMult 1 & 33 & A & Nein & $\mathrm{A}$ & A & $\mathrm{D}$ \\
\hline & HaploMult 5 & 37 & n.d. & Nein & $\mathrm{A}$ & $\mathrm{A}$ & \\
\hline \multirow[t]{2}{*}{$\mathrm{AO} 8$} & HaploMult 1 & 33 & $\mathrm{~A}$ & Nein & A & A & $\mathrm{D}$ \\
\hline & HaploMult 5 & 37 & A & Nein & A & A & \\
\hline \multirow[t]{2}{*}{$\mathrm{AO} 10$} & HaploMult 1 & 33 & A & Nein & A & $\mathrm{A}$ & $\mathrm{D}$ \\
\hline & HaploMult 5 & 37 & A & Nein & $\mathrm{A}$ & n.d. & \\
\hline \multirow[t]{2}{*}{ AO 12} & HaploMult 1 & 33 & A & Nein & A & $\mathrm{A}$ & $\mathrm{D}$ \\
\hline & HaploMult 5 & 37 & $\mathrm{~A}$ & Nein & A & A & \\
\hline \multirow[t]{2}{*}{$\mathrm{AO} 13$} & HaploMult 1 & 33 & A & Nein & A & A & $\mathrm{D}$ \\
\hline & HaploMult 5 & 37 & A & n.d. & A & A & \\
\hline \multirow[t]{2}{*}{ AO 14} & HaploMult 1 & 37 & A & Nein & A & A & $\mathrm{D}$ \\
\hline & HaploMult 5 & 33 & A & Nein & A & A & \\
\hline \multirow[t]{2}{*}{ AO 15} & HaploMult 1 & 33 & A & Nein & A & A & $\mathrm{D}$ \\
\hline & HaploMult 5 & 37 & A & Nein & n.d. & n.d. & \\
\hline \multirow[t]{2}{*}{ AO 18} & HaploMult 1 & 33 & A & Nein & $\mathrm{A}$ & $\mathrm{A}$ & $\mathrm{D}$ \\
\hline & HaploMult 5 & 37 & A & Nein & A & A & \\
\hline \multirow[t]{2}{*}{ AO 19} & HaploMult 1 & 33 & $\mathrm{~A}$ & Nein & $\mathrm{A}$ & $\mathrm{A}$ & $\mathrm{D}$ \\
\hline & HaploMult 5 & 37 & $\mathrm{~A}$ & Nein & A & A & \\
\hline \multirow[t]{2}{*}{ AO 20} & HaploMult 1 & 37 & A & Nein & A & A & $\mathrm{D}$ \\
\hline & HaploMult 5 & 33 & A & Nein & A & A & \\
\hline \multirow[t]{2}{*}{ AO 21} & HaploMult 1 & 33 & A & $\mathrm{Ja}$ & A & $\mathrm{C}$ & B \\
\hline & HaploMult 5 & 37 & A & $\mathrm{Ja}$ & A & $\mathrm{C}$ & \\
\hline \multirow[t]{2}{*}{ EA 1} & HaploMult 2 & 17 & A & $\mathrm{Ja}$ & A & $\mathrm{C}$ & B \\
\hline & HaploMult 4 & 22 & A & $\mathrm{Ja}$ & A & $\mathrm{C}$ & \\
\hline \multirow[t]{2}{*}{ EA 2} & HaploMult 2 & 17 & A & JA & G & $\mathrm{C}$ & B \\
\hline & HaploMult 4 & 22 & A & $\mathrm{Ja}$ & $\mathrm{G}$ & $\mathrm{C}$ & \\
\hline \multirow[t]{2}{*}{ EA 3} & HaploMult 2 & 33 & A & $\mathrm{Ja}$ & A & $\mathrm{C}$ & B \\
\hline & HaploMult 4 & 37 & A & $\mathrm{Ja}$ & A & $\mathrm{C}$ & \\
\hline \multirow[t]{2}{*}{ EA 4} & HaploMult 2 & 33 & A & $\mathrm{Ja}$ & A & $\mathrm{C}$ & B \\
\hline & HaploMult 4 & 37 & A & $\mathrm{Ja}$ & A & $\mathrm{C}$ & \\
\hline \multirow[t]{2}{*}{ EA 5} & HaploMult 2 & 33 & A & $\mathrm{Ja}$ & A & $\mathrm{C}$ & B \\
\hline & HaploMult 4 & 37 & $\mathrm{~A}$ & $\mathrm{Ja}$ & $\mathrm{A}$ & $\mathrm{C}$ & \\
\hline
\end{tabular}




\begin{tabular}{|c|c|c|c|c|c|c|c|}
\hline Ind. & PCR & Extrakt & ${ }_{663}$ & $\begin{array}{c}\text { 9_bp } \\
\text { Deletion }\end{array}$ & $\mathrm{mt}_{132 \overline{6}}$ & $\mathrm{mt}_{5178}$ & HG \\
\hline \multirow[t]{2}{*}{ EA 6} & HaploMult 2 & 33 & A & Nein & G & $\mathrm{C}$ & $\mathrm{C}$ \\
\hline & HaploMult 4 & 37 & A & Nein & $\mathrm{G}$ & $\mathrm{C}$ & \\
\hline \multirow[t]{2}{*}{ EA 7} & HaploMult 2 & 33 & A & $\mathrm{Ja}$ & $\mathrm{A}$ & $\mathrm{C}$ & B \\
\hline & HaploMult 4 & 37 & A & $\mathrm{Ja}$ & A & $\mathrm{C}$ & \\
\hline \multirow[t]{2}{*}{ EA 8} & HaploMult 2 & 33 & A & $\mathrm{Ja}$ & A & $\mathrm{C}$ & $\mathrm{B}$ \\
\hline & HaploMult 4 & 37 & $\mathrm{~A}$ & $\mathrm{Ja}$ & A & $\mathrm{C}$ & \\
\hline \multirow[t]{2}{*}{ EA 9} & HaploMult 2 & 33 & A & Nein & G & $\mathrm{C}$ & $\mathrm{C}$ \\
\hline & HaploMult 4 & 37 & A & Nein & $\mathrm{G}$ & $\mathrm{C}$ & \\
\hline \multirow[t]{2}{*}{ EA 10} & HaploMult 2 & 33 & $\mathrm{~A}$ & $\mathrm{Ja}$ & $\mathrm{A}$ & $\mathrm{C}$ & $\mathrm{B}$ \\
\hline & HaploMult 4 & 37 & $\mathrm{~A}$ & $\mathrm{Ja}$ & A & $\mathrm{C}$ & \\
\hline \multirow[t]{2}{*}{ EA 11} & HaploMult 2 & 33 & $\mathrm{~A}$ & Nein & $\mathrm{G}$ & $\mathrm{C}$ & $\mathrm{C}$ \\
\hline & HaploMult 4 & 37 & A & Nein & G & $\mathrm{C}$ & \\
\hline \multirow[t]{2}{*}{ EA 12} & HaploMult 2 & 33 & A & Nein & G & $\mathrm{C}$ & $\mathrm{C}$ \\
\hline & HaploMult 4 & 37 & $\mathrm{~A}$ & n.d. & $\mathrm{G}$ & $\mathrm{C}$ & \\
\hline \multirow[t]{2}{*}{ EA 13} & HaploMult 2 & 33 & A & Nein & G & $\mathrm{C}$ & $\mathrm{C}$ \\
\hline & HaploMult 4 & 37 & $\mathrm{~A}$ & Nein & $\mathrm{G}$ & $\mathrm{C}$ & \\
\hline \multirow[t]{2}{*}{ EA 14} & HaploMult 2 & 33 & $\mathrm{~A}$ & Nein / Ja & $\mathrm{A}$ & $\mathrm{C}$ & $\mathrm{B}$ \\
\hline & HaploMult 4 & 37 & $\mathrm{~A}$ & $\mathrm{Ja}$ & A & $\mathrm{C}$ & \\
\hline \multirow[t]{2}{*}{ EA 15} & HaploMult 2 & 33 & $\mathrm{~A}$ & Nein / Ja & A & $\mathrm{C} / \mathrm{A}$ & B \\
\hline & HaploMult 4 & 37 & $\mathrm{~A}$ & $\mathrm{Ja}$ & $\mathrm{A}$ & $\mathrm{C}$ & \\
\hline \multirow[t]{2}{*}{ EA 16} & HaploMult 2 & 33 & $\mathrm{~A}$ & $\mathrm{Ja}$ & $\mathrm{A}$ & $\mathrm{C}$ & B \\
\hline & HaploMult 4 & 37 & $\mathrm{~A}$ & $\mathrm{Ja}$ & $\mathrm{A}$ & $\mathrm{C}$ & \\
\hline \multirow[t]{2}{*}{ JA 3} & HaploMult 3 & 22 & $\mathrm{~A}$ & Nein & A & A & $\mathrm{D}$ \\
\hline & HaploMult 8 & 27 & $\mathrm{~A}$ & Nein & $\mathrm{A}$ & $\mathrm{A}$ & \\
\hline \multirow[t]{2}{*}{ JA 5} & HaploMult 3 & 27 & $\mathrm{G}$ & Nein & $\mathrm{A}$ & $\mathrm{C}$ & A \\
\hline & HaploMult 6 & 30 & $\mathrm{G}$ & n.d. & A & $\mathrm{C}$ & \\
\hline \multirow[t]{2}{*}{ JA 6} & HaploMult 4 & PTB 2 & $\mathrm{G}$ & Nein & $\mathrm{A}$ & $\mathrm{C}$ & A \\
\hline & HaploMult 6 & 27 & $\mathrm{G}$ & Nein & n.d. & $\mathrm{C}$ & \\
\hline \multirow[t]{2}{*}{ JA 7} & HaploMult 3 & 22 & $\mathrm{~A}$ & Nein & $\mathrm{A}$ & $\mathrm{A}$ & $\mathrm{D}$ \\
\hline & HaploMult 8 & 35 & $\mathrm{~A}$ & Nein & $\mathrm{A}$ & $\mathrm{A}$ & \\
\hline \multirow[t]{2}{*}{ JA 12} & HaploMult 3 & 22 & A & $\mathrm{Ja}$ & A & $\mathrm{C}$ & B \\
\hline & HaploMult 8 & 35 & $\mathrm{~A}$ & $\mathrm{Ja}$ & $\mathrm{A}$ & n.d. & \\
\hline \multirow[t]{2}{*}{ JA 13} & HaploMult 3 & 18 & $\mathrm{~A}$ & Nein & $\mathrm{A}$ & $\mathrm{A}$ & $\mathrm{D}$ \\
\hline & HaploMult 8 & 25 & $\mathrm{~A}$ & Nein & A & A & \\
\hline \multirow[t]{2}{*}{ JA 14} & HaploMult 3 & 27 & A & Nein & A & A & $\mathrm{D}$ \\
\hline & HaploMult 8 & 35 & $\mathrm{~A}$ & Nein & $\mathrm{A} / \mathrm{G}$ & $\mathrm{A}$ & \\
\hline \multirow[t]{2}{*}{ JA 19} & HaploMult 3 & 27 & $\mathrm{~A}$ & Nein & $\mathrm{A}$ & $\mathrm{A}$ & $\mathrm{D}$ \\
\hline & HaploMult 8 & 36 & $\mathrm{~A}$ & Nein & $\mathrm{A}$ & $\mathrm{A}$ & \\
\hline \multirow[t]{2}{*}{ JA 21} & HaploMult 3 & 18 & A & Nein & A & A & $\mathrm{D}$ \\
\hline & HaploMult 8 & 27 & $\mathrm{~A}$ & Nein & $\mathrm{A}$ & $\mathrm{A}$ & \\
\hline \multirow[t]{2}{*}{ JA 22} & HaploMult 3 & 18 & $\mathrm{~A}$ & Nein & $\mathrm{A}$ & $\mathrm{A}$ & $\mathrm{D}$ \\
\hline & HaploMult 8 & 20 & $\mathrm{~A}$ & Nein & A & A & \\
\hline JA 23 & HaploMult 7 & 18 & A & Nein & A & A & $\mathrm{D}$ \\
\hline & HaploMult 10 & 27 & $\mathrm{~A}$ & Nein & $\mathrm{A}$ & $\mathrm{A}$ & \\
\hline JA 25 & HaploMult 3 & 22 & $\mathrm{~A}$ & Nein & $\mathrm{A}$ & $\mathrm{A}$ & $\mathrm{D}$ \\
\hline & HaploMult 10 & 35 & $\mathrm{~A}$ & Nein & $\mathrm{A}$ & $\mathrm{A}$ & \\
\hline JA 26 & HaploMult 3 & 27 & $\mathrm{~A}$ & $\mathrm{Ja}$ & A & $\mathrm{C}$ & $\mathrm{B}$ \\
\hline & HaploMult 7 & 34 & n.d. & $\mathrm{Ja}$ & A & n.d. & \\
\hline
\end{tabular}




\begin{tabular}{|c|c|c|c|c|c|c|c|}
\hline Ind. & PCR & Extrakt & ${ }_{663}$ & $\begin{array}{c}\text { 9_bp } \\
\text { Deletion }\end{array}$ & ${ }_{132 \overline{6}}$ & $\mathrm{mt}_{5178}$ & HG \\
\hline \multirow[t]{2}{*}{ JA 29} & HaploMult 10 & 18 & $\mathrm{~A}$ & Nein & $\mathrm{A}$ & $\mathrm{A}$ & $\mathrm{D}$ \\
\hline & HaploMult 3 & 35 & $\mathrm{~A}$ & Nein & A & A & \\
\hline \multirow[t]{2}{*}{ JA 34} & HaploMult 7 & 28 & $\mathrm{~A}$ & Nein & $\mathrm{A}$ & $\mathrm{A}$ & $\mathrm{D}$ \\
\hline & HaploMult 10 & 35 & A & Nein & A & A & \\
\hline \multirow[t]{2}{*}{ JA 35} & HaploMult 7 & 18 & A & Nein & A & A & $\mathrm{D}$ \\
\hline & HaploMult 10 & 34 & $\mathrm{~A}$ & Nein & $\mathrm{A}$ & $\mathrm{A}$ & \\
\hline \multirow[t]{2}{*}{ JA 36} & HaploMult 3 & 18 & $\mathrm{~A}$ & Nein & $\mathrm{G}$ & $\mathrm{C}$ & $\mathrm{C}$ \\
\hline & HaploMult 8 & 27 & n.d. & Nein & $\mathrm{G}$ & $\mathrm{C}$ & \\
\hline \multirow[t]{2}{*}{ JA 38} & HaploMult 3 & 11 & $\mathrm{~A}$ & Nein & $\mathrm{G}$ & $\mathrm{C}$ & $\mathrm{C}$ \\
\hline & HaploMult 8 & 34 & $\mathrm{~A}$ & Nein & $\mathrm{G}$ & $\mathrm{C}$ & \\
\hline \multirow[t]{2}{*}{ JA 42} & HaploMult 3 & 23 & $\mathrm{G}$ & Nein & $\mathrm{A}$ & $\mathrm{C}$ & A \\
\hline & HaploMult 8 & 34 & $\mathrm{G}$ & Nein & $\mathrm{A}$ & $\mathrm{C}$ & \\
\hline \multirow[t]{2}{*}{ JA 44} & HaploMult 3 & 27 & A & Nein & n.d. & A & $\mathrm{D}$ \\
\hline & HaploMult 8 & 34 & $\mathrm{~A}$ & Nein & $\mathrm{A}$ & A & \\
\hline \multirow[t]{2}{*}{ JA 45} & HaploMult 3 & 27 & $\mathrm{~A}$ & Nein & $\mathrm{A}$ & $\mathrm{A}$ & $\mathrm{D}$ \\
\hline & HaploMult 8 & 34 & $\mathrm{~A}$ & Nein & $\mathrm{A}$ & A & \\
\hline \multirow[t]{2}{*}{ JA 46} & HaploMult 9 & PTB 3 & $\mathrm{~A}$ & Nein & $\mathrm{A}$ & $\mathrm{A}$ & $\mathrm{D}$ \\
\hline & HaploMult 11 & 35 & n.d. & n.d. & $\mathrm{A}$ & A & \\
\hline \multirow[t]{2}{*}{ JA 48} & HaploMult 9 & 18 & $\mathrm{~A}$ & Nein & $\mathrm{A}$ & $\mathrm{A}$ & $\mathrm{D}$ \\
\hline & HaploMult 11 & 35 & A & Nein & A & A & \\
\hline \multirow[t]{2}{*}{ JA 49} & HaploMult 9 & 23 & A & Nein & A & A & $\mathrm{D}$ \\
\hline & HaploMult 11 & 30 & $\mathrm{~A}$ & Nein & n.d. & $\mathrm{A}$ & \\
\hline \multirow[t]{2}{*}{ JA 50} & HaploMult 9 & 28 & $\mathrm{~A}$ & Nein & $\mathrm{A}$ & $\mathrm{A}$ & $\mathrm{D}$ \\
\hline & HaploMult 11 & 33 & A & Nein & $\mathrm{A}$ & A & \\
\hline \multirow[t]{2}{*}{ JA 51} & HaploMult 9 & 28 & $\mathrm{~A}$ & Nein & $\mathrm{G}$ & $\mathrm{C}$ & $\mathrm{C}$ \\
\hline & HaploMult 13 & 33 & n.d. & Nein & $\mathrm{G}$ & $\mathrm{C}$ & \\
\hline \multirow[t]{2}{*}{ JA 53} & HaploMult 3 & 28 & $\mathrm{~A}$ & NEin & $\mathrm{A}$ & $\mathrm{A}$ & $\mathrm{D}$ \\
\hline & HaploMult 7 & 33 & A & n.d. & $\mathrm{A}$ & A & \\
\hline \multirow[t]{2}{*}{ JA 54} & HaploMult 9 & 28 & A & Nein & A & A & $\mathrm{D}$ \\
\hline & HaploMult 12 & 33 & $\mathrm{~A}$ & Nein & $\mathrm{A}$ & $\mathrm{A}$ & \\
\hline \multirow[t]{2}{*}{ JA 55} & HaploMult 3 & PTB 2 & A & NEin & $\mathrm{A}$ & $\mathrm{A}$ & $\mathrm{D}$ \\
\hline & HaploMult 7 & 34 & $\mathrm{~A} / \mathrm{G}$ & Nein & $\mathrm{A}$ & A & \\
\hline \multirow[t]{2}{*}{ JA 56} & HaploMult 9 & 24 & A & Nein & $\mathrm{G}$ & $\mathrm{C}$ & $\mathrm{C}$ \\
\hline & HaploMult 11 & 34 & A & Nein & $\mathrm{G}$ & $\mathrm{C}$ & \\
\hline \multirow[t]{2}{*}{ JA 58} & HaploMult 8 & 29 & $\mathrm{~A}$ & Nein & $\mathrm{G}$ & $\mathrm{C}$ & $\mathrm{C}$ \\
\hline & HaploMult 12 & 35 & A & Nein & G & $\mathrm{C}$ & \\
\hline \multirow[t]{2}{*}{ JA 61} & HaploMult 8 & 29 & A & Nein & A & A & $\mathrm{D}$ \\
\hline & HaploMult 12 & 36 & $\mathrm{~A}$ & Nein & $\mathrm{A}$ & n.d. & \\
\hline \multirow[t]{2}{*}{ JA 64} & HaploMult 8 & 29 & A & Nein & $\mathrm{A}$ & $\mathrm{A}$ & $\mathrm{D}$ \\
\hline & HaploMult 12 & 36 & A & Nein & $\mathrm{A}$ & A & \\
\hline \multirow[t]{2}{*}{ JA 65} & HaploMult 3 & PTB 1 & A & Nein & $\mathrm{A}$ & $\mathrm{A}$ & $\mathrm{D}$ \\
\hline & HaploMult 7 & 29 & A & Nein & $\mathrm{A}$ & A & \\
\hline MA 1 & HaploMult 5 & 18 & $\mathrm{~A}$ & Nein & $\mathrm{G}$ & $\mathrm{C}$ & $\mathrm{C}$ \\
\hline & HaploMult 12 & 37 & A & Nein & $\mathrm{G}$ & n.d. & \\
\hline MA 2 & HaploMult 5 & 30 & A & Nein & $\mathrm{A}$ & $\mathrm{A}$ & $\mathrm{D}$ \\
\hline & HaploMult 12 & 37 & $\mathrm{~A}$ & Nein & $\mathrm{A}$ & $\mathrm{A}$ & \\
\hline MA 3 & HaploMult 5 & 18 & A & Nein & $\mathrm{A}$ & A & $\mathrm{D}$ \\
\hline & HaploMult 12 & 37 & A & Nein & A & A & \\
\hline
\end{tabular}




\begin{tabular}{|c|c|c|c|c|c|c|c|}
\hline Ind. & PCR & Extrakt & $\mathrm{mt}_{66 \overline{3}}$ & $\begin{array}{c}\text { 9-bp } \\
\text { Deletion }\end{array}$ & $\mathrm{mt}_{132 \overline{6}}$ & $\mathrm{mt}_{5178}$ & HG \\
\hline \multirow[t]{2}{*}{ MA 5} & HaploMult 5 & 33 & $\mathrm{~A}$ & Nein & $\mathrm{G}$ & $\mathrm{C}$ & $\mathrm{C}$ \\
\hline & HaploMult 13 & 37 & n.d. & n.d. & G & $\mathrm{C}$ & \\
\hline \multirow[t]{2}{*}{ MA 6} & HaploMult 5 & 33 & $\mathrm{~A}$ & $\mathrm{Ja}$ & $\mathrm{A}$ & $\mathrm{C}$ & B \\
\hline & HaploMult 13 & 37 & A & $\mathrm{Ja}$ & $\mathrm{A} / \mathrm{G}$ & $\mathrm{C}$ & \\
\hline \multirow[t]{2}{*}{ ME 1} & HaploMult 5 & 30 & $\mathrm{~A}$ & Nein & $\mathrm{A}$ & $\mathrm{A}$ & D \\
\hline & HaploMult 13 & 37 & A & Nein & A & $\mathrm{A}$ & \\
\hline \multirow[t]{2}{*}{ ME 2} & HaploMult 5 & 15 & $\mathrm{~A}$ & Nein & G & $\mathrm{C}$ & $\mathrm{C}$ \\
\hline & HaploMult 13 & 28 & A & Nein & $\mathrm{G}$ & $\mathrm{C}$ & \\
\hline \multirow[t]{2}{*}{ ME 3} & HaploMult 5 & 30 & A & Nein & $\mathrm{A}$ & $\mathrm{A}$ & $\mathrm{D}$ \\
\hline & HaploMult 13 & 37 & n.d. & n.d. & A & n.d. & \\
\hline \multirow[t]{2}{*}{ ME 9} & HaploMult 5 & 33 & $\mathrm{~A}$ & Nein & $\mathrm{A}$ & $\mathrm{A}$ & D \\
\hline & HaploMult 13 & 37 & A & Nein & A & A & \\
\hline \multirow[t]{2}{*}{ ME 13} & HaploMult 5 & 33 & A & Nein & A & A & $\mathrm{D}$ \\
\hline & HaploMult 13 & 37 & A & Nein & n.d. & $\mathrm{A}$ & \\
\hline \multirow[t]{2}{*}{ MS 1} & HaploMult 5 & 12 & $\mathrm{~A}$ & Nein & $\mathrm{G}$ & $\mathrm{C}$ & $\mathrm{C}$ \\
\hline & HaploMult 13 & 35 & $\mathrm{~A}$ & Nein & $\mathrm{G}$ & $\mathrm{C}$ & \\
\hline \multirow[t]{2}{*}{ MS 2} & HaploMult 5 & 12 & $\mathrm{~A}$ & Nein & $\mathrm{A}$ & $\mathrm{A}$ & $\mathrm{D}$ \\
\hline & HaploMult 13 & 35 & A & Nein & n.d. & $\mathrm{A}$ & \\
\hline \multirow[t]{2}{*}{ MS 3} & HaploMult 5 & 13 & $\mathrm{~A}$ & Nein & $\mathrm{G}$ & $\mathrm{C}$ & $\mathrm{C}$ \\
\hline & HaploMult 13 & 35 & A & Nein & $\mathrm{G}$ & $\mathrm{C}$ & \\
\hline \multirow[t]{2}{*}{ MS 4} & HaploMult 5 & 13 & $\bar{A}$ & Nein & $\bar{G}$ & $\mathrm{C}$ & $\mathrm{C}$ \\
\hline & HaploMult 13 & 34 & $\mathrm{~A}$ & Nein & $\mathrm{G}$ & $\mathrm{C}$ & \\
\hline \multirow[t]{2}{*}{ MS 5} & HaploMult 5 & 13 & $\mathrm{~A}$ & Nein & $\mathrm{A}$ & $\mathrm{A}$ & $\mathrm{D}$ \\
\hline & HaploMult 13 & 34 & n.d. & Nein & A & $\mathrm{A}$ & \\
\hline \multirow[t]{2}{*}{ MS 6} & HaploMult 5 & 13 & $\mathrm{~A}$ & Nein & G & $\mathrm{C}$ & C \\
\hline & HaploMult 13 & 34 & $\mathrm{~A} / \mathrm{G}$ & Nein & $\mathrm{G}$ & $\mathrm{C}$ & \\
\hline \multirow[t]{2}{*}{ MS 8} & HaploMult 5 & 12 & A & Nein & $\mathrm{G}$ & $\mathrm{C}$ & $\mathrm{C}$ \\
\hline & HaploMult 13 & 35 & A & Nein & $\mathrm{G}$ & $\mathrm{C}$ & \\
\hline MS 9 & HaploMult 5 & 34 & A & Nein & $\mathrm{G}$ & $\mathrm{C}$ & $\mathrm{C}$ \\
\hline \multirow{2}{*}{ MS 12} & HaploMult 5 & 12 & A & Nein & G & $\mathrm{C}$ & $\mathrm{C}$ \\
\hline & HaploMult 13 & 34 & A & Nein & $\mathrm{G}$ & $\mathrm{C}$ & \\
\hline \multirow[t]{2}{*}{ MS 13} & HaploMult 6 & 26 & $\mathrm{~A}$ & Nein & $\mathrm{A}$ & $\mathrm{A}$ & $\mathrm{D}$ \\
\hline & HaploMult 14 & 34 & A & Nein & A & $\mathrm{A}$ & \\
\hline \multirow[t]{2}{*}{ MS 14} & HaploMult 6 & 8 & $\mathrm{~A}$ & Nein & $\mathrm{G}$ & $\mathrm{C}$ & $\mathrm{C}$ \\
\hline & HaploMult 14 & 35 & $\mathrm{~A}$ & n.d. & $\mathrm{G}$ & $\mathrm{C}$ & \\
\hline \multirow[t]{2}{*}{ MS 15} & HaploMult 6 & 25 & $\mathrm{~A}$ & Nein & A & $\mathrm{A}$ & $\mathrm{D}$ \\
\hline & HaploMult 14 & 36 & A & Nein & $\mathrm{A}$ & $\mathrm{A}$ & \\
\hline \multirow[t]{2}{*}{ MS 18} & HaploMult 6 & 25 & A & Nein & $\mathrm{A}$ & A & $\mathrm{D}$ \\
\hline & HaploMult 14 & 36 & A & Nein & $\mathrm{A} / \mathrm{G}$ & $\mathrm{A}$ & \\
\hline \multirow[t]{2}{*}{ MS 19} & HaploMult 6 & 25 & $\mathrm{~A}$ & Nein & $\mathrm{G}$ & $\mathrm{C}$ & $\mathrm{C}$ \\
\hline & HaploMult 14 & 36 & $\mathrm{~A}$ & Nein & $\mathrm{G}$ & $\mathrm{C}$ & \\
\hline \multirow[t]{2}{*}{ MS 20} & HaploMult 6 & 25 & A & Nein & $\mathrm{G}$ & $\mathrm{C}$ & $\mathrm{C}$ \\
\hline & HaploMult 14 & 36 & $\mathrm{~A}$ & $\mathrm{Ja} / \mathrm{Nein}$ & $\mathrm{G}$ & $\mathrm{C}$ & \\
\hline MS 21 & HaploMult 2 & 25 & A & $\mathrm{Ja}$ & A & $\mathrm{C}$ & $\mathrm{B}$ \\
\hline & HaploMult 7 & 36 & A & $\mathrm{Ja}$ & A & $\mathrm{C}$ & \\
\hline MS 23 & HaploMult 6 & PTB 3 & A & Nein & $\mathrm{G}$ & $\mathrm{C}$ & $\mathrm{C}$ \\
\hline & HaploMult 14 & 25 & A & Nein & G & $\mathrm{C}$ & $\mathrm{C}$ \\
\hline
\end{tabular}




\begin{tabular}{|c|c|c|c|c|c|c|c|}
\hline Ind. & PCR & Extrakt & $\mathrm{mt}_{66 \overline{3}}$ & $\begin{array}{c}\text { 9_bp } \\
\text { Deletion }\end{array}$ & $\mathrm{mt}_{132 \overline{6}}$ & $\mathrm{mt}_{5178}$ & HG \\
\hline \multirow[t]{2}{*}{ MS 24} & HaploMult 15 & 26 & $\mathrm{~A}$ & $\mathrm{Ja}$ & $\mathrm{A}$ & $\mathrm{C}$ & $\mathrm{B}$ \\
\hline & HaploMult 18 & 31 & A & $\mathrm{Ja}$ & A & $\mathrm{C}$ & \\
\hline \multirow[t]{2}{*}{ MS 25} & HaploMult 15 & 26 & A & Nein & A & $\mathrm{A}$ & $\mathrm{D}$ \\
\hline & HaploMult 18 & 31 & $\mathrm{~A} / \mathrm{G}$ & Nein & $\mathrm{A} / \mathrm{G}$ & A & \\
\hline \multirow[t]{2}{*}{ MS 26} & HaploMult 15 & 26 & $\mathrm{~A}$ & Nein & $\mathrm{A}$ & $\mathrm{A}$ & $\mathrm{D}$ \\
\hline & HaploMult 18 & 31 & $\mathrm{~A}$ & Nein & A & A & \\
\hline \multirow[t]{2}{*}{ MS 27} & HaploMult 15 & 26 & $\mathrm{~A}$ & Nein & $\mathrm{A}$ & $\mathrm{A}$ & $\mathrm{D}$ \\
\hline & HaploMult 18 & 31 & A & Nein & A & A & \\
\hline \multirow[t]{2}{*}{ MS 30} & HaploMult 15 & 13 & $\mathrm{~A}$ & Nein & $\mathrm{G}$ & $\mathrm{C}$ & $\mathrm{C}$ \\
\hline & HaploMult 18 & 34 & n.d. & n.d. & n.d. & $\mathrm{C}$ & \\
\hline \multirow[t]{2}{*}{ MS 33} & HaploMult 15 & 26 & $\mathrm{~A}$ & $\mathrm{Ja}$ & $\mathrm{A}$ & $\mathrm{C}$ & B \\
\hline & HaploMult 18 & 34 & A & $\mathrm{Ja}$ & A & $\mathrm{C}$ & \\
\hline MS 34 & HaploMult 15 & 38 & $\mathrm{~A}$ & Nein & $\mathrm{G}$ & $\mathrm{C}$ & $\mathrm{C}$ \\
\hline MS 35 & HaploMult 15 & PTB 3 & A & Nein & $\mathrm{A}$ & $\mathrm{A}$ & $\mathrm{D}$ \\
\hline \multirow[t]{2}{*}{ MS 36} & HaploMult 15 & AL 2 & A & Nein & A & A & $\mathrm{D}$ \\
\hline & HaploMult 18 & 34 & $\mathrm{~A}$ & Nein & A & A & \\
\hline \multirow[t]{2}{*}{ MS 37} & HaploMult 16 & PTB 3 & A & Nein & $\mathrm{G}$ & $\mathrm{C}$ & $\mathrm{C}$ \\
\hline & HaploMult 20 & 36 & A & Nein & $\mathrm{G}$ & $\mathrm{C}$ & \\
\hline \multirow[t]{2}{*}{ MS 38} & HaploMult 16 & PTB 3 & A & Nein & A & A & $\mathrm{D}$ \\
\hline & HaploMult 19 & 36 & A & Nein & A & A & \\
\hline \multirow[t]{2}{*}{ MS 39} & HaploMult 16 & 26 & A & $\mathrm{Ja}$ & A & $\mathrm{C}$ & $\mathrm{B}$ \\
\hline & HaploMult 19 & 32 & A & $\mathrm{Ja}$ & A & n.d. & \\
\hline \multirow[t]{2}{*}{ MS 41} & HaploMult 17 & PTB 3 & A & $\mathrm{Ja}$ & A & $\mathrm{C}$ & $\mathrm{B}$ \\
\hline & HaploMult 19 & 36 & A & $\mathrm{Ja}$ & A & $\mathrm{C}$ & \\
\hline \multirow[t]{2}{*}{ MS 44} & HaploMult 17 & 17 & A & Nein & A & A & $\mathrm{D}$ \\
\hline & HaploMult 19 & 34 & A & Nein & A & A & \\
\hline \multirow[t]{2}{*}{ MS 45} & HaploMult 17 & 17 & A & Nein & A & A & $\mathrm{D}$ \\
\hline & HaploMult 19 & 26 & A & Nein & A & A & \\
\hline \multirow[t]{2}{*}{ MS 46} & HaploMult 17 & 17 & A & $\mathrm{Ja}$ & A & $\mathrm{C}$ & B \\
\hline & HaploMult 19 & 26 & n.d. & $\mathrm{Ja}$ & A & n.d. & \\
\hline \multirow[t]{2}{*}{ PA 1} & HaploMult 16 & 24 & $\mathrm{~A}$ & Nein & A & A & $\mathrm{D}$ \\
\hline & HaploMult 20 & 36 & A & Nein & A & A & \\
\hline \multirow[t]{2}{*}{ PA 2} & HaploMult 16 & 24 & A & Nein & $\mathrm{G}$ & $\mathrm{C}$ & $\mathrm{C}$ \\
\hline & HaploMult 20 & 31 & A & Nein & $\mathrm{G} / \mathrm{a}$ & $\mathrm{C}$ & \\
\hline \multirow[t]{2}{*}{ PA 7} & HaploMult 16 & 30 & $\mathrm{~A}$ & $\mathrm{Ja}$ & $\mathrm{A}$ & $\mathrm{C}$ & B \\
\hline & HaploMult 20 & 36 & A & $\mathrm{Ja}$ & A & $\mathrm{C}$ & \\
\hline \multirow[t]{2}{*}{ PA 10} & HaploMult 16 & 12 & A & $\mathrm{Ja}$ & A & $\mathrm{C}$ & B \\
\hline & HaploMult 20 & 37 & A & $\mathrm{Ja}$ & A & $\mathrm{C}$ & \\
\hline \multirow[t]{2}{*}{ PA 11} & HaploMult 16 & 31 & A & Nein & A & A & $\mathrm{D}$ \\
\hline & HaploMult 20 & 36 & A & Nein & $\mathrm{A}$ & A & \\
\hline PA 12 & HaploMult 16 & 31 & A & Nein & $\mathrm{G}$ & $\mathrm{C}$ & $\mathrm{C}$ \\
\hline PA 15 & HaploMult 20 & 38 & $\mathrm{~A}$ & Nein & $\mathrm{G}$ & $\mathrm{C}$ & $\mathrm{C}$ \\
\hline \multirow[t]{2}{*}{ PA 16} & HaploMult 16 & PTB 3 & $\mathrm{~A}$ & Nein & $\mathrm{A}$ & $\mathrm{A}$ & $\mathrm{D}$ \\
\hline & HaploMult 20 & 38 & A & Nein & n.d. & $\mathrm{A}$ & \\
\hline \multirow[t]{2}{*}{ PA 17} & HaploMult 19 & 31 & $\mathrm{~A}$ & Nein & $\mathrm{A}$ & $\mathrm{A}$ & $\mathrm{D}$ \\
\hline & HaploMult 13 & 38 & A & Nein & A & A & \\
\hline PA 18 & HaploMult 10 & 32 & $\mathrm{~A}$ & Nein & $\mathrm{G}$ & $\mathrm{C}$ & $\mathrm{C}$ \\
\hline & HaploMult 19 & 38 & A & Nein & $\mathrm{G}$ & $\mathrm{C}$ & \\
\hline
\end{tabular}




\begin{tabular}{|c|c|c|c|c|c|c|c|}
\hline Ind. & PCR & Extrakt & $\mathrm{mt}_{-}$ & $\begin{array}{c}\text { 9_bp } \\
\text { Deletion }\end{array}$ & $\mathrm{mt}_{13263}$ & $\mathrm{mt}_{5178}$ & HG \\
\hline \multirow[t]{2}{*}{ PA 19} & HaploMult 10 & 32 & A & Nein & G & $\mathrm{C}$ & $\mathrm{C}$ \\
\hline & HaploMult 21 & 38 & $\mathrm{~A} / \mathrm{G}$ & Nein & $\mathrm{G}$ & $\mathrm{C}$ & \\
\hline \multirow[t]{2}{*}{ PA 20} & HaploMult 10 & 32 & $\mathrm{~A}$ & Nein & $\mathrm{G}$ & $\mathrm{C}$ & $\mathrm{C}$ \\
\hline & HaploMult 21 & 38 & $\mathrm{~A}$ & Nein & $\mathrm{G}$ & $\mathrm{C}$ & \\
\hline \multirow[t]{2}{*}{ PA 21} & HaploMult 10 & 19 & A & Nein & A & A & $\mathrm{D}$ \\
\hline & HaploMult 21 & 29 & $\mathrm{~A}$ & Nein & A & A & \\
\hline \multirow[t]{2}{*}{ PC 1} & HaploMult 21 & 21 & A & Nein & A & A & $\mathrm{D}$ \\
\hline & HaploMult 22 & 27 & $\mathrm{~A}$ & Nein & A & A & \\
\hline \multirow[t]{2}{*}{ PC 2} & HaploMult 21 & 21 & $\mathrm{~A}$ & Nein & $\mathrm{G}$ & $\mathrm{C}$ & $\mathrm{C}$ \\
\hline & HaploMult 22 & 27 & $\mathrm{~A}$ & Nein & $\mathrm{G}$ & n.d. & \\
\hline \multirow[t]{2}{*}{ PC 3} & HaploMult 21 & 21 & $\mathrm{~A}$ & Nein & $\mathrm{A}$ & $\mathrm{A}$ & $\mathrm{D}$ \\
\hline & HaploMult 22 & 27 & n.d. & Nein & $\mathrm{A}$ & n.d. & \\
\hline \multirow[t]{2}{*}{ PC 4} & HaploMult 21 & 21 & $\mathrm{~A}$ & Nein & $\mathrm{A}$ & $\mathrm{A}$ & $\mathrm{D}$ \\
\hline & HaploMult 22 & 27 & $\mathrm{~A}$ & Nein & $\mathrm{A}$ & $\mathrm{A}$ & \\
\hline \multirow[t]{2}{*}{ PC 5} & HaploMult 21 & 21 & A & Nein & A & A & $\mathrm{D}$ \\
\hline & HaploMult 22 & 27 & A & Nein & $\mathrm{A}$ & $\mathrm{A}$ & \\
\hline \multirow[t]{2}{*}{ PC 6} & HaploMult 21 & 21 & $\mathrm{~A}$ & Nein & $\mathrm{A}$ & $\mathrm{A}$ & $\mathrm{D}$ \\
\hline & HaploMult 22 & 27 & n.d. & n.d. & $\mathrm{A} / \mathrm{G}$ & A & \\
\hline \multirow[t]{2}{*}{ PC 8} & HaploMult 21 & 21 & $\mathrm{~A}$ & Nein & $\mathrm{A}$ & $\mathrm{A}$ & $\mathrm{D}$ \\
\hline & HaploMult 22 & 27 & $\mathrm{~A}$ & Nein & $\mathrm{A}$ & $\mathrm{A}$ & \\
\hline \multirow[t]{2}{*}{ PC 10} & HaploMult 21 & 21 & $\mathrm{~A}$ & Nein & $\mathrm{A}$ & $\mathrm{A}$ & $\mathrm{D}$ \\
\hline & HaploMult 22 & 27 & $\mathrm{~A}$ & Nein & $\mathrm{A}$ & $\mathrm{A}$ & \\
\hline \multirow[t]{2}{*}{ PC 11} & HaploMult 21 & 21 & $\mathrm{~A}$ & NEin & $\mathrm{G}$ & $\mathrm{C}$ & $\mathrm{C}$ \\
\hline & HaploMult 22 & 27 & n.d. & Nein & n.d. & $\mathrm{C}$ & \\
\hline \multirow[t]{2}{*}{ PC 12} & HaploMult 21 & 21 & $\mathrm{~A}$ & Nein & $\mathrm{G}$ & $\mathrm{C}$ & $\mathrm{C}$ \\
\hline & HaploMult 22 & 36 & A & Nein & G & $\mathrm{C}$ & \\
\hline
\end{tabular}

\subsubsection{Einzeltypisierungsergebnisse der HVRI-Untersuchungen}

Tab. 44: Einzeltypisierungsergebnisse der HVRI-Untersuchungen. Angegeben sind die Sequenzdaten, die Benennung der Nukleotidpositionen erfolg nach der rCRS. Es sind die Abweichungen zu rCRS genannt, Entsprechungen sind durch leere Felder gekennzeichnet. Bei Positionen an denen mehr als eine Base realisiert war, erflgt die Nennung nach IUB-Code (Bsp. C u. T = Y)

Legende: - = Position wurde in der PCR/Sequenzierung nicht untersucht; Typisierungsergebniss; HG= Haplogruppe 


\begin{tabular}{|c|c|c|c|c|c|c|c|c|c|c|c|c|c|c|c|c|c|c|c|c|c|c|c|c|c|c|c|c|c|c|c|c|c|c|c|}
\hline Individuum & PCR & Extrakt & Seq-Datum & 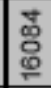 & 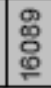 & $\begin{array}{l}\mathscr{0} \\
\text { \% } \\
\end{array}$ & \% & 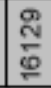 & $\frac{9}{9}$ & $\frac{f}{8}$ & $\begin{array}{l} \\
\stackrel{5}{\circ} \\
\end{array}$ & $\frac{\omega}{6}$ & $\frac{N}{\stackrel{N}{\circ}}$ & 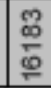 & 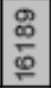 & $\frac{\widetilde{\alpha}}{\Phi}$ & 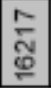 & 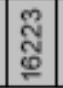 & 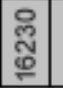 & 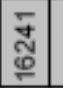 & 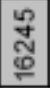 & 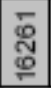 & 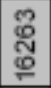 & 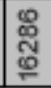 & 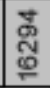 & 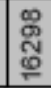 & 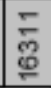 & \begin{tabular}{|l}
$\infty$ \\
\\
0
\end{tabular} & 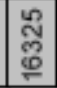 & 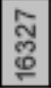 & 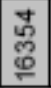 & 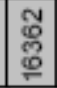 & $\begin{array}{l}\stackrel{8}{8} \\
\stackrel{8}{0} \\
\end{array}$ & 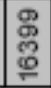 & $H G$ \\
\hline MS 1 & 69 & 14 & 09.06 .2006 & - & - & - & - & - & - & - & - & - & - & - & - & - & & $\mathrm{Y}$ & & & $T$ & & & & & $\mathrm{Y}$ & & & C & $\mathrm{Y}$ & & & & & \\
\hline MS 1 & 78 & 25 & 12.07 .2006 & i- & - & - & - & - & - & - & - & - & - & - & - & - & & & & & & & & & & & & & & & & & $\mathrm{R}$ & & \\
\hline MS 1 & 88 & PTB 3 & 01.09 .2006 & 1- & - & - & - & - & - & - & - & - & - & - & - & - & & $T$ & & & & & & & & C & & & $\mathrm{Y}$ & $T$ & & & & & \\
\hline MS 1 & 90 & PTB 3 & 05.09 .2006 & & 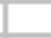 & 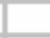 & 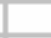 & 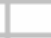 & I & & & & & & & & & $Y$ & & - & - & - & - & - & - & - & - & - & - & - & - & - & - & - & \\
\hline MS 1 & 92 & PTB 3 & 03.10 .2006 & i- & - & - & - & - & - & - & - & - & - & - & - & - & & $\mathrm{T}$ & & & & & & & & C & & & c & $T$ & - & - & - & - & C \\
\hline MS 1 & 106 & 14 & 29.11 .2006 & 1- & - & - & - & - & - & - & - & - & - & - & - & - & & $T$ & & & & & & & & C & & & C & $T$ & & - & - & - & \\
\hline MS 1 & 128 & 35 & 26.03 .2007 & |- & - & - & - & - & - & - & - & - & - & - & - & - & & $Y$ & & & & & & & & $\mathrm{Y}$ & & & $\mathrm{Y}$ & Y & - & - & - & - & \\
\hline MS 1 & 137 & 14 & 24.04 .2007 & |- & - & - & - & - & 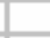 & | & I & I & I & 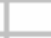 & 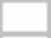 & 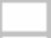 & & $T$ & & - & - & - & - & - & - & - & - & - & - & - & - & - & - & - & \\
\hline MS 2 & 71 & 14 & 20.06 .2006 & F- & - & - & - & F- & F- & F- & F- & F- & F- & - & - & - & & $T$ & & & & & & & & & & & C & & & c & & & \\
\hline MS 2 & 72 & 14 & 22.06 .2006 & & - & & & & & & & & & & & & & $T$ & & - & - & - & - & - & - & - & - & - & - & - & - & - & - & - & \\
\hline MS 2 & 78 & 25 & 12.07 .2006 & 1- & - & - & - & - & - & - & - & - & - & - & - & - & & $Y$ & & & & & & & & & & & C & & & c & & & \\
\hline MS 2 & 106 & 14 & 29.11 .2006 & 1- & - & - & - & - & - & - & - & - & - & - & - & - & & $T$ & & & & & & & & & & & C & & - & - & - & - & \\
\hline MS 2 & 127 & 34 & 11.03 .2007 & !- & - & - & - & - & - & - & - & - & - & - & - & - & & $\mathrm{T}$ & & & & & & & & & & & $Y$ & & & - & - & - & D \\
\hline MS 2 & 128 & 35 & 26.03 .2007 & 1- & - & - & - & - & - & - & - & - & - & - & - & - & & $Y$ & & & & $T$ & & & & & & & C & & & - & - & - & \\
\hline MS 2 & 137 & 35 & 24.04 .2007 & 1- & - & - & - & - & 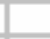 & 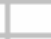 & 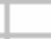 & 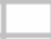 & 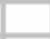 & 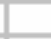 & 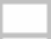 & 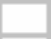 & & $T$ & & - & - & - & - & - & - & - & - & - & - & - & - & - & - & - & \\
\hline MS 2 & 138 & 35 & 24.07 .2007 & & L & - & E & E & E & E & - & - & - & - & - & - & - & - & - & - & - & - & - & - & - & - & - & - & - & - & - & - & - & - & \\
\hline MS 3 & 71 & 14 & 20.06 .2006 & & - & - & - & - & - & - & 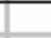 & - & - & - & - & - & & $T$ & & & & $\mathrm{Y}$ & & & & C & & & & $T$ & & & & & \\
\hline MS 3 & 77 & 25 & 03.07 .2006 & & - & - & - & - & - & - & 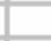 & - & - & - & - & - & & & & & & & & & & & & & & & & & & & \\
\hline MS 3 & 119 & 34 & 12.02 .2007 & & - & - & - & - & - & - & - & - & - & -- & - & - & & $T$ & & & & & & & & C & & & & $T$ & & & & & C \\
\hline MS 3 & 127 & 34 & 11.03 .2007 & & - & - & - & - & - & - & - & - & - & - & - & - & & $T$ & & & & & & & & C & & & & $T$ & & - & - & - & \\
\hline MS 3 & 128 & 35 & 26.03 .2007 & & - & - & - & - & - & - & - & - & - & - & - & - & & $T$ & & & & & & & & C & & & & $T$ & & - & - & - & \\
\hline MS 3 & 137 & 35 & 24.04 .2007 & & - & - & - & - & C & & 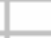 & I & 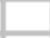 & & & & & $T$ & & - & - & - & - & - & - & - & - & - & - & - & - & - & - & - & \\
\hline MS 3 & 138 & 35 & 02.05 .2007 & & L & L & L & L & C & 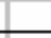 & - & - & - & - & - & - & - & - & - & - & - & - & - & - & - & - & - & - & - & - & - & - & - & - & \\
\hline MS 4 & 61 & 24 & 27.04 .2006 & & 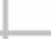 & 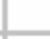 & 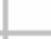 & 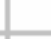 & & 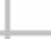 & & & & & & $T$ & & & & & & & & & & C & & & C & $T$ & - & - & - & - & \\
\hline MS 4 & 89 & 24 & 09.06 .2006 & 1- & - & - & - & - & - & - & - & - & - & - & - & - & & & & & & & & $T$ & & & & & & & & & & G & \\
\hline MS 4 & 71 & 24 & 20.06 .2006 & 1- & - & - & - & - & - & - & - & - & - & - & - & - & & Y & & & & & & & & Y & & & $\mathrm{Y}$ & $T$ & & & & & \\
\hline MS 4 & 77 & 25 & 03.07 .2006 & 1- & - & - & - & - & - & - & - & - & - & - & - & - & & $T$ & & & & & & & & $\mathrm{Y}$ & & & $Y$ & $T$ & & & & & \\
\hline MS 4 & 83 & 25 & 26.07 .2006 & i & 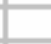 & 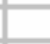 & 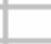 & 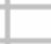 & 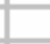 & - & - & & & & & $T$ & & $T$ & & & & - & - & - & - & - & - & - & - & - & - & - & - & - & \\
\hline MS 4 & 88 & PTB 3 & 01.09 .2006 & F- & - & - & - & - & - & - & - & - & - & - & - & - & & Y & & & & & & & & c & & & C & $Y$ & & & & & \\
\hline MS 4 & 90 & PTB 3 & 05.09 .2006 & & 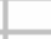 & & & 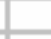 & & & & & & & & $\mathrm{Y}$ & & $T$ & & & & - & - & - & - & - & - & - & - & - & - & - & - & - & c \\
\hline MS 4 & 92 & PTB 3 & 03.10 .2006 & 1- & - & - & - & - & - & - & - & - & - & - & - & - & & $T$ & & & & & & & & C & & & $\mathrm{Y}$ & $T$ & & - & - & - & \\
\hline MS 4 & 106 & 25 & 29.11 .2006 & i- & - & - & - & - & - & - & - & - & - & - & - & - & & & & & & & & & & & & & & & & & & & \\
\hline MS 4 & 108 & PTB 3 & 12.12 .2006 & |- & - & - & - & - & - & & & & & & & $T$ & & T & & - & - & - & - & - & - & - & - & - & - & - & - & - & - & - & \\
\hline MS 4 & 119 & 34 & 15.02 .2006 & 1- & - & - & - & - & $Y$ & & & & & & & $T$ & & $T$ & & & & & & & & C & & & C & $T$ & & & & & \\
\hline MS 4 & 119 & 34 & 12.02 .2006 & 1- & - & - & - & - & - & - & - & - & - & - & - & - & & $T$ & & & & & & & & $\mathrm{Y}$ & & & C & $T$ & & & & & \\
\hline MS 4 & 127 & 34 & 11.03 .2007 & 1- & - & - & - & - & - & - & - & - & - & - & - & - & & $T$ & & & & & & & & $\mathrm{Y}$ & & & Y & Y & - & - & - & - & \\
\hline MS 4 & 136 & 34 & 24.04 .2007 & - & - & - & - & - & & 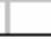 & & & & & & $T$ & & $T$ & & - & - & - & - & - & - & - & - & - & - & - & - & - & - & - & \\
\hline
\end{tabular}




\begin{tabular}{|c|c|c|c|c|c|c|c|c|c|c|c|c|c|c|c|c|c|c|c|c|c|c|c|c|c|c|c|c|c|c|c|c|c|c|c|}
\hline Individuum & PCR & Extrakt & Seq-Datum & $\begin{array}{l}\text {. } \\
\stackrel{0}{\circ} \\
\end{array}$ & $\begin{array}{l}\text { \% } \\
\text { \% } \\
\end{array}$ & \begin{tabular}{|l}
$\%$ \\
\\
\end{tabular} & $\frac{\%}{0}$ & $\begin{array}{l}\stackrel{2}{0} \\
\stackrel{0}{\circ}\end{array}$ & $\begin{array}{l}0 \\
\frac{9}{6} \\
\end{array}$ & 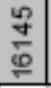 & $\begin{array}{l} \pm \\
\frac{5}{\%}\end{array}$ & $\frac{5}{\%}$ & $\begin{array}{l}\mathbb{N} \\
\bar{N} \\
\end{array}$ & $\begin{array}{l}\infty \\
\frac{1}{\%} \\
\end{array}$ & 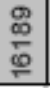 & $\begin{array}{l}\widetilde{\alpha} \\
\Phi \\
\end{array}$ & $\begin{array}{l}\stackrel{N}{\bar{\nu}} \\
\Phi\end{array}$ & 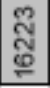 & $\begin{array}{l}\text { ஜ్ } \\
\text { ष్ }\end{array}$ & 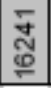 & 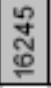 & 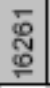 & 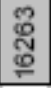 & 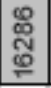 & 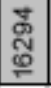 & 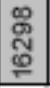 & $\begin{array}{l}\overline{8} \\
\varnothing \\
\end{array}$ & $\begin{array}{l}0 \\
\overline{8} \\
\frac{8}{\tau}\end{array}$ & $\begin{array}{l}\text { స్ } \\
\text { ֻ } \\
\end{array}$ & 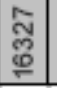 & $\begin{array}{l} \pm \\
0 \\
0 \\
0\end{array}$ & 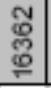 & 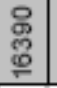 & 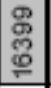 & $\mathrm{HG}$ \\
\hline MS 5 & 56 & 16 & 27.02 .2006 & & & & & & & & & & & & & & & $Y$ & & & & & & & & & & & & & & - & - & -1 & \\
\hline MS 5 & 56 & 16 & 23.02 .2006 & & & & & & & & & & & & & & & $T$ & & & & & & & & & & & & & - & - & - & - & \\
\hline MS 5 & 69 & 16 & 09.06 .2006 & 1- & - & - & - & - & - & - & - & - & - & - & - & - & & $T$ & & & & & & & & & & & & & $T$ & c & & & \\
\hline MS 5 & 71 & 16 & 20.06 .2006 & 1- & - & - & - & - & - & - & - & - & - & - & - & - & & & & & & & & & & & C & & & & & & & & \\
\hline MS 5 & 77 & 25 & 03.07 .2006 & i- & - & - & - & - & - & - & - & - & - & - & - & - & & T & & & & & & & & & & & & & $T$ & C & & & D \\
\hline MS 5 & 106 & 25 & 29.11 .2006 & 1- & - & - & - & - & - & - & - & - & - & - & - & - & & Y & & & & & & & & & & & & & $\mathrm{Y}$ & c & & & \\
\hline MS 5 & 119 & 34 & 15.02 .2007 & 1- & - & - & - & - & - & - & & 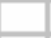 & 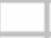 & 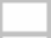 & 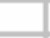 & & & T & & & & & & & & & & & & & & - & - & - & \\
\hline MS 5 & 119 & 34 & 12.02 .2007 & 1- & - & - & - & - & - & - & - & - & - & - & - & - & & $T$ & & & & & & & & & & & & & T & c & & & \\
\hline MS 5 & 136 & 34 & 24.04 .2007 & 1- & - & - & - & - & & & - & & & & & & & $T$ & & - & - & - & - & - & - & - & - & - & - & - & - & - & - & - & \\
\hline MS 5 & 138 & 34 & 02.05 .2007 & & & & & 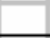 & - & - & - & - & - & - & - & - & - & - & - & - & - & - & - & - & - & - & - & - & - & - & - & - & - & - & \\
\hline MS 8 & 29 & 8 & 20.10 .2006 & $1-$ & - & - & - & - & - & - & - & - & - & - & - & - & & $T$ & & & & & & & & C & & & $\bar{Y}$ & $T$ & & - & -- & - & \\
\hline MS 8 & 61 & 20 & 27.04 .2006 & | & & $\mathrm{Y}$ & & 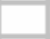 & & & & & & & & T & & $\mathrm{T}$ & & & & & & & & C & & & C & $T$ & - & - & - & - & \\
\hline MS 8 & 69 & 14 & 09.06 .2006 & 1- & - & - & - & - & - & - & - & - & - & - & - & - & & Y & & & & & & & & $\mathrm{Y}$ & & & $\mathrm{Y}$ & $\mathrm{Y}$ & & & & & \\
\hline MS 8 & 71 & 14 & 20.06 .2006 & i. & - & - & - & - & - & - & - & - & - & - & - & - & & $\mathrm{T}$ & & & & & & & & C & & & Y & & & & & & \\
\hline MS 8 & 88 & PTB 3 & 01.09 .2006 & F & - & - & - & - & - & - & - & - & - & - & - & - & & $T$ & & & & & & & & C & & & c & $T$ & & & 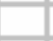 & 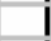 & c \\
\hline MS 8 & 80 & PTB 3 & 05.09 .2006 & & 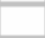 & C & 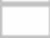 & 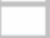 & 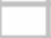 & 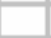 & 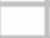 & 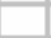 & 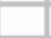 & 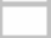 & & $\mathrm{Y}$ & & $\mathrm{Y}$ & & & & - & - & - & - & - & - & - & - & - & - & - & - & - & \\
\hline MS 8 & 92 & PTB 3 & 03.10 .2006 & i. & - & - & - & - & - & - & - & - & - & - & - & - & & $T$ & & & & & & & & C & & & $\mathrm{Y}$ & $T$ & - & - & - & - & \\
\hline MS 8 & 128 & 35 & 26.03 .2007 & F & - & - & - & - & - & - & - & - & - & - & - & - & & $\mathrm{Y}$ & & & & & & & $\mathrm{Y}$ & c & & & c & $T$ & - & - & - & - & \\
\hline MS 8 & 137 & 35 & 24.04 .2007 & F- & - & - & - & - & 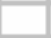 & 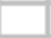 & 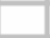 & 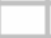 & 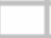 & 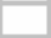 & 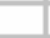 & $T$ & & $T$ & & - & - & - & - & - & - & - & - & - & - & - & - & - & - & - & \\
\hline MS 8 & 138 & 35 & 02.05 .2007 & 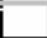 & t & C & . & 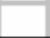 & 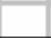 & 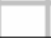 & - & - & - & - & - & - & - & - & - & - & - & - & - & - & - & - & - & - & - & - & - & - & - & - & \\
\hline MS 9 & 81 & 14 & 27.04 .2006 & & 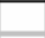 & & & - & - & - & 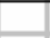 & 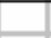 & 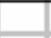 & 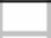 & & & & $T$ & & - & - & - & - & - & - & - & - & - & - & - & - & - & - & - & \\
\hline MS 9 & 89 & 14 & 09.06 .2006 & 1- & - & - & - & - & - & - & - & - & - & - & - & - & & & & & & & & & & & & & & & & & & & \\
\hline MS 9 & 71 & 14 & 20.06 .2006 & i- & - & - & - & - & - & - & - & - & - & - & - & - & & T & & & & & & & & c & & & c & $T$ & & & L & 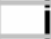 & \\
\hline MS 9 & 88 & PTB 3 & 01.09 .2006 & F. & - & - & - & - & - & - & - & - & - & - & - & - & & $T$ & & & & & & & & c & & & c & $T$ & & & & & \\
\hline MS 9 & 106 & 25 & 01.12 .2006 & F- & - & - & - & - & - & - & - & - & - & - & - & - & & $T$ & & & & & & & & C & & & c & $T$ & - & - & - & - & c \\
\hline MS 9 & 106 & 25 & 29.11 .2006 & i- & - & - & - & - & - & - & - & - & - & - & - & - & & T & & & & & & & & c & & & C & $T$ & - & - & - & - & \\
\hline MS 9 & 112 & 34 & 21.12 .2006 & F- & - & - & - & - & - & - & - & - & - & - & - & - & & $T$ & & & & & & & & $\mathrm{Y}$ & & & & $Y$ & - & - & - & - & \\
\hline MS 9 & 119 & 34 & 15.02 .2007 & F- & - & - & - & - & & & 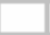 & 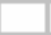 & 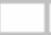 & 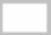 & 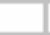 & 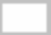 & & T & & & & & & & & $\mathrm{Y}$ & & & Y & $T$ & - & - & - & - & \\
\hline MS 9 & 138 & 34 & 24.04 .2007 & & & & & & & & & - & - & - & - & - & - & - & - & - & - & - & - & - & - & - & - & - & - & - & - & - & - & - & \\
\hline MS 12 & 82 & 25 & 26.07 .2006 & $1-$ & - & - & - & - & - & - & - & - & - & - & - & - & & $\bar{Y}$ & & & & & & & & $\mathrm{Y}$ & & & C & $T$ & & & & & \\
\hline MS 12 & 92 & PTB 3 & 03.10 .2006 & F- & - & - & - & - & - & - & - & - & - & - & - & - & & $T$ & & & & & & & & $\mathrm{Y}$ & & & C & $Y$ & & - & - & - & \\
\hline MS 12 & 106 & 25 & 29.11 .2006 & F & - & - & - & - & - & -- & - & - & - & - & - & - & & T & & & & & & & & C & & & C & $\mathrm{Y}$ & & - & - & - & \\
\hline MS 12 & 106 & 25 & 01.12 .2006 & i- & - & - & - & - & - & - & - & - & - & - & -- & - & & $\mathrm{Y}$ & & & & & & & & $\mathrm{Y}$ & & & c & $T$ & & - & - & - & \\
\hline MS 12 & 107 & 34 & 12.12 .2006 & & & & & & & & & & & & & $T$ & & $T$ & & - & - & - & - & - & - & - & - & - & - & - & - & - & - & - & c \\
\hline MS 12 & 112 & 34 & 21.12 .2006 & i- & - & - & - & - & - & - & - & - & - & - & - & - & & $T$ & & & & & & & & c & & & $\mathrm{Y}$ & $T$ & & - & - & - & \\
\hline MS 12 & 136 & 25 & 24.04 .2007 & 1- & - & - & - & - & & & & & & & & $T$ & & $T$ & & - & - & - & - & - & - & - & - & - & - & - & - & - & - & - & \\
\hline MS 12 & 138 & PTB 3 & 24.07 .2007 & & & & & & & & - & - & - & - & - & - & - & - & - & - & - & - & - & - & - & - & - & - & - & - & - & - & - & - & \\
\hline MS 12 & 138 & 25 & 02.05 .2007 & & & & & & & & - & - & - & - & - & - & - & - & - & - & - & - & - & - & - & - & - & - & - & - & - & - & - & - & \\
\hline
\end{tabular}




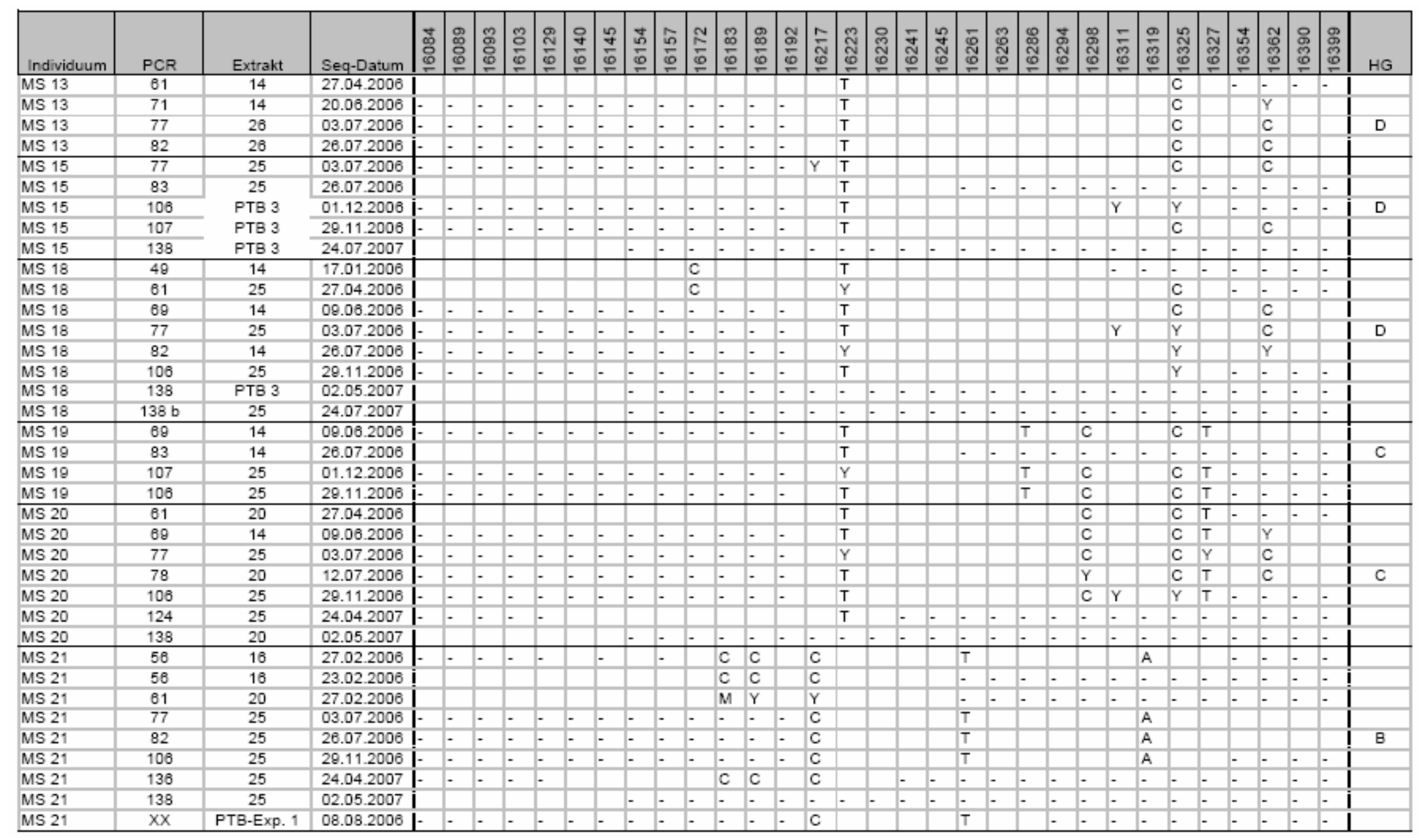




\begin{tabular}{|c|c|c|c|c|c|c|c|c|c|c|c|c|c|c|c|c|c|c|c|c|c|c|c|c|c|c|c|c|c|c|c|c|c|c|c|}
\hline Individuum & PCR & Extrakt & Seq-Datum & $\begin{array}{l}\text { क्ष } \\
\stackrel{8}{0} \\
\end{array}$ & $\begin{array}{l}9 \\
0 \\
0 \\
\end{array}$ & $\begin{array}{l}\stackrel{3}{8} \\
\stackrel{\circ}{\circ}\end{array}$ & 응 & 름 & $\frac{1}{\frac{1}{6}}$ & $\frac{\varphi}{\frac{0}{6}}$ & $\begin{array}{l}\frac{7}{6} \\
\frac{6}{6}\end{array}$ & $\frac{5}{6}$ & $\frac{\mathbb{N}}{\stackrel{N}{\oplus}}$ & 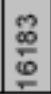 & $\begin{array}{l}0 \\
\frac{9}{6} \\
\stackrel{0}{6}\end{array}$ & $\frac{\widetilde{\sigma}}{6}$ & 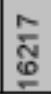 & 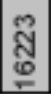 & 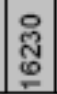 & \begin{tabular}{|l|}
$\bar{Z}$ \\
¿
\end{tabular} & ్ㅗㅀ & \begin{tabular}{|l|}
$\overline{8}$ \\
$\stackrel{8}{0}$
\end{tabular} & 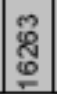 & 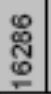 & స్త్రి & 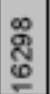 & $\underset{\bar{C}}{\bar{\oplus}}$ & $\frac{\Phi}{\bar{\gamma}}$ & ్ㅠㅇ్ & 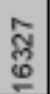 & 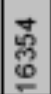 & \begin{tabular}{l}
$\mathbb{1}$ \\
$\mathbb{8}$ \\
\hdashline \\
\hdashline
\end{tabular} & $\begin{array}{l}\text { 융 } \\
0 \\
\end{array}$ & $\begin{array}{l}\mathscr{2} \\
\overline{8} \\
0\end{array}$ & HG \\
\hline MS 23 & 62 & 24 & 27.04 .2008 & & & $\mathrm{C}$ & & . & 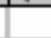 & 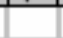 & 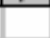 & 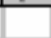 & 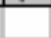 & & 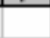 & $T$ & & $T$ & & & & & & & & $\mathrm{Y}$ & & & $\mathrm{Y}$ & $\mathrm{Y}$ & - & - & - & - & \\
\hline MS 23 & 69 & 24 & 09.06 .2008 & - & - & - & - & - & - & - & - & - & - & - & - & - & & $T$ & & & & & & & & C & & & C & $T$ & & & & & \\
\hline MS 23 & 77 & 25 & 03.07 .2008 & F- & - & - & - & - & - & - & - & - & - & - & - & - & & $\mathrm{Y}$ & & & & & & & & C & & & Y & $\mathrm{T}$ & & & & & \\
\hline MS 23 & 78 & 25 & 12.07 .2008 & F- & - & - & - & - & - & - & - & - & - & - & - & - & - & - & - & & & & & & & & & & & & 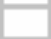 & $\mathrm{Y}$ & & & \\
\hline MS 23 & 83 & 24 & 26.07 .2008 & 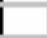 & & C & 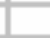 & 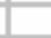 & 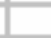 & L & 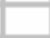 & 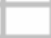 & 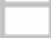 & - & 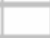 & T & & $\mathrm{T}$ & & & & - & - & - & - & - & - & - & - & - & - & - & - & - & c \\
\hline MS 23 & 88 & PTB 3 & 02.09 .2008 & $1-$ & - & - & - & - & - & - & - & - & - & - & - & - & & $T$ & & & & $\mathrm{Y}$ & & & & C & & & C & $T$ & & & & & \\
\hline MS 23 & 92 & PTB 3 & 03.10 .2008 & F- & - & - & - & - & - & - & - & - & - & - & - & - & - & - & - & - & - & & & & & $\mathrm{Y}$ & & & $\mathrm{Y}$ & $\mathrm{T}$ & & - & - & - & \\
\hline MS 23 & 108 & 25 & 29.11 .2008 & - & - & - & - & - & - & - & - & - & - & - & - & - & & $\mathrm{T}$ & & & & & & & & C & & & C & $\mathrm{T}$ & - & - & - & - & \\
\hline MS 23 & 136 & 25 & 24.04 .2007 & - & - & - & - & - & & 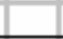 & 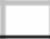 & 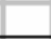 & 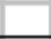 & & & $T$ & & $\mathrm{~T}$ & & - & - & - & - & - & - & - & - & - & - & - & - & - & - & - & \\
\hline MS 24 & 58 & 16 & 23.02 .2008 & & 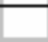 & 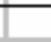 & - & & C & & - & - & 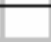 & C & C & & C & & - & - & - & - & - & - & - & - & - & - & - & - & - & - & - & - & \\
\hline MS 24 & 58 & 18 & 27.02 .2008 & - & - & - & - & - & - & - & - & - & - & C & C & & C & & & & & & & & - & - & - & - & - & - & - & - & - & - & \\
\hline MS 24 & 62 & 20 & 27.04 .2008 & & & 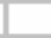 & 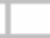 & 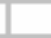 & $\mathrm{Y}$ & 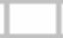 & 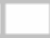 & 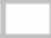 & 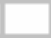 & M & $\mathrm{Y}$ & & $\mathrm{Y}$ & & & & & & & & & & & $\mathrm{R}$ & & & - & - & - & - & \\
\hline MS 24 & 69 & 18 & 09.06 .2008 & - & - & - & - & - & - & - & - & - & - & - & - & - & C & & & & & & & & & & & A & & & & & & & \\
\hline MS 24 & 77 & 28 & 03.07 .2008 & - & - & - & - & - & - & - & - & - & - & - & - & - & C & & & & & & & & & & & A & & & . & & & & B \\
\hline MS 24 & 82 & 28 & 26.07 .2008 & - & - & - & - & - & - & - & - & - & - & - & - & - & $\mathrm{Y}$ & & & & & & & $R$ & & & & $\mathrm{R}$ & & & & & & & \\
\hline MS 24 & 83 & 18 & 26.07 .2008 & 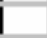 & E & - & - & 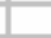 & $\mathrm{Y}$ & - & 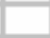 & 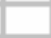 & E & C & C & E & C & & & & & - & - & -- & - & - & - & - & - & - & - & - & -- & - & \\
\hline MS 24 & 92 & PTB 3 & 03.10 .2008 & - & - & - & - & - & - & - & - & - & - & - & - & - & C & & & & & & & & & & & A & & & & & & & \\
\hline MS 24 & 106 & 28 & 29.11 .2008 & F- & - & - & - & - & - & - & - & - & - & - & - & - & C & & & & & & & & & & & A & & & - & - & - & - & \\
\hline MS 24 & 108 & 26 & 12.12 .2008 & - & - & - & - & - & C & & 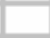 & 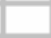 & 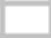 & M & $Y$ & 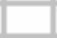 & $\mathrm{Y}$ & & & - & - & - & - & - & - & - & - & - & - & - & - & - & - & - & \\
\hline MS 24 & 138 & PTB 3 & 03.05 .2007 & & 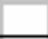 & 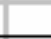 & & 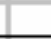 & C & 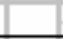 & - & - & - & - & - & - & - & - & - & - & - & - & - & - & - & - & - & - & - & - & - & - & - & - & \\
\hline MS 25 & 62 & 14 & 27.04 .2008 & & 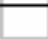 & 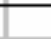 & $G$ & 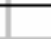 & 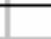 & 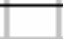 & 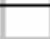 & 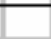 & 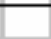 & 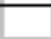 & 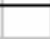 & 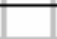 & & $T$ & & - & - & - & - & - & - & - & - & - & - & - & - & - & - & - & \\
\hline MS 25 & 69 & 14 & 09.06 .2008 & F- & - & - & - & - & - & - & - & - & - & - & - & - & & $\mathrm{Y}$ & & & & & & & & & & & $\mathrm{Y}$ & & & C & & & \\
\hline MS 25 & 71 & 14 & 20.06 .2008 & F- & - & - & - & - & - & - & - & - & - & - & - & - & & $\mathrm{Y}$ & & & & & & & $\mathrm{Y}$ & & & & C & & & C & & 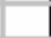 & \\
\hline MS 25 & 78 & 28 & 12.07 .2008 & i- & - & - & - & - & - & - & - & - & - & - & - & - & & $\mathrm{T}$ & & & & & & & & & & & C & & & $\mathrm{C}$ & & & B \\
\hline MS 25 & 128 & 35 & 26.03 .2007 & F- & - & - & - & - & - & - & - & - & - & - & - & - & & $\mathrm{T}$ & & & & & & & & & & & C & & & - & - & - & \\
\hline MS 25 & 136 & 28 & 24.04 .2007 & F- & - & - & - & - & - & & 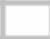 & 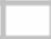 & 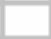 & 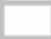 & 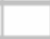 & 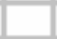 & & $\mathrm{T}$ & & - & - & - & - & - & - & - & - & - & - & - & - & - & - & - & \\
\hline MS 25 & 138 & 35 & 02.05 .2007 & & & & G & & 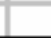 & 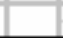 & - & - & - & - & - & - & - & - & - & - & - & - & - & - & - & - & - & - & - & - & - & - & - & - & \\
\hline MS 28 & 83 & 20 & 26.07 .2008 & & & & G & & & & & & & & & & & $T$ & & - & - & - & - & - & - & - & - & - & - & - & - & - & - & - & \\
\hline MS 26 & 107 & 28 & 29.11 .2008 & - & - & - & - & - & - & - & - & - & - & - & - & - & & $T$ & & & & & & & & & & & c & & & c & & & \\
\hline MS 28 & 108 & 28 & 12.12 .2008 & F- & - & - & - & - & & & 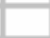 & 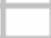 & 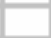 & 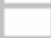 & 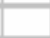 & 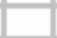 & & $T$ & & - & - & - & - & - & - & - & - & - & - & - & - & - & - & - & D \\
\hline MS 26 & 134 & 28 & 24.04 .2007 & i- & - & - & - & - & & & 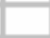 & & & & 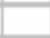 & & & $\mathrm{T}$ & & - & - & - & - & - & - & - & - & - & - & - & - & - & - & - & \\
\hline MS 28 & 138 & 20 & 05.04 .2007 & & & & G & & & & - & - & - & - & - & - & - & - & - & - & - & - & - & - & - & - & - & - & - & - & - & - & - & - & \\
\hline MS 27 & 62 & 20 & 27.04 .2008 & & & & & & & & 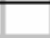 & 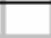 & 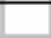 & 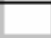 & & 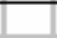 & & & & & & & & & & & & & & & - & - & - & - & \\
\hline MS 27 & 71 & 14 & 20.06 .2008 & I- & - & - & - & - & - & - & - & - & - & - & - & - & & $T$ & & & & & & & & & & & & & $\mathrm{~T}$ & C & & & \\
\hline MS 27 & 78 & 28 & 12.07 .2008 & 1- & - & - & - & - & - & - & - & - & - & - & - & - & & $\mathrm{T}$ & & & & & & & & & & & & & $\mathrm{Y}$ & C & & & \\
\hline MS 27 & 83 & 14 & 26.07 .2008 & $i$ & - & & E & & $\mathrm{Y}$ & & 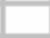 & 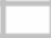 & 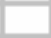 & 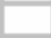 & 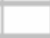 & 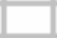 & & $\mathrm{T}$ & & & & - & - & - & - & - & - & - & - & - & - & - & - & - & D \\
\hline MS 27 & 88 & PTB 3 & 01.09 .2008 & i- & - & - & - & - & - & - & - & - & - & - & - & - & & $\mathrm{T}$ & & & & & & & & & & & & & $\mathrm{Y}$ & $\mathrm{Y}$ & & & \\
\hline MS 27 & 90 & PTB 3 & 05.09 .2008 & & & & & & C & & 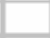 & & & & $\mathrm{Y}$ & & & $T$ & & & & - & - & - & - & - & - & - & - & - & - & - & - & - & \\
\hline MS 27 & 138 & 14 & 24.07 .2007 & & & & & & C & & - & - & - & - & - & - & - & - & - & - & - & - & - & - & - & - & - & - & - & - & - & - & - & - & \\
\hline MS 27 & 139 & PTB 3 & 02.05 .2007 & & & & - & & C & & - & - & - & - & - & - & - & - & - & - & - & - & - & - & - & - & - & - & - & - & - & - & - & - & \\
\hline MS 30 & 72 & Al 1 & 15.06 .2008 & F- & - & - & - & - & - & - & - & - & - & - & - & - & & $T$ & & $G$ & & & & & & $\mathrm{C}$ & & & C & $T$ & & & & & \\
\hline MS 30 & 88 & PTB 3 & 01.09 .2008 & i- & - & - & |- & |- & |- & |- & - & - & - & - & - & - & & $T$ & & & & & & & & $\mathrm{Y}$ & & & $\mathrm{Y}$ & $\mathrm{Y}$ & & & & & \\
\hline MS 30 & 90 & 34 & 05.09 .2008 & iA & & & & & & & & & & & & & & $\mathrm{Y}$ & & & & - & - & - & - & - & - & - & - & - & - & - & - & - & \\
\hline MS 30 & 119 & PTB 3 & 12.02 .2007 & F- & - & - & - & - & & & 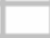 & 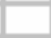 & - & 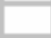 & 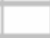 & 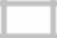 & & $T$ & & & & & & & & & & & - & - & - & - & - & - & D \\
\hline MS 30 & 119 & 34 & 12.02 .2007 & F- & - & - & - & - & - & - & - & - & - & - & - & - & & $T$ & & & & & & & & C & & & C & $T$ & & & & & \\
\hline MS 30 & 127 & 34 & 11.03 .2007 & i- & - & - & - & - & - & - & - & - & - & - & - & - & & $T$ & & & & & & & & c & & & C & $T$ & & - & - & - & \\
\hline MS 30 & 136 & 34 & 24.04 .2007 & i- & - & - & - & - & & & 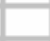 & 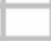 & - & & & & & $\mathrm{T}$ & & & & - & - & - & - & - & - & - & - & - & - & - & - & - & \\
\hline MS 30 & 138 & PTB 3 & 24.07 .2007 & $A$ & & & & & & & - & - & - & - & - & - & - & - & - & - & - & - & - & - & - & - & - & - & - & - & - & - & - & - & \\
\hline
\end{tabular}




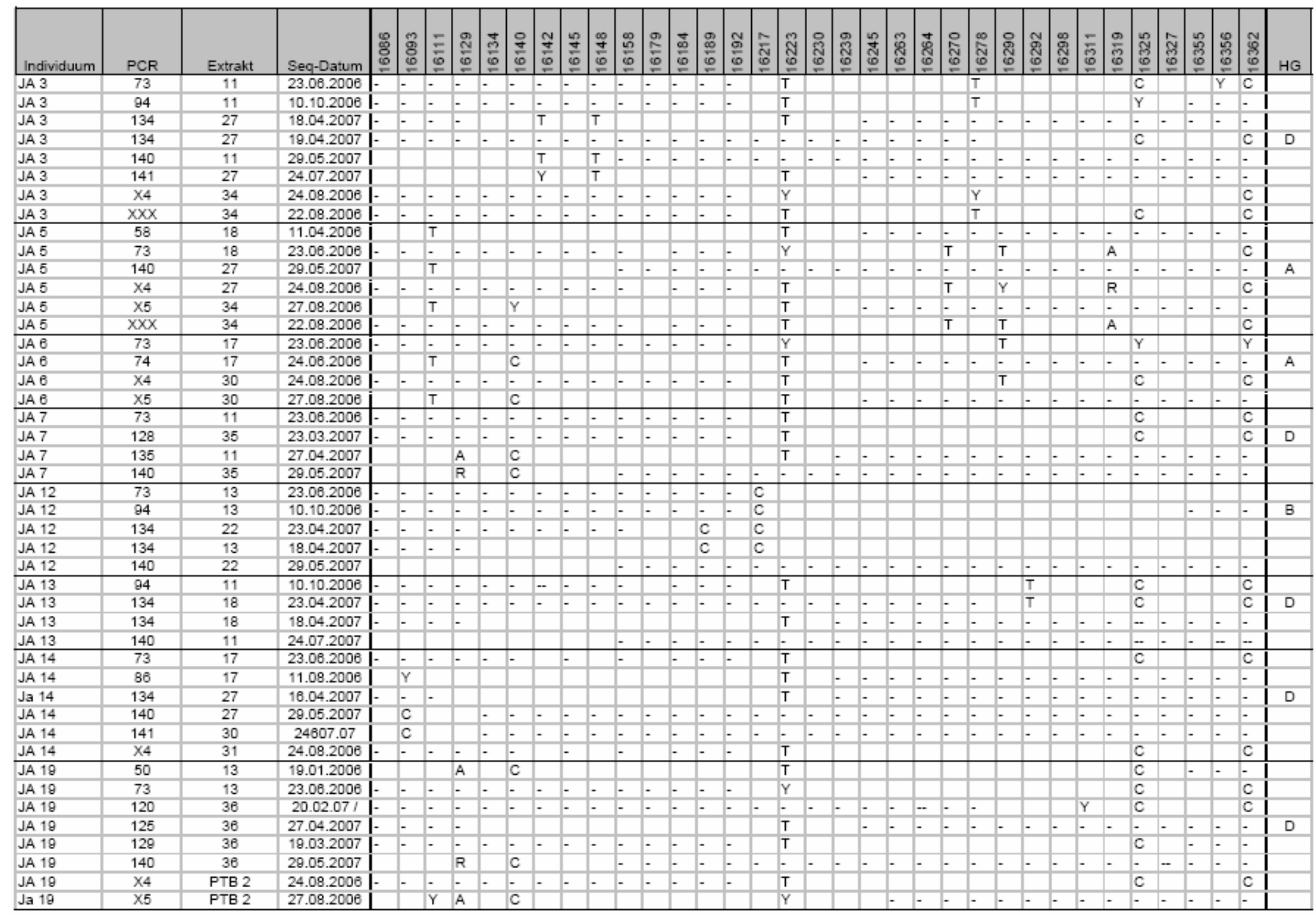




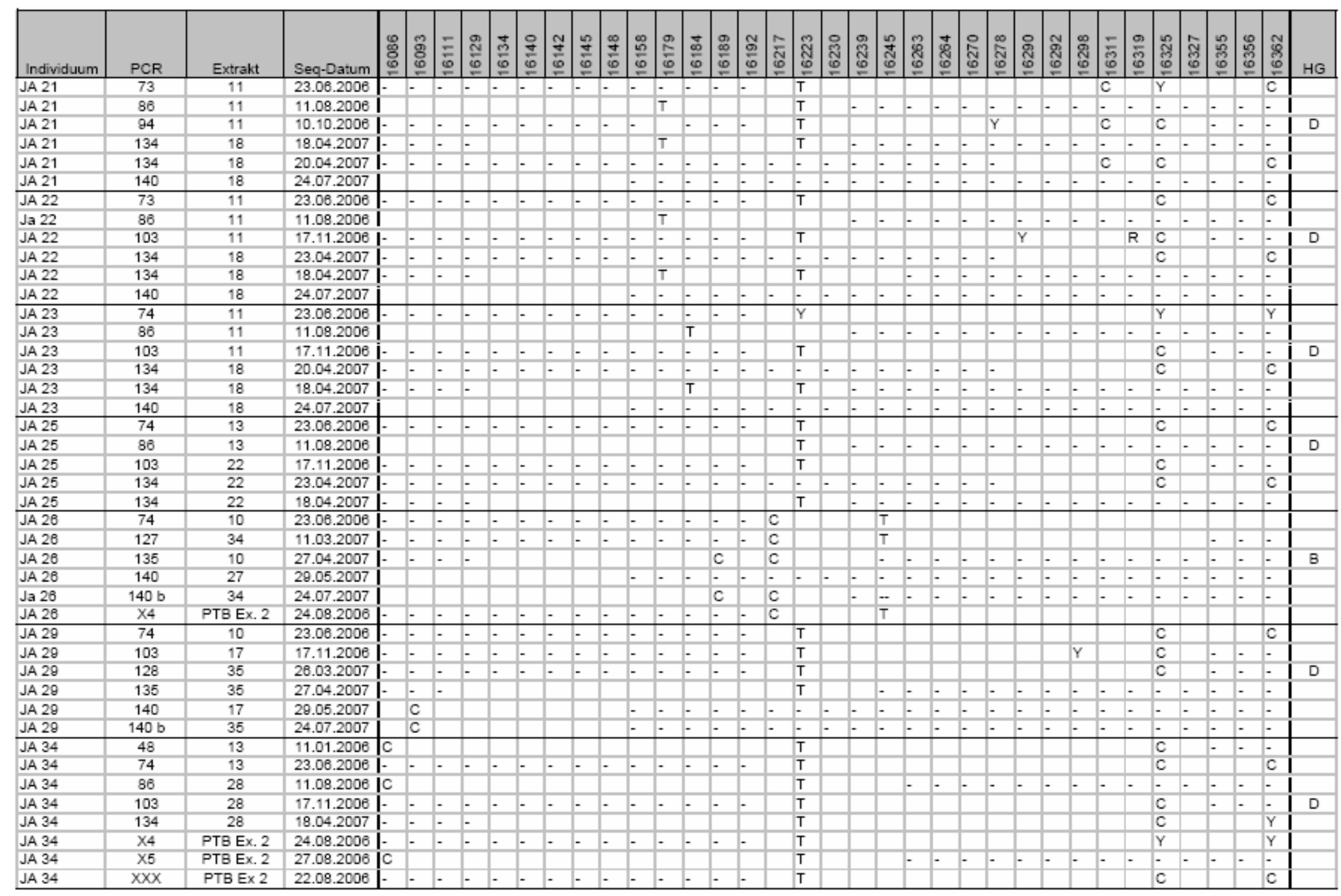




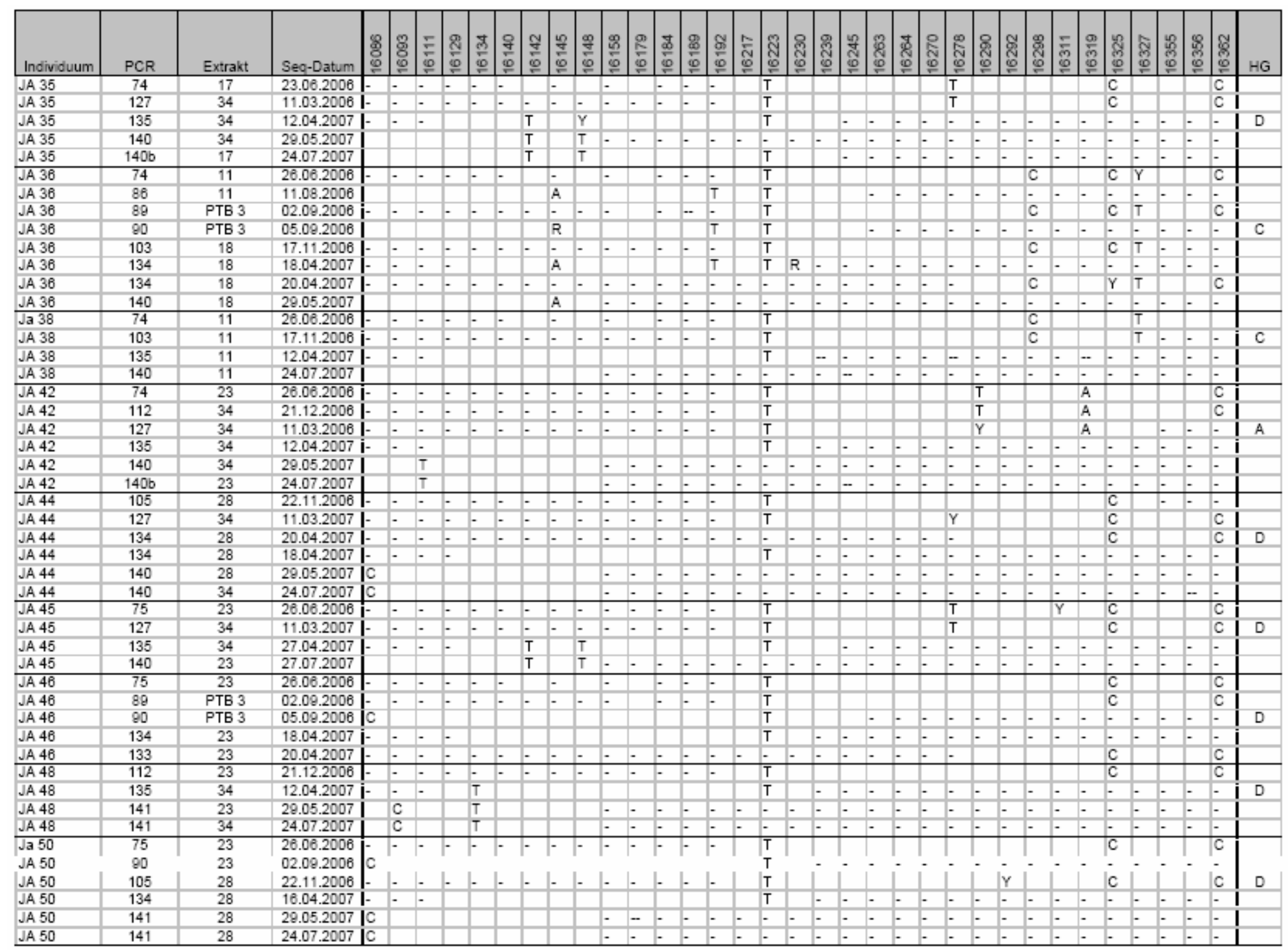




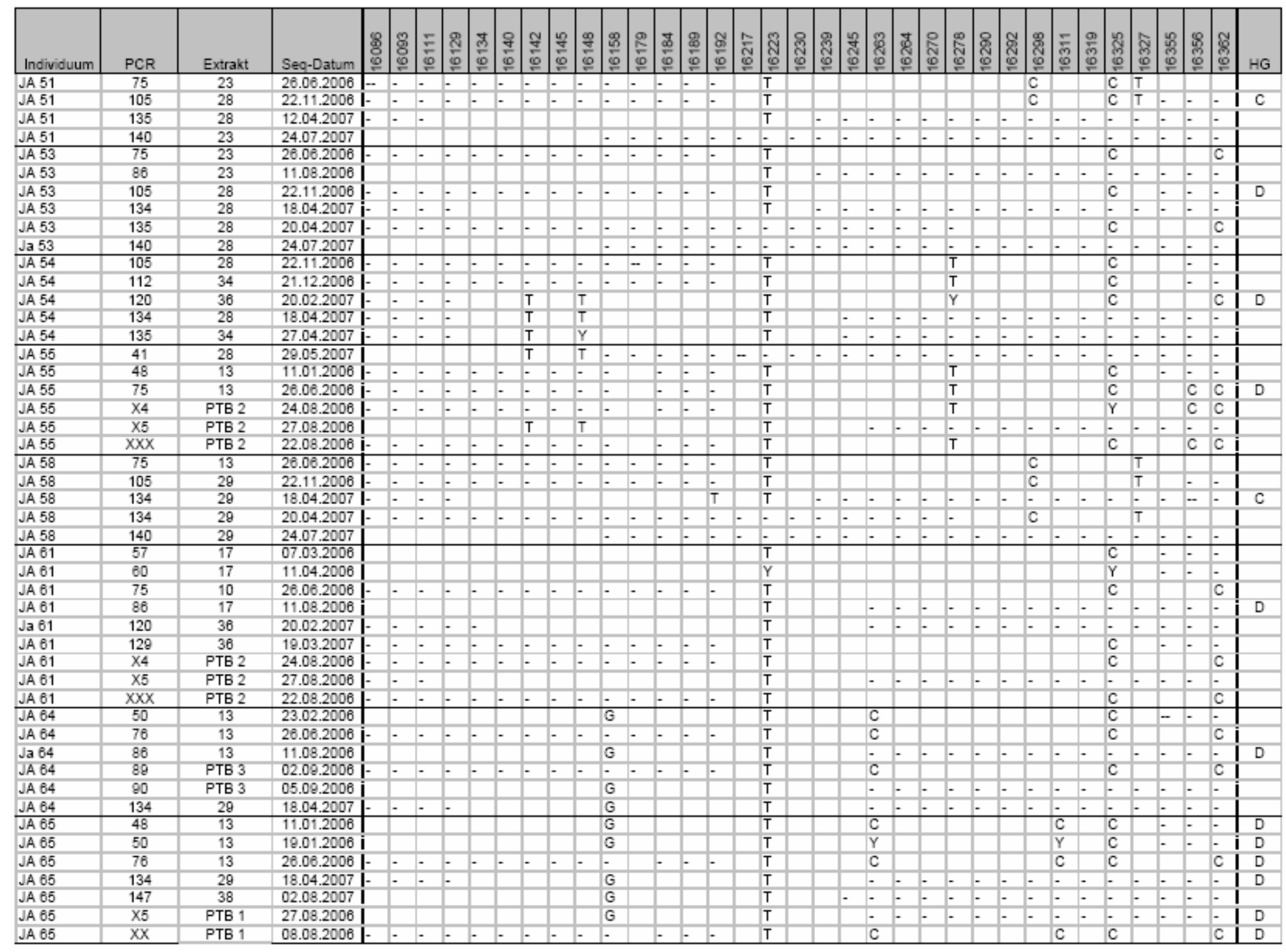




\begin{tabular}{|c|c|c|c|c|c|c|c|c|c|c|c|c|c|c|c|c|c|c|c|c|c|c|c|c|c|c|}
\hline Individuum & PCR & Extrakt & Seq-Datum & $\frac{5}{6}$ & $\frac{O}{6}$ & $\frac{\mathfrak{T}}{\frac{\mathfrak{O}}{6}}$ & $\frac{\infty}{\infty}$ & $\frac{\pi}{0}$ & $\frac{N}{\frac{0}{2}}$ & $\frac{M}{\infty}$ & $\underset{\infty}{\infty}$ & $\begin{array}{l}\mathscr{0} \\
\infty \\
\\
\end{array}$ & $\frac{\pi}{6}$ & 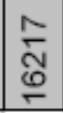 & ָ̃ & $\begin{array}{l}\text { ㅇ } \\
\mathbb{2} \\
0 \\
\end{array}$ & 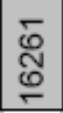 & 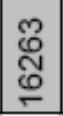 & $\begin{array}{l}\stackrel{0}{N} \\
\stackrel{0}{0}\end{array}$ & $\begin{array}{l}\infty \\
\stackrel{\text { ते }}{0}\end{array}$ & $\frac{}{8}$ & $\underset{\varnothing}{\check{\infty}}$ & $\begin{array}{l}\text { Nิ } \\
\text { లె } \\
\stackrel{0}{\sigma}\end{array}$ & 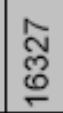 & 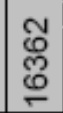 & $\mathrm{HG}$ \\
\hline PA 1 & 110 & 31 & 15.12 .2006 & 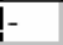 & - & - & - & - & - & - & - & - & - & & $\mathrm{T}$ & & & & & & A & & C & & C & \\
\hline PA 1 & 147 & 38 & 02.08.2007! & & & & & & & & & & & & $\mathrm{T}$ & - & - & - & - & - & - & - & - & - & - & \\
\hline PA 1 & 148 & 38 & 01.09.2007 & - & - & - & - & - & - & - & - & - & - & & $T$ & & & & & & A & & C & & $\mathrm{C}$ & \\
\hline PA 2 & 79 & 12 & 12.07 .2006 & - & - & - & - & - & - & - & - & - & - & & $\mathrm{T}$ & & & & & & & & C & $\mathrm{T}$ & & $\mathrm{C}$ \\
\hline PA 2 & 80 & 12 & 14.07.2006 & & & & & & & & & & & & & - & - & - & - & - & - & - & - & - & - & \\
\hline PA 2 & 110 & 12 & 15.12.2006 & - & - & - & - & - & - & - & - & - & - & & $\mathrm{T}$ & & & & & Y & & & Y & $\mathrm{T}$ & - & \\
\hline PA 2 & 147 & 38 & 02.08.2007ị & & & & & & & & & & & & $T$ & - & - & - & - & - & - & - & - & - & - & \\
\hline PA 2 & 148 & 38 & 01.09.2007 & - & - & - & - & - & - & - & - & - & - & & $\mathrm{T}$ & & & & & & & & C & $\mathrm{T}$ & & \\
\hline PA 7 & 110 & 31 & 15.12 .2006 & - & - & - & - & - & - & - & - & - & - & $\mathrm{C}$ & & & & & & & & & & & - & \\
\hline PA 7 & 120 & 36 & 20.02.2007! & +- & & & & & & & C & C & & C & & & & & & & & & & & & \\
\hline PA 7 & 137 & 31 & 27.04.2007ị & i- & & & $\mathrm{R}$ & & & & C & C & & C & & - & - & - & - & - & - & - & - & - & - & B \\
\hline PA 7 & 141 & 31 & 31.07.2007| & & & & - & - & - & - & - & - & - & - & - & - & - & - & - & - & - & - & - & - & - & \\
\hline PA 7 & 148 & 36 & 12.07 .2006 & - & - & - & - & - & - & - & - & - & - & $\mathrm{C}$ & & & & & & & & & & & & \\
\hline PA 11 & 79 & 12 & 12.07 .2006 & - & - & & - & - & - & - & - & - & - & & $\mathrm{T}$ & & & & & & & & $\mathrm{C}$ & & $\mathrm{C}$ & \\
\hline PA 11 & 90 & 12 & 05.09.2006 & & & & & & $\mathrm{C}$ & & & & & & $T$ & - & - & - & - & - & - & - & - & - & - & $\mathrm{D}$ \\
\hline PA 11 & 120 & 36 & 20.02.2007 & - & & & & & C & & & & & & $T$ & & & & & & & & C & & C & \\
\hline PA 11 & 137 & 36 & 27.04.2007!̣ & - & & & & & $\mathrm{C}$ & & & & & & $T$ & - & - & - & - & - & - & - & - & - & - & \\
\hline PA 11 & 141 & 36 & 31.07 .2007 & & & & - & - & - & - & - & - & - & - & - & - & - & - & - & - & - & - & - & - & - & \\
\hline PA 12 & 77 & 12 & 02.09 .2006 & - & - & - & - & - & - & - & - & - & - & & $\mathrm{T}$ & & & & & $\mathrm{C}$ & & & C & $T$ & & \\
\hline PA 12 & 79 & 12 & 12.07 .2006 & - & - & & - & - & - & - & - & - & - & & $\mathrm{T}$ & & & & & $\mathrm{Y}$ & & & $\mathrm{Y}$ & $T$ & & \\
\hline PA 12 & 90 & 12 & 05.09.2006 & & & & & & & & & & $\mathrm{T}$ & & $\mathrm{T}$ & - & - & - & - & - & - & - & - & - & - & $\mathrm{C}$ \\
\hline PA 12 & 110 & 31 & 15.12.2006 & - & - & - & - & - & - & - & - & - & - & & $T$ & & & & & C & & & C & $\mathrm{T}$ & - & \\
\hline PA 12 & 137 & 31 & 27.04 .2007 & - & & & & & & & & & $T$ & & $T$ & - & - & - & - & - & - & - & - & - & - & \\
\hline PA 12 & 141 & 31 & 31.07 .2007 & & & & - & - & - & - & - & - & - & - & - & - & - & - & - & - & - & - & - & - & - & \\
\hline PA 15 & 110 & 32 & 15.12.2006! & - & - & - & - & - & - & - & - & - & - & & $\mathrm{T}$ & & & & & $\mathrm{C}$ & & & $\mathrm{C}$ & $\mathrm{T}$ & - & \\
\hline PA 15 & 137 & 32 & 27.04.2007) & - & C & & & & & & & & & & $\mathrm{T}$ & - & - & - & - & - & - & - & - & - & - & \\
\hline PA 15 & 141 & 32 & 31.07 .2007 & & C & & - & - & - & - & - & - & - & - & - & - & - & - & - & - & - & - & - & - & - & $\mathrm{C}$ \\
\hline PA 15 & 147 & 38 & 02.08.2007| & & C & & & & & & & & & & $\mathrm{T}$ & - & - & - & - & - & - & - & - & -- & - & \\
\hline PA 15 & 148 & 38 & 12.07.2006 & - & - & & - & - & - & - & - & - & - & & $\mathrm{T}$ & & & & & $\mathrm{C}$ & & & C & $\mathrm{T}$ & & \\
\hline
\end{tabular}




\begin{tabular}{|c|c|c|c|c|c|c|c|c|c|c|c|c|c|c|c|c|c|c|c|c|c|c|c|c|c|c|}
\hline Individuum & PCR & Extrakt & Seq-Datum & $\frac{\check{\sigma}}{\underline{\sigma}}$ & $\stackrel{g}{\stackrel{+}{0}}$ & $\underset{\mathcal{T}}{\stackrel{\mathcal{O}}{0}}$ & $\begin{array}{l}\infty \\
\stackrel{\infty}{0} \\
\stackrel{0}{\infty}\end{array}$ & $\underset{\mathscr{O}}{\mathscr{0}}$ & $\frac{N}{\underline{N}}$ & $\frac{M}{\sigma}$ & $\frac{1}{\infty}$ & $\begin{array}{l}\mathscr{2} \\
\infty \\
\end{array}$ & $\frac{\mathscr{N}}{\sigma}$ & $\underset{\mathbb{N}}{\stackrel{N}{\circ}}$ & $\underset{\mathbb{N}}{\stackrel{N}{-~}}$ & 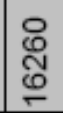 & 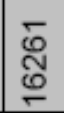 & $\begin{array}{l}\text { m } \\
\text { స్ } \\
0 \\
\end{array}$ & $\begin{array}{l}\stackrel{0}{N} \\
\stackrel{N}{0}\end{array}$ & 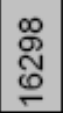 & $\stackrel{\circ}{\stackrel{8}{\infty}}$ & 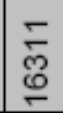 & $\begin{array}{l}\tilde{N} \\
\text { ల్ } \\
\varrho \\
\underline{n}\end{array}$ & స̃ & 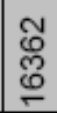 & $\mathrm{HG}$ \\
\hline PA 17 & 110 & 32 & 15.12 .2006 & - & - & - & - & - & - & - & - & - & - & & $T$ & & & $\mathrm{C}$ & & & & C & C & & C & \\
\hline PA 17 & 137 & 32 & 27.04 .2007 & - & & & G & & & & & & & & $\mathrm{T}$ & - & - & - & - & - & - & - & - & - & - & \\
\hline PA 17 & 141 & 32 & 31.07 .2007 & & & & - & - & - & - & - & - & - & - & - & - & - & - & - & - & - & - & - & - & - & D \\
\hline PA 17 & 147 & 38 & $02.08 .2007 \mid$ & & & & G & & & & & & & & $\mathrm{T}$ & - & - & - & - & - & - & - & - & - & - & \\
\hline PA 17 & 148 & 38 & 13.07 .2006 & - & - & & - & - & - & - & - & - & - & & $\mathrm{T}$ & & & C & & & & C & C & & C & \\
\hline PA 18 & 79 & 12 & 13.07 .2006 & - & - & - & - & - & - & - & - & - & - & & $\mathrm{T}$ & & & & & $\mathrm{C}$ & & & $\mathrm{C}$ & $T$ & $\mathrm{C}$ & \\
\hline PA 18 & 80 & 12 & 14.07 .2006 & & & & & & & & & & $\mathrm{~T}$ & & $\mathrm{~T}$ & - & - & - & - & - & - & - & - & - & - & \\
\hline PA 18 & 110 & 32 & 15.12.2006! & í- & - & - & - & - & - & - & - & - & - & & $\mathrm{T}$ & & & & & C & & & C & $\mathrm{T}$ & C & $\mathrm{C}$ \\
\hline PA 18 & 137 & 32 & 27.04 .2007 & - & & & & & & & & & $\mathrm{T}$ & & $\mathrm{T}$ & - & - & - & - & - & - & - & - & - & - & \\
\hline PA 18 & 141 & 32 & 31.07 .2007 & & & & - & - & - & - & - & - & - & - & - & - & - & - & - & - & - & - & - & - & - & \\
\hline PA 19 & 79 & 12 & 13.07 .2006 & 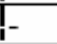 & - & & - & - & - & - & - & - & - & & $\mathrm{T}$ & & & & & & & & C & & C & \\
\hline PA 19 & 80 & 12 & 14.07.2006 & & & & & & & & & & & & $\mathrm{T}$ & - & - & - & - & - & - & - & - & - & - & D \\
\hline PA 19 & 110 & 32 & 15.12 .2006 & 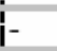 & - & - & - & - & - & - & - & - & - & & $T$ & & & & & & & & C & & C & \\
\hline PA 19 & 137 & 32 & 27.04 .2007 & - & & & & & & & & & & & $\mathrm{T}$ & - & - & - & - & - & - & - & - & - & - & \\
\hline PA 20 & 79 & 12 & 13.07 .2006 & - & - & - & - & - & - & - & - & - & - & & $T$ & & & & & C & & & C & $T$ & C & \\
\hline PA 20 & 86 & 32 & 11.08 .2006 & & & & & & & & & & $T$ & & $\mathrm{~T}$ & - & - & - & - & - & & - & - & - & - & \\
\hline PA 20 & 88 & PTB 3 & 01.09 .2006 & - & - & - & - & - & - & - & - & - & - & & $\mathrm{T}$ & & & & & $\mathrm{C}$ & & & C & $T$ & C & C \\
\hline PA 20 & 90 & PTB 3 & 05.09 .2006 & & & & & & & & & & $\mathrm{Y}$ & & $T$ & - & - & - & - & - & & - & - & - & - & \\
\hline PA 20 & 110 & 32 & 15.12.2006! & i- & - & - & - & - & - & - & - & - & - & & $\mathrm{T}$ & & & & & $\mathrm{Y}$ & & & C & $T$ & - & \\
\hline PA 20 & 137 & 32 & 27.04 .2007 & - & & & & & & & & & $\mathrm{T}$ & & $T$ & - & - & - & - & - & - & - & - & - & - & \\
\hline PA 20 & 147 & 38 & 02.08 .2007 & & & & & & & & & & $\mathrm{~T}$ & & $T$ & - & - & - & - & - & - & - & - & - & - & - \\
\hline PA 21 & 79 & 12 & 13.07 .2006 & - & - & & - & - & - & - & - & - & - & & $T$ & & & & & & & & C & & C & \\
\hline PA 21 & 80 & 12 & 14.07.2006 & & & & $\mathrm{G}$ & & & & & & & & $\mathrm{T}$ & - & - & - & - & - & - & - & - & - & - & $\mathrm{D}$ \\
\hline PA 21 & 110 & 19 & 14.12 .2006 & - & - & - & - & - & - & - & - & - & - & & $\mathrm{T}$ & & & & & & & & C & & C & \\
\hline PA 21 & 137 & 19 & 27.04 .2007 & - & & & G & & & & & & & & $\mathrm{T}$ & - & - & - & - & - & - & - & - & - & - & \\
\hline
\end{tabular}




\begin{tabular}{|c|c|c|c|c|c|c|c|c|c|c|c|c|c|c|c|c|c|c|c|c|c|c|c|c|}
\hline Individuum & PCR & Extrakt & Seq-Datum & $\stackrel{\mathscr{m}}{\complement}$ & ले & $\frac{\hat{m}}{\stackrel{0}{c}}$ & $\frac{8}{6}$ & 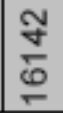 & $\frac{N}{N}$ & $\stackrel{\mathscr{R}}{\complement}$ & $\stackrel{亡}{\infty}$ & $\stackrel{\varpi}{\infty}$ & ָู & ֻू & 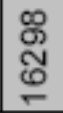 & Е్ & ஜூ & 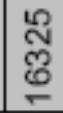 & స్ & $\begin{array}{l}\text { पू } \\
\text { ญొ } \\
\end{array}$ & 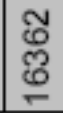 & 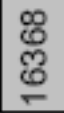 & 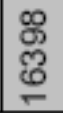 & $\mathrm{HG}$ \\
\hline $\mathrm{PC} 2$ & 89 & 21 & 20.09 .2006 & - & - & - & - & - & - & - & - & & $\mathrm{T}$ & & $\mathrm{C}$ & & & C & $\mathrm{T}$ & & & & & \\
\hline PC 2 & 109 & 21 & 12.12 .2006 & & & & & & & & & & $\mathrm{~T}$ & - & - & - & - & - & - & - & - & - & - & \\
\hline PC 2 & 120 & 36 & 20.02.2007! & & & & & & & & & & $\mathrm{T}$ & & $\mathrm{Y}$ & & & C & $\mathrm{Y}$ & & & & & $\mathrm{C}$ \\
\hline PC 2 & 129 & 36 & 19.03.2007| & - & - & - & - & - & - & - & - & - & $\mathrm{Y}$ & & $\mathrm{C}$ & & & C & $\mathrm{T}$ & & - & - & - & \\
\hline PC 2 & 132 & 36 & 26.03 .2007 & - & - & - & - & - & - & - & - & - & $\mathrm{Y}$ & & $\mathrm{C}$ & & & $\mathrm{Y}$ & $\mathrm{T}$ & & - & - & - & \\
\hline PC 2 & 143 & 21 & 31.07 .2007 & & & & & & - & - & - & - & - & - & - & - & - & - & - & - & - & - & - & \\
\hline PC 3 & 63 & 21 & 21.04 .2006 & & & & & & & & & & $\mathrm{~T}$ & & & & & C & & - & - & - & - & \\
\hline PC 3 & 84 & 21 & 07.08 .2006 & & - & - & - & - & - & - & - & - & $\mathrm{T}$ & & & & & C & & & C & & & \\
\hline PC 3 & 109 & 36 & 12.12 .2006 & & & & & & & & & & $\mathrm{~T}$ & & - & - & - & - & - & - & - & - & - & D \\
\hline PC 3 & 120 & 21 & $20.02 .2007 \mid$ & - & & & $\mathrm{C}$ & & & & & & $\mathrm{T}$ & & - & - & - & - & - & - & - & - & - & \\
\hline PC 3 & 129 & 36 & 19.03.2007! & - & - & - & - & - & - & - & - & - & $\mathrm{T}$ & & & & & $\mathrm{Y}$ & & & C & & & \\
\hline $\mathrm{PC} 3$ & 143 & 36 & $31.07 .2007 \mathbf{j}$ & & & & C & & - & - & - & - & - & - & - & - & - & - & - & - & - & - & - & \\
\hline PC 5 & 109 & 21 & 12.12 .2006 & & & & & & & & $\mathrm{~T}$ & & $\mathrm{~T}$ & - & - & - & - & - & - & - & - & - & - & \\
\hline PC 5 & 111 & 21 & 20.12 .2006 & - & - & - & - & - & - & - & - & - & $\mathrm{T}$ & & 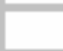 & & & C & & & C & & & \\
\hline PC 5 & 137 & 21 & $27.04 .2006 \mathbf{i}$ & & & & & & & & $\mathrm{T}$ & & $\mathrm{T}$ & - & - & - & - & - & - & - & - & - & - & D \\
\hline PC 5 & 143 & 38 & 31.07.2007! & & & & & & - & - & - & - & - & - & - & - & - & - & - & - & - & - & - & \\
\hline PC 5 & 146 & 38 & 22.06 .2007 & - & - & - & - & - & - & - & - & - & - & - & & & & C & & & C & & & \\
\hline PC 6 & 109 & 21 & 12.12 .2006 & & & & & & & & & & $\mathrm{~T}$ & - & - & - & - & - & - & - & - & - & - & \\
\hline PC 6 & 111 & 21 & 20.12 .2006 & & - & - & - & - & - & - & - & - & $\mathrm{T}$ & & & & & C & & & C & & & \\
\hline PC 6 & 120 & 36 & $20.02 .2007 \mid$ & - & - & - & - & & & & & & $\mathrm{T}$ & & & & & C & & & C & & & D \\
\hline PC 6 & 129 & 36 & 19.03.2007 & - & - & - & - & - & - & - & - & - & $\mathrm{Y}$ & & & & & C & & & - & - & - & \\
\hline PC 6 & 137 & 36 & 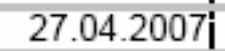 & & & & & & & & & & $\mathrm{T}$ & - & - & - & - & - & - & - & - & - & - & \\
\hline PC 6 & 143 & 36 & $31.07 .2007 \mathbf{i}$ & & & & & & - & - & - & - & - & - & - & - & - & - & - & - & - & - & - & \\
\hline PC 8 & 63 & 21 & 27.04 .2006 & & - & - & - & - & - & - & - & - & $\mathrm{T}$ & & & & & C & & & $\mathrm{C}$ & & & \\
\hline PC 8 & 63 & 21 & 21.04 .2006 & & & & C & & & & & & $\mathrm{T}$ & - & - & - & - & - & - & - & - & - & - & \\
\hline $\mathrm{PC} 8$ & 109 & 36 & 12.12 .2006 & & & & $\mathrm{Y}$ & & & & & & $\mathrm{T}$ & - & - & - & - & - & - & - & - & - & - & D \\
\hline PC 8 & 120 & 36 & $20.02 .2007 \hat{\mathbf{j}}$ & & - & - & - & & & & & & $\mathrm{T}$ & & & & & C & & & C & & & \\
\hline PC 8 & 137 & 36 & 27.04 .2007 & & & & C & & & & & & $\mathrm{T}$ & - & - & - & - & - & - & - & - & - & - & \\
\hline PC 11 & 109 & 21 & 12.12 .2001 & & & & & & & & & & $T$ & - & - & - & - & - & - & - & - & - & - & \\
\hline PC 11 & 111 & 21 & 20.12 .2006 & - & - & - & - & - & - & - & - & - & $\mathrm{T}$ & & $\mathrm{C}$ & & & & $\mathrm{T}$ & & & & & \\
\hline PC 11 & 118 & 32 & $12.02 .2007 !$ & & - & - & - & - & - & - & - & - & $\mathrm{T}$ & & $\mathrm{Y}$ & & & & $\mathrm{T}$ & & & & & $\mathrm{C}$ \\
\hline PC 11 & 132 & 32 & $26.03 .2007 \mathbf{i}$ & - & - & - & - & - & - & - & - & - & $\mathrm{T}$ & & $\mathrm{C}$ & & & & $\mathrm{T}$ & & - & - & - & \\
\hline PC 11 & 137 & 32 & 27.04 .2007 & & & & & & & & & & & - & - & - & - & - & - & - & - & - & - & \\
\hline
\end{tabular}




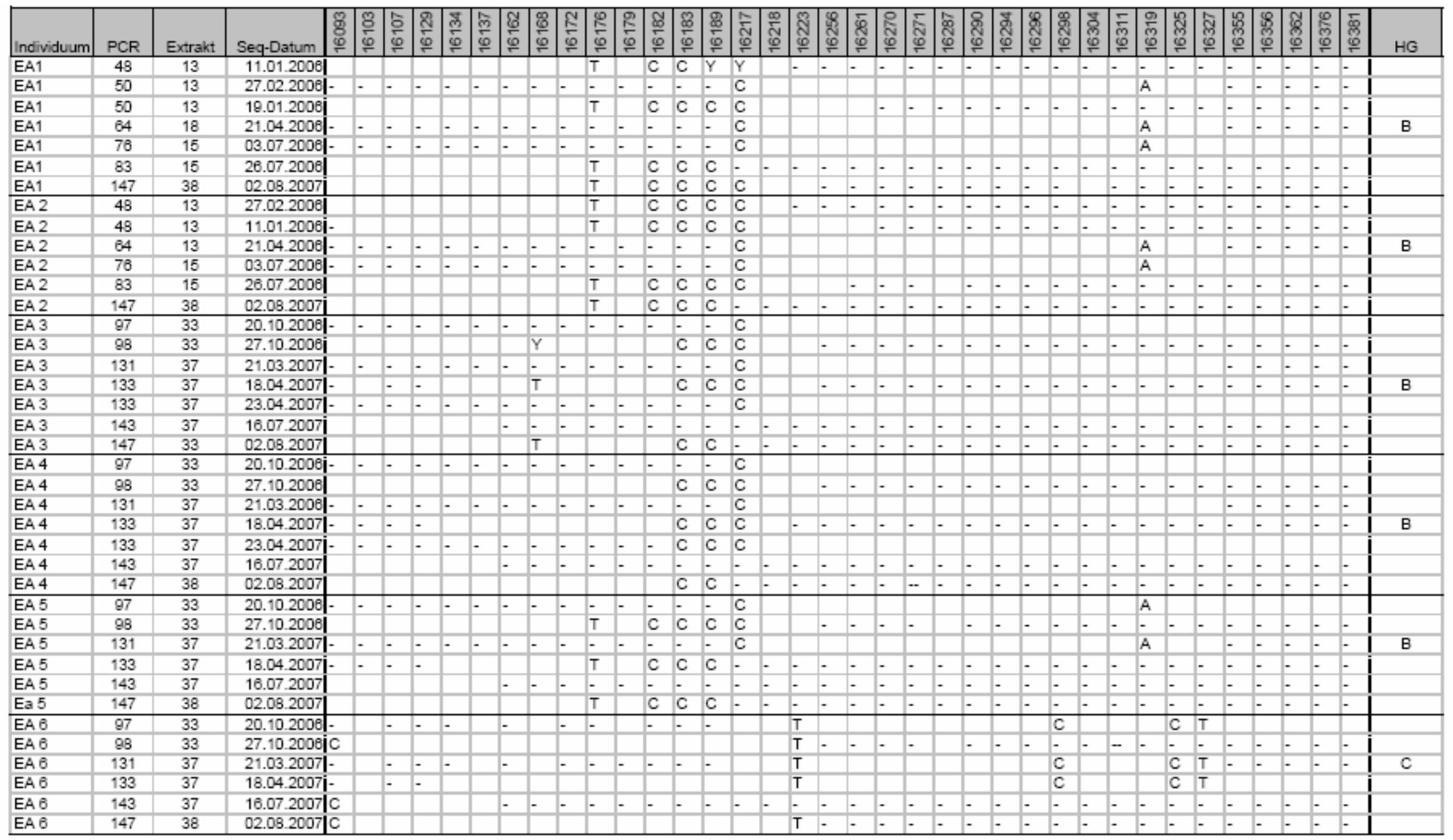




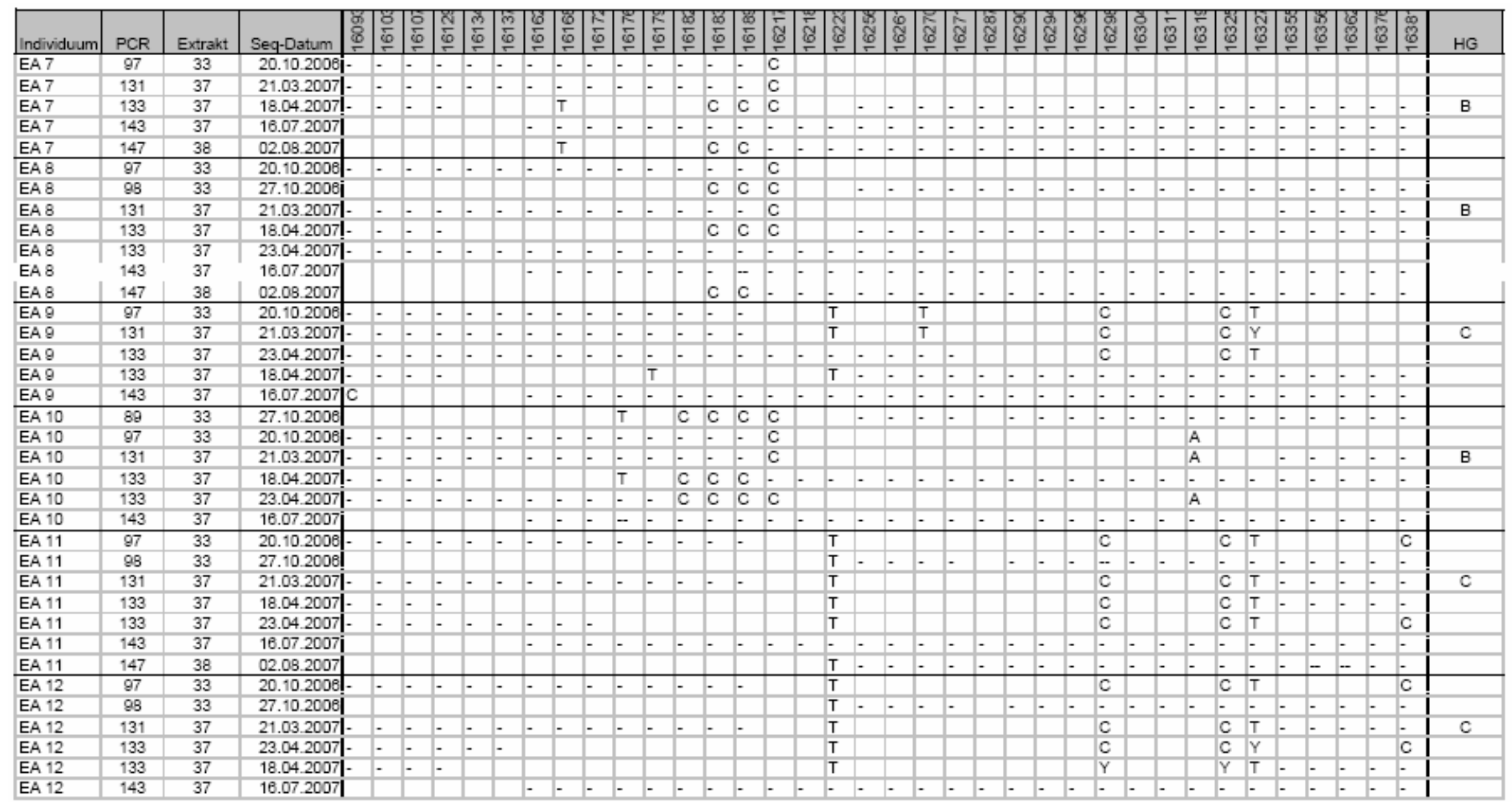




\begin{tabular}{|c|c|c|c|c|c|c|c|c|c|c|c|c|c|c|c|c|c|c|c|c|}
\hline Individuum & PCR & Extrakt & Seq-Datum & $\begin{array}{l}\text { \% } \\
\text { 。 } \\
\varrho\end{array}$ & $\frac{8}{\square}$ & $\frac{\sqrt[b]{0}}{\square}$ & $\frac{\infty}{\infty}$ & $\stackrel{\infty}{\infty}$ & $\begin{array}{l}\text { क } \\
\stackrel{\infty}{\infty}\end{array}$ & $\frac{1}{\infty}$ & $\begin{array}{l}\text { N } \\
\stackrel{0}{ }\end{array}$ & $\underset{\stackrel{\mathbb{J}}{Ð}}{\stackrel{\Gamma}{\circ}}$ & 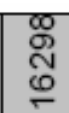 & 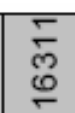 & $\begin{array}{l}\text { w } \\
\text { Nै} \\
0\end{array}$ & 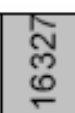 & $\begin{array}{l}\text { N } \\
\text { लू } \\
0\end{array}$ & $\begin{array}{l}\text { ญू } \\
\text { లె } \\
0\end{array}$ & $\begin{array}{l}\text { 寸 } \\
\text { 守 } \\
\text { }\end{array}$ & $\mathrm{HG}$ \\
\hline MA 1 & 76 & 15 & 03.07 .2006 & - & - & - & - & - & - & & $T$ & & C & & $\mathrm{C}$ & $T$ & & & $T$ & \\
\hline MA 1 & 135 & 15 & $27.04 .2007 \mathbf{i}$ & - & & A & & & & & $\mathrm{T}$ & - & - & - & - & - & - & - & - & \\
\hline MA 1 & 143 & 18 & 31.07 .2007 & & & A & - & - & - & - & - & - & - & - & - & - & - & - & - & C \\
\hline MA 1 & 144 & 18 & 03.08 .2007 & 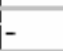 & & A & & & & & $\mathrm{T}$ & - & - & - & - & - & - & - & - & \\
\hline MA 1 & 146 & 18 & 22.06 .2007 & - & - & - & - & - & - & & $\mathrm{T}$ & & $\mathrm{C}$ & & C & $\mathrm{T}$ & & & $\mathrm{T}$ & \\
\hline MA 5 & 96 & 24 & $19.10 .2006 \mathbf{j}$ & - & - & - & - & - & - & & $\mathrm{T}$ & & & & C & $\mathrm{T}$ & & & & \\
\hline MA 5 & 98 & 24 & 27.10.2006 & $\mathrm{C}$ & & & & & & & $\mathrm{T}$ & & - & - & - & - & & - & - & \\
\hline MA 5 & 135 & 33 & 27.04 .2007 & - & & & & & & & $\mathrm{T}$ & - & - & - & - & - & - & - & - & C \\
\hline MA 5 & 143 & 33 & 31.07 .2007 & $\mathrm{C}$ & & & - & - & - & - & - & - & - & - & - & - & - & - & - & \\
\hline MA 5 & 146 & 33 & $22.06 .2007 \mathbf{j}$ & - & - & - & - & - & - & & $\mathrm{T}$ & & & & C & $\mathrm{T}$ & & & & \\
\hline MA 6 & 99 & 24 & 27.10 .2006 & & $\mathrm{C}$ & 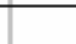 & & $\mathrm{C}$ & C & C & & - & - & - & - & - & - & - & - & \\
\hline MA 6 & 100 & 24 & 29.10 .2006 & - & - & - & - & - & - & C & & & & & & & & & & $\mathrm{B}$ \\
\hline MA 6 & 146 & 33 & 22.06.2007 & - & - & - & - & - & - & - & - & - & & & & & & & & \\
\hline MA 6 & 147 & 33 & $02.08 .2007 \mathbf{i}$ & & $\mathrm{C}$ & & & C & C & - & - & - & - & - & - & - & - & - & - & \\
\hline ME 1 & 76 & 15 & 03.07 .2006 & - & - & - & - & - & - & & $\mathrm{T}$ & & & & C & & & $\mathrm{C}$ & & \\
\hline ME 1 & 98 & 15 & 27.10 .2006 & & & & & & & & $\mathrm{~T}$ & - & - & - & - & - & - & - & - & D \\
\hline $\mathrm{ME} 1$ & 132 & 30 & 26.03.2007 & - & - & - & - & - & - & & $\mathrm{T}$ & & & & C & & & $\mathrm{C}$ & & \\
\hline ME 1 & 147 & 38 & $02.08 .2007 \mathbf{i}$ & & & & & & & & $\mathrm{T}$ & - & - & - & - & - & - & - & - & \\
\hline ME 2 & 48 & 13 & 11.01 .2006 & & & & & & & & $\mathrm{~T}$ & - & - & - & - & - & - & - & - & \\
\hline ME 2 & 76 & 15 & 03.07 .2006 & - & - & - & - & - & - & & $\mathrm{T}$ & & C & & C & & & $\mathrm{C}$ & & $\mathrm{C}$ \\
\hline ME 2 & 142 & 15 & $31.07 .2007 \mid$ & & & & - & - & - & - & - & - & - & - & - & - & - & - & - & \\
\hline ME 2 & 146 & 15 & 20.09 .2006 & - & - & - & - & - & - & & $\mathrm{T}$ & & $\mathrm{C}$ & & C & & & $\mathrm{C}$ & & \\
\hline ME 3 & 76 & 15 & 03.07 .2006 & - & - & - & - & - & - & & $T$ & $\mathrm{~T}$ & & & C & & C & $\mathrm{C}$ & & \\
\hline ME 3 & 132 & 30 & 26.03 .2007 & - & - & - & - & - & - & & $T$ & $\mathrm{~T}$ & & & C & & C & - & - & \\
\hline ME 3 & 142 & 15 & $31.07 .2007 \mathbf{j}$ & & & & - & - & - & - & - & - & - & - & - & - & - & - & - & D \\
\hline ME 3 & 147 & 30 & 02.08 .2007 & $\mathrm{C}$ & & & & & & & $\mathrm{T}$ & - & - & - & - & - & - & - & - & \\
\hline ME 3 & 148 & 30 & $05.08 .2007 \mathbf{i}$ & - & - & - & - & - & - & & $\mathrm{T}$ & $\mathrm{Y}$ & & & C & & C & C & & \\
\hline
\end{tabular}




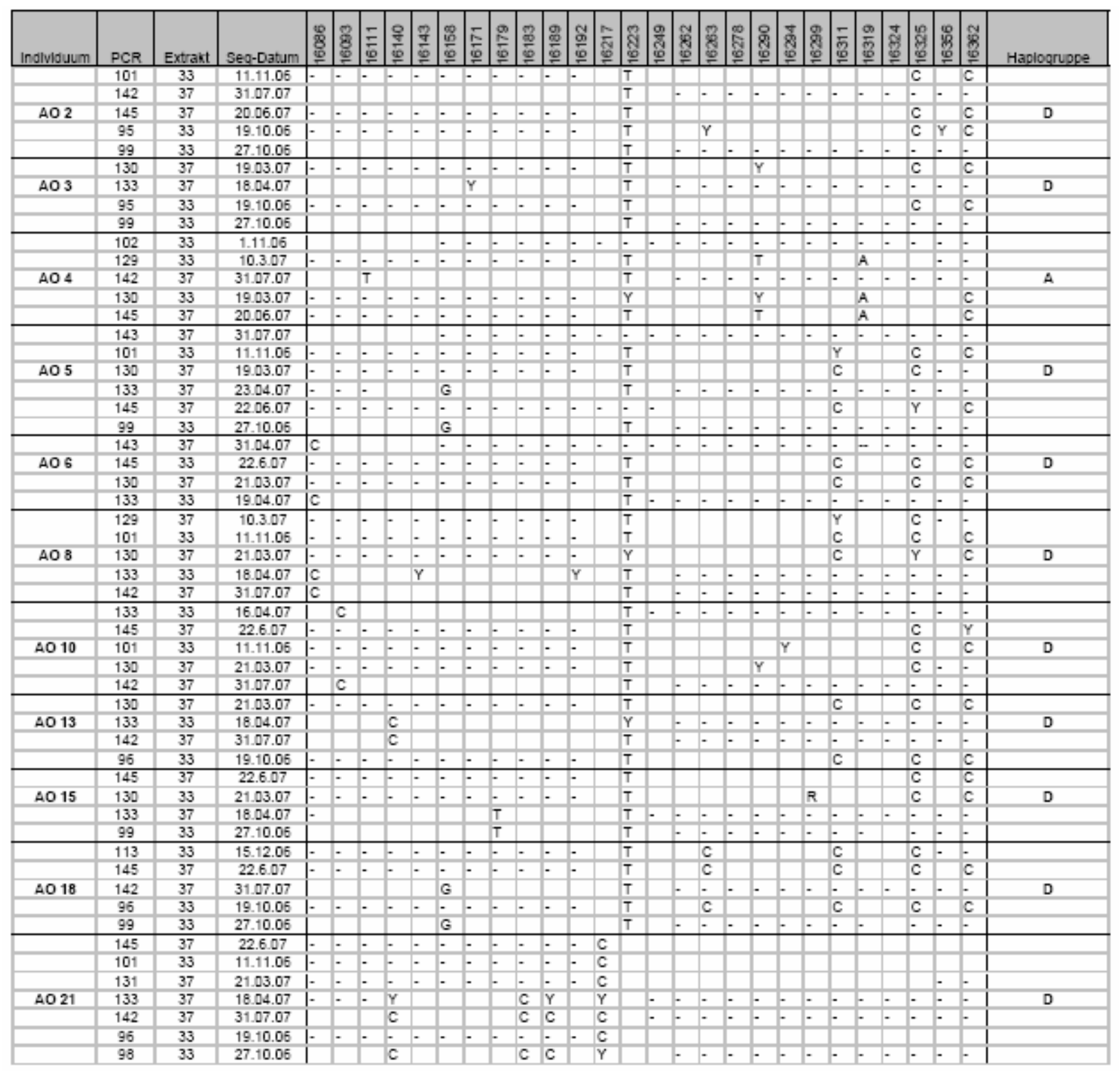




\section{Danksagung}

Meinem Doktorvater Herrn Prof. Dr. Bernd Herrmann möchte ich für die Gelegenheit danken, über dieses Thema zu promovieren. Darüber hinaus danke ich ihm für all die Unterstützung, die Gedankenaustausche und vor allem für sein langjähriges Engagement zur Förderung meiner wissenschaftlichen Karriere. Ich habe einen vorzüglichen Lehrer in ihm gefunden.

Herrn Prof. Dr. Willroth bin ich auch für all die Förderung und Unterstützung zu Dank verpflichtet, die er mir über all die Jahre zuteil hat werden lassen.

Frau Dr. Susanne Hummel danke ich für ihre Hilfe und ihren Rat, führ die langen Gespräche und dafür, dass sie mich in die wundervolle Welt der Paläogenetik eingeführt hat.

Ebenso will ich den langjährigen Kollegen/-innen der Abteilung für Historische Anthropologie, allen voran Frau Dr. Birgit Großkopf, Katharina Boufaden, Ed George und Ulla Schulz für die wissenschaftlichen, freundschaftlichen und alle anderen Gespräche danken. Für all die guten Stunden die wir zusammen im Institut verbracht haben.

Mein besonderer Dank gilt Frau Rebecca Renneberg, die mir eine wundervolle Freundin und Kollegin über die letzten drei Jahre war. Für die Zeit im Feld und dafür, dass wir uns trotz aller Tiefen immer wieder zurück ins Leben geholt haben. Nicht weniger danke ich Jutta Pepperl. Ich denke wir waren insgesamt ein gutes Doktoranden-Trio und Team.

Ich danke den Kollegen des Projektverbundes, allen voran Prof. Dr. Stefan Hölzl, Dr. Markus Reindel, Dr. Jörg Fassbinder für die hervorragende und freundschaftliche Zusammenarbeit im Projekt und im Feld. Ganz besonderer Dank gilt Herrn Prof. Dr. Peter Horn, dafür das er meinen Glauben an die Menschlichkeit in der Wissenschaft gestärkt hat und daran das man dort auch überleben kann, ohne sich Anzupassen.

Ich danke meinen studentischen Hilfskräften und Studenten ohne die es nicht möglich gewesen wäre die gewaltige Masse an Proben zu bewältigen. Namentlich: Rabea Kleindorp, Anke Liebert, Sandra Melchisedech, Conny Wiedwald, Marcel Adler und Max Westenthanner.

Frau Dipl. Psych. Ellen Vogel, Verena Seidenberg und Jan Bolten danke ich, dass sie lange Nächte mit meinem Text verbracht haben, um meine naturgegebene Abneigung gegen die deutsche Rechtschreibung zu kompensieren.

Mein herzlichster Dank gilt meiner Familie, allem voran meinen Eltern für ihre Unterstützung und das sie den Wunsch ihres Sohnes, Archäologe und Anthropologe zu werden und nicht reich und mit einer sicheren Zukunft ausgestattet, unterstützt haben und nicht unterbunden. 
Ich danke all meinen Freunden. Dafür, dass sie zu mir halten und mich unterstützen, dass sie mich lieben wie ich bin und mich zu schätzen wissen. Ohne sie wäre das Leben nichts und aller Erfolg wertlos. An dieser Stelle sei vor allem auch meiner besten Freundin Julia Bornemann gedankt.

"for those I love I will sacrifice"

Die Arbeit wurde aus Mitteln des Bundesministeriums für Bildung und Forschung (BMBF), Förderkennzeichen 03HEX1VP finanziert. 


\section{Lebenslauf}

Lars Fehren-Schmitz

geboren am 09.06.1976 in Aurich

Staatsangehörigkeit: deutsch

Familienstand:ledig

1982-1986

1986-1988

1988-1996

1996-1997

1997-2002

1998-2002

1998-1999

2000-2001

20001-2002

2002

Oktober 2002

$01.2003-12.2003$

$01.2004-06.2004$

$07.2004-12.2004$

$01.2005-04.2008$

1998-2008
Emsschule, Grundschule, Emden

Wallschule, Orientierungsstufe, Emden

Johannes-Althusius-Gymnasium, Emden

Abschluss: Allgemeine Hochschulreife

Zivildienst in Emden; Psychiatrische

Klinik Hans-Susemihl-Krankenhaus

Studium der Ur- und Frühgeschichte und Anthropologie (Biologie) an der Georg-August-Universität Göttingen; Magister-Studium mit zwei gleichwertigen Hauptfächern. Außerdem: Umweltgeschichte, Kulturanthropologie und Medizin.

Gewählter Studentensprecher und Mitglied des Institutsvorstandes; Seminar für Ur- und Frühgeschichte

Stud. Hilfskraft (Hiwi), Institut für Ur- und Frühgeschichte, Universität Göttingen

Stud. Hilfskraft (Hiwi), Historische Anthropologie und Humanökologie, Inst. für Zoologie und Anthropologie, Universität Göttingen

Stud. Hilfskraft (Hiwi), Institut für Ur- und Frühgeschichte, Universität Göttingen

Magisterarbeit am Institut für Zoologie und Anthropologie, Abt.

Historische Anthropologie und Humanökologie der Universität

Göttingen mit dem Titel: Johannisstaße 28 in Göttingen. Auswertung eines umwelt- und sozialhistorischen Archivs.

Absolvierung des Magisters in Ur- und Frühgeschichte und Anthropologie (Biologie). M.A., Georg-August-Universität Göttingen (Note: 1)

wiss. Mitarbeiter, Historische Anthropologie und Humanökologie, Institut für Zoologie und Anthropologie, Universität Göttingen

freier wiss. Mitarbeiter; Historische Anthropologie und Humanökologie, Institut für Zoologie und Anthropologie, Universität Göttingen

Promotionsstipendiat im Graduiertenkolleg 1024 ,Interdisziplinäre Umweltgeschichte" Institut für Zoologie und Anthropologie, Universität Göttingen

wiss. Mitarbeiter \& Projektkoordinator; Historische Anthropologie und Humanökologie, Institut für Zoologie und Anthropologie, Universität Göttingen. Paläogentische Untersuchungen zur Nasca-Kultur in Peru (BMBF-Förderschwerpunkt NTG: Nasca: Entwicklung und Adaptation archäometrischer Techniken zur Erforschung der Kulturgeschichte 03HEX1VP)

über 60 Wochen Grabungs- / Felderfahrung in assistierender und leitender Funktion in Europa, Asien und Südamerika. Archäologische, anthropologische und forensische Grabungen / Massengrabbergungen 